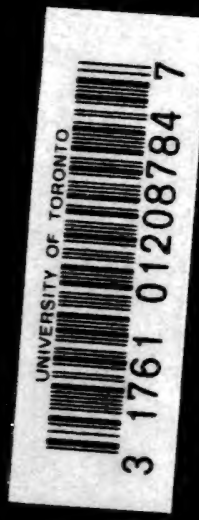





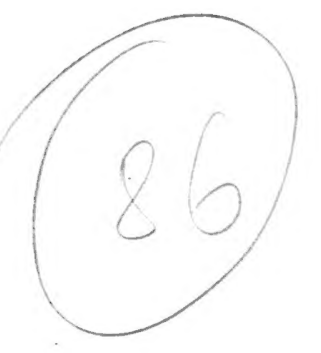

Die Insekten Mitteleuropas insbesondere Deutschlands

Zweiter Band

\section{Hymenopteren}

Zweiter Teil 


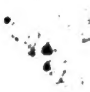




\title{
Die \\ Insekten Mitteleuropas insbesondere Deutschlands
}

\author{
Bearbeitet (in den ersten 8 Bänden)
}

von

Dr. G. Aulmann (Berlin), Dr. C. Börner (St. Julien-Metz), Dr. E. Enslin (Fürth i. B.), Dr. H. Friese (Schwerin i. M.), Dr. K. Grünberg (Berlin), H. Haupt (Halle a. S.), Prof. Dr. J. J. Kieffer (Bitsch i. Lothr.), Dr. L. Lindinger (Hamburg), Prof. Dr. O. Schmiedeknecht (Blankenburg i. Thür.), H. Schumacher (Berlin), Dr. P. Speiser (Labes, Westpr.), H. Stitz (Berlin), Dr. E. Strand (Berlin), Dr. G. Ulmer (Hamburg), Dr. F. Zacher (Dahlem-Berlin).

Herausgegeben

von

Prof. Dr. Christoph Schröder, Berlin

Band II

\section{Hymenopteren}

\section{Zweiter Teil}

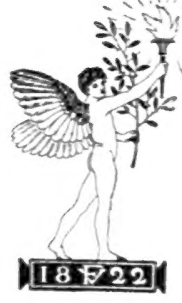

Stuttgart 1914

Franckh'sche Verlagshandlung 


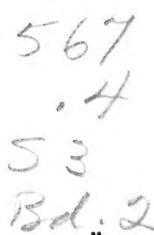

Alle Rechte, besonders das Übersetzungsrecht, vorbehalten

Copyright 1914 by

Franckh'sche Verlagshandlung, Stuttgart

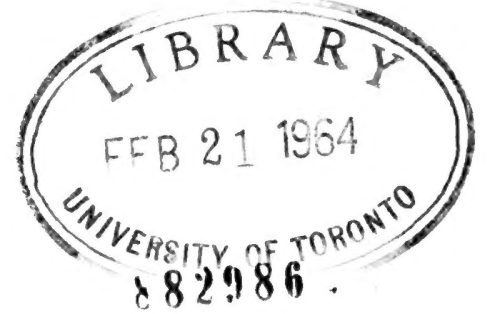




\section{Inhalt.}

Vorwort zum Teile II der Hymenopteren ....
Die Ameisen (Formicidae); mit 73 Textabbildungen und 2 kolorierten Tafeln. Von H. Stitz

Die Schlupf- und Brackwespen (Ichneumonoidea = Ichneumonidae im weiteren Sinne, und Braconidae); mit 51 Textabbildungen und 3 kolorierten Tafeln. Von Prof. Dr. O. Schmiedeknecht . . . . . . . . . . . . 113 



\section{Vorwort zu Band II, Hymenopteren, 2. Teil.*}

Dieser Band enthält die Bearbeitung der "Ameisen“ (Formicidae) wie der "Schlupfwespen" (Ichneumonoidea) durch die Herren H. Stitz (Berlin) und Prof. Dr. O. Schmiedeknecht (Blankenburg i. Thür.), beide Autoren, denen wir bereits hervorragendste Arbeiten auf dem Gebiete gerade auch jener Unterordnungen danken.

Die Biologie der Ameisen hat zwar im letzten Jahrzehnt bereits hie und da eine gute Bearbeitung erfahren; keines dieser Bücher aber berücksichtigt gleichermaßen die systematischen Kategorien, deren Kenntnis vielmehr vorausgesetzt werden. Dem gegenüber zeichnet sich die vorliegende Ausführung durch eine völlig gleichartige Berücksichtigung der systematischen, morphologischen wie gesamten biologischen Gesichtspunkte aus, deren erstere in den Bestimmungstabellen eine sehr präzise Fassung erfahren haben und selbst die Rassen betreffen. Eingehender erscheinen auch die künstlichen Nester für Aufzucht wie Beobachtung, ferner die Ameisengäste behandelt. Übrigens ist dieser Teil bereits zu Beginn 1913 gesetzt gewesen, hat daher die Literatur dieses Jahres nicht benutzen können.

Die Bearbeitung der Schlupfwespen in ihren 8 Familien hat zumal unter den äußerst beschränkten Raumverhältnissen der ganzen umfassenden Kenntnisse bedurft, wie sie ihr Autor bereits namentlich in seinen „Hymenopteren Mitteleuropas ... (Jena, 1907) und „Opuscula Ichneumonologica“ (Blankenburg i. Thür., seit 1902), gezeigt hatte. Nur so konnte er eine derart klare Übersicht der systematischen Kategorien dieser schier unübersehbar formenreichen Gruppe in Bestimmungstabellen durchweg bis zu den Gattungen geben und sie durch die Angabe der mannigfaltigen biologischen Verhältnisse dem Ziele dieses Werkes so weitgehend anpassen.

Beide Autoren haben in den zahlreichen originalen Textabbildungen und auf den mit sehr erheblichen Kosten auf lithographischem Wege wiedergegebenen 6 kolorierten Tafeln eine Fülle von Einzelheiten, zugleich der Formen als Habitusbilder dargestellt.

* Das allgemeine Vorwort zu diesem Werke ist dem ersterschienenen Bande (Hymenopteren, 3. Teil) vorgeheftet. 
Sehr ausführliche Literatur-Verzeichnisse leiten alle jene weiter, welche sich in speziellerer Forschung mit dem Gegenstande zu beschäftigen wünschen; ein Bemühen, das durch Typensammlungen, zu deren Zusammenstellung und Abgabe sich die betr. Autoren verstehen würden, eine erhebliche Erleichterung erfahren müßte. Der eingehende „Systematische Teil“ des Inhaltsverzeichnisses wird das Auffinden der systematischen Kategorien sehr erleichtern.

So möchte auch dieser dem erst erschienenen Bande III der Hymenopteren (Prof. Dr. J. J. Kieffer-Bitsch i. Lothr., "Gallwespen“ [Cynipidae]; Dr. E. EnslinFürth i. Bay., „Blatt- und Holzwespen“ [Tenthredinoidea]) alsbald gefolgte viele Freunde finden und mit ihm dem ganzen Werke die erhoffte Anerkennung und Verbreitung werben.

Im Januar 1914.

\author{
Prof. Dr. Chr. Schröder.
}




\title{
Die Ameisen (Formicidae) Mitteleuropas, insbesondere Deutschlands
}

von

\author{
H. Stitz
}




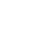




\section{Charakteristik.}

Die Hymenopteren (Hautflügler) verteilen sich auf die beiden Unterordnungen der Symphyta, bei denen der Hinterleib dem nur aus den 3 eigentlichen Brustringen gebildeten Thorax (Brustabschnitt) mit breiter Basis ansitzt (Blatt- und Holzwespen), und der Apocrita, bei denen der Hinterleib mit der Brust durch einen Stiel verbunden ist und sich an der Bildung der letzteren der 1. Hinterleibsring beteiligt. Unter den Apocrita pflegt man 2 weitere Gruppen zu unterscheiden als Terebrantien, deren Weibchen einen Legebohrer (terebra) besitzen (Gall-, Schlupf- und Goldwespen, s. auch Bd. III der Hymenoptera d. W. bezw. den weiteren Inhalt dieses Bandes II), und Aculeaten, deren Weibchen mit einem Giftstachel (aculeus) bewehrt sind; zu diesen zählen neben den Bienen und Wespen (s. Bd. I der Hymenoptera d. W.) auch die Ameisen.

Die Ameisen (Formicidae) sind durch folgende Hauptmerkmale charakterisiert: Das erste oder die beiden ersten Hinterleibssegmente sind zu einem schmalen Verbindungsstück zwischen Thorax und eigentlichem Abdomen umgeformt, und dieses Verbindungsstück ist daher entweder 1-oder 2 gliedrig. Im ersteren Fall bildet es eine mehr oder weniger entwickelte Schuppe oder einen Knoten; im zweiten Fall besteht es aus zwei Knötchen. Die langen, dünnen Antennen zeichnen sich durch einen langen Schaft aus. Da wir bei den Ameisen geschlechtslose Tiere (Arbeiter oder Arbeiterinnen, †) und Geschlechtstiere (Männchen, $\sigma^{7}$, und Weibchen, + , auch Königinnen genannt) antreffen, so sei für letztere noch hinzugefügt, dass sie normalerweise geflügelt sind, dass die Flügel eine unvollständige Aderung zeigen, das Ende des Hinterleibs weit überragen und an der Wurzel mehr oder weniger leicht abbrechen.

Nach dem gegenwärtigen Stand der Forschung nimmt man an, daß die Ameisen von einer ausgestorbenen Urform herzuleiten sind, die mit den $\mathrm{Mu}$ tilliden verwandt ist, und aus der die phylogenetisch älteste Gruppe der Ponerinen hervorgegangen ist, von welcher sich die übrigen Gruppen abgezweigt haben. (Handlirsch lässt die Formiciden aus einer Urform entstehen, die dem Hymenopterengenus Scolia ähnlich gewesen sei.) Während Emery annimmt, dass die Weibchen der Vorfahren der Ameisen ungeflügelt waren und dass sich aus ihnen später sterile Individuen als Arbeiter herausbildeten, sind die meisten anderen Forscher (Forel, Wheeler u. a.) dagegen der Meinung, dass jene ebenso wie die Männchen geflügelt waren.

\section{Geschichtliches.}

Obwohl die Kenntnis sowohl der anatomischen wie der biologischen Verhältnisse der Ameisen ihren Anfang an einheimischen Formen genommen hat, so lässt sich ein Überblick über die geschichtliche Entwicklung dieser Kenntnis von der der ausländischen Formen nicht trennen.

Die auffälligen Äusserungen des Ameiseninstinktes haben die Aufmerksamkeit der Menschen bereits seit alter Zeit auf sich gelenkt. Doch erst bei Swammerdam findet sich eine Darstellung der Entwicklung einer Ameise. 
Er beschreibt $\not+$, 의 und $\sigma^{7}$ einer Knotenameise und gibt auch an, wie er diese Tiere in einem künstlichen Nest beobachtet hat. Ebenso erwähnt er einige ihm bekannt gewordene ausländische Arten. - (Wer sich für ältere Schriften über unseren Gegenstand interessiert, findet eine grössere Zahl derselben angeführt in dem Buch von Eiselt, Geschichte, Systematik und Literatur der Insektenkunde, Leipzig 1836, S. 228-29.)

Das Linnésche Zeitalter der Naturgeschichte steht im Zeichen der Systematik. Linné selbst führt (1758) 17 Arten von Ameisen auf, darunter 7 deutsche, die, sämtlich in der Gattung Formica vereinigt, mit folgenden Worten charakterisiert sind: Squamula erecta, thoraci abdomineque interiecta. Feminis et Neutris reconditus. Alae Maribus et Feminis; sed Neutris nullae. Degeer gibt eine kurze Kennzeichnung der Gruppe der Ameisen sowie Bemerkungen über ihre Lebensweise und schliesst daran die Resultate der Arbeiten Swammerdams, Linnés und Geoffroys, dessen Werk aber nur einige Seiten allgemeinen Inhalts darüber enthält. Linnés Schüler Fabricius, dessen Insektensystem der Bau der Mundwerkzeuge zugrunde liegt, nennt die Ordnung unserer heutigen Hymenopteren Piezata und teilt sie in 2 grosse Gruppen ein: solche mit Maxillen und Palpen, ohne Zunge und solche mit hervorstreckbarer Zunge. Zur ersten Gruppe, die nach der Form der Antennen in 6 Untergruppen zerlegt wird, gehören die Ameisen. Fabricius faßt sie nicht mehr in eine Gattung zusammen, sondern unterscheidet deren sechs. Jede Gattung wird nach den Antennen und Mandibeln kurz charakterisiert; die dazu gehörigen Arten sind zum Teil kurz beschrieben, mit Angabe ihrer Heimat. Bei Latreille finden sich zunächst alle ihm bekannten Ameisen unter dem Gattungsnamen Formica zusammengefasst und in 9 Gruppen geteilt, unter Berücksichtigung vor allem der Antennen und Mandibeln, dann auch der Schuppe, der anschliessenden Hinterleibssegmente, des Vorhandenseins eines Stachels. Später trennt er ein Genus Cephalotes vom Genus Formica, das alle anderen einschliesst; zuletzt unterscheidet er 8 Genera.

Während in den genannten Arbeiten das Systematische überwiegt, begegnen wir in dieser Zeit einer guten Darstellung der Lebensverhältnisse der Ameisen von Gould (1747), und erst über 60 Jahre später gibt Huber (1810) biologische Schilderungen über unseren Gegenstand. Er behandelt Wohnungen und Lebensgewohnheiten der für sein Gebiet in Betracht kommenden Arten, über die am Ende des Buches eine Tabelle über deren 하, 우 und $\sigma^{7} \sigma^{\text {" }}$ zusammengestellt ist. Beide Werke, von denen das erste sehr selten ist, sind, obwohl naturgemäss überholt, jedem zu empfehlen, der sich mit der Kenntnis der Ameisen beschäftigt.

In dem nun folgenden Zeitraum wird die Ameisenkunde kaum gefördert. Erst in den fünfziger Jahren des 19. Jahrhunderts wenden sich ihr wieder mehrere Forscher zu, und man beginnt, einzelne Faunengebiete genauer zu erforschen. $\mathrm{Zu}$ erwähnen sind hier die Arbeiten von Foerster, Gredler, Nylander, Roger, Schenk und Meinert. Einen Überblick darüber nebst kritischer Würdigung gibt $\mathrm{Mayr}^{1}$ ). 1858 gab Smith, der auch die britischen Ameisen bearbeitete und im übrigen mit zahlreichen Arbeiten über Formiciden hervortrat, eine Zusammenstellung nebst kurzen (oft mangelhaften) Beschreibungen nebst Literaturnachweisen aller bis dahin gekannten Formen, die ausländischen eingeschlossen mit 701 Arten, auf 42 Gattungen verteilt, die Arten innerhalb der Gattungen nach den Erdteilen gruppiert.

Indessen fehlte es, mit Mayrs Worten, noch immer an einer durchgreifenden, logischen Charakteristik der Genera, und eine solche gibt er selbst in seinen „Europäischen Formiciden" ${ }^{1}$ ), denen eine ähnliche Arbeit vorangegangen war. 
In jenem Buch findet sich zum erstenmal eine brauchbare, systematische Behandlung des Gegenstandes. Es beginnt mit einem. Kapitel über den Bau des Ameisenkörpers; dann folgen Bemerkungen über den Aufenthalt der Ameisen und ihre Verbreitung und ein Literaturverzeichnis. Daran schliesst sich der systematische Teil, 하, 와 und $\sigma^{7} \sigma^{7}$ in gleicher Weise behandelnd. Mayr ${ }^{1}$ ) hat, wie Forel bemerkt, als erster die Ameisensystematik in natürlicher Weise geordnet und eine natürliche Einteilung in Gattungen aufgestellt. Er behält zunächst die Einteilung in 3 Unterfamilien: Formicidae (24 Gatt.), Ponerinae (28 Gatt.) und Myrmicidae (24 Gatt.) bei, trennt aber noch als besondere Unterfamilie die Odontomachidae (3 Gatt.) ab und stellt als eine neue die der Dorylidae (7 Gatt.) hinzu, deren $\sigma^{7} \sigma^{7}$ schon früher als besondere Gruppe galten. Die Zahl der Gattungen beträgt danach 104, die der Arten ungefähr 1300. Mayrs Arbeiten behandeln ausser der europäischen Fauna auch die fossilen Formen und erweiterten die Kenntnis der ausländischen Gebiete durch Beschreibungen zahlreicher neuer Gattungen und Arten.

Aus der Schule Mayrs hervorgegangen sind die beiden bedeutendsten gegenwärtig noch lebenden Ameisenforscher $\mathrm{Forel}^{2}$ ) und Emery ${ }^{3}$ ), deren Arbeiten alles in den Kreis ihrer Forschung gezogen haben, worauf sich die neuere Ameisenkunde erstreckt. Die ausserordentlich zahlreichen Schriften beider, von denen das angehängte Literaturverzeichnis nur die für den Zweck der vorliegenden Schrift in Betracht kommenden anführt, behandeln Anatomie, Systematik, biologische Verhältnisse im Gemeinschaftsleben der Ameisen und einzelne Faunengebiete sowie Ergebnisse wissenschaftlicher Forschungsreisen.

Das grundlegende Forelsche Werk (1874) ${ }^{4}$ ) bezieht sich auf die Schweizer Ameisen. Teil 1 gibt eine Darstellung der äusseren anatomischen Verhältnisse des Ameisenkörpers für den Zweck der sich anschliessenden systematischen Behandlung. Teil 2 lehrt uns die inneren anatomischen und physiologischen Eigenheiten kennen. Ein Anhang handelt von den Zwischenformen von of und $\sigma^{7} \sigma^{7}$, von Hermaphroditen und Monstrositäten. Teil 3 beschreibt die Wohnungen, Teil 4 behandelt die Verbreitung der Schweizer Ameisen und ihre Bedeutung im Haushalt der Natur. Teil 5 ist wohl der interessanteste. Er enthält Beobachtungen an Nestern, die Bezıehungen der Ameisen und ihrer Kolonien zueinander und schildert eingehend die Lebensgewohnheiten der einzelnen Arten. Eine Art Ergänzung gibt uns ein neuerdings erschienenes Buch Forels ${ }^{5}$ ), nach

1) Gustav Mayr, geb. 1830 in Wien, studierte Medizin, beschäftigte sich ausserdem viel mit Entomologie, besonders mit den Hymenopteren. 1854-55 war er in der Cholera-Abteilung des Wiener allgem. Krankenhauses und im physiologischen Institut tätig, promovierte 1856 und bestand die Prüfung für das Lehramt in Naturgeschichte und Chemie, wurde im selben Jahr Lehrer der Naturgeschichte an der Oberrealschule in Pest und lehrte dasselbe Fach am dortigen deutschen Gymnasium. Infolge der Magyarisierung der deutschen Mittelschule verlor er 1861 seine Stelle und ging nach Wien; hier wurde er 1863 Professor der Naturgeschichte an der Kommunal-Oberrealschule und verblieb in dieser Stellung, bis er 1892 mit dem Titel eines Kaiserlichen Rates pensioniert wurde. Gest. 14. Juli 1908. - Seine Sammlung umfasst 2180 Arten und 378 Rassen und Varietäten von Ameisen.

") August Forel, geb. 1848 in La Gracieuse bei Morges (Lausanne), beschäftigte sich bereits in früher Jugend mit Naturbeobachtungen, besonders solchen an Insekten, studierte 1866-70 in Zürich Medizin, wo er, nach einem Aufenthalt in Wien bei Meynert (Gehirnanatom und -physiologe), promovierte; nachdem er sich in Tübingen mit Ameisenanatomie beschäftigt hatte, war er 1873 -78 in München Assistent bei Gudden und habilitierte sich hier 1877 für Psychiatrie. 1878 unternahm er eine Reise nach Westindien und wurde 1879 (bis 1898) Professor der Irrenheilkunde und Direktor der Irrenanstalt Burghölzli; in diese Zeit fallen mehrere Reisen ins Ausland zum Studium von Ameisen. Jetzt lebt Forel in Yvorne (Kanton Waadt).

3) Carlo Emery, geb. 1848 in Neapel, studierte daselbst Medizin und Naturwissenschaften, war von 1878-80 Professor der Zoologie an der Universität Cagliari, seit 1881 Professor der Zoologie in Bologna; beschäftigte sich besonders in den letzten Jahren mit Morphologie und Ethologie der Ameisen.

4) Lit.-Verz. 119

5) Lit.-Verz. 148 
des Verfassers eigener Angabe Studien, Experimente, Kritiken und Überlegungen enthaltend, die, zu sehr verschiedenen Zeiten gemacht und niedergeschrieben, von ihm für den Zweck des Buches revidiert und ergänzt worden sind.

Forel vereinigte die seinerzeit von Mayr abgetrennten Odontomachiden mit den Ponerinen, schied aber die Unterfamilie der Formiciden in Camponotidae und Dolichoderidae. Eine durch ihn von den Ponerinen abgetrennte Unterfamilie der Amblyoponinae wurde später wieder eingezogen. Die Familie der Formicidae teilt sich danach noch gegenwärtig in 5 Unterfamilien: Dorylinae, Ponerinae, Myrmicinae, Dolichoderinae und Formicinae (=Camponotinae).

Eine grundlegende Übersicht über die 후 der Gattungen dieser 5 Gruppen gab (1896) Emery ${ }^{1}$ ), der gegenwärtig auch mit der Bearbeitung einer kritischen Übersicht sämtlicher bisher bekannten Arten nebst Rassen und Varietäten beschäftigt ist. Ashmeads Versuch, das System umzuändern, wurde von ihm wie von Forel zurückgewiesen.

Für die Formen der paläarktischen Ameisen, das Mittelmeergebiet eingeschlossen, hat Emery durch ihre Zusammenstellung mit Bestimmungstabellen über $\not \not ̧$, , $q+$ und $\sigma^{7} \sigma^{7}$ den Ameisenforschern einen grossen Dienst erwiesen; doch ist diese Arbeit noch nicht vollendet ${ }^{2}$ ).

Nächst der Tätigkeit dieser beiden Forscher müssen die Arbeiten des Amerikaners Wheeler hervorgehoben werden, der sich mit unermüdlichem Fleiß um die Erforschung der biologischen und sozialen Verhältnisse in den Ameisenstaaten, meist in Beziehung auf die nordamerikanische Fauna, verdient gemacht und in vielen systematischen Arbeiten besonders die Kenntnis der letzteren gefördert hat.

Wasmann behandelt in seinen zahlreichen Schriften außer biologischen Verhältnissen vorzugsweise die Gäste der Ameisen und deren Zusammenleben mit ihren Wirten. Seine an sich vorzügliche Darstellung der psychischen Fähigkeiten der $\mathrm{Ameisen}^{3}$ ) ist in manchen Beziehungen vielfach stark angegriffen worden, ebenso die Ansicht von Bethe über letzteren Gegenstand.

Janet erweiterte durch seine Untersuchungen die Kenntnis der Ameisenanatomie. Ihm sowie Miss Fielde, Wasmann und Viehmeyer verdanken wir auch die Vervollkommnung der Beobachtung des Ameisenlebens in künstlichen Nestern.

Im übrigen sei im Anschluss an die erwähnten Forscher auf die Autoren im Literaturverzeichnis hingewiesen, wo wir den Arbeiten von Ruzsky und Karawaiew, ferner von Santschi, Krausse u. a. begegnen.

Eine gemeinverständliche, jetzt zum Teil überholte Darstellung des Ameisenlebens besitzen wir von André ${ }^{4}$ ), dessen systematischer Arbeiten hierbei noch zu gedenken ist, und von Lubbock ${ }^{5}$ ). Die Abbildungen aus dem ersteren Buch, besonders die biologischen, finden sich heute noch in neueren Schriften wieder. Lubbock behandelt die Beziehungen der Ameisen zu den Pflanzen. zu anderen Tieren und zueinander und gibt Beobachtungen über die Sinne und die Intelligenz der Ameisen.

Zur ersten Einführung in die Biologie der einheimischen Ameisen vorzüglich geeignet ist eine kleine Schrift von Viehmeyer ${ }^{6}$ ). Umfangreicher ist das neuere, noch unvollendete $W$ erk $W$ asmanns über die Ameisen Luxemburgs ${ }^{\top}$ ), mit Bestimmungstabellen der 㺕, Übersichten über die Nestformen usw. Knauers Darstellung ${ }^{\nsucc}$ ) zieht auch die ausländischen Ameisen in den Kreis der vergleichenden Betrachtung, und eine wissenschaftliche, eingehende, nicht systematische Arbeit ist das Buch von Escherich"), dem wir ausserdem eine Anzahl Arbeiten über Ameisengäste sowie vortreffliche, orientierende Zusammenfassungen über die
1) Lit.-Verz. 68.
2) Lit.-Verz. 69
3) Lit.-Verz. 397.
$\left.{ }^{6}\right)$ Lit.-Verz. 348.
7) Lit.-Verz. 362
8) Lit.-Verz. 212.
4) Lit.-Verz. 11. ${ }^{5}$ ) Lit.-Verz. 248.
9) Lit.-Verz. 92. 
Leistungen auf dem Gebiet der Ameisenkunde verdanken. Das neueste, umfassende Werk über Ameisenkunde ist von Whe ele ${ }^{1}$ ), auf dessen reich illustrierten Inhalt, dem sich ein bis zu seinem Erscheinen fast vollständiges Literaturverzeichnis der Myrmekologie anschließt, aus Mangel an Raum nicht eingegangen werden kann.

Im Katalog von Dalla Torre (1892) beläuft sich die Zahl der aufgeführten Gattungen auf 165, die der Arten nebst Rassen und Varietäten auf rund 2650. Nach einer Arbeit von Forel betrug bis Februar 1910 die Zahl der bekannten Ameisengattungen 184 lebende und 12 nur fossil bekannte, mit 6254 Arten, die Rassen und Varietäten eingeschlossen.

\section{Allgemeiner Teil.}

\section{Körperbau der Ameisen.}

Unter den Individuen einer Ameisenkolonie lassen sich, ähnlich wie bei den Bienen, 3 verschiedene Formen unterscheiden: Arbeiter, auch Neutra genannt, in der Größe oft erhebliche Unterschiede zeigend, Weibchen und Männchen. Zwischen diesen werden zahlreiche andere Formen beobachtet, deren Entstehung zum grössten Teil auf gewisse biologische Verhältnisse zurückzuführen ist. Näheres darüber findet sich im Abschnitt über Polymorphismus (S. 19). Der Unterschied zwischen Arbeitern und Weibchen kommt am wenigsten zum Ausdruck bei den Ponerinen, am meisten bei den Camponotinen, wenn wir von der hier nicht in Betracht kommenden Gruppe der Dorylinen absehen.

Die Beha arung des Körpers ist teils eine sehr feine, anliegende und wird als Pubescenz bezeichnet, teils besteht sie aus kürzeren oder längeren, mehr oder weniger abstehenden Borsten und heisst Pilosität.

Am Kopf der Ameise sind die folgenden, in Abb. 1 bezeichneten Teile zu unterscheiden:

Das Epistom oder der Clypeus besitzt bei vielen Arten einen in der Mittellinie verlaufenden $\mathrm{Kiel}$.

An den Stirnleisten sind die

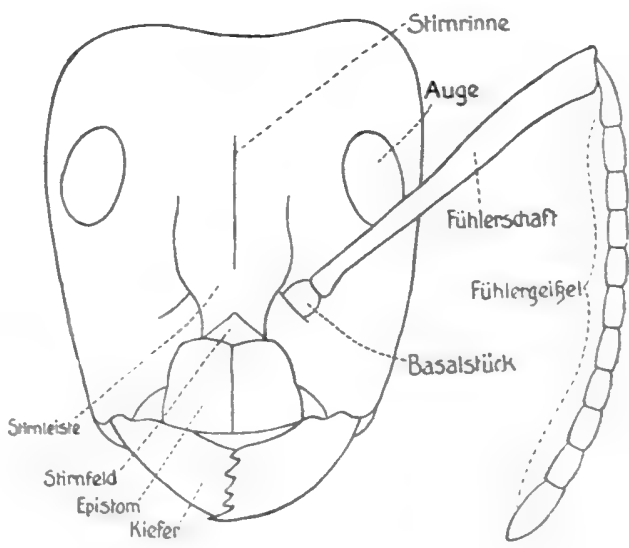

Abb. 1. Kopf von Camponotus ligniperda 우. Ränder mehr oder weniger aufgebogen.

Die Mittellinie zwischen beiden ist häufig als etwas vertiefte, feine Naht zu erkennen, die sich als Stirnrinne auf den Oberkopf fortsetzen kann.

Das Stirnfeld ist die Fläche oberhalb des Epistoms vor oder zwischen den vorderen Enden der Stirnleisten; es ist nicht immer deutlich ausgebildet oder abgegrenzt.

Die Stelle, wo der Hinterrand des Epistoms mit dem Aussenrand der Stirnleiste zusammenstösst, heisst Schildgrube oder Clypealgrube.

Wangen heissen die Kopfseiten außerhalb der Stirnleisten.

1) Lit.-Verz. 400 . 
Stirn wird die Fläche zwischen den Stirnleisten bis zum vorderen Ocellus (S. 10) genannt.

Als Scheitel wird die dahinter auf dem Oberkopf gelegene Fläche bezeichnet.

Die Antennalgrube (Fühlergrube) ist die Stelle, an der die Antennen eingelenkt sind; bei vielen Formen fällt sie mit der Clypealgrube zusammen.

Die Antennen (Fühler) bestehen aus dem Schaft (Scapus), der auf einem Basalstück eingelenkt ist und die außerordentliche Beweglichkeit der Antenne vermittelt, und der Geissel (Flagellum). Am Grunde der Antenne mündet in einer kleinen Vertiefung die Antennendrüse.

Die Antennengeissel besteht aus Gliedern' '), deren Zahl bei den Ameisen zwischen 13 (viele $\sigma^{\prime \prime} \sigma^{7}$ ) und 3 (eine nicht einheimische Gattung, Epitritus) schwankt. Häufig sind die letzten Antennenglieder grösser und dicker und bilden dann eine von der übrigen Geissel mehr oder weniger deutlich abgesetzte Keule (Clava).

Die Antennen sind die wichtigsten Sinnesorgane der Ameisen und dienen der Sinnestätigkeit nicht nur in einer Richtung. Es kommt ihnen zunächst eine mechanische Funktion $\mathrm{zu}$, indem Antennenschläge für die gegenseitige Mit-

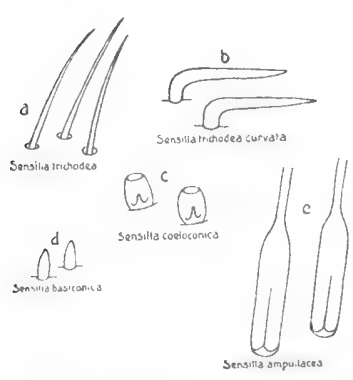

Abb. 2. Sinnesorgane auf den Fühlern (nach Krausse). teilung in Betracht kommen. (W as mann ${ }^{2}$ ) gibt S. 86-88 über die verschiedenen Formen dieses Mitteilungsvermögens eine eingehende Übersicht.] Ferner erkennt schon das unbewaffnete Auge an den Fühlern mehr oder weniger dicht stehende Borsten, während andere Gebilde erst bei genauer Betrachtung mit Hilfe des Mikroskops wahrgenommen werden können. Die Untersuchungen von $\mathrm{Krausse}^{3}$ ) haben gezeigt, dass die Zahl dieser Sinnesorgane bei den Männchen hinter der bei Weibchen und Arbeitern zurücksteht, dass ihre Zahl individuell verschieden ist und auch bei demselben Tier auf beiden Antennen verschieden sein kann. Das 1. Glied der Geissel, das in Gestalt und Länge meist von den übrigen abweicht, enthält, wie bei allen Insekten, im Innern das Johnstonsche Organ, dem man wohl Gehörsfunktion zuschreibt, dessen Bedeutung aber für das Geschlechtsleben der Insekten in Betracht zu kommen scheint. Es ist nach Wheeler beim $\sigma^{7}$ deutlich stärker ausgebildet wie beim Weibchen und Arbeiter.

Die übrigen auf den Antennen auftretenden Organe ${ }^{4}$ ) sind (im Anschluss an die Untersuchungen von Krausse) folgende (Abb. 2):

1. Tastborsten (Sensilla trichodea). Es sind dies die dem Auge bei allen Insekten auffallenden Borsten, welche an ihrem Grund beweglich eingelenkt sind, wohin ein Nerv führt, der hier mit einigen Sinneszellen in Verbindung steht. Sie finden sich in grosser Zahl auf dem Schaft und dem Endglied der Antennen und dienen wahrscheinlich als Tastorgane. Lasius fuliginosus $q$ besitzt auf jeder Antenne über 2000, davon auf dem Schaft ungefähr 500, auf dem Endglied 370.

2. Knieförmig gebogene Haare (Sensilla trichodea curvata). Sie kommen nur bei Ameisen vor und sind auf dem Antennenschaft nicht vor-

1) Wo in den Bestimmungstabellen für Ameisen die Zahl der Antennenglieder angegeben wird, ist, wenn nicht anders bemerkt, der Antennenschaft als erstes Glied gezählt.

2) Lit.-Verz. 397.

3) Lit.-Verz. 215.

4) Miss Fielde schliesst aus ihren Untersuchungen, dass für jedes Antennenglied eine bestimmte Art von Geruchsempfindung in Betracht komme (Brutgeruch, Nestgeruch, Geruch von Feinden usw.). 
handen, finden sich in nicht sehr grosser Menge auf den Geisselgliedern, deren letztes die meisten trägt. Nach Forel dienen sie der Wahrnehmung chemischer Reize und sind vielleicht Geruchsorgane; doch ist ihre Bedeutung noch nicht klar. Bei Formica rufa + besitzt jede Antenne ungefähr 730, das Endglied 85 solcher Haare.

3. Leydigsche Kegel (Sensilla basiconica). Solche sind auch von anderen Insekten bekannt. Sie fehlen dem Schaft, finden sich dagegen in grosser Anzahl auf den folgenden Gliedern, am zahlreichsten auf dem Endglied. Sie werden von vielen Forschern für Tastorgane gehalten, dienen aber wohl zur Wahrnehmung von Gerüchen in der Nähe beim Betasten der betreffenden Körper. Bei Lasius fuliginosus tragen die Antennen ungefähr 2000, das letzte Glied allein 360 davon.

4. Grubenkegel (Sensilla coeloconica). Es sind dies die Forelschen Champagnerpfropfenorgane. Ihre Anzahl ist eine verhältnismässig geringe. Sie fehlen dem Antennenschaft sowie dem 1. Glied der Geissel und sind auf deren letztem in grösserer Menge vorhanden. Sie sind ebenfalls mit Nervenendigungen versehen und wurden früher wohl als Gehörsorgane aufgefasst, dienen aber (nach $\mathrm{Krausse)}$ wahrscheinlich der Wahrnehmung chemischer Reize, zum Riechen in der Nähe. Lasius fuliginosus + trägt auf jeder Antenne ungefähr 18 derselben.

5. Flaschenorgane (Sensilla ampullacea). Für ihre Verteilung auf der Antenne gilt dasselbe wie für die Grubenkegel. ObwohI bei allen Hymenopteren vorkommend, ist ihre Bedeutung noch unentschieden. Sie sind (nach Krausse) wahrscheinlich ebenfalls für die Aufnahme chemischer Reize von Bedeutung, zum Riechen in der Nähe. Lasius fuliginosus + besitzt auf jeder Antenne etwa 18. erwähnt:

Im Anschluss an diese Sinnesorgane der Antennen seien gleichzeitig noch

Sensilla campaniforma. Sie finden sich an den verschiedensten Stellen des Körpers, am Rand der Oberkiefer und an den Gelenken der Flügel und Beine.

Chordotonale Organe. Solche liegen paarig am Antennengrund, im Prosternum (1. Brustring) unter dem mit ihnen verbundenen 1. Thoracalganglion (Nervenknoten), ferner im Metasternum (3. Brustring), in jedem Stielchenknoten, dann in den Tibien (Unterschenkeln) des vorderen Beinpaars, bei manchen Arten auch in denen der übrigen Beine. - Janet vermutet in diesen Organen den Sitz für die Gehörsempfindung. Nach manchen sollen die Ameisen gegen Schallwellen jeder Art, auch gegen solche mit sehr hohen Schwingungszahlen, unempfindlich sein. Ihr Vermögen, sehr hohe Stridulationstöne hervorzubringen (vgl. S. 13), lässt jedoch auch auf eine Empfindung derselben schliessen, und nach Wasmanns Untersuchungen sind die Ameisen für hohe, schrillende Laute sehr empfindlich. Auch mechanische Erschütterungen werden von ihnen gut wahrgenommen.

Wie andere Insekten haben die Ameisen Netz- und Punktaugen. - Die Netzaugen haben ihren Namen bekanntlich daher, dass die sie aussen bedeckende Hornhaut (Cornea) netzartig in sechseckige Felder geteilt ist, welche Facetten heissen. Jede Facette ist die nach aussen gerichtete Basis eines besonderen, das Licht brechenden und die Lichtempfindung vermittelnden Kegels, und in die beisammen liegenden Spitzen dieser Kegel geht der Sehnerv. Nach Exner geben die Netzaugen ein einziges, aufrechtes Bild, dessen Klarheit von der Zahl der Facetten und der Wölbung des Auges abhängt. Grösse, äusserer Umriss und Stärke der Wölbung der Netzaugen sind bei den einzelnen Arten verschieden, ebenso die Zahl der Facetten jedes Auges. Letztere besonders steht mit der Lebensweise und dem durch diese bedingten Grad der Sehfähigkeit 
in engem Zusammenhang. Es gibt Ameisen, deren Auge über 1000 Facetten besitzt. (Camponotus ligniperda o 1760, \& 1250, \& 800, nach Pietschker; Formica rufa-pratensis of 1200, \& 830, \& 600, nach Weismann; Myrmica scabrinodis $\$ 120-130$, Tetramorium caespitum $\& 50-60$, nach Wasmann.) Dagegen hat die im Dunkel fremder Ameisenwohnungen hausende Solenopsis fugax \& deren nur 5-9 ( $\sigma^{2} 400$, ㅇ 400 nach Weismann), und aus nur 1 Facette besteht die Cornea einer afrikanischen Ameise (Tetramorium subcoecum For.), während die $\$$ † der unterirdisch lebenden, afrikanischen Treiberameisen gänzlich augenlos sind.

Bei den Weibchen und Männchen der Ameisen sind die Netzaugen und damit die Sehfähigkeit stärker ausgebildet als bei den Arbeitern, indem sie in Grösse und Zahl der Facetten von denen der letzteren nicht unerheblich abweichen, ohne dass sich indessen bisher in dieser Beziehung eine allgemeine Gesetzmässigkeit feststellen liess. Doch ist zu bemerken, dass diese Unterschiede bei den am Licht lebenden Arten, welche ihre Nester an der Erdoberfläche haben, am geringsten sind, bedeutend dagegen bei solchen, die eine unterirdische Lebensweise führen. So zeigen bei Tapinoma erraticum die 88100 , die 우 260, die $\sigma^{7} \sigma^{7} 400$ Facetten an jedem Auge, bei Formica rufa-pratensis 600, 830, 1200, bei Solenopsis fugax 6--9, 200, 400. Ferner sind die Augen der Männchen stärker gewölbt und besitzen, wie jene Zahlen zeigen, im allgemeinen die meisten Facetten.

Die Punktaugen (Ocellen) liegen auf dem Scheitel und sind normal in der Dreizahl vorhanden; doch können das vordere, die beiden hinteren oder alle drei undeutlich entwickelt sein oder ganz fehlen. Letzteres ist bei den Ameisen häufig der Fall; bei den Geschlechtstieren sind Ocellen fast immer vorhanden. Nach Wasmann werden sich bewegende Körper mit den Netzaugen besser erkannt als ruhende. Cornetz schliesst aus seinen Versuchen, dass die Ameisen ohne Ocellen, was das deutliche Sehen in der Nähe betrifft, geradezu blind sind, und dass die Netzaugen nur die Wahrnehmung grosser und plötzlicher Lichtunterschiede gewähren. Nach He s s e dienen die Ôcellen für das Sehen bei schneller Bewegung, und dieser Auffassung schliessen sich auch die Ergebnisse der Untersuchungen von Demoll und Scheuring ${ }^{1}$ ) an, nach denen die Funktion der Ocellen mit der der Facettenaugen in Zusammenhang steht und von letzterer abhängig ist, zugleich für das Schätzen von Entfernungen von Bedeutung sein wird.

Betreffs der wichtigen Fähigkeiten des Geruchs und Gesichts finden sich unter den Ameisen ähnliche Verhältnisse wie bei höheren Tieren: bei manchen ist der Geruchssinn höher entwickelt (Lasius), bei andern das Gesicht (Formica).

Von den Mundteilen ist die Oberlippe (Labrum) vom Epistom überragt und tritt gewöhnlich nicht zum Vorschein.

Die darunter gelegenen Oberkiefer (Mandibeln) sind die am meisten auffallenden und am verschiedenartigsten ausgebildeten Mundwerkzeuge, wenn dies auch an unseren einheimischen Formen nicht so sehr zum Ausdruck kommt. An den Mandibeln unterscheidet man einen Aussenrand, einen Innenrand und den dazwischen gelegenen Kaurand, der in den meisten Fällen mit Zähnen ausgerüstet ist. Doch ist die Bezeichnung „Kaurand“ eine nicht zutreffende. Die Mandibeln dienen nicht zum Zerkleinern bei der Nahrungsaufnahme, vielmehr als Werkzeuge bei den verschiedenartigsten Tätigkeiten, zum Ergreifen der Beute, zum Transport von Material, zum Zerkleinern und Verarbeiten von Baustoffen, als Werkzeug bei der Arbeit, sowie als Waffe beim Angriff und zur Verteidigung. Ihre Funktion findet also eher eine Parallele in derjenigen der menschlichen Hand. Mit der Art der Ausbildung von Mandibeln und Kaurand 
hängt auch die Lebensweise der Ameisen eng zusammen, und bei solchen, denen Zähne daran ganz fehlen, und deren Kiefer schmal und zugespitzt sind (Abb. 65, S. 87, Abb. 58, S. 77), sind letztere nur als Waffe zu gebrauchen. Solche Ameisen haben sogar die Fähigkeit, sich selbst zu ernähren, verloren und sind auf die Hilfe von Sklavenameisen angewiesen.

Die Unterkiefer (Maxillen) (Abb. 3) bestehen aus 2 basalen, als Cardo und Stip es bezeichneten Stücken, an deren letzteres sich nach innen 2 mehr blattartige Teile, die innere Lade (Lacinia) und die äussere Lade (Galea) setzen, beide an den Rändern teilweise mit Borsten versehen. Die Fläche der äusseren Lade trägt ferner einen als Putzapparat dienenden Borstenkamm sowie eine Anzahl von Gesckmackspapillen. Nach aussen setzen sich an die Stipites die Unterkiefertaster (Maxillarpalpen) an, aus einer Zahl von 1 (Anergates)

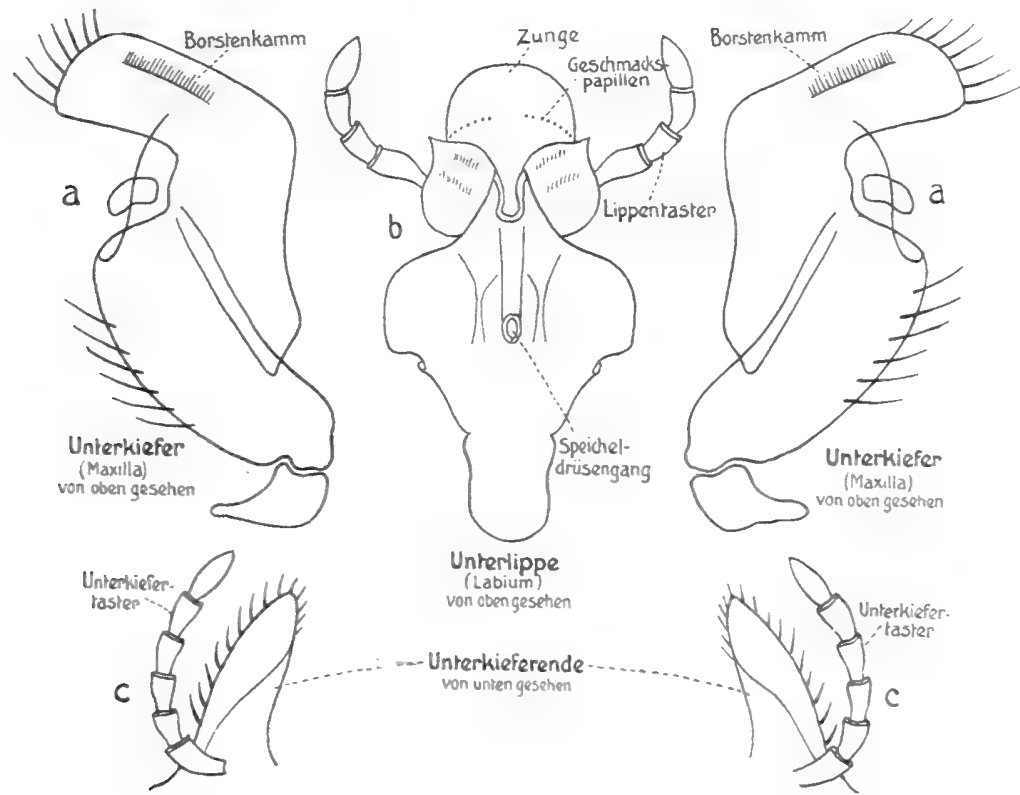

Abb. 3. Mundteile von Myrmica rubra (nach Janet).

bis 6 Gliedern (z. B. Camponotus) bestehend. Die blattartige, wenig kräftige Gestalt der Laden läht erkennen, dass die Ameisen keine feste Nahrung zu sich nehmen können.

Die Unterlippe (Labium) (Abb. 3), in deren Mittellinie die Speicheldrüsen münden, trägt jederseits die aus 1-4 Gliedern bestehenden Lippentaster (Labialpalpen). Zwischen ihnen liegt die Zunge (Glossa); zu ihren beiden Seiten finden sich die nur gering ausgebildeten Nebenzungen (Paraglossae). Die Zunge hat ebenfalls Geschmackspapillen, dient aber auch zur Reinigung. Mit der Mundhöhle im Zusammenhang stehen der Hypopharynx und die Intrabuccaltasche. Letztere hat den Zweck der provisorischen Aufnahme von Nahrungsresten und Abfallprodukten bei der Reinigung.

Die Brust (Thorax) der Ameisen entsteht wie bei allen Insekten aus den drei Brustabschnitten (= Segmenten) der Larve: dem Prothorax, Mesothorax und Metathorax, an denen Rückenteil (Tergit) und Bauchteil (Sternit) unterschieden werden, die seitlich durch die Pleuren verbunden sind. 
Diese Stücke sind aber am entwickelten Tier, der Imago, nicht ohne weiteres deutlich zu unterscheiden. Es kommen hier noch gewisse Teile hinzu, die wiederum durch Verwachsung mehr oder weniger miteinander verschmelzen. Am deutlichsten sind sie, durch Nähte getrennt, an den Geschlechtstieren zu erkennen. Zum Verständnis möge Abb. 4 dienen (Camponotus ligniperda + ); die betreffenden Teile dieser Seitenansicht lassen sich leicht auf dem Rücken eines Tieres hin verfolgen; das $0^{7}$ zeigt sie ebenso, nur in verkleinertem Massstab.

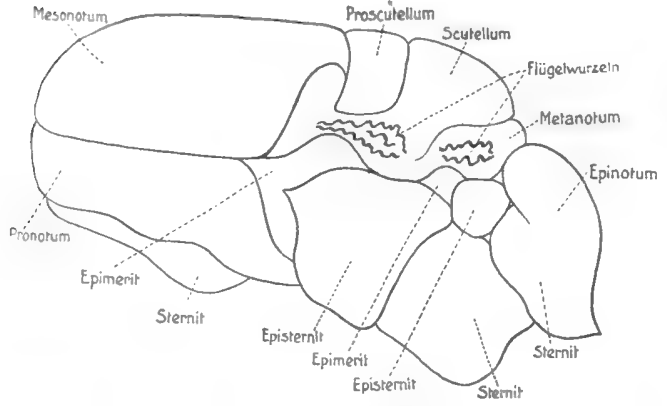

Abb. 4. Thorax von Camponotus ligniperda (Seitenansicht).

Wie aus den Bezeichnungen ersichtlich ist, liegt vorn das Pron o tu m ') (1. Rückenstück), darüber und dahinter das Mes onotum (2. Rückenstück). Das Metanotum (3. Rückenstück) findet sich weit nach hinten gerückt und ist auf ein schmales Stück reduziert, das durch zwei andere Teile, das Proscutellum und das besonders auf der Oberseite breit entwickelte Scutellum, von dem Mesonotum getrennt wird. Endlich schliesst sich hinten das Epinotum an. Die zu den drei Tergiten gehörigen Sternite sind aus der Zeichnung leicht zu ersehen. Es fällt dabei auf, dass das 2. Sternit vom 1. Sternit durch eine breite Platte, ein Episternit, getrennt wird, dem sich, am Epinotum gelegen, noch ein weiteres anschliesst. Dazu kommen noch die an den Flügelwurzeln liegenden Epimerite.

Am Thorax der geschlechtslosen Arbeiter (Abb. 5) sind nun diese Teile so stark zurückgebildet, dass man an ihnen oben nur Pronotum, Mesonotum

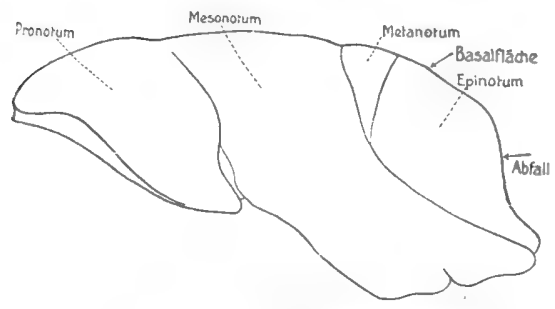

Abb. 5. Thorax von Camponotus ligniperda $\not$ (Seitenansicht). und, als drittes, grosses Stück, das Epinotum, auch Mittelsegment genannt, erkennt, während das vor letzterem liegende, gleichsam keilförmig eingeschobene Metanotum schmal und undeutlich, häufig gar nicht abgegrenzt ist. Das Epinotum wurde früher als Metanotum bezeichnet, ist es aber aus entwicklungsgeschichtlichen Gründen nicht. Die dorsale (obere) Fläche des Epinotums, die sich dem Mesonotum (bezw. Metanotum) anschliesst, nennt man Basalfläche, die sich anschliessende Abfall des Epinotums. Die Gegend, wo beide ineinander übergehen, ist oft durch das Vorhandensein von Dornen oder Zähnen ausgezeichnet.

Die stärkere Entwicklung des Thorax der Geschlechtstiere hängt zusammen mit der Ausbildung der darin gelegenen Flügelmuskulatur, die beim befruchteten Weibchen nach Ảbwerfen der Flügel durch Phagocytose resorbiert wird. (Vgl. S. 32.)

Über die Gestalt des Thorax bei gewissen Z'wischenformen (Abb. 69, Formica rufa) vgl. den nächsten Abschnitt über Polymorphismus (S. 19).

Der Thorax der Ameisen ist mit dem Hinterleib durch das Stielchen (Petiolus) verbunden, das aus einem oder zwei Gliedern (Knoten) bestehen kann. (Vgl. dazu die Zeichnungen im systematischen Teil.) Zahl und Form derselben sind nach den einzelnen Gruppen verschieden. Bei den Formen mit

1) Vgl. S. 58 Mayrsche Furchen. 
2 gliedrigen Stielchen wird das zweite auch als Postpetiolus bezeichnet. Das Stielchen enthält eine kräftige Muskulatur und gestattet dem Hinterleib eine grosse Beweglichkeit, die von Bedeutung ist für die Anwendung des Giftapparates und des Stachels. Morphologisch sind die Stielchenknoten die ersten Segmente des Hinterleibs.

Am eigentlichen Hinterleib (Abdomen) ist dessen erstes Segment am stärksten ausgebildet und umfasst den grössten Teil von jenem. Bei Ameisen mit 1 gliedrigem Stielchen besteht das Abdomen aus 8, bei denen mit 2 gliedrigem Stielchen aus 7 erkennbaren Segmenten, während bei den Männchen noch 1 solches hinzukommt.

Das erste Abdominalsegment zeigt bei den Ponerinen und fast allen Myrmicinen vorn und oben in seinem mittleren Teil eine äusserst feine Querriefung. Darüber bildet der vorhergehende Stielchenknoten eine Kante, die auf jener Fläche bei dessen Bewegung oder der des Abdomens reibt, und beide Teile bilden so einen Stridulationsapparat, mit dem die Ameisen zirpende

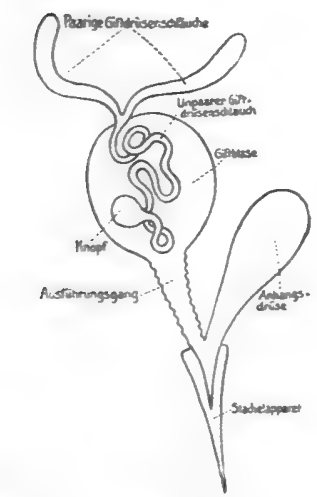

Abb. 6. Giftapparat einer Myrmica (nach Forel).

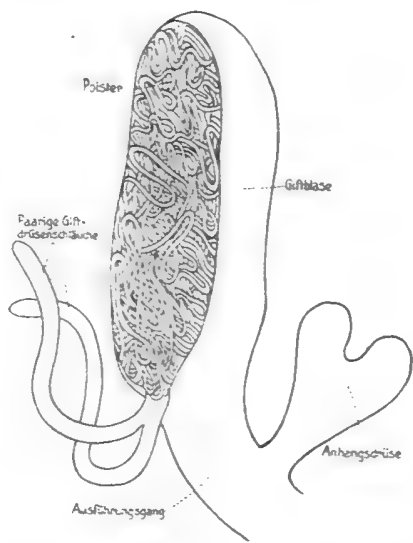

Abb. 7. Giftapparat einer Formica (nach Forel).

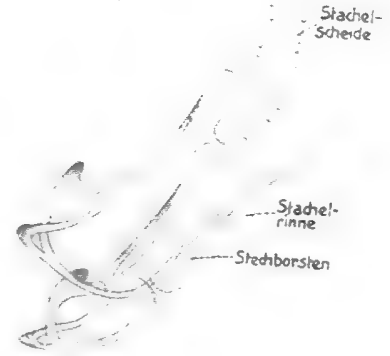

Abb. 8. Chitingerüst des Stechapparats von Myrmica rubida.

Laute hervorzubringen vermögen, die freilich bei den kleinen Formen wegen ihrer Schwäche und ihrer bedeutenden Tonhöhe dem menschlichen Ohr nicht mehr vernehmbar sind ${ }^{1}$ ).

Die Ameisen besitzen im Abdomen einen Giftapparat, der bei den Ponerinen und Myrmicinen, unter ihnen aber niemals bei den Männchen, mit einem Stachel in Verbindung steht. Die Teile dieses Giftapparates sind:

1. Zwei Drüsenschläuche, die sich weiterhin zu einem unpaaren Kanal vereinigen; dieser tritt an der Vereinigungsstelle in

2. die Giftblase, die einen grossen Teil des Abdomens einnimmt. Bei den Ameisen

a) ohne Stachel tritt der unpaare Kanal an dem nach hinten gerichteten Teil der Giftblase in diese ein, bildet innen an deren oberer Wand ausserordentlich zahlreiche, in dichtem Knäuel beisammen liegende Windungen, das Polster, und mündet nach langem Verlauf in den Hohlraum der Blase (Abb. 7). Bei den Ameisen

1) Abgesehen von der Anwendung eines Mikrophons lassen sich solche Laute (nach Janet) auf folgende Weise vernehmbar machen: Man schliesst 200-300 Myrmica rubra zwischen zwei Glasplatten ein, auf deren Rändern sich "mastic de vitrier" befindet, und drückt beide Platten so gegeneinander, dass zwischen ihnen nur so viel Abstand bleibt, als eine der Ameisen dick ist. Hălt man diese Glasschachtel an das $\mathrm{Ohr}$, so hört man ein fortgesetztes, ziemlich regelmässiges Brausen und dazwischen von Zeit zu Zeit sehr deutliche Stridulationsgeräusche. 
b) mit Stachel tritt der unpaare Kanal an dem nach vorn gelegenen Teil der Giftblase in diese ein, ist in nur wenige Windungen gelegt und mündet in deren Hohlraum, an dieser Stelle eine Verdickung, den $\mathrm{Kn}$ opf, bildend (Abb. 6).

3. Aus der Giftblase führt ein Ausführungsgang nach aussen, in den

4. eine Anhangsdrüse mündet. Von dem Sekret derselben wird, da es wie alle Drüsensekrete des Ameisenkörpers alkalisch ist im Gegensatz zu dem sauren der Giftdrüse, vermutet, dass es zur Neutralisation des letzteren dient, damit dieses den betreffenden Ameisen selbst nicht schädlich wird.

An dem Stachelapparat ${ }^{1}$ ), den Abb. 8, aus dem Abdomen heraus präpariert, im Zusammenhang mit den sein Gerüst bildenden Chitinleisten darstellt, unterscheidet man die Stachelrinne, in der die Stechborsten liegen, und die Stachelscheide. Da der Ameisenstachel keine Widerhaken besitzt, so kann er nach dem Stich wieder aus der Wunde herausgezogen werden.

Während bei den mit einem Stachel bewehrten Ameisen das Gift aus der Drüse bei dem Stich unmittelbar in die Wunde entleert wird, verfahren diejenigen ohne Stachel (die Camponotinen) in der Weise, dass sie dem Gegner mittels ihrer Kiefer eine Bisswunde beibringen, und, indem sie gleichzeitig den

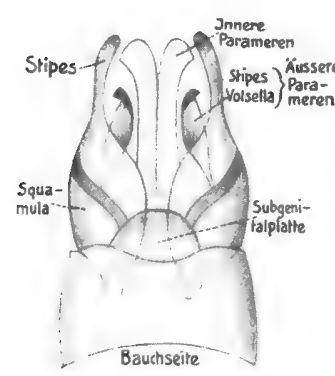

Abb. 9. Genitalanhänge von Camponotus ligniperda $\sigma^{7}$

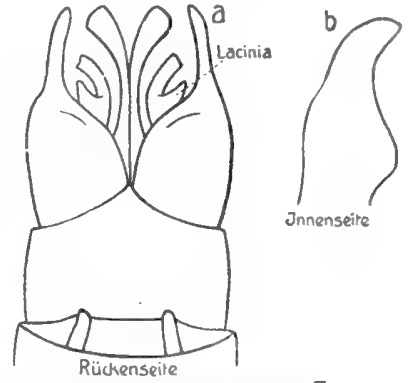

Es wirkt in

Hinterleib gegen diese nach vorn biegen, Gift hineinspritzen.

Letzteres enthält in grösserer Menge Ameisensäure, deren stechend saurer Geruch leicht wahrzunehmen ist, wenn man die flache Hand über ein Nest der Waldameise hält, auf dessen Oberfläche sich die Bewohner zur Verteidigung sammeln und ihr Gift ausspritzen, oder, wenn man eine solche Ameise zwischen den Fingern hält. Es wirkt in grösserer Menge auf die Haut stark blasenziehend. Die eigentliche Giftwirkung auf die Wunde beruht aber sicher weniger auf dem Gehalt der Säure, sondern auf einem enzymartigen, noch unbekannten Stoff.

Bei den Dolichoderinen sind Giftapparat und Stachel zurückgebildet. Die Vertreter dieser Gruppe besitzen dafür, ebenfalls für den Zweck der Verteidigung, über dem Darm jederseits eine Drüse, die in den hinteren Teil je einer geräumigen $\mathrm{S}$ a m melbla se mündet, deren Aussenwand sie anliegt. Beide Behälter vereinigen sich hinten zu einem kurzen Ausführungsgang, durch den das Sekret in den Enddarm, kurz vor dessen Mündung, ergossen wird. Es zeichnet sich bei manchen Arten (Tapinoma) durch einen eigenartigen Geruch aus.

Wie schon bemerkt, fehlen allen männlichen Ameisen Giftapparat und Stachel. Morphologisch entsprechen die Teile des letzteren den Anhängen, die bei ihnen am Abdominalende um die Geschlechtsöffnung stehen. Die Abb. 9 zeigt diese Teile, stark auseinandergezogen, von Camponotus ligniperda, von oben und von unten gesehen. Die am Grunde gelegene Schuppe ist die Subgenitalplatte; die beiden äusseren, klappenartigen Gebilde heissen Stipites; nach innen davon liegen Volsella und Lacinia. Letztere drei Teile werden zusammen als äussere Parameren, die übrigen als innere Parameren bezeichnet. 

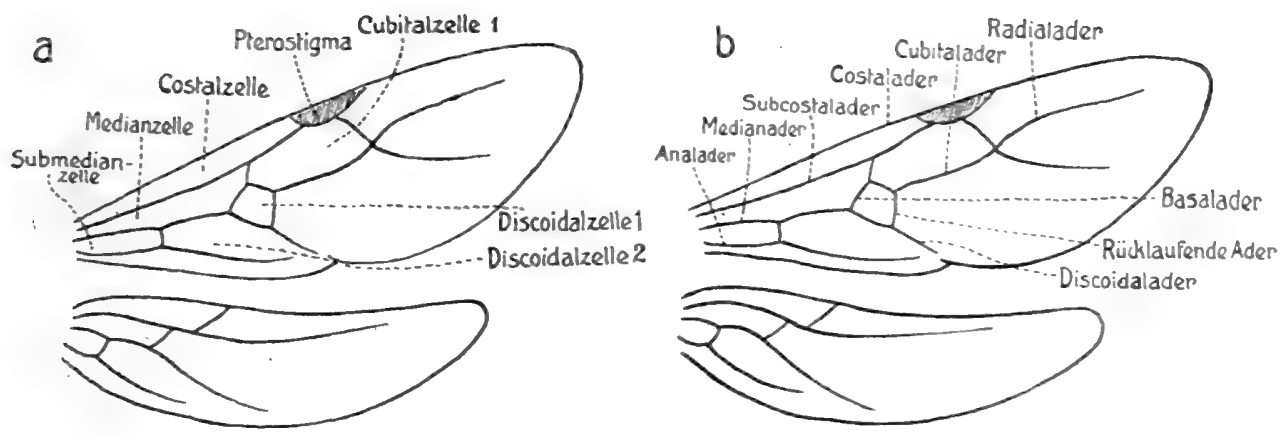

Abb. 10. Flügel von Lasius niger $q$.

Flügel sind allen Geschlechtstieren eigen, obwohl es Ameisen gibt, bei denen das eine oder das andere Geschlecht ungeflügelt ist. Arten, bei denen beide Geschlechter ungeflügelt sind, sind bisher nicht bekannt geworden. Die Flügel brechen an ihrer Wurzel leicht ab und werden von den Weibchen nach der Befruchtung abgeworfen, oder sie werden ihnen von den Arbeitern abgebissen, da sie nach vollendetem Hochzeitsflug (S. 21) keine Bedeutung mehr haben. Das Geäder des Ameisenflügels ist verhältnismässig einfach; seine Anordnung kommt für die Bestimmung der Tiere nicht in dem Grade in Betracht wie bei anderen Insekten und ist in beiden Geschlechtern dieselbe. Die Bezeichnungen ergeben sich aus Abb. 10 (Zellen und Adern) von Lasius niger.

An den Beinen (Abb. 11) unterscheidet man Hüfte (Coxa), im Thorax gelegen, Schenkelring (Trochanter), Oberschenkel (Femur), Unterschenkel (Tibia) und Fuss (Tarsus), dessen erstes Glied am längsten ist, und dessen letztes zwei Krallen trägt, zwischen denen $\mathrm{Haft}$ lappen sitzen.

Die auffallend grösseren und kräftigeren Borsten an den Tibien heissen Sporne. Der Sporn, der gelenkig am Ende der Tibia jedes Vorderbeins sitzt, ist stark verbreitert, am Ende wieder zugespitzt und an seinem Innenrand kammartig gezähnt. Der gegenüberliegende Rand des ersten Fussgliedes besitzt ..eine ähnliche Reihe von Zähnen, an deren Grund die Öffnungen von Drüsen liegen. Beide Kämme bilden den sogenannten Putzapparat, der den Ameisen zur Reinigung der Antennen dient.

Die Organe des Verdauungsapparates sollen hier nur soweit in Betracht gezogen werden, als sie anderen Insektenordnungen gegenüber Besonderheiten bieten.

Die Mundteile wurden gelegentlich der Beschreibung des Kopfes (S. 11) beschrieben. In die Mundhöhle und den mit ihr zusammenhängenden, von starker Muskulatur umgebenen Pharynx, der als Ansaugeapparat dient, münden, den drei Paaren von Mundteilen entsprechend, drei Drüsenpaare.

1. Mandibulardrüsen. Sie sind ziemlich stark entwickelt. Die Ausführungsgänge ihrer Zellen vereinigen sich zu Bündeln, die durch eine Siebplatte aus Chitin (Cribellum) gehen, und münden in einen unter und hinter dem Auge

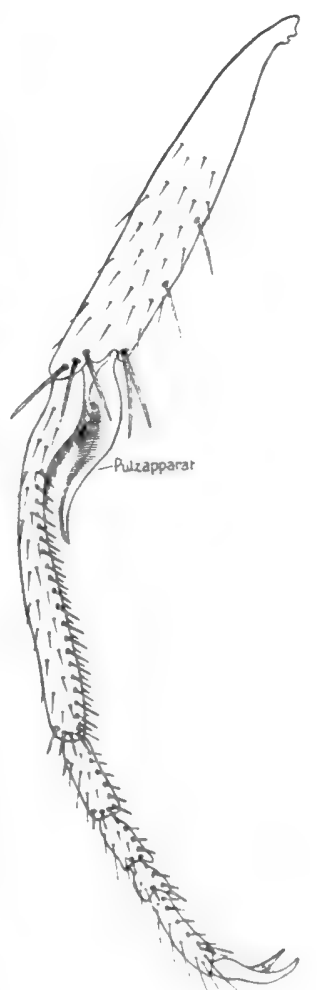

Abb. 11. Distaler Teil des Vorderbeins von Camponotus ligniperda $\not$. 
gelegenen Behälter, aus dem das Sekret durch einen feinen Spalt am Grund der Mandibeln austritt. Wahrscheinlich dient es als Bindemittel für das Baumaterial der Ameisen.

2. Maxillardrüsen. Ihre Ausbildung ist eine geringe. Sie liegen nahe der Mittellinie des Kopfes über der Mundhöhle. Die Zellen sind traubig angeordnet; ihre Ausführungsgänge gehen ebenfalls durch ein Cribellum und münden jederseits seitlich in die Mundhöhle. Sie liefern höchstwahrscheinlich ein Verdauungssekret.

3. Labialdrüsen, auch im engeren Sinn als Speicheldrüsen bezeichnet. Sie sind stärker entwickelt und im Thorax gelegen. Ihre beiden Ausführungskanäle vereinigen sich zu einem unpaaren Gang, der oberhalb der Unterlippe in die Mundhöhle mündet. Das Sekret ist als Nährmaterial für die Aufzucht der Larven von Bedeutung.

Die Speiseröhre (Oesophagus) geht als langes, dünnes Rohr durch Thorax und Stielchen. An sie schliessen sich im Abdomen drei besondere Teile: Kropf, Pumpmagen und Chylusmagen.

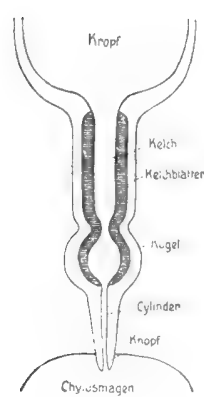

Abb. 12. Schema des Pumpmagens eines Camponotus einer Plach Emery und Forel)
(nach

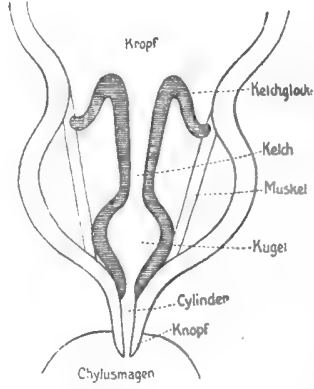

Abb, 13.

Schema des Pumpmagens einer Plagiolepis

Der Kropf (Ingluvies) ist eine dünnwandige, sehr dehnbare Erweiterung der Speiseröhre, in welcher die Ameisen grosse Mengen der aufgenommenen, flüssigen Nahrung aufzuspeichern vermögen, oft in dem Grade, dass, besonders bei manchen Camponotinen, der Hinterleib in auffallender Weise ausgedehnt erscheint, bedeutend weniger bei andern Ameisen, z. B. bei Myrmica. Von dieser Nahrung kann das Tier, wahrscheinlich durch eine vom Pharynx eingeleitete Würgebewegung, willkürlich etwas von sich an andere Individuen abgeben.

Der Pumpmagen (Proventriculus), mit Unrecht auch Kaumagen genannt, ist bei den einzelnen Hauptgruppen der Ameisen in verschiedener Weise entwickelt. In seiner einfachsten Form stellt er ein Rohr dar, das innen in Längsfalten gelegt und mit Chitin überzogen ist, und in dieser Form findet er sich bei den Myrmicinen, Ponerinen (und Dorylinen). Bei den übrigen Gruppen kann man an ihm drei Teile unterscheiden: den Kelch, dessen Wand die vier langen, aus Chitin bestehenden Kelchblätter enthält, die Kugel und den Zylinder. Die Stelle, an welcher der letztere in den Chylusmagen hineinragt, wird Knopf genannt.

Bei den meisten Gattungen der Camponotinen folgen diese drei Abschnitte langgestreckt aufeinander (Abb. 12); bei anderen sind die Kelchblätter in Form eines Pilzhutes, eine Kelchglocke bildend (Abb. 13), nach hinten zurückgefaltet; bei den Dolichoderinen ist auch der Zylinder sehr kurz und wird von dem sich aussen über den Pumpmagen wölbenden Kropf verdeckt.

Die Funktion des Pumpmagens besteht darin, die im Kropf aufgespeicherte Nahrung in den Chylusmagen zu befördern. (Er hat für die Systematik, besonders bei den Dolichoderinen, eine wichtige Bedeutung, kommt aber für die Bestimmung der einheimischen Formen nicht in Betracht.)

Oesophagus, Kropf und Pumpmagen sind von einer kräftigen Ringmuskulatur und einer schwach entwickelten Längsmuskulatur umgeben und innen von einer Chitinhaut ausgekleidet. Ihre Wandung ist drüsenlos.

Der Chylusmagen (Ventriculus) enthält dagegen Drüsen und dient der Verdauung. Da, wo sich ihm der Dünndarm anschliesst, befindet sich ein 


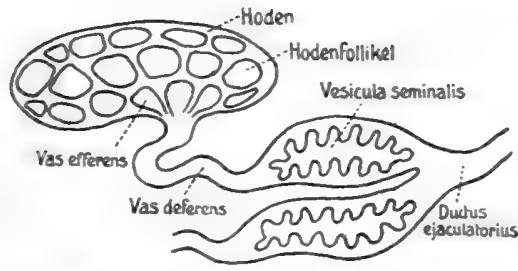

Abb. 14. Schema des $\sigma^{7}$ Genitalapparates von Formica fusca.

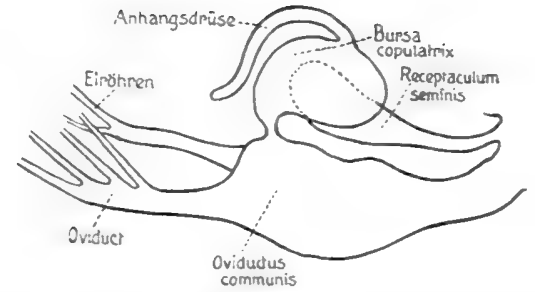

Abb. 15. Schema des $q$ Genitalapparates von Lasius niger.

Klappenverschluss; hinter dieser Stelle gehen zahlreiche (6-20) Malpighische Gefässe in ihn hinein, und an sein Ende schliesst sich der erweiterte Enddarm (Rectum), der in der Analöffnung am Abdominalende mündet.

Diese hat bei den Unterfamilien verschiedene Form. Bei Camponotinen liegt sie an der Hinterleibsspitze, ist rund und von einem Borstenkranz umgeben, bei den Dolichoderinen unterhalb derselben als quergestellte Spalte ohne Borstenkranz. Bei Ponerinen und Myrmicinen ist sie spaltförmig.

Die (inneren) Geschlechtsorgane des Männchens (von Formica fusca, Abb. 14) bestehen aus zwei stark entwickelten, aus zahlreichen Kammern (Follikeln) zusammengesetzten Hoden (Testes) (bei Formica sanguinea 21, bei Leptothorax 3). Die Ausführungsgänge der einzelnen Follikel (Vas a efferentia) vereinigen sich an der Unterseite jedes Hodens in dessen Mitte zu einem kurzen, etwas gewundenen Kanal, dem Samenleiter (Vas deferens), der in eine grosse Samenblase (Vesicula seminalis) mit dicken und ineinander gefalteten Wänden mündet. Die Ausführungsgänge beider Samenblasen münden in den gemeinsamen, kurzen, von Muskeln umgebenen Ductus ejaculatorius, der innerhalb der Genitalanhänge nach aussen mündet.

Die (inneren) Geschlechtsorgane des Weibch en s (von Lasius niger, Abb. 15) zeigen zwei von zahlreichen Luftröhren (Tracheen) umsponnene Eierstöcke (Ovarien). Jeder davon setzt sich aus einer Anzahl Eiröhren zusammen, unter einheimischen Formen beispielsweise bei Camponotus aus 40, Formica rufa 45, Lasius niger 30-40, den Arten von Myrmica um 10 herum, Plagiolepis 4-5; (bei gewissen exotischen Arten sind es mehrere Hundert). Die Eiröhren beginnen mit einem dünnen, fadenförmigen Stück, dem sogenannten Endfaden, und werden nach ihrem Ende hin dicker und geräumiger. Man kann an ihnen eine Kammerung in dicht aufeinander folgende, abwechselnd kleine und grössere Abteilungen erkennen; letztere, die Eikammern, enthalten ein Ei, erstere, die Nährkammern, die für das $E_{i}$ bestimmten $\mathrm{Nährzellen,} \mathrm{die} \mathrm{aber} \mathrm{gegen} \mathrm{die}$ Mündung der Eiröhre hin verschwinden. Beide Röhren vereinigen sich zu einem mit Muskulatur
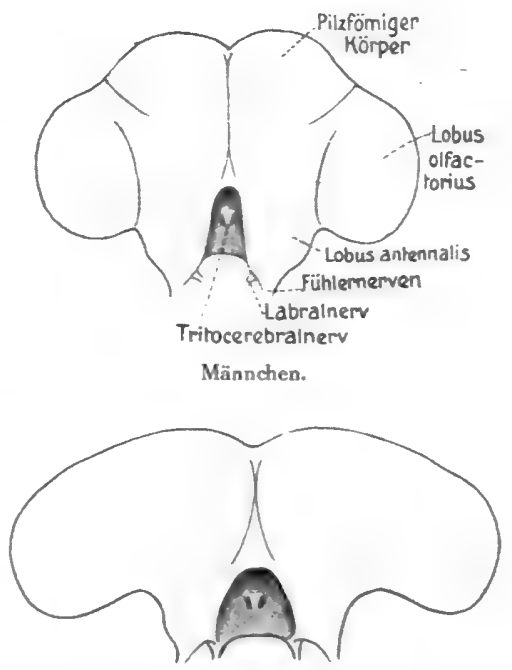

Weibchen.

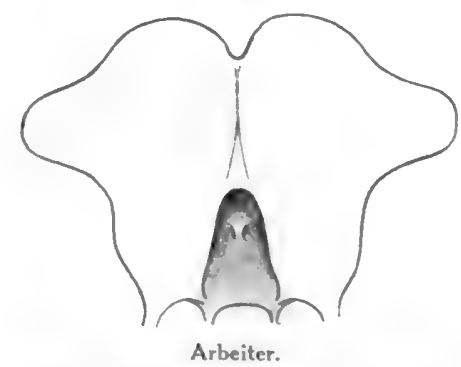

Abb. 16. Aussere Gestalt des Gehirns von Camponotus ligniperda, von vorn gesehen (nach Pietschker). 
umgebenen Ausführungsgang (Oviductus communis), in dessen starkwandigen, letzten Teil zwei andere Organe münden, die dickwandige Bursa copulatrix und das Receptaculum seminis. Letzteres ist innen in Falten gelegt und trägt zwei (Lasius niger eine) Anhang sdrü sen von schlauchförmiger Gestalt.

Die Genitalorgane der Arbeiter sind, da letztere als modifizierte Weibchen zu betrachten sind, dieselben wie bei den Weibchen, aber stark zurückgebildet. Daher vermögen die Ameisen unter gewissen Umständen aus Arbeitern Ersatzköniginnen zu ziehen (S. 29), deren Nachkommenschaft aber

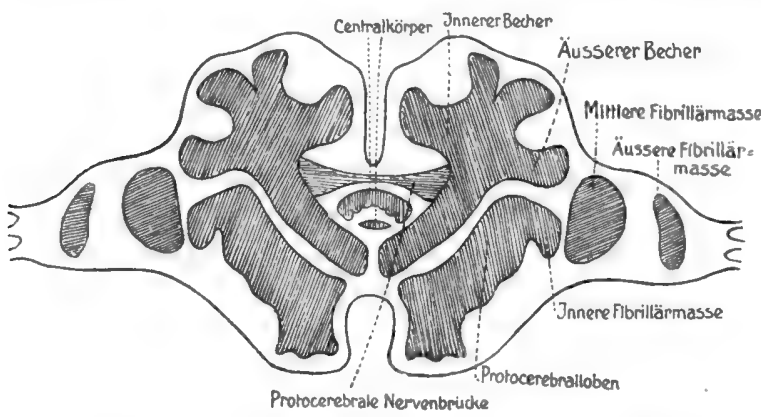

Abb. 17. Frontalschnitt durch das $\not \subset$ Gehirn (nach Pietschker). immer Arbeiter oder Männchen sind. Nach Jan et hat Myrmica rubra $\not{q}$ jederseits nur ei e Ovarialröhre(Receptaculum und Bursa fehlen), nach Bickford Lasius flavus $\$$ jederseits 2-6, Tetramorium caespitum \& gar keine.

Zum Nervensystem: Das Gehirn der Ameisen ${ }^{1}$ ) besteht aus einem Paar miteinander verbundener Nervenanschwellungen, die oberhalb des Schlundes gelegen sind, und einem zweiten, darunter liegenden, ebenfalls zusammenhängenden Paar. Óbere und untere Knoten sind durch sogenannte Kommissuren verbunden, die bei den Ameisen so kurz sind, dass beide Knoten dicht nebeneinander liegen. Durch den auf diese Weise gebildeten Ring geht der Schlund, von dem Ring aus das Bauchmark mit seinen Nervenknoten und den davon ausgehenden peripheren Nerven. (Bei Formica fusca of verteilen sich die Knoten in folgender Weise: im Prothorax 1, in den beiden folgenden Thoraxabschnitten 2 dicht hintereinander liegende, im Stielchen unter der Schuppe 1, im Abdomen

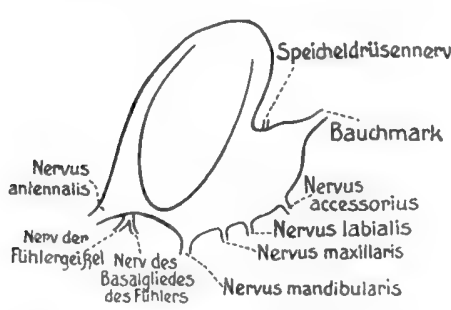

Abb. 18. Gehirn des , von der Seite gesehen (nach Pietschker). vorn 1 , weiter hinten ein aus mehreren zusammengesetztes Ganglion.)

Die beiden oberen Nervenknoten (Oberschlundganglien, Hirnhälften) (Abb. 16-18) werden durch eine mediane Furche oben geschieden, unterhalb derer im Innern des Gehirns der Zentralkörper gelegen ist. In ihnen liegen die sogenannten pilzförmigen Körper, an denen man Stiel und Becher unterscheidet. Unterhalb des Stiels verläuft jederseits der Gehirnstamm (Protocerebrallobus), und unter diesem findet sich der Lappen für die Antennennerven (Lobus antennalis). Die nach aussen ragenden Verdickungen sind die Sehlappen (Lobus opticus).

Im Zentralkörper kommen die Nervenfasern aus den verschiedenen Teilen des Gehirns zusammen. - Die pilzförmigen Körper sind auch bei anderen Insekten vorhanden, aber nur sehr gering entwickelt. Sie treten am deutlichsten hervor bei den Hymenopteren und erreichen unter diesen bei den gesellig lebenden Arten, den Ameisen, Bienen, Hummeln, Wespen, ihre höchste Ausbildung; bei letzteren sind sie am grössten. Bei den Arbeitern finden sie sich stärker ausgebildet als bei den Geschlechtstieren und stehen, wenn auch nicht allein, in 
engem Zusammenhang mit geistigen Fähigkeiten der Tiere. - Der Gehirnsta $\mathbf{m m}$ ist in allen drei Formen der Ameisen in gleicher Weise entwickelt. Mit dem Lobus opticus zusammen hängen die Nerven der Facettenaugen. Er ist bei den Männchen, im Zusammenhang mit deren verhältnismässig grossen Augen, am stärksten entwickelt. Die Nerven der Ocellen stehen zu anderen Centren in Beziehung.

\section{Polymorphismus.}

Von den zu Anfang des vorigen Kapitels angeführten drei Grundformen der Ameisen gibt es Abweichungen, die durch biologische Verhältnisse hervorgerufen werden, die aber in ihrer Vollständigkeit und Mannigfaltigkeit nur bei Berücksichtigung auch der exotischen Arten aufgeführt werden könnten. (Wheeler stellt 24 solcher Formen zusammen.) Bei vielen dieser Zwischenformen ist kaum festzustellen, ob sie als umgebildete sie werden daher als ergatogyne Formen bezeichnet.

Über die Entstehung der Zwischenformen hat man verschiedene Ansichten zur Geltung zu bringen gesucht. Nach Weismann ist sie auf bereits im Keimplasma vorhandene Anlagen zurückzuführen. Spencer hält die Verschiedenartigkeit in der Fütterung der Larven für die Ursache. Emerys Ansicht ist eine vermittelnde. Die Ursache der Ausbildung polymorpher Formen ist nach ihm allerdings bereits im Keimplasma vorhanden; die Verschiedenheit in der Ernährung der Larven gibt aber erst den Anstoss zur Entwicklung der betreffenden Zwischenform.

Einen Beweis dafür, dass die Ernährung in der Ausbildung von Zwischenformen ein wichtiger Faktor ist, haben wir in den Ergebnissen der Wasmannschen Untersuchungen über die Entstehung der Pseudogynen. Doch ist es nicht angängig, alle Formen des Polymorphismus daraus zu erklären. Es müssen dabei auch stammesgeschichtliche Momente mitsprechen.

Für unser Gebiet kommen folgende Abweichungen in Betracht:

\section{Arbeiter.}

1. Makroergaten. - Es sind (Wasmann) Arbeiter aus solchen Ameisengattungen, bei denen normaler Weise die Arbeiter gleich gross und gleich gestaltet sind; die Makroergaten unterscheiden sich von ihnen durch bedeutendere Grösse, besonders des Kopfes, ohne indessen durch diese Eigenschaft einer besonderen Tätigkeit im Verband angepasst zu sein. Sie wurden von Wasmann bei Myrmica scabrinodis und ruginodis beobachtet.

2. Soldaten (나) ). - Diese sind gegenüber den eigentlichen Arbeitern durch einen auffallend grossen Kopf kenntlich und mit ihnen nicht durch Zwischenformen verbunden. Bei den einheimischen Arten finden sich solche Soldaten nur in der Untergattung Colobopsis (S. 96). Sehr auffallend zeigt sich diese Gestaltung bei der Gattung Pheidole, die auch in Südeuropa vertreten ist (Abb. 46, S. 67). Die grossen Arbeiter der Gattung Camponotus sind nicht als Soldaten zu bezeichnen, da sie mit den kleinen durch Übergangsformen jeder Grösse verbunden sind.

3. Gynaekoide Arbeiter. - Wie auf S. 29 erwähnt, sind manche Ameisenarten (von Formica, Polyergus), wenn ihre Kolonie die Königin verloren hat, imstande, aus grösseren Arbeitern eine solche zu züchten, die sich dann durch ein mässig grösseres Abdomen von ihren Genossen unterscheidet. Doch ist dieser Zustand kein dauernder und bildet sich zurück, wenn die Kolonie wieder in den Besitz einer normalen Königin gelangt. 


\section{Weibchen.}

4. Mikrogynen. - Diese sind kleiner als die normalen (makrogynen) Weibchen, mit denen sie sonst in der Körperform und in ihrer Tätigkeit übereinstimmen. Sie kommen vor bei Formica fusca, Formicoxenus nitidulus, Myrmica und Leptothorax, fast stets zusammen mit Makrogynen.

5. Pseudogynen. ${ }^{1}$ ) - Sie sind ebenfalls kleiner als die normalen Weibchen. Ihr Kopf ist schmaler als der Rücken, letzterer in seinem Mittelteil (Mesonotum + Scutellum) buckelartig gewölbt, ohne Flügel. Das Abdomen mit dem Genitalapparat entspricht dem der Arbeiter. - Die Ursache der Entstehung solcher Formen ist auf das Vorhandensein gewisser Ameisengäste (Lomechusa, Xenodusa, Atemeles) zurückzuführen. Wheeler sucht die Erklärung für diese Formen in einer mangelhaften Ernährung der weiblichen Larven, Wasmann in einer „positiven Modifikation des Brutpflegeinstinktes der Arbeiterinnen, durch die eine Mischung der Arbeiter-Erziehung mit der Weibchen-Erziehung bewirkt wird, die in der andauernden Pflege der Lomechusa-Larven ihren Grund hat".

Die gewöhnlichsten Formen der Pseudogynen sind '):

a) Mikropseudogynen, von der Grösse der kleinsten Arbeiter.

b) Mesopseudogynen, von der Grösse der mittleren Arbeiter. Seltener sind

c) Makropseudogynen, welche nur in $1 / 10$ aller pseudogynenhaltigen Kolonien vorkommen; sie zeigen allmähliche Übergänge zu den Mesopseudogynen, den grossen normalen Arbeitern und den makronoten brachypteren Weibchen, sogar zu den normalen, schmalrückigen Weibchen.

* Echte Makropseudogynen. - Pronotum deutlich kleiner als der halbkugelig gewölbte Mittelteil des Rückens.

* Ergatoide Makropseudogynen. - Pronotum fast so gross als der Mittelteil des Rückens, der nur wenig mehr gewölbt ist als der des normalen Arbeiters.

* Gynaekoide Makropseudogynen. - Diese zeigen mehr oder weniger ausgebildete Rudimente von Flügeln.

6. Makronote brachyptere Weibchen. - Es sind Weibchen, die sich durch einen stark verbreiterten Thorax, aber sehr kurze Flügel auszeichnen. Ihre Entstehung ist gleichfalls auf das Auftreten gewisser Ameisengäste (Lomechusa) in einem Nest zurückzuführen.

\section{Männchen.}

7. Ergatomorphe. - Sie sehen den Arbeitern so ähnlich, dass sie von ihnen schwer zu unterscheiden sind, stellen jedoch keine degenerierten Formen dar, sondern scheinen den normal gebildeten vollkommen gleichwertig zu sein. Sie kommen vor bei Formicoxenus.

8. Degenerierte Männchen. - (S. Anergates, Abb. 44, S. 66.)

\section{Leben der Ameisen.}

Im Laufe des Sommers bis in den Herbst hinein, vorzugsweise aber im Hochsommer, treten, je bei den einzelnen Ameisenarten zu einer gewissen Zeit, zuweilen auch Tageszeit, grössere Mengen von Geschlechtstieren in einem Nest auf. Ihr Erscheinen bewirkt, dass auch die Arbeiter in Menge und in grosser Aufregung auf dem Nest umherlaufen, zum Teil damit beschäftigt, die Geschlechtstiere am Verlassen des Nestes zu verhindern.

1) Nach Wasmann. 


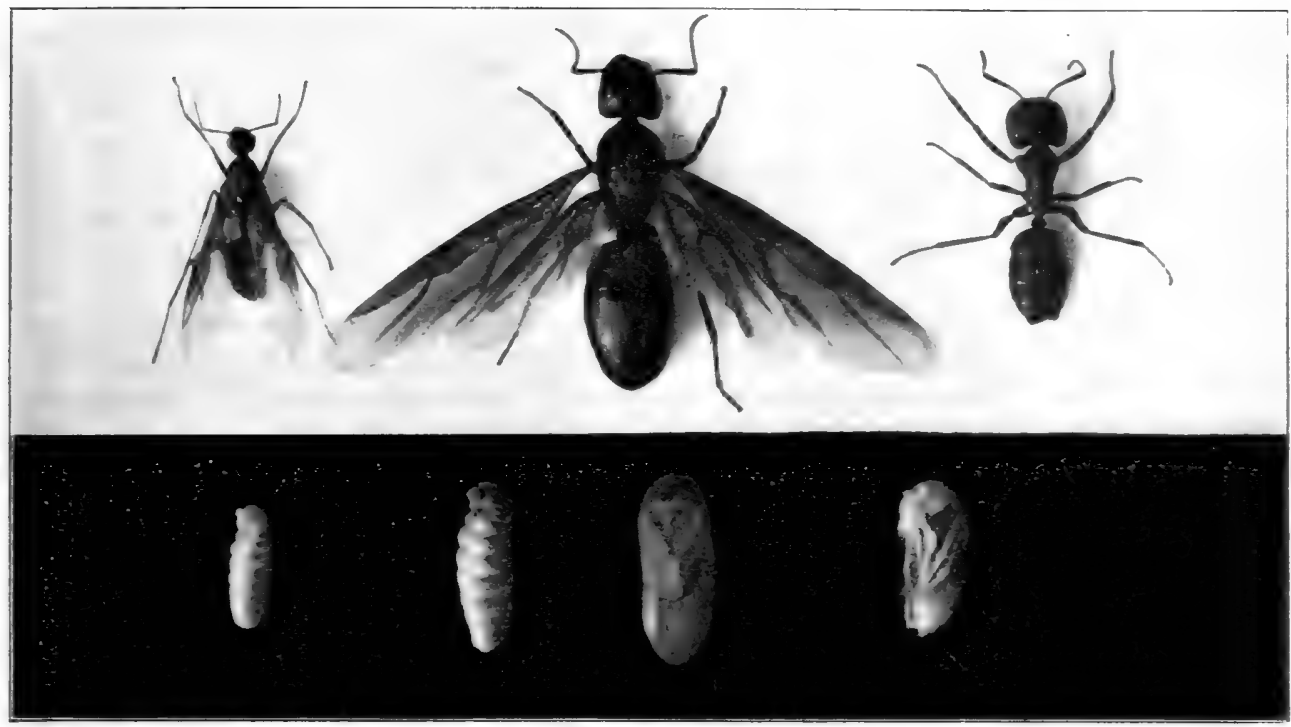

Abb. 19. Camponotus ligniperda.

Bei vielen Ameisenarten erheben sich schliesslich die geflügelten Tiere, oft grosse Schwärme bildend (Lasius, Myrmica), in die Luft zum sogenannten Hochzeitsflug, wie er auch vom Schwärmen der Bienen bekannt ist. Warmes, schwüles Wetter begünstigt diese Erscheinung; Kälte und Regen hält sie zurück. Bei manchen Arten findet dabei gleichzeitig die Kopulation statt, bei anderen (Formica) erst, nachdem sich die Tiere auf Bäumen oder Sträuchern niedergelassen haben oder auf die Erde zurückgelangt sind. Auch Kopulation auf dem heimatlichen Nest sowie innerhalb desselben kommt vor, nach der dann die befruchteten Weibchen freiwillig in das alte Nest zurückkehren oder von den Arbeitern dazu gezwungen werden. Auch Kopulation eines Weibchens mit mehreren Männchen nacheinander ist beobachtet worden. In der Zeit des Schwärmens kommt es häufig zu Kämpfen zwischen benachbarten Kolonien.

Männchen sind in einem Schwarm in der Mehrzahl vorhanden; oft sind in einem solchen mehrere, sogar viele Ameisenarten vertreten. Doch scheint Bastardbildung zwischen verwandten Arten trotz stattgefundener Kopulation selten zu sein, und die Übergangsformen, die vorkommen, sind vielleicht durch Variation zu erklären (Viehmeyer).

Wie bereits vorher angegeben, sind bei den meisten Arten beide Geschlechter mit Flügeln ausgerüstet, während es auch Ameisen gibt, bei denen nur die Männchen, und andere, bei denen nur die Weibchen geflügelt sind. Im zweiten Fall können die Weibchen auf ihrem Weg vom Nest leicht von Männchen aufgefunden werden, oder die Männchen gehen in andere Nester, um dort die weiblichen Tiere aufzusuchen. Auch können beide Geschlechter in dem ursprünglichen Nest verbleiben, was auch im dritten Fall stattfinden wird. Doch führen diese Verhältnisse leicht zur Degeneration.

Der Hochzeitsflug hat eine dreifache Bedeutung. Einmal bezweckt er im allgemeinen die Vereinigung der Geschlechter. Teils dadurch, dass die Tiere flugfähig sind, teils dadurch, dass sie während des Fluges durch den Wind leicht weggetrieben werden, wird ferner die weitere Ausbreitung der Art begünstigt. Endlich wird durch ihn eine Inzucht, die Degeneration zur Folge hat, vermieden, 
und zwar ausserdem noch durch die Tatsache, dass bei vielen Arten die Geschlechter nicht zu gleicher Zeit in demselben Nest auftreten.

Die Männchen fristen nach dem Hochzeitsflug nur noch ein kümmerliches Dasein und gehen, nachdem sie noch mehr oder weniger lange Zeit gelebt haben, zu Grunde, wozu auch ihre geringen psychischen Fähigkeiten beitragen. Zuweilen werden die im Nest zurückbleibenden dort noch geduldet, oder sie werden, wenn sie ausserhalb des Nestes fremden Arbeitern in den Weg kommen, von diesen getötet.

Unbefruchtet gebliebene Weibchen bleiben zuweilen während des Winters im Nest und kommen wohl im Jahr darauf zur Kopulation. Während die innerhalb des Nestes zur Kopulation gelangten Weibchen in dessen Verband verbleiben, woraus sich das Vorhandensein mehrerer bis vieler Königinnen erklärt, geht das ausserhalb des Nestes befruchtete Tier an die Gründung einer neuen Kolonie. Es entledigt sich seiner Flügel an deren Wurzeln, was ihm leicht gelingt, während die Flügel unbefruchteter Individuen schwieriger abbrechen. Die starke Flügelmuskulatur im Thorax wird nach und nach resorbiert. Dann stellt sich das Weibchen in der Erde unter einem Stein, in einem morschen Baumstumpf oder einem seiner Art sonst zusagenden Schlupfwinkel eine Höhlung her, die es ringsum verschliesst. Aus den hier gelegten Eiern zieht es selbständig, ohne Hilfe von Arbeitern, also anders wie die Bienenkönigin, die ersten Larven auf, die es füttert, reinigt usw., bis aus ihnen nach vollendetem Puppenstadium die ersten Arbeiter hervorgegangen sind. Auffällig ist es, dass die Königin in dieser Zeit den Nestraum niemals verlässt, um Nahrung für sich und für die Brut herbeizuschaffen. Sie selbst kann lange Zeit ohne solche bestehen; doch werden auch häufig einige der gelegten Eier verzehrt. Das Fütterungsmaterial für die Nachkommenschaft besteht wahrscheinlich aus Stoffen, die mit den Speichelsekreten des Weibchens ausgeschieden werden. Sie bilden sich in ihrem Körper zum Teil aus den Umwandlungsprodukten der resorbierten Flügelmuskulatur, zum Teil aus denen des stark entwickelten Fettkörpers des Tieres.

Es ist auch beobachtet worden, dass zwei oder mehrere Weibchen derselben Art in einem solchen primären Nest gemeinschaftlich ihre Brut aufziehen, dass aber, nachdem die ersten Arbeiter fertig entwickelt waren, diese Freundschaft in das Gegenteil umschlug, so dass schliesslich nur die stärkste Königin übrig blieb.

\section{Unabhängige Koloniegründung.}

So einfach, wie die Verhältnisse im vorhergehenden dargestellt sind, verlaufen sie beispielsweise bei Camponotus, bei Formica fusca und deren Verwandten, bei den meisten Arten der Gattung Lasius u. a., wo die Weibchen fähig sind, selbständig eine neue Kolonie zu gründen.

Abhängige Koloniegründung.

Schon etwas abweichend gestaltet sich die Koloniegründung bei Formica rufa und ihren Verwandten. Hier ist das einzelne Weibchen nicht mehr imstande, selbständig eine neue Kolonie zu gründen ${ }^{1}$ ) und ist

1. auf die Hilfe von Arbeitern ihrer Art angewiesen, indem sie von ihnen als Königin angenommen wird, falls diese ohne eine solche sind, und auf diese Weise ein neues Gemeinwesen sich entwickelt, das aber eine reine Kolonie ist.

2. Es kann das einzelne Weibchen versuchen, in eine königinlose Kolonie einer anderen Art einzudringen (Formica rufa bei fusca, Lasius fuliginosus bei mixtus),

1) In der Gefangenschaft beobachtete $\bigcirc \bigcirc$ (Viehmeyer) beschäftigten sich zwar mit Erdarbeiten; diese machten aber den Eindruck des Planlosen. Ganz selten kommt es zur Ablage von Eiern, die dann aber vernachlässigt oder verzehrt werden. 
mit deren Hilfe es dann eine neue Kolonie gründet. So entsteht eine temporär gemischte Kolonie, die aber nach dem Aussterben der Hilfsameisen, die ja keine Nachkommen haben, wieder zu einer reinen Kolonie wird.

3. In ähnlicher Weise, also durch Eindringen in das Nest einer verwandten Art (Formica fusca und rufibarbis), gründet das Weibchen von Formica sanguinea eine neue Kolonie; eine bei ersteren vielleicht vorhandene Königin wird von ihm getötet. Die gelegten Eier werden von den Hilfsameisen aufgezogen, so dass also ebenfalls eine gemischte Kolonie aus 2, unter Umständen auch 3 verschiedenen Arten entsteht. Sie bleibt aber eine dauernd gemischte dadurch, dass die Nachkommen der sanguinea-Königin Raubzüge zu anderen Nestern unternehmen, aus diesen Puppen rauben und in ihr eigenes Nest schleppen, wo sie aufgezogen werden und als Sklaven in dem gemeinsamen Haushalt tätig sind; von einer Sklaverei im gewöhnlichen Sinn ist also keine Rede. In stärker besiedelten Nestern wird ein Teil der geraubten Puppen verzehrt.

Viehmeyer hat (in künstlichen Nestern) eine dreifache Art der Koloniegründung bei der Formica sanguinea beobachtet: a) durch Adoption (wie unter 2 beschrieben), b) durch Puppenraub, c) durch Allianz (indem sich das sanguinea-Weibchen einem anderen Weibchen der erwähnten Arten anschliesst, von welchem die von der sanguinea gelegten Eier mit den eigenen aufgezogen werden,) und späteren Puppenraub.

4. Während Kolonien von Formica sanguinea unter Umständen auch als einfache Kolonien ohne Sklavenameisen zu bestehen imstande sind (fakultative Skla verei; dulotische Kolonien), ist letzteres bei den Arten der Gattung Polyergus (Amazonenameisen) nicht mehr möglich; (obligatorische Sklaverei; dulotische Kolonien). Der Instinkt, Sklaven zu rauben, sowie Puppen, die aber zum grössten Teil als Nahrung verwendet werden, ist bei diesen Ameisen so einseitig ausgebildet, dass ihnen die Fähigkeiten des Bauens, des Aufziehens der Brut und sogar der selbständigen Nahrungsaufnahme verloren gegangen sind. Dass dies alles, besonders das letztere, auf einem Verlust psychischer Fähigkeiten beruht, zeigt sich darin, dass ihre Mundteile zur selbständigen Nahrungsaufnahme wohl fähig wären, dass diese Ameisen sich aber von ihren Sklaven füttern lassen müssen, sonst bei der ihnen zusagendsten Nahrung verhungern würden. Die Mundteile sind in einseitiger Weise zu Waffen umgebildet und spielen bei den Raubzügen eine bedeutende Rolle.

Nach Emery (1909) kommt auch bei Polyergus Koloniegründung durch Adoption vor, indem ein Weibchen in die Nester der Hilfsameisen eindringt.

5. Harpagoxenus vertreibt die Bewohner eines Nestes von Leptothorax, welche ihre Puppen zurücklassen müssen, die dann mit den eigenen grossgezogen werden. Der Bestand der Kolonie wird durch nachträgliches Rauben von Puppen erhalten.

Die Individuen von Harpagoxenus sind zwar imstande, sich einige Zeit selbst zu ernähren, vermögen aber keine Nester zu bauen und ihre Kolonie ohne Hilfsameisen auf die Dauer nicht zu erhalten.

6. Eine von den bisher erwähnten Formen abweichende Art der Koloniegründung findet sich bei Strongylognathus testaceus, der in der Bildung seiner Mandibeln an Polyergus erinnert, aber in seinem ganzen Wesen nur ein schwaches Abbild desselben ist. Das Weibchen von Strongylognathus sucht sich mit einem solchen von Tetramorium caespitum zu vereinigen. Letzteres zieht die von jenem gelegten Eier zusammen mit seinen eigenen auf, und diese Tätigkeit wird von den später auftretenden Tetramorium-Arbeitern fortgesetzt. Man nennt eine so entstehende Kolonie Allianzkolonie. In dieser Kolonie sind, da die Tetramorium-Arbeiter sich mit viel mehr Sorgfalt der Aufzucht der kleineren Strongylognathus hingeben, Geschlechtstiere von diesen vorhanden; von Tetramorium ist dagegen die Mehrzahl Arbeiter. 
7. Den höchsten Grad von Abhängigkeit in betreff der Koloniegründung kennt man von dem in Nestern von Tetramorium lebenden Anergates (vgl. S. 66), von welchem es keine Arbeiter, sondern nur Geschlechtstiere gibt. Letztere suchen wahrscheinlich die Nester von Tetramorium caespitum auf, die keine Königin haben und deren Bewohner nun für die Aufzucht der von jenen gelegten Eier sorgen (Parasitismus). Eine Degeneration bei Anergates liegt auf der Hand; aber über ihre Entstehung ist man noch im unklaren.

Von solchen arbeiterlosen Ameisen sind in aussereuropäischen Gebieten noch eine Anzahl anderer Arten bekannt.

Die Verhältnisse, in denen die $\nmid \uparrow$ zu ihren Kolonien stehen können, sind, durch Übergänge miteinander verbunden, folgende (nach Wasmann):

I. Pleometrose. - Vorkommen mehrerer 우 derselben Art (Rasse) in einer Kolonie.

1. Primäre Pleometrose. - Allianz zweier oder mehrerer if zur Koloniegründung.

2. Sekundäre Pleometrose. - Erst nachträglich erfolgendes Auftreten mehrerer 우 in einer Kolonie;

a) durch Nachzucht aus der eigenen Kolonie,

b) durch Adoption von if aus fremden Kolonien,

c) durch Allianz von verschiedenen Kolonien derselben Art.

II. Allometrose (Forel). - Vorkommen mehrerer if verschiedener Arten (Rassen) in einer Kolonie.

1. Primäre Allometrose. - Allianz zwischen $+\ngtr$ verschiedener Arten (Rassen) zum Zweck der Gründung einer gemischten Kolonie;

a) zwischen 와 verschiedener Arten,

b) zwischen 우 verschiedener Rassen.

2. Sekundäre Allometrose. - Vorhandensein von 와 verschiedener Arten (Rassen) in einer Kolonie, das erst nach der Gründung zustande kam;

a) durch Adoption von 와 fremder Arten,

b) durch Adoption von if fremder Rassen,

c) durch Allianz von bereits fertigen, aber schwachen Kolonien verschiedener Art oder verschiedener Rasse.

Was den Zusammenhang dieser verschiedenen Stufen der Koloniegründung (von denen hier nur auf die Verhältnisse bei einheimischen Arten Rücksicht genommen ist) betrifft, so steht die Ansicht von Wasmann derjenigen von Emery, dem sich Viehmeyer anschliesst, entgegen.

Nach Wasmann beginnt die abhängige Koloniegründung bei denjenigen Arten, welche die Fähigkeit verloren, selbständig neue Kolonien zu gründen. „Von diesem Punkt aus führen zwei verschiedene Entwicklungsrichtungen, die sich immer weiter voneinander entfernen: einerseits zum sozialen Parasitismus, andererseits zur Sklavenzucht. Den ersteren Pfad haben jene Arten eingeschlagen, die (wie $F$. truncicola, exsecta usw.) ihre neuen Kolonien regelmässig durch friedliche Adoption bei fremden Hilfsameisen gründen; den letzteren haben jene Arten verfolgt, die (wie $F$. sanguinea) Sklavenräuber geworden sind und deren Königinnen ihre Kolonien meist nicht mehr auf friedlichem Wege, sondern durch gewaltsame Annexion von Arbeiterpuppen gründen. Die Raublust der Weibchen und Arbeiter, die anfangs nur in gelegentlicher (fakultativer) Sklavenzucht sich äusserte, steigert sich und führt dadurch zu den gesetzmässigen (obligatorischen) Formen der Sklavenhalterei." Auf der Höhe des Sklaverei-Instinktes steht Polyergus, bei dem bereits der Beginn parasitischer Degeneration zu erkennen ist, so dass zu vermuten ist, dass er im Lauf der 
Entwicklung zum sozialen Parasiten wird wie Strongylognathus, bei dem aber Anhaltspunkte zur Rekonstruktion seiner Vorgeschichte fehlen. Die Gattung Anergates ist durch die stufenweise Degeneration eines ehemaligen SklavereiInstinktes bis zum tiefsten sozialen Parasitismus herabgesunken.

Emery bestreitet die Wasmannsche Ansicht, dass der Sklaverei-Instinkt (Dulosis) die Ursache einer bis zu Anergates absteigenden Degeneration sei. Er leitet die temporär-parasitischen Formica-Arten ab von einer räuberischen Urform, von ihm als $F$. prosanguinea bezeichnet, die sich in zweifacher Richtung entwickelte:

1. Zu Formica rufa, truncicola usw. - Die Weibchen werden gleichgültig gegen die Brut, aber geschickter in der Fähigkeit, sich als Parasiten adoptieren zu lassen. Die von ihnen herstammende Nachkommenschaft war nicht raubsüchtig.

2. Zu Formica sanguinea und Polyergus. - Die Weibchen zeigten keine Fähigkeit zur Erziehung der Larven (sanguinea), Indifferenz gegen die Brut, Duldsamkeit (Polyergus). Die Arbeiter liessen im Gegensatz dazu in der Entwicklung ihres Raubinstinktes nicht nach; so kam es zur Ausbildung einer fakultativen Dulosis (sanguinea), die sich zur streng obligatorischen steigern liess (Polyergus).

Ebenso führt Viehmeyer den Sklaverei-Instinkt von sanguinea nicht auf einen früheren, temporär sozialen Parasitismus zurück, sondern neigt sich der Darwinschen Anschauung zu. Nach dieser „wurden die Puppen ursprünglich nur als Futter eingetragen. Als sich aber die zufällig aufgezogenen fremden Ameisen der Kolonie als nützlich erwiesen, wurde die Gewohriheit, Puppen als Futter einzusammeln, durch die natürliche Zuchtwahl verstärkt und für den Zweck, Sklaven zu erziehen, abgeändert und dauernd befestigt." Auch Viehmeyer hält die Sklaverei für die Ursache des sozialen Parasitismus und die Abstammung der Ameisen von räuberischen Vorfahren schon deshalb für wahrscheinlich, weil räuberische Lebensweise in dem Charakter der Ameisen besonders hervortritt. Er hält für die ursprüngliche Form der Koloniegründung von sanguinea diejenige durch Raub von Puppen, dann durch Puppenraub nach vorangegangener Allianz, zuletzt durch Adoption, nach welcher die Königin der Hilfsameisen getötet wird.

Die aus den ersten Eiern sich entwickelnden Arbeiter sind klein; indem aber unter deren Tätigkeit und infolge der zunehmenden Zahl der Arbeiter die Arbeitsteilung eine vollkommnere und damit die Brutpflege eine ausgiebigere wird, nehmen die später auftretenden Tiere an Grösse zu, und die Individuenzahl kann, je nach der betreffenden Ameisenart, eine ganz bedeutende werden. Während beispielsweise in Kolonien von Myrmecina und Ponera nur eine geringe Zahl von Tieren vorhanden ist, beläuft sich diese bei Lasius-Arten (fuliginosus) oft auf Tausende, in grossen Kolonien von F. rufa auf oft eine halbe Million. Wie bereits erwähnt, sind die Arbeiter in ihrer Entwicklung veränderte weibliche Tiere, und da beim Mangel einer Königin beobachtet wird, dass auch jene imstande sind, Eier hervorzubringen, so ist die grösste Wahrscheinlichkeit vorhanden, dass solches auch unter normalen Verhältnissen geschieht.

Die von der Königin gelegten, weissen bis gelblichweissen Eier (bei Lasius flavus nach Forel schwarz) werden meist sofort von den Arbeitern, die bei diesem Akt oft das Abdomen der Königin umstehen, in Pflege genommen, sehr häufig und ausgiebig durch Belecken gereinigt und im Nest hin und her getragen an die Stellen, wo die Temperatur- und Feuchtigkeitsverhältnisse, je nach den Tageszeiten und dem Wetter, für die Entwicklung am günstigsten sind. Der Transport ist dadurch erleichtert, dass die Eier in kleinen Klümpchen aneinander kleben. Ein Teil der gelegten Eier wird jedoch von den Ameisen 
selbst verzehrt, besonders in solchen Kolonien, die ohne Königin sind und wo sie von den Arbeitern gelegt werden. Ebenso verzehrt, wie schon erwähnt, die Königin im Beginn ihrer Nestgründung etwas von ihrem Gelege. Sich selbst überlassen, sterben die Eier ab.

Die sich entwickelnden weisslichen Larven, die im allgemeinen ähnlich wie die Eier von den Arbeitern umhergetragen werden, zeigen ausser dem Kopf ein 13 gliedriges Abdomen und sind beinlos. Sie haben ein dickeres Hinterende und ein verschmälertes, gegen die Bauchseite hin gebogenes Vorderende. Augen und Antennen, letztere nur bei einigen ausländischen Formen angedeutet, besitzen die Larven unserer Ameisen nicht. Die Mundteile sind dieselben wie die des entwickelten Tiers (Mandibeln, Maxillen, Labium), aber nur sehr schwach ausgebildet. Die meisten Ameisenlarven, auch unter den einheimischen, sind daher nur fähig, flüssige Nahrung aufzunehmen, die ihnen von den Arbeitern in die Mundöffnung gebracht wird, während beobachtet ist, dass die Larven von Lasius flavus auch imstande sind, selbständig zu fressen. Larven von Lasius, Formica, Tapinoma, Tetramorium sind auch an Insektenresten fressend angetroffen worden. Das Bedürfnis der Larve nach Nahrung erkennen die Arbeiter an den lebhaften Bewegungen des Vorderendes der ersteren. In den Mund, auf den Papillen der Mundteile, münden die Ausführgänge der Spinndrüsen, die sich weit in den Körper hinein erstrecken. Der Verdauungskanal ist einförmiger gebaut als der des entwickelten Tiers. Er besitzt an dem Übergang der Speiseröhre in den geräumigen Magen einen Pharynx, durch welchen die Schluckbewegungen bei Aufnahme der Nahrung zustande kommen. Doch steht der Magensack noch nicht mit dem Enddarm in Zusammenhang, und die geringen Reste unverdauter Nahrung sammeln sich am Grunde des ersteren an. Die Oberhaut der Larve trägt Chitinborsten.: Ausser einfachen, zugespitzten, wie sie allgemein bei Insektenlarven vorkommen und als Schutzorgane dienen, finden sich solche, die verzweigt, gebogen oder am Ende hakig gekrümmt sind. Sie dienen den Larven einerseits als Haftorgane an den Nestwänden, andererseits zum Haften aneinander, was in ähnlicher Weise wie bei den Eiern ermöglicht, dass sie von den Arbeitern, zu Päckchen verbunden, rascher von einem Ort zum andern getragen werden können.

Die Larven mancher Ameisengattungen (Camponotus, Lasius) sind sehr beweglich, die von anderen (Leptothorax, Solenopsis, Tapinoma) sehr träge. Diejenigen der Weibchen machen sich bald durch ihre bedeutendere Grösse kenntlich.

Nach Ablauf des Larvenstadiums, dessen Dauer verschieden ist (am längsten bei Lasius), verwandelt sich die Larve in eine Puppe (Nymphe), die bei den Unterfamilien der Myrmicinen, Dolichoderinen und bei manchen Camponotinen (Colobopsis) nackt, bei den Ponerinen und den meisten übrigen Camponotinen, normalerweise allen einheimischen (bei Formica rufa und fusca fehlt sie unter Umständen), in einer Puppenhülse (Kokon) ruht, welche die Larve mit Hilfe der erwähnten Spinndrüsen herstellt, und deren Hinterende häufig einen schwarzen Fleck hat, der sich schon zeigt, bevor die Umwandlung in die Puppe vor sich gegangen ist. In Wirklichkeit besteht dieser Fleck aus den durch die Hülle scheinenden Resten von Nahrung, die nach der bei der Verwandlung erfolgenden Verbindung des Magens mit dem Enddarm samt den Innenhäuten des Verdauungskanals ausgestossen werden.

Nach vollendetem Puppenstadium ist aus der Nymphe das geschlechtsreife Insekt (Imago) entstanden. Die Puppenhülse wird meist von den Arbeitern geöffnet; doch sind (nach Forel) die Imagines auch selbständig dazu fähig. Wie bei allen Insekten, ist die Imago noch nicht ausgefärbt und blass, mit noch weicher Chitinbekleidung, in ihren Bewegungen langsam, wird aber bald den 
anderen Ameisen ähnlich und beteiligt sich an deren Geschäften. Die Zeit der Entwicklung vom Ei bis zur Imago ist bei den einzelnen Arten verschieden. Sie wird im allgemeinen beeinflusst von den Ernährungsverhältnissen und der Witterung. Nach Fielde entwickelt sich die parthenogenetische Nachkommenschalt der Arbeiter langsamer als die Nachkommenschaft der Weibchen.

Obwohl beim ersten Anblick auch eines ungestörten Ameisennestes dessen Bewohner planlos durcheinander zu laufen scheinen, so zeigt doch ein längeres Beobachten bald, dass jedes Tier einer bestimmten Tätigkeit nachgeht, dass also, wie schon an den verschiedenen Formen der Ameisen (Polymorphismus) zum Ausdruck kommt, eine weitgehende Arbeitsteilung unter den Bewohnern einer Kolonie besteht, und dass weiterhin, wie festgestellt ist, für jede bestimmte Art der Arbeit immer dieselben Individuen in Betracht kommen. Solche von grosser Bedeutung ist die Brutpflege und der Nestbau.

Unter den Tätigkeiten der Ameisen nimmt ferner eine wichtige Stelle ein das Herbeischaffen der Nahrung und die Ernährung. Wie bereits erwähnt, können die Ameisen und ihre Larven, im Zusammenhang mit dem Bau ihrer Mundteile, nur mehr oder weniger flüssige Nahrung zu sich nehmen. Letztere ist, je nach der betreffenden Ameisenart, eine animalische, vegetabilische oder gemischte und besteht aus Insekten und deren Larven (in beiden Fällen auch aus anderen Ameisen), aus tierischen und pflanzlichen Resten, wie sie im Freien ja in Menge vorkommen, aus Süssigkeiten, die teils aus Blüten, teils aus Früchten bezogen werden, aus den Exkrementen von Pflanzenläusen und den Exsudaten mancher Ameisengäste.

Die Arbeitsteilung findet bei der Ernährung darin ihren Ausdruck, dass bestimmte Individuen die Nahrung, oft in weiter Entfernung vom Nest, aufsuchen, sich an Ort und Stelle zunächst selbst sättigen oder das erbeutete Material erst in das Nest schleppen. Die aufgenommenen Stoffe gelangen in den Vormagen, dessen Mechanismus ermöglicht, dass ihr Fintreten in den anschliessenden Teil willkürlich verhindert oder bewirkt werden kann. Ersterer dehnt sich mit zunehmender Füllung aus, oft so stark, dass die Abdominalsegmente auseinandergetrieben werden und die Intersegmentalhäute dazwischen als helle Ringe erscheinen.

Diesen im Vormagen aufgespeicherten Nahrungssaft verteilen nun die Arbeiter an ihre Nestgenossen, und zwar in der Weise, dass sie ihnen einen Tropfen davon in die Mundöffnung fliessen lassen. Die Tätigkeit der so gefütterten Tiere besteht nun darin, von der aufgenommenen Nahrung den Larven abzugeben sowie denjenigen Ameisen, die einer anderen Beschäftigung nachgehen.

Bei gewissen in wärmeren Gebieten vorkommenden Gruppen von Ameisen sind die Verhältnisse bei der Ernährung noch komplizierter und interessanter. (Körnersammler, Pilzzüchter, Honigameisen.)

Abfälle von der Nahrung, Exkremente, tote Ameisen, Puppenhäute sowie alle Unreinigkeiten im Nest werden mit Sorgfalt aus diesem geschafft, kommen auch teilweise gewissen Ameisengästen zugute. Gelingt es den Ameisen unter Umständen nicht, einen in das Nest geratenen Fremdkörper herauszuschaffen, so verfahren sie ähnlich den Bienen, indem sie ihn mit einer Schicht Erde umgeben.

Die Sorgfalt der Ameisen in betreff der Reinlichkeit erstreckt sich nicht nur auf die Eier und Larven, sondern auch auf ihren eigenen Körper. Die Beweglichkeit seiner einzelnen Teile ermöglicht eine fast allseitige, sorgfältige Säuberung mit Hilfe der Mundwerkzeuge. Häufig sieht man auch zwei Ameisen sich gegenseitig reinigen, wobei auch in Betracht kommen mag, dass sie, ähnlich gewissen Ameisengästen, die Exsudate auf der Körperoberfläche aufnehmen. Zur Reinigung der Antennen dient der an den Vorderbeinen befindliche Putz- 
apparat. Die Abfälle bei der Reinigung werden vorläufig in Form von kleinen Kügelchen in die Infrabuccaltasche aufgenommen und später beseitigt.

Wie für Reinhaltung ihres Nestes, so sorgen die Ameisen auch für dessen Sicherheit nach aussen hin. Die Arbeitsteilung findet auch hierbei ihren Ausdruck, indem für diesen Zweck wieder besondere Individuen, wohl auch immer dieselben, in Betracht kommen. Bei manchen Ameisengattungen werden gewisse grossköpfige Formen geradezu als Soldaten bezeichnet (S. 19), obschon nicht feststeht, dass sich gerade diese immer als besonders mutig erweisen. Bei drohender Gefahr, über die sich die Ameisen durch gewisse Bewegungen ihrer Antennen, vielleicht auch durch Stridulationstöne (S. 13) verständigen, sowie nachts werden die Nesteingänge verschlossen; bei Tage sind ausgestellte Wachen zu beobachten. Bei Colobopsis halten die Soldaten mit ihren sonderbaren Köpfen die Nestzugänge verschlossen (S.96). In welcher Weise Ameisen beim Öffnen ihres Nestes in kurzer Zeit ihre Brut in Sicherheit bringen, während andere die Verteidigung übernehmen, hat wohl schon jeder beobachtet.

Doch sind nicht alle Arten, auch nicht alle Individuen derselben Kolonie, in ihrem Charakter gleich. So sind z. B. Lasius brunneus, Formica fusca, auch Camponotus ligniperda trotz seiner Grösse, furchtsam, während andere, wie Formica sanguinea ${ }^{1}$ ), Polyergus rufescens, sich durch ihre kriegerischen Eigenschaften auszeichnen, die bei ihren Raubzügen gegen andere Kolonien (Sklavenraub) in Erscheinung treten. Als Waffen gebrauchen die Tiere ihre Mandibeln, die Giftdrüsen und den Stachel.

Vorzügliche Darstellungen von Ameisenraubzügen und -Schlachten verdanken wir Huber, Forel und Wasmann.

Dass die verwundeten oder sonst kranken Tiere von ihren Artgenossen gepflegt werden, ist beobachtet worden, ebenso aber auch, dass sie sich um diese nicht kümmern, oder, wenn sie dem Tode nahe sind, als unbrauchbare Glieder des Gemeinschaftslebens aus dem Nest hinausschaffen. Doch ist die Lebenszähigkeit der Ameisen bedeutend. Geköpfte Ameisen liefen (nach Fielde) bis 45 Tage lang im künstlichen Nest umher; solche, denen der Hinterleib abgeschnitten war, verrichteten ihre gewöhnlichen Beschäftigungen 5-14 Tage lang. Ein abgetrennter Kopf von Formica fusca bewegt seine Antennen noch stundenlang.

Durch Störungen, die eine Kolonie öfter treffen, durch ungünstige Witterungsverhältnisse u. a. werden Ameisen häufig veranlasst, ihr Nest zu verlassen, auszuwandern und eine neue Behausung zu errichten. Gewöhnlich suchen gewisse Tiere für diesen Zweck eine geeignete Ortlichkeit und veranlassen dann ihre Gefährten, ihnen dorthin zu folgen. Diejenigen, die sich weigern, das alte Nest zu verlassen, werden auf alle mögliche Weise dazu veranlasst und von manchen Arten, wie Formica rufa und fusca, Camponotus, mit den Kiefern erfasst und dorthin getragen. Auch viele Ameisengäste werden bei einem solchen Umzug mitgenommen oder folgen den Wirten freiwillig, während andere, wie die Larve von Cetonia floricola, in dem verlassenen Nest verbleiben.

Während der kalten Jahreszeit ruht die intensive Tätigkeit der Ameisen. Sie haben sich in die geschützten, tieferen Teile des Nestes zurückgezogen, und, ähnlich dem Winterschlaf höherer Tiere, halten sie diese Zeit ohne Aufnahme von Nahrung aus, indem sie sich möglichst bewegungslos verhalten, wodurch der Energieaufwand und mit ihm der Stoffwechsel sehr stark vermindert werden. Die warmen Tage im ersten Frühjahr locken sie allmählich wieder nach oben, und mit der steigenden Temperatur beginnt auch das Leben in der Kolonie aufs neue.

1) In einem Nest von Formica sanguinea und fusca konnte Wan ach aber auch feststellen, dass erstere sich ziemlich feige benahm, während letztere das Nest verteidigte. 
Im künstlichen Nest dauert diese Überwinterungsperiode je nach der Temperatur des Raumes, in dem es sich befindet, nur ungefähr 2 Monate im Wohnzimmer. Die Bewohner beginnen bald wieder, besonders bei guter Fütterung, ihre Tätigkeit.

Die Dauer des Bestehens einer Ameisenkolonie, die bis zu 40 Jahren beobachtet ist, hat naturgemäss ihre. Grenzen. Abgesehen von meist gewaltsamer Zerstörung durch Menschen und Tiere (darunter auch durch andere Ameisenarten) oder Wetterverhältnisse hängt sie in erster Linie ab von dem Vorhandensein der für die Nachkommenschaft sorgenden Königin. Geht diese verloren oder stirbt sie, nachdem sie eine gewisse Altersgrenze überschritten hat (10 bis 15 , sogar 20 Jahre sind festgestellt), oder ist der Inhalt ihres Receptaculum seminis erschöpft, so stirbt die Kolonie aus, wenn nicht mehrere Weibchen darin sind, die jüngeren Generationen angehören, oder eine andere Königin adoptiert wird. Doch können sich königinlose Kolonien mitunter noch längere Zeit halten. ${ }^{1}$ ) Häufig übernimmt dann eine dazu gezüchtete Arbeiterin das Legen von Eiern, aus denen sich nur männliche Tiere oder auch Arbeiter entwickeln, und die von den Tieren meist verzehrt werden. Der Untergang einer Kolonie wird ferner beschleunigt durch das zahlreiche Auftreten gewisser Ameisengäste (S. 47) und durch Pilzbildungen an den Ameisen selbst.

\section{Wohnungen der Ameisen.}

Die Nester der einzelnen Ameisenarten zeigen im allgemeinerı gewisse typische Formen. Von diesen lassen sich aber zahlreiche Variationen beobachten, da die Tiere in ihrer Bautätigkeit sich der Bodengestaltung und den Witterungsverhältnissen einer Gegend vorzüglich anzupassen vermögen, bei der Anlage ihres Nestes möglichst die Bestrahlung durch die Morgensonne auszunutzen verstehen und sich nach den Wetterverhältnissen der Jahre richten. Nach Wasman $n$ baut z. B. Formica rufa ihre Kuppeln höher in kühlen, regenreichen, flacher in heissen, trockenen Sommern. Häufig kommt es auch vor, dass eine Art das von einer anderen verlassene Nest bezieht. Wenn man die mannigfaltigen Nestformen der ausländischen Ameisen ausser Betracht lässt, so kann man diejenigen der einheimischen Arten in der folgenden Weise gruppieren:

Morphologisch betrachtet, sind zu unterscheiden:

1. Erdnester. Diese bestehen aus einem System von Gängen in der Erde mit eingeschalteten Kammern, die zur Aufnahme der Brut dienen. Sie sind im einfachsten Fall minierte Nester ohne Bedeckung mit einem anderen Material. Sehr häufig ist diese Nestform bei Formica rufibarbis, Tapinoma erraticum und Tetramorium caespitum, seltener bei Formica sanguinea, Camp. ligniperda, Lasius flavus, niger, alienus. Auch Myrmecina latreillei und Ponera coarctata bewohnen solche Nester, letztere Art oft am Grund von Bäumen.

Vorzugsweise in Gebirgsland finden sich Erdnester unter flachen Steinen, dadurch geschützt gegen Feuchtigkeit und zu starke Sonnenbestrahlung, jedoch so angelegt, dass beide Faktoren in geeigneter Weise für das Wohlbefinden der Kolonie ausgenutzt werden. Viele Arten, die in der Ebene gewisse Nestformen haben, finden sich im Gebirge an trockenen Stellen unter Steinen. Formica gagates nistet wohl immer unter solchen. An denselben Ortlichkeiten kommen vor Formica fusca, cinerea, rufibarbis, zuweilen Formica sanguinea, truncicola, pratensis, pressilabris, ferner Camponotus ligniperda, seltener pubescens und lateralis, dann gewisse Myrmica-Arten, Lasius umbratus, brunneus, Leptothorax acervorum, tuberum, sowie Cremastogaster scutellaris.

1) Formica fusca in dem Viehmeyer-Nest Abb. 32, S. 41 über 3 Jahre, aus dem Stamm Abb. 21, S. 31, Eier legend, aus denen sich meist $¥$, , im letzten Sommer auch mehrere $\sigma^{7}$ entwickelten. 
Aus Bodenmaterial, besonders bindigem Boden, aufgebaut sind die Kuppelnester, denen Grasbüschel, Pflanzenstengel oder Baumstücke als Gerüst dienen, um die herum die Kuppel errichtet ist. Am meisten typisch ist diese Nestform für Lasius flavus. (Bruchstück: Abb. 20.) Ferner bauen Kuppeln Lasius niger, auch alienus, umbratus, mixtus, Formica fusca, Tetramorium caespitum und manche Myrmica-Arten; selten sind sie bei den in Betracht kommenden Camponotus-Arten. Die von Tapinoma erraticum errichteten Bauten dieser Form werden nur zeitweise bewohnt.

2. Holznester. Solche werden von den einheimischen Camponotus-Arten in lebenden Stämmen hergestellt (Abb. 22), so dass die miteinander in

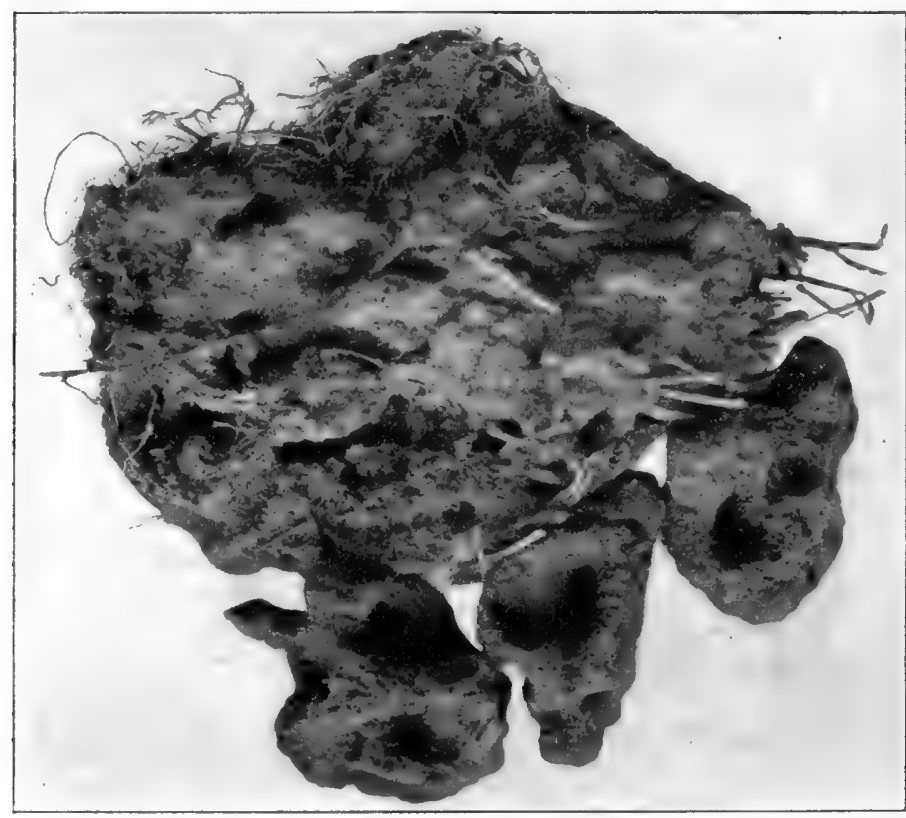

Abb, 20. Bruchstück aus einem Nest von Lasius favus.

Verbindung stehenden Gänge, den Jahresringen folgend, im weichen Sommerholz angelegt und daher konzentrisch sind. Bei Colobopsis münden nur wenige Gänge nach aussen und werden durch dieKöpfe der Soldaten versperrt. Die Arten von Camponotus wohnen auch in Baumstümpfen, teilweise den Detritus derselben als Baumaterial verwendend, ebenso wie Formica fusca (Abb. 21), sanguinea, Lasius niger, auch brunneus und alienus, Myrmica laevinodis und ruginodis.

In hohlen Zweigen finden sich Nester von Leptothorax und Dolichoderus, von letzterem besonders in Nussstämmen, was wohl damit zusammenhängt, dass deren Zweige ein gefächertes Mark besitzen.

Unter Baumrinde nisten Leptothorax corticalis, acervorum (in der Ebene), affinis, nylanderi, häufig Formica fusca, cinerea, sanguinea, Lasius niger, alienus, Tetramorium caespitum, zuweilen Camponotus lateralis, Lasius brunneus.

3. Nester in Gesteins- und Mauerspalten. In solchen finden sich häufig Kolonien von Lasius emarginatus und Cremastogaster scutellaris, zuweilen auch von Lasius brunneus, Tetramorium caespitum, sowie Leptothorax-Arten.

4. In Häusern treten zeitweise auf Lasius umbratus (in morschen Balken), emarginatus, niger, sowie Monomorium pharaonis. Durch Schiffe eingechleppt, kommt in Hafenstädten Pheidole megacephala vor.

5. Haufennester errichten unsere Formica-Arten. Sie bestehen aus einem oft tief in die Erde reichenden Unterbau und einem aus pflanzlichem Material zusammengetragenen Oberbau, der aber nicht, wie es auf den ersten Blick scheint, regellos angehäuft ist, sondern ebenfalls Kammern und Gänge enthält, die nach aussen münden und nachts oder bei ungünstigem Wetter verschlossen werden. 
6. Kartonnester stellt Lasius fuliginosus her, die Hohlräume von Stämmen benutzend und sie durch Kartonmasse in Stockwerke und Kammern teilend (Abb. 23). Diese besteht aus zernagtem Holz und Erde, mit Hilfe von Speicheldrüsensekret verarbeitet; gegen Säuren und Alkalien sehr widerstandsfähig, wird sie in ihnen nur bröckelig, in Wasser weich und biegsam. Sie ist von den Hyphen von Septosporium myrmecophilum Fres. durchwachsen und sieht deshalb in frischem Zustand sammetartig aus.

Als Nebenbauten bezeichnet man die Ameisenstrassen, die, von hinderndem Pflanzenwuchs gesäubert, vom Nest ausgehen, den Ameisen den

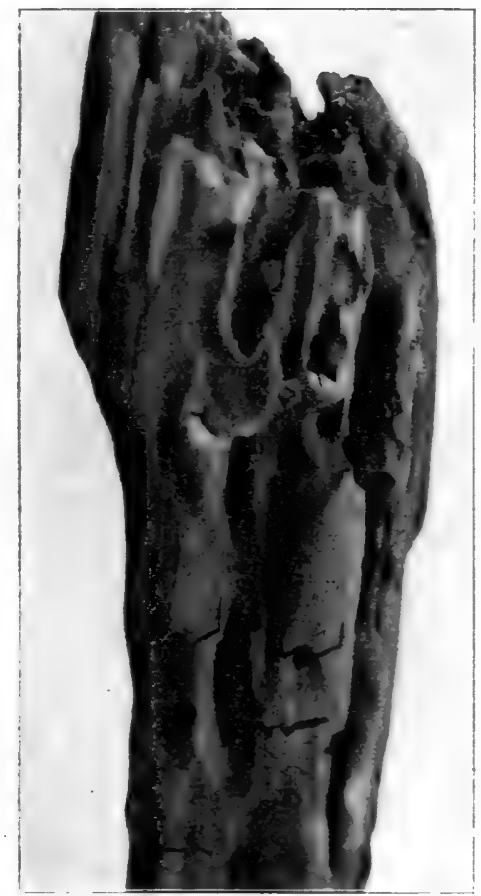

Abb. 21

Aus einem Nest von Formica fusca (morscher Birkenast).

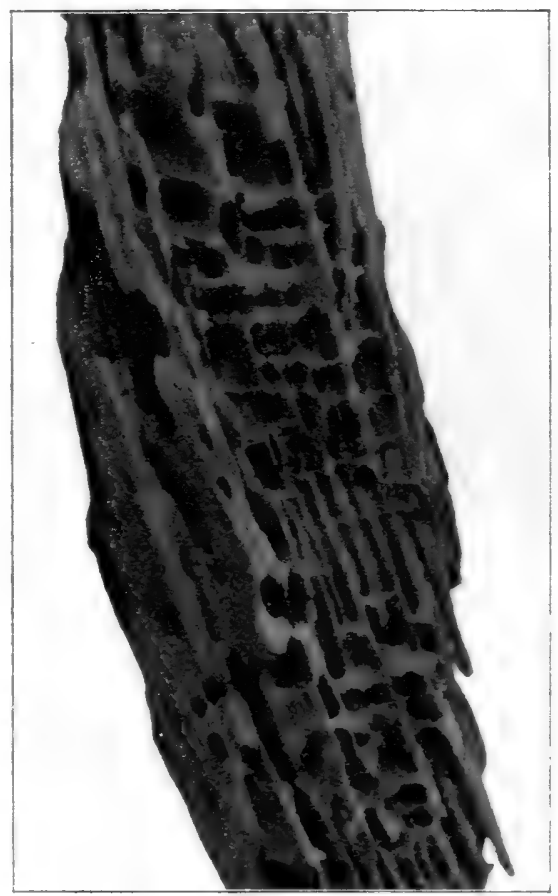

Abb. 22 .
Bruchstück aus einem Holznest von Campanolus ligniperda.

Transport von Baumaterial, Beute usw. erleichtern und von Formica rufa, pratensis, Lasius fuliginosus auch an Bäumen und Sträuchern hinauf errichtet werden, um zu Blattläusen zu gelangen. Bei manchen Arten (Lasius, Myrmica) sind sie gedeckt, ebenso wie die von den Blattläusen besetzten Stellen der Pflanze; im letzten Fall nennt man sie auch Ställe. Bei Lasius flavus führen sie unterirdisch zu Wurzelläusen.

Biol'ogis'ch lassen sich die Wohnungen der Ameisen unterscheiden in:

1. Einfache Nester, die nur von einer einzigen Ameisenart bewohnt werden; oft stehen, wie bei Formica rufa, viele von ihnen in Verbindung.

In vielen Fällen finden sich aber die Kolonien von zwei oder mehr Ameisenarten nebeneinander, und sie bilden dann

2. Zusammengesetzte Nester. Das Verhältnis der Kolonien in solchen, in denen nur ein äusseres Zusammenwohnen ohne gemeinsamen Haushalt stattfindet, kann ein verschiedenes sein: 


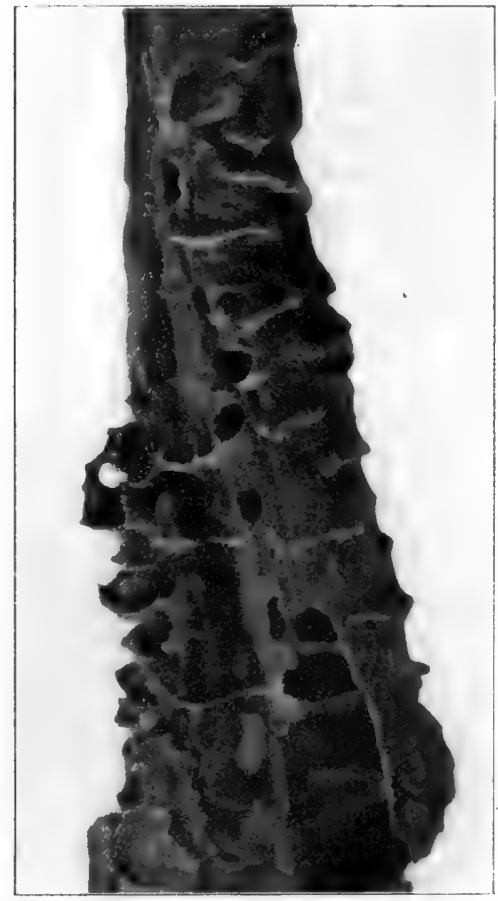

Abb. 23. Bruchstück aus einem Kartonnest von Lasius fuliginosis.

a) Plesiobiosis nennt man es, wenn die Kolonien, verschiedenen Arten (z. B. Camponotus ligniperda und Formica fusca) angehörend, nur râumlich nebeneinander liegen. Die Bewohner stören sich zwar nicht in ihren gewöhnlichen Geschäften, stürzen aber in den meisten Fällen bei eintretenden ausserordentlichen Verhältnissen sofort feindlich aufeinander los.

b) Lestobiosis (Forel) [Cleptobiosis (Wheeler)] ist das Verhältnis der Solenopsis fugax zu grösseren Ameisen (der Gattung Formica, Lasius, Polyergus u. a.). Die sehr kleinen, aber äusserst kampflustigen Ameisen haben ihre ausserordentlich stark bevölkerten Nester mit Kammern und Gängen neben dem Nest grösserer Arten, in welches Gänge führen, sowie innerhalb der Wandungen desselben. Von hier aus greifen sie die Larven und Puppen ihrer Wirte an und verzehren sie. Gegen die Wirtsameisen, die ihnen in die kleinen Gänge nicht zu folgen vermögen, verteidigen sie sich, wenn sie von ihnen angegriffen werden, erfolgreich durch ihren Stachel.

c) Xenobiosis heisst das freundliche Verhältnis grösserer Arten (Formica rufa und pratensis) zu den Gastameisen der Art Formicoxenus nitidulus. Diese legt ihr kleines, nussschalenförmiges Nest, das nur wenig, gegen 100 Bewohner, beherbergt, innerhalb des Haufens von Formica an. Welches die Ursachen des friedlichen Verhältnisses zwischen beiden Arten ist, ist noch nicht aufgeklärt. Formicoxenus selbst hat den Vorteil eines warmen, für die Entwicklung seiner Brut vorteilhaften Nestes, sowie einen gewissen Schutz seitens der kräftigen Wirte.

Diese Verhältnisse, die man als soziale Symbiose dem Zusammenleben von Ameisen mit anderen Insekten als individuelle Symbiose gegenüberstellt, führen zu den sogenannten gemischten Kolonien (S. 23), in denen Ameisen verschiedener Gattungen oder Arten zusammenwohnen und in dem gemeinsamen Haushalt gemeinsame Interessen verfolgen.

\section{Künstliche Nester.}

So wichtig die Beobachtung des Lebens und Treibens der Ameisen im Freien und in ihren Nestern ist, so lassen sich doch sehr viele Äusserungen des Ameiseninstinktes auf diesem Wege nicht erkennen. Die inneren Teile des Nestes sind unseren Blicken entzogen, und wird es gewaltsam geöffnet, so gebärden sich dessen Bewohner in der Aufregung über die plötzliche Störung natürlich ganz anders als gewöhnlich bei ruhiger Tätigkeit und wissen sich der Störung ausserdem sehr schnell zu entziehen. Wir müssen deshalb unsere Beobachtungen an Tieren in künstlichen Nestern zu ergänzen suchen, obwohl hier wieder daran zu denken ist, dass ein künstliches Nest seinen Bewohnern die natürlichen Verhältnisse nicht vollkommen ersetzt und in mancher Beziehung ihren Instinkt in anderer Richtung entwickelt.

Die einfachste Form eines künstlichen Ameisennestes wäre ein zum Teil mit Nestmaterial und einer Anzahl von Bewohnern gefülltes Gläschen, das der 
Luft Zutritt gewährt, ohne die Ameisen entweichen zu lassen. Darin kann man die Tiere auch einige Zeit erhalten, wenn sie mit Nahrung und der nötigen Feuchtigkeit versehen werden. Doch liegen die Nachteile einer solchen Behausung auf der Hand. Einmal entzieht sich alles, was die Ameisen im Nestinnern an Verrichtungen vornehmen, der Betrachtung, und dann ist es auch schwierig, Nahrungsreste aus dem Nest zu entfernen und dasselbe rein zu halten, was in Verbindung mit der ungeregelten Zufuhr von Feuchtigkeit bald zur Schimmelbildung führt, deren Folge allmähliches Eingehen der Kolonie ist.

Diese Nachteile werden vermieden bei der Benutzung praktisch eingerichteter Nester, deren wichtigste Formen in folgendem beschrieben und dargestellt sind. Das Lubbock-Nest ist ein flaches, viereckiges Kästchen aus Holz mit fest eingesetztem Glasboden. Damit im Nestinnern Luftwechsel stattfinden kann, befestigt man auf den oberen Rändern der Seitenwände des Kästchens Filz-, Tuchoder Wattestreifen, und darauf kommt als Deckel eine aufgelegte Glasscheibe, die zum Zweck des Hineinbringens von Nahrung und Wasser und des Entfernens von Verunreinigungen und abgestorbenen Tieren so weit als nötig entfernt werden kann. Man bedeckt diese Scheibe ganz oder teilweise mit einem glatten Streifen aus Tuch. Um ein Entweichen der Ameisen zu verhindern und um sie in ihrer Bewegungsfreiheit nicht zu sehr zu beschränken, wurde ein solches Kästchen von älteren Beobachtern mit einer seitlichen Öffnung versehen und innerhalb eines ringförmig geschlossenen Gipswalls aufgestellt. Näheres über letzteren findet sich am Ende dieses Abschnittes, wo auch die Mängel einer solchen Einrichtung erwähnt sind.

$\mathrm{Zu}$ beachten ist, dass man das Nest

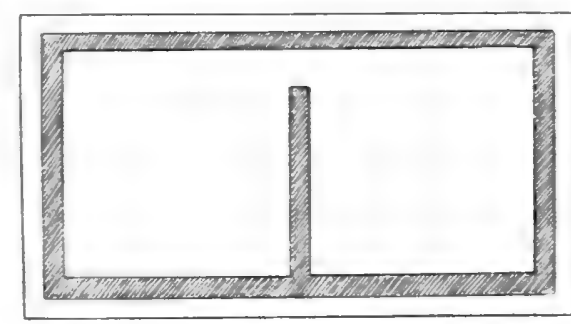

Abb. 24. Nest nach Fielde. nicht zu gross herstellt, da sich sonst ähnliche Misstände bei der Beobachtung ergeben würden, wie sie sich bei Verwendung eines einfachen Glases geltend machen. Die Grösse des Kästchens richtet sich nach seinen Bewohnern. Für unsere grösseren einheimischen Arten genügen Seitenlängen von ungefähr $10-15 \mathrm{~cm}$, für die kleineren $8-10 \mathrm{~cm}$. Die Entfernung zwischen Boden und Deckel beträgt im ersten Fall nicht über $15 \mathrm{~mm}$, im zweiten $4-7 \mathrm{~mm}$.

Ähnlich eingerichtet wie das Lubbock-Nest ist das Fielde-Nest (Abb. 24). Sein Boden ist eine Glasplatte, auf welcher die Seitenwände des rechteckigen Nestes (zusammengekittete Glasleisten) sowie eine dasselbe in zwei verbundene Kammern teilende Mittelwand stehen. Die eine Kammer ist das Hauptnest; die andere dient zur Darreichung des Futters und zur Zuführung der nötigen Feuchtigkeit mittels eines angefeuchteten Schwammstückchens oder Wattebausches. Der Verschluss ist der gleiche wie beim Lubbock-Nest.

Das Lubbock-Nest hat, um den Lebensbedingungen der Ameisen besser Rechnung zu tragen, verschiedene Verbesserungen erfahren.

Nach Viehmeyer werden drei solcher Kästchen, die durch Glasröhrenstücke miteinander in Verbindung stehen, zu einem Nest zusammengestellt (Abb. 25, I; III im Längsschnitt). Das erste, grösste wird als Hauptnest bezeichnet; in ihm befindet sich die eigentliche Ameisenwohnung. Der vorher beim LubbockNest erwähnte aufgelegte Rand von Watte usw. fällt hier (bei allen drei Kästchen) weg. Der Glasdeckel läuft vielmehr nach Art des Schiebedeckels einer Schachtel in einem Falz und ist ein doppelter (Längsschnitt Abb. 25, Il rechts und in der Mitte). Der untere a trägt in der Mitte einen kreisförmigen Ausschnitt c zum Zweck des Hineingreifens in das Nest für irgendwelchen Zweck; der andere, 
darauf liegende, ebenso grosse $\mathrm{b}$ dient zum Verschluss und wird mit einer entsprechend grossen Tuchscheibe (Abb. 25, I g) zum Zweck des Verdunkelns belegt. (Die kreisförmig ausgeschnittene Scheibe kann, da ihre Herstellung etwas kostspielig ist, auch fortgelassen werden.)

Um die Scheiben nach beiden Seiten hin bequem verschieben zu können, haben die Holzleisten im Durchschnitt die aus Abb. 25, II links (für die Längswände) und II Mitte oder noch besser II rechts (für die Querwände) ersichtliche Form. Für die Anfertigung der Kästchen lässt man am besten vom Tischler eine Anzahl langer Holzleisten von entsprechender Form anfertigen, von denen man nach Bedarf die Stücke abschneidet und zusammensetzt. Von den Scheiben, die jeder Glaser von der gewünschten Grösse schneidet, werden die für den Boden nach Art einer Fensterscheibe eingefügt.

Die querliegenden Seiten des Hauptnestes sind durchbohrt. In der einen Durchbohrung steckt eine im rechten Winkel nach oben gebogene Glasröhre,
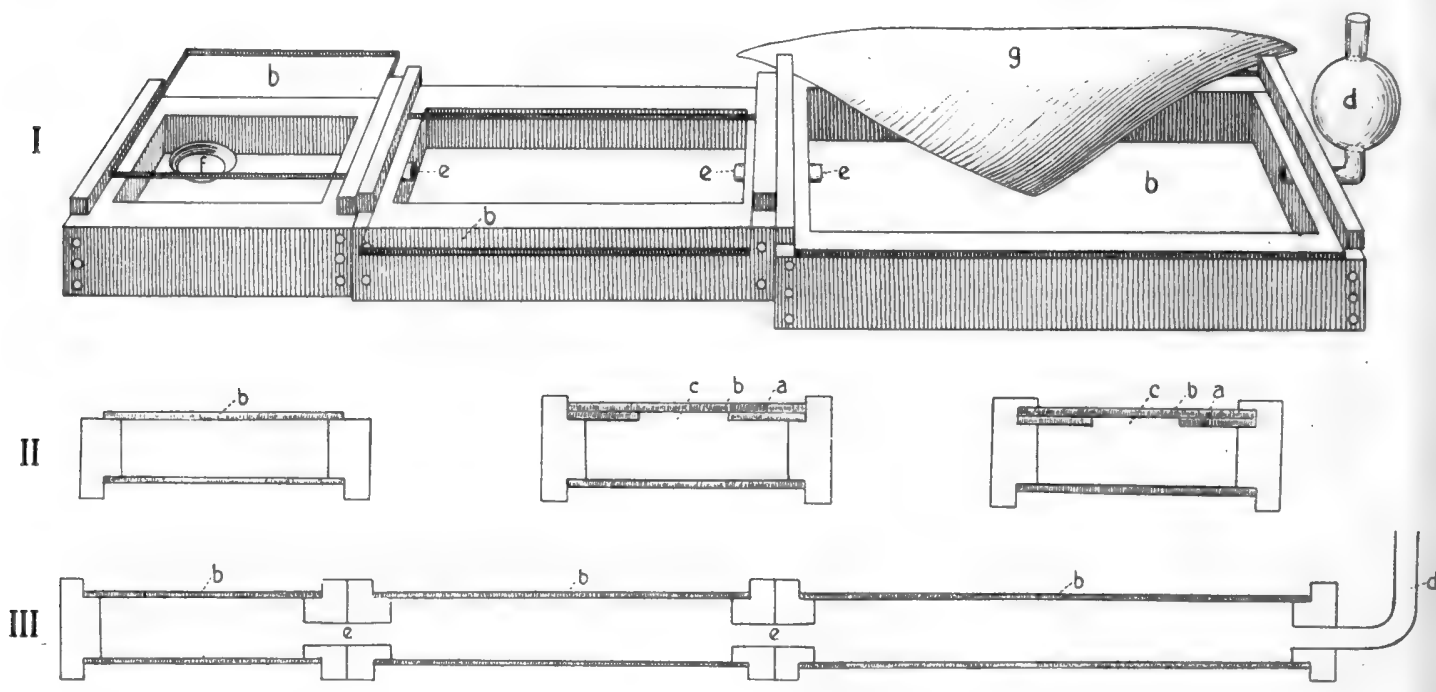

Abb. 25. Nest nach Viehmeyer.

deren äusserer Schenkel mittels eines durchbohrten Korkes in einem breiteren Ansatz befestigt ist. Noch besser eignet sich für diese Vorrichtung ein Fülltrichter, wie er für chemische Zwecke benutzt wird, dessen Röhrenansatz entsprechend umgebogen wird, oder man lässt sich vom Glasbläser kugelförmig erweiterte Röhren herstellen (Abb. 25, I d). In den in der Nestwand steckenden Schenkel stopft man einen Wattebausch, nicht zu locker und nicht zu fest, damit der Zutritt des Wassers, mit dem der erweiterte Ansatz gefüllt ist, im Nest ein allmählicher ist.

Die Durchbohrung der gegenüberliegenden Wand des Hauptnestes trägt ein Glasröhrenstück e, wodurch ersteres mit dem ebenso gebauten, aber etwas kleineren Vornest oder Abfallnest in Verbindung steht. Den Glasboden desselben giesst man zweckmässig mit einer dünnen Gipsschicht aus, von der sich die Ameisen gut abheben, oder bedeckt ihn mit Erde; unterlässt man es, so sorgen die künftigen Bewohner bald selbst für eine Bedeckung. Dieses Vornest ist ihnen gleichsam die Umgebung ihrer Wohnung. Hier lagern sie auch Abfälle ab sowie abgestorbene Nestbewohner, die man von Zeit zu Zeit entfernt. Diese Nestabteilung erhält keine verdunkelnde Decke. 
In derselben Weise wie das zweite Kästchen dem Hauptnest, ist dem ersteren ein drittes, noch kleineres angehängt, das Futternest. Es dient zur Aufnahme der den Ameisen zu verabreichenden Nahrung (S. 27) in einem kleinen, flachen Tuschnäpfchen $\mathrm{f}$, deren verdorbene Reste ebenfalls beseitigt werden müssen. Auch der Glasdeckel dieser Kammer bleibt unbedeckt.

Eine andere Verwendung des Lubbock-Nestes stellt das Wasmann-Nest dar (Abb. 26). Es besteht zunächst aus einem grösseren Hauptnest $\mathrm{H}$ und einem damit verbundenen kleineren Nebennest $\mathrm{N}$, wie bei dem vorher beschriebenen Viehmeyer-Nest; beide sind durch verdunkelnde Tuchscheiben bedeckt. Ebenso steht das grössere Hauptnest auf einer zweiten Seite zweckmässig mit einem Wassertrog W in Verbindung, auf einer dritten weiterhin mit einer Anzahl von Glasgefässen.

Das Vornest V, in welches die Verbindungsröhre c führt, ist am Boden mit einer Schicht Erde bedeckt und enthält ein bis oben reichendes Holzstäbchen

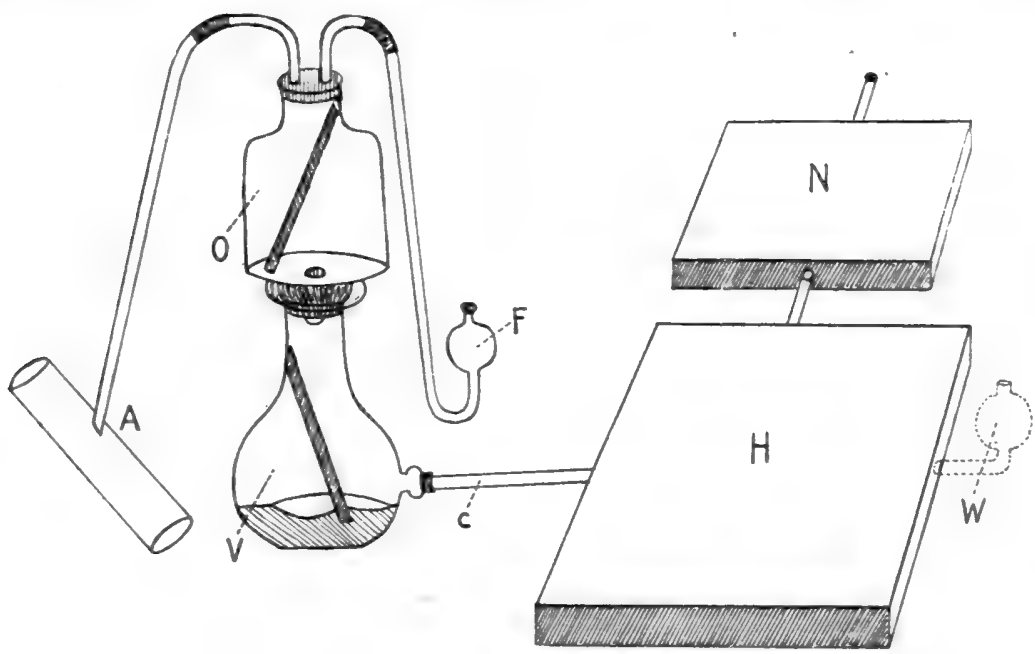

Abb. 26. Wasmannsches Nest (nach Wasmann).

oder Zweigstückchen, das den Ameisen erleichtert, in das darüber befindliche, ebenfalls aus Glas bestehende Obernest $\mathrm{O}$ zu gelangen, in dem sich ebenfalls ein Stäbchen befindet. Vom Obernest führen ein Röhrengang in das Abfallnest A, ein anderer in das Futternest F. Die Form der Gläser kann man natürlich nach Bedarf anders gestalten.

Etwas einfacher gestaltet sich das Wasmann-Nest in der Form, die ihm Schmitz gegeben hat (Abb. 27).

An Stelle von Holz wird nach Dankler ein Nest aus Torf (Insektentorfplatten) hergestellt (Abb. 28), indem ein Holzkästchen auf seiner Innenwandung mit breiten Torfstreifen belegt und durch ebensolche in Kammern geteilt wird, die durch eingefügte Glasröhrenstücke verbunden sind. Die Kammern werden, eine jede besonders, mit Glasplatten bedeckt und nach Belieben verdunkelt. Bei einigen Kammern ist, um die Durchlüftung zu ermöglichen, die Aussenwand durchbrochen und an diesen Stellen mit feinem Drahtnetz verschlossen.

Nach Brun schneidet man praktisch ein solches Nest einheitlich, ohne einen Boden zu lassen, aus einer Torfplatte heraus, die man zum Zweck der Festigkeit aussen mit einem Streifen von Drahtnetz umgibt. Oberfläche und Bodenfläche sind Glasscheiben, die durch Klammern angepresst werden. Einen 
Wassertrog (wie in Abb. 25, I d) steckt man mit seinem zugespitzten Ende in die Torfwand, in der sich das Wasser nach demselben Prinzip verteilt wie in den im folgenden beschriebenen Nestern aus Gips. Da sich derartige Nester leicht in kleinerem Massstab herstellen lassen, so empfehlen sie sich (neben den kleinen Gipsnestern) zu Beobachtungen an kleinen

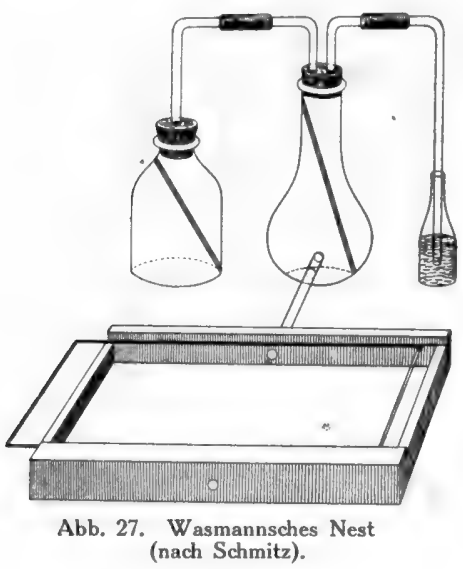
Ameisen sowie an kleinen Kolonien grösserer Arten. In den aus Gips geformten künstlichen $\mathrm{Ne}$ stern ist die Kammerung eine ähnliche wie bei denen der vorigen Gruppe. Doch erfolgt die $\mathrm{Zu}$ fuhr von Wasser nach einem anderen Prinzip, das einerseits den Vorteil hat, dass die Feuchtigkeit in dem Gipsblock von dem einen zum anderen Ende gleichmässig abnimmt und die Bewohner den ihnen in dieser Beziehung am meisten zusagenden Nestraum aufsuchen können, während andererseits in solchen Gipsnestern viel leichter Schimmelbildung eintritt.

Ein Janet-Nest zeigt Abb. 29, IV im Längsschnitt, Abb. 29, III in der Ansicht von oben. Es hat vier flache Kammern. Die drei grösseren von ihnen (b, c, d), über deren Grössenverhältnisse dasselbe gilt, was beim Lubbock-Nest angegeben wurde, stehen durch die Gänge s in Verbindung und sind für den Aufenthalt der Ameisen bestimmt; eine vierte, kleinere a ist allseitig abgeschlossen und wird beim Gebrauch des Nestes mit Wasser gefüllt. $\mathrm{Da}$ die poröse Gipsmasse letzteres allmählich aufnimmt, so

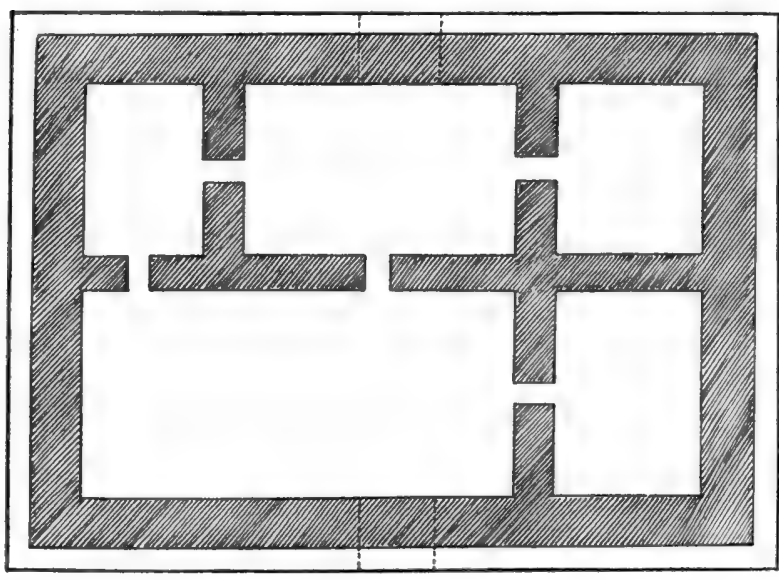

Abb. 28. Nest nach Dankler. werden die Wandungen feucht erhalten, und zwar so, dass die an den Wassertrog grenzenden am feuchtesten sind, die anschliessenden in immer geringerem Grade. Geschlossen wird das Janet-Nest ebenfalls durch Glasplatten. Die drei Nesträume deckt eine einzige Scheibe (Abb. 29, II $g$, IV g), die in der Mitte über je einem der ersteren eine Öffnung $r$ hat, und jede einzelne Kammer erhält, unabhängig von den benachbarten, eine zweite Scheibe (Abb. 29, I h, IV h) als Verschluss. Wie bei den anderen Nestern wird die erste an den Wassertrog grenzende Kammer, nach Bedarf auch die folgende, durch einen Tuchstreifen (Abb. 29, IV i) verdunkelt. Der Festigkeit wegen setzt man das Ganze in einen passenden Holzkasten.

Das Janet-Nest hat, ebenfalls durch Viehmeyer, einige praktische Verbesserungen erfahren. Der Gipsblock kommt in einen anschliessenden Kasten aus Zink. Von dessen Seitenwänden aus verläuft über jede Querscheidewand hinweg ein Bügel aus Messing (Abb. 29, V k) so, dass zwischen ihm und der ersteren ein Abstand $\mathrm{f}$ von der Dicke der deckenden Glasplatte bleibt. So lässt sich unter alle Bügel hinweg die aus einem Stück bestehende, durchlochte 
Scheibe schieben und liegt nun dem Nest fest an. Um den oberen Deckscheiben, die von der Seite her eingeschoben werden, Halt zu geben, trägt jeder Messingbügel auf der Seite, welche einer Kammer zugewendet ist, zwei
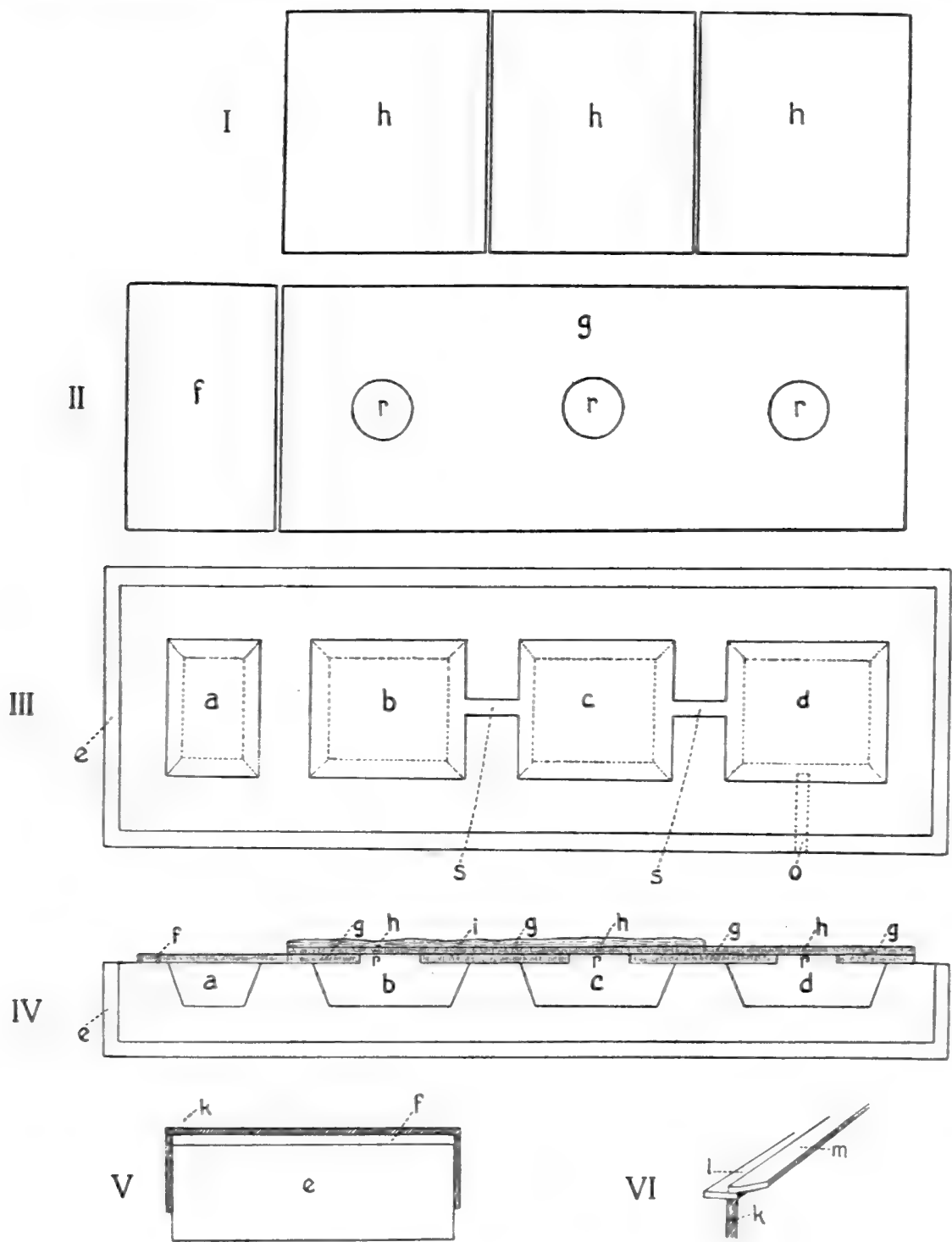

Abb. 29. Janet-Nest.

aufgelötete Messingstreifen, Abb. 29, IV l und m, von welchen m etwas aufgebogen ist, so dass Falze entstehen. Am festesten sitzen die Deckscheiben, wenn die aufgelöteten Streifen ein wenig konvergieren, so dass sich also die Scheiben etwas einklemmen. Eine das Nest mit der Aussenwelt verbindende Öffnung, bei Besetzung des Nestes in Anwendung kommend (Abb. 29, III o), wird durch einen dünnen Blechstreifen geschlossen, den man zwischen Gipswand und Blechumhüllung schiebt. 
Für die Herstellung einer Form eines solchen Gipsnestes gibt Viehmeyer eine Anleitung: Man lässt sich vom Tischler zunächst eine Holzform anfertigen. „Zu beachten is: dabei, dass das Holz vollkommen glatt gehobelt wird. Die Holzklötzchen, welche die Nestkammern darstellen, müssen aufgemacht (nicht geleimt), die Aussenwände am besten nur mit Schrauben befestigt werden. Nachdem die Form noch mit Schellacklösung in Spiritus ausgestrichen und darauf tüchtig eingeölt ist, kann der dick angerührte Gips hineingezogen werden. Janet empfiehlt, den Gips etwas mit rotem Ocker zu versetzen, so dass er etwa die Farbe der Ziegelsteine erhält. $\mathrm{Da}$, wo es sich darum handelt, die Eiablage der Ameisenkönigin und der Ameisengäste zu verfolgen oder sehr kleine, weissliche Mitbewohner der Nester zu beobachten, wird es sicher angebracht sein, den Gips zu färben; für andere Beobachtungen aber dürfte gerade der weisse Gips besonders geeignet sein. Die Verwendung von gefärbtem Gips hat allerdings noch den Vorteil, dass man nämlich an ihm genau erkennen kann, wie gross

W

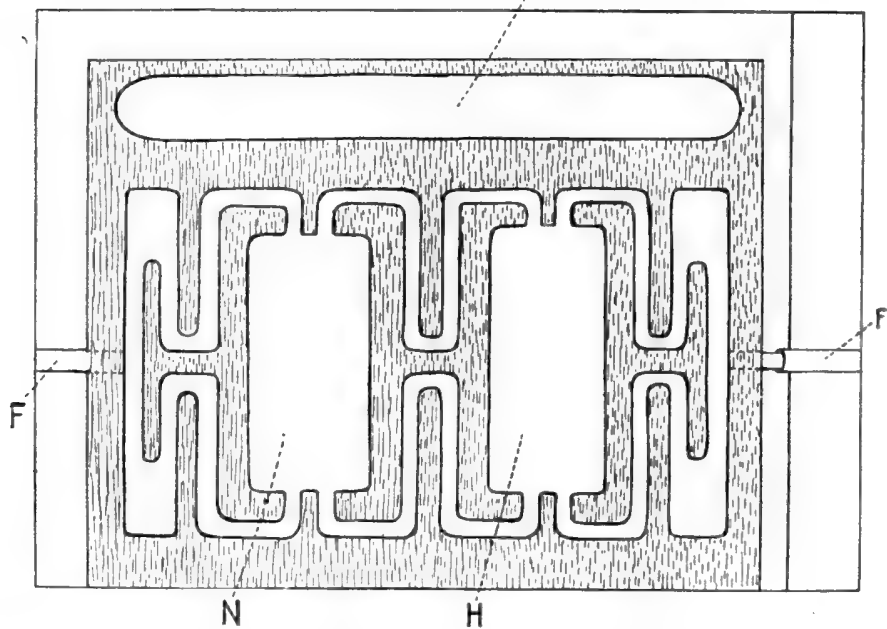

Abb. 30. Janet-Nest, nach Wasmann. der Feuchtigkeitsgehalt des Nestinnern ist. Der feuchte rote Gips sieht stets dunkler aus als der trockene, so dass bei angemessener Sättigung mit Wasserdie demTroge zunächst liegenden Partien die dunkelsten, die $\mathrm{ihm}$ entgegengesetzten die hellsten sind. Ein vollständig gleichmässiges Hellwerden des Blockes würde uns also darauf aufmerksam machen, dass der Wasserbehälter frisch gefüllt werden muss. Nach dem Festwerden der Gipsmasse schraubt man die Seitenwände los, und wenn das Holz vollständig glatt und gut eingeölt war, löst sich der Block leicht aus der Form. Solange er noch feucht ist, bohrt man in die Seitenwand der dritten Kammer (Abb. 29, III o) ein Loch, welches die Verbindung des Nestinnern mit der Aussenwelt herstellt. Ausserdem ist noch nötig, mit einem Messer die Gänge (Abb.29, III s) einzuschneiden."

Eine etwas abgeänderte Gestalt gibt Wasmann dem Janet-Nest, dessen Form und Verwendung aus dem vorher Gesagten und dem Grundriss Abb. 30 ohne weiteres hervorgehen.

Eine Kombination von Fielde-Nest und Janet-Nest nach Wheeler (Abb.31) besteht ebenfalls aus Gips, der vorher mit einem schwach rötlichen Farbstoff vermischt und nach dem Guss aussen mit Firniss überzogen wird. Der Block enthält zwei Abteilungen, die durch eine Querscheidewand getrennt sind, durch eine Offnung in derselben in Verbindung stehen und mit Glasscheiben bedeckt werden. Letztere ruhen aber nicht unmittelbar auf der Gipswand, sondern auf einem dieser aufliegenden Belag (T) von Stoff („turkish twelling“). A ist das Hauptnest; das Nebennest hat in einer Ecke eine Vertiefung N (oder ein Näpfchen) zur Aufnahme des Futters und enthält ausserdem ein angefeuchtetes Stückchen Schwamm. Zur Verdunkelung des Hauptnestes dient eine Scheibe Tuch. Das 
Ganze steht in einem anschliessenden Kasten, der seitlich bei $\mathrm{O}$ eine auch die Gipswand durchsetzende Durchbohrung hat, die gewöhnlich mit Watte verstopft ist. Die Grösse der inneren Bodenfläche beträgt $20-25 \mathrm{~cm}$.

Ein von Santschi verwendetes künstliches Nest, das in jeder gewünschten Grösse schnell hergestellt werden kann und das besonders für die Beobachtung sehr kleiner Ameisen und Ameisengäste empfohlen ist, wird in folgender Weise angefertigt: Zum Boden des Nestes nimmt man eine rechteckige Glasplatte, auf welcher aus noch weichem Gipsbrei ein Wall hergestellt wird, welcher 2 bis 3 Kammern mit Verbindungsgängen einschliesst. Noch ehe der Brei erstarrt ist, legt man auf die Wandungen eine Glasscheibe, welche deren obere Ränder ebnet. Nach dem Erhärten des Gipses wird die Scheibe in die entsprechende Zahl von Deckscheiben zerschnitten.

Kleine Gipsnester dieser Art lassen sich ausserdem anfertigen mit Hilfe einer leicht herzustellenden Form aus Plastilina, die einen Glasboden bekommt, der nachher als Deckel verwendet wird.

Verwandt mit dieser Art von Nestern ist schliesslich ein Beobachtungsnest im kleinsten Massstab (z. B. für einzelne befruchtete Weibchen bei der Koloniegründung), wie es Emery empfiehlt. Man schneidet einen Luftstein, wie solche zu Wandungen von Erkern usw. vermauert werden, mit einer Säge der Quere nach in Scheiben. Die Schnittflächen werden dann geglättet, und der Hohlraum wird zur Herstellung eines Bodens unten mit Gips ausgegossen. Den Verschluss bildet ein Glasdeckel. „Je nach Belieben kann man die einzelnen Fächer entweder getrennt lassen und jedes für sich benutzen, oder mittelst Rinnen miteinander verbinden, oder sogar ein Loch zur Aufnahme einer

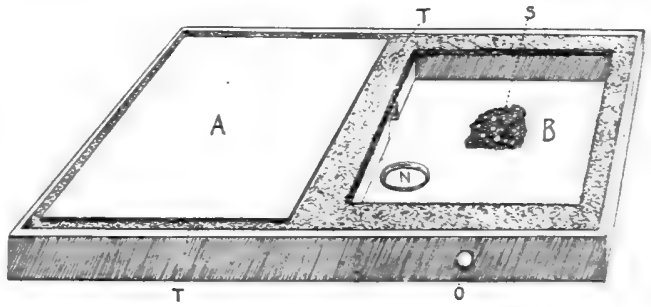

Abb. 31. Nest nach Wheeler. Glasröhre, durch welche das Nest mit einem beliebigen anderen Apparat in Verbindung gesetzt werden kann, bohren. Es kann das eine Fach als Wasserkammer benutzt werden und abgesondert gelassen, die übrigen Gemächer verbunden werden. Ein bequemes Mittel, um in den Nestern den passenden Grad von Feuchtigkeit zu unterhalten, ist feuchtes Moos, auf welches die Nester gelegt werden."

Von den beiden beschriebenen Gruppen von Nestern weicht eine von Barth beschriebene Vorrichtung ab. Sie besteht aus zwei ineinander stehenden Glaszylindern, von denen der innere kürzer und nur wenig schmäler ist als der äussere. Ihre Grösse richtet sich nach der der aufzunehmenden Ameisen. Der schmale Raum zwischen beiden ist fest mit Erde angefüllt bis unter dem Rand des Innengefässes, in welchem ein oder mehrere Hölzchen stehen, um den Bewohnern die Verbindung zwischen beiden Räumen zu erleichtern. Bedeckt wird das äussere Glas mit einem Stück Gaze, das über einen Eisenring oder Drahtring gespannt ist, und über das Ganze kommt zum Zweck der Verdunkelung ein Zylinder aus dunklem Stoff oder schwarzem Papier. Das Futter wird in einem kleinen Zinngefäss gegeben, das auf dem Boden des inneren Glases steht oder in dieses hineingehängt wird. - Von den Vorteilen einer solchen Behausung wird einerseits die Möglichkeit hervorgehoben, dass man die fortwährenden Änderungen, welche die Ameisen an ihren Kammern und Gängen vornehmen, leicht erkennen und an der eine grosse Fläche darbietenden Aussenwand registrieren kann. Andererseits eignet sich ein solches Nest für die Beobachtung des Zusammenlebens gewisser Ameisen mit Wurzelläusen, indem man die Oberfläche der Erdschicht dünn mit Grassamen besät und die Wurzeln der sich entwickelnden Pflanzen leicht beobachten kann. 
Für den Zweck des Einsammelns von Ameisen (und ihrer Gäste) zur Besetzung künstlicher Nester eignet sich am besten das erste Frühjahr, wenn die Tiere noch weniger lebhaft sind und, um sich zu erwärmen, der Erdoberfläche nahekommen. Dann ist auch die günstigste Gelegenheit, eine Königin mit zu erbeuten. Später sitzen die letzteren in der Tiefe der Nester und sind nur schwierig oder durch Zufall zu erlangen. (Die Zucht einer Königin aus Eiern im künstlichen Nest ist nur sehr selten beobachtet.) ${ }^{1}$ )

Um ein künstliches Nest zu besiedeln, muss man sich im Freien aus einem Ameisenbau die gewünschte Anzahl von Bewohnern, mit Puppen und Larven, verschaffen; ein längerer Bestand der Kolonie und deren normale Entwicklung ist aber nur zu erwarten, wenn auch eine befruchtete Königin darunter ist. Man bringt die Ameisen mit dem nötigen Nestmaterial in einen Sack, in den man zuvor, um seine Wände auseinander zu halten und die Gefangenen auf dem Transport vor Verletzungen zu schützen, einige zerknickte Zweige gesteckt hat, und der dann gut zugebunden wird. Man kann statt des Sackes auch ein weithalsiges Glasgefäss nehmen, das mit einem durchbohrten Korken verschlossen ist, dessen Durchbohrung natürlich während des Transportes durch einen Stöpsel verschlossen sein muss. Schmitz empfiehlt eine Zigarrenkiste, die man mit einem gut schliessenden Glasdeckel sowie in einer Seitenwand dicht über dem Boden mit einer Öffnung versehen hat, welche beim Transport ebenfalls geschlossen wird.

Um die erbeuteten Ameisen in eins der künstlichen Nester zu bringen, kann man verschiedene Wege einschlagen. Nach Forel stellt man auf einem Brett einen ringförmigen, geschlossenen Wall aus Gipspulver von genügendem Umfang her, der sich, ebenso wie seine Höhe, nach Zahl und Grösse der in Betracht kommenden Ameisen richtet. Um Verunreinigungen möglichst zu vermeiden, stellt man diese „Forelsche Arena“ innerhalb eines grossen Pappkartons her. In sie hinein bringt man das künstliche Nest, oder man setzt es mittels der nach aussen führenden, sonst verschlossenen Öffnung oder des Loches, in welchem das gläserne Wassergefäss steckt, durch eine Glasröhre, welche den Gipswall, also auch die Kartonwand, durchbricht, mit jener in Verbindung. In den Ringwall wird nun der Inhalt des Sackes entleert. Die Gefangenen stürmen aufgeregt sofort nach allen Seiten auseinander, finden aber an dem losen Gips ein für sie fast unüberwindliches Hindernis. Zwar gelingt es wohl der einen oder anderen Ameise, ihn nach vielen Anstrengungen zu ersteigen; doch lassen sich solche vereinzelte Ausreisser mit einer Pinzette leicht zurückbringen.

Man kann ferner in die vorher zugebundene Öffnung des Sackes ein Stück Glasröhre schieben, dieses einbinden und mit dem Nest in Verbindung setzen, das man zuvor mit etwas befeuchtetem Nestmaterial versehen und verdunkelt hat, und dasselbe gilt bei Verwendung des oben erwähnten Sammelglases oder der Sammelkiste. Man hat dabei den Vorteil, dass man sich nicht weiter um die Ameisen zu kümmern braucht, die das verdunkelte Nest (auch innerhalb der Gipsarena) bald als willkommenen Schlupfwinkel auffinden und es mit Puppen, Larven und Nestmaterial beziehen. Etwa zurückbleibende Tiere bringt man mit der Pinzette hinein. Starke Belichtung der Arena oder des Glases sowie Beunruhigungen jeder Art beschleunigen die Einwanderung.

Haben sich die Tiere in ihrem neuen Heim erst beruhigt und sich gegenseitig von dem ihnen etwa anhaftenden Gipsmehl gereinigt, so fühlen sie sich bald heimisch und gehen ihren gewohnten Beschäftigungen nach. Eine übersichtliche $\mathrm{Zu}$ sammenstellung dessen, was sich in künstlichen Nestern der Beobachtung darbietet, was unter anderem mit einer aufgesetzten Lupe geschehen kann, gibt Vieh mey er ${ }^{2}$ ).

1) Bei manchen Ameisen (z. B. Myrmica, Formica fusca, Camponotus ligniperda) erhält

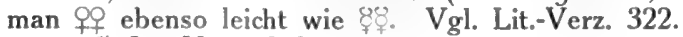

2) Lit.-Verz. 359. 


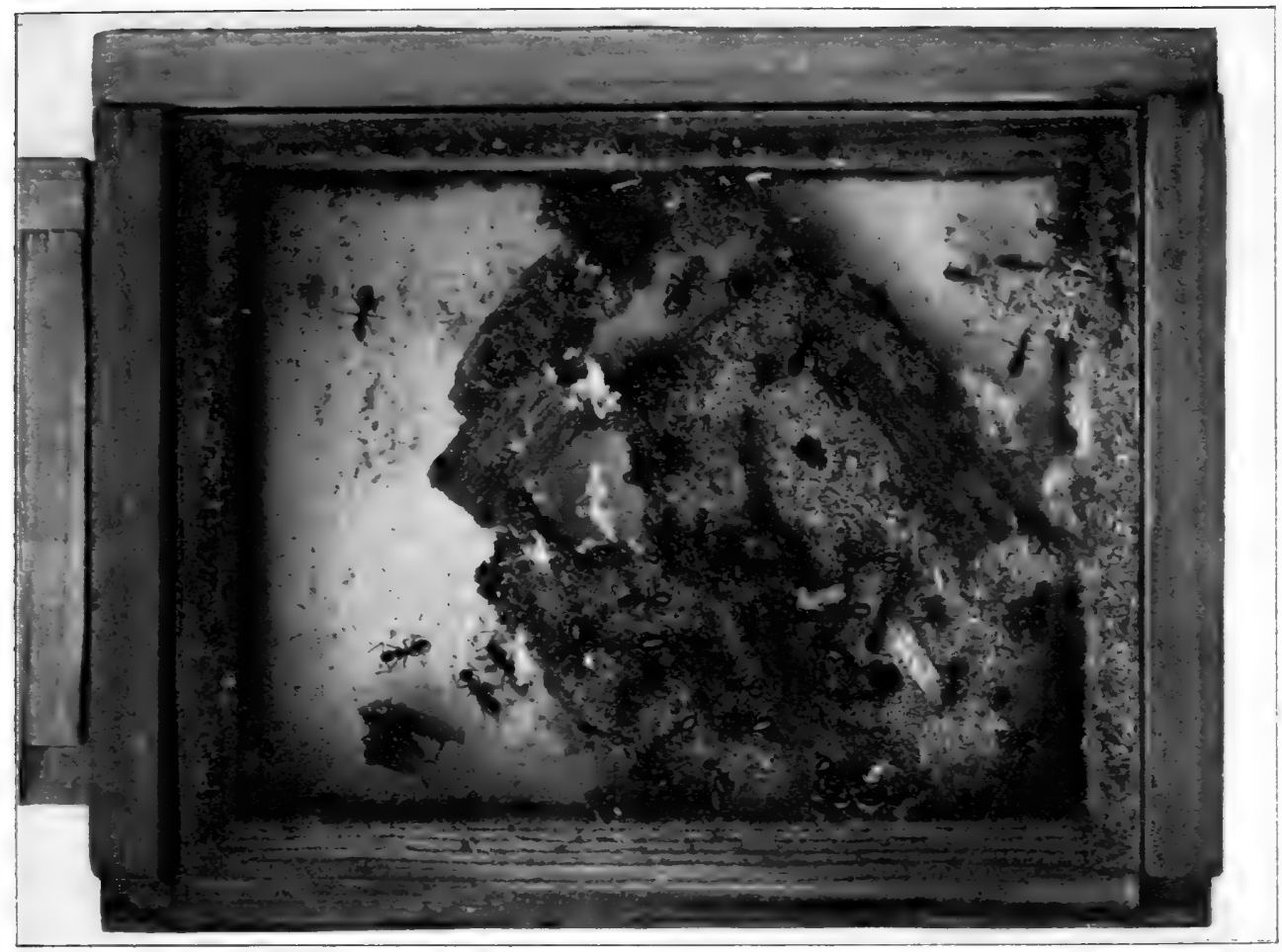

Abb. 32. Hauptkammer aus einem Viehmeyerschen Nest.

Betreffs Fütterung der Ameisen ist daran zu denken, dass diese trotz ihrer meist kräftig ausgebildeten Oberkiefer nicht imstande sind, feste Nahrung aufzunehmen, sondern nur flüssige. Man bringt solche in die betreffende Nestabteilung, und zwar, um sie möglichst sauber zu halten, in kleinen Gefässen, wozu sich sehr gut kleinste, flache Tuschnäpfchen eignen. Die Ameisen erhalten, je nach den Neigungen der betreffenden Art, zerstückelte Inseikten sowie deren Larven und Puppen in demselben Zustand, auch von anderen Ameisen, kleine Fleischstückchen, ferner Sirup, Honig, gelösten Zucker, Stückchen von Obst usw. Hunger, den die Tiere nach den Beobachtungen von Fielde 2, sogar bis zu 7 Wochen ertragen können, führt sie leicht dazu, sich an ihren eigenen Larven, Puppen und Eiern zu vergreifen.

Die Versorgung mit Wasser ist schon bei der Beschreibung der einzelnen künstlichen Nester erwähnt worden (in den einen der Wassertrog, in den anderen angefeuchtete Schwammstücke oder Wattebäusche). Trockenheit wird im allgemeinen besser und länger ertragen als übermässige Feuchtigkeit, die zur Schimmelbildung führt. Eine davon betroffene Kolonie muss anderweitig untergebracht, das Nest gut gereinigt werden, ehe man es wieder verwendet.

Man kann die künstlichen Nester, wenn man dafür sorgt, dass sie nicht austrocknen, mit ihren Bewohnern in einem kalten, vor Frost geschützten Raum überwintern. In einem warmen Zimmer kommen die Ameisen auch über ihre Winterruhe hinweg. In den ersten Wintermonaten lässt zwar ihre Tätigkeit nach, setzt aber, wenn die Königin beginnt, Eier zu legen (Ende Januar, Februar), wieder ein. Man muss alsdann wieder reichlich Nahrung geben.

Im Sommer ist es nicht ratsam, das Nest einer zu intensiven Sonnenbestrahlung auszusetzen, da die Ameisen in dem flachen Raum ja nicht in der 
Lage sind, sich und ihre Brut der übermässigen Wärme zu entziehen, wie es ihnen unter den Verhältnissen möglich ist, die ihnen ihre natürlichen Wohnungen bieten.

Letzteres ist überhaupt in Beziehung auf Beobachtungen an künstlichen Nestern zu beachten, in denen die Tiere, wie bereits hervorgehoben, immer in einem mehr oder weniger hohen Grade gezwungen sind, ihren Instinkt in dieser und jener Richtung verändert zu betätigen. Man darf nicht alle am künstlichen Nest wahrgenommenen Erscheinungen ohne weiteres auf das Leben der Tiere in der Freiheit beziehen. Beide Arten von Beobachtungen müssen einander kontrollieren und ergånzen.

\section{Geographische Verbreitung.}

Die im systematischen Teil aufgeführten Ameisenarten gehören zur Fauna des paläarktischen Gebietes, das sich von Westeuropa ostwärts über Sibirien bis an das Ochotskische Meer erstreckt und im Süden abgegrenzt wird von den Pyrenäen, den höchsten Alpenkämmen, den nördlichen Gebirgen der Balkanhalbinsel, dem Nordrand des Schwarzen Meeres und dem Kaukasus; weiterhin geht diese Grenze über die Nordufer des Aral- und Balkaschsees und über die nördlichen Teile der innerasiatischen Gebirge. Die nördlichen Ränder Europas (Lofoten, Nordrand von Skandinavien und der Halbinsel Kola und Russland) sowie Asiens sind bereits arktisches Gebiet. Die südlichen europäischen Halbinseln, Nordafrika ungefähr bis, zur Breite von Timbuktu-Chartum, ferner Vorderasien, die arabische Halbinsel mit Ausnahme ihres südlichen Teiles bilden das Mittelmeergebiet, das sich auch in das südliche Frankreich und Tirol hinein erstreckt.

Das von uns berücksichtigte mitteleuropäische Gebiet der Paläarktis schliesst die Britischen Inseln, Island und Skandinavien aus, ebenso Russland. Betreffs des letzteren lässt sich naturgemäss keine Grenze ziehen, indem die Ameisenformen Mitteleuropas vielmehr weit nach Osten bis an die paläarktische Grenze reichen, in diesen Gegenden vielfach besondere Rassen und Varietäten bildend. Das letztere gilt auch für die in das Mittelmeergebiet hineinreichenden Arten (z. B. aus den Gattungen Formica, Myrmica, Tetramorium, Solenopsis u. a.). Mitteleuropäische Formen besitzt ferner die Skandinavische Halbinsel, als Eigenheiten Formica suecica Adl., Formica rufa L. v. alpina Sant. (zuerst aus dem Veltlin bekannt), Formica rufa L. r. dusmeti For., Myrmica rubra L. v. champlaini For. v. europaea For., Leptothorax acervorum F. v. nigrescens Ruzsky; im südlichen Norwegen, sicher eingeschleppt, wurden festgestellt Camponotus maculatus F. v. thoracicus F., Acantholepis frauenfeldi Mayr. Der arktische Teil Norwegens besitzt nur die Gattungen Camponotus, Formica, Myrmica, Leptothorax, Formicoxenus mit zusammen 10 Arten. Auf Island wurden noch keine Ameisen beobachtet.

Andererseits sind, abgesehen von durch Schiffs- und Eisenbahnverkehr eingeschleppten exotischen Formen, deren eine Anzahl am Ende des systematischen Teils angegeben ist, Ameisenarten aus dem Mittelmeergebiet in das mitteleuropäische vorgedrungen, von Südosten her bis zur Donau Liometopum microcephalum, von Süden, meist im Elsass angetroffen, Angehörige der Gattung Camponotus, Dolichoderus quadripunctatus, auch bei Berlin festgestellt, Cremastogaster scutellaris; aus dem Süden stammen auch die bei uns vorkommenden Vertreter der Gattungen Messor, Aphaenogaster, Stenamma.

Von den mitteleuropäischen Ameisen sind nach Nordamerika gelangt Tetramorium caespitum L. und Myrmica rubra L. v. laevinodis Nyl. 


\section{Ameisengäste.}

Die Beziehungen zwischen Ameisen und anderen Gliedertieren sind sehr mannigfache. Man nennt die mit Ameisen zusammen vorkommenden und zu ihnen in bestimmte Beziehungen tretenden Arthropoden in weiterem Sinn Ameisengäste oder Myrmekophilen, und die Zahl ihrer Arten wird von Wasmann (1911), auf dessen Forschungen sich unsere Kenntnis derselben gründet, auf über 2000 geschätzt. Zum Sammeln von Myrmekophilen ist die geeignetste Zeit der Beginn des Frühjahrs. Die Ameisen sind dann infolge der niedrigen Temperatur noch nicht so angriffslustig als später. Man muss besonders die tiefer gelegenen Teile des Nestes mittels Durchsieben durchsuchen ${ }^{1}$ ). Auch von der Unterseite flacher Steine, die man während der Nacht auf die Nester legt, kann man in der Frühe myrmekophile Insekten sammeln. Nach dem Verhältnis zu ihren Wirtsameisen sind die Ameisengäste in 5 Hauptgruppen zu unterscheiden:

1. Trophobionten (Nutztiere) sind solche, an deren Körper gewisse Organe Stoffe ausscheiden, die den Ameisen sehr angenehm sind, so dass viele Arten zu ihrer Erlangung jene Insekten aufsuchen (Blattläuse), andere sie sogar züchten (Wurzelläuse). (Vgl. S. 49.) Hierher gehören auch die Raupen gewisser Schmetterlinge aus der Gattung Lycaena.

2. Symphilen (echte Gäste). Das freundschaftliche Verhältnis, in dem die Ameisen zu diesen Gästen stehen, ist auf Exsudate zurückzuführen, die letztere aus besonderen Drüsen abscheiden, die durch Poren an der Körperoberfläche münden und häufig durch auffallende Haare oder Haarbüschel (Trichome) kenntlich

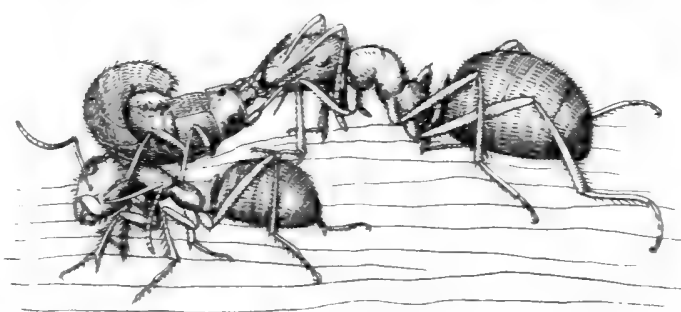

Abb. 33. Atemeles, gefüttert von Formica (nach Wasmann). sind (Abb. 33). Die Begier der Ameisen nach diesen Ausscheidungen hat eine sorgfältige Pflege der Symphilen durch sie zur Folge, indem erstere sie schützen, sie füttern und solches in den höchstentwickelten Fällen auch mit deren Brut tun (S. 47 Lomechusa).

3. Synoeken (indifferent geduldete Gäste). In diese Gruppe gehören die meisten Myrmekophilen. Ihre Duldung im Ameisenstaat ist damit zu erklären, dass sie von dessen Bewohnern entweder ihrer geringen Grösse wegen nicht bemerkt oder wegen ihrer Körperbeschaffenheit oder der Geschwindigkeit in ihren Bewegungen von den Ameisen nicht ergriffen werden können. Ihre Nahrung besteht aus den Abfällen im Nest, aus Ameisenkadavern oder Milben; manche verzehren auch die den Ameisenkörper bedeckenden Ausscheidungsstoffe desselben durch Belecken; andere wieder rauben von dem Futtersaft, der im Augenblick der Fütterung einer Ameise durch eine andere aus deren Mund tritt. In seltenen Fällen vergreifen sich Synoeken an den Eiern und der Brut ihrer Wirte.

4. Synechthren (feindlich verfolgte Gäste) stellen den Ameisen, ihren Eiern und der Brut nach, und diese stehen ihnen deswegen feindlich gegenüber. Daher suchen sich Gäste dieser Gruppe vor ihnen zu schützen in geeigneten Verstecken im Nest oder neben demselben und gehen vorzüglich des Nachts oder bei kühlem Wetter, wenn die Ameisen weniger beweglich sind, auf ihren Raub aus.

5. Ectoparasiten und Entoparasiten. Als letztere seien gleich vorweg gewisse Nematoden (Pelodera) angeführt, die in den Pharynxdrüsen der

1) Über Siebetechnik vgl. Holdhaus, Zeit. wiss. Insektenbiol., B. 6, 1910, S. 1-4, S. 40-57. 
Ameisen ihre Entwicklung durchlaufen, vielleicht auch Gordius formicarum, nach Siebold im Innern des Ameisenkörpers lebend.

Die grösste Zahl der Ameisengäste findet sich in der Ordnung der Käfer. Unter ihnen kommen wiederum bestimmte Familien in Betracht, und innerhalb dieser sind es eine Anzahl Gattungen bezw. Arten, die sich durch gewisse körperliche Merkmale als Ameisengäste charakterisieren. Als solche sind ausser den schon erwähnten Trichomen und Drüsen zu erwähnen eine mehr oder weniger grosse Ameisenähnlichkeit (Mimikry) in Gestalt, Färbung und Glanz des Körpers, sowie Übereinstimmung in der Körpergrösse mit der Ameisenart, bei der sie leben (besonders bei Symphilen und auch Synoeken). Als Anpassung an das Gemeinschaftsleben mit Ameisen kommen weiter in Betracht vielfach eine besondere Bildung der Antennen und eine Rückbildung der Mundteile.

Im folgenden geben wir eine kurze Übersicht mit einigen Beispielen über die Arthropodengruppen, welche zu Ameisen in gewisse Beziehungen treten, soweit sie für unser Gebiet in Betracht kommen.

\section{Crustacea.}

Häufig finden sich in Ameisennestern Asseln als Synoeken; gesetzmässig nur bei Ameisen lebt Platyarthrus hoffmannseggi Brdt. (Taf. II, Abb. 38).

\section{Myriopoda.}

Myriopoden finden sich oft in Ameisennestern (Schendyla nemorensis Koch bei Formica exsecta, Geophilus truncorum Mein. bei Formica rufa) (Taf. II, Abb. 39); doch stehen ihnen die Bewohner feindlich gegenüber. Blaniulus guttulatus Bosc. lebt bei Lasius umbratus und hält sich in den von den Ameisen weniger besuchten Regionen des Nestes auf; er ist ausserdem durch das Sekret seiner Drüsen geschützt.

\section{Arachnoidea.}

I. Acarina. - Milben werden bei Ameisen sehr häufig angetroffen; die meisten von ihnen gehören zu den Gamasinen. Manche Arten der Gattung Loelaps scheinen zu den Ameisen in freundschaftlicher Beziehung zu stehen, während andere als Synoeken in Betracht kommen, die sich (manche Gamasinen)

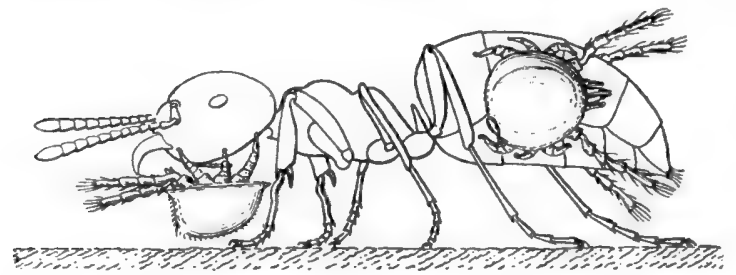

Abb. 34. Antennophorus an Lasius (nach Janet). von den Nahrungsabfällen oder von toten Ameisen im Ameisennest nähren.

Loelaps oophilus Wasm. sitzt auf den Eierklümpchen der Wirtsameisen und wird bei dem Belecken der Eier durch die Ameisen mit ernährt.

Die Jugendstadien von Tyroglyphus finden sich als Ectoparasiten an lebenden Ameisen, während die; weiter entwickelten Stadien sowie die entwickelten Tiere von toten Ameisen leben. - Als Ectoparasit ist ferner zu nennen Discopoma comata, die sich am Körper der Ameisen ansaugt. Antennophorus (Abb. 34) hält sich mit den beiden hinteren Beinpaaren an der Unterseite des Kopfes von Lasius-Arten fest und reizt mit seinen Vorderbeinen die Ameise so lange, bis sie einen Tropfen Futtersaft von sich gibt, den der Parasit aufnimmt ${ }^{1}$ ). Urobovella wasmanni Kneissl sitzt am Ende des Kamms vom Putzapparat der Vorderbeine von Lasius flavus.

${ }^{1)}$ Janet nennt eine solche Art des Sich-transportieren-lassens Phoresie. 
II. Pseudoscorpionidea. - Ein gelegentlicher Gast ist zuweilen Chelifer.

III. Araneida. - Als Synoeken trifft man Arten von Walckenaeria, in den Tiefen des Nestes von Formica rufa Thyreostenius biovatus Cbr. Arten von Enyo (Zodarium), Phrurolithus, Leptorchestes und Hahnia, die zum Teil ameisenähnlich sind, lauern den Ameisen am Eingang ihrer Nester auf.

Theridium-Arten (Taf. II, Abb. 36 u. 37) überfallen einzelne Ameisen von einem Grashalm oder Pflanzenstengel aus und umspinnen sie, um dann die Beute an einem Faden zu sich emporzuziehen.

\section{Insecta.}

I. Thysanura. - Als Synoeken kommen Poduriden vor (Cyphodeirus albinos Nic.), auch Campodea staphylinus Westw., eine Thysanure im engeren Sinn. Wohl wegen der Schnelligkeit in ihren Bewegungen sind sie vor Verfolgungen der Ameisen geschützt. Dasselbe gilt von den Lepisminen. Lepisma polypoda Grassi nimmt von dem Nahrungssaft einer fütternden Ameise (Abb. 35). (Doch gibt es auch solche mit Trichomen [Lepisma myrmecophila Luc. in Algerien], die zu den Ameisen in einem näheren Verhältnis stehen.)

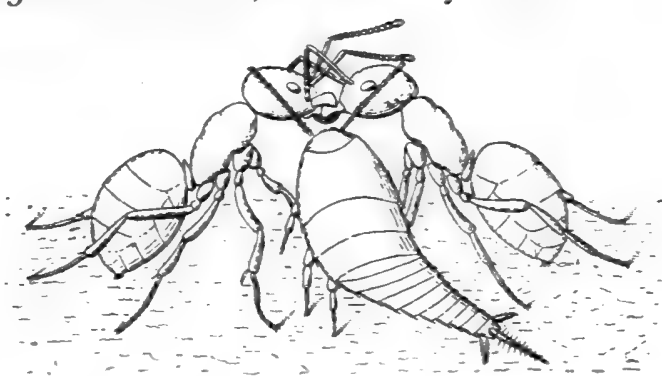

Abb. 35. Lepisma bei zwei sich fütternden Ameisen (nach Janet)

II. Rhynchota. - Unter den wanzenartigen Insekten dieser Gruppe kommen als Synoeken in Betracht Piezosthetus, Philomyrmex und Systellonotus (triguttatus L.). Das Weibchen des letzteren, das die Puppen von Lasius flavus aussaugt (das $\sigma^{7}$ nährt sich von Pflanzenkost), zeichnet sich ebenso wie Myrmecoris (gracilis Sahlb.; Taf. II, Abb. 33) in beiden Geschlechtern durch ausserordentlich grosse Ameisenähnlichkeit aus. Letzteres gilt auch von den Larven und Nymphen anderer Arten (Alydus [Taf. II, Abb. 34], Megalonotus, Camptopus).

Von den Cikaden stehen Tettigometra und Centrotus den Ameisen als Trophobionten gegenüber, indem sie aus dem Enddarm in ähnlicher Weise wie die Blattläuse einen den ersteren angenehmes Exkret ausscheiden und von ihnen in entsprechender Weise geschützt werden.

Das Verhältnis der Ameisen zu den Pflanzenläusen ist S. 49 erwähnt. Auch Schildläuse werden von ihnen besucht.

III. Orthoptera. - Myrmecophila acervorum Panz. (Abb. 36) steht zu den Ameisen in einem freundschaftlichen Verhältnis und nährt sich von den Ausscheidungen auf der Oberfläche des Ameisenkörpers, raubt aber auch gelegentlich von dem Futtersaft einer Ameise, während diese eine andere füttert.

IV. Neuroptera. - Von ihnen ist die Larve von Myr-

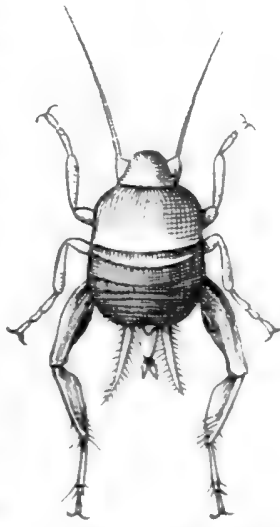

Abb. 36. Myrmecophila acervorum (nach Brunner v. Wattenwyl). meleon, der Ameisenlöwe, als Feind der Ameisen zu erwähnen, die er in den bekannten Sandtrichtern erbeutet. Nach Brauer kommen, wohl aus demselben Grund, Larven von Panorpa und Bittacus in der Nähe von Ameisennestern vor.

V. Diptera. - Die Zahl der zu den Dipteren gehörigen Ameisengäste ist gering. Am auffälligsten ist die nacktschneckenähnliche Larve von Microdon 
(Taf. II, Abb. 35) (mutabilis L., apiformis Meig.), die von den Ameisen gepflegt wird, während sie die Larven von Ceratopogon nur dulden. Das entwickelte Insekt des letzteren sieht man oft auf dem Haufen herumlaufen oder darüber schweben.

VI. Hymenoptera. - Arten aus den Familien der Braconiden, Chalci-

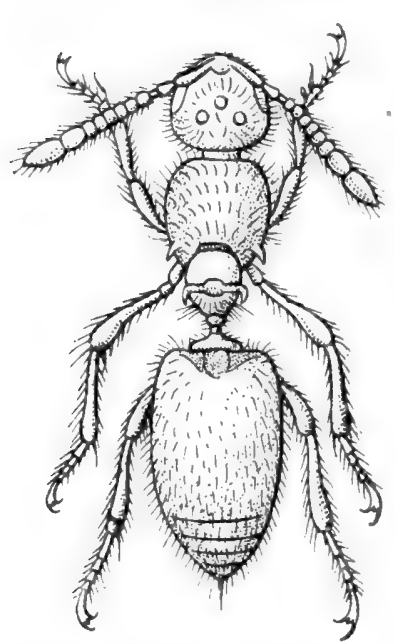

Abb. 37. Solenopsia imitatrix Wasm (nach Wasmann). diden und Proctotrupiden legen ihre Eier an Ameisen und deren Larven ab. Die sich aus ihnen entwickelnden Parasitenlarven dringen in das Abdomen der ersteren ein und verzehren dessen Inhalt (Elasmosoma berolinense Ruthe). Von den Proctrotrupiden lebt Solenopsia imitatrix Wasm. (Abb. 37) als gesetzmässiger Gast bei Solenopsis fugax, dieser Ameise in der Körperform ähnlich. Im Verhältnis der Symphilie zur Wirtsameise Tetramorium caespitum steht Tetramopria aurocincta Wasm., die am Hinterrand des Körpers und am Vorderrand des Thorax gelbe Trichome besitzt, ähnlich wie Claviger (S. 47), und ihre Eier in die Ameisenlarven ablegt. Pachylomma cremieri Rom., eine Braconide legt ihre Eier in von Lasius niger getragene Larven während des Transportes.

VII. Lepidoptera. - In dieser Gruppe begegnen wir solchen Arten, die ihre Entwicklung als Synoeken in Ameisennestern durchmachen (manche Kleinschmetterlinge, Myrmecozela ochracella und danubicella, Orrhodia rubiginea [Noctuide]), sowie anderen, die den Ameisen, ohne sie zu schädigen, als Trophobionten gewisse Vorteile bieten. Zu letzteren gehören gewisse Lycaena-Raupen.

Lycaena argus L. (Taf. II, Abb. 31 u. 32) ist auf ihrer Nährpflanze (Oxytropus pilosa Dec.) von zahlreichen Ameisen umgeben, besonders um das hintere Ende des Abdomens, ohne sich derselben zu erwehren. Es besitzt dieses in seinem drittletzten Segment eine Drüse, deren Sekret sich durch einen queren Spalt in der Mitte des Rückenteils, den die Raupe willkürlich öffnen und schliessen kann, nach aussen entleert. Dieses wird von den Ameisen eifrig aufgesucht und die Raupe deswegen von ihnen geschützt sowie vor Eintritt in das Puppenstadium in das Nest gebracht, wo auch der Schmetterling ausschlüpft. Eine entsprechende Bedeutung haben vielleicht zwei kurze, zylindrische, ausstülpbare Vorsprünge auf dem vorletzten Segment, die am Ende mit einem feinen Borstenkranz umsäumt sind. Nach Viehmeyer veranlasst das Ausstülpen dieser Organe die Ameisen, sich zu den hinteren Körperringen zu begeben, wo der Querspait ist; die Organe werden eingezogen, wenn die Ameisen nach hierher angelockt sind.

VIII. Coleoptera.

Tenebrionidae: Fast alle Arten, die bei Ameisen unseres Gebietes gefunden werden, sind nur zufällige Gäste.

Endomychiidae: Einige Arten sind gesetzmässige, andere zufällige Gäste.

Chrysomelidae: Die in Betracht kommenden Arten finden sich als Larven und Puppen in Ameisenkolonien. So verläuft vielleicht die Entwicklung der meisten Arten von Cryptocephalus in solchen. Clythra (quadripunctata L.) (Taf. II, Abb. 27 u. 28) legt ihre Eier, von einer tannenzapfenähnlichen Kothülle umgeben, in die Nähe eines Ameisennestes, und dessen Bewohner tragen sie, wohl durch die Ähnlichkeit mit Pflanzenmaterial getäuscht, mit hinein. Die sich hier entwickelnde Larve, die nach Janet von Nestabfällen lebt, nach anderen Ameiseneier verzehrt, steckt, ähnlich einer Köcherfliegenlarve, in einem schützenden Kokon, den sie aus ihren Exkrementen herstellt. 
Cleridae: Clerus (formicarius L.); gehört nicht zu den gesetzmässigen Gästen.

Scarabaeidae: Von den einheimischen Arten ist vor allem zu erwähnen Cetonia (Potosia) floricola Hrbst. (Taf. II, Abb. 28, 29, 30), welche als Larve erst in den äusseren, dann mehr in den inneren Teilen des Nestes lebt und als Puppe sich in dessen oberen Teilen findet. Während beide in den Ameisenkolonien normal als indifferent geduldet vorkommen und von dem vermodernden Pflanzenmaterial darin leben, wird der Käfer feindlich verfolgt.

Lathriidae: Monotoma (synoek bei Formica-Arten).

Cryptophagidae: Myrmecoxenus (subterraneus Chevr.) (Taf. II, Abb. 26) bei Formica und Lasius), Emphylus (glaber Gyll. bei Formica rufa und sanguinea), als Übergang von Synoeken zu Symphilen.

Histeridae: Eine grosse Menge von Gattungen dieser Familie kommt als Ameisengäste in Betracht. Es sind meist Synoeken, die sich von den Abfällen der animalischen Nahrung der Ameisen und von abgestorbenen Tieren der letzteren, auch von Larven und Puppen nähren. Dendrophilus (bei Formica und Lasius), Satrapes (bei Lasius, sehr selten), Abraeus (bei Lasius fuliginosus), Myrmetes (bei Formica-Arten). Hetaerius (ferrugineus Ol.) (Taf. II, Äbb. 25) findet sich bei Formica fusca sowie solchen Arten, die letztere als Sklaven halten, auch bei anderen Formica-Arten, ferner bei Lasius, Tapinoma, Leptothorax, Myrmica scabrinodis.

Ptilidae: Unter ihnen findet sich eine Anzahl gelegentlicher sowie gesetzmässiger Gäste. ginosus).

Ptenidium (Taf. II, Abb. 24) (bei Formica rufa, seltener bei Lasius fuli-

Silphidae: Catops (Taf. II, Abb. 23) (umbrinus Er. bei Lasius fuliginosus).

Scydmaenidae: Die betreffenden Arten sind nur gelegentlich Ameisengäste und nähren sich wahrscheinlich von Milben. Euthia (Taf. II, Abb. 22) (plicata Gyll. bei Formica rufa und exsecta), Euconnus (bei Formica, seltener bei Lasius), Scydmaenus (bei Formica rufa und Lasius).

Pselaphidae: Die grösste Zahl der hierher gehörigen Gäste kommt in unserem Gebiet nicht vor; für dieses kommen in Betracht als Symphilen: Claviger (Taf. II, Abb. 20). Die Vertreter dieser Gattung (2 einheimische Arten, die bei einigen Lasius-Arten auftreten, und deren Entwicklungsgang noch vollkommen unbekannt ist) zeigen recht deutlich ihre Anpassung an myrmekophile Lebensweise: Hinter dem Ende der verkürzten Flügeldecken liegen auf dem Hinterleib Sekret absondernde Gruben, und hinter den äussersten Spitzen der ersteren stehen goldgelbe Haarbüschel, zwischen denen Drüsen münden. Ausserdem sind die Tiere augenlos und haben zurückgebildete Mundteile, vermögen sich aber nach Beobachtungen im künstlichen Nest auch längere Zeit selbständig zu ernähren, wenn man sie mit Nahrung (frischgetöteten Insekten) versorgt, welch letztere ihnen aber in der freien Natur fehlen würden. Synoeken: Trichonyx, Amauronyx, Batrisodes (Taf. II, Abb. 21); Batrisus lebt von Milben in Kolonien von Lasius, Tetramorium, Ponera. Einen Übergang von den Symphilen zu den Synoeken bilden Arten der sehr seltenen Gattungen Chennium und Centrotoma.

Staphylinidae: Zu dieser Familie gehört über die Hälfte der in Betracht kommenden Ameisengäste. Symphilen: Lomechusa strumosa Grav. (Taf. II, Abb. 16) lebt vorzugsweise bei Formica sanguinea. Sie trägt goldgelbe Haarbüschel, die paarweise auf den Seiten der ersten vier Hinterleibssegmente stehen und zwischen denen die Ausführungsgänge von Drüsen münden, deren Sekret von den Ameisen sehr geschätzt wird. Sie belecken den Käfer, reinigen ihn und schützen ihn in jeder Weise; ferner wird er von ihnen gefüttert, und im Zusammenhang mit dieser Tatsache sind seine Mundteile, ausgenommen die Zunge, stark zurückgebildet. Auch die aus seinen Eiern hervorgehenden Larven, die eine den 
Ameisenlarven ähnliche gekrümmte Haltung einzunehmen pflegen, werden von den Ameisen gefüttert, fressen ausserdem aber auch deren Eier und Larven. Durch die ausserordentliche Sorgfalt, mit der die Ameisen diese Käfer in ihrem Nest behandeln, wird die Pflege ihrer eigenen Brut stark beeinträchtigt, und eine weitere Folge ist, dass sich in den Kolonien mit einer grösseren Zahl von Lomechusa verkümmerte Formen von Ameisen (Pseudogynen) in immer grősserer Menge entwickeln (S. 20).

Die Atemeles-Arten (Taf. II, Abb. 17), in ähnlicher Weise mit Haarbüscheln ausgerüstet wie Lomechusa, sind merkwürdig durch ihren Wirtswechsel, indem sie in den Herbst- und Wintermonaten in den Nestern von Myrmica-Arten zu finden sind und im Frühjahr zu Arten der Gattung Formica wandern, wo die Eier abgelegt werden und die daraus entstehenden Larven ihre Entwicklung durchmachen, um als entwickelte Käfer im Herbst wieder Myrmica-Kolonien aufzusuchen. Sie werden von den Ameisen nicht eigentlich gefüttert, sondern nehmen selbständig von dem Futtersaft aus dem Mund ihrer Wirte.

Synoeken: Dinarda dentata Grav. (Taf. II, Abb. 18) (mit einigen Var.) findet sich bei Arten der Gattung Formica und ist durch die Form ihres Körpers in Verbindung mit der glatten Oberfläche desselben sowie dessen Farbe vor Angriffen der Ameisen geschützt. Ihre Nahrung besteht in Futterabfällen und Milben.

Synechthren: Myrmedonia, Leptacinus, Xantholinus, Quedius u. a.

Arten der Gattung Myrmedonia (Taf. II, Abb. 19) leben in den Nestern (oder in deren Nähe) gewisser Lasius-Arten und töten vor allem vereinzelte schwächere Individuen, deren Köpfe sie aber nicht verzehren und deren Vorkommen in grösserer Anzahl bei solchen Nestern auf die Anwesenheit dieser Käfer schliessen lassen. Geschützt sind sie durch eine gewisse Ameisenähnlichkeit sowie durch die zur Verteidigung dienenden, stark riechenden Sekrete von im Hinterleib gelegenen Drüsen.

\section{Bedeutung der Ameisen.}

Die Bedeutung der Ameisen in Beziehung auf die sie umgebende Pflanzenwelt und Tierwelt sowie auf den Haushalt des Menschen ist eine grössere, als man gewöhnlich anzunehmen geneigt ist. Allerdings tritt auch sie uns in ihren mannigfachsten Äusserungen in den wärmeren Gegenden entgegen; doch ist auch sehr viel an unseren einheimischen Ameisen zu beobachten.

Die Arten der Gattung Formica haben in forstwirtschaftlicher Beziehung einen unmittelbaren Nutzen, indem sie grosse Mengen dem Waldbau schädlicher Insekten aller Art vertilgen und zu diesem Zweck auch die Bäume ersteigen. Nach einer von Forel angestellten Beobachtung uud Berechnung braucht eine grosse Kolonie unserer roten Waldameise in jeder Minute 28 Insekten. Ihr Bedarf im Lauf des Tages während ihrer grössten Tätigkeit würde sich darnach auf 100000, in einem Sommer gegen 10 Millionen belaufen, und da in manchen Waldungen zahlreiche Ameisenhaufen vorkommen, so vermag man sich einen ungefähren Begriff von der ökonomischen Bedeutung ihrer Bevölkerung zu machen. . Eine künstliche Vermehrung der Nester, wie sie bereits Ratzeburg vorgeschlagen hatte, wäre daher wohl an manchen Stellen lohnend, ist aber noch nicht mit Erfolg durchgeführt worden. Das Sammeln von Puppen (Kokons) dieser Ameisen („Ameiseneier") ist deshalb bei uns gesetzlich verboten. In Steiermark ist es dagegen als gewinnbringende, forstliche Nebennutzung von Bedeutung ${ }^{1}$ ). Als Vertilger dieser Ameisen berüchtigt ist der Grünspecht, der besonders im Winter die Kolonien ausplündert.

1) Nach Henschel werden in einem kleinen Dorf in Steiermark jährlich 50-60 hl getrockneter Kokons verkauft, mit einem Gewinn von je 6-7 Gulden. Nach seiner Schätzung werden dadurch jährlich 96-134 Millionen Ameisen vernichtet. 
Ameisen spielen ferner eine Rolle durch Verbreiten der Samen mancher Pflanzenarten, zum grossen Teil solcher, bei denen wegen ihres Standortes, besonders in Buchen- und Eichenwaldungen, das Ausstreuen des Samens durch Wind erschwert ist. Man nennt derartige "Ameisenpflanzen“ Myrmecochoren. Als solche sind zu nennen Schneeglöckchen, Lungenkraut, kreuzblättrige Wolfsmilch, Bienensaug, Ehrenpreis, Wachtelweizen, Haselwurz, wohlriechendes Veilchen, Schöllkraut u. a. Ihre Samen tragen einen weichen Anhang, die Nabelschwiele, der wegen seines Gehaltes an Öl Eleiosom genannt wird. Dieses wird von den Ameisen gern gefressen; sie schleppen daher die Samen mit sich, beissen die weichen Teile ab und lassen erstere, die trotzdem keimfähig bleiben, liegen. Nach von Sernander angestellten Versuchen und Berechnungen vermag eine Kolonie der roten Waldameise während der wärmeren Jahreszeiten auf solche Weise 36480 Samen, eine kleine von Lasius niger in 8 Wochen 638 Samen auszustreuen. Doch sind auch hier Einschränkungen zu beobachten. So ist beispielsweise die schwarze Nieswurz ausgesprochen myrmecochor und wird von den Ameisen stark verbreitet, ist aber trotzdem nicht häufig, da die Samen schwer keimen und von Insekten und Schnecken angegriffen werden.

Wirtschaftlich schädlich werden vor allem die Arten der Gattung Lasius, und zwar indirekt dadurch, dass sie Pflanzenläuse schützen und sogar züchten, sowohl solche, die an Wurzeln, als andere, die an grünen Teilen von Pflanzen leben. Die Darmausscheidungen dieser Tiere, welche als glänzender, klebriger Überzug auf Blättern bekannt sind, werden von den Ameisen ausserordentlich geschätzt und bilden für manche Arten deren ausschliessliche Nahrung. Um sich dieselbe zu verschaffen, veranlasst die Ameise eine Blattlaus durch Antennenschläge auf deren Hinterleib, einen gelben Exkrementtropfen von sich zu geben, den sie begierig aufnimmt. Früher war man der Meinung, dass ein aus den beiden Röhren am Hinterleib vieler Blattläuse abgesondertes Sekret von den Ameisen aufgesucht würde. Bei den von Ameisen besuchten Blattläusen sind aber gerade diese Organe nicht ausgebildet, was wiederum bei den von Ameisen verfolgten Blattläusen der Fall ist, durch deren wahrscheinlich stark riechendes Sekret erstere abgeschreckt werden. Die von Ameisen besuchten Läuse tragen ferner um die Analöffnung herum Härchen, durch welche das ausgeschiedene Sekret zurückgehalten wird.

$\mathrm{Da}$ ein mit Blattläusen besetzter Baum oder Strauch durch ständigen Besuch der Ameisen, nicht nur aus der Gattung Lasius, sondern auch aus anderen, wie Formica, Camponotus, von Feinden der Blattläuse frei gehalten und gegen sie verteidigt wird, so können sich die Läuse ungestört entwickeln. Häufig bauen die Ameisen Schutzwälle (Ställe, Pavillons, Zelte) um die Schädlinge und pflegen die Eier der Wurzelläuse während der kälteren Jahreszeit in ihrem Nest, um sie später wieder auszusetzen; wie es Lasius flavus tut, der dadurch unter Umständen ausserordentlich forstschädlich werden kann. In Nestern von Tetramorium caespitum finden sich oft grosse Mengen der Wurzellaus Paracletus cimiciformis Heyd.

Camponotus ligniperda, der ebenfalls Blattlaus-Ausscheidungen nachgeht, schadet durch Anlage seines Nestes in Bäumen, indem er deren weiches Sommerholz zernagt, und lockt durch seine Anwesenheit Spechte an, welche die Löcher im Holz noch vergrössern. Vielfach schädigen Ameisen die Blüten, indem sie solche zerbeissen, um zu den im Innern gelegenen Honiggefässen zu gelangen. Ein unmittelbares Beschädigen von Früchten im Garten durch Ameisen ist dagegen nicht festgestellt; sie gehen nur an schon verletzte Stücke.

Ohne grösseren Schaden anzurichten, können auch manche Ameisen recht lästig werden. Tetramorium caespitum und manche Lasius-Arten lockern und 
verunstalten oft Stellen auf Rasenflächen bei Anlage ihrer Nester, durch Minieren in der Erde und Aufwerfen kleiner Erdhügel. Letzteres ist auch auf Wiesen der Fall und wird auch bei gewissen Arten von Myrmica beobachtet, so dass das Mähen erschwert wird. Es ist ziemlich schwer, solche Nester dauernd zu beseitigen, und auch der Pflanzenwuchs leidet unter den angewendeten Mitteln. Empfohlen wird Eingiessen von kochendem Wasser, Kalkwasser, Lösungen von Kupfervitriol oder Quecksilbersalzen, ferner gebrannter Kalk, der in die Nester gebracht und mit Wasser begossen wird. Schwefelkohlenstoff kann man in der Weise anwenden, dass man mittelst eines Pfahles ein Loch mitten in das Nest stampft, dieses mit der Flüssigkeit tränkt und mit der nötigen Vorsicht anzündet. Nach dem Erlöschen der Flamme wird das Loch mit Erde zugeschüttet. Indessen gelingt es meist dennoch einer Anzahl Ameisen, rechtzeitig zu entrinnen. Werden Ameisen durch Beschützen von Pflanzenläusen, z. B. an Obstbäumen, schädlich, so kann man diese durch Ringe von Teer oder Leim einigermassen vor ihnen schützen.

Wo sich Ameisen im Hause unangenehm bemerkbar machen (Lasius niger, Monomorium, auch Tetramorium), ködert man sie durch ein mit Honig getränktes Schwamm- oder angefeuchtetes Zuckerstückchen. Die sich daran sammelnden Tiere tötet man durch Einwerfen des Ganzen in kochendes Wasser oder Spiritus und wiederholt das Verfahren öfter, von dem man sich aber ebenfalls keinen durchgreifenden Erfolg versprechen darf. Auch Eingiessen stark riechender Flüssigkeiten (Benzin mit darin gelöstem Naphthalin) in die von den Ameisen bewohnten Löcher und Fugen wird zu deren Vertreibung empfohlen. Insektenpulver, auch mit Borax vermischt, vertreibt die Ameisen, tötet sie aber wohl nicht.

\section{Hinweis auf offene Fragen.}

Wenn auch ein grosser Teil der Ameisen unseres Gebietes in diesem nahezu überall oder wenigstens weit verbreitet vorkommt, so gibt es doch eine Anzahl von Arten (s. d. speziellen Teil), die selten und nur an bestimmten Örtlichkeiten festgestellt worden sind. Es ist daher von Wichtigkeit, auf das weitere Vorkommen dieser Formen zu achten sowie auf das Auftreten solcher Arten, die aus angrenzenden Gebieten in das unsere vordringen. Dasselbe gilt für die Ameisengäste.

Wer sich weiter nicht nur darauf beschränkt, Ameisen zu sammeln und sie nach deren Bestimmung in die Sammlung zu reihen, dem bieten sich bei der Beobachtung der Lebensweise dieser Tiere nicht nur die interessanten, bereits bekannten Tatsachen, sondern er wird bald in die Lage kommen, neue zu beobachten und sich weiterhin vor Fragen stehen sehen, die noch der Lösung harren. Die Äusserungen des Ameiseninstinktes sind ja so vielseitig, dass es auf diesem Gebiet noch viel zu erkunden gibt. Es betrifft das z. B. den Nestbau unter den verschiedenen Lebensbedingungen, das Verhältnis der Ameisenarten zueinander in zusammengesetzten Nestern und gemischten Kolonien, die Koloniegründung, die morphologischen und biologischen Verhältnisse der Ameisengäste usw. Mit den Beobachtungen in der freien Natur müssen solche in künstlichen Nestern Hand in Hand gehen, und in bezug auf letztere sei noch einmal an die kleine Schrift von Viehmeyer (Beobachtungsnester für Ameisen [Aus der Heimat 1905, S. 14-17]) erinnert.

Die in der Ameisen-Literatur festgelegten Tatsachen sind aber so mannigfach, und die Ziele für die sich daraus ergebenden, weiteren Beobachtungen so zahlreich, dass man sich mit ersterer eingehend beschäftigen muss, zu welchem Zweck auf das Literaturverzeichnis zu verweisen ist. 


\section{Sammeln und Präparieren.}

Der Abschnitt über die Wohnungen der Ameisen (S. 29) gibt uns gleichzeitig einen Hinweis, wo wir letztere für den Zweck des Beobachtens und Sammelns aufzusuchen haben. Die Haufen unserer Waldameisen sind jedem bekannt. Abgestorbene Stämme und Äste, die längere Zeit an demselben Ort liegen, werden, wenn die betreffende Stelle genügend Wärme und die nötige Feuchtigkeit bietet, in Hohlräumen, unter der Rinde oder in dem Erdreich unterhalb derselben von Ameisen besetzt. Im Gebirge können wir fast unter jedem Stein, der nicht zu dick ist, um jene beiden Faktoren zur Wirkung kommen zu lassen, nach dem Umwenden eine kleinere oder grössere Ameisenkolonie antreffen. Häufig liegen mehrere Nester ganz verschiedener Arten unmittelbar nebeneinander. Die Art der Wohnung ist bei denselben Arten oft verschieden und den jeweiligen Bodenverhältnissen angepasst. Ausserdem treffen wir Ameisen überall auf den von ihrem Nest führenden Wegen, oft weit entfernt von ersterem, sowie auf Pflanzen aller Art, Sträuchern und Bäumen, den Blattläusen nachgehend oder Jagd auf Insekten machend.

Beim Sammeln von Material aus einem Nest achte man gleichzeitig auf die mit Ameisen in irgendeiner Form des Gemeinschaftslebens vorkommenden Tiere, Ameisengäste oder Myrmekophilen. Über alle auffallenden Befunde beim Sammeln (und bei späteren Beobachtungen in künstlichen Nestern) mache man sich Notizen. Es ist ferner in Betracht zu ziehen, dass sich meist in derselben Kolonie of und $\sigma^{\prime \prime} \sigma^{7}$ nicht gleichzeitig vorfinden, sondern zu verschiedenen Zeiten (S. 21). Manche Ameisen lassen sich auch durch Köder anlocken, wie Süssigkeiten, tierische Reste usw.

Für eine Exkursion ist es am einfachsten, die gefangenen Ameisen in ein mitgenommenes Gläschen (weithalsiges Fläschchen) zu bringen, das von Dämpfen von Essigäther (100 g ca. 0,30 Mk.) erfüllt ist. Letzteres erreicht man, indem man den Grund des Gläschens mit einer Schicht grober Sägespäne oder Watte fest vollstopft und von diesem Material etwas von jener Flüssigkeit aufsaugen lässt. Die Verwendung von Essigäther hat gegenüber der von Cyankalium, das sonst zum Töten von Insekten verwendet wird, den Vorteil, dass dieser ungiftig ist. Die Tiere werden auch darin nicht hart, sondern bleiben in den Gelenken biegsam (bei Anwendung von Chloroform nicht) und lassen sich für die Sammlung leicht präparieren.

Das für den Zweck einer solchen erbeutete Material kann trocken oder in Alkohol von $60-70^{\circ} \%$ aufbewahrt werden. Steht eine grössere Zahl von Exemplaren zur Verfügung, so empfiehlt es sich, einen Teil davon für spätere Untersuchungen oder als Reservematerial in Alkohol zu behalten und den andern trocken aufzubewahren, beide aber mit korrespondierenden Etiketten zu versehen, auf denen auch auf Notizen über Beobachtungen beim Sammeln hinzuweisen ist. Eier, Larven und Puppen kommen in Alkohol, zuerst einige Stunden in solchen von $30 \%$, dann $60 \%$, um Schrumpfungen zu vermeiden. Erwähnt mag noch werden, dass für den Zweck etwaiger mikroskopischer Untersuchung innerer Organe das lebende Material nach den üblichen Konservierungsmethoden behandelt werden muss, worüber die technischen Schriften Auskunft geben ${ }^{1}$ ).

Auch Material, das in Alkohol aufbewahrt wurde, lässt sich für die Sammlung leicht präparieren, obwohl häufig die Extremitäten in ihren Gelenken starr geworden sind und störende Stellungen angenommen haben, die sich höchstens durch Aufweichen (s. unten) beseitigen lassen. Geschlechtstiere aus Alkohol

3) Mayer-Lee, Grundzüge d. mikrosk. Technik. Berlin. 
haben den Übelstand, dass ihre Flügel weich und schlaff sind und aneinander kleben. In vielen Fällen werden sie wieder glatt, wenn man die Tiere mit dem Rücken auf die glatte Fläche des Spannbrettes legt, die Flügel mit einer Nadel oder einem Pinsel vorsichtig glatt richtet und von den Falten befreit. Nach dem Verdunsten des Alkohols sind sie starr genug geworden, und man kann sie dann häufig auch noch spannen. Exemplare, die man in stark getrocknetem Zustand erhält, und die daher sehr brüchig sind, erweicht man, um sie für die Sammlung zu präparieren. Sie werden in einem Schälchen auf einen Teller mit feuchtem Sand gebracht, nachdem man zur Vermeidung von Schimmelbildung dem zum Anfeuchten des letzteren dienenden Wasser etwas von einem antiseptischen Stoff zugesetzt hat, und lässt sie hier, von einer Glasglocke bedeckt, ungefähr einen Tag stehen, worauf sie wieder biegsam geworden sind.

Für Ameisen, die trocken aufbewahrt werden sollen, ist das Aufspiessen mit Nadeln oder feinen Stiften nach Möglichkeit zu vermeiden. Oft zerbrechen die Tiere dabei; ferner wird dadurch der Thorax verletzt oder durch das Einstecken der Nadel, besonders von oben her, eingedrückt und in seiner Gestalt verändert. Nur sehr grosse Arten - einheimische kommen dabei, höchstens die grossen Camponotus-Weibchen ausgenommen, überhaupt nicht in Betracht möge man mit einer passenden Nadel (Nr. 2) spiessen, und zwar durch den vorderen Teil des Thorax.

Die zweckmässigste Art der Aufbewahrung besteht darin, die Ameise auf ein schmales, rechteckiges, vorn zugespitztes, nicht zu dünnes Kartonblättchen mit Fischleim aufzukleben, wie es ja für andere Insekten auch zur Anwendung kommt, und zwar so, dass die Spitze des Blättchens in der Längsachse des Tieres unter dessen Brust zu liegen kommt, oder so, dass sie senkrecht zu dieser darunter liegt. Um schnell zum Ziel zu kommen, durchsticht man eine Anzahl Blättchen an derselben Stelle mit einer nicht zu dicken Nadel (Nr. 3), die den Boden des Sammelkastens nicht zu stark durchlöchert, schiebt das Blättchen bis zum obersten Drittel der Nadel und bedeckt die Spitze des ersteren mit einem Tröpfchen Fischleim, der Grösse des Tieres angemessen. Dann setzt man es mit einer Pinzette vorsichtig so darauf, dass es die vorher erwähnte Stellung einnimmt. Dabei ist darauf zu achten, dass die Beine jeder Körperseite von dieser etwas abgespreizt sind, damit sie nicht in den Leim geraten, bei winzigen Formen oft eine schwierige Sache. Ein zweites Exemplar kann man zweckmässig mit dem Rücken aufkleben, um die Bauchseite der Betrachtung zugänglich zu machen, obwohl grössere Stücke in dieser Stellung keinen besonders schönen Eindruck machen. Ein später etwa erforderliches $\mathrm{Ab}$ lösen der Ameise von dem Blättchen geschieht durch Einstellen unter die Glasglocke oder in dünnem Essig.

Jedes einzelne Exemplar muss besonders etikettiert werden, und zwar am besten mit zwei Etiketten aus steifem Papier, das eine mit dem Fundort bezw. der Nummer, die auf die beim Sammeln gemachten Notizen hinweist, das andere mit dem wissenschaftlichen Namen des Tieres, bei dem im übrigen der Anfänger nicht vergessen möge, die Abkürzung des Autornamens (desjenigen, der die Art zuerst beschrieben und ihr den Namen gegeben hat) hinzuzusetzen. Für die Sammlung fertige Stücke würden darnach so aussehen, wie in Abb. 38 dargestellt, wobei die Etiketten gleichzeitig als Schutzvorrichtung dienen.

Bei sehr grossen Stücken, die gespiesst worden sind, stützt man bis zum Trocknen den Hinterleib durch ein von unten her auf die Nadel geschobenes Kartonblättchen, das man zum Schutz auch dauernd darunter lassen kann. Abgebrochene Hinterleiber, auch andere Körperteile, klebt man am besten auf das Blättchen hinter dem aufgeklebten Tier. 
Von ganz kleinen Ameisen sowie von einzelnen Körperteilen (Antennen, Mundteilen, Beinen) werden zweckmässig mikroskopische Dauerpräparate angefertigt. Man bringt das betreffende Objekt in verdünnte Kalilauge, die nach mehreren Stunden, je nach der Grösse desselben, die Weichteile darin zerstört hat. Aus dieser Flüssigkeit kommt das Präparat mehrere Stunden in destilliertes Wasser, um die Lauge und mit ihr die Reste der zerstörten Weichteile auszuwaschen. Benutzt man gewöhnliches Wasser, so setzt man ihm zweckmässig einige Tropfen Essigsäure hinzu, um Kristallbildung am Präparat zu verhindern. Ein leichter Druck mit der Pinzette auf hohle Teile fördert das Heraustreten mazerierten Materials, und so bleibt schliesslich nur das reine Chitinskelet zurück. Dieses wird nun, um es zu entwässern, in absoluten Alkohol gebracht, der ein bis zweimal erneuert wird. (Ganz kleine Ameisen und sehr kleine Teile kann man, wenn sie zuvor in Spiritus lagen, aus diesem unmittelbar in absoluten Alkohol bringen.) Aus ihm kommt das Präparat in Xylol. War es gut entwässert, so wird es in dieser

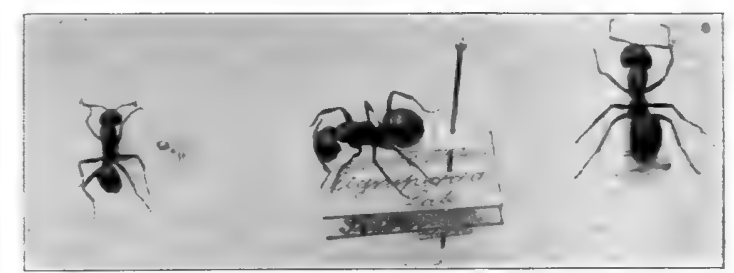

Abb. 38. Aufstellung in der Sammlung. Flüssigkeit zusehends hell und durchsichtig; geschieht das nicht, oder bemerkt man um das Objekt herum eine schwach milchige Trübung, so ist dies ein Zeichen, dass es noch nicht wasserfrei ist, und es muss nochmals einige Zeit, oft genügen einige Minuten, in absoluten Alkohol zurückgebracht werden. Ist das Óbjekt im Xylol klar, so bringt man auf einen Objektträger einen Tropfen Kanadabalsam. der Dicke des Präparates angemessen, legt das Präparat hinein und setzt ein Deckgläschen auf, das man leicht oder kräftiger, aber vorsichtig, andrückt. Dadurch werden z. B. bei einem Präparat der Mundteile diese auseinander getrieben und stören sich nicht durch gegenseitiges Überdecken; platzt bei grösseren Ameisen dabei der Kopf, so hat dies ja für den Zweck des Studiums der Mundteile keine Bedeutung. Welche Lage man dem Präparat zu geben hat, hängt natürlich davon ab, was man daran zu sehen wünscht; einem Kopf mit Mundteilen z. B. wird man Rückenlage geben.

Für diese Art der Präparation sind am geeignetsten kleine Glasdosen mit Deckel von 2-3 cm Durchmesser. 


\section{Systematischer Teil. $\left.{ }^{1}\right)$}

\section{Familie: Formicidae.}

\section{Unterfamilien :}

I. Stielchen 1 gliedrig.

1. Erstes (eigentliches) Abdominalsegment vom folgenden abgeschnürt. (Imagines mit Stachel; Puppen mit Kokon.)

2. Erstes (eigentliches) Abdominalsegment vom folgenden nicht abgeschnürt.

A. Epistom zwischen den Stirnleisten über die Einlenkungsstellen der Antennen hinaus nach hinten verlängert; Stielchen mit schwach entwickelter Schuppe oder ohne solche. (Imagines ohne Stachel; Puppen ohne Kokon.)

B. Epistom nicht über die Einlenkungsstellen der Antennen nach hinten hinausreichend; Stielchen mit hoher, breiter Schuppe. (Imagines ohne Stachel; Puppen meist mit Kokon.)

Ponerinae (S. 54).

Dolichoderinae

(S. 77).

Camponotinae

(S. 80).

II. Stielchen 2gliedrig. (Imagines mit Stachel; Puppen ohne Kokon.)

In dem hier in Betracht kommenden Verbreitungsgebiet nicht vertreten ist die Unterfamilie der

Myrmicinae (S. 55).

Dorylinae.

\section{Unterfamilie Ponerinae.}

Stielchen 1gliedrig; Pumpmagen ohne Kelch und Kugel; Kloakenöffnung spaltförmig; Giftdrüse und Stachel entwickelt; Puppen mit Kokon.

Aus dieser grossen und formenreichen Unterfamilie, welche grösstenteils die warmen Erdstriche bewohnt, ist in Europa nur eine Gattung vertreten, die in den Mittelmeerländern in einigen Arten nebst Varietäten vorkommt und auch fossil bekannt ist.

\section{Gattung: Ponera (Latr.) Em.}

8. - Antennen 12 gliedrig $\left.^{2}\right)$, gedrungen, mit allmählich hervorgehender, dicker, 4 gliedriger Keule. Maxillartaster 1-2gliedrig, Labialtaster 2gliedrig. Epistom

1) Ausser der Bastardierung sind die Einwirkung klimatischer Verhältnisse, vor allem die Temperatur, ferner die Belichtung sowie die Einflüsse der Umwelt Faktoren, welche nicht nur die Lebensgewohnheiten, sondern auch Färbung und Körpergestalt der Ameisen beeinflussen. Wir müssen daher auser den einzelnen Arten (Spezies) auch noch Rassen (Subspezies) und Varietäten derselben unterscheiden, deren Ursprung auf die genannten Faktoren zurückzuführen ist. Damit zusammen hängt auch die Tatsache, dass in geographisch weit auseinanderliegenden Gebieten mit sonst gleichen Existenzbedingungen ähnliche Formen mit ähnlichen Lebensgewohnheiten auftreten, und dass auch in unserem in Betracht kommenden Verbreitungsgebiet an weit getrennt liegenden Oertlichkeiten mit gleichen Lebensbedingungen die gleichen Arten und Varietäten zu finden sind. So beobachtet man in den Alpen bei $2000 \mathrm{~m}$ Höhe dieselbe Ameisenfauna wie in Nordeuropa zwischen $60^{\circ}$ und $70^{\circ}$.

2) Vergl. S. 8 Anmerkung 1 . 
kurz, breit, mit starkem Mittelkiel. Stirnleisten über der Antenneneinlenkung stark lappenartig verbreitert. Augen sehr klein, nahe dem Kiefergelenk liegend. Ocellen fehlen. Rücken zwischen Mesonotum und Epinotum in der Naht ganz wenig eingeschnürt. Epinotum flach gerundet, ohne Dornen. Schuppe dick, Vorder- und Hinterfläche fast parallel, Oberrand vorn stark, hinten kurz abgerundet, mit der Hinterfläche an die Vorderfläche des Abdomens passend.

+. - Augen gross.

$\sigma^{7}$. - Augen im Verhältnis noch grösser. Antennen 12-13gliedrig. Maxillartaster 4gliedrig, Labialtaster 3gliedrig.

In unserem Gebiet finden sich, ziemlich selten und nicht leicht zu unterscheiden, die beiden folgenden Arten :

Arbeiter und Weibchen.

I. Punktierung des Kopfes sehr fein und dicht. Stielchenknoten mässig dick:

P. punctatissima Rog.

II. Punktierung des Kopfes weniger fein und dicht. Stielchenknoten dick:

$P$. coarctata Latr.

I. Antennen 12 gliedrig :

Männchen.

II. Antennen 13gliedrig:

$P$. punctatissima Rog.

$P$. coarctata Latr.

Beide sind ziemlich kleine Formen. Färbung dunkler oder heller braun, Mandibeln, Antennen und Beine hell gelbbraun, die beiden ersteren meist, besonders die Antennenkeule nach dem Ende zu, etwas dunkler. Körper äusserst fein und dicht punktiert, mit sparsamer, anliegender Pubescenz, seidenartig schimmernd. Vorderrand des Epistoms und Ende des Abdomens mit sparsamen, abstehenden Borsten.

$P$. punctatissima Rog. findet sich in Mitteleuropa an vereinzelten Orten von England, Frankreich, Deutschland und der Schweiz, zum Teil in Gewächshäusern.

P. coarctata Latr. (Abb. 39; Taf. II, Abb. 15) kommt vor (ausser in Südeuropa und Nordafrika) an einzelnen Stellen Mitteleuropas bis Nordfrankreich, in der Rheinprovinz, auch in der Provinz Brandenburg.
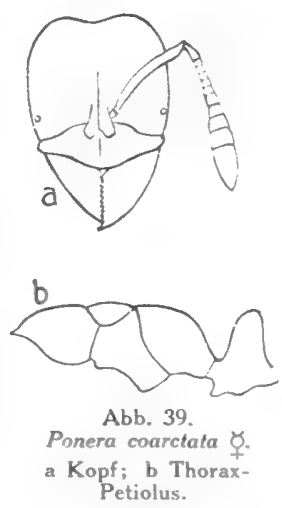

\section{Unterfamilie Myrmicinae.}

Stielchen 2gliedrig; Pumpmagen ohne Kelch und Kugel; Kloakenöffnung spaltförmig; Giftdrüse und Stachel entwickelt; Puppen mit Kokon.

\section{Gattungen:}

Arbeiter.

I. Mandibeln ohne gezähnten Innenrand.

1. Mandibeln schmal, zugespitzt:

2. Mandibeln breit:

II. Mandibeln mit gezähntem Innenrand.

Strongylognathus (S. 76). Harpagoxenus (S. 64).

1. Stielchenglied 2 oberhalb der Mitte des 1. Abdominalsegments eingelenkt; Abdomen hinten zugespitzt:

Cremastogaster (S. 73). 
2. Stielchenglied 2 in der Mitte des 1 . Abdominalsegments eingelenkt.

A. Stielchenglied 1 von der Seite gesehen viereckig umgrenzt, von oben gesehen quadratisch: Myrmecina (S. 59).

B. Stielchenglied anders geformt.

a) Stielchenglied 2 unten mit spitzem Dorn: Formicoxenus (S. 66).

b) Stielchenglied 2 unten ohne Dorn.

= Antennenkeule deutlich ausgebildet, 2 gliedrig, ungefähr halb so lang wie die ganze Geissel:

$=$ Antennenkeule aus mehr als 2 Gliedern

Solenopsis (S. 74). bestehend, bezw. undeutlich ausgebildet.

Epinotum ohne Dornen. (Wenn Epinotum ohne Dornen, Antennenkeule aber 5 gliedrig, so ist unter Myrmica weiter zu vergleichen.)

- Antennenkeule von dem übrigen Teil der Geissel deutlich zu unterscheiden, 3 gliedrig. (Sehr kleine Formen.)

Monomorium (S. 65).

Antennenkeule undeutlich, aus den vorangehenden Gliedern allmählich hervorgehend, 4gliedrig: ${ }^{1}$ )

Messor (S. 69).

Epinotum mit Dornen.

Antennenkeule undeutlich, aus den vorangehenden Gliedern allmählich hervorgehend: Aphaenogaster Antennenkeule als solche deutlich ausgebildet. * Die 3 letzten Antennenglieder zusammen ebenso lang oder kürzer als der übrige Teil der Geissel.

** Stielchen des 1 . Knotens unten und vorn ohne Dorn:

** Stielchen des 1. Knotens unten mit Dorn: Myrma (S. 67).

* Die 3 letzten Antennenglieder zusammen länger als der übrige Teil der Geissel.

** Pronotum von oben und hinten gesehen mit stumpfwinkligen Vorderecken:

** Pronotum von oben und hinten gesehen mit abgerundeten Vorderecken:

Tetramorium (S.75).

Leptothorax (S. 59).

\section{Weibchen.}

I. Beide Stielchenknoten plump, der vordere breiter als lang, der hintere dem Abdomen glockenförmig anliegend: Anergates (S. 65).

II. Beide Stielchenknoten schlanker, der vordere gestielt, der hintere vom Abdomen abgeschnürt.

1. Mandibeln ohne gezähnten Innenrand.

A. Mandibeln schmal, zugespitzt:

B. Mandibeln mit breitem Innenrand:

2. Mandibeln mit gezähntem Innenrand.

A. Stielchenglied 2 oberhalb der Mitte des 1 . Abdominalsegments eingelenkt (bedeutend grösser

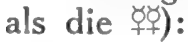

\section{Cremastogaster}

Strongylognathus

Harpagoxenus (S.64).

) Epinotum nur bei ganz grossen 辞 zuweilen mit stumpfen Zähnen. 
B. Stielchenglied 2 in der Mitte des 1 . Abdominalsegments eingelenkt.

a) Stielchenglied 1 von der Seite gesehen viereckig umgrenzt, von oben gesehen quadratisch: Myrmecina (S. 59).

b) Stielchenglied 1 von der Seite gesehen anders gestaltet.

$=$ Stielchenglied 2 unten mit spitzem Dorn: Formicoxenus (S.66).

$=$ Stielchenglied 2 unten ohne Dorn.

Antennenkeule deutlich ausgebildet, 2 gliedrig, ungefähr halb so lang wie die ganze Geissel; ( † bedeutend grösser

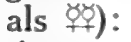

Antennenkeule aus mehr als 2 Gliedern

Solenopsis (S. 74). bestehend, bezw. undeutlich ausgebildet. Opinotum ohne Dornen. (Wenn Epinotum ohne Dornen, Antennenkeule aber 5 gliedrig, so ist unter Myrmica zu vergleichen.)

* Antennenkeule von dem übrigen Teil der Geissel deutlich zu unterscheiden,

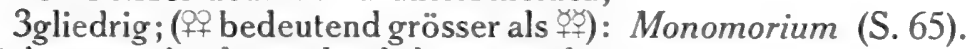

* Antennenkeule undeutlich, aus den vorangehenden Gliedern allmählich hervorgehend:

Epinotum mit Dornen.

* Die 3 letzten Antennenglieder zusammen deutlich kürzer als der übrige Teil der Geissel.

** Antennenkeule als solche nicht deutlich ausgebildet, aus den vorangehenden Gliedern allmählich hervorgehend. (Endglieder nicht viel stärker als die Anfangsglieder.):

** Antennenkeule als solche deutlich ausgebildet.

$\uparrow$ Stielchen des 1. Stielchenknotens unten und vorn ohne Dorn:

+ Stielchen des 1. Stielchenknotens unten und vorn mit Dorn:

* Die 3 letzten Antennenglieder zusammen ungefähr eben so lang, nur wenig kürzer als der übrige Teil der Geissel.

** Stielchenknoten 1 von der Seite gesehen spitzwinklig, mit abgerundeter Kuppe und konkaver Vorderseite; (ㅇ bedeutend grösser als 하):

** Stielchenknoten 1 von der Seite gesehen recht- oder stumpfwinklig, mit abgerundeter Kuppe und fast gerader Vorderseite ( +7 wenig grösser als $\left.\nvdash^{\circ}\right)$ :

Aphaenogaster

Messor (S. 69).

Stenamma (S. 67).

Myrmica (S. 69).

Tetramorium (S. 75).

Leptothorax (S. 59). 
I. Antennen 10 gliedrig.

Männchen.

1. Mandibeln ohne gezähnten Innenrand.

A. Mandibeln schmal, zugespitzt:

B. Mandibeln mit breitem Innenrand:

2. Mandibeln mit gezähntem Innenrand:

II. Antennen 11 gliedrig:

III. Antennen 12-13 gliedrig.

Strongylognathus

[(S. 76).

Harpagoxenus (S.64).

Tetramorium (S. 75).

Anergates (S. 65).

1. Stielchenglied 2 unten mit spitzem Dorn; (Antennen 12 gliedrig):

Formicoxenus (S. 66).

2. Stielchenglied 2 unten ohne Dorn.

A. Geisselglied 1 sehr kurz, kugelförmig; (Antennen 12 gliedrig).

a) Stielchenglied 2 oberhalb der Mitte des 1 . Abdominalsegments eingelenkt:

b) Stielchenglied 2 in der Mitte des 1. Abdominalsegments eingelenkt:

B. Geisselglied 1 anders gestaltet.

Cremastogaster(S.73).

Solenopsis (S. 74).

a) Mandibeln unter der Oberlippe zurückgezogen;

(Antennen 13gliedrig):

Myrmecina (S. 59).

b) Mandibeln frei.

$=$ Geisselglied 1 deutlich dicker als das folgende:

$=$ Geisselglied 1 nicht dicker als das folgende.

Leptothorax (S. 59).

Thorax sehr hoch gewölbt; Mesonotum über das Pronotum hinaus nach vorn geneigt.

Geisselglied 2 ungefähr doppelt so lang als breit; Epinotum am Grund mit 2 starken, einen kurzen Dorn tragenden Höckern; (ziemlich kleine Formen) :

- Geisselglied 2 fast dreimal so lang als breit; Epinotum mit 2 wenig hervortretenden, kaum gezähnten Höckern; (grosse Formen):

|| Thorax mässig gewölbt; Mesonotum nicht Aphaenogaster(S.68). über das Pronotum hinaus nach vorn geneigt.

- Pronotum mit Mayrschen Furchen. ${ }^{1}$ )

* Stielchenknoten 1 vorn lang gestielt, verlängert :

Stenamma (S. 67).

* Stielchenknoten 1 vorn kurz gestielt: Myrmica (S. 69).

Pronotum ohne Mayrsche Furchen. ${ }^{1}$ ) Monomorium (S. 65).

1) „Bei vielen Männchen der Myrmiciden beginnen vorne seitlich am eigentlichen Mesonotum zwei vertiefte Furchen, die nach hinten und einwärtsziehend sich in der Mitte desselben vereinigen, von wo eine Furche gerade nach hinten zieht." (Mayr, Europ. Formiciden. Lit.-Verz. 256. S. 5.) 
Tribus: Myrmicii.

\section{Gattung: Myrmecina Curtis.}

ㅎ. - Antennen 12 gliedrig, gedrungen, Antennenschaft hinter dem Grunde stark gebogen, Geissel mit 3 gliedriger Keule, die länger ist als der übrige Teil der Geissel, dessen Glieder mit Ausnahme des ersten deutlich kürzer als lang sind. Maxillartaster 4 gliedrig, Labialtaster 3 gliedrig. Epistom mit abgerundetem Hinterrand, mit 2 Längskielen, die über dem Vorderrand als Zähnchen enden. Stirnfeld vertieft, undeutlich. Ocellen fehlen. Netzaugen ziemlich klein. Rücken zwischen Mesonotum und Epinotum nicht eingedrückt. Epinotum mit kräftig entwickelten Dornen, vor diesen am Vorderrand des Epinotums jederseits ein Zähnchen.

+. - Epinotaldornen viel länger als beim $\zeta$.

$\sigma^{7}$. - Antennen 13gliedrig, Geisselglied 1 am kürzesten, das letzte am längsten. Mandibeln von der Oberlippe bedeckt. Epistom ohne die Zähnchen des ఛ. Epinotum mit Zähnen. Mesonotum mit Mayrschen Furchen.

Die Gattung enthält rund 20 Arten, die über Europa, Nordamerika, Indien, die malayischen Inseln, Neu Guinea und Australien verbreitet sind.

Myrmecina graminicola Foerst. (= M. latreillei Curt.) (Abb. 40; Taf. I, Abb. 35.)

ఫ. - Färbung dunkelbraun, Antennen, Mandibeln, Beine und Abdominalende hellbraun. - Kopf, Thorax und Stielchen längs gerieft, der Kopf etwas schwächer als der Thorax, mit etwas netzartigen Anastomosen. Abdomen glatt, glänzend. - Auf allen Teilen abstehende Borsten in mässiger Verteilung.

9. - Etwas dunkler braun, Oberkopf, Postscutellum und Abdomen, dessen Ende ausgenommen, schwarzbraun; Antennen braun; Beine gelb.

77. - Färbung schwarzbraun; Antennen braun; Beine hellbraun. Flügel bräunlich trübe. - Kopf und Thorax sehr fein, weitläufig und oberflächlich gerunzelt. Abdomen glatt und glänzend.

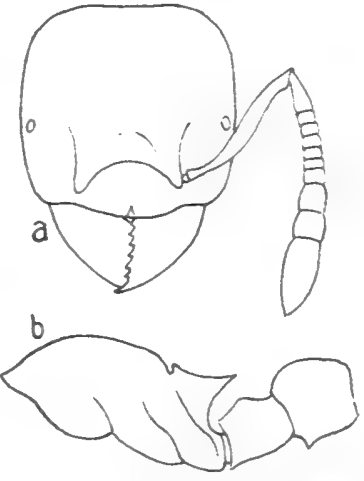

Abb. 40. Myrmecina graminicola a Kopf; b Thorax-Petiolus.

Bewohnt Mittel- und Südeuropa, eine Rasse und zwei Varietäten Nordamerika. - Kolonien wenig volkreich; Erdnester sehr klein, ungefähr $5 \mathrm{~cm}$ im Durchmesser, an schattigen Stellen, am Grunde von Bäumen, unter Steinen, in Mauerritzen; die Bewohner führen eine verborgene Lebensweise, sind in ihren Bewegungen langsam, furchtsam, stellen sich beim Ergreifen tot.

\section{Gattung: Leptothorax Mayr.}

ఫ. - Antennen $11-^{1}$ ) oder 12gliedrig, mit kräftig entwickelter Keule, die länger ist als die übrige Geissel; Geisselglieder 2 bis 5 breiter als lang. Maxillartaster 5 gliedrig, Labialtaster 3gliedrig. Hinterrand des Epistoms halbkreisförmig abgerundet. Stirnfeld vertieft, nach hinten nicht abgegrenzt. Ocellen fehlen. Rücken zwischen Mesonotum und Epinotum flach eingeschnürt. Pronotum von hinten und oben gesehen mit stark abgerundeten Vorderecken. Epinotum mit Dornen. Körper mit abstehenden Borsten.

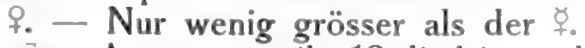

$c^{-}$- Antennen teils 12gliedrig und ohne deutliche Keule ${ }^{1}$ ) (dann Geissel-

1) Die Arten mit 11 gliedriger Keule werden von Ruzsky zu dem Subgenus Mychothorax zusammengefasst. 
glied 2 länger als der Schaft), teils 13gliedrig und mit 4gliedriger Keule. Mesonotum mit Mayrschen Furchen.

Von der Gattung Leptothorax sind über 100 Arten (auch fossile) bekannt, die über alle Faunengebiete mit Ausnahme von Australien verbreitet sind.

Arten:

Arbeiter.

I. Antennen 11gliedrig:

1. Beine mit abstehenden Borsten:

$[($ N. 1).

2. Beine ohne abstehende Borsten:

II. Antennen 12gliedrig.

L. acervorum (F.) Mayr

L. muscorum (Nyl.) Mayr

(N. 2).

1. Epistom mit je einer feinen, ungefähr unterhalb der Antenneneinlenkung entspringenden Längsleiste:

L. clypeatus Mayr (N. 3)

2. Epistom ohne Leisten.

A. Kopf vollständig braunschwarz:

B. Kopf braun bis gelb.

a) Epinotaldornen kurz, gedrungen:

b) Epinotaldornen lang und dünn.

= Thorax grob längs gerieft:

$=$ Thorax fein längs gerieft.

I| Antennenkeule braun.

Oberkopf und Abdomen, letzteres gleichmässig, braun:

Oberkopf und Abdomen gelb, letzteres mit braunen Querbinden.

* Abdominalsegment 1 mit breiter, vollständiger, dunkler Querbinde: L. unifasciatus (Latr.)

* Abdominalsegment 1 mit unvollständiger, in der Mitte unterbrochener Querbinde:

L. nigriceps Mayr (N. 7).

L. corticalis (Schnck.) Mayr (N. 8).

L. affinis Mayr (N. 5).

L.tuberum(F.) Mayr (N.4).

Antennenkeule rötlichgelb bis gelb.

$\circ$ Abdominalsegment 1 ohne dunkle Querbinde:

Abdominalsegment 1 mit dunkler Querbinde.

* Binde an den Segmenthinterrand grenzend:

* Binde nicht an den Segmenthinterrand reichend:

L. interruptus (Schnck.)

Mayr (N. 10).

L. luteus For. (S. 6).

L. nylanderi (Foerst.) Mayr (N. 11).

L. parvulus (Schnck.) Mayr (N. 12).

\section{Weibchen.}

I. Antennen 11 gliedrig.

1. Beine mit abstehenden Borsten:

$[($ N. 1).

2. Beine ohne abstehende Borsten:

II. Antennen 12 gliedrig.

1. Mesonotum glatt:

2. Mesonotum längs gerieft.

A. Kopf vollkommen braunschwarz:

B. Kopf braun bis gelb.

L. acervorum (F.) Mayr

L. muscorum (Nyl.) Mayr

L. corticalis (Schnck.) (N. 2). Mayr (N. 8).

L. nigriceps Mayr (N. 7). 
a) Antennenkeule braun

$=$ Abdomen gleichmässig braun:

$=$ Abdomen gelb, mit braunen Querbinden .

L. tuberum (F.) Mayr

II Abdominalsegment 1 mit breiter, vollständiger, dunkler Querbinde; (die folgenden mit schmalen Binden; lange Epinotaldornen):

Abdominalsegment 1 mit unvollstänständiger dunkler Querbinde; (ebenso die folgenden mit schmalen Binden).

Epinotum grob längs gerieft:

Epinotum fein längs gerieft:

b) Antennenkeule gelb.

$=$ Abdominalsegment 1 mit breiter, vollständiger, dunkler Querbinde; (die folgenden mit schmalen Binden):

$=$ Abdominalsegment 1 mit unvollstăndiger, dunkler Querbinde; (ebenso die folgenden mit schmalen Binden):

\author{
L. unifasciatus (Latr.) \\ Mayr (N. 9). \\ L. affinis Mayr (N. 5). \\ L. interruptus (Schnck.)
}

Mayr (N. 10).

L. nylanderi (Foerst.)

Mayr (N. 11).

L. luteus For. (N. 6).

\title{
Männchen。
}

I. Antennen 12gliedrig, Schaft kürzer als Geisselglied 2.

1. Beine dunkler, mit langen, abstehenden Borsten: L. acervorum (F.) Mayr

2. Beine heller, mit sparsamen Borsten: L. muscorum (Nyl.) Mayr

II. Antennen 13gliedrig, Schaft länger als Geisselglied 2.

1. Mesonotum zwischen den Mayrschen Furchen mit kräftiger Längsskulptur:

2. Mesonotum zwischen den Mayrschen Furchen mit feiner Längsskulptur:

L. tuberum (F.) Mayr

(N. 2).

L. unifasciatus (Latr.) Mayr (N.9).

L. interruptus (Schnck.)

3. Mesonotum zwischen den Mayrschen Furchen glatt und glänzend:

Mayr (N. 10).

L. nylanderi (Foerst)

Mayr (N. 11).

1. L. acervorum (F.) Mayr (Taf. I, Abb. 41).

ł. - Antennen 11 gliedrig; Epinotaldornen länger und schlanker als bei L. muscorum. - Gelb bis bräunlichrot, Vorderfläche des Kopfes, Antennenkeule und Oberseite des Abdomens braun, am Kopf und Abdomen über deren Seiten hin nach unten lichter werdend. - Kopf kräftig, Thorax oberflächlich längsgerieft; Beine mit abstehenden Borsten.

+. - Antennen 11gliedrig; Epinotaldornen kräftig und spitz, mit breiter Basis, länger als bei $L$. muscorum. - Gelbrot, Kopf, Antennenkeule, Mesonotum und Abdomen, meist auch die oberen Flächen der Stielchenknoten, dunkelbraun. - Kopf kräftig, Mesonotum feiner längsgerieft; Beine mit abstehenden Borsten.

6.- - Antennen 12gliedrig, Schaft kürzer als das 2. Geisselglied; Mandibeln ohne Zähne. - Dunkelbraun, Beine braun, Gelenke der Beine und die Tarsen gelb; Kopf, Thorax und Abdomen reich mit abstehenden Borsten bedeckt.

Von Norwegen (hier auch die var. nigrescens Ruzsky) durch ganz Mitteleuropa. Nester unter Baumrinde, in morschen Ästen, unter Moos und Steinen. Geschlechtstiere im Spätsommer. 
2. L. muscorum (Nyl.) Mayr.

ఛ. - Antennen 11 gliedrig; Epinotaldornen kürzer und gedrungener als bei L. acervorum. - Gelb bis bräunlichrot, Vorderfläche des Kopfes und Oberseite des Abdomens dunkelbraun, Antennenkeule braun. - Skulptur wie bei L. acervorum, auf dem Kopf etwas feiner; Beine ohne abstehende Borsten.

+. - Antennen 11 gliedrig; Epinotaldornen kräftig, kurz, zugespitzt, mit breiter Basis, kürzer als bei L. acervorum. - Gelbrot, Kopf, Antennenkeule und Abdomen braun, Thorax um die Flügelwurzeln herum, oft auch der Hinterrand des Scutellums, dunkelbraun. - Kopf und Mesonotum fein längsgerieft, auf den hinteren Teilen des letzteren zuweilen quer; Beine ohne abstehende Borsten.

$\sigma^{7}$. - Antennen 12gliedrig, Schaft kürzer als das 2. Geisselglied; Mandibeln ohne Zähne. - Dunkelbraun, Beine heller. Kopf, Thorax und Abdomen sparsam mit abstehenden Borsten.

\section{L. clypeatus Mayr.}

ఛ.. - Antennen 12 gliedrig; Epistom mit je einer feinen, in der Höhe der Antenneneinlenkung entspringenden Längsleiste; Epinotum mit kräftigen Dornen. - Gelbrot, Abdomen braun, der vordere Teil um die Stielcheneinlenkung herum heller. - Kopf und Thorax fein und oberflächlich längsgerunzelt, letzterer mehr netzförmig.

․ - Antennen 12 gliedrig; Epistom wie beim 支; Epinotum mit kräftigen, zugespitzten Dornen auf breiter Basis. - Rötlichgelb, Thorax um die Flügelwurzeln herum, oft auch auf dem Hinterrand des Scutellums, dunkelbraun, Abdomen braun. - Kopf und Mesonotum fein und oberflächlich längsgerieft. ○. - Antennen 13 gliedrig; Schaft länger als das 1. Geisselglied; Mandibeln gezähnt.

Nester unter Baumrinde.

\section{L. tuberum (F.) Mayr.}

ఛ. - Antennen 12 gliedrig; Epinotaldornen kurz, kräftig und gedrungen. Rötlichgelb, Vorderfläche des Kopfes und Antennenkeule braun, Abdomen lichtbraun, der vordere Teil desselben gelb. - Kopf und Thorax sehr fein, besonders der Kopf sehr gleichmässig längsgerieft.

\%. - Antennen 12 gliedrig; Epinotaldornen kurz, zahnartig, zugespitzt. Braun, Mandibeln, Antennenschäfte, proximaler Teil der Geissel und Beine gelb, Antennenkeule braun. - Kopf und Thorax gleichmässig und kräftig längsgerieft. $\sigma^{7}$. - Antennen 13 gliedrig, Schaft länger als das 1. Geisselglied; Mandibeln gezähnt; Mesonotum zwischen den Mayrschen Furchen kräftig längsgerieft.

Nester unter Baumrinde, in morschen Ästen, unter Moos, auf trockenem Boden unter Steinen, in Gesteinsspalten.

\section{L. tuberum (F.) Mayr v. affinis Mayr.}

ఈ. - Antennen 12 gliedrig; Epinotaldornen lang und schlank. — Thorax rotgelb, Vorderfläche des Kopfes, meist die Antennenkeule, ferner Schenkel und Abdomen, ausgenommen dessen vorderer Teil, braun. - Kopf sehr fein, Thorax kräftig längsgerunzelt, letzterer mehr netzartig.

f. - Antennen 12 gliedrig; Epinotaldornen kurz, spitz, mit breiter Basis. Bräunlichgelb bis braun, Antennenkeule braun, Abdomen vor dem Rand jedes Segments mit brauner Binde, die Segmentränder selbst gelb. dibeln gezähnt.

$\sigma^{7}$. - Antennen 13gliedrig, Schaft länger als das 1. Geisselglied; Man-

Nester unter Baumrinde und in abgestorbenem Holz. 


\section{L. tuberum (F.) Mayr v. luteus Mayr.}

Eine mehr südliche Form von hellgelber Farbe, Antennenkeule ein wenig dunkler, die dunkle Querbinde auf dem 1. Abdominalsegment undeutlich, unvollständig. - Epinotaldornen kräftig, mit breiter Basis. Thorax fein längsgerieft.

Unter Steinen, in Felsspalten.

\section{L. tuberum (F.) Mayr v. nigriceps Mayr.}

ఛ. - Antennen 12 gliedrig; Epinotaldornen kräftig, spitz, mit breiter Basis. - Kopf und Antennenkeule schwarzbraun, Thorax und Stielchenknoten rotbraun, Abdomen gelblichbraun, nach hinten dunkler werdend, Schenkel, ausgenommen deren Enden, braun. - Kopf und Thorax lederartig längsgerunzelt, Riefen nicht gerade; Skulptur kräftiger als bei der Stammform.

+. - Schwarzbraun. - Mesonotum grob längsgerieft. Epinotaldornen kürzer als bei der Stammform.

Eine mehr südliche Form, unter Steinen, in Felsspalten.

8. L. tuberum ( $\left.\mathrm{F}_{\text {. }}\right)$ Mayr v. corticalis (Schnck.) Mayr.

ఫ. - Antennen 12gliedrig; Epinotaldornen kurz und zahnförmig. Bräunlichgelb, Vorderfläche des Kopfes und Oberseite des Abdomens braun. Kopf und Thorax fein längsgerunzelt, letzterer mehr netzartig.

f. - Antennen 12 gliedrig; Epinotaldornen kurz und zahnförmig. Braun, Mandibeln, Antennen und Beine lichtbraun.

$0^{7}$. - Antennen 13gliedrig, Schaft länger als das 1. Geisselglied; Mandibeln gezähnt.

Nester unter Baumrinde, auch in leeren Gallen.

9. L. tuberum (F.) Mayr v. unifasciatus (Latr.) Mayr (Taf. I, Abb. 38).

ఫ. - Antennen 12 gliedrig; Epinotaldornen kurz, kräftig und gedrungen. Rötlichgelb, Vorderfläche des Kopfes zuweilen dunkler (oft nur deren untere Hälfte) und Antennenkeule braun, Abdomen gelb, auf dem 1. Segment mit vollständiger, nicht sehr breiter Binde. - Kopf und Thorax fein längsgerunzelt, ersterer etwas ungleichmässig.

f. - Antennen 12gliedrig, Epinotaldornen kurz und zahnartig. - Gelb, Kopf hellbraun, Antennenkeule dunkelbraun, Abdomen mit Querbinden.

ช. - Antennen 13gliedrig, Schaft länger als das 1. Geisselglied; Mandibeln gezähnt; Mesonotum zwischen den Mayrschen Furchen fein und dicht längsgerieft.

Nester unter Rinde, in altem Holz, in Felsspalten, unter Steinen.

10. L. tuberum (F.) Mayr v. interruptus (Schnck.) Mayr.

ఛ. - Antennen 12 gliedrig; Epinotaldornen lang, schlank und spitz. - Gelb, die untere Hälfte der vorderen Kopffläche und Antennenkeule braun, Abdomen auf dem 1. Segment ohne braune Binde oder mit einer solchen, die in der Mitte verwischt ist. - Kopf und Thorax fein längsgerunzelt.

9. - Antennen 12 gliedrig; Epinotaldornen kräftig, zugespitzt, auf breiter Basis. - Braun, Kopf und Antennenkeule dunkler, Thorax um die Flügelwurzeln herum, auch der Hinterrand des Scutellums, braun. - Kopf mit scharf eingeschnittener, Thorax mit mehr oberflächlicher Längsskulptur.

ช. - Antennen 13 gliedrig, Schaft länger als das 1. Geisselglied; Mandibeln gezähnt. - Schwarzbraun, Mandibeln, Antennen und Beine heller oder dunkler gelb. - Mesonotum zwischen den Mayrschen Furchen mit sehr feirer Längsskulptur, fast glatt.

Nester unter Rinde, in altem Holz, in Felsspalten, unter Steinen. 
11. L. nylanderi (Foerst.) Mayr (Abb. 41; Taf. I, Abb. 39 ৮, 40 ㅇ).

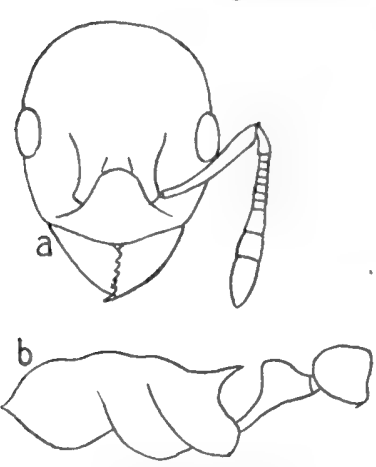

Abb. 41. Leptothorax nylanderi 후. a Kopf; b Thorax-Petiolus.

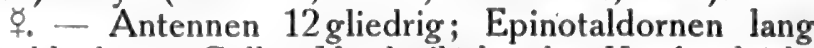
und schlank. - Gelb, Vorderfläche des Kopfes leicht hellbraun, zuweilen so auch die Stielchenknoten oben, Abdomen gelb, auf dem 1. Segment mit breiter, dunkler Querbinde. - Kopf und Thorax sehr fein, ersterer sehr gleichmässig, längsgerieft.

․ - Antennen 12 gliedrig; Epinotaldornen lang, spitz, auf breiter Basis. - Gelb, Kopf braun, Stielchenknoten oben meist braun, 1. Abdominalsegment mit breiter, die anderen Segmente mit schmalen Binden. $0^{7}$. - Antennen 13 gliedrig, Schaft länger als das 1. Geisselglied; Mandibeln gezähnt.

Im Süden häufiger, an schattigen Stellen in Holz, unter Rinde.

12. L. nylanderi (Foerst.) Mayr v. parvulus (Schnck.) Mayr.

Unterscheidet sich von der Stammform durch die Querbinde auf dem 1. Abdominalsegment, welche blasser ist und den Segmenthinterrand nicht erreicht.

\section{Gattung: Harpagoxenus Forel. ${ }^{1}$ )}

ఫ̧. - Antennen 11 gliedrig, mit 4 gliedriger Keule, die länger ist als der übrige Teil der Geissel. Mandibeln mit breitem, ungezähntem Innenrand. Maxillartaster 5 gliedrig, Labialtaster 3 gliedrig. Epistom trapezförmig, mit abgerundeten Hinterecken. Stirnfeld kaum ausgebildet, undeutlich umgrenzt. Stirnleisten bis auf den Oberkopf verlängert, eine flache Furche bildend, die den Antennen-
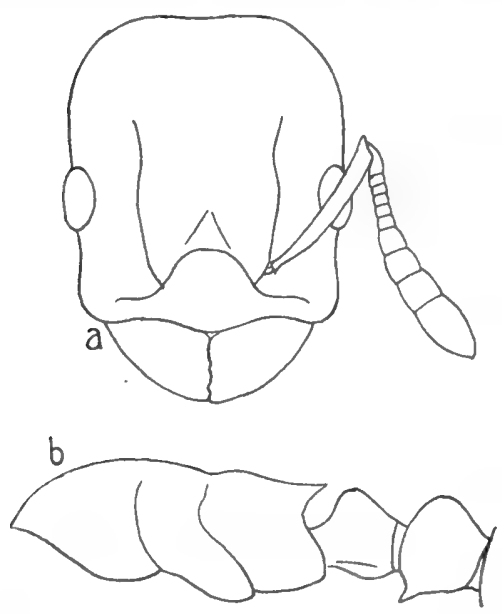

Abb, 42. Harpagoxenus sublaevis $\not$. a Kopf; b Thorax-Petiolus. schaft aufnehmen kann. Ocellen kaum entwickelt. Rücken zwischen Mesonotum und Epinotum eingeschnürt. Epinotum mit Dornen.

9. - Es kommen vor geflügelte und ungeflügelte (ergatoide) 오궁 erstere besitzen 3 Ocellen und zeigen keine Übergangsformen zu den 하; letzteres ist der Fall bei den ungeflügelten of, die 1 Ocellus haben.

๑7. - Antennen 12 gliedrig, Geisselglied 2 kürzer als der Schaft. Netzaugen und Ocellen sehr gross. Mesonotum mit Mayrschen Furchen. Epinotum mit schwachen, abgestumpften Höckern.

\section{(Abb. 42).}

Harpagoxenus sublaevis ( $\mathrm{Nyl}_{\text {.) }}$ For.

ఛ.. - Kopf rechteckig, mit flach ausgerundetem Hinterrand. - Kopf, Thorax, Stielchenglieder und Beine gelbbraun bis braun, Antennenkeule braun, mit hellerem Ende; Mandibeln gelb, mit braunem Innenrand. Abdomen dunkelbraun, um die Stielcheneinlenkung herum heller. - Kopf zwischen den Stirnleisten und deren Verlängerung dicht längsgerieft, weniger scharf ausserhalb derselben. Oberkopf glatt, mit wenigen, zerstreuten Punkten; Thorax oberflächlich und dicht längsgerieft, die Stielchen-

1) = Tomognathus Mayr. 


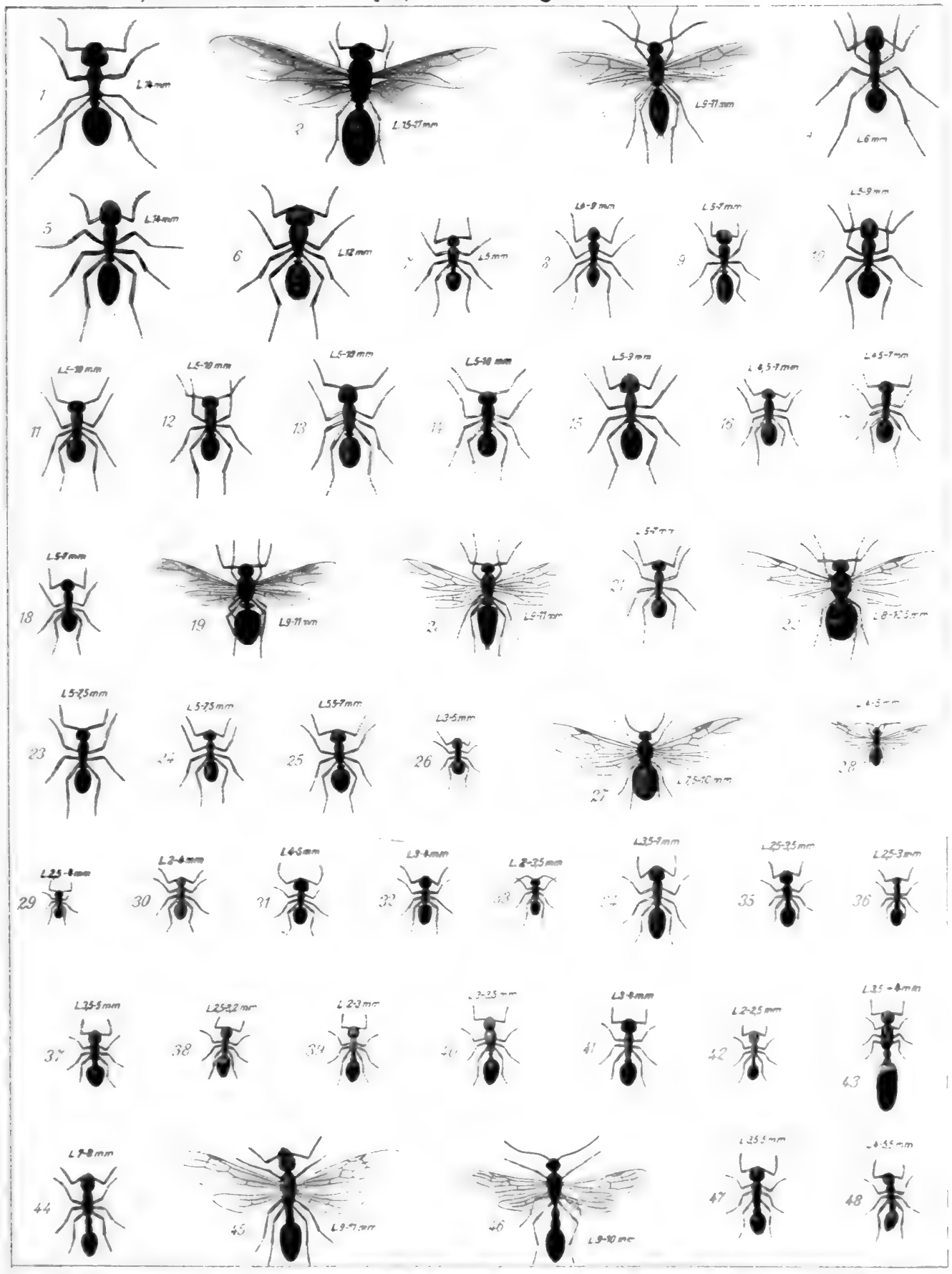

1. Camponotus ligniperda maj. 2. Camponotus ligniperda $q .3$. Camponotus ligniperda $\sigma^{\prime}$. 4. Camponotus ligniperda $\not$ min. 5. Camponotus herculaneus $\not$ maj. tus 'vagus $\forall$ min. 8. Camponotus marginatus $\not$. 9. Colobopsis truncata $\%$. 10. Formica sanguinea $\gamma$. 11.12. Formica rufa $\not$. 13. Formica rufa, Oberg. zu pratensis $\not$. 14. Formica rufa-pratensis $\varnothing$. 15. For. mica rufa-truncicola $\not$. 16. Formica fusca-cinerea $\measuredangle$. 17. Formica fusca-rufibarbis $\varnothing$. 18. Formica fusca-

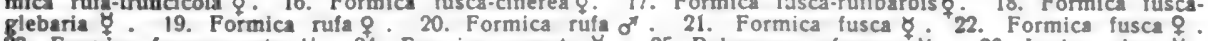

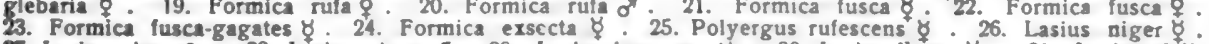

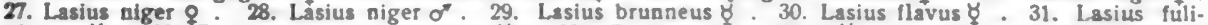
ginosus $\not$. 32. Dolichoderus 4 punctatus $\not$. 33. Tapinoma erraticum $\gamma$. 34. Liometopum microcephalum $\not$. 35. Myrmecina latreillei $\not$. 36. Formicoxenus nitidulus $\not{q}$. 37. Cremastogaster scutellaris $\not$. 38. Leptothorax unifasciatus $\not$. 39. Leptothorax nylanderi $\not$. 40. Leptothorax nylanderi $q$. 41. Leptothorax acervorum $q$. 42. Monomorium pharaonis $\forall$ 43. Monomorium pharaonis of. 44. Myrnica rabida 8 . 45. Myrmica rubida $q$. 46. Myrmica rubida $\sigma^{7}$. 47. Myrmica scabrinodis 8 . 48. Myrmica ruginodis $\Varangle$. (Original zeichaung von R. Flanderky.) 
, 
knoten fast gar nicht. Abdomen glatt und glänzend. - Körper reichlich mit abstehenden, gelben Borsten bekleidet. wie 媒.

9. - Geflügelte wie ungeflügelte in Färbung, Skulptur und Behaarung

ơ. - Dunkelbraun, Antennen und Beine braun. - Kopf und Seiten des Thorax gerunzelt-punktiert; Epinotum zerstreut punktiert.

Ursprünglich nur aus Nordeuropa bekannt, von Viehmeyer auch in der Nähe von Dresden gefunden und vielleicht noch weiter verbreitet, doch sehr selten. Besitzt keine eigenen Nester, sondern lebt in solchen von Leptothorax (vgl. S. 23).

\section{Gattung: Monomorium Mayr.}

ఫ̧. - Antennen 12 gliedrig, mit stark ausgebildeter, 3 gliedriger Keule, die länger ist als der übrige Teil der Geissel. Maxillartaster $1-2$ gliedrig, Labialtaster 2 gliedrig. Epistom mit 2 Längskielen, die als Zähnchen über den Epistomrand verlängert sind, Epistomfläche dazwischen eingedrückt. Stirnfeld stark vertieft. Ocellen fehlen. Rücken zwischen Mesonotum und Epinotum schwach eingeschnürt, letzteres bei den paläarktischen Arten ohne Zähne.

․ - Bedeutend grösser als die †̧̧. Epistomleisten undeutlich.

o. - Antennen 13gliedrig. Mandibeln gezähnt. Mesonotum mit Mayrschen Furchen.

In rund 180 Arten (Rassen und Varietäten) vorzugsweise über die wärmeren Gegenden der Erde verbreitet und auch fossil bekannt. Einige Arten sind, durch Schiffsverkehr verschleppt, zu Kosmopoliten geworden.

Monomorium pharaonis (L.) Mayr (Abb. 43; Taf. I, Abb. 42 ఛ, 43 †).

ł. - Sehr kleine Form. - Hell bernsteingelb, die hintere Hälfte des Abdomens mehr oder weniger braun. - Kopf und Thorax äusserst fein und dicht punktiert; Abdomen glatt und glänzend. - Auf alien Teilen spärlich verteilte, abstehende Borsten.

f. - Bräunlichgelb, Kopf ein wenig dunkler. Skulptur wie beim $\stackrel{\not}{+}$, der Grösse des $\nmid$ entsprechend deutlicher zu erkennen. Bedeutend grösser als der 支. 7. - Schwarzbraun, mit blassgelben Antennen und Beinen, an letzteren die Femora dunkel. Augen sehr gross.

Heimat ursprünglich Indien, aber seit ungefähr 50 Jahren über alle warmen Länder verbreitet und in die Hafenstädte eingedrungen, von dort weiter in die Grossstädte, bis Nordeuropa, in Deutschland durch Apfelsendungen aus Amerika. - Findet sich an warmen Ortlichkeiten, in Häusern, besonders Bäckereien, und

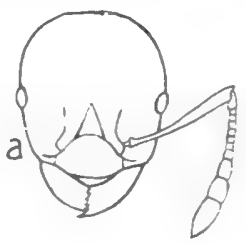
kann sehr lästig werden. (Wa nach fand sie auf einem ihm in einem Restaurant vorgesetzten Teller, Forel auf einem transatlantischen Dampfer eine Kolonie im Griff eines Dessertmessers, Jacobson eine solche mit Puppen in einer Schreibmappe.)

\section{Gattung: Anergates Forel.}

子. - Nicht vorhanden.

f. - Antennen 11 gliedrig, mit längerem, dickem 1. und kurzem 2., sehr kurzem 3. Geisselglied; Antennenkeule undeutlich. Maxillartaster 2 gliedrig, 
Labialtaster 1 gliedrig. Epistom in der Mitte der Länge nach eingedrückt, sein Vorderrand breit ausgerundet. Stirnleisten kurz, dazwischen ein breites, flaches, hinten abgerundetes Stirnfeld. Mandibeln mit Apicalzahn, sonst ungezähnt. Ocellen vorhanden. Epinotum mit 2 zahnartigen Höckern. Stielchenglied 2 wie ein Segment der Vorderfläche des Abdomens breit anliegend.

$\sigma^{7}$. - Antennen 11 gliedrig, kürzer und dicker als beim 9 . Abdomen nach unten gekrümmt. Mesonotum ohne Mayrsche Furchen. Ungeflügelt.

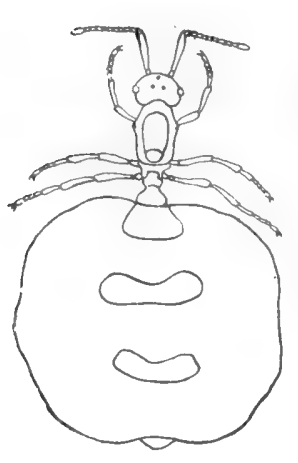

오

Abb. 44. Anergates atratulus (nach Forel).

Besitzt keine eigenen Nester, sondern wohnt in denen von Tetramorium caespitum. Das $\&$ bekommt nach der Befruchtung und dem Abwerfen der Flügel einen stark angeschwollenen Hinterleib mit auseinander getriebenen Segmenten

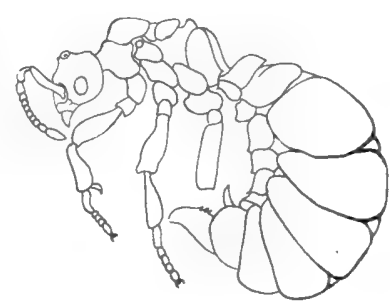

$\sigma^{7}$ und vermag sich dann nur mit Unterstützung der Wirtsameisen zu bewegen.

Nur die folgende, in Mitteleuropa vorkommende Art ist bekannt.

Anergates
For. (Abb. 44).

क. - Schwarz, mit braunem Abdomen; Mandibeln, Antennen und Beine gelblich. - Thorax fein längsgerieft, mit grübchenartigen Punkten, wenig glänzend.

$0^{7}$. - Blassgelb. - Skulptur wie beim $q$, aber kräftiger.

Über ihre Lebensweise vgl. S. 24.

Geschlechtstiere im Juni und Juli.

\section{Gattung: Formicoxenus Mayr.}

‘. - Antennen verhältnismässig dick, 11 gliedrig, mit einer Keule aus 3 grossen Gliedern, die länger ist als der übrige Teil der Geissel. Maxillartaster 4 gliedrig, Labialtaster 3 gliedrig. Epistom gross, flach, hinten abgerundet. Stirn-
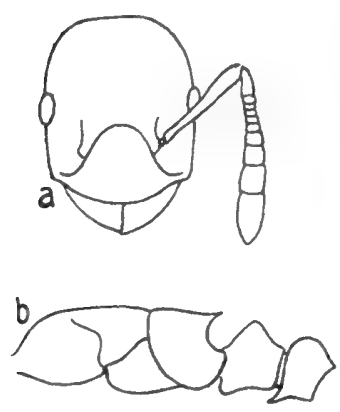

Abb. 45.

Formicoxenus nitidulus $\varnothing$. a Kopf; b Thorax-Petiolus. feld sehr klein, undeutlich entwickelt, nur wenig vertieft, die Kopffläche in seiner Umgebung abgeflacht. Stirnleisten kurz, ihre Ränder breit voneinander entfernt. Ocellen fehlen. Rücken zwischen Mesonotum und Epinotum kaum etwas eingedrückt. Epinotum mit kurzen, kräftigen Dornen. ․ - 우 mit den 故 in Grösse, Färbung, besonders in der Ausbildung der Teile des Rückens, durch Zwischenformen verbunden.

$\sigma^{7}$. - Den 䇏 ausserordentlich ähnlich. Antennen 12 gliedrig, mit 4 gliedriger Keule.

3 auf Europa beschränkte Arten.

Formicoxenus nitidulus (Nyl.) Mayr. (Abb. 45; Taf. I, Abb. 36).

ఛ.. - Braungelb, Abdomen dunkelbraun, um die Stielcheneinlenkung herum und am Ende so hell wie der Thorax. - Glatt und stark glänzend.

Kleine Kolonien in den Nestern von Formica rufa und pratensis; Nester (nach Wasmann) von der Form eines Näpfchens, aus dem feineren Nestmaterial der Wirtsameise hergestellt (vgl. S. 32). 


\section{Gattung: Pheidole Westwood.}

7. - Die charakteristische Form des Kopfes zeigt am besten die Zeichnung (Abb. 46).

६. - Antennen 12 gliedrig, mit deutlicher, 3 gliedriger Keule, die so lang ist wie der übrige Teil der Geissel. Epinotum mit Dornen.

ㅇ. - Bedeutend grösser als der ㅎ․

$0^{7}$. - Antennen 13 gliedrig, mit kurzem Schaft, der etwas länger ist als die beiden ersten Geisselglieder. Kopf mit auffallend grossen, halbkugligen Augen, wodurch der Oberkopf sehr stark verschmälert, erscheint. 3 grosse Ocellen. Mesonotum ohne Mayrsche Furchen.

Die Gattung enthält eine ausserordentlich grosse Zahl von Arten (Rassen und Varietäten), deren Unterscheidung schwierig ist. Bei weitem die meisten lassen sich ohne die dazu gehörigen 24. थ, die am charakteristischsten sind, gar nicht bestimmen.

Pheidole megacephala (F.) Rog. (Abb. 46 भ, 47 ఛ; Taf. II, Abb. 1 \%, 2 , 3 \&, $\left.40^{77}\right)$.

In unserem Gebiet zuweilen mit Pflanzen- und Tiersendungen eingeschleppt (vgl. dazu S. 96).

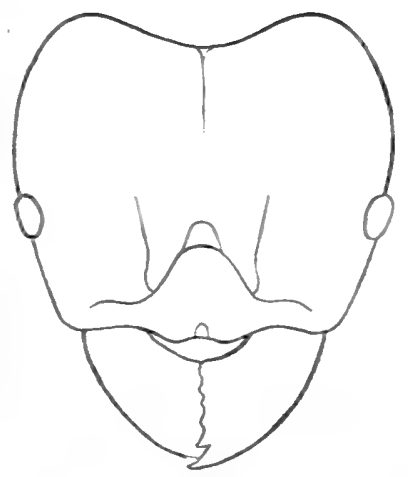

Abb. 46. Pheidole megacephala $)($ Kopf.

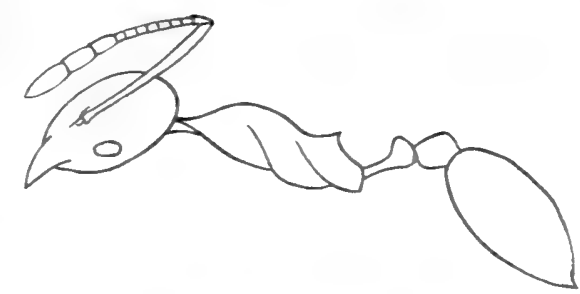

Abb. 47. Pheidole megacephala $\not{x}$.

\section{Gattung: Stenamma Westwood.}

ఫ̧. - Antennen 12 gliedrig, nach dem Ende hin allmählich in eine mässig verdickte, 4 gliedrige Keule übergehend, die länger ist als der übrige Teil der Geissel. Maxillartaster 4 gliedrig, Labialtaster 3 gliedrig. Epistom jederseits mit einem Längskiel, dazwischen eingedrückt. Stirnfeld stark vertieft. Ocellen fehlen. Rücken zwischen Mesonotum und Epinotum schwach eingedrückt. Epinotum mit zwei kurzen Dornen.

‥ - Von der Grösse der $\not \ngtr$, Stielchenknoten 1 vorn aber kürzer gestielt.

0. - Antennen 13 gliedrig, mit undeutlicher Keule; Schaft so lang wie die 3 ersten Geisselglieder zusammen; Geisselglied 1 kürzer und dicker als 2; Zähne am Epinotum schwach entwickelt. Mesonotum mit Mayrschen Furchen; Stielchenknoten 1 vorn länger gestielt als beim

In den wärmeren Gebieten von Europa, Asien und Nordamerika.

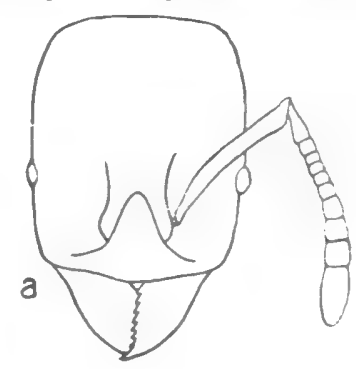

Stenamma westwoodi Westw. (Abb. 48; (Taf. II, Abb. 6).

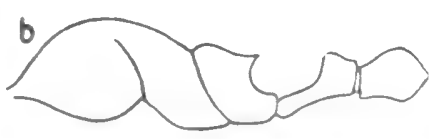

Abb. 48. Stenamma uestunodi ç. a Kopf; b Thorax.Petiolus.

ఛ. - Antennenschaft den Hinterrand des Kopfes nicht erreichend; Epinotum mit kräftigen, schräg nach oben gerichteten, zahnartigen Dornen. - 
Gelbrot bis gelbbraun, Fühler, Beine und Abdominalende heller. - Kopf und Thorax fein längsgerunzelt, mit netzartigen Anastomosen, Stielchenknoten kaum gerieft, Abdomen um die Stielcheneinlenkung herum fein längsgerieft, sonst glatt und glänzend. - Körper mit abstehenden Borsten, die auf dem Abdomen länger sind.

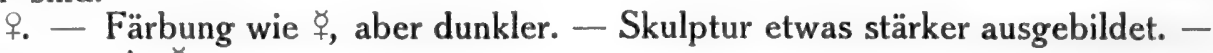
Behaarung wie $\not$.

$0^{7}$. - Braun, Mandibeln, Antennen und Beine hellbraun. - Kopf und Thorax dicht punktiert, letzterer an den Seiten gerunzelt; Epinotum, Stielchenknoten und Abdomen glatt und glänzend. - Behaarung wie

In Mittel- und Südeuropa; Nester, nur schwache Kolonien enthaltend, an feuchten Stellen, in der Erde, unter Laub; Lebensweise unterirdisch.

\section{Gattung: Aphaenogaster Mayr.}

६. - Antennen 12 gliedrig, mit 4 gliedriger Keule, die kürzer ist als der übrige Teil der Geissel. Maxillartaster 4-5 gliedrig, Labialtaster 3 gliedrig. Epistom dreieckig, hinten abgerundet, mit konkaven Seitenrändern und in der Mitte breit ausgerandetem Vorderrand. Stirnfeld stark vertieft. Ocellen fehlen. Pronotum und vorderer Teil des Mesonotums in ihrer Gesamtheit halbkuglig; Mesonotum, von der Seite gesehen, schwach eingedrückt. Epinotum mit Dornen.

+. - Scutellum höckerartig nach hinten ragend.

$\sigma^{7}$. - Antennen 13 gliedrig, mit 5 gliedriger Keule, Schaft kürzer oder ebenso lang wie die 3 ersten Glieder zusammen. Mesonotum mit Mayrschen Furchen.

In den wärmeren Gebieten von Europa, hier besonders zahlreich im Mittelmeergebiet, von Asien bis Vorderindien und Japan, in Nordamerika.

Aphaenogaster subterranea (Latr.) Rog. (Abb. 49; Taf. II, Abb. 5).

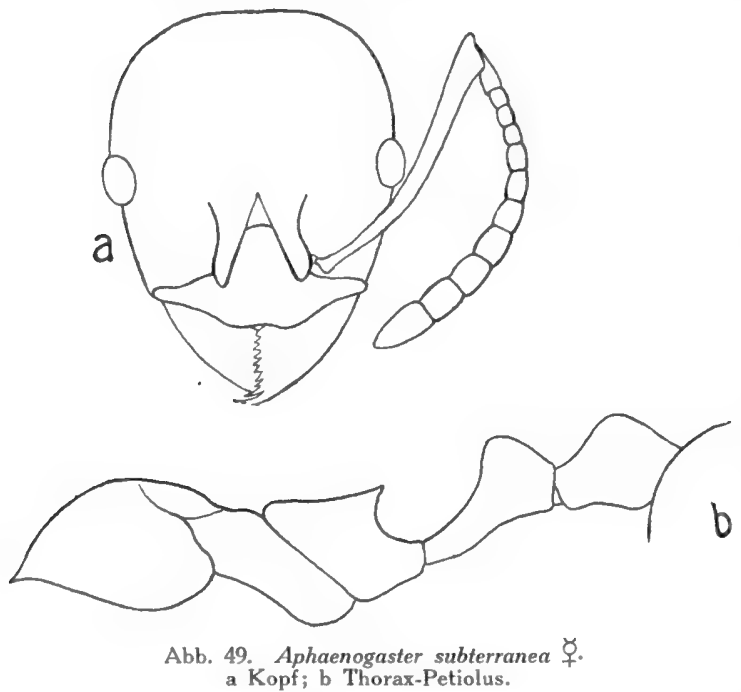

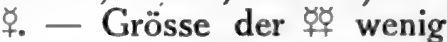
verschieden. - Antennenschaft den Hinterrand des Kopfes um ein Geringes überragend. Epinotum mit kurzen Dornen. Braun bis rötlichbraun, Vorderkopf meist dunkler, oft auch das Abdomen; Antennen und Beine heller. - Vorderkopf fein lederartig längsgerunzelt, weitläufiger der Oberkopf, Skulptur hier verschwindend; Pronotum glatt, glänzend, Epinotum fein quergerieft, dicht punktiert. - Körper mit abstehenden, gelblichen Borsten.

q. - Färbung wie beim $\not$. Kopfskulptur kräftiger und schärfer ausgebildet, Pro- und Mesonotum glatt und glänzend. - Behaarung länger als beim $\not{q}$.

○’. - Färbung wie beim $\stackrel{+}{+}$, aber dunkler, Beine bräunlichgelb. - Oberkopf fein gerunzelt, Abdomen glatt und glänzend.

Eine südliche Form, die auch im mittleren und südlichen Deutschland vorkommt. Nester an feuchten Stellen, in der Erde, unter Steinen. 


\section{Gattung: Messor Forel.}

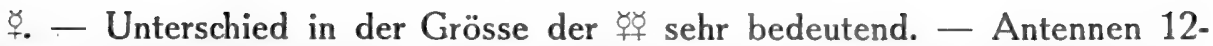
gliedrig, mit 4 gliedriger Keule, letztere aber bei den grossen $\not \ngtr \ngtr$ undeutlich ausgebildet. Epistom dreieckig, hinten abgerundet, im mittleren Teil des Vorderrandes ganz wenig ausgerundet. Stirnfeld vertieft. Ocellen fehlen. Mesonotum, von der Seite gesehen, unter einem flachen, stumpfen Winkel eingedrückt. Epinotum ohne Dornen, nur bei den grössten $\not \Varangle$ zuweilen 2 ganz kurze zahnartige Höcker.

9. - Thorax sehr stark gewölbt.

$\sigma^{7}$. - Antennen 13 gliedrig, ohne deutliche Keule, Schaft so lang wie die 3 ersten Glieder der Geissel zusammen. Scutellum höckerartig aufgetrieben und nach hinten ragend. Mesonotum ohne Mayrsche Furchen.

Die Vertreter dieser Gattung finden sich in den wärmeren Gegenden der nördlichen Halbkugel und reichen bis Südafrika und bis Indien; sie sind zum Teil Bewohner von Steppen und Wüsten. Nester in der Erde. Sammeln Körner und Samen, von denen sie sich nähren, und die sie im Nest in Vorratskammern aufspeichern.

Messor barbarus (L.) Em. r. structor (Latr.) Rog. (Abb. 50; Taf. II, Abb. 7).

†. - Dunkelbraun bis braunrot, bei den grossen $\not \xi q$ der Thorax und die Gliedmassen meist etwas heller, bei kleineren braun wie der übrige Körper. - Kopf fein und dicht längsgestreift, um die Antenneneinlenkung herum im Bogen; Rücken quergestreift; Skulptur bei kleineren 喡 schwächer ausgebildet, die kleinsten glatt. - Behaarung mässig.

†. - Färbung wie beim 支. - Skulptur des Kopfes gröber, Oberkopf oberflächlich gestreift, seine Seiten zuweilen glatt, mit zerstreuten Punkten.

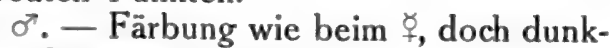
ler. - Mesonotum glatt.

Die Art ist im Mittelmeergebiet in vielen Rassen und Varietäten vertreten. Die var. mutica Nyl. kommt in Mitteldeutschland vor (Umgegend von Wiesbaden, in Schlesien, Böhmen, dem Donautal) und

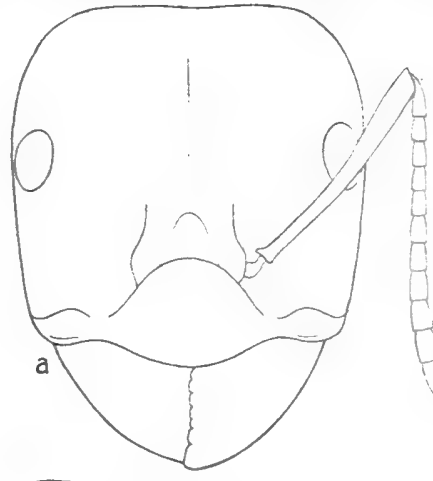
weiter auf der Balkanhalbinsel, in Kleinasien, am Kaspischen Meer.

\section{Gattung: Myrmica Latreille.}

ఫ̧. - Antennen 12 gliedrig, mit 3 gliedriger (5 gliedriger) Keule, Geisselglied 2-5 nicht kürzer als breit, die 3 letzten Antennenglieder kürzer als der übrige Teil der Geissel; Schaft je nach den einzelnen Arten verschieden lang, bei manchen hinter dem Grunde geknickt. Maxillartaster 6 gliedrig, Labialtaster 4 gliedrig; Epistom dreieckig, mit halbkreisförmig gerundetem Hinterrand; Stirnfeld dreieckig, vertieft, ziemlich scharf umgrenzt. Ocellen fehlen. Rücken zwischen Mesonotum und Epinotum flach eingeschnürt (stärker bei M. rubida). 
Epinotum mit Dornen ( $M$. rubida unbewehrt). - Kopf, Thorax und Stielchenknoten mit mehr oder weniger ausgebildeter Skulptur, der Hauptsache nach längs, nach den Arten verschieden entwickelt. Abdomen glatt, glänzend.

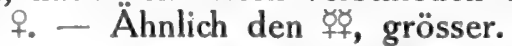

$\sigma^{7}$. - Antennen 13 gliedrig, Geisselglied 1 kürzer als 2; Antennenschaft je nach den einzelnen Arten verschieden lang; Mandibeln mit gezähntem Innenrand; Mesonotum mit Mayrschen Furchen.

Von der Gattung Myrmica sind rund 100 Arten (Rassen und Varietäten) beschrieben, die fast sämtlich über Europa, Nordamerika und in Asien bis nach Indien verbreitet sind. Ebenso kennt man fossile Formen. Die Arten zeichnen sich durch starke Schwarmbildung der Geschlechtstiere aus.

Arten:

\section{Arbeiter und Weibchen.}

I. Epinotum ohne Dornen; Antennenkeule 5 gliedrig:

II. Epinotum mit Dornen; Antennenkeule 3-4 gliedrig.

1. Antennenschaft hinter seiner Einlenkung plötzlich gebogen; Antennenkeule 3 gliedrig.

A. Antennenschaft an der Biegung mit deutlich hervortretendem Anhang (Lobus). ${ }^{1}$ )

a) Rand des Lobus in der Richtung des Schaftrandes liegend:

b) Rand des Lobus an der Biegung des Schaftes spitz heraustretend.

= Epinotaldornen länger und kräftiger:

$=$ Epinotaldornen kürzer und dünner:

B. Antennenschaft an der Biegung ohne Anhang (Lobus).

a) Riefen auf dem Kopf gerade; Skulptur schwach: M. rugulosa Nyl.(Nr.5).

b) Riefen auf dem Kopf gewunden; Skulptur kräftig:

2. Antennenschaft am Grunde dünn, allmählich gebogen; Antennenkeule 4 gliedrig.

A. Epinotum zwischen den Dornen glatt; Stielchenglied 2 glatt:

B. Epinotum zwischen den Dornen quergestreift; Stielchenglied 2 rauh, mit Punkten und Riefen:

\section{Männchen.}

M. scabrinodis Nyl. (Nr. 2).

M. schencki Em. (Nr.3). M. lobicornis $\mathrm{Nyl}$.

(Nr. 4).

M. sulcinodis Nyl.

(Nr. 6).

M. laevinodis $\mathrm{Nyl}$.

$\left.(\mathrm{Nr}, 7)^{2}\right)$.

M. ruginodis $\mathrm{Nyl}$.

$\left.(\mathrm{Nr} .8)^{2}\right)$.

I. Geisselglieder mit Ausnahme des 1. sehr lang, wenigstens 3 mal so lang als breit:

II. Geisselglieder kurz, höchstens doppelt so lang als breit.

M. rubida Latr. (Nr. 1).

1. Antennenschaft sehr viel kürzer als die Hälfte der Geissel.

A. Kopf, Antennen und Beine mit langen, abstehenden Borsten:

$[(N r .2)$.

M. scabrinodis Nyl.

M. schencki Em. (Nr. 3).

B. Kopf, Antennen und Beine mit kürzeren, mehr anliegenden Borsten.

1) Am deutlichsten zu erkennen, wenn man ihn von oben und hinten her betrachtet (Abb. 52 u. 53 b).

2) Zwischen beiden Formen Ubbergänge. 
a) Kopf und Thorax kräftig längsgerieft:

M. lobicornis Nyl.

b) Kopf und Thorax äusserst fein und dicht punktiert gerunzelt:

2. Antennenschaft ungefähr so lang wie die Hälf́te der Geissel.

A. Thorax deutlich und kräftig gerunzelt; Stielchenknoten 1 ebenso längsgerieft:

B. Thorax meist glatt, teilweise undeutlich und schwach gerunzelt; Stielchenknoten 1 glatt.

a) Schienen mit abstehenden Borsten:

b) Schienen ohne abstehende Borsten:

M. sulcinodis Nyl.

(Nr. 6). M. rugulosa Nyl.(Nr.5).

1. M. rubida (Latr.) Schnck. (Abb. 51; Taf. I, Abb. 44 ㅎ, 45 ₹, 46 ơ).

ఫ. - Mandibeln vorn mit 2 grösseren Zähnen, am Innenrand mit einer Reihe kleinerer. Epinotum ohne Dornen, mit 2 Höckern. - Rötlichgelb bis rötlichbraun, Abdomen in der Mitte dunkler. - Kopf und Thorax längsgerieft, die Stielchenknoten feiner, der 2. oben fast glatt. - Die grösste Art der Gattung.

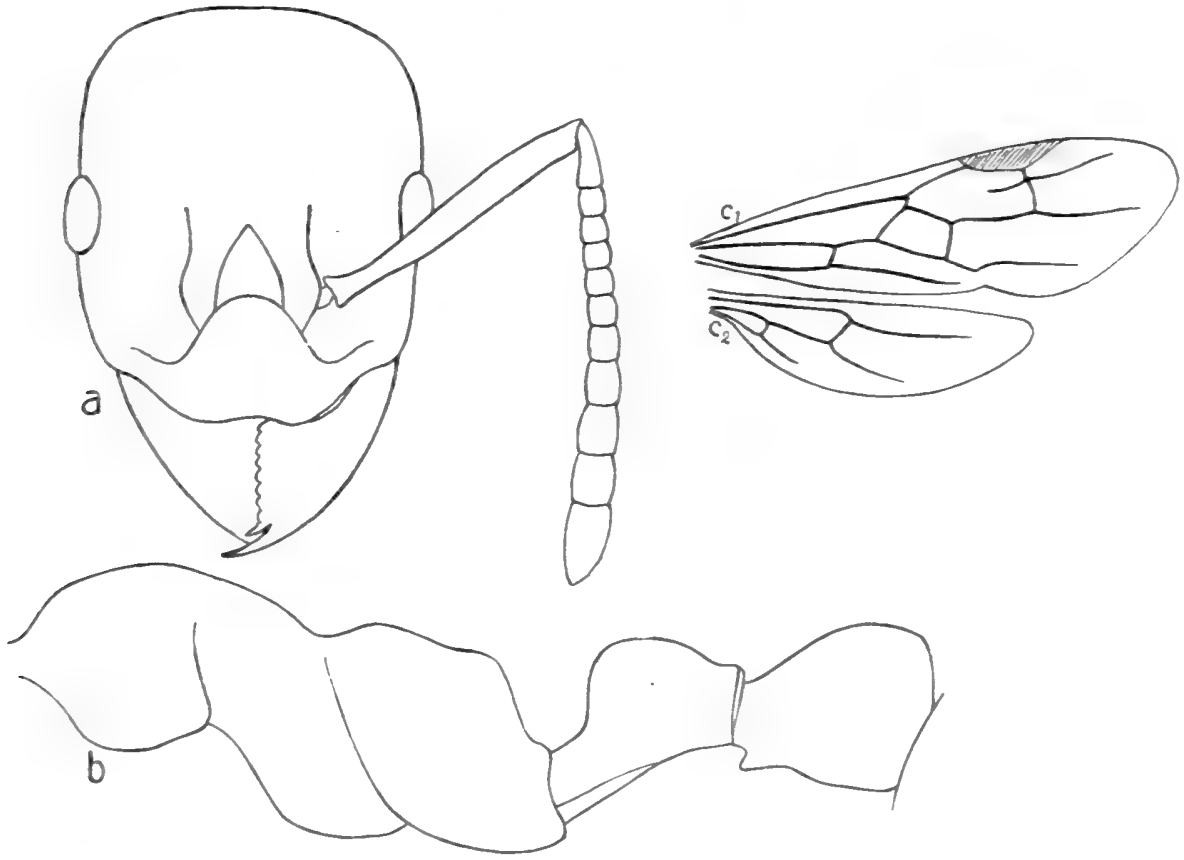

Abb. 51. Myrmica rubida $\not$. a Kopf; b Thorax-Petiolus; c Flügel + .

0". - Schwarz, distale Hälfte der Geissel, Gelenke der Beine, die Tarsen, Spitze des Abdomens gelbbraun. - Kopf oben längsgerieft, Thorax oben gerunzelt.

In Gebirgsgegenden der wärmeren Gebiete Europas (deutsches Mittelgebirge, Alpen usw.) und Asiens. Nester in der Erde, in Sandboden, mit kraterförmigem Eingang, unter Steinen, selten mit Oberbau. Sticht langsam, aber schmerzhaft. Geschlechtstiere Mai bis August.

2. M. scabrinodis Nyl. i. sp. (Taf. I, Abb. 47).

ซ. - Antennenschaft scharf geknickt, mit quergestelltem Lobus; Epinotaldornen lang und kräftig; Stielchenknoten 1 vorn oben einen Winkel bildend. - 
Hell- bis dunkelbraun. - Skulptur kräftig und scharf ausgebildet; Kopf längsgerunzelt, Stirnfeld wenig längsgestreift, glänzend, Stielchenknoten längsgerunzelt.

․ - Knickung des Antennenschaftes und Ausbildung des Lobus, ebenso die Skulptur, kräftiger hervortretend als beim

$0^{7}$. - Antennenschaft gerade.

In Nord- und Mitteleuropa und Sibirien. Nester mehr an trockenen Stellen, in Sandboden, unter Steinen, auch in zerfressenen Kiefernstämmen beobachtet. (Von Escherich auch in einem wasserdurchtränkten Sphagnumpolster gefunden.)

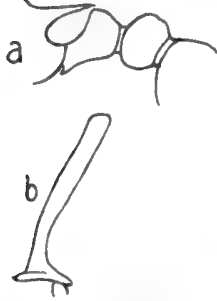

Abb. 52. Myrmica scabrinodis-schencki $\varnothing$ (nach Emery).

a Epinotum-Petiolus b Antennenschaft.

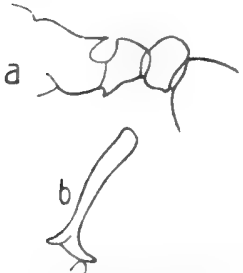

Abb. 53. Myrmica scabrinodis - lobicornis $\not$ (nach Emery).

Erkl. s. Abb. 52. Geschlechtstiere im Spätsommer.

3. M. scabrinodis Nyl. r. schencki Em. (Abb. 52).

ซ. - Antennenschaft scharf geknickt, mit quergestelltem Lobus; Epinotaldornen lang und kräftig; Stielchenknoten 1 vorn oben abgerundet. - Braun, Kopf und Abdomen dunkler. Skulptur kräftig und scharf ausgebildet, wie bei scabrinodis i. sp.

ㅇ. - Wie der 星.

$\sigma^{7}$. - Nicht von scabrinodis i. sp. zu unterscheiden. China.

In Mitteleuropa und Asien bis zur Mandschurei und

4. M. scabrinodis Nyl. r. lobicornis Nyl. (Abb. 53).

६. - Antennenschaft scharf geknickt, mit quergestelltem Lobus; Epinotaldornen kürzer und dünner als bei den beiden vorigen Arten; Stielchenknoten 1 vorn oben einen Winkel bildend. - Braun, Kopf und Abdomen dunkler. - Skulptur kräftig und scharf ausgebildet, auch das Stirnfeld ebenso gerieft. +. - Wie der

0. - Antennenschaft hinter dem Grunde geknickt.

Verbreitung wie die vorige Art. Nester vorzugsweise in trockenem Sandboden, unter Steinen, an Waldrändern. Geschlechtstiere im Spätsommer.

\section{M. scabrinodis Nyl. r. rugulosa Nyl.}

ఈ. - Kleiner als die vorher erwähnten Formen, Antennenschaft weniger scharf geknickt als bei diesen, ohne Lobus; Stielchenknoten vorn oben einen etwas gerundeten Winkel bildend. - Hell gelblichrot, Abdomen etwas dunkler. Skulptur schwächer ausgebildet als bei den vorigen Formen, die Seiten des Kopfes netzartig, das Stirnfeld hinten längsgerieft.

․ - Wie der 字.

In Nord- und Mitteleuropa und Sibirien. Nester in härterem, trockenem Boden, unter Steinen. Geschlechtstiere im Spätsommer.

\section{M. sulcinodis Nyl.}

ఫ. - Antennenschaft gebogen, ohne Lobus, selten mit einem Zähnchen; Vorderrand des Epistoms bogenartig vorragend; Epinotaldornen lang und kräftig; Stielchenknoten 1 vorn oben einen Winkel bildend. - Gelblichrot, Kopf und Abdomen braun bis dunkelbraun. - Riefen des Vorderkopfes wurmförmig gewunden, auf den Kopfseiten netzartig; Thorax grob längsgerunzelt; beide Stielchenknoten grob längsgerieft.

․ - Skulptur stärker ausgebildet als beim $\stackrel{\not}{;}$; Scutum (des Mesonotums) scharf und grob längsgerieft.

Mittel- und Südeuropa, in Asien weit nach Osten reichend (Mandschurei). Geschlechtstiere im August. 
7. M. rubra L. r. laevinodis Nyl. (Abb. 54).

ఫ. - Antennenschaft am Grunde allmählich gekrümmt; Epinotaldornen kurz, der Abfall des Epinotums dazwischen glatt und glänzend; Stielchenknoten 1 vorn oben abgerundet, mehr als bei ruginodis. - Rötlichgelb, Oberkopf und Abdomen dunkler. (Kleiner als ruginodis, Färbung heller als bei dieser.)

q. - Wie der $\not$.

0 . - Tibien mit abstehenden Haaren.

In Nord- und Mitteleuropa und Mittelasien (bis zum Himalaja und Japan). Nester mehr an feuchten Stellen, auf schwerem Boden und Kulturland, doch auch auf Sandboden, unter Baumrinde, in morschen Stümpfen. In den Nestern zu jeder Zeit mehrere bis zahlreiche, befruchtete of. Geschlechtstiere Juli bis September.

Zwischen dieser Form und der folgenden sind Übergänge zu beobachten.

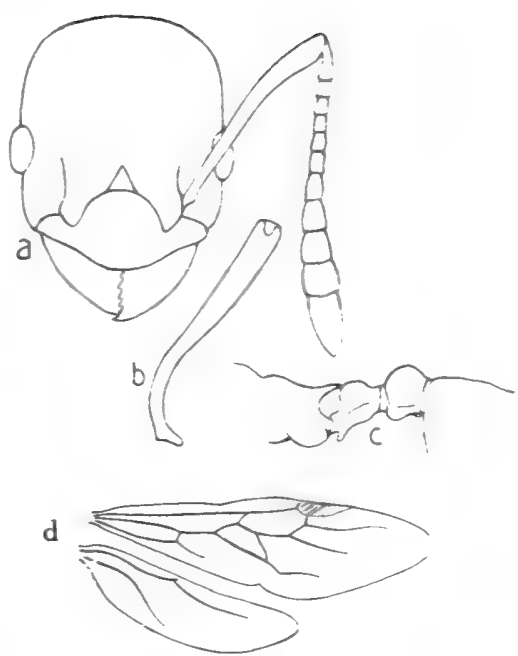

Abb. 54. Myrmica laerinodis $¥$ (a, b, c nach Emery). a Kopf; b Antennenschaft; c EpinotumPetiolus; d Fiügel ${ }_{+}$.

8. M. rubra L. r. ruginodis Nyl. (Taf. I, Abb. 48).

ఛ. - Antennenschaft am Grunde allmählich gekrümmt; Epinotaldornen lang, der Abfall des Epinotums dazwischen mehr oder weniger quergerieft; Stielchenknoten 1 vorn oben abgerundet, weniger als bei laevinodis. - Rötlichgelb, Oberkopf und Abdomen dunkler. Grösser als laevinodis, Färbung heller als bei dieser.

In Nord- und Mitteleuropa, in Asien, aber nicht bis zum äussersten Osten. Nester an feuchten Stellen, in bindigem wie in Sandboden, auch unter Moos und in morschen Ästen. Befruchtete +7 im Nest weniger zahlreich als bei der vorigen. Geschlechtstiere Juli bis September.

\section{Tribus: Cremastogastrii.}

\section{Gattung: Cremastogaster Lund.}

ఛ. - Antennen 11 gliedrig. Maxillartaster 5 gliedrig, Labialtaster 3 gliedrig. Epinotum bei vielen Arten und der hier in Betracht kommenden mit 2 divergierenden Dornen. Stielchen am oberen Teil des hinten zugespitzten Abdomens eingelenkt.

f. - Viel grōsser als der

. - Antennen 12 gliedrig, Schaft etwas länger als Geisselglied 1, welches kuglig ist. Epinotum ohne Dornen. Mesonotum ohne Mayrsche Furchen.

In zahlreichen Arten über die warmen Gebiete der Erde verbreitet; in Südeuropa eine Anzahl Arten mit Varietäten, von denen die folgende in unserem Gebiet gefunden wurde.

Cremastogaster scutellaris (Ol.) Mayr (Abb. 55; Taf. I, Abb. 37).

ఫ. - Kopf rot bis hellrot, Thorax und Stielchenglieder rotbraun bis dunkelbraun, Abdomen braun bis dunkelbraun. - Mandibeln kräftig, Vorderkopf fein längsgerieft, Oberkopई mit weitläufiger, feiner Punktierung; Pronotum und Meso- 
notum, das in der Mittellinie des ersteren als kleiner Höcker hervorragt, ungleichmässig längsgerunzelt, an den Seiten feiner; Epinotum im basalen Teil längsgestreift, der Abfall glatt; Stielchenknoten 1 trapezförmig, flach, mit eingedrückter Vorderfläche, Stielchenknoten 2 gerundet, durch eine tiefe, mediane Furche geteilt, beide Knoten oberflächlich gerunzelt; Abdomen matt.

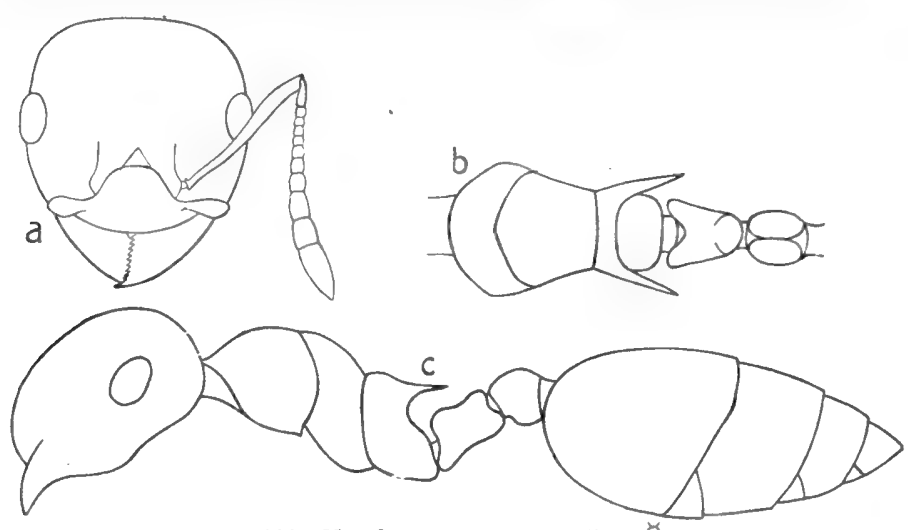

Abb. 55. Cremastogaster scutellaris $\not$.

a Kopf; b Thorax-Petiolus von oben; c Seitenansicht des ganzen Körpers.

schwarzbraun, Mandibeln, Antennen und Beine heller braun.

f. - Kopf braun bis rot, Thorax oben und an den Seiten, Stielchenglieder und Beine dunkel kastanienbraun. - Kopfskulptur wie

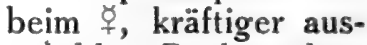
gebildet. Rücken glatt, Seiten des Thorax, besonders hinten, längsgerieft. Epinotum zwischen den kurzen Dornen quer gerunzelt; Abdomen glatt, alle Teile stark glänzend. $\sigma^{7}$. - Dunkel kastanienbraun, Kopf

Von Scherdlin in dèr Nähe von Strassburg (an den Vorhügeln der Vogesen) mit Brut in einem Pfirsichkern gefunden. Nester sonst unter Rinde, Steinen, in Mauer- und Felsspalten. Schadet (in seiner Heimat) durch Anlage der Nester den Korkeichen und durch Zucht von Blattläusen und Schildläusen.

\section{Tribus: Solenopsidii.}

\section{Gattung: Solenopsis Westwood.}

ఛ. - Antennen 10 gliedrig, mit sehr stark ausgebildeter, 2 gliedriger Keule, die länger ist als der übrige Teil der Geissel, wovon Geisselglied 1 am längsten. Maxillartaster 2 gliedrig, Labialtaster 2 gliedrig. (Mandibeln der einheimischen Art 4 zähnig). Epistom mit 2 Längskielen, die als Zähnchen über den Epistomrand verlängert sind; Epistom dazwischen eingedrückt. Epinotum ohne Dornen.

+. - Viel grösser als der $\not{q}$. Antennen 11 gliedrig, mit 2 gliedriger Keule.

$\sigma^{7}$. - Antennen 12 gliedrig, Schaft so lang wie die beiden ersten Geisselglieder zusammen, Geisselglied 1 kuglig (Abb. 59 b). Mesonotum ohne Mayrsche Furchen.

In ungefähr 100 Arten (Rassen und Varietäten) über die ganze Erde verbreitet, vorzugsweise in wärmeren Ländern. Auch fossil bekannt.

Solenopsis fugax (Latr.) For. (Abb. 56; Taf. II, Abb. 12 ఛ, 13 q, $14 \circ^{7}$ ). ఛ. - Sehr winzige Formen; Augen sehr klein, dem Mandibulargelenk ziemlich naheliegend. - Blass rötlichgelb bis bräunlichgelb, Beine heller. Glatt, glänzend, mit weitläufig stehenden, feinen Punkten. Abstehende Behaarung ziemlich reichlich.

f. - Bedeutend grösser als der $\not{q} ;$ Augen grösser. - Kopf und Thorax dunkelbraun, Abdomen etwas heller braun, unten und an den Segmenträndern ebenso wie die Antennen und Beine gelbbraun. - Kopf weitläufig und kräftig 
punktiert, weniger deutlich der vordere Teil des Thorax. - Abstehende Behaarung wie beim $\Varangle$, am reichsten auf dem Kopf, am spärlichsten auf dem Thorax.

$\sigma^{7}$. - Dunkelbraun, Antennen und Beine heller. Behaarung wie beim + , aber kürzer.

In Mittel- und Südeuropa, Vorderund Mittelasien. Nester, die oft sehr stark bevölkert sind, und deren Kammern durch sehr enge Gänge in Verbindung stehen; in den Wandungen der Nester grösserer

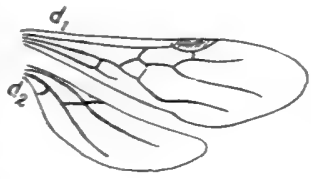

Abb. 56. Solenopsis fugax $\Varangle$. a Kopf; b Antenne $\sigma^{\nearrow}$; c Thorax-Petiolus $\Varangle ;$ d Flügel $\bigcirc$

Kopf; b Antenne $\bigcirc^{7}$
$(a, b, c$ nach Emery).

Arten (Lasius,

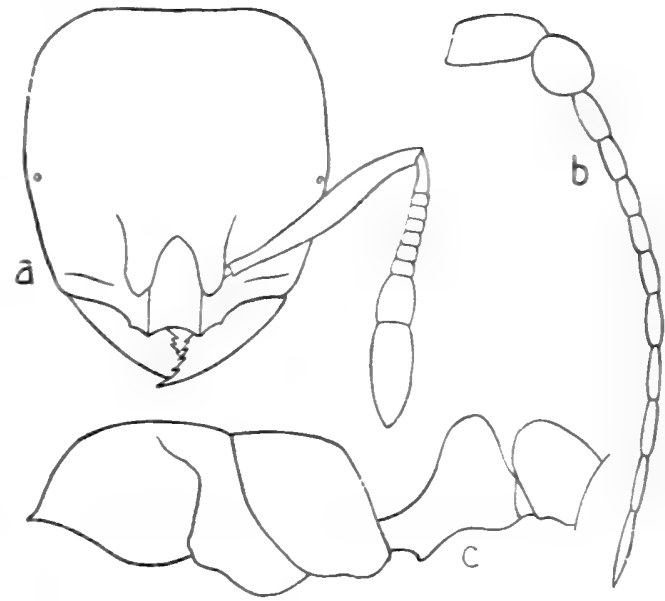

Formica) (vgl. S. 32), von deren Brut sie leben. Besitzen aber auch zuweilen eigene Nester. Auch Zucht von Wurzelläusen ist bei ihnen beobachtet worden. Sie sind sehr kampflustig. Geschlechtstiere im Spätherbst.

\section{Tribus: Tetramorii.}

\section{Gattung: Tetramorium Mayr.}

ఫ. - Antennen 12 gliedrig, mit deutlicher, 3 gliedriger Keule (Geisselglied 3 bis 7 bei der einheimischen Art breiter als lang). Maxillartaster 4 gliedrig, Labialtaster 3 gliedrig. Epistom hinten abgerundet. (Stirnfeld bei der einheimischen Art nicht abgegrenzt.) Die Seitenränder der Stirnleisten sind flach aufgebogen und setzen sich als stärkere Leisten nach hinten auf den Oberkopf fort, eine Antennengrube (Scrobus) bildend. Ocellen fehlen. (Rücken zwischen Mesonotum und Epinotum bei der einheimischen Art wenig eingeschnürt.) Pronotum, von oben und hinten gesehen, mit stumpfen, winkligen Vorderecken. Epinotum mit verschieden stark ausgebildeten Dornen.

ๆ. - Bedeutend grösser als der $\not$.

$\sigma^{7}$. - Etwas kleiner als das $q$. Antennen 10 gliedrig, Schaft ungefähr so lang wie Geisselglied 2, dieses so lang wie die 3 folgenden zusammen. Mandibeln mit gezähntem Innenrand. Mesonotum mit Mayrschen Furchen.

Die Gattung Tetramorium (im engeren Sinn) umfasst über 100 Arten (Rassen und Varietäten), die über alle Gebiete verbreitet sind und an Anzahl nach den Tropen hin zunehmen. Eine sehr häufige Form ist hier Tetramorium guineense (F.) Mayr, die auch zuweilen mit exotischen Pflanzen in Gewächshäuser verschleppt wird. Eine andere tropische Form, Tetramorium simillimum Sm. (Tetrogmus caldarius Rog.), wurde von Roger in Schlesien (Rauden) gefunden.

Tetramorium caespitum (L.) Mayr (Abb. 57; Taf. II, Abb. 8 q, 9 q, 10 c).

†. - Braun bis dunkelbraun, Fühler, Mandibeln, mehr oder weniger der Vorderrand des Epistoms, die Gegend um die Mandibelgelenke herum und die Beine gelbbraun. - Kopf mit scharf ausgeprägter Längsskulptur, eine ebensolche, 

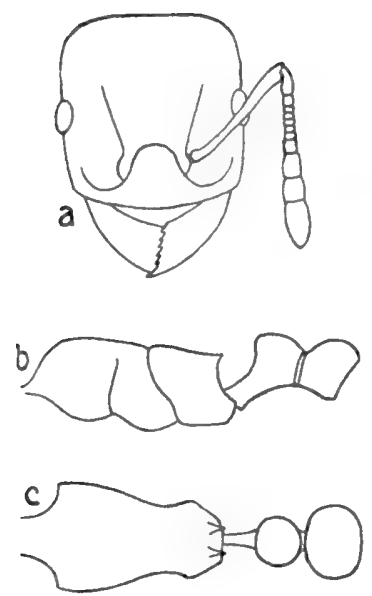

Abb. 57. Tetramorium caespitum 호. a Kopf; b Thorax-Petiolus von der Seite; c Thorax-Petiolus von oben.

etwas weniger gleichmässige auf dem Thorax; Stielchenknoten feingerunzelt punktiert; Abdomen glatt und glänzend. - Körper ziemlich reich mit abstehenden Borsten bekleidet.

†. - Dunkler gefärbt als der $\Varangle$. Kopfskulptur wie beim ఢ̧. Mesonotum vorn fast glatt, glänzend, nach hinten mit undeutlich entwickelter, an den Seiten und auf dem Epinotum stärker ausgebildeter Längsskulptur.

$0^{7}$. - Färbung wie das + . Kopfseiten schräg gestreift, Mesonotum zwischen den Mayrschen Furchen fast glatt, Rücken dahinter längs gerieft, ebenso grösstenteils die Seiten des Thorax.

Im Mittelmeergebiet, besonders dessen östlichem Teil, eine grössere Zahl Varietäten dieser Art.

Gemein in Europa und Asien, die nördlichsten Gebiete ausgenommen, in Nordafrika und Nordamerika eingeschleppt. Die oft sehr ausgedehnten Nester mit zahlreichen Ausgängen finden sich an trockenen, sandigen Stellen, oft eine Kuppel bildend, im Gebirge zuweilen in Felsspalten, ferner unter Steinen (oft neben Nestern anderer Gattungen, wie Camponotus ligniperda, Formica sanguinea), selten mitten im Wald, dagegen an lichten Stellen darin sowie an Wald- und Wegrändern, in Anlagen, auch auf viel betretenen Wegen; als Hausameise in Vorratskammern und gelegentlich in Blumentöpfen. Sie sind sehr kampflustig, züchten, wie es scheint, zuweilen auch Wurzelläuse (Wanach) und legen in wärmeren Gegenden, ausnahmsweise auch in Süddeutschland beobachtet (Escherich), Vorräte von Samen (Panicum sanguinale L., Stellaria media L.) an. In den Nestern sind zu finden Strongylognathus (siehe folgende Art) und Anergates (S. 23 u. 24). Geschlechtstiere im Juni, Juli, auch noch im August.

\section{Gattung: Strongylognathus Mayr.}

ఈ. - Antennen 12 gliedrig, mit verdickter, 3 gliedriger Keule, Geisselglied 1 länger als 2. Maxillartaster 4 gliedrig, Labialtaster 3 gliedrig. Epistom dreieckig, mit halbkreisförmig abgerundetem Hinterrand. Stirnfeld vertieft, undeutlich abgegrenzt. Ocellen fehlen. Rücken zwischen Mesonotum und Epinotum ohne Einschnürung; mit ganz flach eingesenkter Naht, von der Seite gesehen fast eben.

ๆ. - Zähne am Epinotum stärker und spitzer als beim

$\sigma^{7}$. - Antennen 10 gliedrig, Schaft kürzer als das 1. Geisselglied, das so lang wie breit ist. Mesonotum mit Mayrschen Furchen.

Eine Art mit einer Anzahl Varietäten bewohnt die Mittelmeerländer; die andere kommt in Mitteleuropa vor:

Strongylognathus testaceus (Schnck.) Mayr (Abb. 58; Taf. II, Abb. 11).

ఫ. - Kopf rechteckig, hinten ausgerundet; mit stark nach hinten ausgezogenen Hinterecken. Bräunlichgelb, Kopf und Abdomen zuweilen dunkler. Kopf, Thorax und Stielchenglieder längsgerieft, Abdomen glatt und glänzend. Körper mit ziemlich langen, abstehenden Borsten.

+. - Färbung und Skulptur wie beim $\not{q}$; doch setzen sich die Längsriefen des Kopfes auf die Occipitalhöcker divergierend fort; dazwischen auf dem Oberkopf ganz hinten einige Querstreifen.

$\sigma^{7}$. - Kopf undeutlich gerunzelt punktiert; Mesonotum zwischen den Mayrschen Furchen glatt und glänzend. 
Besitzt keine eigenen Nester, sondern findet sich bei Tetramorium caespitum (vgl. S. 23), wo er nicht sehr selten ist, aber wegen der geringen Anzahl und der den Wirtsameisen ähnlichen Färbung leicht übersehen wird. Nach Viehmeyer erlangt man Strongylognathus am besten im Sommer, wenn seine Geschlechtstiere oder deren Puppen in den Tetramorium-
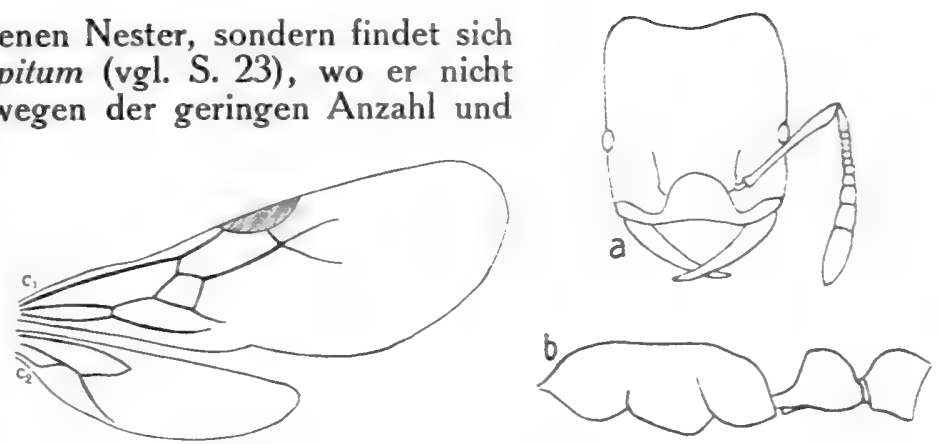

Abb. 58. Strongglognathus testaceus $\not$ a Kopf; b Thorax-Petiolus; c Flügel $q$.

Nestern vorhanden sind und durch ihre geringe Grösse auffallen. Im Frühjahr lässt sich die Anwesenheit von Strongylognathus in diesen Kolonien daran feststellen, dass darin die grossen Larven der Wirtsameisen fehlen. In ihren Kämpfen nennt sie For el eine traurige Karikatur von Polyergus rufescens.

\section{Unterfamilie Dolichoderinae.}

Stielchen 1 gliedrig; Pumpmagen vollständig, mit Kelch und Kugel, beide in den Vormagen eingestülpt; Kloakenöffnung spaltförmig; Stachel, auch Giftdrüse, zurückgebildet; Analdrüsen vorhanden, die ein aromatisch riechendes Sekret absondern; Puppen ohne Kokon.

\section{Gattungen:}

\section{Arbeiter.}

I. Epinotum mit 2 Zähnen; zwischen Epinotum und Mesonotum eine tiefe Einsenkung; Abfall des Epinotums ausgehöhlt:

II. Epinotum ohne Zähne; zwischen Epinotum und Meso-

Dolichoderus (S. 79). notum keine tiefe Einsenkung: Abfall des Epinotums flach.

1. Antennenschaft den Hinterrand des Kopfes überragend:

2. Antennenschaft nur bis zum Hinterrand des Kopfes reichend:

Tapinoma (S. 78).

Liometopum (S. 78). Weibchen.

I. Epinotum mit 2 Zähnen; Abfall des Epinotums ausgehöhlt:

II. Epinotum ohne Zähne; Abfall des Epinotums flach.

1. Vorderrand des Epistoms mit schmalem Einschnitt: Tapinoma (S. 78).

2. Vorderrand des Epistoms ohne Einschnitt: Liometopum (S. 78).

Dolichoderus (S. 79).

Männchen.

I. Stielchen knotenförmig, ohne Schuppe.

1. Antennenschaft deutlich kürzer als die Geisselglieder 1-5:

Dolichoderus (S. 79).

2. Antennenschaft so lang wie die Geisselglieder 1-5: Tapinoma (S. 78).

II. Stielchen mit oben ausgerundeter Schuppe: Liometopum (S. 78). 


\section{Gattung: Tapinoma Foerster.}

ఫ. - Antennen 12gliedrig, Geisselglied 1 und 11 am längsten, die übrigen unter sich gleich lang. Maxillartaster 6 gliedrig, Labialtaster 4 gliedrig. Epistom ohne Mittelkiel, zwischen die Stirnleisten verlängert und hier stark abgerundet, Vorderrand aufgebogen, mit einem tiefen, medianen Einschnitt. Stirnfeld nicht ausgebildet. Ocellen fehlen. Rücken zwischen Mesonotum und Epinotum ganz flach eingesenkt. Epinotum mit schrägem, flachem Abfall, ohne Zähne. Schuppe klein, knotenförmig, nach vorn geneigt, von dem nach vorn überragenden Abdomen bedeckt.

$0^{7}$. - Antennen 13 gliedrig, Schaft so lang wie die Glieder 1-5 zusammen.

Die Gattung umfasst ungefähr 40 Arten (3 fossile), die besonders wärmere Gebiete bewohnen.

Tapinoma erraticum (Latr.) Sm. (Abb. 59; Taf. I, Abb. 33).

ఢ̧. - Dunkelbraun bis schwarz, Mandibeln, Antennen und Beine etwas heller, Tarsen gelb. - Körper mikroskopisch fein gerunzelt punktiert. Pubescenz weisslich, spärlich.

․ - Schwarzbraun, Gelenke der Beine, die Tarsen, auch

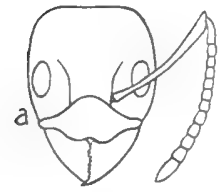
Antennengeissel und Schienen rotgelb. - Oberseite des Abdomens zerstreut punktiert.

$0^{7}$. - Färbung und Skulptur wie der $\not{q}$.

In Nord-, Mittel- und Südeuropa. Nester, die häufig ge-

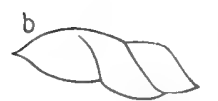

Abb. 59. Tapinoma erraticum $\gamma$.

a Kopf; b Thorax. wechselt werden, an trockenen, sonnigen Stellen, in der Erde, mit sehr flachem Oberbau, auf Wiesen, unter Steinen. In einer Kolonie mehrere befruchtete $P^{2}$ während des ganzen Jahres. Sie sind sehr schnell in ihren Bewegungen, verteidigen sich durch Ausspritzen des Sekretes der Analdrüsen und nehmen tierische Nahrung zu sich (Kadaver, andere Insekten, tote, in den "Ameisenschlachten" gebliebene Ameisen) Gehen auch den Ausscheidungen von Schildläusen nach. Geschlechtstiere im Juni.

\section{Gattung: Liometopum Mayr.}

ఫ. - Antennen 12gliedrig, Geisselglieder nach dem Ende hin ganz wenig stärker, ebenso kürzer werdend, mit Ausnahme des letzten. Maxillartaster 6 gliedrig, Labialtaster 4 gliedrig. Epistom dreieckig, hinten kurz abgerundet, ohne Mittelkiel, zwischen die Stirnleisten verlängert, Vorderrand in der Mitte wenig ausgeschweift. Stirnfeld nicht vertieft und undeutlich abgegrenzt. Ocellen schwach ausgebildet. Rücken zwischen Mesonotum und Epinotum nicht vertieft, seitlich schwach eingedrückt, Epinotum flach gerundet abfallend. Stielchen schmal, mit vorn etwas gewölbter, oben verschmälerter, ganzrandiger Schuppe.

‥ - Bedeutend grösser als der $\not$. Stirnfeld dreieckig, deutlicher abgegrenzt als beim $\Varangle$. Oberrand der Schuppe ausgerundet.

$\sigma^{7}$. - Antennen 13 gliedrig, die ersten 3 Glieder länger als der Schaft. Oberrand der Schuppe ausgerundet.

Hierzu nur wenige Arten, darunter auch fossile, in Europa, Asien und Nordamerika.

Liometopum microcephalum (Panz.) Mayr (Abb. 60; Taf. I, Abb. 34).

‡. - Kopf, Beine und Antennen braun, der Vorderkopf heller, Thorax bernsteingelb, Abdomen braun. Mandibeln kräftig, Thorax ziemlich fein und 
weniger dicht punktiert. - Kopf, Antennen und Thorax mit spärlicher, feiner, grauweisser Pubescenz, Abdomen mit ebensolcher, reicher Pubescenz; Beine mässig, Tarsen dicht pubescent. Abstehende Borsten in mässiger Anzahl vorhanden.

9. - Graubraun bis dunkelbraun, Vorderrand des Epistoms und Seiten des Kopfes gelbbraun, Antennen und Beine mit bräunlichem Schimmer. - Mandibeln grob punktiert, Kopf und Abdomen sehr fein und dicht lederartig gerunzelt punktiert, Thorax oben mit etwas gröberen Punkten, Mesonotum vorn und in der Mitte leicht längsgestreift. - Pubescenz wie beim $\not$, abstehende Behaarung dichter.

$\sigma^{7}$. - Färbung dunkelbraun, das äusserste Ende der Antennen und die Gelenke der Beine gelblich.

Eine südliche Form, die nordwärts bis Ungarn vordringt. Bewohnt in häufig sehr grossen Kolonien hohle Äste und Zweige, auch die Gänge von Borkenkäfern verwendend. Leben von animalischer Nahrung und sind sehr kriegerisch und angriffslustig.
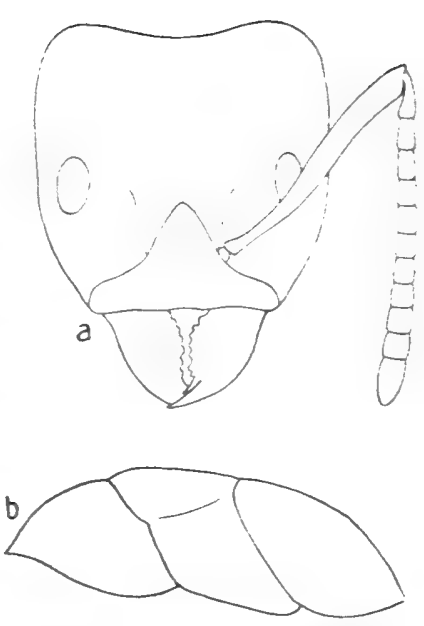

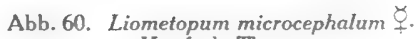
a Kopf; b Thorax.

Drüsensekret übelriechend.

\section{Gattung: Dolichoderus Lund.}

ఛ. - Antennen 12 gliedrig, mit kaum entwickelter Keule. Maxillartaster 6 gliedrig, Labialtaster 4 gliedrig. Epistom dreieckig, flach, ohne Mittelkiel, zwischen die Stirnleisten verlängert. Stirnfeld vertieft, undeutlich abgegrenzt. Ocellen fehlen. Rücken zwischen Mesonotum und Epinotum tief eingeschnürt; Epinotum hinten jederseits mit einem Zahn, zwischen beiden Zähnen eine Kante. Abfall des Epinotums steil, ausgehöhlt. Schuppe dick, keilförmig, nach vorn geneigt.

$0^{\lambda}$. - Antennen 13 gliedrig, Antennenschaft deutlich kürzer als Geisselglied 1-5 zusammen, Geisselglied 1 am kürzesten, 2 am längsten. Mandibeln mit Zähnen. An Stelle der Schuppe besitzt das Stielchen nur einen Knoten. bekannt.

In nahezu 100 Arten über die wärmeren Länder verbreitet, auch fossil

Dolichoderus quadripunctatus (L.) Em. et For. (Abb. 61; Taf. I, Abb. 32).

†. - Kopf schwarz, Mandibeln und Vorderrand des Epistoms gelbbraun, Thorax und Schuppe braunrot, Antennen, Gelenke der Beine und die Tarsen rotgelb, Abdomen schwarz, mit zwei vorderen kleinen und zwei dahinter liegenden, grossen, gelblich-weissen Flecken. Kopf, Thorax und Schuppe mit dicht nebeneinander liegenden Grübchen (fingerhutartig punktiert), Abdomen glänzend, mikroskopisch fein gerunzelt. Pubescenz sparsam.

o. - Thorax und Schuppe rot, mit dunklen Flecken,

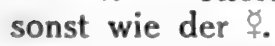

o". - Schwarz, Antennenschaft, Geisselglied 1, Schienen und Tarsen bräunlichgelb. Kopf und Pronotum fein, Epinotum grob längsgerieft, sonst wie der

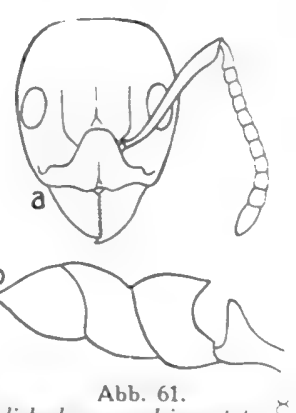

Dolichoderus quadripunctatus a Kopf; b Thorax-Petiolus.

In Mittel- und häufiger in Südeuropa; (in der Nähe von Berlin bei Woltersdorf 1912 gefunden). Die nur kleine Kolonien beherbergenden Nester finden 
sich in den Höhlungen trockener Zweige (Nussbaum) und werden von den Bewohnern nur bei warmem Sonnenschein verlassen. Vermögen sich sehr fest an ihrer Unterlage zu halten und lassen sich nicht von den Zweigen abschütteln. Geschlechtstiere in Spätsommer.

\section{Unterfamilie Camponotinae.}

Stielchen 1 gliedrig, bei den hier in Betracht kommenden Formen mit einer Schuppe (dick bei Polyergus); Pumpmagen vollständig, mit Kelch und Kugel; Kloakenöffnung rund, von einem Borstenkranz umgeben; kein Stachel; dieser ist umgewandelt in einen Stützapparat für die Giftdrüse, die ein Giftblasenpolster besitzt. Puppen (der einheimischen Gattungen, ausser Colobopsis) mit Kokon.

\section{Gattungen:}

Arbeiter und Weibchen.

I. Mandibeln schmal, spitz, ohne gezähnten Innenrand: Polyergus (S. 87).

II. Mandibeln breit, mit gezähntem Innenrand.

1. Antenneneinlenkung an der Grenze von Epistom und Stirnleisten.

A. Antennen 11 gliedrig:

Plagiolepis (S. 81).

B. Antennen 12 gliedrig.

a) Glied $2-5$ der Antennengeissel einzeln ebenso lang oder kürzer als jedes der folgenden Glieder; Stirnfeld undeutlich umgrenzt:

b) Glied 2-5 der Antennengeissel einzeln länger als jedes der folgenden Glieder; Stirnfeld deutlich umgrenzt:

2. Antenneneinlenkung oberhalb des Winkels an der Lasius (S. 81). Grenze von Epistom und Stirnleisten.

A. Seitenränder des Epistoms nach hinten konvergierend:

B. Seitenränder des Epistoms nach hinten nahezu parallel; (Kopf der grösseren Formen vorn scharf abgestutzt):

Formica (S. 88).

Camponotus (S. 93).

Colobopsis (S. 96).

Männchen.

I. Mandibeln schmal, dünn, am Ende zugespitzt:

II. Mandibeln breit, flach, mit breitem Innenrand.

Polyergus (S. 87).

1. Antenneneinlenkung im Winkel an der Grenze von Epistom und Stirnleisten.

A. Antennen 12gliedrig:

B. Antennen 13 gliedrig.

a) Stirnfeld undeutlich umgrenzt:

b) Stirnfeld deutlich umgrenzt:

2. Antenneneinlenkung oberhalb des Winkels an der Grenze von Epistom und Stirnleisten.

A. Geisselglied 1 nicht dicker und länger als das folgende:

B. Geisselglied 1 dicker und viel länger als das folgende: 


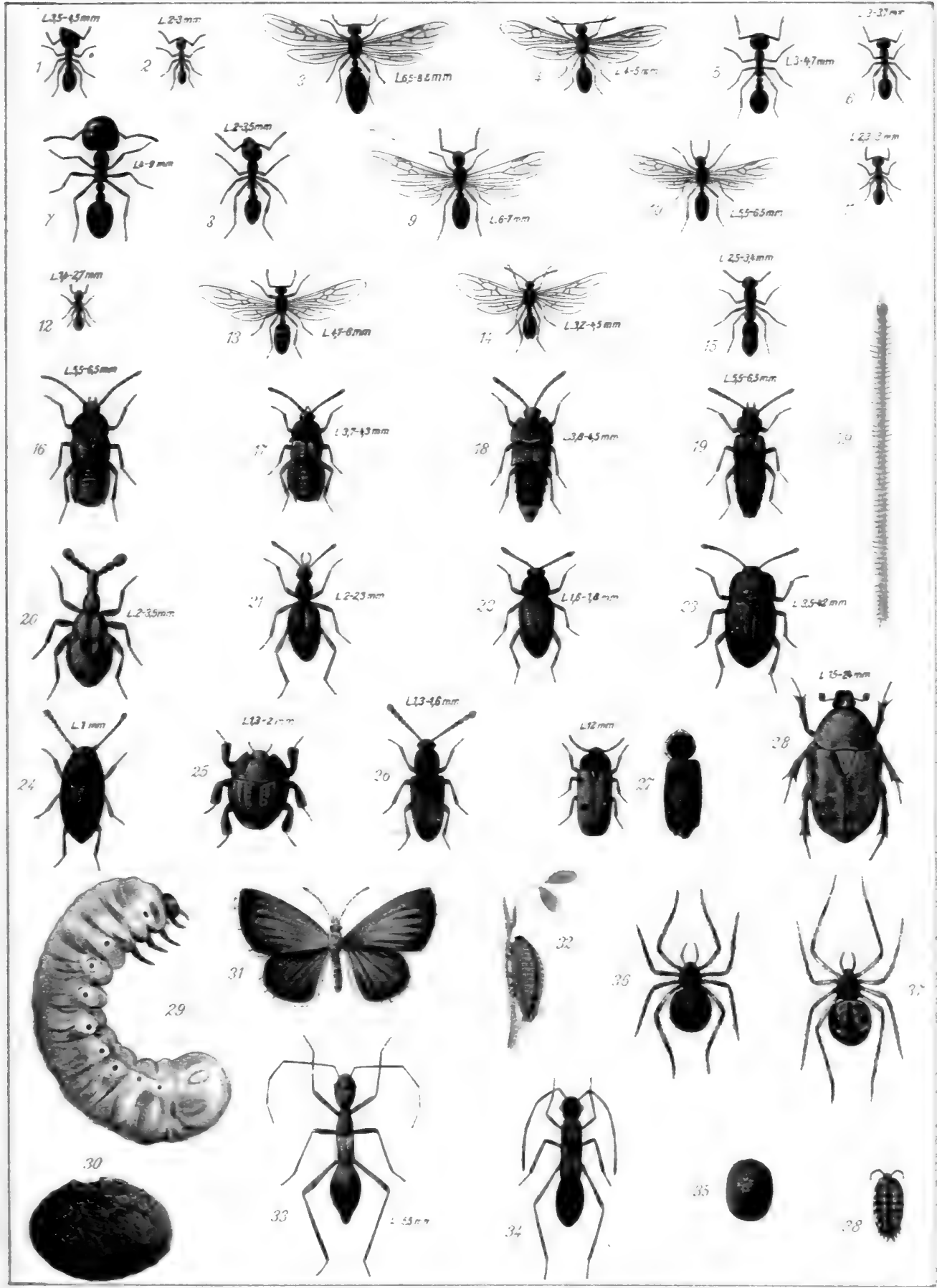

1. Pheidole megacephala $x$. 2. Pheidole megacephala $\not$. 3. Pheidole megacephala. 9 . 4. Pheidole megacephala $\sigma^{*}$. 5. Aphaenogaster subteranea $\not$. 6. Stenamma westwoodi $\not$. 7. Messor barbarus $\Varangle$. 8. Tetramorium caespitum 8 . 9. Tetramorium caespitum ${ }^{\circ}$. 10. Tetramorium caespitum of. 11. Stron8ylognathu testaceus 8 . 12. Solenopsis fugax 8 . 13. Solenopsis fugax 7 . 14. Solenopsis fugax or 16. Ponera coarctata "16. Lomechusa strumosa oriv. 17. Atemeles emarginatus Payk. 18. Dinarda dentati Grav. 19. Myrmedonia humeralis Orav. 20. Claviger testaceus Preyssl. 21. Bathrisodes adnexus Hmpe. 22. Eutia plicata Gyll. 23. Catops umbrinus Er. 24. Ptenidium formicetorum. Kr. 25. Hetaerius ferrugineus Ol. 26. Myrmecoxenus subterraneus Chevr. 27. Cytra \& punctats, L mit Kokon, 28, Centonia floricola Hrbst. 29. C. flor. Larve. 30. C. flor. Kokon. 31. Lycaena argus L. 32. L. argus Raupe. 33. Myrmecoris gracilis Sahbg. 34. Alydus calcaratus L. Larve. 35. Microdon mutabilis L. Larve. 36. Theridium triste Hahn. Theridium eaxatile Blackw. 38. Platyarthrus hoffmanseggi Brdt. 39. Geophilus truncorum Mein. 



\section{Tribus: Plagiolepidii.}

\section{Gattung: Plagiolepis Mayr.}

ఫ. - Antennen 11 gliedrig, die Geissel nach dem Ende zu mässig keulenförmig, Geisselglied 1 am längsten, 2 am kürzesten. Maxillartaster 6 gliedrig, Labialtaster 4 gliedrig. Epistom mit Mittelkiel. Stirnfeld gross, undeutlich umgrenzt. Ocellen fehlen. Rücken zwischen Mesonotum und Epinotum kaum eingedrückt.

\section{ఫ. - Epistom ohne Mittelkiel.}

ऽ. - Antennen 12 gliedrig. Mandibeln mit 3 Zähnen.

Die Gattung enthält nur eine kleine Zahl von Arten, welche Südeuropa, Afrika, die warmen Gebiete von Asien und Australien bewohnen, und von denen auch fossile bekannt sind.

\section{Plagiolepis pygmaea (Latr.) Mayr. (Abb. 62).}

ఫ. - Sehr kleine Art. - Braun, Mandibeln, Antennengeissel, Schienen und Tarsen, zuweilen auch Epistom und Schenkel, rötlichgelb. Körper mit feinen, zerstreuten Punkten, glatt und glänzend. Kopf und Abdomen mit abstehenden Borsten spärlich bedeckt. ‥ - Wie der $\dot{+}$.

$\sigma^{7}$. - Dunkler braun als der $q$, Antennenschäfte und Beine gelb; Antennengeissel geringelt. - Körper glatt, wenig glänzend, sparsam punktiert. - Behaarung sehr sparsam.

In Südeuropa heimisch, in Frankreich (André) gemein, wurde aber auch im Elsass (bei Rufach) gefunden. Nester an steinigen Stellen und in Felsspalten; sie soll auch zuweilen Wurzelläuse halten. In ihrem Wesen langsam, wenig zur Verteidigung geneigt.

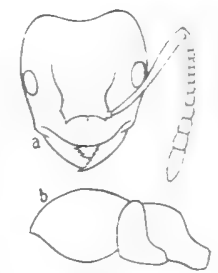

Abb.62. Plagiolepis pygmaea $\varnothing$. a Kopf; b Thorax.

\section{Tribus: Formicii.}

\section{Gattung: Lasius Fabricius.}

ఛ. - Antennen im Winkel an der Grenze von Epistom und Stirnleisten eingelenkt; Antennengeissel nach dem Ende hin wenig stärker werdend, 12gliedrig, Glied 2-5 einzeln ebenso lang oder kürzer als jedes der folgenden. Maxillartaster 6 gliedrig, Labialtaster 4 gliedrig. Epistom gewölbt, ohne Mittelkiel, seine Seitenränder stark nach hinten konvergierend. Stirnfeld dreieckig, undeutlich abgegrenzt. Ocellen undeutlich oder nicht vorhanden (deutlich bei L. fuliginosus). Rücken zwischen Mesonotum und Epinotum eingedrückt. Abdomen kurz, gedrungen. Beine verhältnismässig kurz. Kleinere Formen.

․ - Im Verhältnis zu den 하 sehr gross.

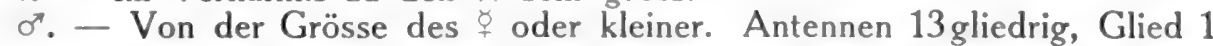
der Antennengeissel dicker als die übrigen, welche doppelt so lang als breit und unter sich ziemlich gleich lang sind. Innenrand der Mandibeln, vom apicalen Zahn abgesehen, glatt oder gezähnt.

Die Gattung umfasst ungefähr 40 Arten (mit Varietäten) nebst einer Anzahl fossiler Formen. In Europa, Vorderasien, bis Indien. Bei allen Arten findet Schwarmbildung statt; die Kopulation wird während des Fluges vollzogen; beide Geschlechter treten zu derselben Zeit auf; doch scheint L. umbratus zuweilen eine Ausnahme zu machen. Larven und Nymphen entwickeln sich sehr langsam. Können wirtschaftlich schädlich werden durch Zucht von Pflanzenläusen (vgl. S. 49). 
Arten: $\left.{ }^{1}\right)$

\section{Arbeiter.}

I. Körper schwarz, stark glänzend:

II. Körper braun, grau, bräunlichgelb.

1. Thorax braun, wenig heller als Kopf und Abdomen.

L. fuliginosus (Latr.) Mayr (Nr. 1).

A. Antennenschäfte und Schienen mit abstehenden Borsten:

B. Antennenschäfte und Schienen ohne abstehende Borsten:

2. Thorax gelbbraun, Kopf und Abdomen braun.

A. Antennenschäfte und Schienen mit abstehenden Borsten:

B. Antennenschäfte und Schienen ohne abstehende Borsten :

III. Körper gelb.

1. Oberer Rand der Schuppe mit tiefem, halbkreisförmigem Ausschnitt:

2. Oberer Rand der Schuppe ganzrandig oder nur wenig ausgeschnitten.

A. Schuppe kurz, oben breiter als unten:

B. Schuppe länglich, oben schmaler als unten.

a) Schienen mit abstehenden Borsten:

b) Schienen ohne abstehende Borsten.

$=$ Schuppenoberrand zuweilen mit schwachem Ausschnitt:

$=$ Schuppenoberrand meist dreieckig ausgeschnitten :

L. niger (L.) F. (Nr. 2).

L. alienus (Foerst.)

Mayr (Nr. 3).

$[(\mathrm{Nr} .4)$.

L. emarginatus $(\mathrm{Ol}$.) $\mathrm{F}$.

L. brunneus (Latr.)

Mayr (Nr. 5).

L. bicornis (Foerst.)

Mayr (Nr. 10).

L. flavus (Deg.) Mayr (Nr. 6).

L.umbratus (Nyl.) Mayr (Nr. 7). $[(\mathrm{Nr} .8)$.

L. mixtus (Nyl.) Mayr

L. affinis (Schnck.)

Weibchen.

I. Körper schwarz, stark glänzend:

II. Körper braun, grau, bräunlichgelb.

1. Kopf schmaler oder ungefähr so breit wie der

L. fuliginosus (Latr.) Mayr (Nr. 1).

Thorax; Thorax breit; Abdomen viel breiter als der Thorax.

A. Antennenschäfte und Schienen mit abstehenden Borsten.

a) Mesonotum oben flach; Thorax mit wenig entwickelter Pubescenz:

L. emarginatus $(\mathrm{Ol}$.) $\mathrm{F}$.

b) Mesonotum gewölbt; Thorax mit kräftig entwickelter Pubescenz:

B. Antennenschäfte und Schienen ohne abstehende Borsten.

a) Kopf ungefähr so breit wie der Thorax:

b) Kopf viel schmaler als der Thorax.

$=$ Dunkler braun, mit rötlichen Antennen und Beinen:

$=$ Heller braun, mit braungelben oder gelben Antennen und Beinen:

2. Kopf breiter als der Thorax; Thorax schmal; Ab(Nr. 4).

L. niger (L.) F. (Nr. 2).

L. brunneus (Latr.) Mayr (Nr. 5)

L. alienus (Foerst.) Mayr (Nr. 3).

L. flavus (Deg.) Mayr (Nr. 6). domen wenig breiter als der Thorax.

$\left.{ }^{1}\right)$ Ruzsky gruppiert die Arten neuerdings in 3 Untergattungen: Dendrolasius (Nr. 1), Lasius (Nr. 2, 3, 4, 5) und Chtonolasius (Nr. 6, 7, 8, 9, 10). 
A. Schienen mit abstehenden Borsten:

L. umbratus (Nyl.)

B. Schienen ohne abstehende Borsten. Mayr (Nr. 7).

a) Oberer Rand der Schuppe zuweilen mit flachem Ausschnitt:

L. mixtus (Nyl.) Mayr

b) Oberer Rand der Schuppe mit dreieckigem Ausschnitt:

(Nr. 8).

c) Oberer Rand der Schuppe mit tiefem, halbkreisförmigem Ausschnitt:

L.affinis(Schnck.)Mayr.

[Mayr (Nr. 10).

L. bicornis (Foerst.)

\section{Männchen. $\left.{ }^{1}\right)$}

I. Körper schwarz, stark glänzend:

II. Körper anders gefärbt, heller.

1. Innenrand der Mandibeln ohne Zähne (nur ein

L. fuliginosus (Latr.)

Mayr (Nr. 1). Apicalzahn vorhanden).

A. Antennenschäfte und Schienen abstehend behaart.

a) Stirn glänzend; Mesonotum mit vertieften Punkten :

b) Stirn matt; Mesonotum ohne Punkte.

$=$ Färbung dunkler; Flügel im Basalteil bräunlich getrübt:

L. niger (L.) F. (Nr. 2).

= Färbung heller; Flügel gleichmässig hell.

B. Antennenschäfte und Schienen nicht abstehend behaart.

a) Antennengeissel gelb:

b) Antennengeissel braun:

2. Innenrand der Mandibeln gezähnt.

A. Augen fast kahl.

a) Mandibeln gelbbraun, meist nur ihr Innenrand:

b) Mandibeln schwarzbraun, zuweilen mit gelbbraunem Innenrand:

B. Augen deutlich behaart.

a) Mandibeln am distalen Ende bräunlichgelb oder rötlich:

b) Mandibeln am distalen Ende dunkelbraun:

L. mixtus (Nyl.) Mayr

L. affinis (Schnck.) (Nr. 8). Mayr (Nr.9). [Mayr (Nr. 7).

L. umbratus (Nyl.)

L. bicornis (Foerst.)

Mayr (Nr. 10).

1. L. fuliginosus (Latr.) Mayr (Abb. 63; Taf. I, Abb. 31).

‡. - Kopf hinten stark ausgebuchtet. - Schwarz, Antennenschaft, Schenkel und Schienen dunkelbraun, Mandibeln, Antennengeisseln und Tarsen bräunlichrot. - Glatt, glänzend, mikroskopisch fein gerunzelt. - Abstehende Behaarung gering.

+. - Wie der

$0^{7}$. - Kopf hinten stark ausgebuchtet. Mandibeln mit Apicalzahn und ungezähntem Innenrand. - Schwarz, stark glänzend, Antennengeisseln, Gelenke der Beine und Tarsen gelbbraun; proximaler Teil der Flügel bräunlich getrübt. Äbdomen weitläufig punktiert.

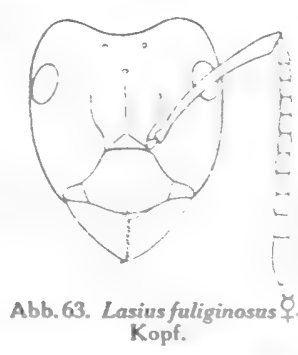

1) Die $\sigma^{7} \sigma^{7}$ dieser Gattung sind sehr schwer zu unterscheiden. Die in der Tabelle angegebenen Merkmale sind zum Teil nur relative. Zur Kenntnis der $C^{7} \sigma^{7}$ ist es am ratsamsten, sich solche aus Nestern zu verschaffen und miteinander zu vergleichen. 
In Nord-, Mittel- und Südeuropa (Griechenland) bis Asien (Indien, Himalaja); fehlt in Nordamerika. Nester in Baumhöhlungen, ${ }^{1}$ ) gekammert, aus schwarzbrauner Kartonmasse, die aus Holzstaub, Erdteilchen u. dgl. mittelst des Sekretes der Oberkieferdrüse hergestellt wird. Die diese Masse durchziehenden Pilzfäden werden möglicherweise von den Ameisen gezüchtet und als Futter verwertet. Beobachtet ist auch, dass auf die erwähnte Weise Sand zum Nestbau verwendet wird. Die Nester erstrecken sich meist noch in die Erde hinein, besonders am Grund von Bäumen, zwischen Wurzeln, und sind oft sehr ausgedehnt. Sie scheuen das Sonnenlicht und ziehen Schatten vor; leben von animalischen Stoffen und rauben auch Larven und Puppen anderer Ameisen; lieben besonders die Ausscheidungen von Blattläusen und besitzen einen eigenartigen Geruch. Geschlechtstiere im Juni und Juli, auch noch im August; schwärmen abends und nachts. Koloniegründung erfolgt jedenfalls in der S. 22 erwähnten Weise, indem aus einer temporär gemischten Kolonie mit $L$. flavus allmählich eine reine aus $L$. fuliginosus wird.

2. Lasius niger (L.) F. (Abb. 64; Taf. I, Abb. 26 ‡, 27 q, $28 \sigma^{\circledR}$ ).

ఫ. - Kopf, Thorax und Abdomen braun, Antennenschäfte, Gelenke der Beine und die Tarsen bräunlich bis rötlichgelb. Antennenschäfte und Schienen
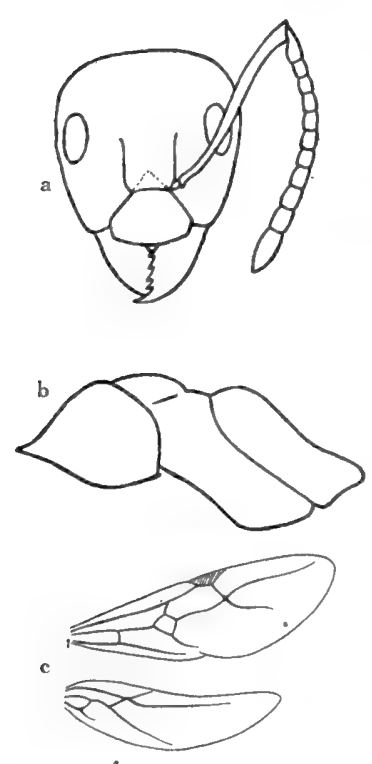

Abb. 64. Lasius niger ్․ a Kopf; b Thorax; c Flügel ㅇ․ mit abstehenden Borsten.

9. - Kopf schmaler als der Thorax, Abdomen nicht breiter als dieser. - Dunkelbraun, Mandibeln, Antennenschäfte, Schienen und Tarsen rotbraun; Flügel nicht bräunlich getrübt. - Antennenschäfte und Schienen mit abstehenden Borsten, Abdomen mit dichter Pubescenz.

$\sigma^{7}$. - Oberkopf hinten mässig ausgerundet; Mandibeln mit Apicalzahn und ungezähntem Innenrand. Braun bis dunkelbraun, Antennengeisseln, Gelenke der Beine und die Tarsen hellbraun; Flügel nicht bräunlich getrübt. - Antennenschäfte und Schienen abstehend behaart.

Eine der häufigsten Ameisen. In ganz Europa, Asien (bis Indien, Himalaja). Nester in der Erde, oft mit kuppelartigem Oberbau, der häufig um Stengel, Halmbüschel usw. herum angelegt ist, aus demselben Material, ferner unter Rinde und unter Steinen, sowie an solche oder an Baumstümpfe gelehnt, auch in letzteren; ist in seinem Nestbau ausserordentlich anpassungsfähig und findet sich daher auch in der Stadt zwischen den Pflastersteinen, wird oft im Garten sehr lästig, kommt auch in die Vorratskammern. Die Tiere schaden durch indirekte Begilnstigung der Vermehrung der Blattläuse, indem sie zum grossen Teil ober- und unterirdisch lebende Tiere dieser Art züchten, zu denen sie in ersterem Fall bedeckte Gänge bauen. Geschlechtstiere im Hochsommer, grosse Schwärme bildend; Männchen kommen noch im Herbst vor.

3. L. niger r. alienus (Foerst.) Mayr.

ఫ. - Kopf, Thorax und Abdomen braun, Antennenschäfte, Gelenke der Beine und die Tarsen bräunlich bis rötlichgelb. Antennenschäfte und Schienen ohne abstehende Borsten.

1) W a n a ch erwähnt ein solches in einer $5 \mathrm{~m}$ langen, $30 \mathrm{~cm}$ oben und $10 \mathrm{~cm}$ unten breiten Baumhöhle, das zum grossen Teil noch in die Erde ragte. 
7. - Kopf viel schmaler als der Thorax, Abdomen noch breiter als dieser. Dunkelbraun, Mandibeln, Antennen und Beine rötlichgelb; Flügel nicht bräunlich getrübt. Antennenschäfte und Schienen ohne abstehende Borsten, Abdomen mit dichter Pubescenz.

$\sigma^{\prime \prime}$. - Oberkopf hinten mässig ausgerundet; Mandibeln mit Apicalzahn und ungezähntem Innenrand. - Braun bis dunkelbraun, Antennengeissel, Gelenke der Beine und die Tarsen hellbraun; Flügel nicht bräunlich getrübt. Antennenschäfte und Schienen nicht abstehend behaart.

In ganz Europa, Asien (bis Indien, Himalaja), etwas weniger häufig als L. niger. Nester auf trockenem Boden (Heideboden), in der Erde unter Steinen, auf Wiesen, selten mit Oberbau, auch unter Rinde und in Baumstümpfen. Geschlechtstiere im Hochsommer.

4. L. niger r. emarginatus (Ol.) F.

๖. - Kopf, Abdomen und Beine braun, Thorax gelbrot, Gelenke der Beine und die Tarsen gelb. - Antennenschäfte und Schienen mit abstehenden Borsten.

f. - Kopf schmaler als der Thorax, Abdomen breiter als dieser. - Kopf, Thorax und Abdomen oben braun, sonst bräunlich rotgelb; Flügel nicht bräunlich getrübt. - Antennenschäfte und Schienen mit abstehenden Borsten, Abdomen mit dichter Pubescenz.

8. - Oberkopf hinten mässig ausgerundet; Mandibeln mit Apicalzahn und ungezähntem Innenrand. - Braun bis dunkelbraun, Antennengeisseln, Gelenke der Beine und die Tarsen hellbraun; Flügel nicht bräunlich getrübt. Antennenschäfte und Schienen abstehend behaart.

In ganz Europa, doch im Norden scheinbar fehlend. Nester unter Steinen, in Gesteins- oder Mauerspalten. Schaden indirekt durch Schutz von Blattläusen. Geschlechtstiere im Hochsommer.

5. L. niger r. brunneus (Latr.) Mayr (Taf. I, Abb. 29).

ఛ.. - Kopf und Abdomen braun, Thorax bräunlichgelb. Antennenschäfte und Schienen mit abstehenden Borsten.

9. - Kopf nahezu so breit wie der Thorax, Abdomen noch breiter als dieser. - Dunkelbraun, Mandibeln gelbrot, Antennen und Beine rötlichgelb; proximale Hälfte der Flügel bräunlich getrübt. - Abdomen mit dichter Pubescenz, Antennenschäfte und Schienen ohne abstehende Borsten.

$\sigma^{7}$. - Kopf hinten mässig ausgerundet; Mandibeln mit Apicalzahn und ungezähntem Innenrand. - Braun bis dunkelbraun, Antennen, Glieder der Beine und die Tarsen hellbraun; proximaler Teil der Flügel bräunlich getrübt. - Antennenschäfte und Schienen ohne abstehende Borsten.

In ganz Europa, auch im Norden, in Asien bis zum Himalaja. Nester in Baumstümpfen und zwischen Wurzeln, unter Baumrinde, unter Steinen, auch in Mauer- und Felsspalten, mitunter auch in Wirtschaftsräume eindringend; Gänge in der Erde oft in weitem Umkreis verzweigt. Geschlechtstiere im Hochsommer.

6. L. flavus (Deg.) Mayr (Taf. I, Abb. 30).

ซ. - Schuppe oben breiter als unten, ihr Oberrand kaum ausgeschnitten. Gelb. - Thorax und Abdomen auf der Oberseite reich mit abstehenden Borsten, Schienen ohne solche.

7. - Kopf viel schmaler als der Thorax, Abdomen breiter als dieser. Kopf und Thorax dunkelbraun, Abdomen braun, Mandibeln, Seiten des Kopfes, Antennen und Beine rötlichgelb; proximale Hälfte der Flügel bräunlich getrübt. Abdomen mit dichter Pubescenz, Antennenschäfte und Schienen ohne abstehende Borsten. 
$0^{7}$. - Kopf hinten mässig ausgerundet; Mandibeln mit Apicalzahn und ungezähntem Innenrand; Flügel hell, im proximalen Teil zuweilen getrübt. Antennenschäfte und Schienen mit abstehenden Borsten.

In ganz Europa, eine Varietät in Nordamerika. Nester unter Steinen oder in der Erde, besonders auf feuchten Wiesen mit bindigem Boden, in letzterem Fall mit Kuppel bis $30 \mathrm{~cm}$ hoch und höher, oft mit einer Grasnarbe überzogen, die Kuppel im Zusammenhang mit der unterirdischen Lebensweise, ohne Ausgangsöffnungen. (In Norwegen unter Steinen in rein minierten Nestern, selten mit Kuppeln.) Nester oft im Bezirk von Formica pratensis. Ist in seinen Bewegungen langsam, schadet durch Zucht von Wurzelläusen, deren Kot als Nahrung benutzt wird. Geschlechtstiere von Juli bis Oktober; Schwarmbildung in den Nachmittagsstunden.

7. L. umbratus (Nyl.) Mayr.

ఫ. - Schuppe meist schwach eingekerbt. - Gelb. - Oberseite des Thorax und das Abdomen reich mit langen, abstehenden Borsten bedeckt; Schienen mit abstehenden Borsten.

. - Kopf breiter als der Thorax, Abdomen wenig breiter als dieser; Oberrand der Schuppe meist etwas eingeschnitten. - Gelblich rotbraun, Antennen und Beine bräunlichgelb; proximale Hälfte der Flügel nicht bräunlich getrübt. Abdomen mit dichter Pubescenz, Thorax und Abdomen oben mit kurzen, abstehenden Borsten, Schienen abstehend behaart.

$\sigma^{7}$. - Kopf hinten mässig ausgerundet; Mandibeln 5zähnig, mit hellbraunem Innenrand. - Dunkelbraun; proximaler Teil der Flügel nicht bräunlich getrübt. - Schienen abstehend behaart.

In ganz Europa häufig, in Nordamerika einige Varietäten. Nester am Grund von Bäumen, zwischen Baumwurzeln, unter Steinen, seltener auf Wiesen, zuweilen auch Hügelnester, auch in Häusern, Gänge in der Erde oft weit im Umkreis verzweigt. Geschlechtstiere von Juli bis Oktober.

\section{L. umbratus r. mixtus (Nyl.) Mayr.}

ఫ. - Oberrand der Schuppe zuweilen schwach eingekerbt. - Gelb bis bräunlichgelb. - Kopf, Thorax und Abdomen sehr sparsam mit kurzen, abstehenden Borsten bedeckt.

9. - Kopf breiter als der Thorax, Abdomen wenig breiter als dieser; Schuppe zuweilen schwach eingekerbt. - Gelbbraun bis rotbraun, Thorax und Schuppe teilweise, Beine vollständig rötlichgelb; proximale Hälfte der Flügel nicht bräunlich getrübt. - Abdomen mit dichter Pubescenz, Thorax kaum, Abdomen mit wenigen abstehenden Borsten.

$\sigma^{7}$. - Kopf hinten mässig ausgerundet; Mandibeln 5 zähnig, gelbbraun, meist nur mit hellbraunem Innenrand. - Braun bis dunkelbraun, Antennengeissel, Gelenke der Beine. und Tarsen hellbraun; proximaler Teil der Flügel nicht bräunlich getrübt.

In ganz Europa häufig. Nester unter Steinen, am Grund von Baumstümpfen und zwischen Wurzeln, auch unter Rasen gefunden, diesen schädigend; Gänge in der Erde oft über ein weites Gebiet verzweigt, zuweilen Hügelnester. Wurde auch in Nestern von $L$. fuliginosus beobachtet, hier offenbar als Sklavenameise lebend und aus geraubten Puppen stammend, die nicht zur Nahrung gedient hatten. Nach Emery gründet $L$. fuliginosus seine Kolonien mit Hilfe von L. mixtus.

9. L. umbratus r. affinis (Schnck.) Mayr.

ఫ. - Schuppenoberrand ziemlich tief dreieckig ausgeschnitten. - Gelb. Thorax und Abdomen auf der Oberseite reich mit abstehenden Borsten bedeckt, Schienen ohne abstehende Behaarung. 
ఛ. - Kopf breiter als der Thorax, Abdomen wenig breiter als dieser; Oberrand der Schuppe dreieckig ausgeschnitten. - Dunkel gelblichbraun, Antennen und Beine bräunlichgelb; proximale Hälfte der Flügel nicht bräunlich getrübt. - Abdomen mit dichter Pubescenz, Thorax und Abdomen reich mit abstehenden Borsten bedeckt.

0". - Kopf hinten mässig ausgerundet; Mandibeln 5 zähnig, schwarzbraun, ihr Innenrand zuweilen gelbbraun. - Dunkelbraun; proximale Hälfte der Flügel nicht bräunlich getrübt.

10. L. umbratus r. bicornis (Foerst.) Mayr.

ఛ. - Oberrand der Schuppe mit tiefem Ausschnitt. - Gelb.

\%. - Kopf breiter als der Thorax, Abdomen wenig breiter als dieser. Schuppe hoch, ihr Oberrand tief halbkreisförmig ausgeschnitten. - Kopf und Thorax dunkelbraun, Abdomen heller braun, Mandibeln, Antennen und Beine rötlichgelb; proximale Hälfte der Flügel bräunlich getrübt. - Abdomen mit dichter Pubescenz, Thorax und Abdomen reich mit abstehenden Borsten.

In Mittel- und Südeuropa, sehr selten.

\section{Gattung: Polyergus Latreille.}

ఫ. - Antennen im Winkel an der Grenze von Epistom und Stirnleisten eingelenkt, 12 gliedrig, Schaft am Ende plötzlich verdickt, die beiden ersten Geisselglieder einzeln länger als jedes der folgenden, das letzte ausgenommen. Maxillartaster 4 gliedrig, Labialtaster 2 gliedrig. Epistom ohne Mittelkiel, dreieckig, hinten bogenförmig abgerundet. Stirnfeld vertieft, scharf umgrenzt, abgerundet dreieckig. Stirnleisten kurz, schmal, mit fast parallelen Rändern. Ocellen vorhanden. Rücken zwischen Mesonotum und Epinotum eingedrückt, das Epinotum in Form einer abgerundeten Kuppe stark aufgetrieben. Schuppe dick, in Seitenansicht oben stark abgerundet, mit paralleler Vorder- und Hinterfläche. - Sind nicht fähig, ihr Gift auszuspritzen.

f. - Ohne den Epinotalbuckel des ఫ.

$\sigma^{7}$. - Ohne den Epinotalbuckel des $\not{q}$. Antennen 13 gliedrig, mit kurzem Schaft von ${ }^{1 / 4}$ der Länge der Geissel. Schuppe dick, ihr Oberrand hinten flach eingedrückt.

In nur einigen Arten aus Mittel- und Südeuropa sowie Nordamerika bekannt.

Polyergus rufescens Latr. (Abb. 65; Taf. I, Abb. 25).

ఛ. - Körper, Antennen und Beine rot, die Antennen zuweilen etwas heller. Abdomen und Beine mit anliegender, gelblicher, seidenschimmernder Pubescenz. Vorderrand des Epistoms, Schuppe oben und hinten und Abdomen mit langen, abstehenden, bräunlichgelben Borsten ziemlich reich bedeckt.

+. - Ebenso.

$0^{7}$. - Schwarzbraun, mit braunen Antennen und bräunlichgelben Beinen, die Tarsen blassgelb.

In Nordeuropa (Südskandinavien), Mittel- und Südeuropa. Besitzt keine eigenen Nester; über diese sowie Koloniegründung vgl. S. 23. Betreffs ihrer Beutezüge hat Forel festgestellt, dass eine Kolonie in 33 Tagen 44 Raubzüge ausführte und dabei ungefähr 30000 Larven und Puppen erbeutet haben muss. Königinnen oft zahlreich in einem Nest. Geschlechtstiere im Hochsommer, ihr Auszug um die Mittagszeit.
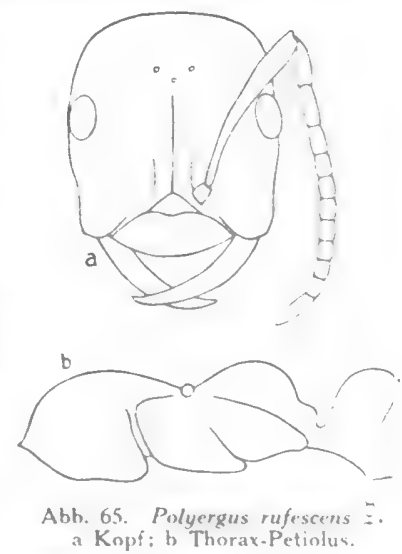


\section{Gattung: Formica Linné.}

ఫ. - Antennen im Winkel an der Grenze von Epistom und Stirnleisten eingelenkt, die Geissel nach dem Ende hin wenig stärker werdend, 12 gliedrig, Glied 2-5 einzeln länger als jedes der folgenden. Maxillartaster 6 gliedrig (selten 5 gliedrig), Labialtaster 4 gliedrig. Epistom mit Mittelkiel, seine Seitenränder nach hinten konvergierend. Stirnfeld scharf umgrenzt, dreieckig. Ocellen vorhanden. Rücken zwischen Mesonotum und Epinotum winklig eingedrückt. Puppen mit Kokon (vgl. S. 26).

q. - Abdomen gedrungener als beim

$\sigma^{7}$. - Antennen 13 gliedrig, mit langem Schaft, Geisselglied 1 kürzer als 2; Schuppe verhältnismässig dicker als beim $\not{\xi}$, oben meist eingedrückt.

Von der Gattung Formica sind, ausser einer Anzahl fossiler Formen, weit über 100 Arten (Rassen und Varietäten) bekannt, die fast sämtlich die nördliche Halbkugel bewohnen. Die Nester enthalten meist grosse Kolonien, die in unseren Gegenden für den Forstschutz von Bedeutung sind (vgl. S. 48). iq und $\sigma^{7} \sigma^{7}$ finden sich häufig zu verschiedenen Zeiten im Nest; Schwarmbildung findet nicht statt; Kopulation vollzieht sich auf Bäumen.

Arten:

\section{Arbeiter.}

I. Vorderrand des Epistoms in der Mitte eingekerbt: $F$. sanguinea Latr.

II. Vorderrand des Epistoms ganzrandig.

1. Hinterrand des Kopfes, von vorn gesehen, tief ausgerundet; Schuppenoberrand tief ausgeschnitten.

A. Vorderrand des Epistoms schwach aufgebogen, darüber ein dem Rand paralleler Eindruck:

B. Vorderrand des Epistoms flach, über demselben kein Eindruck:

F. pressilabris Nyl. $F$. exsecta Nyl. (Nr. 2).

2. Hinterrand des Kopfes, von vorn gesehen, gerade; Schuppe ganzrandig (nur zuweilen schwach eingekerbt).

A. Kopf fast ebenso breit als lang; Körper gedrungen; Geisselglieder 3 und 4 viel schlanker als $6-8$.

a) Stirn, Scheitel und Abdomen schwarz.

$=$ Auf dem Pronotum meist ein dunkler Fleck, der nicht bis zu dessen Hinterrand reicht (rote Farbe vorherrschend):

$=$ Auf dem Pronotum ein dunkler Fleck, der F. rufa L. (Nr. 4). dessen Hinterrand erreicht; Mesonotum ebenfalls mit dunklem Fleck (schwarze Farbe mehr oder weniger vorherrschend): F.pratensis Retz.(Nr.5).

b) Stirn, Scheitel und Vorderfläche des Abdomens rot; auf ersterer nur selten ein dunkler Fleck: F.truncicola Nyl.(Nr.6).

B. Kopf länger als breit; Körper schlank; Geisselglieder 3 und 4 wenig schlanker als $6-8$.

a) Körper schwarz bis schwarzbraun.

$=$ Körper stark glänzend; Winkel des Epinotums, von der Seite gesehen, stark abgerundet: 
$=$ Körper matt und wenig glänzend; Winkel des Epinotums, von derSeitegesehen, eckig. ॥ Pubescenz, besonders auf dem Abdomen, spärlich :

II Pubescenz, besonders auf dem Abdomen, reichlich und seidenartig:

b) Körper rot oder braun.

F. fusca L. (Nr. 7).

F. glebaria Nyl. (Nr. 9).

$=$ Unterseite des Kopfes mit langen Borsten; anliegende Behaarung mit starkem, grauem Seidenschimmer; Färbung braun:

F. cinerea Mayr (Nr.10).

$=$ Unterseite des Kopfes ohne Borsten; anliegende Behaarung mit nur geringem Seidenschimmer; Färbung rotbraun oder rot:

F. rufibarbis F. (Nr.11).

Weibchen.

I. Vorderrand des Epistoms in der Mitte eingekerbt: F. sanguinea Latr.

II. Vorderrand des Epistoms ganzrandig.

1. Hinterrand des Kopfes, von vorn gesehen, tief ausgerundet; Schuppenoberrand tief ausgeschnitten.

A. Körper mit dichter Pubescenz; Maxillartaster 6 gliedrig; kleiner als exsecta:

B. Körper mit spärlicher Pubescenz; Maxillartaster 5 gliedrig (Glied 4 zuweilen aus 2 sekundären Teilen); grösser als pressilabris:

2. Hinterrand des Kopfes, von vorn gesehen, gerade; Schuppe ganzrandig (nur zuweilen schwach eingekerbt).

A. Stirnfeld glänzend; Kopf und Thorax mit roter Färbung.

a) Abdomen glänzend, nur um die Stielcheneinlenkung herum eine helle Fläche von grösserer Ausdehnung:

b) Abdomen matt; der helle Fleck um die Einlen-

kung des Stielchens herum geringer entwickelt: F.pratensisRetz.(Nr.5).

c) Abdomen matt; Abdominalsegment 1 ungefähr zur Hälfte hellrostrot:

B. Stirnfeld matt, wenn glänzend, so sind Kopf und Thorax schwarz.

a) Anliegende Pubescenz sparsam.

$=$ Kopf und Thorax mit roter oder rötlicher Färbung:

$=$ Kopf und Thorax nur schwarz.

II Die sparsame Pubescenz erzeugt einen schwachen Seidenschimmer:

II OhneSeidenschimmer;Körperoberfläche an und für sich stark glänzend:

b) Mit dichter, anliegender, seidenartig glän-

F.truncicola Nyl.(Nr.6).

F. pressilabris $\mathrm{Nyl}$. (Nr. 3). F. exsecta Nyl. (Nr. 2). (Nr. 1).

F. rufa L. (Nr. 4). zender Pubescenz.

$=$ Unterseite des Kopfes mit abstehenden Borsten:

$=$ Unterseite des Kopfes ohne abstehende Borsten:

F.rufibarbis F.(Nr.11).

F. fusca L. (Nr. 7).

F. gagates Latr. (Nr. 8).

F. cinerea Mayr (Nr.10).

F. glebaria Nyl. (Nr.9). 


\section{Männchen.}

I. Vorderrand des Epistoms in der Mitte eingekerbt: $F$. sanguinea Latr.

II. Vorderrand des Epistoms ganzrandig.

1. Hinterrand des Kopfes, von vorn gesehen, tief ausgerundet; Schuppenoberrand tief ausgeschnitten.

A. Hinterrand des Kopfes stärker ausgerundet; Maxillarpalpen 6 gliedrig; kleiner als exsecta: $F$. pressilabris Nyl.

B. Hinterrand des Kopfes schwächer ausgerundet; Maxillarpalpen 5 gliedrig (Glied 4 zuweilen aus

2 sekundären Teilen); grösser als pressilabris: F. exsecta Nyl. (Nr. 2).

2. Hinterrand des Kopfes, von vorn gesehen, gerade; Schuppe ganzrandig.

A. Mit breiterem, behaartem Abdomen und stärker behaartem Thorax:

Alle drei Arten sehr schwer zu unterscheiden, nur durch die relativ stärkere oder schwächere Behaarung, die bei rufa am geringsten, bei pratensis eine mittlere und bei truncicola am stärksten ist.

B. Mit gestreckterem, schwach behaartem Abdomen und schwach behaartem Thorax.

a) Mit dichter, anliegender Pubescenz.

$=$ Pubescenz seidenártig glänzend:

F. cinerea $\operatorname{Mayr}(\mathrm{Nr} .10)$.

$=$ Pubescenz ohne seidenartigen Glanz:

b) Anliegende Pubescenz sparsam.

$=$ Schuppenoberrand stark ausgerundet:

$=$ Schuppenoberrand schwach ausgerundet. Mit stårkerer Pubescenz:

Mit schwächerer Pubescenz:

F. rufa L. (Nr. 4).
F. pratensis Retz.(Nr.5).
F. truncicola Nyl.
(Nr. 6). F. glebaria Nyl. (Nr.9). F. rufibarbis F. (Nr.11). F. gagates Latr. (Nr. 8). F. fusca Latr. (Nr. 7).

1. F. sanguinea Latr. (Abb. 66; Taf. I, Abb. 10).

ఛ. - Vorderrand des Epistoms in der Mitte eingekerbt. - Hell- oder dunkelrot, Oberkopf und Stirn mehr oder weniger braun. - Stirnfeld ohne Glanz. Abdomen mit grauer Pubescenz.

†. - Dunkler als der $\not{+}$, Kopf und Beine braun.

$\sigma^{\pi}$. - Schwarz, Antennenschäfte und Beine gelbbraun, ebenso, doch heller, das Abdominalende.

In den gemässigten Gegenden Europas, bis ins Mittelmeergebiet (Sizilien und Asien (Indien, Himalaja); in Nordamerika an Stelle der Stammform deren Rassen und Varietäten. Ihre Nester, die sich der Umgebung in

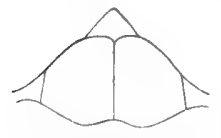

Abb. 66. Formica sanguinea $\not$. (Epistom.)

hohem Grade anzupassen vermögen und daher recht verschiedenartig sind, finden sich an Waldrändern oder lichten Stellen im Wald, und zwar in morschen Baumstümpfen oder in der Erde (Heideboden) mit einem flachen Oberbau aus Erde oder feinem Pflanzenmaterial, oder unter Steinen und Geröll, ferner auch in Baumstümpfen und unter Rinde. Häufig besitzt jede Kolonie ein Winternest, das geschützt im Gebüsch unter Baumstümpfen gelegen ist und während der Wintermonate bewohnt wird, und ein freier gelegenes Sommernest, ersteres wird auch bei sehr heisser Sommertemperatur benutzt. Ist kampflustig. Koloniegründung vgl. S. 23. Nester mit F. fusca als Sklaven; auch Zusammenleben mit $F$. rufa und pratensis ist beobachtet, ferner auch Kolonien 
ohne Sklaven. (Eine in Nordamerika lebende Rasse besitzt überhaupt keine Sklaven.) Geschlechtstiere im Juni und Juli, ziehen meist in den frühen Morgenstunden aus.

2. F. exsecta Nyl. (Abb. 67; Taf. I, Abb. 24).

ఈ. - Hinterrand des Kopfes und Schuppenoberrand tief halbkreisförmig ausgerundet; Maxillartaster länger als bei $F$. pressilabris; Augen behaart. - Rot bis schmutzig gelbrot, Oberkopf, Stirn und Pronotum mit braunem Fleck, Abdomen dunkelbraun. Grösser als F. pressilabris.

+. - Färbung matter als bei $F$. pressilabris.

In Europa vom Norden bis in die Alpen und zum Kaukasus, in Nordasien bis zum Altai. Die oft sehr stark bevölkerten Nester findet man an Waldrändern oder lichten Stellen im Walde; sie sind denen von $F$. rufa ähnlich, aber in den meisten Fällen weniger hoch und bestehen aus feinerem, mit Erde vermischtem Pflanzenmaterial; im Gebirge zuweilen auch unter Steinen; mitunter steht eine Anzahl von Nestern eines Bezirks miteinander in Verbindung. Sehr kampflustig. Geschlechtstiere im Juni und Juli.

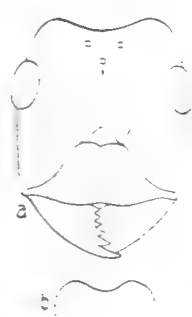

Abb. 67

Formica exsecta a Kopf; b Oberrand der Schuppe.

\section{F. exsecta Nyl. r. pressilabris (Nyl.) For.}

ఫ. - Unterscheidet sich von der Stammform durch den schwach aufgebogenen Vorderrand des Epistoms, über dem ein schwacher Eindruck verläuft, und durch die kürzeren, meist nur 5 gliedrigen Maxillartaster. - Färbung dunkler als bei jener.

+. - Färbung dunkler als bei $F$. exsecta.

o. - Hinterrand des Kopfes weniger stark ausgerundet.

In Nordeuropa und Nordasien, südlich bis zum Kaukasusgebiet. (In der Mark bei Buckow und Potsdam gefunden.) Selten. Nester ähnlich denen der vorigen Art.

4. F. rufa L. (Abb. 68, 69; Taf. I, Abb. 11, $12 \Varangle, 19$ \&, 20 ○).

ఈ. - Hell oder dunkel rostrot, Oberkopf und Stirn braun oder braunschwarz; Fleck auf dem Pronotum den Hinterrand desselben nicht erreichend, oft fehlend; Abdomen schwarzbraun. Augen nicht behaart; Kopf und Thorax kahl oder kaum behaart; Abdomen mit feiner Pubescenz.

\%. - Rot, Oberkopf, Mesonotum und Abdomen, ausgenommen um die Stielcheneinlenkung herum, dunkelbraun; Abdomen glänzend.

Weit verbreitet über Europa ${ }^{1}$ ) (von Lappland bis zu den Pyrenäen und dem Südabhang der Alpen) und Asien (Kaukasus, Sibirien); in Nordamerika in mehreren Rassen und Varietäten vertreten. Nester sowohl im Wald als an Waldrändern, besonders Nadelwald, oft eine bedeutende Ausdehnung erreichend. ") Der bekannte Ameisenhaufen ist der Oberbau und besteht aus trockenen Stückchen von
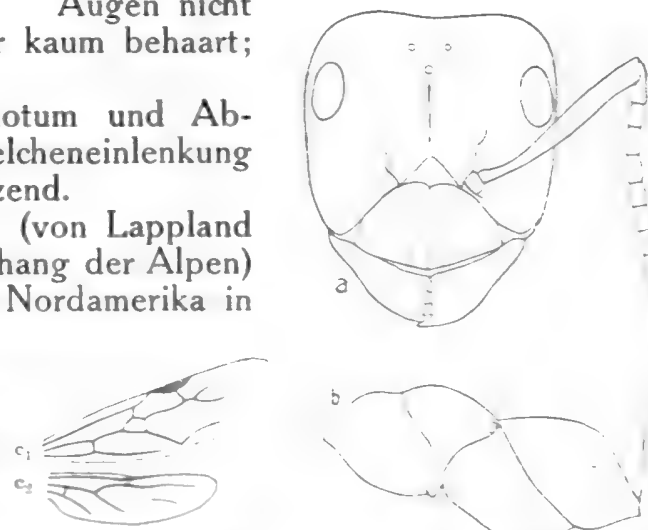

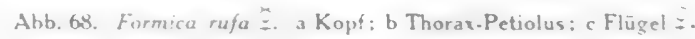

1) Auf der Insel Alnö (Bottnisch. Meerb.) ausserdem F. rufa L. v. suecica Adlerz, in Norwegen $F$. rufa L v. dusmeti $\mathrm{Em}$.

2) Ein von Wasmann in Luxemburg beobachtetes Nest hatte bei einer Kuppelhöhe von $1,5 \mathrm{~m}$ einen Umfang von $15 \mathrm{~m}$. 


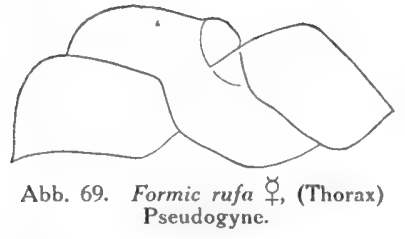

Zweigen, Grashalmen, Moos, Koniferennadeln und -zapfen. Es bedeckt den in der Erde befindlichen Unterbau mit vielen Kammern und Verbindungsgängen, die zum Teil nach aussen münden. Häufig steht eine Anzahl über eine mehr oder weniger grosse Fläche verbreiteter Nester durch Gänge und Strassen in Verbindung. Die Zahl der 9 in cinem Nest ist eine grosse und kann bis zu 100 betragen. ${ }^{1}$ ) Geschlechtstiere in den Sommermonaten, schon im Mai. Als Gastameise findet sich in den Nestern Formicoxenus nitidulus. Über die forstliche Bedeutung von F. rufa vgl. S. 48.

5. F. rufa L. r. pratensis (Retz.) For. (Taf. I, Abb. 14).

ఈ. - Färbung wie $F$. rufa, doch erreicht der Pronotalfleck den Hinterrand des Pronotums; ein solcher Fleck auch auf dem Mesonotum, beide Flecke oft stark über den ganzen vorderen Thorax ausgedehnt. Augen behaart; Kopf und Thorax sparsam mit abstehenden Borsten.

f. - Färbung wie $F$. rufa, die helle Fläche des Abdomens um die Stielcheneinlenkung herum geringer entwickelt.

Verbreitung wie F. rufa (bis Süditalien). Nester mehr an lichteren Stellen, am Waldrand, neben Gebüschen, auf Wiesen, auch unter Steinen, kleiner und niedriger als die von $F$. rufa.

Zwischen der Stammform und dieser Rasse gibt es betreffs der auf dem Rücken befindlichen Flecke viele Übergänge (Taf. I, Abb. 13).

6. F. rufa L. r. truncicola (Nyl.) For. (Taf. I, Abb. 15).

ఈ. - Färbung heller rot, selten mit Scheitel- und Pronotalfleck. Augen behaart; Kopf und Thorax mit abstehenden Borsten.

9. - Durch die heller roten Flecke auf dem Oberkopf und dem Pronotum von den beiden vorigen Formen zu unterscheiden; Abdomen vorn in grösserer Ausdehnung hell rostrot.

Verbreitung wie bei $F$. rufa (in Asien bis zur tibetanisch-indischen Grenze und in Indien). Nester häufig um Baumstümpfe herum, mit ähnlichem Oberbau wie bei $F$. rufa, der aber auch fehlen kann, jüngere Kolonien auch unter Steinen.

Zwischen $F$. pratensis und truncicola werden Übergänge selten beobachtet.

7. F. fusca Latr. (Abb. 70; Taf. I, Abb. 21 ఛ, 22 ).

ఛ. - Basalteil und Abfall des Epinotums gehen, von der Seite gesehen, abgerundet ineinander über. - Schwarzbraun, oft mit einem leichten Schimmer ins Grünliche, mit schwachem Glanz, Antennen und

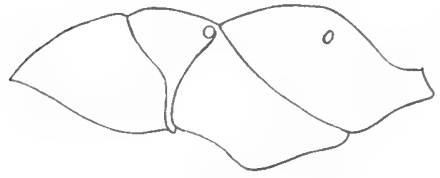

Abb. 70. Formica fusca $\not$ Thorax. Beine braun. Pubescenz und abstehende Behaarung gering.

+. - Färbung wie der 衣, Abdomen stark glänzend.

$\sigma^{7}$. - Schwer von F. rufa zu unterscheiden; spärlicher behaart als $F$. gagates.

Weit verbreitet über Europa (von Lappland bis Südeuropa, hier im Gebirge) und Asien; in Nordamerika in mehreren Varietäten. Bauen keine Haufen aus pflanzlichem Material, wenn auch bei grösseren Kolonien ein Oberbau aus Erde vorkommt; Nester in Baumstümpfen, im Holz trockener und morscher Äste sowie unter Rinde, unter Steinen in der Erde. Kolonien nicht so volkreich als die der rufa-Gruppe, darin zuweilen nur 1, aber auch bis

$\left.{ }^{1}\right)$ In einem kleinen Nest (Haufen $30 \mathrm{~cm}$ hoch) am Zürichberg wurden (nach Brun) im Mai 1911 im Laufe von 2 Wochen 256 normale, entflügelte Weibchen gefunden. 
zu 10 Weibchen, unter denen man grosse (makrogyne) und kleine (mikrogyne) unterscheidet (vgl. S. 20), beide normal entwickelt. Im Charakter furchtsam, vielfach als Sklavenameise anderer Arten. Geschlechtstiere im Juli und August.

8. F. fusca Latr. r. gagates (Latr.) For. (Abb. 71; Taf. I, Abb. 23).

ఫ. - Basalteil und Abfall des Epinotums gehen, von der Seite gesehen, unter einem Winkel ineinander über. - Schwarzbraun bis schwarz, stark glänzend, Antennen, Unterschenkel und Tarsen braun. - Pubescenz und abstehende Behaarung gering.

+. - In Färbung und Glanz wie der $\dot{q}$. Flügel dunkler bräunlich als bei $F$. fusca.

$\sigma^{7}$. - Stärker behaart als $F$. fusca.

In Südeuropa stärker verbreitet als in Mittel-

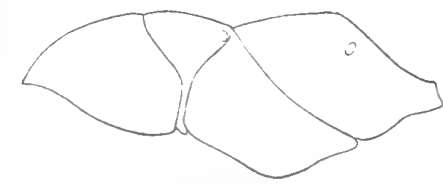

Abb. 71. Formica fusca-gagates $q$. Thorax. europa, auch in Nordeuropa (Öland), ferner in Asien; in Nordamerika in mehreren Varietäten. Nester fast immer unter Steinen. Geschlechtstiere im Juli und August.

9. $\boldsymbol{F}$. fusca Latr. v. glebaria (Nyl.) Em. (Taf. I, Abb. 18).

ఛ. - Wie $F$. fusca, doch mit reicher Pubescenz, besonders auf dem Abdomen.

f. - Abdomen durch die starke Pubescenz seidenartig schimmernd.

In ganz Europa, auch in Asien. Nester in der Erde, mit Oberbau, der bei trockenem Boden fehlen kann, auf Wiesen, in Gärten.

10. F. fusca Latr. r. cinerea (Mayr) For. (Taf. I, Abb. 16).

ఫ. - Schwarzbraun, die Seiten des Kopfes und die Ränder des Pronotums zuweilen rotbraun, Antennen, Schienen und Tarsen rötlich. - Pubescenz dicht, mit starkem Seidenschimmer, Körper, auch die Unterseite des Kopfes, reich mi abstehenden Borsten bekleidet.

‥ - Pubescenz und Behaarung wie beim $\not$.

In Mittel- und Südeuropa. Nester, oft mehrere miteinander in Verbindung stehend, ohne Oberbau, besonders auf sandigem Boden, unter Rinde, auch unter Steinen. Geschlechtstiere Ende Juni bis Mitte Juli.

11. F. fusca Latr. r. rufibarbis(F.) For. (Taf. I, Abb. 17).

ఈ. - Hellrot, Oberkopf und Abdomen dunkelbraun. „Bei kleinen Exemplaren nimmt die braune Färbung zu; deswegen sind solche Stücke einzeln genommen von fusca-rubescens kaum zu unterscheiden" (Emery). Pubescenz ohne Seidenschimmer, Körper mit wenigen Borsten, Unterseite des Kopfes ohne solche.

+. - Rot, Oberkopf, der grösste Teil des Thorax und die Oberseite des Abdomens braun.

In Mitteleuropa (bis in die Alpen) und Nordasien (bis zum Himalaja). Nester meist ohne Oberbau, ein solcher zuweilen nur bei grösseren Kolonien, in der Erde oder unter Steinen. Kolonien nicht sehr volkreich, häufig nur 1 Königin, doch deren bis zu 15 beobachtet. Geschlechtstiere im Juli. Im Gegensatz zu $F$. fusca kampflustig.

\section{Tribus: Campon otii.}

\section{Gattung: Camponotus Mayr.}

‡. - Antennen oberhalb des Winkels an der Grenze von Epistom und Stirnleisten eingelenkt, 12 gliedrig, die Geissel nach dem Ende hin wenig stärker werdend. Maxillartaster 6 gliedrig, Labialtaster 4 gliedrig. Epistom ohne oder 
mit schwach ausgebildetem Mittelkiel, seine Seitenränder nach hinten konvergierend, Hinterrand eingekerbt. Stirnfeld dreieckig, klein, hinten undeutlich abgegrenzt. Ränder der Stirnleisten schwach s-förmig gebogen, etwas aufgebogen. Ocellen fehlen. Rücken zwischen Mesonotum und Epinotum nicht ein-

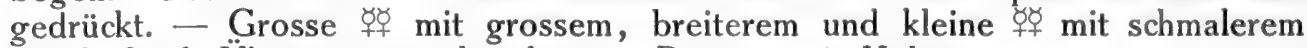
Kopf, durch Übergänge verbunden. - Puppen mit Kokon.

+. - Kopf mit den Merkmalen des

$\sigma^{\prime}$. - Kopf mit den Merkmalen des $\grave{+}$, Antennen 13 gliedrig.

Die Gattung Camponotus, von der, die Untergattung Colobopsis eingeschlossen, rund gegen 1000 Arten (Rassen und Varietäten) bekannt sind, ist über die ganze Welt verbreitet und auch fossil bekannt. (Sogar auf den Kerguelen ist eine vermutlich aber eingeschleppte Art gefunden worden.) Unter ihnen ist im Mittelmeergebiet und in allen wärmeren Erdstrichen Camponotus maculatus F. in zahlreichen Rassen und Varietäten vertreten.

\section{Arten:}

\section{Arbeiter.}

I. Thorax und Schuppe mehr oder weniger braun.

1. Vorderfläche des Abdomens höchstens dicht um die C. herculeanus (L.) Stielcheneinlenkung herum hellbraun, sonst schwarz:

2. Vorderfläche des Abdomens in grösserer Aus- C. ligniperda (Latr.) dehnung um das Stielchen herum hellbraun: Mayr (Nr. 1).

II. Thorax und Schuppe schwarz.

1. Antennenschäfte schwarz:

2. Antennenschäfte (und -Geisseln) braun:

C. vagus (Scop) Rog. [(Nr. 3).
(Nog.) Rog.

C. marginatus (Latr.) Rog. (Nr. 4).

\section{Weibchen.}

I. Schuppe braun; Thorax unten an den Seiten und Abdomen um die Stielcheneinlenkung herum mehr oder weniger braun.

1. Vorderfläche des Abdomens höchstens dicht um die

Stielcheneinlenkung herum hellbraun, sonst schwarz: C. herculeanus (L.)

2. Vorderfläche des Abdomens in grösserer Ausdehnung um die Stielcheneinlenkung herum hellbraun:

Mayr (Nr. 2).

C. ligniperda (Latr.)

II. Schuppe, Thorax und Abdomen schwarz.

1. Mattschwarz; Epistom in der Mitte des Vorder- C. vagus (Scop.) Rog. randes nicht ausgerundet:

2. Glänzend schwarz; Epistom in der Mitte des Vorder- C. marginatus (Latr.) randes ausgerundet:

Rog. (Nr. 4).

\section{Männchen. ${ }^{1}$ )}

I. Mesonotum ohne Punktierung; Skulptur desselben sehr fein, aber scharf ausgeprägt, der Thorax daher matt.

1. Abdomen (auch der Kopf) spärlicher behaart.

a) Abdomen wenig glänzend; Flügel weniger bräun- C. herculeanus (L.) lich getrübt:

Mayr (Nr. 2).

1) Die zur Unterscheidung herangezogenen Unterschiede sind nur relative; die Arten sind daher schwer zu unterscheiden, besonders, da sie sämtlich schwarz sind, mit dunkelbraunen Beinen und Antennen, die nach dem Ende hin heller werden. Auch das Merkmal der Punktierung des Thorax ist unbeständig. 
b) Abdomen mehr glänzend; Flügel stärker bräun- $C$. ligniperda (Latr.) lich getrübt:

2. Abdomen (auch der Kopf) stärker behaart:

II. Mesonotum auf den Seiten und vorn (weniger in der

Mitte) schwach und spärlich punktiert; Skulptur der-

selben oberflächlicher, der Thorax daher mehr glänzend: C. marginatus (Latr.)

Mayr (Nr. 1).

C. vagus (Scop.) Rog.

(Nr. 3).

Rog. (Nr. 4).

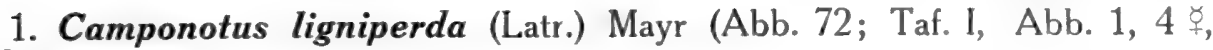
2 ₹, $3{ }^{\circ)}$ ).

2. Camponotus herculeanus (L.)..Mayr (Taf. I, Abb. 5).

$\mathrm{Da}$ es zwischen beiden Formen Übergänge gibt, so sind sie wohl als Rassen einer Art anzusehen. Es kommen Exemplare vor, bei denen nur das Epinotum einen braunen Schein hat, während der übrige Körper schwarz ist, sowie solche mit hell rotbraunem Thorax. C. herculeanus ist im allgemeinen dunkler und besitzt auf dem matten Abdomen eine reichere Pubescenz als $C$. ligniperda mit glattem Abdomen.

Beide bewohnen Nord- und Mitteleuropa; $C$. ligniperda reicht weiter nach Norden, $C$. herculeanus weiter nach Süden, ist aber höher im Gebirge zu finden, während $C$. ligniperda sowohl im Flachland, wo auch die andere Form nicht fehlt, als im Gebirge vorkommt. Nester in abgestorbenem
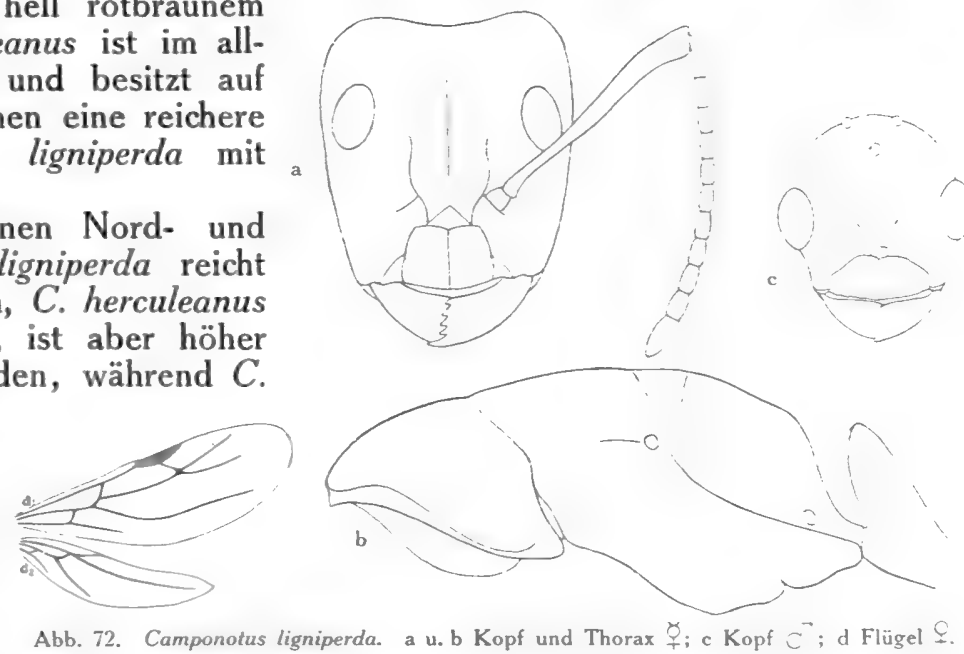
und lebendem $\mathrm{Holz}$, besonders von Kiefern und Tannen, denen sie dadurch schaden, dass sie die Sommerschichten der Jahresringe streckenweise zernagen, so dass konzentrisch angeordnete Kammern entstehen; ferner in Baumstümpfen, im Gebirge unter Steinen in der Erde, selten in rein minierten Nestern ${ }^{1}$ ); einzelne Weibchen, die im Begriff sind, eine Kolonie zu gründen, findet man fast immer unter Steinen, so dass eine Einwanderung in den Stamm möglicherweise erst erfolgt, wenn erstere einen gewissen Umfang erreicht hat. Trotz seiner Grösse furchtsam. Geschlechtstiere von Ende April bis Juli; auch Schwarmbildung ist in neuerer Zeit beobachtet (Viehmeyer).

3. C. herculeanus (L.) Mayr v. vagus (Scop.) Rog. ${ }^{2}$ ) (Taf. I, Abb. 6, 7, 狜).

Schwach mattglänzend, höchstens wie Seide schimmernd, mit stärker beborstetem Abdomen.

Eine südeuropäische Art, die aber auch in Süddeutschland (Pfalz, Elsass), angeblich auch auf den Inseln Gotland und Öland, vorkommt. Nester ähnlich wie bei der vorigen Art, lässt aber im $\mathrm{Holz}$ stärkere Zwischenwände und bevorzugt hartes, trockenes Holz in mehr sonniger Lage; selten unter Steinen. Geschlechtstiere im Juni und Juli.

1) Beide Formen sind auch als Hausameisen beobachtet worden.

2) = Camponotus pubescens (F.) Mayr. 
4. C. maculatus F. r. aethiops (Latr.) Mayr vo marginata (Latr.) Rog. ${ }^{1}$ ) (Taf. I, Abb. 8).

Schwarz, glatt und glänzend, mit hellbraunen Beinen und Antennen. Von Schirmer in der Mark (Buckow) zwischen den Doppelwänden von Bienenkörben gefunden, im Elsass in einem Garten bei Strassburg. Nester in trockenen Ästen und Stämmen, zuweilen unter Rinde.

Im Elsass sind ferner gefunden die südeuropäischen Formen

C. maculatus F. r. aethiops (Latr.) Mayr und letzteren.

C. lateralis (Ol.) Mayr, in Stein a. Rh. die r. piceus (Leach) Rog. des

\section{Untergattung: Colobopsis Mayr.}

ఫ̧. - Kopfvorderfläche stark abgestutzt, nur deutlich bei den grössten Individuen (난, Soldaten) und den Weibchen; Augen stark nach den Hinterecken des Kopfes zu liegend; Ocellen fehlen. Schuppe dick, vorn stark gewölbt, Oberrand hinten etwas abgeplattet oder eingedrückt.

+. - Etwas grösser als der 2 .

๙" - Ungefähr von der Grösse des kleinen ఛ. Geisselglied 1 doppelt so lang als 2 (im Gegensatz zu Camponotus).

Der eigenartige Kopf des $\mathcal{H}$ dient dazu, die Ausgänge des in Holzstämmen befindlichen Nestes zu verschliessen und ihn nur auf gewisse Verständigungszeichen der Einlass begehrenden $\not$ 芓 zurückzuziehen. Puppen ohne Kokon.

Colobopsis truncata (Spin.) Mayr (Abb. 73; Taf. I, Abb. 9).

2. - Vorderfläche des Kopfes abgestutzt, flach, scharf umgrenzt. Rotbraun, der Oberkopf, auch die Oberseite des Thorax und das Abdomen etwas dunkler, alle Teile stark glänzend. Vorderer Teil des Kopfes grob und dicht fingerhutartig punktiert, der hintere Teil sowie der Thorax äusserst dicht und fein gerieft.
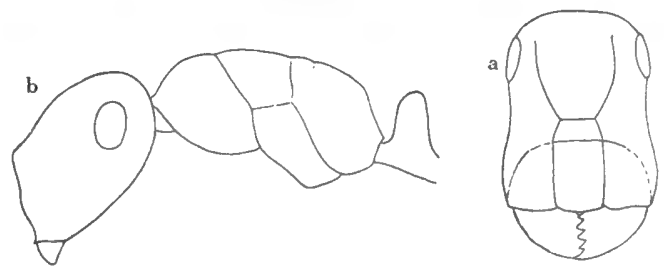

Abb. 73. Colobopsis truncata 2)

a Kopf von vorn; b Kopf, Thorax-Petiolus von der Seite.

ఫ. - Vorderfläche des Kopfes nicht scharf abgestutzt.

Eine südeuropäische Form, die sich aber auch in den wärmeren Gebieten Deutschlands findet. Nester besonders in Walnussbäumen, schwierig aufzufinden; auch in Gallen sind solche beobachtet. Geschlechtstiere im Juli und August.

$\left.{ }^{1}\right)=$ Camponotus fallax (Nyl.) Mayr. 
Von den durch den Schiffsverkehr, durch Pflanzen- und Tiersendungen eingeschleppten Ameisen wurden bereits mehrere aufgeführt. Von Reh (Station für Pflanzenschutz in Hamburg) wurden ferner gesammelt und von Forel (1900) als eingeschleppt bestimmt:

Ponera solitaria Sn. Japan.

Monomorium pharaonis L. Amerika.

- floricola Jerd. Südamerika.

Triglyphothrix striatidens $\mathrm{Em}$. Heimisch im trop. Asien, eingeschleppt aus Zentralamerika.

Pheidole fervida Sm. Japan.

- flavens Rog. r. asperithorax Em. v. rehi For. Südamerika.

- anastasii Em. Zentralamerika.
Tapinoma sessile Say. Nordamerika.

Prenolepis flavipes Sm. Japan.

Lasius niger $\mathrm{L}$. Aus Tasmanien, vielleicht dorthin zuvor importiert und wieder zurückgebracht.

- niger L. v. americanus Em. Nordamerika.

- niger L. v. neoniger Em. Kalifornien.

Camponotus zoc For. Antillen. 


\section{Literaturverzeichnis.}

1. Acloque, Les fourmis sont-elles nuisibles? (Cosmos. N. S. Bd. 58. Paris 1908. S. 651-53.

2. Adlerz, Myrmecologiska Studier I. [Fornicoxenus nitidulus Nyl.]. (Ofversigt Kongl. Vet. Akad. Förhandl. Bd. 8. Stockholm 1884. S. 43-48.)

3. - Myrmecologiska Studier II. [Svenska Myror]. (Bih. Svensk. Vet. Akad. Handl. Bd. 11. Stockholm 1886. S. 1-329.)

4. - Myrmecologiska Studier III. [Tomognathus sublaevis Mayr.). (Bih. Svensk. Vet. Akad. Handl. Bd. 21. Stockholm 1896. S. 1-76.)

5. - Myrmecologiska Studier IV. (Formica suecica n. sp.]. (Öfversigt Kongl. Vet. Akad. Handl. Bd. 59. Stockholm 1902. S. 263-65.)

6. - Myrmecologiska Notiser. (Ent. Tidskr. Bd. 17. Stockholm 1896. S. 129-41.)

7. - Stridulationsorgan och ljudförnimmelser hos myror. (Öfversigt Kongl. Vet. Akad. Förh. Bd. 10. Stockholm 1895. S. 769-82.)

8. - Zwei Gynandromorphen von Anergates atratulus Schnck. (Arkiv Zool. [5] Bd. 2. 1908. S. 1-6.)

9. Altmann, Überträgt die Ameise den Hausschwamm? (Zool. Garten Bd. 43. Frankfurt a. M. 1902. S. $202-203$.

10. André, Spécies des hyménoptères d'Europe et d'Algérie. (Bd. 2: Fourmis. Beaune 1881. S. 1 -404.)

11. - Les fourmis. (Paris 1885.)

12. - Description d'une nouvelle fourmi de France [Formicoxenus ravouxi n. sp.). (Bull. Soc. ent. France 1896. S. 367-68.)

13. Aurivillius, Svensk Insektfauna. (Ent. Tidskr. Bd. 29. Stockholm 1908. S. 213-48.)

14. Axmann, Vorbeugungsmittel gegen die Beschädigungen durch Lasius flavus Latr. (Centralbl. ges. Forstwesen Bd. 21. Wien 1895. S. 249-52.)

15. Ballerstedt, Zurückziehung einer Ameisenkolonie durch den Mutterstaat. (Naturw. Wochenschrift N. F. Bd. 3. Jena 1903/04. S. 824-25.)

16. Barth, An artificial ant-nest. (Entomol. News. Bd. 20. Philadelphia 1909. S. 113.)

17. Bethe, Dürfen wir den Ameisen und Bienen psychische Qualitäten zuschreiben? (Archiv ges. Physiol. Bd. 70. Bonn 1898. S. 15-100.)

18. - Noch einmal über die psychischen Ruditäten der Ameisen. (Archiv ges. Physiol. Bd. 79. Bonn 1900. S. 39-52.)

19. - Die Heimkehrfähigkeit der Ameisen und Bienen, zum Teil nach neuen Versuchen. (Erwiderung auf die Angriffe von Forcl und Buttel-Reepen.) (Biolog. Centralbl. Bd. 22. Leipzig 1902. S. $193-215$, S. 234-2;8.)

20. Beyer, Der Giftapparat von Formica rufa, ein reduziertes Organ. (Jena. Zeitschr. Naturw. Bd. 25. S. 26-112.)

21. Bickford, Über die Morphologie und Physiologie der Ovarien der Ameisen-Arbeiterinnen. (Zoolog. Jahrb. Syst. Bd. 9. Jena 1895. S. 1-26.)

22. Boudroit, Les fourmis de Belgique. (Ann. Soc. ent. Belgique. Bd. 53. Bruxelles 1910. S. 479-500.)

23. - Fourmis exotiques importées au jardin botanique de Bruxelles. (Ann. Soc. ent. Belgique Bd. 55. Bruxelles 1911. S. 14.)

24. Bos, Bijdrage tot de Kennis von den lichaamsbouw der roode boschmier, Formica rufa L. (Dissert. Groningen 1885.)

25. - Lets over de nederlandsche Mierenfauna. (Tijdschr. Entom. Bd. 30. 's Gravenhage 1887. S. $181-98$.

26. - Mieren en Bladluizen. (Tijdschr. Entom. Bd. 31. 's Gravenhage 1888. S. 235-44.)

27. - Een nest van Lasius fuliginosus. (Tijdschr. Entom. Bd. 36. 's Gravenhage 1893. S. 230-39.)

28. - Die Pharao-Ameise (Monomorium pharaonis). (Biolog. Centralbl. Bd. 13. Leipzig 1893. S. $244-55$. 
29. Bourgeois, L'origine des fourmilières etc. (Bull. Soc. hist nat. Colmar N. S. Bd. 7. 1904. S. 121 - 127.)

30. Brandes, Die Blattläuse und der Honigtau. (Zeitschr. Naturw. Bd. 66. Leipzig 1893. S. 98-103.)

31. - Der Intellect der Ameisen. (Zeitschr. Naturw. Bd. 71. Leipzig 1898. S. 238-41.)

32. Brun, Zur Biologie und Psychologie von Formica rufa und anderen Ameisen. (Biolog. Centralbl. Bd. 30. Leipzig 1910. S. 524-28.)

33. - Weitere Beiträge zur Frage der Koloniegründung bei den Ameisen, mit besonderer Berücksichtigung der Phylogenese, des sozialen Parasitismus und der Dulosis bei Formica. (Biolog. Centralbl. Bd. 32. Leipzig 1912. S. 154-187.)

34. Buckingham, A light-weight portable outfit for the study and transportation of ants. (Americ. Natural. Boston 1909. S. 611-14.)

35. - Division of labor in ants. (Proc. Americ. Acad. arts sc. Bd. 46. Boston 1912. S. 426-507.)

36. v. Buttel-Reepen, Soziologisches und Biologisches vom Ameisenstaat. (Archiv Rassen-Ges. Biol. Jhrg. 2. Berlin 1905. S. 1-16.)

37. - Zur Biologie der Baumameisen. (Naturw. Wochenschr. N. F. Bd. 6. Jena 1907. S. 477.)

38. - Psychobiologische und biologische Beobachtungen an Ameisen, Bienen und Wespen. (Naturw. Wochenschr. N. F. Bd. 6. Jena 1907. S. 465-476.)

39. - Biologische und soziologische Momente aus den Insektenstaaten. (C. R. 6. Congr. internat. zool. Berne. 1909. S. $462-82$.)

40. Buxbaum, Das Einsammeln der Ameisenpuppen. (Zoolog. Garten Bd. 29. Frankfurt a. M. 1888. S. $124-26$.

41. Cholodkovsky, Ein interessanter Ameiseninstinkt. (IIl. Zeitschr. Entom. Bd. 4. Neudamm 1899. S. 363.)

42. Cobelli, Il sensu del gusto nel Lasius emarginatus Ol. (Verh. zool. bot. Ges. Wien Bd. 52 . 1902. S. $254-257$.)

43. - L'ibernazione delle formiche. (Verh. zool. bot. Ges. Wien Bd. 53. 1903. S. 369-80.)

44. - I veleni ed il Lasius emarginatus Ol. (Verh. zool. bot. Ges. Wien Bd. 53. 1903. S. 18-21.)

45. Cornetz, Das Problem der Rückkehr zum Nest der forschenden Ameise. (Zeitschr. wiss. Insektenbiol. Bd. 7. Berlin 1911. S. 181-84, S. 218-23, S. 347-50.)

46. Coupin, Les parasites des fourmis et des fourmilières. (Nature Bd. 25. Paris 1897. S. 81-83.)

47. - Les plantes myrmécophiles. (Nature Bd. 27. Paris 1898. S. 70-74.)

48. - Le monde des fourmis. (Paris 1904.)

49. Crawley, Queens of Lasius umbratus Nyl. accepted by colonies of Lasius niger L. (Entom. Monthl. Mag. [2] Bd. 45. London 1909. S. 94-98.)

50. - How ants greet members of the same colony. (Entom. Record. Journ. Var. Bd. 22. London 1910. S. 43.)

51. - Workers of Lasius flavus (? L. umbratus) among L. fuliginosus. (Entom. Record. Journ. Var. Bd. 22. London 1910. S. 67.)

52. - Summary of experiments with fertile $P$ of several species of ants. (Entom. Record. Journ. Var. Bd. 22. London 1910. S. 152.)

53. - Parthenogenesis in worker ants with special reference to 2 colonies of Lasius niger L. (Trans. entom. Soc. London. 1912. S. $657-63$.

54. Dahl, Das Leben der Ameisen im Bismarckarchipel. (Mitteil. Zool. Mus. Berlin Bd. 2. 1901. S. 46-49: Übersicht der deutschen Arten nach ihrer Lebensweise.)

55. Dale, A battle between ants of the species Myrmica rubra and M. caespitum. (Ann. Mag. Nat. Hist [1] Bd. 7. London 1834. S. 267-68.)

56. Degeer, Mémoires pour servir à l'histoire des insectes. Bd. 2 Teil 2. 18. mém. (Stockholm 1771. S. 1042-93.)

57. Demoll und Scheuring, Die Bedeutung der Ocellen der Insekten. (Zool. Jahrb. Anat. Bd. 34. 1912. S. 519-628.)

58. Devaux, Sur quelques expériences concernant le sens du goût chez les fourmis. (C. R. Soc. Philom. Paris 1890.)

59. - Le sens du goût chez les fourmis. (Bull. Soc. Philom. Paris 1892. S. 159-60.)

60. Dewitz, Über Bau und Entwicklung des Stachels der Ameisen. (Zeitschr. wiss. Zool. Bd. 28. Leipzig 1877. S. 527-56.)

61. - Über die Bildung der Brustgliedmassen bei den Ameisen. (Sitzber. Ges. naturf. Freunde Berlin 1878. S. $122-25$.)

62. Donisthorpe, Apparatus to determine the strength of the formic acid discharged by the ant in defence of its nest. (Trans. entom. Soc. London 1901. Proc. S. XIII.)

63. - On the founding of nests by ants. (Entom. Record. Journ. Var. Bd. 22. London 1910. S. 820

64. - Further observations on temporary social parasitism and slavery in ants. (Trans. enteit Soc. London 1911. S. 175-183.) 
65. Donisthorpe und Crawley, Experiments on the formation of colonies by Lasius fuliginosus 99. (Trans. entom. Soc. London 1912. S. 664-72.)

66. - - Experiments on the Formation of colonies by Lasius fuliginosus 92. (Trans. Ent. Soc. London 1912. S. 664-72.)

67. Ebrard, Nouvelles observations sur les fourmis. (Bibl. Univ. Rev. Suisse. Genève 1861. S. 466.)

68. Emery, Clef analytique des genres de la famille des formicides pour la détermination des neutres. (Ann. Soc. entom. Belgique Bd. 40. Bruxelles 1896. \$. 172--89.)

69. - Beiträge zur Monographie der Formiciden des paläarktischen Faunengebietes. (Deutsche entom. Zeitschrift 1908. S. $165-205$, S. 305-338, S. 437-465, S. 549-558, S. $663-686$. -1909 . S. $19-37$, S. $179-204$, S. $355-376$, S. $695-712$. -1910 . S. $127-132$. 1912. S. $651-672$.

70. - Intorno ad alcune formiche della fauna palaearctica. (Ann. Mus. Civ. Stor. Nat. Genova 1889 [2] Bd. 7 [27]. S. 485-520.)

71. - Die Entstehung und Ausbildung des Arbeiterstandes bei den Ameisen. (Biolog. Centralbl. Bd. 14. Leipzig 1894. S. 53-59.)

72. - Le polymorphisme des fourmis et la castration alimentaire. (C. R. 3. Congr. internat. zool. Leyden 1896. S. $395-410$.)

73. - Zur Kenntnis des Polymorphismus der Ameisen. (Zool. Jahrb. Syst. [Suppl.] Bd. 7. Jena 1904. S. $587-610$.)

74. - Zur Kenntnis des Polymorphismus der Ameisen. (Biolog. Centralbl. Bd. 26. Leipzig 1906. S. $624-30$.)

75. - Einiges über die Ernährung der Ameisenlarven und die Entwicklung des temporären Parasitismus bei Ameisen. (Deutsche entom. Nationalbibl. Bd. 2. Berlin 1911. S. 4-6.)

76. - Über den Ursprung der dulotischen, parasitischen und myrmekophilen Ameisen. (Biolog. Centralbl. Bd. 29. Leipzig 1909. S. 352-62.)

77. - Remarques sur les observations de M. de Lannoy touchant l'existence de Lasius mixtus dans les fourmilières de Lasius fuliginosus. (Ann. Soc. entom. Belgique Bd. 52. Bruxelles 1908. S. $182-83$.)

78. - Nuove osservazione ed esperimenti sulla formica amazona. (Rendic. Acc. Bologna. 1908. S. $49-62$.)

79. - Beobachtungen und Versuche an Polyergus rufescens. (Biolog. Centralbl. Bd. 31. Leipzig 1911. S. $625-42$.)

80. - Über den sogenannten Kaumagen einiger Ameisen. (Zeitschr. wiss. Zool. Bd. 46. Leipzig 1888. S. $378-412$.)

81. - Intorno al torace dei formiche. (Bull. Soc. entom. Ital. Bd. 32. Firenze 1900. S. 1-17.)

82. - Végétarisme chez les fourmis. (Arch. Sc. Phys. Nat. Genève [4] Bd. 8. 1899. S. 488-90.)

83. - Ethologie, phylogenie et classification. (C. R. 6. Congr. internat. zool. Berne. 1905. S. 459-62.)

84. - Intelligenz und Instinkt der Tiere. (Biolog. Centralbl. Bd. 13. Leipzig 1893. S. 151-53.)

85. - Über Entstehung des Soziallebens bei Hymenopteren. (Biolog. Centralbl. Bd. 14. Leipzig 1894. S. $60-62$.)

86. - Sur l'origine des fourmilières. (C. R. 6. Congr. internat. zool. Berne. 1905. S. 459-62.)

87. - Origine de la faune actuelle des fourmis de l'Europe. (Bull. Soc. Vaudoise [3] Bd. 27. Lausanne 1892. S. 258-60.)

88. - Kleine, künstliche Ameisennester. (Zeitschr. wiss. Insektenbiol. Bd. 5. Berlin 1909. S. 402.)

89. Emery und Forel, Catalogue des Formicides d'Europe. (Mitth. Schweiz. entom. Ges. Bd. 5. Schaffhausen 1879. S. 441-81.)

90. Ernst, Einige Beobachtungen an künstlichen Ameisennestern. (Biolog. Centralbl. Bd. 25. Leipzig 1905. S. 47-51. Bd. 26. 1906. S. 210-220.)

91. - Neue Beobachtungen an Ameisen. (Biolog. Centralbl. Bd. 32. Leipzig 1912. S. 146-53.)

92. Escherich, Die Ameise. (Braunschweig 1907.)

93. - Die myrmekologische Literatur von Januar 1906 bis Juni 1909. (Zeitschr. wiss. Insektenbiol. Bd. 5. Berlin 1909. S. $285-89$, S. $320-25$, S. $405-15$. Bd. 6. 1910. S. $25-36$, S. $73-80$.)

94. - Über die Biologie der Ameisen. (Zoolog. Centralbl. Bd. 10. Leipzig 1903. S. 209-44. Bd. 13. 1906. S. 405-40.)

95. - Ameisen und Pflanzen. (Tharandt. forstl. Jahrb. Bd. 60. 1909. S. 66-96.)

96. - Zwei Beiträge zum Kapitel Ameisen und Pflanzen. (Biol. Centralbl. Bd. 31. Leipzig 1911. S. $44-51$.)

97. - Ameisensklaverei. (A. d. Natur Bd. 3. Leipzig 1907/08. S. 1-6, S. 43-48.)

98. - Über Ameisengäste und Ameisenstaat. (Verhandl. nat. Ver. Karlsruhe Bd. 13.1900. S. $137-39$.)

99. Escherich und Ludwig, Beiträge zur Kenntnis der elsässischen Ameisenfauna. (Mitteil. philomat. Ges. Elsass-Lothr. 1906. S. $381-89$.) 
100. Fabricius, Systema Piezatorum. (1804。 S. 395-428.)

101. Fallou, Note sur un nid de fourmi. (Ann. Soc. entom. France Bd. 60. Paris 1891. Bull. S. CXCVI.)

102. Fenger, Allgemeine Orismologie der Ameisen, mit besonderer Berücksichtigung des Wertes der Classificationsmerkmale. (Arch. Naturg. Bd. 28. Berlin 1862. S. $282-350$. )

103. - Anatomie und Physiologie des Giftapparates bei den Hymenopteren. (Arch. Naturg. Bd. 29. Berlin 1863. S. 139-78.)

104. Fielde, Portable ant-nests. (Biolog. Bull. Bd. 2. Boston 1900. S. 81-85. Bd. 7. 1904. S. $215-20$.)

105. - Artificial mixed nests of ants. (Biolog. Bull. Bd. 6. Boston 1903. S. 320-25.)

106. - On the artificial creation of mixed nests of ants. (Biolog. Bull. Bd. 6. Boston 1903. S. 326.)

107. - Observations on ants in their relation to temperature and to submergence. (Biolog. Bull Bd. 7. Boston 1904. S. $170-74$.

108. - Tenacity of life in ants. (Biolog. Bull. Bd. 7. Boston 1904. S. 300-309.)

109. - Temperature as a factor in the development of ants. (Biol. Bull. Bd. 9. Boston 1905. S. $361-67$.

110. - The progressive ador of ants. (Biolog. Bull. Bd. 10. Boston 1905. S. 1-16.)

111. - The sense of smell in ants. (Ann. New York Acad. Sc. Bd. 16. 1905. S. 394).

112. - The reactions of ants to material vibrations. (Proc. Acad. Nat. Sc. Philadelphia Bd. 56. 1905. S. $642-50$.)

113. Foerster, Hymenopterologische Studien. (Jahresber. Bürgerschule Aachen. Heft 1. 1850. Heft 2. 1856.)

114. - Eine neue Centurie neuer Hymenopteren. (Verhandl. nat. Ver. preuss. Rheinland Bd.7. 1850.)

115. Förster, Vergleichend anatomische Untersuchungen über den Stechapparat der Ameisen. (Zool. Jahrb. Anat. Bd. 34. 1912. S. 347-81.)

116. Fontana, Sur la nature de l'acide des animaux etc. (Obs. Phys. Hist. nat. Bd. 12. Paris 1778. S. $64-75$, S. $169-76$.

117. Fromholz, Die ägyptische Hausameise. (Entom. Nachr. Bd. 12. Berlin 1886. S. 122-25.)

118. F ürth, Vergleichende chemische Physiologie der niederen Tiere. (Jena 1903. S. 346-50, 351.)

119. Forel, Les fourmis de la Suisse. (Genf 1874.)

120. - Die Ameisenfauna Bulgariens. (Verh. zool. bot. Ges. Wien Bd. 42. 1892. S. 305-14.)

121. - Faune myrmécologique des noyers dans le canton de Vaud. (Bull. Soc. Vaudoise [4] Bd. 39. Lausanne 1903. S. 83-94.)

122. - Fourmis importées. (Mitteil. Schweiz. entom. Ges. Bd. 10. Schaffhausen 1900. S. 284-87.)

123. - Der Giftapparat und die Analdrüsen der Ameisen. (Zeitschr. wiss. Zool. Bd. 30. Suppl. Leipzig 1878. S. 28-68.)

124. - Die Nester der Ameisen. (Neujahrsblatt nat. Ges. Zürich. 1893. S. 1-36.)

125. - Norwegische Ameisen und Drüsenkitt als Material zum Nestbau der Ameisen. (Mitteil. Schweiz. entom. Ges. Bd. 8. Schaffhausen 1893. S. 229-33.)

126. - Observations sur les mœurs du Solencpsis fugax. (Mitteil. Schweiz. entom. Ges. Bd. 3. Schaffhausen 1869. S. 105.)

127. - . . Strongylognathus testaceus. (Bull. Soc. Vaudoise [5] Bd. 44. Lausanne 1908. S. 1-22.)

128. - Konflikt zwischen zwei Raubameisen. (Biolog. Centralbl. Bd. 28. Leipzig 1908. S. 445-47.)

129. - Lettre à la Société Entomologique de Belgique. (Ann. Soc. entom. Belgique Bd. 52. Bruxelles 1908. S. 180-81.)

130. - Fourmilière triple naturelle. (Mitteil. Schweiz. entom. Ges. Bd. 10. Schaffhausen 1900. S. $280-82$.)

131. - Une colonie polycalique de Formica sanguinea sans esclaves dans le canton de Vaud. (1. Congr. internat. entom. 1910. S. $101-104$.

132. - Über den Polymorphismus und Ergatomorphismus der Ameisen. (Verhandl. Ges. deutsch. Naturf. u. Ärzte. Wien 1894. S. 142-47.)

133. - La parabiose chez les fourmis. (Bull. Soc. Vaudoise [4] Bd. 34. Lausanne 1898. S. 380 - 84.)

134. - Über Polymorphismus und Variation bei den Ameisen. (Zool. Jahrb. Syst. [Suppl.] Bd. 7. Jena 1904. S. $571-86$.)

135. - Sklaverei, Symbiose und Schmarotzertum bei den Ameisen. (Mitteil. Schweiz. entom. Ges. Bd. 11. Schaffhausen 1905. S. $85-89$.)

136. - Einige neue biologische Beobachtungen über Ameisen. (C. R. 6. Congr. internat. zool. Berne 1905. S. 449-56.)

137. - Études myrmécologiques en 1875. (Bılll. Soc. Vaudoise Bd. 14. Lausanne 1875. S. 33 - -62.)

138. - Études myrmécologiques en 1878 (Bull. Soc. Vaudoise Bd. 15. Lausanne 1878. S. 337-92.)

139. - Études myrmécologiques en 1884. (Bull. Soc. Vaudoise Bd. 20. Lausanne 1891. S. 316 - 80.) 
140. Forel, Études myrmécologiques en 1886. (Ann. Soc. entom. Belgique Bd. 33. Bruxelles 1886. S. 131[ -140$]-215$.

141. - Variétés myrmécologiques. (N. 2.) (Ann. Soc. entom. Belgique Bd. 46. Bruxelles 1902. S. 284--96.)

142. - Mélanges entomologiques et autres. (Ann. Soc. entom. Belgique Bd. 47. Bruxelles 1903. S. 249-68.)

143. - Quatre notices myrmécologiques. (Ann. Soc. entom. Belgique Bd. 46. Bruxelles 1902. S. $170[180-182]$.)

144. - Expériences et remarques critiques sur les sensations des insectes. (Receuil zool. Suisse Bd. 2. 1886. S. $1-50$, S. $145-240$.)

145. - Appendices à mon mémoire sur les sensations des insectes. (Receuil zool. Suisse Bd. 4. 1888. S. $516-22$.)

146. - Die psychischen Fähigkeiten der Ameisen und einiger anderer Insekten. (Verhandlungen 5. internat. Zool. Congr. Berlin 1901. S. 141-169. - sep. München 1901.)

147. - Nochmals Herr Dr. Bethe und die Insekten-Psychologie. (Biolog. Centralbl. Bd. 23. Leipzig 1903. S. 1-3.)

148. - Das Sinnesleben der Insekten. (München 1910.)

149. - Les fourmis percoivent-elles l'ultra-violet avec leurs yeux ou avec leur peau? (Arch. Sc. Phys. Nat. Genève Bd. 16. 1886. S. 346-50.)

150. - und Dufour, Über die Empfindlichkeit der Ameisen für Ultraviolett und Röntgen'sche Strahlen. (Zool. Jảhrb. Syst. Bd. 17. Jena 1902. S. 335-38.)

151. - Ameisen und Ameisenseele. (Köln 1908.)

152. Gauckler, Bombardierende Ameisen. (Insektenbörse Bd. 15. Leipzig 1898. S. 46.)

153. Ge offroy, Histoire abrégée des insectes des environs de Paris. (Bd. 2. 1773. S. 63-67.)

154. Geyer, Die Facettenaugen der Hymenopteren. (Zool. Anz. Bd. 39. 1912.)

155. Göldi, Der Ameisenstaat. (Leipzig 1911.)

156. Gould, An account of english ants. (London 1747.)

157. Graber, Die chordotonalen Sinnesorgane und das Gehör der Insekten. (Arch. mikr. Anat. Bd. 20. Bonn 1882. S. 506-30.)

158. Gredler, Die Ameisen Tirols. (8. Progr. Gymnas. Bozen 1858.)

159. - Die geographische Verbreitung der Ameisen in Österreich. (Verh. zool. bot. Ges. Wien Bd. 9. 1859. S. $127-128$.)

160. v. Hagens, Über Ameisen mit gemischten Kolonien. (Berlin. entom. Zeitschr. Bd. 11. 1867. S. 101-108.)

161. - Einzelne Bemerkungen über Ameisen. (Berlin. entom. Zeitschr. Bd. 12. 1868. S. 265 - 68.)

162. Handlirsch, Die fossilen Insekten. (Leipzig 1906-08. S. 859-83.)

163. Gr. Harra ch, Über das Sammeln von Ameisengästen. (Humboldt 1890. S.143-44, S. 183-84.)

164. Heim, Dégâts occasionnés sur les tubercules de pommes de terre par les fourmis. (Ann. Soc. entom. France Bd. 43. Paris 1894. S. 29-32.)

165. v. Meister, Einleitung in die Geschichte der Ameisen, Bienen und Termiten. (Naumburg 1860.)

166. Henschel, Schonet die Waldameise! (Centralbl. ges. Forstwes. Bd. 2. Wien 1876. S. 160-61.)

167. Hetschko, Der Ameisenbesuch bei Centaurea montana L. (Wien. entom. Zeitschr. Bd. 26. S. $329-32$.)

168. Hilbert, Zur Biologie von Tetramorium caespitum L. (Zeitschr. wiss. Insektenbiol. Bd. 4. Berlin 1908. S. 308.)

169. Hoffer, Skizzen aus dem Leben unserer einheimischen Ameisen. (Mitteil. naturwiss. Ver. Steiermark Bd. 26. Graz 1890. S. 149-171.)

170. Holmgren, Ameisen als Hügelbildner in Sümpfen. (Zool. Jahrb. Syst. Bd. 20. Jena 1904. S. 553-70.)

171. Holliday, A study of some ergatogynic ants. (Zool. Jahrb. Syst. Bd.19. Jena 1904. S.293 - 328.)

172. Huber, Recherches sur les mours de fourmis indigènes. (Paris u. Genf 1810.)

173. Huth, Ameisen als Pflanzenschutz. Verzeichnis der bisher bekannten myrmekophilen Pflanzen. (Samml. naturw. Vortr. her. v. Huth, Frankfurt a. O. 1886, Heft 3.)

174. Imhoff, Grosse Schwärme von Formica nigra (Ber. Verh. naturf. Ges. Basel Bd. 5. 1843. S. $181-83$.

175. Jan et, Les fourmis. (Bull. Soc. zool. Paris Bd. 21. 1896. S. 60-93.)

176. - Sur la présence de nymphes nues dans les nids de Lasius flavus. (Bull. Soc. zool. France Bd. 24. Paris 1898. S. 192-93.)

177. - Anatomie de la tête du Lasius niger. (Limoges 1905.)

178. - Sur les nerfs de l'antenne et les organs chordotonaux chez les fourmis. (C. R. hebdom. Sc. Ac. Sc. Bd. 118. Paris 1894. S. $814-17$.) 
179. Jan et, Sur les nerfs céphaliques, les corpora alata et le tentorium de la fourmi (Myrmica rubra L.). (Mém. Soc. zool. France Bd. 12. Paris 1899. S. 295-335.)

180. - Anatomie du corselet de la Myrmica rubra reine. (Mém. Soc. zool. France Bd. 11. Paris 1898. S. 393-450.)

181. - Structures des membranes articulaires des tendons et des muscles. (Myrmica, Camponotus.) (Limoges 1895.)

182. - Sur les muscles des fourmis, des guèpes et des abeilles. (C. R. hebdom. Sc. Ac. Sc. Bd. 121. Paris 1895. S. 610-13.)

183. - Limites morphologiques des anneaux post-céphaliques et musculature des anneaux postthoraciques chez la Myrmica rubra. (Lille 1897.)

184. - Remplacement des muscles vibrateurs du vol par des colonnes adipocytes chez les fourmis après le vol nuptial. (C. R. hebdom. Sc. Ac. Sc. Bd. 142. Paris 1906. S. 1095-98.)

185. - Histolyse sans phagocytose des muscles vibrateurs histolysés après le vol nuptial chez les reines de fourmis. (C. R. hebdom. Sc. Ac. Sc. Bd. 144. Paris 1907. S. 1070-73.)

186. - Histolyse des muscles de mise en place des ailes après le vol nuptial chez les reines de fourmis. (C. R. hebdom. Sc. Ac. Sc. Bd. 145. Paris 1907. S. 1205-08.)

187. - Anatomie du corselet et histolyse des muscles vibrateurs après le vol nuptial chez la reine de la fourmi (Lasius niger). (Limoges 1907.)

188. - Sur un organe non décrit du thorax de fourmis ailées. (C. R. hebdom. Sc. Ac. Sc. Bd. 143. Paris 1906. S. $522-24$.)

189. - Sur l'anatomie du pétiole de Myrmica rubra. (Mém. Soc. zook. France Bd. 7. Paris 1894. S. $185-203$.)

190. - Anatomie du gaster de la Myrmica rubra. (Paris 1902.)

191. - Sur le système glandulaire des fourmis. (C. R. hebdom. Sc. Ac. Sc. Bd. 118. Paris 1894. S. $989-92$.)

192. - Aiguillon de la Myrmica rubra. Appareil de fermeture de la glande à vénin. (Paris 1898.)

193. - Sur un organe non décrit servant à la fermeture du réservoir du vénin et sur le mode de fonctionnement de l'aiguillon chez les fourmis. (C. R. hebdom. Sc. Ac. Sc. Bd. 127. Paris 1898. S. 638-41.)

194. - Réaction alcaline des chambres et galeries des nids de fourmis. Durée de la vie des fourmis décapitées. (C. R. hebdom. Sc. Ac. Sc. Bd. 127. Paris 1898. S. 130-33.)

195. - Sur l'organe de nettoyage tibio-tarsien de Myrmica rubra. (Ann. Soc. entom. France Bd. 63. Paris 1894. S. 691-703.)

196. - Sur les corpuscules de nettoyage des fourmis. (Bull. Soc. zool. France Bd. 24. Paris 1899. S. $177-78$.)

197. - Sur la production des sons chez les fourmis et sur les organes qui les produisent. (Ann. Soc. entom. France Bd. 62. Paris 1893. S. 159-68.)

198. - Sur l'appareil de stridulation de Myrmica rubra. (Ann. Soc. entom. France Bd. 63. Paris 1894. S. 109-117.)

199. - Appareil pour l'élevage et l'observation des fourmis. (Ann. Soc. entom. France Bd. 62. Paris 1893. S. 467-82.)

200. - Nids artificiels en plâtre. Fondation d'une colonie par une femelle isolée. (Bull. Soc. zool. France Bd. 18. Paris 1893. S. 168-71.)

201. - Appareils pour l'observation des fourmis et des animaux myrmécophiles. (Mém. Soc. zool. France Bd. 10. Paris 1897. S. 302.)

202. - Rapports des animaux myrmécophiles avec les fourmis. (Limoges 1897.)

203. Jankow ski, Ein neuer Forstschädling. (Centralbl. ges. Forstwes. Bd. 20. Wien 1894. S. 431-34.)

204. Judeich-Nitsche, Lehrbuch der mitteleuropäischen Forstinsektenkunde. (Wien 1885. Bd. 1. S. $711-20$.)

205. Karawaiew, Vorläufige Mitteilung über die innere Metamorphose bei Ameisen. (Zool. Anzeig. Bd. 20. Leipzig 1897. S. 415-22.)

206. - Die nachembryonale Entwicklung von Lasius flavus. (Zeitschr. wiss. Zool. Bd. 64. Leipzig 1898. S. $385-478$.)

207. -- Beobachtung von Ameisen in künstlichen Gipsnestern. (Rev. Russe Ent. Bd. 3. 1903. S. $94-98$, S. $174-76$.

208. - Versuche an Ameisen in Bezug auf das Übertragen der Larven in die Dunkelheit. (Zeitschr. wiss. Insektenbiol. Bd. 1. Berlin 1905. S. 215-24, S. 257-67.)

209. Kienitz-Gerloff, Besitzen die Ameisen Intelligenz? (Naturw. Wochenschr. Bd. 14. 1899. S. $225-31$, S. $240-43$.)

210. King, Mixed colonies of ants. (Entom. News Bd. 7. Philadelphia 1896. S. 167-70.)

211. Klug, Note zu den auf Taf. 31853 abgebildeten Hermaphroditen. (Stettin. entom. Zeitschr. Bd. 15. 1853 54. S. $102-103$. 
212. Knauer, Die Ameisen. (Leipzig 1906.)

213. Kneissl, Beiträge zur Trophobiose bei den Ameisen. (Zeitschr. wiss. Insektenbiol. Bd. 5. 1909. S. 76-82.)

214. Kraepelin, Untersuchungen über den Bau, Mechanismus und die Entwicklungsgeschichte des Stachels der bienenartigen Tiere. (Zeitschr. wiss. Zool. Bd. 23. Leipzig 1873. S. 303 bis 305.)

215. Krausse, Die antennalen Sinnesorgane der Ameisen. (Diss. Jena 1907.)

216. - Einiges Terminologisches über die Begriffe "Reflex, Instinkt, Intelligenz" usw. speziell in der Ameisenpsychologie. (Insektenbörse Bd. 19. Leipzig 1902. S. 259-60.)

217. - Die moderne Ameisen-Biologie und Psychologie. (Nerthus Bd. 5. Berlin 1903. S. 493-96, S. $688-90$.)

218. - Erkennen Ameisen einer Kolonie andere derselben Art angehörende, aber aus einer anderen Kolonie stammende Ameisen? (Nerthus Bd. 5. Berlin 1903. S. 7-8.)

219. - Beobachtungen an einer Ameisenstrasse. (Entom. Jahrb. Bd. 13. 1904. S. 200-01.)

220. - Lasius flavus, Tetramorium caespitum und Formica nigra. Biolog. Beobacht. (Entom. Jahrb. Bd. 14. 1904. S. 214-16.)

221. - Über Stridulationstöne bei Ameisen. (Zool. Anzeig. Bd. 35. Leipzig 1910. S. 523-26.)

222. - Stridulierende Ameisen. (Zeitschr. wiss. Insektenbiol. Bd. 6. Berlin 1910. S. 148.)

223. - Zirplaute bei Ameisen. (Zeitschr. wiss. Insektenbiol. Bd. 7. Berlin 1911. S. 359.)

224. - Ein einfach herzustellendes, praktisches, künstliches Ameisennest. (Naturw. Wochenschr. N. F. Bd. 10. Jenả 1911. S. 133-34.)

225. Lacaze-Duthiers, Recherches sur l'armûre génitale femelle des insectes. (Ann. Sc. Nat. [3] Bd. 14 [Zool.] Paris 1850. Form.: S. 27-31.)

226. Lagerheim, Über Lasius fuliginosus Latr. und seine Pilzzucht. (Entom. Tidskr. Bd. 21. Stockholm 1900. S. 17-29.)

227. Lame ere, Note sur les fourmis de la Belgique. (Ann. Soc. entom. Belgique Bd. 36. Bruxelles 1892. S. $61-69$.

228. - Notes sur les mœurs du Lasius niger. (Ann. Soc. entom. Belgique Bd. 50. Bruxelles 1906. S. $43-46$.

229. Landois, Stridulationsapparat bei Ameisen. (31. Gen.-Vers. nat. Ver. preuss. Rheinlande usw. Bonn 1874. S. 820.)

230. - Der Bau von Lasius fuliginosus in einem Backofen. (Jahresber. westf. Provinzialver. [zool. Sekt.] Münster 1896-97. S. 74-75.)

231. de Lannoy, Notes sur le Lasius niger et le Lasius fuliginosus. (Ann. Soc. entom. Belgique Bd. 52. Bruxelles 1908. S. 47-53.)

232. - Observations sur les fourmis. (Ann. Soc. entom. Belgique Bd. 52. Bruxelles 1908. S. 313-19.)

233. Latreille, Essai sur l'histoire des fourmis de la France. (Brives 1798.)

234. - Description d'une nouvelle espèce de fourmis (F. coarctata). (Bull. Soc. philomath. Paris Bd. 3. 1802. S. $65-66$.

235. - Histoire naturelle des fourmis. (Paris 1802.)

236. - Histoire naturelle générale et particulière des crustacées et des insectes. (Paris 1802-05. Fourmis: Bd. 3. S. 352-58.)

237. - Genera crustaceorum et insectorum. (Paris 1806-09. Fourmis Bd. 4. S. [122] 124-132.)

238. Lemoine, Observations biologiques et anatomiques à propos de trois fourmilières artificielles. (Bull. Soc. entom. France 1896. S. 129-31.)

239. Lepeletier, Histoire naturelle des insectes hyménoptères. (Paris 1836-46. Fourmis Bd. 1. S. $98-230$.)

240. Le spè s, Observations sur les fourmis neutres. (Ann. Sc. Nat. [4] Bd. 19 [Zool.] Paris 1863. S. $241-51$.)

241. Linder, Observations sur les fourmilières boussoles. (Bull. Soc. Vandoise [5] Bd. 44. Lausanne 1908. S. 303-310.)

242. Linné, Anmärkning öfwer wisen hos myrorne. (Kongl. Swensk. Wetenskaps Acad. Handling Bd. 2. Stockholm 1741 [1743].)

243. - Systema naturae. (Stockholm 1758. Form. S. 579 - 582.)

244. Los an a, Mémoire pour servir à l'histoire des insectes. (Mem. Acad. Turin. Bd.16. 1809. S. 80.)

245. Lubbock, Observations on the habits of ants. (Entomol. Bd. 15. 1882. S. 33-36.)

246. - Observations on ants, bees and wasps. (Nature Bd. 23. London 1881. S. 255-58.)

247. - Longevity of ants. (Americ. Natural. Bd. 20. Boston 1885. S. 170-71.)

248. - Ants, bees and wasps. (deutsch Leipzig 1885.)

249. - Observations on ants, bees and wasps. (Journ. Linn. Soc. [Zool.] Bd. 20. London 1888. S. 118-136.) 
250. Ludwig, Die Ameisen im Dienst der Pflanzenverbreitung. (Ill. Zeitschr. Entom. Bd. 4. Neudamm 1899. S. 38-40.)

251. - Weiteres zur Biologie von Helleborus foetidus. (Zeitschr. wiss. Insektenbiol. Bd. 3. Berlin 1907. S. $45-50$. S. $130-131$.)

252. Marshall, Leben und Treiben der Ameisen. (Leipzig 1889.)

253. Ma yr, Ungarns Ameisen. (3. Progr. stådt. Oberrealsch. Pesth 1857.)

254. - Ausflug nach Szegedin. (Verh. zool. bot. Ges. Wien Bd.6. 1856. S. 175-78.)

255. - Formicina austriaca. (Verh. zool. bot. Ges. Wien Bd. 5. 1855. S. 273-478.)

256. - Die europäischen Formiciden. (Wien 1861.)

257. - Das Leben und Wirken der einheimischen Ameisen. (Oesterr.-ungar. Rev. Bd. 1. Wien 1865. S. 201-209.)

258. - Formicidarum index synon. (Verh. zool. bot. Ges. Wien Bd. 13. 1863. S. 385-460.)

259. - Beiträge zur Kenntnis der Ameisen. (Verh. zool. bot. Ges. Wien Bd. 3. 1853. S. 10 - 114.)

260. - Die Ameisen des baltischen Bernsteins. (Schrift. phys. ök. Ges. Königsberg Bd. 1. 1868.)

261. Meckel, Mikrographie einiger Drüsenapparate. Der Giftapparat der Hymenopterenweibchen. (Archiv Anat. Phys. Leipzig 1846. S. 47-50.)

262. Meinert, Bidrag til de danske myrers naturhistorie. (Danske Vidensk. Selsk. Skrf. [5] Bd. 5. Kebenhavn 1860. S. $275-340$.)

263. - Bio einene hos Tomognathus sublaevis. (Entom. Meddel. Bd. 2. 1890. S. 212 - 26.)

264. Meissner, Über die Lebenszähigkeit der Insekten. (Entom. Wochenbl. Bd. 24. Leipzig 1907. S. $191-92$.

265. - Das Orientierungsvermögen der Ameisen. (Zeitschr. wiss. Insektenbiol. Bd. 4. Berlin 1908. S. 344.)

266. Miller, The strength of ants. (Science. N. S. Bd. 16. New York 1902. S. 514-15.)

267. Mordwilko, Die Ameisen und Blattläuse in ihren gegenseitigen Beziehungen. (Biolog. Centralbl. Bd. 27. Leipzig 1907. S. $212-14$. S. 233-52.)

268. Morley, Early appearance of Formica rufa. (Entom. Monthl. Mag. [2] Bd. 33. London 1897. S. 183.)

269. Mrazek, Gründung neuer Kolonien bei Lasius niger. (Zeitschr. wiss. Insektenbiol. Bd. 2. Berlin 1906. S. 109-111.)

270. Nylander, Adnotationes in monographiam formicarum borealium Europae. (Act. Soc. sc. Fennicae Bd. 2. Helsingfors 1846. S. 875-944.)

271. - Additamentum adnotationum in monographiam formicarum borealium Europae. (Act. Soc. sc. Fennicae Bd. 2. Helsingfors 1846 [47]. S. $1041-1062$.)

272. - Additamentum alterum adnotationum in monographiam formicarum borealium Europae. (Act. Soc. sc. Fennicae Bd. 3. Helsingfors 1848. [S. 25-48.])

273. - Remarks on „Hymenopterol. Studien“ by Arn. Förster. (Ann. Mag. Nat. Hist. [2] Bd. 8. London 1851. S. $126-29$.

274. - Synopsis des formicides de France et d'Algérie. (Ann. Sc. nat. [4] Bd. 5. Paris 1856. S. $51-109$.

275. Oudemans, Zwei merkwürdige Hymenopteren-Nester von Lasius fuliginosus Latr. (usw.). (Allg. Zeitschr. Entom. Bd. 6. Neudamm 1901. S. 179-181.)

276. Pérez, Sur quelques phénomènes de la nymphose chez la fourmi rousse. (C. R. Soc. Biol. Paris Bd. 53. 1901. S. 1046-49.)

277. - Sur quelques points de la métamorphose des fourmis. (Bull. Soc. entom. France. Paris 1901. S. 22-25.)

278. - Histolyse des tubes de Malpighi et des glandes séricigènes chez la fourmi rousse. (Bull. Soc. entom. France. Paris 1901. S. 307-310.)

279. - Sur les oenocytes de la Formica rufa. (Bull. Soc. entom. France. Paris 1901. S. 351-53.)

280. - Contribution à l'étude des métamorphoses. (Bull. scientif. France Belgique Bd. 37. Paris 1903. S. $195-427$.

281. Piéron, Du rôle du sens musculaire dans l'orientation des fourmis. (Bull. Inst. gén. psych. Paris Bd. 4. 1904. S. $168-185$.

282. - Contribution à l'étude du problème de la reconnaissance chez les fourmis. (C. R. 6. Congr. internat. zool. Berne 1905. S. $482-91$.)

283. - Généralité du processus olfactif de reconnaissance chez les fourmis. (C. R. Soc. Biol. Paris Bd. 61. 1906. S. $385-87$.

284. - Exceptions et variations dans le processus olfactif de reconnaissance chez les fourmis. (C. R. Soc. Biol. Paris Bd. 61. 1906. S. 433-35.)

285. - Le mécanisme de la reconnaissance chez les fourmis. Rôle des données olfactives. (C. R. Soc. Biol. Paris Bd. 61. 1906. S. 471-73.) 
286. Piéron, Le rôle de l'olfaction dans la reconnaissance des fourmis. (C. R. Acad. Sc. Paris Bd. 143. 1906. S. 845-48.)

287. - L'adoption à la recherche du nid chez les fourmis. (C. R. Soc. Biol. Paris Bd. 62. 1907. S. $216-18$.

288. Piets chker, Das Gehirn der Ameise. (Jena. Zeitschr. Naturw. Bd. 47. 1911. S. 43-114.)

289. Popp, Können Ameisen hören? (A. d. Natur. Bd. 2. Leipzig 1906-07. S. 221.)

290. Prowazek, Ameisenbeobachtungen. (Zool. Garten Bd. 42. Frankfurt a. M. 1901. S. 49-52.)

291. Rabl-Rückhard, Studien über Insektengehirne. Das Gehirn der Ameise. (Archiv Anat. Phys. Leipzig 1875. S. 480 -99.)

292. Reiche $\mathrm{n} b$ ach, Über lebende Ameisenkolonien in künstlichen Nestern. (Ber. Senckenbg. naturf. Ges. Frankfurt a. M. 1899. S. XCV-CCVI.)

293. - Über Parthenogenese bei Ameisen und andere Beobachtungen an Ameisen in künstlichen Nestern. (Biolog. Centralbl. Bd. 22. Leipzig 1902. S. 461-65.)

294. - Der Ameisenstaat und die Abstammungslehre. (Ber. Senckenbg. naturf. Ges. Frankfurt a. M. 1908. S. 126-47.)

295. Reissing, Zur Ameisenpsychologie. (Allg. Zeitschr. Entom. Bd. 7. Neudamm 1902. S. 61.)

296. Re uter, Monomorium pharaonis L., en ny fiende till vor hus ro. (Öfversigt Finsk. Vet. Soc. Förh. Bd. 26. Helsingfors 1885. S. 1-21.)

297. - Lasius alienus Foerst. funnen i Finland. (Meddel. Soc. Faun. Flor. Fenn. Bd. 29. 1904. S. $120-21$.

298. Robert, Observations sur les moeurs des fourmis. (Ann. Sc. nat. [2] Bd. 18. Paris 1842. S. $151-58$.)

299. Rog er, Beiträge zur Kenntnis der Ameisenfauna der Mittelmeerländer. (Berlin. entom. Zeitschr. Bd. 3. 1859. S. $225-59$. Bd. 6.1862 . S. $255-62$.)

300. - Verzeichnis der Formiciden-Gattungen und Arten. (Berlin 1862.)

301. Romanes, The use of ants to aphids and Coccidae. (Nature Bd. 48. London 1893. S. 54.)

302. Rudow, Beobachtungen bei Ameisen. (Insektenbörse Bd. 14. Leipzig 1897. S. 67-69.)

303. - Die Wohnungen der Ameisen. (Entom. Jahrb. Bd. 15. 1905. S. 148-71.)

304. Sadownikowna, Stereoskopische Bilder aus dem Leben der Ameisen. (Verkauf bei Friedländer, Berlin.)

305. Sajó, Krieg und Frieden im Ameisenstaat. (Stuttgart o. J.)

306. - Nützlichkeit der Ameisen. (Zeitschr. Pflanzenkrankh. Bd. 12. Stuttgart 1902.)

307. Santschi, Quelques observations nouvelles et remarques sur la variabilité de l'instinct de lindification chez les fourmis. (Journ. Psych. Neurol. Bd. 13. Leipzig 1908. S. 136-49.)

308. - Notes sur la polyandrie chez les fourmis. (Bull. Soc. Hist. nat. Afrique Nord Bd. 2. 1910. S. 1-3.)

309. - Observations et remarques critiques sur le mécanisme de l'orientation chez les fourmis. (Rev. Suisse Zool. Bd. 19. Genève 1911. S. 303-38.)

310. Saunders, The male of Formicoxenus nitidulus Nyl. (Entom. Monthl. Mag. Bd. 23. London 1886. S. 42.)

311. - Honey bees destroyed by wood ants (Formica rufa). (Entom. Monthl. Mag. [II. Bd. 7] Bd. 32. London 1896. S. 161.)

312. Schäffer, Über die geistigen Fähigkeiten der Ameisen. (Verh. naturw. Ver. Hamburg [3] Bd. 9. 1902. S. 14-42.)

313. Schenck, Die nassauischen Ameisen-Species. (Stettin. entom. Zeitschr. Bd. 14. 1853-54. S. $157-163$, S. $185-198$, S. $225-32$, S. $296-301$. Bd. 15 . S. $63-64$.

314. -- Systematische Einteilung der nassauischen Ameisen nach Mayr. (Jahrb. Ver. Nat. Herzogt. Nassau. Heft 11. Wiesbaden 1856. S. 90-94.)

315. - Naturgeschichte der Ameisen. (Weilburg 1863.)

316. - Über die (im Heft 8) Eciton testaceum genannte Ameise. (Jahrb. Ver. Nat. Herzogt. Nassau. Heft 10. 1855. S. 150-59.)

317. - Les fourmis d'Alsace. (Ann. Soc. entom. Belgique Bd. 53. Bruxelles 1909. S. 107-112.)

318. S ch immer, Beitrag zur Ameisenfauna des Leipziger Gebietes. (Sitzber. naturf. Ges. Leipzig Bd. 35. 1908. S. $11-20$.)

319. - Über die Wasmannsche Hypothese des „Duldungsinstinktes“ der Ameisen gegenüber synoeken Myrmekophilen. (Zool. Anzeig. Bd. 36. Leipzig 1910. S. 81-85.)

320. Schlüter, Die Intelligenz der Ameisen. (IIl. Zeitschr. Entom. Bd. 1. Neudamm 1896. S. $142-44$.)

321. Sch miedeknecht, Die Hymenopteren Mittel-Europas. (Jena 1907. Formic.: S. 352-54.)

322. S ch mitz, Wie besiedelt man künstliche Ameisennester? (Entom. Wochenbl. Bd. 24. Leipzig 1907. S. $23-24$, S. $26-28$.) 
323. Schmitz, Künstliche Ameisennester. (Entom. Wochenbl. Bd. 24. Leipzig 1907. S. 121-22, S. $125-26$, S. $137-38$.)

324. - Das Leben der Ameisen und ihrer Gäste. (Regensburg 1906.)

325. S ch n a b l, Zur Ameisenpsychologie. (Allg. Zeitschr. Entom. Bd. 7. Neudamm 1902. S. 61.)

326. Schneider. Hymenoptera aculeata im arktischen Norwegen. (Tromsö Mus. Bd. 29. 1909. Formic.: S. $94-101$.

327. Schön, Bau und Entwicklung des tibialen Chordotonalorgans bei der Honigbiene und bei Ameisen. (Zool. Jahrb. Anat. Bd. 31. Jena 1911. S. 439-72.)

328. S ch o e $\mathrm{n}$ i ch e n, Pilzzucht bei Lasius fuliginosus. (Prometheus Bd. 12. Berlin 1901. S. 467-68.)

329. S chröder, Formica rufa $\not$ als Blütenbestäuber. (III. Zeitschr. Entom. Bd. 4. Neudamm 1899. S. 281.)

330. Strohmayer, Beobachtungen über Ameisen-Gefrässigkeit. (Entom. Jahrb. Bd. 16. 1906. S. $180-81$.)

331. Sergi, Ricerche su alcuni organi di senso nelle antenne delle formiche. (Bull. Soc. entom. Ital. Firenze 1892. S. $18-25$.)

332. Sernander, Entwurf einer Monographie der europäischen Myrmecochoren. (Upsala 1906.)

333. Sichel, Note sur les fourmis introduites dans les serres-chaudes. (Ann. Soc. entom. France [3] Bd. 4. Paris 1856. Bull. S. 23-24.)

334. Smalian, Altes und Neues aus dem Leben der Ameisen. (Zeitschr. Naturw. Bd. 67. Leipzig 1894. S. 1 -46.)

335. S mith, Catalogue of hymenopterous insects in the collection of the British Museum. (London 1858. Teil 6 S. 1-200. 1859. Teil 7 S. 1-10 [Dorylinae].)

336. - Essay on the genera and species of british Formicidae. (Trans. entom. Soc. London [2] Bd. 3. 1854-56. S. 95-135)

337. - Revision of an essay on the british Formicidae. (Trans. entom. Soc. London [2] Bd. 4. 1856-58. S. $274-84$.)

338. Southcombe, Formation of a new nest by Lasius niger. (Trans. entom. Soc. London 1906. [Proc.] S. LXXV-LXXVII.)

339. Staes, De Mieren. (Tijdschr. Plantenziekten Bd. 3. 1897. S. 135-150.)

340. Swammerdam, Biblia naturae. (Übers. Leipzig 1752. Formic. S. 121-25.)

341. Swinton, Note on the stridulation of Myrmica ruginodis and other Hymenoptera. (Entom. Monthl. Mag [2] Bd. 14. London 1878-79. S. 187.)

342. Thomann, Beobachtungen über eine Symbiose zwischen Lycaena argus L. und Formica cinerea Mayr. (Jahresber. nat. Ges. Graubünden. N. F. Bd. 44. 1901. S. 1-40.)

343. - Über das Zusammenleben der Raupen von Psecadia pusiella Röm. und Ps. decemguttata Hb. mit Formiciden. (Jahresber. nat. Ges. Graubünden. N. F. Bd. 50. 1901. S. 21-31.)

344. T isch bein, Zwitter von Formica sanguinea. (Stettin. entom. Zeitschr. Bd. 12. 1851. S. $295-97$. - vgl. Bd. 15. 1854. S. 102.)

345. Treat, Notes on the slave-making ant (Formica sanguinea). Americ. Natural. Bd. 13. Boston 1879. S. 707-708.)

346. Turner, Do ants form practical judgements? (Biolog. Bull. Bd. 13. Lancaster Pa. 1907. S. $333-34$.)

347. Viehme yer, Allerhand aus dem Leben der Ameisen. (Entom. Jahrb. Bd. 12. 1902. S. 210 -15.)

348. - Bilder aus dem Ameisenleben. (Leipzig 1909.)

349. - Beiträge zur Ameisenfauna des Königreichs Sachsen. (Abh. nat. Ges. Isis. Dresden 1906. S. $55-69$.

350. - Hochzeitsflug und Hybridation bei Ameisen. (Deutsche entom. Nationalbibl. Bd. 2. Berlin 1911. S. $28-30$.)

351. - Beobachtungen über das Zurückfinden von Ameisen (Leptothorax unifasciatus Latr.) zu ihrem Nest. (III. Zeitschr. Entom. Bd. 5. Neudamm 1900. S. 311-313.)

352 - Zur Koloniegründung der parasitischen Ameisen. (Biolog. Centralbl. Bd. 28. Leipzig 1908. S. $18-32$.)

353. - Ontogenetische und phylogenetische Beobachtungen über die parasitische Koloniegründung von Formica sanguinea. (Biolog. Centralbl. Bd. 30. Leipzig 1910. S. 570-80.)

354. - Beobachtungen und Experimente zur Koloniegründung von Formica sanguinea Latr. (Zeitschr. wiss. Insektenbiol. Bd. 5. Berlin 1909. S. 353-56, S. 390-94.)

355. - Lomechusa strumosa F. und die Pseudogynen. (Allg. Zeitschr. Entom. Bd. 7. Neudamm 1902. S. 472-76.)

356. - Experimente zu Wasmanns Lomechusa-Pseudogynen-Theorie und andere biologische Beobachtungen an Ameisen. (Allg. Zeitschr. Entom. Bd. 9. Neudamm 1904. S. 334 44.)

357. - Bemerkungen zu Wasmanns neuester Arbeit: Über den Ursprung des sozialen Parasitismus und der Myrmekophilie bei den Ameisen. (Zoolog. Anzeig. Bd. 35. Leipzig 1910. S. 450-57.) 
358. Viehmeyer, Vorläufige Bemerkungen zur Myrmekophilie der Lycaenidenraupen. (Entom. Wochenbl. Bd. 24. Leipzig 1907. S. 4.)

359. - Beobachtungsnester für Ameisen. (A. d. Heimat Bd. 19. Stuttgart 1905. S. 7-17.)

360. W a n a ch, Einige auffällige Beobachtungen aus dem Insektenleben. (Berlin. entom. Zeitschr. Bd. 50. 1905. S. $235[-36]$.)

361. - Beobachtungen an Ameisen. (Berlin. entom. Zeitschr. Bd. 52. 1907. S. 220-23. Bd. 54. 1909. S. $220-28$. Bd. 55. 1910. S. 203-11.)

362. Wasmann, Zur Kenntnis der Ameisen und Ameisengäste von Luxemburg. (Luxemburg. Teil 1-2: 1906. Teil 3: 1909; noch nicht vollendet.)

363. - Zur Ameisenfauna von Helgoland. (Deutsche entom. Zeitschr. Berlin 1902. S. 63-64.)

364. - Kritisches Verzeichnis der myrmekophilen und termitophilen Arthropoden. (Berlin 1894.)

365. -- Die Ameisen und ihre Gäste. (1. Congr. internat. Entom. Bruxelles 1910. [1911.] S. 209-232.)

366. - Die zusammengesetzten Nester und gemischten Kolonien der Ameisen. (Münster 1891.)

367. - Neues über die zusammengesetzten Nester und gemischten Kolonien der Ameisen. (Allg. Zeitschr. Entom. Bd. 6. 1901. S. $353-57$, S. 369-71. - Bd. 7. 1902. S. 1-15. S. $33-37$, S. $72-77$, S. $100-108$, S. $136-39$, S. $167-73$, S. $206-08$, S. $235-40$, S. $260-65$, S. $293-98$, S. $340-45$, S. $385-90$, S. $422-27$, S. $441-48-49$.

368. - Über gemischte Kolonien von Lasius-Arten. (Zoolog. Anzeig. Bd. 35. Leipzig 1909. S. $129-141)$.

369. - Formica exsecta und ihre Nestgenossen. (Verh. nat. Ver. Bonn Bd. 51. 1894. S. 10-22.)

370. - Die Gäste der Ameisen und Termiten. (Ill. Zeitschr. Ent. Bd. 3. Neudamm 1898. S. 10--16.)

371. - Lasius fuliginosus als Raubameise. (Zoolog. Anzeig. Bd. 22. Leipzig 1899. S. 85-87.)

372. - Parthenogenesis bei Ameisen durch künstliche Temperaturverhältnisse. (Biolog. Centralbl. Bd. 11. Leipzig 1891. S. 21-23.)

373. - Ameisenarbeiterinnen als Ersatzköniginnen. (Mittheil. Schweiz. entom. Ges. Bd. 11. Schaffhausen 1905 . S. $67-70$.)

374. - Über die verschiedenen Zwischenformen von Weibchen und Arbeiterinnen bei Ameisen. (Stettin. entom. Zeitschr. Bd. 51. 1890. S. 300 309.)

375. - Die ergatogynen Formen bei den Ameisen und ihre Erklärung. (Biolog. Centralbl. Bd. 15. Leipzig 1895. S. 606-22, S. 625-46.)

376. - Über ergatoide Weibchen und Pseudogynen bei den Ameisen. (Zoolog. Anzeig. Bd. 20. Leipzig 1897. S. 521-53.)

377. - Über Atemeles pubicollis und die Pseudogynen von Formica rufa L. (Deutsche entom. Zeitschr. Berlin 1899. S. $407-09$.

378. - Über die Verbreitung und die geflügelten Weibchen von Harpagoxenus sublaevis. (Entom. Mitteil. Bd. 1. 1912. S. 193-97.)

379. - Neue Bestätigung der Lomechusa-Pseudogynentheorie. (Verh. deutsch. zool. Ges. Bd. 12. Leipzig 1902. S. 98-108.)

380. - Zur Brutpflege der blutroten Raubameise (Formica sanguinea Latr.). (Insektenbörse Bd. 20. Leipzig 1903. S. $275-76$.

381. - Ursprung und Entwicklung der Sklaverei bei den Ameisen. (Biolog. Centralbl. Bd. 25. Leipzig 1905 . S. $117-27$, S. $129-44$, S. $161-69$, S. $256-70$, S. $273-92$.

382. - Zur Geschichte der Sklaverei beim Volk der Ameisen (Stimmen aus Maria-Laach Bd. 70. Freiburg i. B. 1906 . S. $405-25$, S. 517-31.)

383. - Weitere Beiträge zum sozialen Parasitismus und der Sklaverei bei den Ameisen. (Biolog. Centralbl. Bd. 28. Leipzig 1908. S. $257-71$, S. $290-306$, S. 321-33, S. 353-82, S. $417-41$, S. $726-31$.)

384. - Nachträge zum sozialen Parasitismus und zur Sklaverei bei den Ameisen. (Biol. Centralbl. Bd. 28. Leipzig 1908. S. 475-96, S. 515-24.)

385. - Zur Geschichte der Sklaverei und des sozialen Parasitismus bei den Ameisen. (Naturw. Wochenschr. N. F. Bd. 8. Jena 1909. S. 401-407.)

386. - Über den Ursprung des sozialen Parasitismus, der Sklaverei und der Myrmekophilie bei bei den Ameisen. (Biolog. Centralbl. Bd. 29. Leipzig 1909. S. 587-604, S. 619 - 37, S. $651-63$, S. $683-703$.

387. - Zur Frage nach dem Gehörvermögen der Ameisen. (Biolog. Centralbl. Bd. 11. Leipzig 1891. S. 26.)

388. - Lautäusserun£en der Ameisen. (Biolog. Centralbl. Bd. 13. Leipzig 1893. S. 39-40.)

389. - Einige neue Hermaphroditen von Myrmica scabrinodis und M. laevinodis. (Stettin. entom. Zeitschr. Bd. 51. 1890. S. 298-99.)

390. - Ameisennester „Boussole du montagnard“. (Naturw. Wochenschr. N. F. Bd. 6. Jena 1907. S. $391-92$.) 
391. Wasmann, Ein merkwürdiges Heizmaterial bei Formica pratensis. (Zeitschr. wiss. Insektenbiol. Bd. 2. Husum 1906. S. $42-43$.)

392. - Zur Myrmekophagie des Grünspechts. (Tijdschr. Entom. Bd. 48. 's Gravenhage 1906. S.6-12.)

393. - Instinkt und Intelligenz im Tierreich. (Freiburg i. B. 1897.)

394. - Zur Entwicklung der Instinkte. (Verh. zool. bot. Ges. Wien Bd. 47. 1897. S. 168-83.)

395. - Eine neue Reflextheorie des Ameisenlebens. (Biolog. Centralbl. Bd. 18. Leipzig 1898. S. 578-89.)

396. - Vergleichende Studien über das Seelenleben der Ameisen und der höheren Tiere. (2. Aufl. Freiburg i. B. 1900.)

397. - Die psychischen Fähigkeiten der Ameisen. (2. Aufl. Stuttgart 1909.)

398. - Zum Orientierungsvermögen der Ameisen. (Allg. Zeitschr. Entom. Bd. 6. Neudamm 1901. S. 19-21, S. $41-43$.)

399. Weld, The sense of hearing in ants. (Science N. S. Bd. 10. New York 1899. S. 766-68.)

400. Wheeler, Ants, their structure, development and behavior. (New York 1910.)

401. - Comparative ethologie of the European and North American ants. (Journ. Psych. Neurol. Bd. 13. Leipzig 1908. S. 404-35.)

402. - Observations on some European ants. (Journ. New York entom. Soc. Bd. 17. 1909. S. 172.)

403. - Extraordinary females in the species of Formica, with remarks on mutation in the Formicidae. (Bull. Americ. Mus. Nat. Hist. Bd. 19. New York 1903. S. 639-51.)

404. - The polymorphism of ants, with an account of some singular abnormalities due to parasitism. (Bull. Americ. Mus. Nat. Hist. Bd. 23. New York 1907. S. 1-93.)

405. - The polymorphism of ants. (Ann. entom. Soc. Americ. Bd. 1. 1908. S. 39-69.)

406. - The parasitic origin of Macroergates among ants. (Americ. Natural. Bd. 35. Boston 1901. S. $877-86$.)

407. - The origin of female and worker ants from the eggs of parthenogenetic workers. (Science N. S. Bd. 18. New York 1903. S. $830-33$.)

408. - How the queens of the parasitic and slave-making ants establish their colonies. (Journ. Americ. Mus. Bd. 5. 1905. S. 144-48.)

409. - On the founding of colonies by queen ants, with special reference to the parasitic and slave-making species. (Bull. Americ. Mus. Nat. Hist. Bd. 22. New York 1906. S. 33-107.)

410. - Social parasitism among ants. (Journ. Americ. Mus. Bd. 4. 1904. S. 74-75.)

411. - An interpretation of the slave-making instinct in ants. (Bull. Americ. Mus. Nat. Hist. Bd. 21. New York 1905. S. 1-16.)

412. - Some remarks on temporary social parasitism and the phylogeny of slavery in ants. (Biolog. Centralbl. Bd. 25. Leipzig 1905. S. 37-44.)

413. - The compound and mixed nests of american ants. (Americ. Natural. Bd. 35. Boston 1901. S. $431-48$, S. $513-39$, S. $701-24$, S. $791-815-818$.

414. - Small artificial ant-nest of novel patterns. (Psyche Bd. 17. Cambridge Mass. 1910. S. 73-75.)

415. Yung, Combien y a-t-il de fourmis dans une fourmilière? (Rev. scientif. [4] Bd. 14. Paris 1900. S. 269-72.)

416. Zimmer, Nest von Lasius fuliginosus Latr. (Zeitschr. wiss. Insektenbiol. Bd. 4. Berlin 1908. S. $229-30$.)

417. - Nest von Lasius fuliginosus Latr. in einem Sarg. (Zeitschr. wiss. Insektenbiol. Bd. 8. Berlin 1912. S. 32.) 


\section{Inhalt.}

\section{Allgemeiner Teil.}

1. Charakteristik. Abstammung

2. Geschichtliches … . . . . . 1

3. Körperbau der Ameisen . . . . . . . . . . . . . 7

Kopf und dessen Teile. Antennen und deren Sinnesorgane. Chordotonale Organe. Netzaugen, Punktaugen. Mundteile. - Brust und deren Teile. Stielchen. Hinterleib. Giftapparat und Stachel. Genitalanhänge. Flügel. Beine. Verdauungsorgane. Speicheldrüsen. Magen. Geschlechtsorgane. Nervensystem.

4. Polymorphismus . . . . . . . . . . . . . . . . . . 19

5. Leben der Ameisen. . . . . . . . . . . . . . . . 20

Schwärmen. Koloniegründung (unabhängige, abhängige). Ansichten über die verschiedenen Stufen der Koloniegründung.

Eier, Larven und deren Pflege, Puppen, entwickelte Tiere.

Ernährung. Reinlichkeit. Verteidigung und Kämpfe. Nesterwechsel. Überwinterung. Dauer des Bestehens einer Kolonie.

6. Wohnungen der Ameisen
Morphologisch. Biologisch.

7. Künstliche Nester

Lubbock-Nest. Fielde-Nest. Viehmeyer-Nest. Wasmann-Nest. Wasmann-Nest nach Schmitz. Torfnester nach Dankler, Brun. Janet-Nest. Janet-Nest nach Wasmann. Gipsnest nach Wheeler. Kleinere Nester. Nest nach Barth. Einsammeln der Ameisen für künstliche Nester, Besetzung, Pflege.

8. Geographische Verbreitung . . . . . . . . . . . . . . . . . . . 42

9. Ameisengäste . . . . . . . . . . . . . . . . . . . . . . . . . . . 43

10. Bedeutung der Ameisen . . . . . . . . . . . . . . . . . . . . . . 48

Nutzen. Schaden. Vertilgung.
auf offene Fragen . . . . . . . . . . . . . . . . . . . 50

11. Hinweis auf offene Fragen
12. Sammeln und Präparieren

Einsammeln. Töten. Konservieren (in Alkohol und trocken). Aufstellen für die Sammlung. Mikroskop. Präparate.

\section{Systematischer Teil.}

(Namen der Unterfámilien, Gattungen und Arten alphabetisch geordnet.)

\begin{tabular}{|c|c|c|c|c|c|c|c|c|c|c|c|c|c|}
\hline & & & & & & & & & & & & & \\
\hline erc & & $\bullet$ & & 61 & brunneus : . & • & ${ }^{\circ}$ & & 85 & Dolichoderina & & & \\
\hline & & & • & 96 & notinae & . & - & & 80 & Dolichoderus & . & & \\
\hline (Lasiu & & & . & 86 & & . & . & & 93 & & . & & \\
\hline Lepto & oth & & & 6 & & . & & & & ratus & . & & \\
\hline & . & . & - & 8 & & & & & 93 & $u m$ & . & & \\
\hline & & . & & 6 & & & & & & $a$ & • & & \\
\hline gaste & & . & $\bullet$ & 68 & & & & & & flavus. & & & \\
\hline & & . & . & 66 & osis & & . & & 9 & Formica & & & \\
\hline & . & . & & 69 & & & & & & Formicoxenus & • & & \\
\hline & & . . & & 87 & Cremastogaster & & & & 73 & fuliginosus & & & \\
\hline
\end{tabular}


Inhalt.

\begin{tabular}{|c|c|c|c|c|c|c|c|c|c|c|c|c|c|c|}
\hline & & & & Seite & & & & & Seite & & & & & Seite \\
\hline fugax & & . & & 74 & Myrmecina & & & & 59 & ruginodis. & . & & . & 73 \\
\hline fusca. & . & . & & 92 & Myrmica. & - & - & . & 69 & rugulosa. & . & . & . & 72 \\
\hline gagates & . & . & & 93 & Myrmicinae & . & . & . & 55 & sanguinea & . & . & . & 90 \\
\hline glebaria & & . & & 93 & niger . & . & . & - & 84 & scabrinodis & . & . & . & 71 \\
\hline graminicola . & & . & & 59 & nigrescens & . & . & . & 61 & schencki. & . & . & & 72 \\
\hline pagoxenus & & - & & 64 & nigriceps. & . & . & & 63 & scutellaris & . & . & & 73 \\
\hline leanus. & & . & & 95 & nitidulus. & . & . & . & 66 & Solenopsis & . & & . & 74 \\
\hline interruptus & . & . & & 63 & nylanderi. & . & . & . & 64 & Stenamma & & & & 67 \\
\hline nodis. & & . & & 73 & parvulus. & . & . & . & 64 & Strongylogna & athus & & & 76 \\
\hline Lasius & . & . & & 81 & pharaonis & . & . & . & 65 & structor & . . & . & & 69 \\
\hline alis & & . & & 96 & Pheidole. & . & . & . & 67 & sublaevis. & . & . & & 64 \\
\hline latreillei & . & . & & 59 & piceus. & & & & 96 & subterranea & . & & & 68 \\
\hline thorax. & & . & & 59 & Plagiolepis & & . & . & 81 & suecica . & & . & & 91 \\
\hline ligniperda . & . & . & & 95 & Polyergus & & . & . & 87 & sulcinodis & . & . & . & 72 \\
\hline Liometopum . & & . & & 78 & Ponera & ${ }^{\circ}$ & . & • & 54 & Tapinoma & . & . & . & 78 \\
\hline lobicornis. . & & . & & 72 & Ponerinae & & & . & 54 & & . & & & 76 \\
\hline luteus & • & . & & 63 & pratensis. & & $\cdot$ & & 92 & norium & & . & & 75 \\
\hline ginatus & & - & & 96 & pressilabris & & ${ }^{\circ}$ & & 91 & Tomognathus & & & & 64 \\
\hline megacephala & & - & & 67 & punctatissima & & 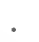 & & 55 & truncata & & & & 96 \\
\hline Messor & & . & & 69 & pygmaea. & . & . & • & 81 & truncicola & & & & 92 \\
\hline microcephalun & & . & & 78 & quadripuncta & & & & 79 & tuberum. & . & & & 62 \\
\hline us. . & & . & & 86 & rubida . & . & . & & 71 & umbratus . & . & & & 86 \\
\hline nomorium & & . & & 65 & rubra. & & & & 73 & unifasciatus & & & & 63 \\
\hline corum. & * & • & & 62 & rufa & & 。 & & 91 & & . & . & & 95 \\
\hline Muchothorax & & $\cdot$ & & $\begin{array}{l}69 \\
59\end{array}$ & rufescens. & & & & 87 & westwoodi & $\cdot \cdot$ & $\cdot$ & & 67 \\
\hline
\end{tabular}




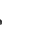




\title{
Die Schlupfwespen (Ichneumonidae) Mitteleuropas, insbesondere Deutschlands
}

\author{
Prof. Dr. O. Schmiedeknecht
}





\section{Einleitung.}

Das Studium der Hymenopteren hat in den letzten 20 Jahren einen ausserordentlichen Antrieb erfahren, zugleich auch jenes der Schlupfwespen insbesondere. Zahlreiche Arbeiten sind erschienen; so hat auch mein jüngst erschienenes Werk: „Die Hymenopteren Mitteleuropas“ (Verlag G. Fischer, Jena) diesem Zweige der Entomologie zahlreiche Jünger zugeführt, und wenigstens für die Ichneumoniden unter den „Schlupfwespen“ bilden meine „Opuscula Ichneumonologica“ eine bequeme Grundlage.

Woher der Name „Schlupfwespen“? Manche wollen ihn daraus erklären, dass diese kleinen Insekten die Eier in ihre Wirte hineingleiten, hineinschlüpfen lassen. Ich meine, es soll damit das ganze geheimnisvolle, man könnte sagen, unheimliche Treiben dieser Tiere, das Umherschlüpfen und Umhersuchen nach ihren Opfern bezeichnet werden. Nichts ist vor dem Legestachel dieser behenden, mit den höchsten Sinnen, namentlich Spürsinnen begabten Tiere sicher. Alle Insektenordnungen werden von ihnen heimgesucht, selbst Spinnen und Tausendfüsser erscheinen nicht sicher. Hauptsächlich sind es die freilebenden Schmetterlingsraupen, auf die sie es abgesehen haben, aber auch die tief unter der Oberfläche sitzenden Larven werden heimgesucht, mögen sie im Innern einer Galle oder eines Pilzes wohnen, mögen sie tief im Holz oder gar hinter Stein und Mörtel sitzen; ja nicht einmal das Wasser schützt vor den Angriffen der Schlupfwespen. Wir haben da eine kleine Anzahl seltener Arten, die die Larven der Köcherfliegen und die Eier von Wasserkäfern, Wasserwanzen und der schönen blauflügligen Wasserjungfer (Calopteryx) anstechen. Ich will überhaupt gleich hier bemerken, dass gerade auf dem Gebiete der wasserbewohnenden Schlupfwespen noch recht wenig getan ist und dass ein eifriger Forscher gerade da noch viele Entdeckungen machen wird. Und was ist noch alles aufzuklären in bezug auf die Lebensbedingungen der Schlupfwespen untereinander, ich meine das Schmarotzertum zweiten und weiteren Grades. Nehmen wir ein allbekanntes Beispiel. Die Kohlweisslingsraupe wird von einer Braconide, dem Apanteles glomeratus L. angestochen, bei diesem schmarotzt aber wieder eine kleine Ichneumonide, der Hemiteles fulvipes Grav. Wir haben also in dem erwähnten Apanteles eine sehr nützliche, in dem Hemiteles dagegen eine schädliche Art. Wie kritiklos urteilt in diesen Punkten der Laie; das kann man so recht erfahren, wenn das beliebte Thema vom Nutzen der Vögel erörtert wird. Nehmen wir noch ein Beispiel. Man trage von den bekannten Rosenschlafäpfeln eine Anzahl nach Hause; welche Menge kleiner Hautflügler wird aus ihnen hervorgehen! Da ist zunächst der eigentliche Erzeuger der Galle, die an dem braunroten Hinterleib leicht kenntliche Rhodites rosae L. und daneben eine kleinere Gallwespe, welche als Einmieter oder Inquiline oder Kommensale bei Rhodites lebt. Dann kommt in grosser Menge eine echte Ichneumonide, Orthopelma luteolator Grav. zum Vorschein; zugleich schlüpfen aber auch zwei mit langem Bohrer versehene Chalcididen aus, der schwarz gefärbte Oligosthenus stigma F. und der prachtvoll blau, grün und rotgolden strahlende Torymus bedeguaris Nees. Bei welchem 
Wirte leben die beiden? Bei den Gallwespen oder bei Orthopelma? Schliesslich kommt noch eine Chalcidide hervor, der Habrocytus bedeguaris Thoms. Bei welchem der Gallenbewohner schmarotzt dieser? Das ist nur eines von den unzähligen Beispielen; die meisten werden immer im Dunkel bleiben; die Natur ist zu gross und das Menschenleben zu kurz.

\section{Allgemeine Charakteristik.}

Die Schlupfwespen gehören zu den Hymenopteren, bei welchen der Metathorax geschlossen ist; der Hinterleib sitzt also nicht wie bei den Blatt- und Holzwespen breit an, sondern er ist anhängend, in vielen Fällen kurz oder lang gestielt (Apocrita; s. Teil 1 dieses Bandes). Flügel sind meist vorhanden; die lanzettförmige Zelle fehlt. Die Beine besitzen zwei Trochanteren (Schenkelringe). Der nicht sägeartige Legebohrer besteht aus drei Teilen, dem eigentlichen Bohrer und den beiden Klappen. Die Larven haben keine Beine.

Die Schlupfwespen zerfallen in die folgenden 8 Familien:

1. Flügel vorhanden. 2.

Flügel fehlend oder stummelhaft. 9.

2. Flügel meist mit vielverzweigter Nervatur, in der Regel mit mehreren geschlossenen Zellen, wenigstens mit einer geschlossenen Cubitalzelle, stets mit deutlichem Stigma. Antennen nicht gekniet. 3.

Flügel ohne geschlossene Zelle; nur bei wenigen Proctotrupidengattungen treten geschlossene Zellen auf, bei diesen ist jedoch das letzte Bauchsegment (Hypopygium) nicht geteilt. Antennen gekniet oder gerade. 8.

3. Hinterleib gestielt, am oberen Ende des Metathorax eingefügt, von der Seite mehr oder weniger zusammengedrückt. Die wenigen Gattungen und Arten von auffallender Körpergestalt.

Hinterleib am unteren Ende des Metathorax eingefügt. 4.

5. Evaniidae.

4. Prothorax in einen langen Hals ausgezogen; Scheitel mit einem Kranz von Dornen. Hinterschenkel geschwollen, unten mit Stacheln. Hinterleib schmal, nach vorn verdünnt; Legebohrer weit vorstehend. In Deutschland nur eine einzige, ziemlich grosse, höchst seltene Art.

4. Stephanidae. kranz. 5.

Prothorax nicht in einen langen Hals ausgezogen. Scheitel ohne Dornen-

5. Vorderflügel mit nur einem rücklaufenden Nerven. Zwischen dem 2. und 3. Hinterleibssegment, mit Ausnahme der Aphidiinen, kein bewegliches Gelenk. Kleinere, selten mittelgrosse Tiere.

6. Braconidae.

Vorderflügel mit zwei rücklaufenden Nerven. Meist grössere Tiere. 6.

6. Die 1. Cubital- und die 1. Discoidalzelle voneinander durch einen Nerv getrennt. Vorderflügel mit 4 Cubitalzellen, die beiden mittleren klein. Das einzige hierhergehörende, etwa $1 \mathrm{~cm}$ lange Tier ist glänzend schwarz mit dunkler Flügelbinde; seine Stellung bei den Schlupfwespen ist fraglich.

3. Trigonalidae.

Die 1. Cubital- und die 1. Discoidalzelle zu einer einzigen Zelle, der Discocubitalzelle verschmolzen. Vorderflügel mit 3 , seltener mit 2 Cubitalzellen. 7.

7. Bauchsegmente weich und häutig, beim Eintrocknen gewöhnlich eine Längsfalte bildend. Rückensegmente 2 und 3 miteinander gelenkig verbunden. Schildchen sehr selten in einen Dorn auslaufend; in diesem Falle sind es grössere, mehr oder weniger bunt gezeichnete Arten.

1. Ichneumonidae.

Bauchsegmente nicht weich und häutig, sondern hart und chitinös, beim Eintrocknen keine Falte bildend. Rückensegmente 2 und 3 miteinander ver- 
wachsen. Schildchen mit Dorn. Das einzige hierhergehörende, etwa $6 \mathrm{~mm}$ lange Tier ist einfarbig schwarzbraun; die Lebensweise ist hochinteressant, indem das Tier unter Wasser taucht, um die Larven bestimmter Phryganeiden anzustechen.

2. Agriotypidae.

8. Der Prothorax erreicht nicht die Flügelbasis. Der Legebohrer des + entspringt vor der Hinterleibsspitze an der Bauchseite. Antennen stets gekniet, mit 1-3 kleinen Gliedern, den sogenannten Ringgliedern, zwischen Pedicellus und Geissel. Körperfärbung in der Regel metallisch grün. 7. Chalcididae.

Der Prothorax reicht bis zur Flügelbasis. Der Legebohrer des $q$ entspringt aus der Hinterleibsspitze selbst. Antennen gekniet oder nicht gekniet; im ersteren Falle zwischen Pedicellus und Geissel keine Ringglieder. Körperfärbung nicht metallisch, sondern meist schwarz, seltener braun oder rötlich. 8. Proctotrupidae.

9. Antennen nicht gekniet. 10.

Antennen gekniet. 12 .

10. Antennen mit höchstens 16 Gliedern. Körper kurz und gedrungen. Hinterleib mehr oder weniger von der Seite zusammengedrückt. cf. Cynipidae.

Antennen mit mehr als 16 Gliedern. Hinterleib nicht von der Seite zusammengedrückt. 11 .

11. Rückensegmente 2 und 3 miteinander gelenkig verbunden, die übrigen nicht. Hinter dem 1. Geisselglied folgt ein sehr kurzes Glied. 1. Ichneumonidae.

Alle Rückensegmente miteinander ungelenkig verwachsen oder alle gelenkig; letzteres ist nur bei den Aphidiinen der Fall, wo die Flügel höchst selten fehlen. Hinter dem 1. Geisselgliede kein besonders kurzes Glied. 6. Braconidae.

12. Hinterleibsstiel mit aufrechter Schuppe oder aus zwei, sehr selten nur aus einem Knoten bestehend. Nur 1 Trochanter vorhanden. Antennen peitschenförmig, indem der Schaft stark verlängert ist. cf. Formicidae. Hinterleibsstiel ohne Schuppe und nicht aus 1 oder 2 Knoten bestehend. 13.

13. Scheitel mit deutlichen Ocellen (Nebenaugen). Der Legebohrer des $f$ entspringt vor der Hinterleibsspitze an der Bauchseite.

7. Chalcididae.

Scheitel ohne Ocellen oder diese sind winzig klein und kaum zu erkennen. Der Legebohrer des $q$ entspringt aus der Hinterleibsspitze selbst.

8. Proctotrupidae.

\section{Ichneumonidae.}

\section{Charakteristik.}

Antennen nicht gekniet, indem der Schaft kurz ist, mindestens 16 gliedrig. Flügel selten fehlend, mit Stigma und zwei rücklaufenden Nerven, ohne lanzettförmige Zelle; die 1. Cubital- und die 1 . Discoidalzelle nicht vollständig voneinander getrennt, sondern zu einer einzigen Zelle, der Discocubitalzelle, verschmolzen. Beine meist nackt, selten mit Borsten oder Dörnchen; Schienen mit Sporen, selten die Hinterschienen ohne solche. Hinterleib sitzend oder gestielt, dem unteren Ende des geschlossenen Metathorax durch deutliche Artikulation angefügt, aus 7 oder 8 Segmenten bestehend, das letzte oft verborgen. Legebohrer der i stets vorhanden, oft sehr weit vorragend. - Larven parasitisch an oder in Eiern, Larven und Puppen von Insekten, seltener in Spinneneiern. Das vollkommene Insekt einsam lebend. 


\section{Körperbau der Ichneumoniden.}

Kopf gewöhnlich von Thoraxbreite; Scheitel mehr oder weniger hinten ausgerandet; Stirn !beiderseits oberhalb der Antennen meist mit geglätteten,. oft-

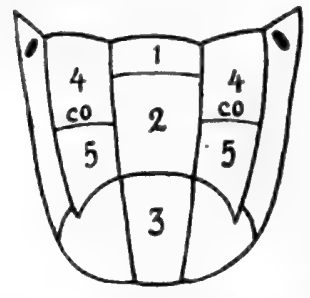

Abb. 1.

Metathorax von Ichneumon. 1 area basalis; 2 area superomedia; 3 area petiolaris (a. postica); 4 area externa ; 5 area dentipara; co costula.

mals scharf gerandeten Gruben, den sogenannten Fühlergruben; Stirnmitte zuweilen mit Zahn, Horn oder Leiste; Äugen mehr oder weniger länglichrund, innen, neben den Augen meist ausgerandet, nackt, selten behaart; Nebenaugen (Ocellen) in der Zahl von 3, ein Dreieck bildend, der dazwischenliegende Raum, das sogenannte Stemmaticum, oft durch dunklere Färbung ausgezeichnet; Antennen meist schlank, faden- oder borstenförmig, sehr selten in der Mitte oder gegen das Ende zu verdickt; die einzelnen Glieder meist walzenförmig, seltener am Ende verdickt oder einseitig vortretend, wodurch die Antennen knotig oder gesägt erscheinen. Als 1. Fühlerglied wird der meist durch seine Grösse ausgezeichnete Schaft betrachtet; seine Gestalt ist vorwiegend oval, am Ende schräg abgestutzt oder ausgeschnitten; das darauffolgende Glied, der Pedicellus, schliesst sich eng diesem Ausschnitt an; darauf

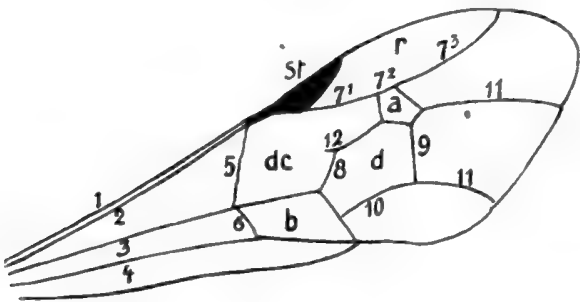

Abb. 2. Vorderflügel von Ichneumon.

1 costa; 2 subcosta; 3 cubitus ; 4 brachium; 5 nervus basalis; 6 nervulus; 7 radius; $7^{1}, 7^{\Perp}, 7^{3} 1$., 2 . und 3 . Abschnitt des radius; 8 nervus discocubitalis; 9 nervus recurrens; 10 nervus parallelus; 11 nervi spurii; 12 ramellus; st stigma; $r$ cellula radialis; a areola de cellula discocubitalis; $d$ cellula discoidalis; b cellula brachialis.

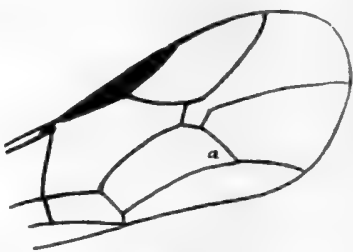

Abb. 3. Vorderflügel von Hemiteles. Areola nach aussen offen.

Der untere Aussenwinkel der Discoidalzelle (a) ein spitzer.

folgt als 3. Glied der schmale, ringförmige Annellus; die nun folgenden Glieder bilden die eigentliche Geissel; das 1. Glied derselben, das an Länge die übrigen Glieder meist übertrifft, bezeichnet man wohl auch als Postannellus. Das Gesicht

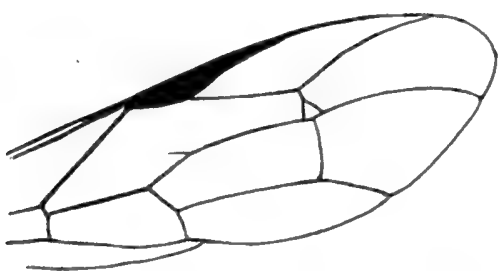

Abb. 4.- Vorderflügel von Rhyssa.

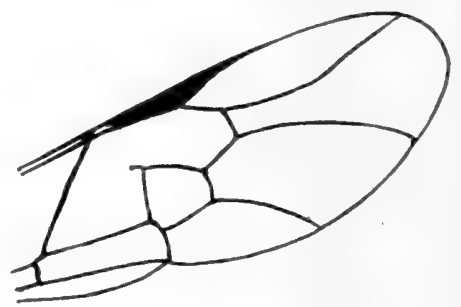

Abb. 5. Vorderflügel von Ophion.

ist in der Mitte in der Regel schwach erhöht, bei manchen Gattungen aber auch stark aufgetrieben. Die Seitenränder der Stirn und des Gesichtes (orbitae frontales und faciales), ebenso die hintere Umgrenzung der Augen (orbitae externae) sind oft durch helle Färbung ausgezeichnet. Clypeus meist durch eingedrückte 
Linie vom Gesicht getrennt, beiderseits mit Gruben, der Vorderrand verschieden und für die Systematik wichtig; Mandibeln am Ende mit 2 Zähnen, selten nur mit einem oder abgestutzt, der obere Zahn zuweilen gespalten. Maxillarpalpen meist mit 5, Labialpalpen mit 4 Gliedern.

Der Thorax zerfällt in Pro-, Meso- und Metathorax. Von Wichtigkeit sind die seitlichen Längsfurchen des oberen Teils des Mesothorax, des Mesonotums, ob sie vorhanden sind oder fehlen, ob sie tief oder flach, ob sie nur vorn ausgeprägt oder ob sie durchlaufend sind; von Wichtigkeit ist ferner das Vorhandensein oder Fehlen eines polierten Raumes im oberen Endwinkel der Mittelbrustseiten (Mesopleuren), des sogenannten Spekulums. Von grosser Wichtigkeit für die Systematik ist die Felderung und die Gestalt der Luftlöcher

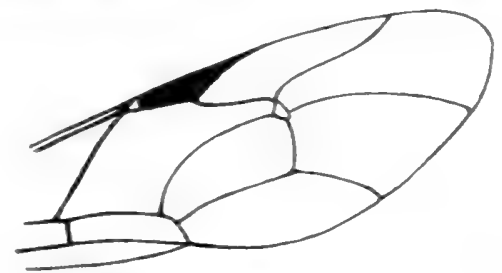

Abb. 6. Vorderflügel von Paniscus.

des Metathorax. Die Bezeichnung der Felder ergibt sich am besten aus der Zeichnung; von grosser Bedeutung ist die Form des mittelsten Feldes der Mittelreihe (Area superomedia) und das Fehlen oder Vorhandensein der von ihr seitwärts ungefähr in der Mitte ausgehenden Leiste, der Costula; ist sie vorhanden, dann sind die Seitenfelder voneinander getrennt; fehlt sie, so sind sie verschmolzen.

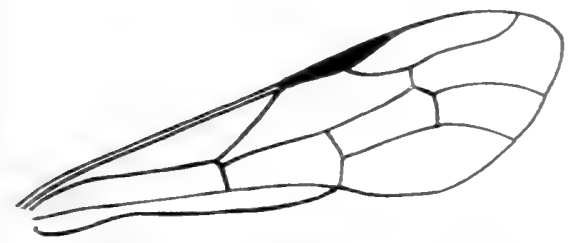

Abb. 7. Vorderflügel von Exochilum.

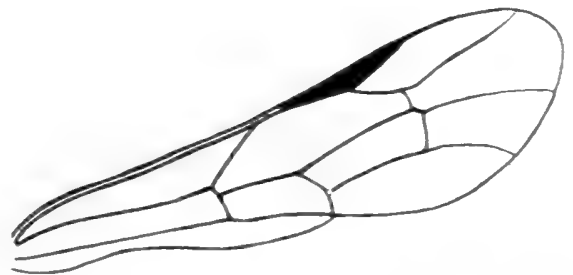

Abb. 8. Vorderflügel von Anomalon.

Von noch grösserer Bedeutung für die Systematik ist die Nervatur der Flügel, namentlich der Vorderflügel. An letzteren unterscheiden wir zunächst im Basalfeld 4 Längsnerven; der erste wird als Costa, der zweite als Subcosta bezeichnet; beide vereinigen sich etwas hinter der Mitte des Vorderrandes und bilden das Stigma (Pterostigma), aus welchem der Radius entspringt; letzterer umschliesst die nach ihm benannte Radialzelle. Der dritte Längsnerv führt den Namen Cubitus, der vierte wird Brachialnerv (Brachium) genannt.

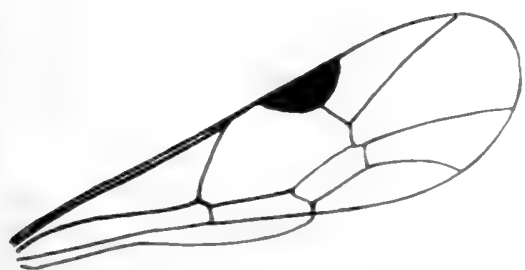

Abb. 9. Vorderflügel von Porizon.

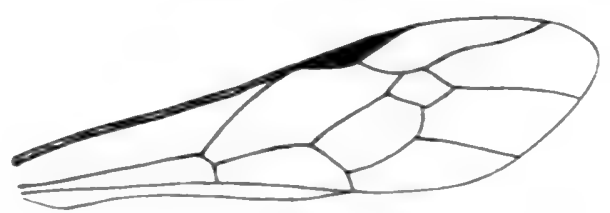

Abb. 10. Vorderflügel yon Melopius.

Was die Quernerven anbelangt, so erstreckt sich vom Cubitus bogenförmig nach oben der Basalnerv, unter ihm steht der kleine aber wichtige Nervulus; er ist entweder interstitial, oder er ist antefurkal, d. h. er steht vor dem Basalnerv oder er ist postfurkal, d. h. hinter dem Basalnerv. Die vom Basalnerv 
nach aussen gelegene grosse Zelle ist die Discocubitalzelle, entstanden aus der 1. Cubital- und der 1. Discoidalzelle. Der diese Zelle nach aussen abschliessende Nerv wird als Discocubitalnerv bezeichnet; er ist nicht selten oberhalb der Mitte winklig gebrochen und es findet sich an dieser Stelle häufig ein kleiner Nervenast, der Ramellus. Als wichtigste Zelle ist die 2. Cubitalzelle, kurzweg Areola genannt, zu betrachten; ihr Vorhandensein oder Fehlen, ihre Grösse und Form bilden ein wichtiges Merkmal für die Unterscheidung der Unterfamilien und Gattungen. Sie hat meist die Form eines Fünfecks, sie kann aber auch vier- oder noch häufiger dreieckig sein; in den letzteren Fällen ist sie dann oft gestielt, indem die Seitennerven sich vereinigen, ehe sie den Radius erreichen, während sie im anderen Falle als sitzend bezeichnet wird. Bei vielen Gattungen fehlt die Areola ganz, und dann ist nur ein kurzer Quernerv, der sogenannte Areolarnerv, vorhanden. Derjenige Nerv, welcher von unten in die Areola, oder hinter, sehr selten vor dem Areolarnerv mündet, ist der rücklaufende Nerv. Zwischen ihm und dem Discocubitalnerv befindet sich die Discoidalzelle; wichtiger als diese ist die nach aussen vom Nervulus liegende Zelle, die Brachialzelle. Von dem diese Zelle aussen begrenzenden Nerv geht ein gebogener Längsnerv, der Parallelnerv, aus, dessen Einmündung, ob über, in oder unter der Mitte, in vielen Fällen sehr wichtig ist. Vom Parallelnerv erstreckt sich nach oben der bereits erwähnte rücklaufende Nerv. - Einfacher und weniger wichtig ist die Nervatur des Unterflügels. Der Radius erreicht selten den Flügelrand; der kleine von unten auf ihn treffende Quernerv wird als rücklaufender Nerv angesehen. Die beiden mittleren Längsnerven werden wie beim Vorderflügel als Cubitus und Brachialnerv bezeichnet. Sehr wichtig ist der kleine dazwischenliegende Quernerv, der Nervellus; er ist gewöhnlich gebrochen und schickt an dieser Stelle einen Längsnerv aus; ist er schief nach innen gestellt und dann meist unter der Mitte gebrochen, so wird er als antefurkal bezeichnet, ist er steil gestellt, so nennt man ihn vertikal, und ist er schräg nach aussen gestellt, so haben wir einen postfurkalen Nervellus.

Die Beine bestehen aus Hüfte, den beiden Trochantern oder Schenkelringen, Schenkel, Schiene und Tarsen. Auf der Unterseite der Hüfte befindet sich zuweilen, namentlich bei den echten Ichneumoninen, eine dicht filzig oder samtartig behaarte Stelle, die sogenannte Bürste. Das 2. Glied der Trochantern wird wohl auch als Trochantellus bezeichnet. Die Schienen tragen am Ende innen gewöhnlich 2 Sporen, die vordersten in der Regel nur einen. Das erste der 5 Tarsenglieder führt den Namen Metatarsus, das letzte ist das Klauenglied; die Klauen selbst sind entweder einfach oder sie sind mit Kammborsten oder eigentlichen Kammzähnen besetzt.

Der Hinterleib ist meist von gestreckt ovaler Gestalt; er ist flach oder er ist namentlich gegen das Ende von der Seite zusammengedrückt, zuweilen sehr stark. Die Zahl der Rückensegmente, die auch als Tergite bezeichnet werden, beträgt höchstens 8 , von denen jedoch die letzten nur wenig vortreten. Das 1. Segment ist entweder nach vorn nur wenig, oder es ist stark, mehr oder weniger stielartig verschmälert; danach unterscheidet man einen sitzenden oder gestielten Hinterleib; zwischen den beiden extremen Formen gibt es die mannigfaltigsten Übergänge. Das gestielte 1. Segment ist in der Regel hinter der Mitte gekniet und von da an verbreitert. An der Beugungsstelle treten die Luftlöcher meist knötchenartig vor. Das 1. Segment zerfällt dadurch in zwei Teile, den vorderen dünneren und längeren Teil, den eigentlichen Stiel (petiolus) und den breiten hinteren Teil, den Hinterstiel (postpetiolus). Fast ebenso wichtig wie das erste ist das 2. Segment. An seiner Basis befinden sich, ganz besonders bei Ichneumon, Amblyteles und verwandten Gattungen, mehr oder minder tiefe Eindrücke, die den Namen Gastrocölen führen. 
Während die vorderen Segmente durch einfache, bewegliche Suturen miteinander verbunden sind, greifen die hinteren Segmente mit dem Endrande über das folgende; die Segmente sind also ineinander geschoben. Die vorderen und mittleren Segmente haben an der Bauchseite eine weiche Haut, die im Tode meist eine erhabene Längsfalte bildet. Das 6. Bauchsegment ist in der Regel durch Grösse ausgezeichnet, steht auch meist ab und hat nicht selten eine pflugscharförmige Gestalt; es wird auch als Hypopygium oder Valvula ventralis bezeichnet; hinter ihm tritt bei dem + der Legebohrer hervor. Seine Länge ist höchst verschieden, je nach der Lebensweise des Wirtes. So erreicht er bei vielen Pimplinen, z. B. bei den Gattungen Thalessa und Rhyssa, welche die tief im Holze sitzenden Larven der Holzwespen anstechen, eine ganz enorme Länge; es gibt aber auch Gattungen, bei denen der Bohrer ganz versteckt ist, so dass die Unterscheidung der Geschlechter schwierig ist; zwischen diesen beiden Extremen gibt es alle möglichen Übergänge. Der Bohrer selbst besteht aus drei Teilen, den beiden, meist dicht und kurz behaarten Seitenklappen, die als Schutz des eigentlichen Bohrers dienen; dieser besteht ebenfalls wieder aus drei Teilen, welche zusammen eine Röhre bilden. Viele Ichneumoniden mit kurzem Bohrer können denselben als Wehrstachel benützen und nach dem sehr schmerzhaften Stich, den manche Arten, so besonders die grösseren Ophioninen, beibringen, kann man wohl annehmen, dass sich beim Stich ein Gift in die Wunde ergiesst. Der Unterschied der Geschlechter ist in den meisten Fällen nicht schwer. Der gedrungenere Bau und namentlich der Bohrer charakterisieren die $f ?$ sattsam; in Fällen, wo dieser versteckt ist, dienen die kräftigeren, mehr gebogenen und eingerollten, oft hell geringelten Antennen, der breite Hinterleib dazu, die of kenntlich zu machen, während die $\sigma^{7} \sigma^{7}$ eine schlankere Form und meist längere, mehr vorgestreckte und selten hell geringelte Antennen besitzen.

\section{Lebensweise der Ichneumoniden.}

Die Fabel erzählt, dass der bekanntlich zu den Mardern gehörende ägyptische Ichneumon den Krokodileiern nachgehe und so der Vermehrung dieser Tiere steuere oder dass er gar den schlafenden Krokodilen in den Leib krieche und deren Eingeweide verzehre. Wegen einer gewissen Ähnlichkeit zwischen dieser Lebensweise und der Tätigkeit der Schlupfwespen hat sich für diese im Laufe der Zeit die Benennung „Ichneumonen“ festgesetzt. Diese Bezeichnung wird zuerst von Aristoteles im 5. Bande seiner Naturgeschichte der Tiere gebraucht. Freilich erzählt er von seinem Ichneumon, dass derselbe Spinnen töte und in sein Nest trage; wir haben also darunter wohl eher eine Weg-oder Grabwespe, als eine Schlupfwespenart zu verstehen.

Alle Ichneumoniden sind Schmarotzer, und zwar leben sie bei den Larven der verschiedensten Insektenordnungen, selten von Spinneneiern. Die Weibchen legen die Eier vermittelst des Legebohrers unter die Haut des Wirtes, seltener an dessen Oberfläche; in letzterem Falle bohrt sich die Schlupfwespenlarve, sobald sie ausgeschlüpft ist, entweder in den Wirt ein, oder sie saugt an der Oberfläche. Wie fein müssen die Sinnesorgane der ihre Opfer aufsuchenden Schlupfwespen-Weibchen sein; sie spüren die tief im Innern sitzenden Larven auf, sie wissen genau die Stelle, wo sie sind, sie wissen auch, ob sie bereits angestochen sind oder nicht. So trägt denn das unglückliche Opfer in seinem Innern einen oder mehrere, von kleineren Arten oft eine Menge Schmarotzer, und das Wunderbare ist, dass es diesen Angriffen nicht bald unterliegt. In der Tat, eine wunderbare und doch wieder so grausame Einrichtung der Natur. Man betrachte so eine Schwärmerraupe, aus der sich Hunderte von kleinen Schlupfwespen, meist Braconiden, vor dem Einspinnen herausgearbeitet haben; 
wie ein Sieb ist sie durchlöchert; was muss sie ausgehalten haben, ehe sie verendet ist! So leben die Larven im Innern ihres Opfers, ohne die für das Leben desselben wichtigen und notwendigen Organe anzugreifen; sie lassen ihm die Fähigkeit, zu leben, sich zur Puppe umzuwandeln, ja es sind genug Fälle bekannt, dass auch aus dem vollkommenen Insekt noch Schmarotzer hervorgegangen sind. - Man könnte nun meinen, dass solch eine Schlupfwespe ganz ungestört und unangefochten ihr wehrloses Opfer überfallen könnte, dem ist aber nicht so. Auch hier zeigt sich der ewige Kampf in der Natur, und zwar droht ihr

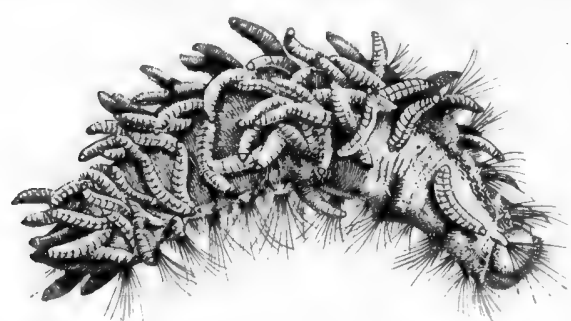

Abb. 11. Raupe eines Spinners, aus welcher sich die ausgewachsenen Apanteles-Larven hervorbohren, um sich zu verspinnen.

Gefahr von ihresgleichen, indem sie wieder von anderen Schlupfwespen angestochen wird, die als Schmarotzer zweiten Grades oder Hyperparasiten bezeichnet werden. Werden auch diese wieder befeindet, so haben wir es mit Schmarotzern dritten Grades zu tun. Das sind nun freilich schwer klarzulegende Fälle und ich habe bereits bei Gelegenheit der zahlreichen in den Rosengallen vorkommenden Schmarotzerarten darauf hingewiesen. Wir haben 2 Ichneumoniden-Gattungen, Hemiteles und $\mathrm{Pe}$ zomachus, deren zahlreiche Arten als Schmarotzer zweiten Grades leben und deren Biologie ausserordentlich schwierig zu entziffern ist, wissen wir doch über die Zusammengehörigkeit der Geschlechter, namentlich der Gattung Pezomachus, noch herzlich wenig. Ausser ihren Verwandten haben die Schlupfwespen ihre Hauptfeinde in den Vögeln, die somit schädlich wirken. Wie verhält sich damit der bis zum Überdruss gerühmte Nutzen der Vögel? Der Laie hält eben jedes Insekt für schädlich und wehe dem, der ihn eines Bessern belehren wollte.

Die Ichneumonen suchen ihre Opfer unter allen Insektenordnungen, vorzugsweise werden jedoch die Schmetterlinge heimgesucht. Es mögen, was Parasitismus bei Insekten betrifft, rund etwa 2000 Fälle bekannt sein, davon entfällt etwa die Hälfte auf Schmetterlinge; der Hauptgrund liegt freilich darin, dass das Larvenleben der Schmetterlinge so ausserordentlich gut bekannt ist, während von anderen Ordnungen höchstens die raupenähnlichen Larven der Blattwespen oder Gallen und vielleicht noch einzelne holzbewohnende Insekten, namentlich Käfer, gezüchtet worden sind. Nächst den Schmetterlingen kommen als Wirte Hautflügler und Käfer in Betracht. Fliegenlarven werden hauptsächlich von Braconiden und Proctotrupiden heimgesucht. Wenige Schlupfwespen sind als Schmarotzer von Neuropteren bekannt, doch sind selbst die im Sande lebenden Larven der Ameisenlöwen nicht sicher vor den Angriffen dieser kleinen Feinde, indem sie von einer merkwürdig gebauten Chalcidine, dem Hybothorax Graffi Ratzeb., angestochen werden. Am allerwenigsten kommen Schlupfwespen bei Orthopteren vor. - Es gibt wohl kaum eine Schmetterlingsart, deren Raupe nicht von Schlupfwespen angestochen würde; jeder Schmetterlingszüchter weiss von diesen verhassten Tieren zu erzählen. Er hat von dieser oder jener seltenen Schmetterlingsart Raupen gefunden; er hat sie sorgfältig gefüttert und abgewartet und sie haben sich alle verpuppt und er freut sich schon auf das Ausschlüpfen der Falter; aber siehe da, eine nach der andern der Puppen wird steif und eines schönen Tages spaziert statt des seltenen Schmetterlings eine zierliche Schlupfwespe hervor. Meist wird eine Schmetterlingsart auch nur von einer bestimmten Schlupfwespe angestochen, manche Ichneumonen, wie z. B. die höchst nützlichen Pimpla-Arten, schmarotzen dagegen bei einer ganzen Reihe von Wirten; umgekehrt gibt es auch wieder Schmetterlingsarten, wie z. B. der gefürchtete Kiefernspinner, die von zahlreichen Schlupfwespenarten befallen werden. Die Grösse 
des Schmarotzers richtet sich in der Regel nach der Grösse des Wirtes und es beherbergt dieser dann nur ein Stück. So leben bei den grossen Schwärmerarten die grossen, prächtig gezeichneten Arten der Gattungen Ichneumon, Amblyteles, Trogus usw. - Trotz des häufigen Vorkommens der Schlupfwespen wird man den Vorgang des Anstechens nur selten beobachten können; am ehesten hat man Gelegenheit, die grossen Arten der Gattungen Thalessa, Rhyssa und Ephialtes dabei anzutreffen. Die Stellung, die die Schlupfwespen beim Anstechen einnehmen, ist verschieden. Die erwähnten, mit langem Bohrer versehenen grossen Pimplinen stützen sich dabei auf die Vorderbeine, gleichsam auf die Hände, richten den Hinterleib steil in die Höhe, indem sie ihn gleichzeitig so weit als möglich ausrecken und setzen den Bohrer senkrecht von oben ein. Die ganze Prozedur, den Bohrer durch die Zwischenräume des harten Holzes hindurchzuzwängen und ihn dann wieder herauszuziehen, erfordert Stunden; während dieser Zeit ist das Tier durch den Bohrer vollständig festgehalten. Ganz rätselhaft ist mir, wie manche tropische Schlupfwespenarten, deren Bohrer die Körperlänge mindestens um das Zehnfache übertrifft, es sind ganz wunderbare Tiere, beim Stechen

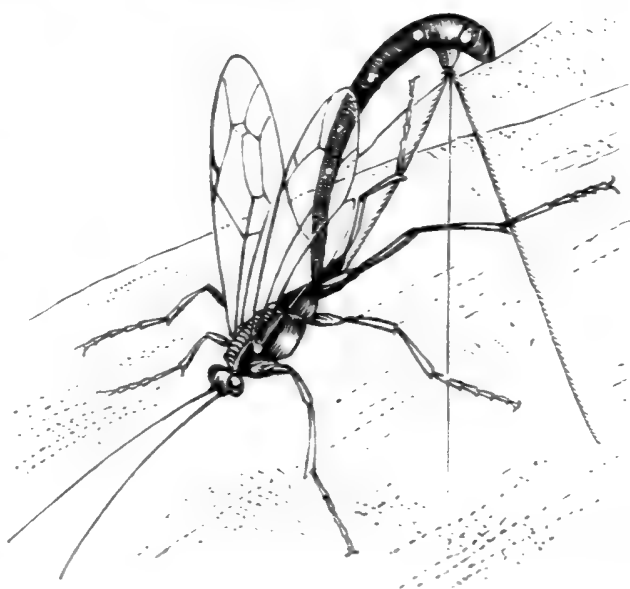

Abb. 12. Rhyssa persuasoria L., eine Sirex-Larve anstechend.

den Bohrer einsetzen. Die angestochenen Opfer, so besonders die vielen Raupenarten, zeigen im allgemeinen nach dem Angestochensein keine besonderen Anzeichen eines veränderten Zustandes. Geübte Schmetterlingszüchter erkennen solche Raupen meist an den dunklen oder missfarbigen Punkten, welche der Stich hervorbringt. Ich habe bereits oben bemerkt, dass die Eier der Schlupfwespen, wenn auch in weniger Fällen, auch aussen an die Haut des Wirtes gelegt werden. Manche dieser Eier sind gestielt, wie z. B. die von $P a$ niscus testaceus Grav., einer ziemlich grossen rötlichgelben Schlufwpespe, die es hauptsächlich auf Spinner und Eulen abgesehen hat. Die Eier sitzen so fest an der Haut, dass sie durch keine Bewegung der Raupe abgestreift werden können.

Die Schlupfwespen machen natürlich, wie alle Hymenopteren, eine voll-

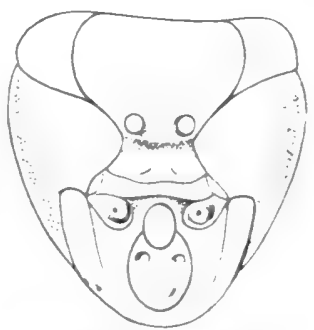

Abb. 13. Mund der ausgewachsenen Larve von Exochilum circumflexum L. (Nach Ratzeburg.)

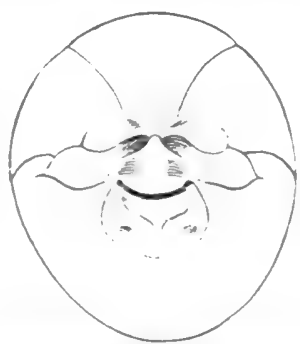

Abb. 14. Vorderansicht des Kopfes der ausgewachsenen Larve von Apanteles fulvipes Hall. (Nach Ratzeburg.) kommene Verwandlung durch. Die Larven sind fusslos, also madenförmig und haben auch die entsprechende weissliche oder gelbliche Farbe; sie bewegen sich wie alle Maden durch Ausdehnung oder Zusammenziehung der Leibesringe fort; ein After fehlt ihnen, da die aufgenommenen Nahrungsstoffe vollkommen verdaut werden. Gegen die namentlich von den älteren Autoren, wie Réaumur, vertretene Ansicht, dass die Schmarotzer hauptsächlich den Fettkörper ihrer Wirte verzehren, wendet sich 
Ratzeburg; er stützt seine Meinung hauptsächlich darauf, dass viele Schmarotzer nur aussen an der Raupe saugen und nie in das Innere dringen, dass sie also nur feine Nahrung, nur Flüssigkeit gebrauchen können. Da ist noch sehr viel zu beobachten und noch gar manche Frage zu lösen. Schon Ratzeburg sagt, dass sich kaum in einer anderen Abteilung der Insekten so viel Gelegenheit zu biologischen und physiologischen Beobachtungen bieten dürfte, wie in der der Ichneumonen; man glaube sich in eine Wunderwelt versetzt zu sehen. Die Atmungsweise der Schlupfwespenlarven, welche im Innern ihrer Wirte leben, ist noch

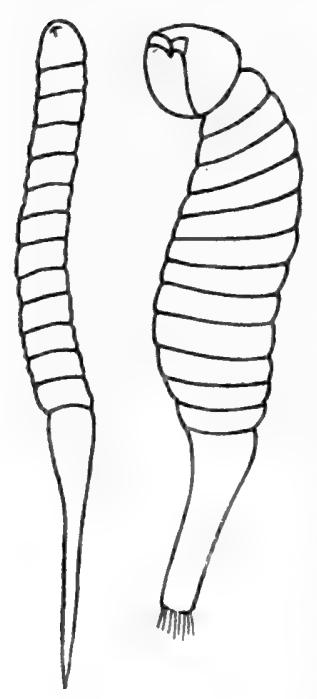
wenig erforscht. Ratzeburg glaubt, dass das schwanzähnliche Gebilde, das bei vielen Schlupfwespen auftritt, wahrscheinlich die Respiration vermittle. Ist die Larve erwachsen, dann verspinnt sie sich; meist geschieht dies im Innern des Wirtes; nur wenige Ichneumoniden, besonders Ophioninen und Arten der Gattung Banchus, arbeiten sich aus dem Wirt heraus; sie gleichen darin vielen Braconiden, namentlich den Microgasterinen. Die Kokons selbst sind von verschiedener Beschaffenheit; manche sind dünn und weich und dann meist von heller Farbe; andere wieder sind von einem zähen, zuweilen mehrfach geschichteten Stoffe von schwarzbrauner Färbung; zu den letzteren Kokons gehören z. B. die der Gattung Paniscus. Die ausgebildete Wespe nagt sich eine kreisrunde Öfnung am Ende des Kokons, um daraus herauszuschlüpfen; Schmarotzer zweiten Grades machen das Ausgangsloch meist an der Seite. Auffallend sind die Grössenunterschiede mancher Schlupfwespenarten, je nachdem sie bei einem grossen oder kleinen Wirt schmarotzt haben; gute Beispiele bieten dafür besonders die Gattungen Ephialtes

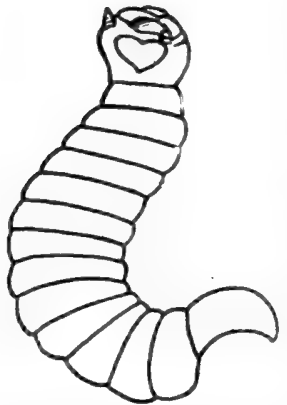

Abb. 15, 16, 17. Larve von Exochilum circumflexum L., im 1., 2. und 3. Stadium. (Nach Ratzeburg.) und Pimpla; gerade bei der ersteren Gattung stösst die Unterscheidung der Arten dadurch auf grosse Schwierigkeiten. Höchst verschieden ist auch die Dauer der Zeit, welche eine Ichneumonbrut zu ihrer Entwicklung braucht. Wahrscheinlich hängt diese von der Entwicklungszeit des Wirtes $a b$, nicht von der Grösse der Art, denn grosse Pimpla-Arten können sich schon in 3 Wochen entwickeln, während kleine Schlupfwespen erst nach fast Jahresfrist ausgeschlüpft sind. Aus der kurzen Entwicklungszeit mancher Arten lässt sich wohl schliessen, dass mehrere Generationen aufeinander folgen, oder besser gesagt folgen können, denn Genaues ist darüber noch nicht bekannt, auch nicht über die Frage, in welchem Entwicklungszustande die einzelnen Arten überwintern. Wir wissen nur, dass man im Winter, namentlich unter Moospolstern an alten Bäumen, Schlupfwespen antrifft; das sind aber immer nur bestimmte Arten, namentlich aus der Unterfamilie der Ichneumoninen. Diese überwinternden Tiere sind immer nur Weibchen, die die Eierablage noch nicht beendet hatten, überhaupt ist die Lebensdauer der Weibchen durchweg länger als die der Männchen; letztere sterben bald nach der Paarung. Letztere wird trotz der Riesenmenge von Arten und Individuen nur selten gesehen, ausnahmsweise hatte ich im Juli des an heissen Tagen so reichen Jahres 1911 einmal Gelegenheit in einem feuchten Hohlweg im Walde, wo das sonst seltene Anomalon biguttatum Grav. in Menge flog, zahlreiche Pärchen in copula fliegen zu sehen. 


\section{Geographische Verbreitung.}

Was diese betrifft, so finden sie sich überall, ihre Hauptverbreitung haben sie jedoch in der nördlichen gemässigten Zone. Während Europa, namentlich das nördliche und mittlere, zum Teil auch das nördliche Amerika, ziemlich gut bekannt sind, wird uns der nördliche und gemässigte Teil von Asien noch massenhaftes Material liefern. Eine auffallende Armut an Schlupfwespen zeigen die südlichen Länder, ich meine speziell Südeuropa und Nordafrika; das ist um so auffallender, als die eigentlichen Tropenländer wieder eine ganze Reihe schöner, namentlich durch bunte Flügel ausgezeichneter Arten beherbergen.

\section{Bedeutung der Schlupfwespen.}

Aus all dem Gesagten ist zur Genüge schon hervorgegangen, von welcher grossen Bedeutung die Schlupfwespen durch Vernichten einer Menge Schädlinge, namentlich gefrässiger Raupen sind. In ihrem Tun und Treiben werden sie unterstützt durch die ganz gleich lebende Dipterenfamilie der Tachinen. Beide Schmarotzerfamilien halten mit der Vermehrung der Schädlinge gleichen Schritt, bis schliesslich fast alle Stücke der letzteren mit Parasiten besetzt sind. Wer einen Gemüsegarten hat, kann das so leicht beobachten an dem Auftreten der Kohlweisslingsraupen und ihrer schliesslichen Vernichtung durch Apanteles glomeratus L. Da, wie die Erfahrung lehrt, wenn der Schädlingsfrass am höchsten ist, meist auch verheerende Pilzkrankheiten auftreten, so schloss Ratzeburg daraus, dass die Ichneumonen mit Vorliebe kranke Raupen befielen, ähnlich wie die Borkenkäfer mit Vorliebe kränkelnde Bäume. Mit Recht ist diese Hypothese von späteren Beobachtern unter den Forstleuten, wie Altum und Nitsche, als irrtümlich zurückgewiesen worden und somit erscheint der Nutzen, den die Ichneumonen leisten, weit grösser als ihn Ratzeburg annahm. Wenn die ungeheure nutzenbringende Tätigkeit der Schlupfwespen auch jetzt noch viel zu wenig anerkannt wird, so liegt das einfach daran, dass der Laie ohne alle Kenntnis von diesen Tieren ist; haben doch selbst Zoologen von Fach, selbst Entomologen, meist einseitige Käfer- oder Schmetterlingssammler, kaum einen Einblick in dieses Riesengebiet. Hochinteressant sind die Experimente im grossartigen Masstab, die neuerdings in Amerika gemacht worden sind, um durch massenhaftes Einführen der betreffenden Schlupfwespen aus Europa die beiden nach den Vereinigten Staaten eingeschleppten und verheerend auftretenden Spinner, den Schwammspinner, Lymantria dispar L. (gipsy-moth) und den Goldafter, Euproctis chrysorrhoea L. (brown-tailed moth) zu bekämpfen. Ein ähnliches Experiment bereitet sich jetzt vor zur Bekämpfung des in den letzten Jahren namentlich in der Pfalz und an der Mosel so schädlich aufgetretenen Heu- oder Sauerwurms und des Springwurms. Ich möchte diese kleine Auslassung über den Nutzen der Schlupfwespen mit denselben Worten schliessen, mit denen ich seinerzeit meinen in der Leipziger Illustrierten Zeitung erschienenen Artikel schloss: „Es war nur ein kleines Bild, das ich in kurzen Umrissen im vorstehenden gezeichnet habe, eine Momentaufnahme einer wunderbaren Tiergruppe, ein kurzer Blick, der uns zeigt, dass die Natur bei dem, was sie schafft, immer das Gleichgewicht zu erhalten weiss, dass sie auch Krieg und Mord, mag er noch so grausam geführt und ausgeführt werden, für einen wichtigen Faktor hält, um ihren Haushalt zu regeln. Die grösste Rolle in dieser Regulierungsarbeit haben die Schlupfwespen übernommen. Wollten sie einmal in einen Generalausstand treten, die Folgen würden unberechenbar sein ; zum Glück ist ein solcher nicht zu befürchten.“ 


\section{Sammeln und Präparieren der Ichneumoniden.}

Schlupfwespen finden sich überall und können das ganze Jahr, sogar im Winter unter Moos gesammelt werden. Der Schlupfwespensammler hat nie Grund, in das Klagelied anderer Entomologen einzustimmen, dass es das Jahr nichts zu fangen gäbe. So wurde z. B. im Jahre 1911 hier in Thüringen von den Lepidopterologen allgemein Klage geführt, dass die abnorme Hitze dem Schmetterlingsfange ausserordentlich nachteilig gewesen wäre; im Gegensatz dazu waren an solchen glühendheissen Tagen in feuchten Schluchten, Waldwegen usw. die niederen Büsche und Pflanzen mit Schlupfwespen geradezu bedeckt; Tausende und aber Tausende konnte ich in wenigen Minuten durch Abstreifen im Netze haben. Auch denen gegenüber, die andere Gruppen der Hymenopteren, vielleicht Bienen oder Grabwespen, sammeln, ist der Schlupfwespensammler im Vorteil, einesteils weil er, wie bereits gesagt, immer reiche Ausbeute findet, und andernteils, weil die eingefangenen Stücke fast durchweg frisch und tadellos sind. Wo die meisten Schlupfwespen zu finden sind, ist schwer zu sagen, der geübte Sammler wird das bald herausfinden; im Frühling und anfangs Sommer wird man sie hauptsächlich an Gebüsch, an Hecken, Waldränndern usw. antreffen, kommt dann die Zeit, wo die Doldengewächse blühen, dann wird man auf diesen die Hauptausbeute haben, in manchen Jahren kann man auf den Dolden von Heracleum und Pastinaca in Menge die grossen und prächtigen Arten der Gattungen Ichneumon, Amblyteles und verwandter antreffen. - Was die Ausrüstung zum Fang betrifft, so verweise ich auf das betreffende Kapitel in meinem Werke „Die Hymenopteren Mitteleuropas" und will hier nur das Wichtigste kurz wiederholen. Mein Netz hat einen Durchmesser von etwa $25 \mathrm{~cm}$, der Reifen besteht aus starkem Draht, ist nicht zusammenlegbar und unten mit den beiden Enden beiderseits an eine Blechhülse gelötet, an die der Fangstock, ein gewöhnlicher Spazierstock ohne Griff, passt. Ich benütze das Netz gleichzeitig auch als Kätscher. Meine Fangflasche ist ohne Pfropfen $12 \mathrm{~cm}$ lang und etwa $6 \mathrm{~cm}$ breit; durch den Pfropfen führt eine $14 \mathrm{~mm}$ weite, oben und unten vorstehende Röhre, die man sich durch Zusammenrollen und Zusammenleimen von Papier selbst herstellt; man wickelt am besten das Papier über ein entsprechendes Probiergläschen. Oben ist die Röhre durch einen Kork verschlossen. Die ganze Fangflasche steckt bis etwas unter dem Hals in einem Futteral, am besten von Wollstoff; oben muss die Flasche so weit davon frei sein, dass man sehen kann, ob das Tier durch die Röhre in die Flasche gelangt ist. Die Tiere selbst nehme ich mit den Fingern aus dem Netz und stecke sie in die Röhre. Die Flasche selbst ist zum Teil mit Streifen von Löschpapier gefüllt. Zum Töten benütze man, wie das schon vielfach erörtert worden ist, nur reinen Schwefeläther, und zwar giesst man beim Fangen nur wenige Tropfen in die Flasche, nur so viel, dass die Tiere nur betäubt und regungslos werden; um die Tiere zu Hause zu töten, giesst man ein grösseres Quantum, vielleicht 20-30 Tropfen in die Flasche und lässt die Tiere eine Zeitlang darin. Die Praxis wird bald das gehörige Mass finden lassen; man vermeide vor allen Dingen das Zuviel, die Flasche darf innen nie beschlagen, sonst verkleben die Tiere, namentlich die Flügel. Ich nadle meine sämtlichen Ichneumoniden, nur die kleinen und kleinsten ungeflügelten Formen, so z. B. die Arten der Gattung Pezomachus, klebe ich auf Kartonpapier. Die kleinen geflügelten Arten kommen an Silbernadeln auf Klötzchen aus dem Marke der Kerria japonica L. (Corchorus japonicus Thunb.), des sogenannten Goldröschens, eines in Anlagen sehr verbreiteten Strauches. - Gespannte Ichneumoniden, aber nur gut gespannte, mögen besser aussehen als ungespannte, 
allein das Spannen erfordert weit mehr Zeit als bei Schmetterlingen, da wegen der starken Muskeln die Flügel schwer auszurichten sind. Ungespannte Tiere müssen in eine gefällige Form gebracht werden, so dass die Körperteile, namentlich Mund und Flügelnervatur, gut zu untersuchen sind.

Am Schluss dieses Kapitels möchte ich noch ganz besonders den Rat geben, Ichneumonen zu züchten, in erster Linie natürlich aus Schmetterlingen, dann aber auch aus anderen Wirten, also z. B. aus Holz, Rinden, Gallen, Schwämmen, Tannenzapfen, Schilfstengeln usw. Reicher Lohn wird dem zuteil, der sich diese Arbeit nicht verdriessen lässt.

\section{Geschichtliches; kurzer Abriss der Literatur über Ichneumoniden.}

Ich habe bereits oben erwähnt, dass Aristoteles der erste war, welcher die Bezeichnung "Ichneumon" gebraucht, wenn auch jedenfalls in einem andern Sinne. Der erste Autor, der eine sichere Notiz über das Leben der Schlupfwespen bringt, ist Aldrovandus in seinem 1623 zu Frankfurt a. M. erschienenen Werke „De animalibus insectis“, und zwar bezieht sich seine Notiz auf den so oft erwähnten Parasitismus von Apanteles glomeratus L. bei der Kohlweisslingsraupe; auch er verfällt, wie heutzutage noch viele Menschen, in den Irrtum, dass die gelben Kokons die Eier der Kohlraupen seien. Weitere biologische Notizen brachten Frisch in seinem Werke „Beschreibung von allerley Insekten in Teutschland“ und namentlich der scharfsichtige Réaumur, einer der besten Beobachter, im 2. und 6. Bande seiner "Mémoires pour servir à l'histoire des insectes". Von Frisch werden zum erstenmal die Ichneumonen als „Schlupfwespen“ bezeichnet; Réaumur züchtete bereits viele Arten aus Schmetterlingen; er beobachtete mehrfach das Anstechen des Wirtes, er kannte schon Schmarotzer zweiten Grades; er erklärt bereits, dass der Versuch, ein System der Ichneumonen aufzustellen, angesichts ihrer ungeheuren Artenzahl ein vergeblicher sei. Nach Réaumur war es der schwedische Naturforscher Degeer, der sich hohe Verdienste auf dem Gebiete der Schlupfwespenkunde erwarb. Er erzog nicht allein eine Menge Arten aus allen möglichen Wirten, er versuchte sich auch auf dem Gebiete der Systematik. Im Jahre 1797 veröffentlichte der Engländer Marsham in seiner Schrift „Observations on the oeconomy of the lchneumon manifestator" seine ausgezeichneten Beobachtungen über das merkwürdige Tun und Treiben dieser Schlupfwespe. Im Anfang des vorigen Jahrhunderts wurden durch Latreille und kurz darauf durch Fabricius die ersten Versuche gemacht, ein System der Ichneumonen aufzustellen. Waren diese Versuche auch noch sehr mangelhaft, so finden wir doch schon eine natürliche Gruppierung der Arten; denn wir finden bereits die Gattungen: Ichneumon, Cryptus, Pimpla, Ophion, Banchus, Bassus, Bracon, Foenus, Stephanus, Codrus usw. Eine neue Einteilung gab bald darauf Nees von Esenbeck; er zerlegte die eigentlichen Schlupfwespen in Ichneumonides s. str., Evaniales und Proctotrupini; die 1. Familie wurde wieder in 2 Gruppen eingeteilt: Ichneumonides genuini, mit zwei rücklaufenden Nerven, und Ichneumonides adsciti, mit nur einem oder keinem rücklaufenden Nerven; später stellte Nees den echten Ichneumoniden die übrigen Schlupfwespen als Hymenoptera ichneumonibus affinia gegenüber. Im Jahre 1829 veröffentlichte Gravenhorst seine "Ichneumonologia Europaea“, ein umfangreiches Werk in 3 Bänden, die erste grössere systematische Arbeit über Ichneumoniden, worin zahlreiche Arten beschrieben wurden. So veraltet das Werk auch ist, so muss doch immer auf die Gravenhorstschen Artbeschreibungen zurückgegriffen werden. 
So bedeutsam das Werk war, es hatte einen grossen Fehler, bei den Beschreibungen war hauptsächlich auf die Färbung Rücksicht genommen. Das Bestreben der späteren Forscher war deshalb darauf gerichtet, zuverlässigere Merkmale zur Unterscheidung heranzuziehen. Dies tat zuerst Wesmael, der als der eigentliche Begründer der wissenschaftlichen Systematik der Ichneumoniden zu betrachten ist. In seinem „Tentamen dispositionis methodicae Ichneumonum Belgii 1844" legte er das Hauptgewicht auf die Felderung des Metathorax und den Bau des Hinterleibs; seine späteren Publikationen sind nur eine Fortsetzung resp. Ergänzung der erwähnten Schrift. In den Jahren $1844-1852$ veröffentlichte Ratzeburg seine in 3 Quartbänden erschienenen „Ichneumonen der Forstinsekten“; sie enthalten eine erstaunliche Menge von Zuchtresultaten und anderen Beobachtungen; man muss freilich damit rechnen, dass die Systematik zu jener Zeit noch sehr zurück war. Wesmaels sämtliche Arbeiten behandeln fast nur die Unterfamilie der echten Ichneumoninen. Die übrigen Unterfamilien fanden dann in dem Schweden Holmgren einen gründlichen Bearbeiter, ebenso wurden später von ihm die schwedischen Arten der Ichneumoninen in der „Ichneumonologia Suecica“ eingehend behandelt. In einer im Jahre 1868 erschienenen Schrift "Synopsis der Familien und Gattungen der Ichneumonen" zerlegt Förster die Ichneumoniden in eine Unmenge von Gattungen, nämlich in über 600; er bezeichnet selbst diese Arbeit als einen vorläufigen Entwurf, die Gattungen sind auch nicht ausführlich beschrieben, sondern nur kurz in Bestimmungstabellen nach geringfügigen und schwankenden Merkmalen skizziert, die Zersplitterung ist überhaupt soweit getrieben, dass die grosse Mehrzahl dieser Gattungen unbrauchbar ist; immerhin ist eine Anzahl gedeutet worden, und ich selbst habe aus den hinterlassenen Schriften Försters versucht, eine Reihe zweifelhafter Gattungen klarzustellen. Ausserordentlich wertvoll sind die Arbeiten des scharfsichtigen schwedischen Entomologen Thomson über die Systematik der Ichneumoniden; er verstand es, eine Menge neuer Gesichtspunkte für die Einteilung zu verwerten; alle diese Arbeiten sind enthalten in den Opusculis Entomologicis. Als scharfer Kritiker erwies sich Kriechbaumer in München; leider brachte er es nicht fertig, eine zusammenhängende Arbeit zu liefern, seine zahlreichen Aufsätze, meist über einzelne Arten, sind in den verschiedensten, oft sehr schwer zugänglichen Zeitschriften zerstreut. Von neueren Schriften sind zu erwähnen eine Bearbeitung der echten Ichneumoninen durch Berthoumieu, sowie die hübsche Arbeit meines alten Freundes Professor Brauns in Schwerin über die Ophioninen im engeren Sinne, ich selbst behandelte verschiedene Unterfamilien und Gattungen monographisch. So war denn das Studium der Ichneumoniden zwar wesentlich gefördert worden, aber wer sich ihm widmen wollte, stand doch zuerst ziemlich ratlos da; es fehlte eben ein einheitliches Werk. So entschloss ich mich denn zu einer umfassenden Arbeit über die Ichneumoniden. Das Werk führt den Titel „Opuscula Ichneumonologica“ und erscheint seit dem Jahre 1902 in Lieferungen; bis jetzt (Mai 1913) sind 33 Hefte erschienen, enthaltend in deutscher Sprache die Bestimmungstabellen und Beschreibungen der Gattungen und aller paläarktischen Arten. Etwa alle 4 Monate erscheint ein Heft; Preis der Hefte $1-16$ je $3 \mathrm{Mk}$., der folgenden je $3.50 \mathrm{Mk}$. Behandelt sind bis jetzt die Ichneumoninen, Cryptinen, Pimplinen, Ophioninen und ein grosser Teil der letzten Unterfamilie, der Tryphoninen; in den nächsten Jahren wird das Werk zum Abschluss kommen. Dass das Werk noch nicht vollständig vorliegt, beeinträchtigt seinen Wert nicht, das ganze Gebiet wird wohl keiner gleichzeitig in Angriff nehmen wollen. 


\section{Systematik der Ichneumoniden.}

Entsprechend den Gravenhorstschen 5 Hauptgattungen Ichneumon, Cryptus, Pimpla, Ophion und Tryphon zerfallen die Ichneumoniden in 5 Unterfamilien, deren Grenzen freilich nicht scharf zu ziehen sind, so dass der Anfänger häufig in Verlegenheit gerät, zu welcher Unterfamilie er das eine oder das andere Tier zu stellen hat.

1. Hinterleib deprimiert, höchstens gegen das Ende etwas komprimiert, immer gestielt. Das 1. Segment gegen das Ende gekrümmt oder knieförmig gebogen, an der Basis stielförmig verschmälert, von den Luftlöchern an meist jäh erweitert und einen deutlich abgesetzten Postpetiolus bildend; die Luftlöcher hinter, höchst selten in der Mitte. Areola 5 seitig, wenigstens in der Anlage, seltener quadratisch oder ganz fehlend, niemals gestielt oder rhombisch. 2.

Hinterleib sitzend und dann deprimiert, wenn gestielt, dann mehr oder weniger komprimiert. Das 1. Segment in der Regel gerade oder leicht gekrümmt, nicht knieförmig gebogen; seine Luftlöcher vor oder in der Mitte, sehr selten hinter der Mitte; im letzteren Falle der Hinterleib deutlich komprimiert. Areola selten 5 seitig, meist unregelmässig dreieckig und gestielt, zuweilen rhombisch, häufig ganz fehlend. 3.

2. Luftlöcher des 1. Segmentes weiter voneinander entfernt als vom Hinterende; Postpetiolus deshalb in der Regel quer, meist längsrissig. Hinterleib dicht punktiert und matt, wenigstens auf der vorderen Hälfte; das 2. Segment an der Basis gewöhnlich mit Eindrücken (Gastrocölen). Bohrer des + verborgen oder nur wenig vorstehend. Areola selten mit fehlendem Aussennerv. In der Mehrzahl grosse und kräftige Tiere. 1 Ichneumoninae.

Luftlöcher des 1. Segmentes einander näher gerückt als dem Hinterrande; Postpetiolus weniger jäh erweitert, etwa so lang als breit, beim $\sigma^{7}$ oft linear und länger als breit. Hinterleib oft glatt; das 2. Segment an der Basis ohne oder mit undeutlichen Eindrücken. Bohrer des $q$ deutlich vorragend, sehr selten versteckt. Aussennerv der Areola zuweilen fehlend. Zahlreiche flügellose Formen. Mittelgrosse bis sehr kleine Tiere.

2. Cryptinae.

3. Bohrer selten unter halber Hinterleibslänge, oft sehr lang. Hinterleib sitzend, selten etwas gestielt, in letzterem Falle der Kopf kugelig oder kubisch; Oberfläche meist durch Höcker oder schräge, nach vorn zusammenlaufende Furchen uneben und meist dicht punktiert. Metathorax gewöhnlich nur mit der hinteren Querleiste; dies in vielen Fällen ein gutes Unterscheidungsmerkmal von den $\sigma^{7} \sigma^{7}$ der Tryphoninen. Areola dreieckig oder fehlend, bei Echthrus fünfeckig.

Bohrer kurz, wenn stärker vorragend, dann der Hinterleib gestielt und von der Seite zusammengedrückt. Oberfläche des Hinterleibs nicht durch Höcker oder Furchen uneben. 4.

4. Hinterleib mehr oder weniger komprimiert, meist gestielt und mit deutlich abgesetztem Postpetiolus; Bohrer oft vorragend, bis zu Hinterleibslänge; selten der Hinterleib sitzend. Areola besonders bei den kleinen Arten meist vierseitig und gestielt, oft auch fehlend. Gesicht oft seidenartig.

4. Ophioninae.

Hinterleib meist sitzend und niedergedrückt, sehr selten bei dem $q$ gegen das Ende etwas komprimiert; Postpetiolus nicht jäh erweitert und nicht scharf abgesetzt. Bohrer kurz. Areola meist verschoben dreieckig, oft gestielt, sehr häufig auch ganz fehlend.

5. Tryphoninae. 


\section{Übersicht der in Mitteleuropa, speziell in Deutschland vorkommenden Gattungen.}

\section{Unterfamilie. Ichneumoninae.}

Areola fünfseitig, sehr selten mit fehlendem Aussennerv, zuweilen stossen die Seitennerven oben ganz oder fast ganz zusammen. Metathorax meist deutlich und vollständig gefeldert. Postpetiolus in der Mitte mit höher gelegenem, meist längsrissigem Felde. Die ㅇ? meist mit hellem Fühlerringe. - Zu den Ichneumoninen gehören die grössten und schönsten Schlupfwespen. - Fast alle schmarotzen in Schmetterlingsraupen.

1. Luftlöcher des Metathorax langgestreckt, linear, elliptisch, oval, sehr selten fast rund; in diesem Falle die letzten Hinterleibssegmente breit weiss gerandet oder gefleckt oder die Klauen gekämmt. (Ichneumoninae stenopneusticae) 2.

Luftlöcher des Metathorax kreisförmig, bei Alomya breit oval. Die letzten Hinterleibssegmente nicht oder unmerklich weiss gerandet. Hinterleibsfärbung schwarz oder schwarz und rot. Klauen einfach. Mit Ausnahme von Alomya kleine Tiere, deren Gattungs- und Artunterschiede sehr schwierig sind. (Ichneumoninae cyclopneusticae) 51 .

2. 우 3.

$0^{7} 0^{\pi} 28$.

3. Hinterleibsende spitz; Bohrer deutlich vorstehend; das letzte Bauchsegment selten länger als das vorhergehende, vom Hinterleibsende abgerückt und nur die Basis der Endspalte bedeckend. (Ichneumonides oxypygi) 4.

Hinterleibsende stumpf; Bohrer nur kurz vorstehend; das letzte Bauchsegment deutlich länger als das vorhergehende und wenigstens die Hälfte der Endspalte bedeckend. 8.

4. Schildchen bucklig, hinten steil abfallend. Metathorax meist mit spitzen Seitendornen. Antennen und Beine schlank. Bohrer ziemlich weit vorstehend. Schmarotzen bei Vanessa-Arten und Pararge maera.

Schildchen flach oder nur wenig konvex. 5.

5. Mandibeln schmal, in eine lange, dünne Spitze auslaufend. Kopf kurz und breit, hinten tief ausgerandet; Gesicht unter den Antennen aufgetrieben und oben rundlich ausgeschnitten. Metathorax hinten mit tiefer Längsfurche, oben undeutlich gefeldert, Area superomedia durch polierten Raum angedeutet. Die einzige höchst seltene Art, H. eudoxius Wesm., ist schwarzbraun, auf Schildchen und Hinterschildchen, sowie Segment 2 gelb gefleckt; Länge etwa $10 \mathrm{~mm}$.

Heresiarches Wesm.

Mandibeln 2 zähnig. Gesicht und Metathorax von anderer Bildung. 6.

6. Clypeus vorn in der Mitte oder beiderseits von der Mitte ausgerandet. Kopf des + gross und etwas aufgetrieben. Area superomedia so lang oder länger als breit. Hinterleib schmal und spitz, schwarz oder an der Basis rot. Die Arten schmarotzen besonders bei der Eulengattung Nonagria.

Clypeus am Vorderrande nicht ausgerandet. 7.

Chasmias Ashm.

7. Hinterleib mit 7 Rückensegmenten; Bohrer mit schmalen Klappen. Das letzte Bauchsegment nicht auffallend gross und nicht länger als das vorhergehende. Eine an Arten ungemein reiche Gattung.

Ichneumon L. 
Hinterleib mit 8 Rückensegmenten; Bohrer mit breiten Klappen. Das letzte Bauchsegment gross, länger als das vorhergehende. In Deutschland 8-10 Arten, welche namentlich in Eulenraupen, besonders Arten von Leucania und Nonagria, vorkommen.

Exephanes Wesm.

8. Petiolus (der vordere schmale Teil des 1 . Hinterleibssegmentes) nicht deprimiert, mindestens so hoch wie breit. (Ichneumonides amblypygi) 9.

Petiolus deprimiert, breiter als hoch. (Ichneumonides platyuri) 23.

9. Die hinteren Klauen mit Kammzähnen. 10.

Klauen einfach. 11.

10. Luftlöcher des Metathorax fast rund. Clypeus in der Mitte des Endrandes schwach winklig vorspringend. Schildchen pyramidenförmig. Nur eine sehr zierliche, höchst seltene Art, L. nycthemerus Grav.; schwarz, reich gelb gezeichnet.

Listrodromus Wesm.

Luftlöcher des Metathorax gross und länglich. Vorderrand des Clypeus gerade. Schildchen schwach konvex. Hierher 2 zierliche Arten; Thorax bei

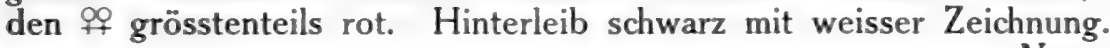

Neotypus Först.

11. Halsrand oben in der Mitte mit Kiel oder Höcker und beiderseits davon mit einem tiefen Grübchen. Die hintersten Beine weit kräftiger als die vorderen. Hinterleibsmitte rot, Endsegmente weiss gerandet. In Deutschland mehrere Arten, am häufigsten $A$. cingulatorius. Anisobas Wesm.

Halsrand oben ohne Mittelkiel und ohne Seitengrübchen. 12.

12. Clypeus breit zugerundet, in der Mitte jedoch winklig oder zahnartig vorspringend. Das 2. Segment mit verwischten Gastrocölen. Die beiden hierher gehörenden Arten gehören mit zu den seltensten Schlupfwespen. Der Hinterleib ist schwarz mit schmalen roten Endrändern; Schenkel schwarz; Schildchen bei der einen Art am Ende blassgelb. Acolobus Wesm.

Vorderrand des Clypeus gerade oder leicht zugerundet, in der Mitte nicht spitzig vorspringend. 13 .

13. Schildchen flach oder nur mässig gewölbt. 14 .

Schildchen pyramidal oder stark bucklig. 19.

14. Metathorax sehr kurz und abschüssig, vom Hinterschildchen durch eine sehr tiefe Furche getrennt. Flügel blauschwarz, Hinterleibsmitte gelbrot. Hierher nur ein grosses, prachtvolles Tier, der $C$. arrogator $F_{0}$; es schmarotzt bei Pterogon proserpina und wohl auch Sphinx galii. Catadelphus Wesm.

Metathorax von normaler Länge, vom Hinterschildchen nicht durch eine tiefe Furche getrennt. Flügel nicht blauschwarz. 15.

15. Körper sehr gestreckt, namentlich der Hinterleib sehr schmal oder stark zusammengedrückt. Antennen lang und dünn. 16.

Körper, namentlich der Hinterleib gedrungener, gegen das Ende nicht zusammengedrückt. 17.

16. Körper sehr schlank. Hinterleib schwarz, nur gegen das Ende zusammengedrückt, mit 8 Rückensegmenten, das letzte Bauchsegment hervorragend. Ring der Antennen und Hintertarsen weiss. Hierher nur $H$. quadriannulatus Grav., Schmarotzer von Cidaria luctuosa und berberaria, sowie Cabera trilinearia. Hypomecus Wesm.

Körper etwas kräftiger. Hinterleib in der Basalhälfte rotgelb, stark zusammengedrückt, gegen das Ende fast messerförmig. Das 2. Segment fast ohne 
Gastrocölen. Die einzige Art, L. arctiventris Boie, ist höchst selten; sie lebt in den Eulengattungen Hydrilla, Apamea, Tapinostola und Miana.

Limerodes Wesm.

17. Tarsen an der Unterseite kurz filzig behaart, fast ohne alle Borsten. Hierher 2 grosse Arten, die eine, $H$. variegatorius Panz., schwarz mit gelber Zeichnung, namentlich mit gelben Hinterecken der vorderen Segmente, die zweite, nicht allzu seltene, $H$. leucostigmus Grav., schwarz, mit weissem Antennenring und Schildchen.

Hepiopelmus Wesm.

Tarsen an der Unterseite mit Borsten besetzt. 18.

18. Hinterleib flach. Antennen lang borstenförmig, mit weissem Ring. Beine schlank, schwarz, Vorderbeine vorn hell. Schildchen weiss. Segment 2 und 3 zum Teil rot. Einzige Art ist D. tricolor Kriechb. Die Gattung ist sehr zweifelhaft; vielleicht ein Platylabus.

Diphyus Kriechb.

Hinterleib mehr oder weniger konvex. Antennen kürzer und kräftiger. Beine nicht schlank. Hierher zahlreiche Arten vom Habitus der Gattung Ichneumon, von letzterer verschieden durch den stumpfen Hinterleib.

19. Metathorax mit deutlichen Seitenzähnen. 20.

Amblyteles Wesm.

Metathorax ohne oder mit nur ganz schwachen Seitenzähnen, kurz, vom Hinterschildchen durch eine tiefe Furche getrennt. 21.

20. Hinterleib kurz, oval, schwarz, an der Basis gelbrot. Antennen in beiden Geschlechtern mit gelbem Ring. Metathorax mit spitzen Zähnen. Hinterschenkel schwarz, am Ende gelbrot. Die einzige, mittelgrosse Art ist $H$. aulicus Grav.; sie ist selten.

Hybophorus Kriechb.

Hinterleib gestreckt, schwarz, die Endwinkel der Segmente gelb, Metathoraxzähne stark und breit. Sehr grosses Tier. cf. Pyramidophorus Tischb.

21. Segmente mit grob runzliger und nadelrissiger Skulptur, die mittleren durch tiefe Einschnitte voneinander getrennt, an den Seiten mit scharfen Leisten. In Deutschland 2 durch die erwähnte Skulptur auffallende Arten: D. pictus Kriechb., schwarz, Gesicht und Thorax mit weissen Zeichnungen, Parasit von Apatura iris, und D. caeruleator F., blauschwarz, nicht seltener Schmarotzer des Schwalbenschwanzes.

Dinotomus Först.

Hinterleib punktiert oder glatt; die mittleren Segmente ohne tiefe Quereinschnitte. 22.

22. Metathorax in der Mitte buckelförmig erhoben, auf der Spitze mit der kleinen, glatten Area superomedia. Die beiden Arten gehören zu den grössten Schlupfwespen. Die kleinere, T. lutorius $F_{\text {. }}$, hat fast ganz rotgelben Hinterleib und wenig verdunkelte Flügelspitzen, die zweite Art, T. exaltatorius Panz., hat rotgelbe Hinterleibsbasis und stark verdunkelte Flügelspitzen; beide schmarotzen in Schwärmerraupen.

Trogus Grav.

Metathorax nicht buckelförmig, mit normaler Felderung. Antennenring und Schildchen weiss; Hinterleib schwarzblau. Die einzige Art, A. alboguttatus Grav., ist eine unserer schönsten Schlupfwespen. Schmarotzt bei Dasychira, Thyatira, Liparis und Psilura.

Automalus Wesm.

23. Schildchen pyramidal. Metathorax mit starken und breiten Zähnen. Tarsen ohne Borsten, kurz, filzhaarig. Die einzige, bis jetzt nur wenige Male beobachtete Art, P. flavoguttatus Tischb., ist ein grosses auffallendes Tier, schwarz mit gelber Zeichnung, namentlich gelben Hinterecken der Segmente; sie lebt bei Schwärmern, wahrscheinlich Sphinx elpenor. Pyramidophorus Tischb.

Schildchen flach oder nur wenig konvex. Körper mit anderer Zeichnung. 24. 
24. Das 1. Segment an der Beugungsstelle zwischen Petiolus und Postpetiolus höckerartig aufgetrieben. Metathorax runzlig, undeutlich gefeldert. Die einzige in Deutschland vorkommende Art, $P$. alticola Grav., ähnelt sehr manchen Amblyteles-Arten; sie ist schwarz, Antennenring und Schildchen weiss, Hinterleibsmitte rot. Probolus Wesm.

Das 1. Segment an dieser Stelle ohne höckerartige Auftreibung. 25.

25. Metathorax oben flach, in der Mitte mit 2 Längsleisten, hinten beiderseits mit starken, dreikantigen Zähnen. Das 1. Segment ziemlich breit. Die einzige, seltene Art, $R$. bassicus Tischb, ist schwarz; Antennenring weiss; Beine grösstenteils rot, die mittleren Segmente an den Seiten gewöhnlich braun; Länge etwa $10 \mathrm{~mm}$.

Rhyssolabus Berth. breit. 26.

Metathorax ohne starke Seitenzähne. Das 1. Segment an der Basis weniger

26. Schildchen wenigstens bis zur Mitte, oft bis zur Spitze mit scharfen Seitenkanten. Antennen lang und schlank, borstenförmig, hinter der Mitte oft verdickt. Hierher zahlreiche, nicht leicht zu unterscheidende Arten, welche vorwiegend bei Spannern leben. Körper meist von Mittelgrösse.

Schildchen nur an der Basis gerandet. Grössere Arten. 27. Platylabus Wesm.

27. Kopf mehr oder weniger aufgetrieben. Das letzte Bauchsegment erreicht fast die Spitze des Hinterleibs und bedeckt zuweilen den ganzen Bohrer. Antennen lang borstenförmig, hinter der Mitte etwas verdickt. In Mitteleuropa etwa 6 Arten; alle sind schwarz, nur bei einer Art das Schildchen zum Teil gelb; alle sind selten.

Eurylabus Wesm.

Kopf nicht aufgetrieben. Das letzte Bauchsegment von der Hinterleibsspitze entfernt. Metathoraxfelder verwischt. Antennen schlank borstenförmig, mit weissem Ring. Postpetiolus glatt oder runzlig-punktiert. Die einzige Art, A. pseudonymus Wesm., ist schwarz, Vorderschienen vorn weisslich. Hinterleib meist mit roten Einschnitten. Lebt bei Clostera anachoreta, Pygaera curtula und reclusa, Hylophila prasina.

Anisopygus Kriechb.

28. Schildchen pyramidal oder stark bucklig, hinten steil abfallend. 29.

Schildchen nur schwach konvex. 34.

29. Hinterleib mit gelben Hinterwinkeln der Segmente. Metathorax mit starken und breiten Zähnen. Grosse Art.

Pyramidophorus.

Hinterleib anders gezeichnet. Metathorax mit spitzen Zähnen oder ohne solche. 30 .

30. Metathorax kurz, ohne Seitenzähne, von dem Hinterschildchen durch eine tiefe Furche getrennt. 31.

Metathorax mit Seitenzähnen, ohne tiefe Furche an der Basis, meist von normaler Länge. 33.

31. Segmente durch tiefe Runzlung und Streifung rauh, die mittleren durch tiefe Einschnitte voneinander getrennt.

Dinotomus Först.

Segmente punktiert oder glatt; die mittleren ohne tiefe Einschnitte. 32.

32. Metathorax in der Mitte höckerartig aufgeworfen, auf der Spitze mit kleiner glatter Area superomedia. Hinterleib ausgedehnt gelbrot.

Metathorax nicht buckelförmig, mit normaler Felderung. Hinterleib schwarzblau. Automalus Wesm. 
33. Seitenzähne des Metathorax gross und spitz. Schienensporen fast gerade. Hoplismenus Grav.

Seitenzähne des Metathorax schwach. Schienensporen gross und stark gekrümmt. Nervulus weit hinter der Gabel.

Hybophorus Kriechb.

34. Petiolus nicht deprimiert, mindestens so hoch wie breit. 35 .

Petiolus deprimiert, breiter als hoch. 47. oval. 36.

35. Nervulus deutlich vor dem Basalnerv. Luftlöcher des Metathorax kurz

Nervulus interstitial oder hinter dem Basalnerv. Luftlöcher des Metathorax meist linear. 37.

36. Clypeus in der Mitte winklig. Schildchen ziemlich konvex. Brustseiten mit granulierten Furchen. Hinterleib gelb gefleckt. Listrodromus Wesm.

Clypeus leicht zugerundet. Schildchen schwach konvex. Furchen der Brustseiten nur angedeutet. Hinterleib weiss gezeichnet. Neotypus Först.

37. Hals oben mit 2 tiefen Grübchen, die durch einen Kiel oder Höcker voneinander getrennt sind. Hinterleib schwarz und rot, die Endsegmente weiss gerandet. Anisobas Wesm.

Hals oben ohne Kiel oder Höcker und ohne Seitengrübchen. 38.

38. Metathorax kurz, vom Hinterschildchen durch tiefe Furche getrennt; Area superomedia ebenfalls kurz. Grosse Art mit fast schwarzen Flügeln.

Catadelphus Wesm. hell. 39.

Metathorax ohne tiefe Furche an der Basis, von normaler Länge. Flügel

39. Clypeus stark abgerundet, in der Mitte des Endrandes winklig bis zahnartig vorspringend. Gastrocölen kaum angedeutet. Acolobus Wesm.

Clypeus mit geradem oder schwach zugerundetem Endrand, in der Mitte nicht spitz vorspringend. 40.

40. Antennenglieder 12-16 schwach verbreitert, oben weiss. Körper schlank, schwarz, Schildchenspitze und Ring der hintersten Tarsen weiss. Schenkel und Schienen rot, die hintersten Schenkel am Ende schwarz, Vorderhüften weiss.

Hypomecus Wesm.

Antennenglieder 12-16 nicht verbreitert. Körper anders gefärbt. 41.

41. Hinterleib auffallend langgestreckt; Segment 2-5 länger als breit. Antennen und Beine schlank. Gesicht gelb, der glatte Postpetiolus und Segment 2-4 gelbrot. Die hintersten Schenkel und Schienenspitzen schwarz.

Segment $2-5$ breiter als lang, selten quadratisch. 42 .

Limerodes Wesm.

42. Tarsen unten kurz filzhaarig, nur an der Spitze der Glieder mit einigen kurzen Börstchen. Die bekannteste Art schwarz, Schildchen und Innenseite der Antennenbasis weiss.

Tarsen an der Unterseite beborstet. 43.

43. Mandibeln schmal, in eine dünne Spitze auslaufend. Kopf kurz und breit, hinten tief ausgerandet. Gesicht aufgetrieben, unter den Antennen mit rundem Ausschnitt. Metathorax mit undeutlicher Felderung, hinten mit breiter Furche.

Heresiarches Wesm.

Mandibeln zweizähnig. Kopf und Metathorax von anderer Bildung. 44. 
44. Clypeus vorn in der Mitte oder zu beiden Seiten ausgerandet. Area superomedia länger als breit.

Chasmias Ashm.

Clypeus am Vorderrande nicht ausgerandet. 45.

45. Das 4. Bauchsegment mit wenigen Ausnahmen ohne Längsfalte in der Mitte. In zweifelhaften Fällen meist durch die vorstehenden Genitalklappen gekennzeichnet; trotz alledem ist die Unterscheidung der Männchen von Amblyteles und Ichneumon sehr schwierig.

Amblyteles Wesm.

Das 4. Bauchsegment mit Mittelfalte. 46.

46. Hinterleib lang und linear; Postpetiolus nadelrissig; das 3. Segment quadratisch, die folgenden von gleicher Länge. Gastrocölen klein.

Exephanes Wesm.

Nicht alle diese Merkmale vereinigt, besonders der Hinterleib breiter.

Ichneumon L.

47. Das 1. Segment an der Beugungsstelle zwischen Petiolus und Postpetiolus höckerartig aufgetrieben. Metathorax zart runzlig, mit undeutlicher Felderung.

Probolus Wesm.

Das 1. Segment an der Beugung nicht höckerartig aufgetrieben. 48.

48. Metathorax in der Mitte mit 2 Längsleisten, hinten beiderseits mit starken dreikantigen Zähnen. Das 1 . Segment ziemlich breit, wie die nächstfolgenden Segmente grob runzlig punktiert. Schwarz; Schenkel und Vorderschienen rot.

Rhyssolabus Berth.

Metathorax ohne starke Seitenzähne. Das 1. Segment weniger breit und mit feinerer Skulptur. 49.

49. Schildchen wenigstens bis zur Mitte mit scharfen Seitenkanten. In der Mehrzahl mittelgrosse Arten.

Platylabus Wesm.

Schildchen nur an der Basis gerandet. 50.

50. Gesicht und Antennenring weiss.

Nur die Gesichtsseiten weiss.

Anisopygus Kriechb. Eurylabus Wesm.

51. Körper gross und schlank, bis $20 \mathrm{~mm}$ lang. Metathorax mit breit ovalen Luftlöchern. Kopf fast kubisch, Antennen des $q$ sehr kurz und stark eingerollt. Hinterleib langgestreckt, glatt und glänzend; das 2. Segment ohne Gastrocölen. Die bekannteste Art A. debellator F. hat zum Teil roten Hinterleib, bei einer Varietät des $\sigma^{7}$ ist derselbe ganz schwarz.

Alomya Panz.

Durchweg kleine oder sehr kleine Arten. Metathorax mit kleinen, kreisrunden Luftlöchern. 52.

52. Metathorax mit deutlichen Seitendornen. Hinterleib des $q$ am Ende abgestutzt. Clypeus fast quadratisch. Gastrocölen deutlich. Apaeleticus Wesm.

Metathorax ohne Seitendornen. Hinterleib des $q$ am Ende nicht abgestutzt. Clypeus quer. 53.

53. Schildchen sehr konvex und erhaben. 54.

Schildchen nicht besonders erhaben. 55 .

54. Bohrer beim $q$ ganz gerade, der Hinterleib zugespitzt. Ischnus Grav.

Bohrer beim + aufwärts gekrümmt; Hinterleibsende stumpf.

Heterischnus Wesm.

55. Stirn glänzend, fast poliert. Das 2. Segment an der Basis mit deutlichen Thyridien. 56.

Stirn nicht poliert. 59. 
56. Clypeus in der Mitte des Endrandes mit Zahn. Seiten des Gesichts rötlich (+) oder weisslich $\left(0^{7}\right)$; Schildchen weisslich; Hinterleib grösstenteils rot. Misetus Wesm.

Clypeus in der Mitte des Endrandes ohne Zahn. Metathorax von der Basis an allmählich abfallend. 57.

57. Metathorax nicht oder ganz undeutlich gefeldert. Beim $q$ Augenränder zum Teil, beim $\sigma^{7}$ das ganze Gesicht hell. Areola geschlossen.

Nematomicrus Wesm.

Metathorax deutlich gefeldert. Augenränder des $q$ und Gesicht des $\sigma^{7}$ schwarz. Areola zuweilen mit fehlendem Aussennerv. 58.

58. Hinterleib stark verlängert, nicht oder nur an der Basis rauh. Segment 2 und 3 meist rot. Kopf von vorn gesehen rundlich. Areola beim + mit fehlendem Aussennerv.

Hemichneumon Wesm.

Der ganze Hinterleib rauh und matt, schwarz, das 2. Segment am Ende rötlich. Kopf von vorn gesehen dreieckig.

Trachyarus Thoms.

59. Postpetiolus sehr verbreitert und stark und dicht punktiert; die Luftlöcher des 1. Segments fast in der Mitte. Clypeus ebenfalls dicht punktiert. Nervellus vertikal.

Baeosemus Först.

Postpetiolus mit anderer Skulptur, nur bei einigen Herpestomus - Arten mit ähnlicher; bei diesen jedoch der Nervellus antefurkal. Luftlöcher des 1 . Segments weit hinter der Mitte. 60.

60. Nervellus antefurkal, nur bei Dicaelotus zum Teil vertikal. Antennen mehr oder weniger tief eingefügt. Schaft mehr zylindrisch. 61.

Nervellus postfurkal, selten bei Phaeogenes vertikal. 67.

61. Mandibeln schlank, am Ende einfach zugespitzt. Clypeus vom Gesicht nicht getrennt. Stirnränder und Schildchenseiten blassgelb. Hinterleib glänzend; Postpetiolus glatt; Gastrocölen an der Basis des 2. Segments deutlich.

Stenodontus Berth.

Mandibeln am Ende zweizähnig. Clypeus vom Gesicht getrennt. 62.

62. Das 2. Segment an der Basis mit deutlichen Eindrücken. Postpetiolus verbreitert und meist dicht punktiert. 63.

Das 2. Segment an der Basis ohne Eindrücke. 64.

63. Mesonotum und Schildchen nicht abgeplattet. Stirn konvex. Mandibelzähne ungleich, der untere Zahn viel kürzer.

Herpestomus Wesm.

Mesonotum und Schildchen abgeplattet. Stirn flach. Gesicht in der Mitte stark vorragend. Mandibelzähne gleich. Hinterleib braunschwarz, punktiert, die Segmentränder rötlich.

Eriplatys Först.

64. Area superomedia lang, Costula etwas vor der Mitte. Antennen tief unten eingelenkt. Hinterleib dicht fein punktiert, schwarz oder braunschwarz.

Deloglyptus Först.

Area superomedia kurz, herz- oder nierenförmig ; Costula hinter der Mitte. 65.

65. Kopf gross und aufgetrieben, breiter als der Thorax. Der abschüssige Raum des Metathorax in der Mitte stark ausgehöhlt. Schwarz, die vorderen Segmente mit rötlichen Einschnitten.

Kopf nicht oder kaum breiter als der Thorax. 66.

Euryptilus Holmgr.

66. Mandibelzähne fast gleich, der obere Zahn wenig länger als der untere. Area superomedia nierenförmig; Area posteromedia ausgehöhlt. Hinterleib schwarz oder einige Segmente verschwommen rot.

Dicaelotus Wesm. 
Mandibelzähne sehr ungleich, der obere Zahn weit länger. Hinterleib wenigstens beim + ausgedehnt rot. Metathorax mit Spuren von Seitenzähnchen.

Cinxaelotus Holmgr.

67. Clypeus in der Mitte des Endrandes mit halbkreisförmiger Ausrandung. Schaft am Ende aufgetrieben. Area superomedia quer, fast nierenförmig. Das 2. Segment an der Basis eingedrückt. Die hintersten Hüften unbewehrt. Antennenbasis und Hinterleibsmitte beim + rot.

Oiorhinus Wesm.

Clypeus vorn in der Mitte ohne Ausrandung. 68.

68. Areola im Flügel klein, der Aussennerv fehlend. Sehr kleine Arten mit hellen Hinterleibsrändern; beim $\sigma^{7}$ das Gesicht weiss. Epitomus Först.

Areola im Flügel vollständig geschlossen. 69.

69. Clypeus vom Gesicht nicht oder nur durch eine schwache Furche geschieden, so dass das Gesicht von der Seite betrachtet gleichmässig gewölbt erscheint. Antennen meist schlank, das 1. Geisselglied lang, Hinterhüften beim o sehr selten mit Zahn oder Leiste. 70 .

Clypeus quer, durch deutliche Querfurche vom Gesicht getrennt, so dass von der Seite gesehen eine deutliche Einschnürung sichtbar ist. Antennen nicht schlank, das 1. Geisselglied nicht länger als das folgende. 76.

70. Metathorax über die Einlenkung der Hüften hinaus verlängert, von der Basis an abschüssig; Area superomedia lang und schmal. Das 2. Segment an der Basis dicht gestreift. Hinterleib schmal, Segment 1-4 rot, beim of das 2. Segment mit 2 schwarzen Punkten.

Oronotus Wesm.

Metathorax nicht über die Einlenkung der Hüften verlängert, hinten steil abfallend. Das 2. Segment an der Basis nicht gestreift. 71.

71. Kopf mehr oder weniger aufgetrieben, nach hinten nicht verschmälert, etwas breiter als der Thorax. Thorax beim $q$ zum Teil rot. 72 .

Kopf quer oder rundlich, nicht breiter als der Thorax. 73.

72. Kopf schwarz; Hinterleibsmitte rot. Nervulus vor dem Basalnerv. Mandibeln schmal, Zähne ungleich.

Thyraeella Holmgr.

Kopf hell gezeichnet; Hinterleib schwarz. Nervulus interstitial. Mandibeln mit ziemlich gleichen Zähnen.

Notosemus Först.

73. Beim $\uparrow$ das 1. Geisselglied deutlich kürzer als das zweite und die hintersten Hüften unten mit zahnartiger Leiste; Schildchenspitze und Segment 2-4-5 rot. Beim o" das Schildchen und eine Makel unter den Antennen weiss.

Beim $\circ$ das 1. Geisselglied so lang oder länger als das zweite. Die $\sigma^{\prime \prime} \sigma^{7}$ mit anderer Gesichtszeichnung. 74.

74. Kopf quer, selten fast kubisch. Hinterleib fein punktiert oder gerunzelt. Nervellus deutlich unter der Mitte gebrochen. Diadromus Wesm.

Kopf kugelig oder halbkugelig. 75.

75. Hinterleib fein gerunzelt. Thorax gestreckt, mit langer Area superomedia. Hinterleibsmitte rot. Beim Gesicht schwarz. Nervellus in der Mitte gebrochen.

Micrope Först.

Hinterleib besonders beim $q$ glatt und glänzend. Beim $\sigma^{7}$ das Gesicht weiss. Nervellus nicht gebrochen.

Mevesia Holmgr.

76. Körper sehr schlank; Hinterleib des + langgestreckt und schmal, gegen das Ende stark komprimiert. Kopf breiter als der Thorax. Metathorax von der Basis an abschüssig und der Länge nach ausgehöhlt. Diaschiaspis Först. 
Hinterleib gedrungen, gegen das Ende nicht komprimiert. Metathorax hinten steil abfallend, nicht ausgehöhlt. 77.

77. Das 2. Segment an der Basis ohne allen Eindruck. Die hintersten Hüften des $q$ meist ohne Zahn oder Leiste. Hinterleibsmitte rot. 78.

Das 2. Segment an der Basis mit deutlichen Eindrücken. Die hintersten Hüften des + meist bewehrt. 79.

78. Unterer Rand der Mandibeln an der Basis beim $q$ seicht ausgebuchtet. Bohrer versteckt, Hinterleib deshalb stumpf. Beim $\sigma^{7}$ die Antennengeissel an der Basis kaum verdünnt.

Colpognathus Wesm.

Unterer Rand der Mandibeln beim 9 nicht ausgebuchtet. Bohrer vorstehend, Hinterleib deshalb spitz. Geissel beim $\sigma^{7}$ an der Basis deutlich verdünnt.

Centeterus Wesm.

79. Kopf nack hinten verbreitert. Antennen kurz. Hüften unbewehrt. Proscus Holmgr.

Kopf nach hinten meist verschmälert. Die hintersten Hüften der 우 unten meist mit Zahn oder Leiste. 80.

80. Schaft ziemlich lang, am Ende wie aufgetrieben, beim $\sigma^{7}$ oft hinten eckig vortretend. Clypeus am Ende meist mit Eindruck. Aethecerus Wesm.

Schaft einfach, am Ende nicht aufgetrieben oder eckig vortretend. Clypeus am Ende ohne Grube.

Phaeogenes Wesm.

\section{Unterfamilie. Cryptinae.}

Flügel vorhanden oder fehlend; Areola meist fünfseitig, zuweilen mit fehlendem Aussennerv, seltener vierseitig, in diesem Falle manchmal sehr klein. Metathorax entsprechend den beiden Haupttribus der Cryptinen und Phygadeuoninen entweder nur mit 2 Querleisten oder auch mit Längsleisten und dann meist vollständig gefeldert. Hinterleib gestielt, das 1. Segment gekrümmt; Postpetiolus meist glatt; Bohrer in der Regel deutlich vorstehend. Die Cryptinen schmarotzen bei den verschiedensten Insektenordnungen.

Die heimischen Cryptinen zerfallen in die folgenden 6 Tribus:

1. Flügel vollständig entwickelt. 2.

Flügel fehlend oder stummelhaft. 8.

2. Metathorax ohne deutliche Längsleisten, in der Regel mit 2, seltener nur mit 1 Querleiste. 3.

Metathorax mit deutlichen Längsleisten, oft vollständig gefeldert. .5.

3. Areola im Vorderflügel klein, quadratisch oder rechteckig, zuweilen fast punktförmig.

2. Mesostenini.

Areola gross und deutlich, pentagonal. 4.

4. Areola geschlossen, die Seiten nach oben konvergierend, seltener parallel. Grössere Arten.

1. Cryptini.

Aussennerv der Areola fehlend. Kleinere Arten. 7.

5. Area superomedia und posteromedia verschmolzen und vertieft, fast bis zur Basis des Metathorax hinaufreichend; letzterer meist von der Basis an abschüssig. Körper bei den meisten Arten poliert. Bohrer sehr kurz oder versteckt.

6. Stilpnini.

Metathorax nicht von der Basis an abschüssig, sondern mit deutlicher horizontaler Fläche. Bohrer vorragend. 6. 
6. Antennen und Beine mehr oder weniger kräftig, auch der Körper robust. Areola im Vorderflügel geschlossen, nur bei wenigen Arten, deren Stellung zweifelhaft ist, nach aussen offen.

3. Phygadeuonini.

Antennen und Beine mehr oder weniger schlank, auch der Körper zart. Aussennerv der Areola fast stets fehlend. 7.

7. Basalnerv an der Basis nicht oder nur schwach einwärts gekrümmt. Stigma im Vorderflügel nicht besonders breit. Felderung des Metathorax meist deutlich. Weibchen und Männchen.

4. Hemitelini.

Basalnerv an der Basis stets einwärts gekrümmt. Stigma breit dreieckig. Felderung des Metathorax meist undeutlich oder fehlend. Nur Männchen.

5. Pezomachini.

8. Thorax der if ohne deutlich abgesetztes Schildchen. Bei den $0^{7} 0^{7} \mathrm{oft}$ deutlich, aber diese dann ungeflügelt.

5. Pezomachini.

Thorax der ㅇ mit deutlich abgesetzten Schildchen. $0^{7} \sigma^{7}$ stets geflügelt. 9.

9. Das vorletzte Tarsenglied tief eingeschnitten, zweilappig. Antennen lang und dünn. Die hintersten Schienen an der Basis weiss. 1. Cryptini.

(Arten der Gattung Spilocryptus.)

Das vorletzte Tarsenglied nicht tief eingeschnitten. 10.

10. Antennen kräftig und mehr oder weniger kurz.

Antennen schlank, mehr oder weniger lang.

3. Phygadeuonini.

4. Hemitelini.

\section{Tribus. Cryptini.}

1. Flügel rudimentär, über den Metathorax nicht oder wenig hinausreichend. Antennen dreifarbig.

Flügel vollständig entwickelt. 2 .

Spilocryptus Thoms.

(Subg. Agrothereutes Först.)

2. Das 2. Glied der Maxillarpalpen stark erweitert, breit dreieckig. Metathorax grob runzlig, mit Spur einer Area superomedia. Hierher nur ein sehr grosses, schwarzes Tier, M. monticola Grav., mit blauschwarzem Hinterleib und weissem Antennenring in beiden Geschlechtern.

Megaplectes Först.

Das 2. Glied der Maxillarpalpen nicht erweitert. Weit schlankere Tiere. 3.

3. Hinterleibsstiel lang, linear, nach hinten wenig verbreitert, von der Seite gesehen nur schwach gekrümmt. Metathorax mit 2 Querleisten und stark verlängerten Luftlöchern.

Acroricnus Ratzeb.

Hinterleibsstiel mehr oder weniger kurz, der Postpetiolus deutlich abgesetzt und verbreitert. 4.

4. Radialzelle im Vorderflügel verlängert. Areola ziemlich klein, mit nach vorn konvergierenden Seiten. Cubitalnerv der Hinterflügel an der Basis schwach gebogen. Hinterleibsspitze nicht weiss gezeichnet. 5.

Radialzelle im Vorderflügel kurz. Areola im Verhältnis gross, oft nach vorn wenig verengt. Cubitalnerv der Hinterflügel an der Basis deutlich gekrümmt. Hinterleibsspitze oft weiss gezeichnet.

5. Kopf quer, nach hinten meist verschmälert; Clypeus ohne Endzahn. Flügel ohne Querbinde.

Cryptus F.

Kopf mehr oder minder kubisch; Clypeus in der Mitte des Endrandes mit Zahn. Flügel meist mit dunkler Querbinde.

Xylophrurus Först. (Macrocryptus Thoms.). 
6. Mesonotum vorn nicht abschüssig, die Parapsidenfurchen fehlend, nur vorn angedeutet. Hinterleibsstiel lang. Metathorax kurz. Kopf und Thorax bei of und $\sigma^{7}$ ohne helle Zeichnung. Hinterleibsmitte rot, Hinterleibsspitze nicht weiss gezeichnet. 7 .

Mesonotum vorn abschüssig, mit deutlichen Parapsidenfurchen. 9.

7. Seiten der Areola nach vorn konvergierend. Gesicht schmal, Wangen kurz. Kleine Arten. Brachycryptus Thoms.

Areola gross mit parallelen oder fast parallelen Seiten. Gesicht nicht schmal, Wangen lang. 8. Basalnerv.

8. Das 2. Segment mit deutlicher Skulptur. Nervulus deutlich hinter dem

Das 2. Segment poliert. Nervulus interstitial oder vor dem Basalnerv.

Idiolispa Först.

9. Kopf mit breitem Scheitel, fast kubisch; Clypeus mit Zahn in der Mitte des Endrandes. Antennen des 9 mit weissem Ring; Flügel mit dunkler Querbinde.

Kaltenbachia Först. (Nyxeophilus Thoms.).

Kopf quer, nicht kubisch. Flügel ohne deutliche dunkle Querbinde. 10.

10. Der untere Aussenwinkel der Discoidalzelle ein rechter; Areola klein, nach vorn konvergierend. Luftlöcher des Metathorax klein und rund. Clypeus oft mit Endzahn. Antennen des $q$ meist mit weissem Ring. Gesicht des $\sigma^{7}$ weiss gezeichnet.

Caenocryptus Thoms.

Der untere Aussenwinkel der Discoidalzelle stumpf. Areola meist gross und mit parallelen Seiten. 11.

11. Klauenglied und Klauen lang und kräftig. Metathorax dicht behaart. Vorderschienen des $q$ deutlich aufgeblasen; das 4. Tarsenglied tief eingeschnitten. Areola mit parallelen Seiten. Thorax nicht selten rot. Hygrocryptus Thoms.

Klauenglied und Klauen von normaler Grösse. Metathorax nicht auffallend behaart. 12 .

12. Schenkel dick; die hintersten Tarsen kurz. Hinterleibsspitze ohne weisse Makel. Bohrer mindestens so lang wie der Hinterleib, dieser in der Mitte rot.

Pycnocryptus Thoms.

Schenkel nicht dick. Bohrer kürzer als der Hinterleib. 13.

13. Areola klein, nach vorn deutlich konvergierend. Luftlöcher des Metathorax klein, rund oder kurz oval. Hinterleibsspitze nicht weiss. Antennen des $\sigma^{7}$ meist mit weissem Ring.

Habrocryptus Thoms.

Areola gross, nach vorn wenig konvergierend; in zweifelhaften Fällen Antennen dreifarbig und Hinterleibsspitze weiss. 14.

14. Clypeus mit deutlichem Endzahn. Nervellus postfurkal, über, selten in der Mitte gebrochen. Die vordersten Schienen des $q$ meist aufgetrieben.

Hoplocryptus Thoms.

Clypeus ohne Endzahn. Nervellus unter, sehr selten in der Mitte gebrochen. Die hintersten Schienen bei den häufigsten Arten an der Basis weiss.

Spilocryptus Thoms.

\section{Tribus. Mesostenini.}

1. Klauenglied und Klauen ausserordentlich klein. Das letzte Glied der hintersten Tarsen viel kürzer als das 3.; das 1 . Glied der vordersten so lang oder fast so lang wie die Schienen. Metathorax poliert, nur mit der vorderen 
Querleiste. Bohrer weit kürzer als der Hinterleib. Körper sehr schlank und zart. Ein schmaler Antennenring bei $q$ und $\sigma^{7}$ und das Gesicht weiss; Hinterleib schwarz.

Nematopodius Grav.

Klauenglied und Klauen weit kräftiger. Das letzte Glied der hintersten Tarsen ungefähr so lang wie das 3.; das 1. Glied der Vordertarsen viel kürzer als die Schienen. 2.

2. Stirn ohne Dorn zwischen den Antennen. Postpetiolus oft länger als breit und glatt.

Mesostenus Grav.

Stirn mit einem spitzen Dorn zwischen den Antennen. Kopf, Thorax, Postpetiolus und das 2. Segment dicht punktiert, letzteres mit schwieligem Endrand. Listrognathus Tschek.

\section{Tribus. Phygadeuonini.}

1. Flügel entwickelt, sehr selten verkürzt und nur bis zur Hinterleibsmitte reichend. 2.

Flügel stummelhaft, höchstens etwas über die Basis des Metathorax reichend. 20.

2. Metathorax nur mit einer Querleiste. Areola klein. Vorderschienen aufgetrieben, an der Basis eingeschnürt. Petiolus kurz. Habitus von Pimpla. Brachycentrus Taschenb.

Metathorax mit meist vollständigen Längs- und Querleisten. 3. rechter. 4.

3. Der untere Aussenwinkel der Discoidalzelle ein stumpfer, selten ein

Der untere Aussenwinkel der Discoidalzelle spitz. 15.

4. Luftlöcher des Metathorax länglich oder oval. 5.

Luftlöcher des Metathorax klein und rund. 8.

5. Der hinterste Trochantellus unten ausgehöhlt und gerandet. Kopf kubisch. Hinterleib und Beine rot, Hüften und Trochantern schwarz.

Der hinterste Trochantellus unten nicht ausgehöhlt. 6 .

Listrocryptus Brauns.

6. Antennengruben deutlich. Schienen mit stärkeren Dörnchen. Antennen des $q$ fadenförmig.

Plectocryptus Thoms.

Antennengruben fast fehlend. Schienen mit schwachen Dörnchen. Antennen des $q$ in der Mitte verdickt. 7.

7. Stirn und Mesonotum sehr fein und dicht punktiert, matt, mit bläulichem Schimmer. Schildchen und Antennenring, beim $0^{7}$ auch das Gesicht gelblichweiss.

Giraudia Först.

Stirn stark punktiert. Antennen schwarz, ohne gelblichweissen Ring, beim $q$ mit roter Basis. Schildchen, beim $\sigma^{7}$ auch das Gesicht schwarz.

Coelocryptus Thoms.

8. Der ganze Körper mit dichter anliegender Behaarung. Hinterleib schwarz, meist mit roter oder weisser Binde. Antennen ohne weissen Ring; Schildchen beim $q$ weiss. Gesicht des $\sigma^{\prime \prime}$ schwarz.

Körper ohne dichte und auffallende Behaarung. 9.

9. Metathorax hinten mit starken Seitendornen oder Zähnen, bei der häufigsten Art mit 4 Zähnen. Acanthocryptus Thoms.

Metathorax hinten ohne oder mit ganz schwachen Seitendornen. 10. 
10. Hinterleib schwarz. Clypeus an der Spitze ohne Zähne. Gesicht des $\sigma^{7}$ meist weiss. 11.

Hinterleibsmitte rot oder der Clypeus an der Spitze mit 2 Zähnen. Metathorax oft gezähnt. 14.

11. Clypeus in der Mitte des Endrandes mit dreieckigem Ausschnitt. Hinterleib glatt und glänzend. Antennen ohne weissen Ring. Gesicht des $\sigma^{7}$ schwarz. Demopheles Först.

Clypeus ohne Ausschnitt. Das 2. Segment fein gerunzelt oder punktiert. 12.

12. Kopf quer. Antennen lang, mit weissem Ring; Schaft oval, am Ende deutlich ausgeschnitten. Bohrer so lang wie das 1. Segment.

Kopf mehr oder weniger kubisch, in zweifelhaften Fällen der Bohrer

13. Antennen lang, Schaft ausgeschnitten. Das 2.Segment dicht punktiert, matt. Cratocryptus Thoms.

Antennen kurz, Schaft mehr zylindrisch, am Ende wenig ausgeschnitten.

Cubocephalus Ratzeb. schlank.

14. Antennen des 9 mit weissem Ring; Basalglieder der Geissel nicht sehr

Antennen des ㅇ ohne weissen Ring. Basaldieder shr gestrect, das 1. und 2. Geisselglied 4 mal so lang als breit. Stiboscopus Först.

15. Basalgrube des Schildchens durch einen Längskiel geteilt. Schienen oft verdickt und aussen stark gedornt. Stylocryptus Thoms.

Basalgrube des Schildchens einfach. Schienen nicht gedornt. 16.

16. Antennen und Schenkel kräftig. 17.

Antennen und meist auch Schenkel schlank. Gesicht und meist auch Unterseite des Thorax dicht weisslich behaart. Wangen kurz. 18.

17. Hinterleib des + mehr oder weniger oval oder länglich oval, höchstens am Ende etwas zusammengedrückt.

Phygadeuon Grav.

Hinterleib des + schmal lanzettlich, nach hinten stark zusammengedrückt. Ischnocryptus Kriechb.

18. Hinterleib mit breitem Petiolus, dicht und ziemlich grob punktiert, am Ende glatt, schwarz; Bohrer von Hinterleibslänge.

Lochetica Kriechb.

Hinterleib glatt oder mit feiner Skulptur. 19.

19. Hinterleib länglich oval oder elliptisch. Bauchfalte schwach, das letzte Bauchsegment nicht vorragend. Hinterleibsmitte meist hell gezeichnet.

Leptocryptus Thoms.

Hinterleib lanzettlich, von der Basis des 3. Segmentes nach hinten verschmälert. Bauchfalte stark entwickelt, das letzte Bauchsegment vorragend. Hinterleib schwarz; Bohrer von Hinterleibslänge.

Hemicryptus Kriechb.

20. Antennen 3 farbig, mit weissem Ring. Metathorax mit undeutlicher Felderung.

Microcryptus Thoms.

(Subgen. Aptesis Först.)

Antennen ohne weissen Ring, an der Basis meist rötlich. Metathorax fast vollständig gefeldert.

Phygadeuon Grav.

(Subgen. Stibeutes Först.) 


\section{Tribus. Hemitelini.}

Die Gattung Hemiteles mit über 200 Arten ist eine der schwierigsten; wohl alle Arten sind Schmarotzer zweiten Grades.

Kopf hinter den Augen verlängert. Thorax gestreckt, länger als hoch; Metathorax deutlich in einen horizontalen und in einen abschüssigen Raum geteilt, meist vollständig gefeldert. Hinterleib mehr oder weniger oval. Körperfärbung meist schwarz oder schwarz und rot.

Hemiteles Grav.

Kopf quer, sehr kurz, hinten kaum über die Augen hinaus verlängert. Thorax kurz und gedrungen, fast kubisch; Metathorax ganz steil abfallend, ohne horizontalen Raum. Hinterleib schmäler als der Thorax. Körper schwarz, mit reicher gelber Zeichnung.

Brachycyrtus Kriechb.

\section{Tribus. Pezomachini.}

Eine der schwierigsten Gruppen. Hierher gehören alle diejenigen Gattungen und Arten, deren fᄋ vollständig flügellos sind und welche kein deutlich abgesetztes Schildchen haben. Die $\sigma^{7} \sigma^{7}$ sind teils ungeflügelt, teils geflügelt. Der Unterschied der geflügelten von den Hemiteles-Arten ist in der Tabelle angegeben. Die Arten selbst sind sehr schwer abzugrenzen; wie die HemitelesArten scheinen sie sämtlich Schmarotzer zweiten Grades zu sein.

1. Das 2. Segment sehr gross, den grössten Teil des Hinterleibs von oben gesehen einnehmend. Metathorax hinten ziemlich steil abfallend, mit scharfer Querleiste. Das 1. Segment sehr lang und schlank, hinten kaum erweitert. Bohrer versteckt oder sehr kurz.

Thaumatotypus Först.

Das 2. Segment von normaler Länge. Bohrer deutlich vorstehend, in der Regel so lang wie das 1 . Segment. 2.

2. Gesicht und Stirn von gewöhnlicher Länge. Metathorax meistens mit Querleiste. Pezomachus Grav.

Gesicht stark um die Hälfte verkürzt und deshalb sehr breit; auch der Clypeus niedrig und breit. Stirn sehr gross. Metathorax ohne Querleiste.

Pezolochus Först.

\section{Tribus. Stilpnini.}

Metathorax gleich von der Basis an abschüssig; Area superomedia und A. posteromedia verschmolzen und eine breite, meist querrunzlige Längsfurche bildend. Körper glatt und glänzend; Bohrer sehr kurz oder ganz versteckt.

1. Hinterleib etwa vom 4. Segment an sehr stark zusammengedrückt. 2. Hinterleib nicht oder nur gegen das Ende etwas zusammengedrückt. 3.

2. Einschnitt des Hinterleibs kaum sichtbar. Kopf aufgetrieben. Antennengeissel des $\$ 26$ gliedrig.

Seleucus Holmgr.

Einschnitte des Hinterleibs deutlich sichtbar. Kopf ziemlich klein, quer. Antennen des ? 19-23, des o 22-24gliedrig. Hinterleib fast messerförmig zusammengedrückt.

Asyncrita Först.

3. Antennen 20 gliedrig; das 1 . Geisselglied deutlich länger als das zweite, das dritte sehr stark ausgebuchtet, das letzte ungefähr doppelt so lang als das vorletzte.

Zetesima Först.

Das 3. Antennenglied nicht ausgebuchtet. 
4. Hinterleib gestreckt und schmal. 5 .

Hinterleib kurz und mehr oder weniger breit oder rundlich. 7.

5. Das letzte Glied der Labialpalpen verlängert. Luftlöcher des 1. Segmentes in der Mitte. Antennen des $q$ dreifarbig. Hinterleib fast ganz rot.

Mesatractodes Morley.

Das letzte Glied der Labialpalpen normal. Luftlöcher des 1. Segmentes hinter der Mitte. 6.

6. Kopf schwach kubisch. Metathorax über den Ursprung der Hinterhüften hinaus verlängert. Hinterleibsstiel lang und gerade. Areola aussen offen; Mediannerv im Hinterflügel an der Basis erloschen. Hinterleibsmitte rot. Grössere Arten.

Kopf quer. Hinterleibsstiel kürzer und mehr gekrümmt. Areola zuweilen geschlossen; Mediannerv im Hinterflügel an der Basis nicht erloschen. Hinterleib bei einzelnen Arten ganz schwarz. Kleinere Arten. Atractodes Grav.

7. Areola nach aussen offen. Antennen 17- oder 18 gliedrig, das erste Geisselglied deutlich länger als das zweite. Nervellus nicht oder ganz undeutlich gebrochen.

Xestophya Först.

Areola nach aussen geschlossen. Nervellus unter der Mitte gebrochen. 8.

8. Antennen beim ㅇ 18-22-, beim $\sigma^{7} 20-26$ gliedrig, beim $\sigma^{7}$ das 9. bis 11. Glied mit Kiel versehen und das Pronotum vorn mit heller Stelle Alle Arten sind schwarz.

Polyrhembia Först.

Antennen beim o 16 - oder 17 gliedrig, beim $\sigma^{7} 19-22$ gliedrig. Pronotum vorn ohne helle Stelle. Hinterleibsmitte zuweilen verschwommen rot.

Stilpnus Grav.

\section{Unterfamilie. Pimplinae.}

Hinterleib sitzend, in den meisten Fällen flach, entweder grob punktiert mit Eindrücken oder Höckern oder, wie bei den Lissonotinen, mit feiner Punktierung; Bohrer stets vorragend, oft von grosser Länge. Die Arten schmarotzen meist bei Coleopteren und Lepidopteren, selten bei Dipteren und Hymenopteren.

1. Kopf quer, selten etwas aufgetrieben; Mandibeln mit dem Clypeus keine scheinbare Mundöffnung bildend. 2.

Kopf mehr oder weniger kubisch, seltener kuglig; Mandibeln vorgestreckt und mit dem Clypeus in der Regel eine Art Mundöffnung bildend. Hinterleib zuweilen fast gestielt. (Tribus: Xoridini) 44.

2. Hinterleib deprimiert, selten am Ende seitlich zusammengedrückt; das letzte Bauchsegment nicht gross. Die hintersten Beine weder auffallend verlängert noch verdickt. Antennen in der Regel lang borstenförmig. 3.

Hinterleib nach hinten deutlich seitlich zusammengedrückt; das letzte Bauchsegment meist gross und abstehend. Hinterbeine verlängert und meist stark verdickt. Antennen in der Regel kurz und dick. (Tribus: Acoenitini) 37.

3. Hinterleib mit mehr oder weniger deutlichen Eindrücken oder Höckern, meist auch stark punktiert. (Tribus: Pimplini) 4.

Hinterleib ohne oder mit ganz undeutlichen Eindrücken oder Höckern und ohne grobe Skulptur, mehr oder weniger glatt oder fein punktiert oder lederartig. (Tribus: Lissonotini) 22.

4. Die mittleren Segmente, besonders das zweite, länger als an der Spitze breit, selten quadratisch. Bohrer oft länger als der Körper. 5. 


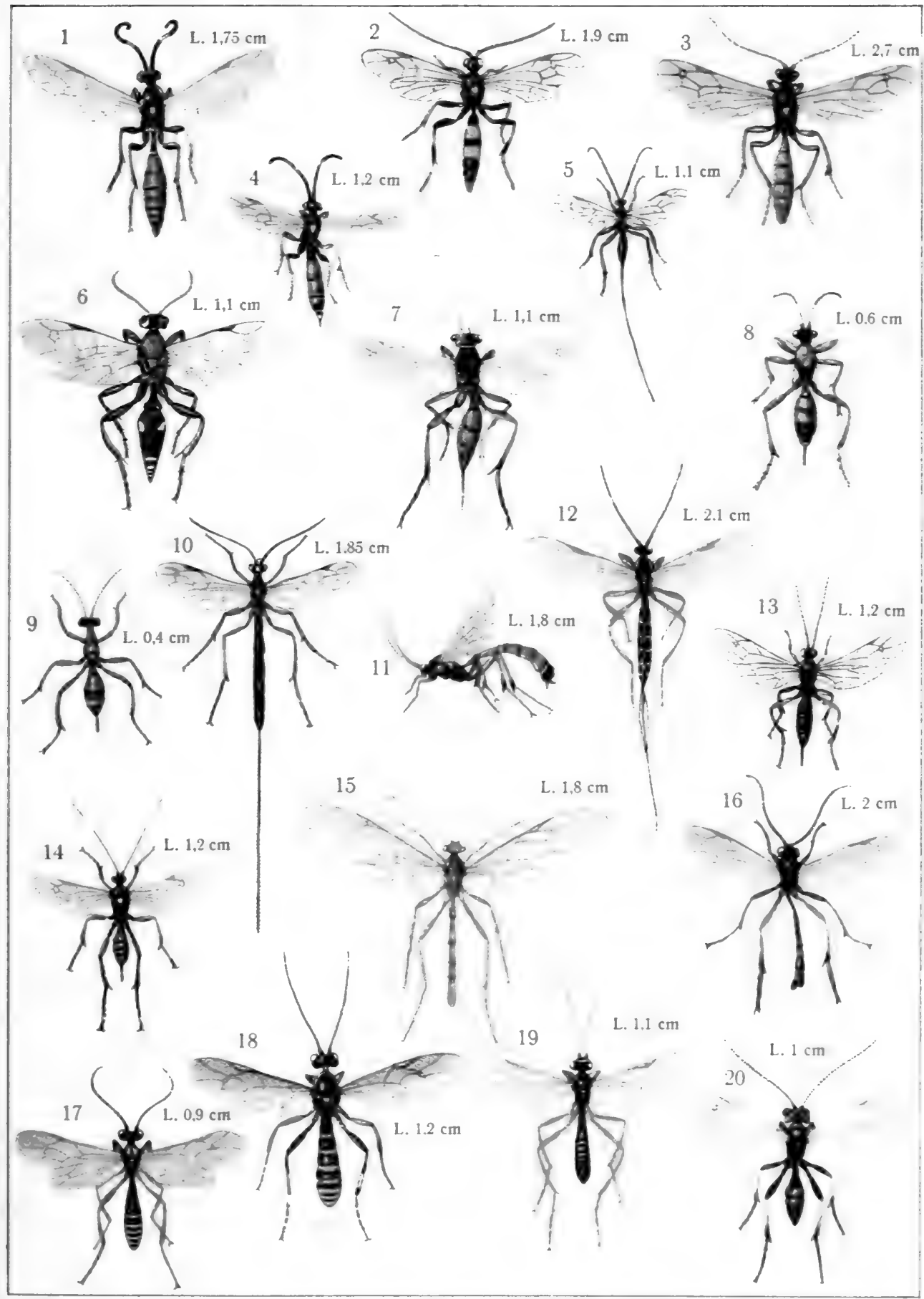

1. Ichneumon Coqueberti. 2. Amblyteles armatorius. 3. Trogus lutorius. 4. Exephanes hilaris. 5. Mesostenus gladiator. 6. Neotypus melanocephalus. 7. Cryptus sponsor. 8. Microcryptus nigrocinctus. 9. Pezomachus fasciatus. 10. Ephialtes manifestator. 11. Exochilum circumflexum. 12. Rhyssa persuasoria. 13. Pimpla examinator. 14. Exetastes guttatorius. 15. Ophion luteus. 16. Schizoloma amictum. 17. Microplectron Bohemani. 18. Tricamptus apiarius. 19. Mesoleptus cingulatas. 20. Perilissus erythrocephalus. 

Die mittleren Segmente, namentlich das zweite, quer. Bohrer meist kürzer als der Körper. 9.

5. Mesonotum grob querrunzlig. Durchweg grosse Tiere, welche bei Holzwespen schmarotzen. 6 .

Mesonotum nicht querrunzlig. 7.

6. Hinterleibssegmente an der Spitze weder ausgerandet noch tief eingeschnitten. Clypeus in der Mitte des Endrandes meist vorgezogen. Die häufigste Art, $R$. persuasoria L., schwarz mit weissen Hinterleibsflecken. Rhyssa Grav.

Hinterleibssegmente 3-7 am Ende ausgerandet oder tief ausgeschnitten, besonders bei dem $0^{x}$; bei diesem der Hinterleib glatt. Clypeus am Ende abgestutzt.

Thalessa Holmgr.

7. Hinterleib des + mehr oder weniger spindelförmig, beim $\sigma^{7}$ gleich breit, beim $q$ das 2. und 3., beim $\sigma^{7}$ das 2. - 5. Segment mit schiefen Furchen. Seiten des Gesichts gelb. Bohrer etwas kürzer als der Körper. Grosse Art.

Atractogaster Kriechb.

Hinterleib in beiden Geschlechtern fast gleich breit, die vorderen Segmente von den hinteren nicht in Skulptur verschieden. 8.

8. Das letzte Glied der hintersten Tarsen wenig länger als das vorletzte; Klauen des $q$ an der Basis erweitert. Beim $\sigma^{7}$ der innere Augenrand kaum ausgebuchtet. Thorax höchst selten rot gezeichnet.

Ephialtes Grav.

Das letzte Glied der hintersten Tarsen wenigstens dreimal so lang wie das vorletzte; Klauen an der Basis nicht erweitert. Beim o der innere Augenrand tief ausgebuchtet. Thorax meist rot gezeichnet. Hinterleibssegmente mit hellem Endrand. Perithous Holmgr.

9. Der ganze Körper, namentlich der Hinterleib glatt und glänzend. 10.

Hinterleib deutlich und dicht punktiert, seltener mit zerstreuten Runzeln. 11.

10. Flügel mit Areola. Vorderschenkel unten nicht ausgerandet. Bohrer länger als das 1. Segment. Körper kräftig; Habitus von Pimpla. Die bekannteste der beiden Arten, T. atalantae Poda, ist fast ganz gelb. Theronia Holmgr.

Flügel ohne Areola. Vorderschenkel verdickt, unten von der Mitte bis zur Spitze sehr verschmälert und wie ausgerandet. Bohrer kaum so lang wie das 1. Segment. Körper klein, schlank.

Colpomeria Holmgr.

11. Das letzte Antennenglied länger als die beiden vorhergehenden zusammen. Das letzte Glied der Hintertarsen nicht völlig doppelt so lang wie das vorletzte. Gesicht mit dichten silberglänzenden Haaren bedeckt.

Stilbops Först.

Das letzte Antennenglied nicht länger als die beiden vorhergehenden zusammen. Das letzte Glied der Hintertarsen doppelt oder mehr als doppelt so lang wie das vorletzte. 12.

12. Schildchen erhaben, hinten abgestutzt und dadurch vierseitig, gelb gezeichnet. Hinterleibssegmente 2-4 mit Schräglinien und vor dem Ende mit Quereindruck, wodurch ein erhabener dreieckiger Raum abgegrenzt wird. Bohrer kürzer als der Hinterleib. Körper kurz und gedrungen, wie bei Pimpla.

Lycorina Holmgr.

Schildchen abgerundet. Hinterleib nur bei Glypta mit nach vorn konvergierenden Eindrücken, aber hinten ohne Quereindrücke und mit langem Bohrer. 13. 
13. Die mittleren Segmente ohne schiefliegende, nach der Basismitte konvergierende Eindrücke. 14.

Die mittleren Segmente mit Schrägeindrücken, welche einen nach vorn gerichteten Winkel bilden. 18.

14. Flügel mit Areola. 15.

Flügel ohne Areola. 16.

15. Metathorax meist nur mit 2 genäherten Längsleisten, selten mit Spur der Area superomedia. Hinterleib gestreckt, mit deutlichen Eindrücken und Buckeln. Zahlreiche durch Zerstören vieler schädlicher Insekten höchst wichtige Arten.

Pimpla F.

Metathorax mit Area superomedia und A. posteromedia. Hinterleib kurz, etwa $2 \mathrm{mal}$ so lang als breit, gewölbt, fast ohne Eindrücke, dicht und grob punktiert, rot, am Ende schwarz.

Brachypimpla Strobl.

16. Augen behaart. Clypeus nicht abgesetzt. Beine kräftig, die Schenkel und das letzte Tarsenglied verdickt. Antennen wenig länger als der halbe Körper. Mesonotum deutlich dreilappig. Hinterleib schmal, das 1. Segment mit 2 Kielen; Bohrer wenig vorragend. Die Gattung gleicht durch den kurzen Bohrer mehr den Tryphoninen als den Pimplinen.

Schizopyga Grav.

Augen unbehaart. Clypeus deutlich vom Gesicht getrennt. Schenkel nicht verdickt. Bohrer vorstehend. 17.

17. Die letzten Bauchsegmente bilden wie bei Pimpla eine Längsspalte, aus welchen der Bohrer tritt; letzterer nicht gebogen. Gesicht in beiden Geschlechtern nach unten verschmälert. Fussklauen klein. Polysphincta Grav.

Das letzte Bauchsegment gross, bis zur Hinterleibsspitze reichend, nicht geteilt; Bohrer nach oben gebogen, etwas kürzer als der halbe Hinterleib. Gesicht nach unten nicht verschmälert. Fussklauen gross.

Clistopyga Grav.

18. Flügel mit Areola. Segmente mit weisslichem oder gelblichem Hinterrand. Bohrer von Hinterleibslänge. 19.

Flügel ohne Areola. Segmente ohne hellen Hinterrand. 20.

19. Stirn mit 2 Hörnern. Schildchen schwarz. Segmente mit weisslichem Hinterrand.

Hoplitophrys Först.

Stirn ohne Hörner. Schildchen und Hinterrand der Segmente gelblich.

Teleutaea Först.

20. Stirn ohne Zapfen oder Horn. Metathorax bei den meisten Arten unvollständig gefeldert. Klauen einfach.

Glypta Grav.

Stirn mit 1 oder 2 Zapfen oder Hörnern. 21.

21. Stirn mit nur 1 Zapfen oder Horn. Metathorax mehr oder weniger gefeldert. Klauen höchstens an der Basis etwas gekämmt. Conoblasta Först.

Stirn mit 2 Zapfen. Metathorax ohne Felder, nur hinten mit Querleiste. Klauen lang, innen gekämmt.

Diblastomorpha Först.

22. Flügel ohne Areola, dieselbe auch nicht in der Anlage vorhanden. Metathorax mit 2 deutlichen Längskielen. Mesonotum dreilappig. Nervulus vor der Gabel. Beim ơ das 3. Geisselglied an der Spitze, das 4. an der Basis ausgenagt.

Lampronota Hal.

Flügel mit Areola, der Aussennerv derselben zuweilen schwach. 23.

23. Luftlöcher des Metathorax gross und langgestreckt. Durchweg grössere Arten. 24.

Luftlöcher des Metathorax klein und rund. 27. 
24. Nervellus stark postfurkal und weit über der Mitte gebrochen. Metathorax ohne Spur von Felderung, auch die hintere Querleiste fehlend. Flügel mit deutlichem Ramellus. Das letzte Bauchsegment gross. Hinterleibsmitte rot. Procinetus Först.

Nervellus deutlich unter der Mitte gebrochen. Metathorax mit deutlicher hinterer Querleiste. 25.

25. Metathorax grob runzlig-punktiert, an den Seiten mit deutlicher Längsleiste. Klauen kräftig, weit länger als der Pulvillus. Radius nicht gleichmässig gekrümmt. Sehr grosse Arten mit braunroter Hinterleibsmitte.

Echthrodoca Schmiedekn.

Metathorax mit groben Punkten, meist glänzend, an den Seiten ohne oder mit ganz schwacher Längsleiste. Klauen zart, den Pulvillus nicht überragend. Radius mehr oder weniger gleichmässig gekrümmt. Segmente meist mit gelben Hinterrändern. 26.

\section{Längskiel.}

26. Stirn ohne Horn oder Zapfen. Metathorax an den Seiten ohne feinen Längskiel.

Syzeuctus Först.

Stirn mit 2 deutlichen Hörnchen. Metathorax an den Seiten mit feinem

27. Hinterleib fast gestielt. 28.

Hinterleib mehr oder weniger breit ansitzend. 29.

28. Das 1. Segment flaschenförmig, vorn lang gestielt, nach hinten verbreitert. Hinterleibsmitte trüb rot; Bohrer von Hinterleibslänge. Die einzige Art, T. modesta Grav., fliegt zeitig im Frühjahr auf Grasplätzen.

Taschenbergia Schmiedekn.

Das 1. Segment lang und dünn, am Ende kaum verbreitert. Hinterleib etwas keulenförmig, die Segmente mit rötlichen, nach hinten mehr weisslichen Endrändern. Bohrer wenig vorragend.

Stenolabis Kriechb.

29. Die letzten Antennenglieder des + perlschnur- oder knotenförmig. Beine schlank, die hintersten verlängert. Bohrer unter Hinterleibslänge. 30.

Die letzten Antennenglieder nur schwach voneinander abgesetzt. Die hintersten Beine nicht auffallend länger als die vorderen. Bohrer meist lang. 32 .

30. Nur das letzte Drittel der Geissel beim $q$ mit deutlich abgesetzten Gliedern; diese Endglieder sind aber nicht eckig, sondern oben und unten abgerundet.

Cryptopimpla Taschenb.

Endhälfte der Antennen beim $q$ mit knotenförmig abgesetzten Gliedern; diese Endglieder sind so breit wie lang und treten oben und unten eckig vor. 31.

31. Kopf und Thorax dicht runzlig-punktiert, fast matt. Körper schwarz; Beine grösstenteils rot. Xenacis Först.

Kopf und Thorax zerstreut und ziemlich grob punktiert, wie der Hinterleib glänzend; letzterer grösstenteils rot.

Xenocornia Schmiedekn.

32. Metathorax ohne alle Leisten, auch die hintere Querleiste fehlend. 33.

Die hintere Querleiste deutlich. 35.

33. Der ganze Körper, besonders der Kopf, zottig behaart. Metathorax grob punktiert. Das 1. Segment rauh, die folgenden glatter. Bohrer etwas kürzer als der Hinterleib, leicht nach oben gekrümmt. Arenetra Holmgr.

Körper, namentlich der Kopf, nicht auffallend zottig behaart. 34 . 
34. Fussklauen dicht und lang gekämmt. Die letzten Antennenglieder kaum voneinander abgesetzt. Hinterleib glatt, meist mit hellen Segmenträndern; Bohrer höchstens so lang wie der Hinterleib.

Phytodietus Grav.

Fussklauen nicht gekämmt. Die letzten Antennenglieder deutlich voneinander geschieden. Hinterleib breit ansitzend; Bohrer von Körperlänge.

Anarthronota Schmiedekn.

35. Antennengeissel beim $q$ hinter der Mitte schwach verdickt, gegen das Ende zugespitzt; Basalglieder langgestreckt, die vorletzten Glieder quer, deutlich voneinander abgesetzt, das Endglied das schmalste, wenig länger als das vorletzte. Aussennerv der Areola undeutlich. Hinterleibsmitte beim $q$ zum Teil rot. Habitus von Lissonota.

Campocineta Schmiedekn.

Antennen gegen das Ende nicht zugespitzt und hinter der Mitte nicht verdickt, die vorletzten Glieder nicht quer, das Endglied deutlich länger als breit. 36.

36. Fussklauen deutlich, wenn auch nicht dicht gekämmt. Durchweg robuste Arten von meist schwarzer Färbung.

Meniscus Schiödte.

Fussklauen einfach, höchstens an der Basis mit einzelnen Zähnchen oder Börstchen. Meist kleinere und schlankere Arten.

Lissonota Grav.

37. Areola im Flügel vorhanden. 38.

Flügel ohne Areola. 41.

38. Areola sehr gross, rhombisch. Kopf und Thorax mit feiner Skulptur; Hinterleib glatt und glänzend; Bohrer so lang oder länger als der Hinterleib. Körper schwarz. Die Gattung steht besser bei den Ophioninen.

Leptobatus Grav.

Areola weit kleiner, nicht rhombisch. Bohrer oft kürzer als der Hinterleib. 39.

39. Metathorax vollständig gefeldert, kurz, hinten abgestutzt, mit kleinen runden Luftlöchern. Hinterleib grösstenteils rot; Bohrer etwas kürzer als der Hinterleib. Die einzige Art, A. abdominale Grav., gleicht sehr einer kleinen Pimpla.

Aphanoroptrum Först.

Metathorax unvollständig gefeldert, mit grossen ovalen Luftlöchern. Bohrer länger als der Hinterleib. 40.

40. Antennen länger als der halbe Körper. Metathorax rauh, mit 2 bis 4 Längsleisten. Beine lang und schlank. Das letzte Bauchsegment des + sehr gross, lanzettförmig, abstehend. Hinterleib des $\sigma^{7}$ sehr lang und schmal, stark von der Seite zusammengedrückt. Sehr grosse Arten. Coleocentrus Grav.

Antennen kurz. Metathorax an den Seiten grob punktiert; Area superomedia glänzend, punktiert. Hinterbeine gross und verdickt. Schwarz, mit roten Beinen. Von Mittelgrösse.

Mesoclistus Först.

41. Rücklaufender Nerv vor dem Cubitalquernerv mündend. Bohrer von Körperlänge. In Deutschland nur eine einzige, höchst seltene Art, A. albicinctus Grav. Körper gross, schwarz; Antennen bei $q$ und $\sigma^{7}$ mit weissem Ring, auch die hintersten Tarsen und beim $\sigma^{7}$ das Gesicht weiss.

Arotes Grav.

Rücklaufender Nerv hinter dem Cubitalquernerv mündend. Bohrer kürzer als der Körper. 42.

42. Hinterleib hinten keilförmig zusammengedrückt; Bohrer nach unten gebogen. Cubitalquernerv fast fehlend.

cf. Tropistes Grav.

Hinterleib hinten nicht keilförmig zusammengedrückt. Cubitalquernerv deutlich. 43. 
43. Das 2. Segment nicht länger als an der Spitze breit. Das letzte Bauchsegment beim $q$ sehr gross und über die Hinterleibsspitze hervorragend. Hinterschenkel stark verdickt. Hinterleib schwarz oder zum Teil rot. Körper robust.

Acoenitus Grav.

Das 2. Segment länger als an der Spitze breit. Das letzte Bauchsegment beim + sehr klein und weit von der Hinterleibsspitze abstehend. Bohrer wenig vorstehend. Hinterleibsmitte rot gezeichnet. Körper von Mittelgrösse, ziemlich schlank.

Collyria Schiödte.

44. Stirn mit einem am Ende ausgehöhlten Fortsatz oder Horn. Antennen dünn faden- oder borstenförmig. Metathorax gefeldert. Hinterleib fast gestielt. Flügel ohne Areola.

Ischnocerus Grav.

Stirn ohne Fortsatz oder Horn. 45.

45. Flügel mit Areola; der Aussennerv in seltenen Fällen undeutlich. 46. Flügel ohne Areola, dieselbe auch nicht in der Anlage vorhanden. 51.

46. Bohrer stark nach oben gekrümmt, länger als der Hinterleib. Körper klein, grösstenteils gelb gefärbt. Nur eine einzige höchst seltene Art.

Tryphonopsis Brauns.

Bohrer nicht auffallend nach oben gekrümmt. Körper schwarz, Hinterleibsmitte zuweilen rot. 47.

47. Areola auffallend klein, vier- oder fünfseitig, der Aussennerv sehr schwach oder ganz fehlend. 48.

Areola vollständig geschlossen, nicht auffallend klein. 49.

48. Clypeus in der Mitte lamellen- oder zahnartig vorspringend. Metathorax undeutlich gefeldert. Hierher 2 seltene Arten, die bei Sesien schmarotzen.

Perosis Först.

Clypeus kurz, am Ende breit ausgerandet. Metathorax nur mit der vorderen Querleiste. Bohrer kurz. Die einzige Art ähnelt sehr einer Pimpla.

cf. Brachycentrus Taschenb.

(Unterfamilie der Cryptinen.)

49. Areola dreiseitig. Körper und Beine sehr schlank. Hinterleib dünn, schwarz; Bohrer höchstens von Hinterleibslänge. Metathorax nicht gefeldert.

Calliclisis Först.

Areola fünfseitig. Körper kräftiger. Die vordersten Schienen stark aufgetrieben. Hinterleibsmitte rot. 50 .

50. Das 1. Segment ohne scharfe Längskanten an den Seiten, seine Luftlöcher in der Mitte. Nervellus stark postfurkal, deutlich über der Mitte gebrochen. Die einzige Art ist ein grosses, auffallendes Tier. Echthrus Grav.

Das 1. Segment mit deutlichen Längskanten, seine Luftlöcher hinter der Mitte. Flügel mit dunkler Querbinde; Nervellus unter der Mitte gebrochen.

cf. Xylophrurus Först.

(Unterfamilie der Cryptinen.)

51. Hinterleib nach hinten kielartig zusammengedrückt, glatt; auch der Bohrer stark zusammengedrückt, nach unten gebogen. Kopf nur schwach verdickt. Cubitalquernerv sehr kurz oder fehlend. Tropistes Grav.

Hinterleib nach hinten nur ganz schwach oder gar nicht von der Seite zusammengedrückt; Bohrer mehr oder weniger gerade, nicht zusammengedrückt. 52.

52. Metathorax vollständig gefeldert. Vorderschienen stark verdickt, an der Basis verengt. Das 2. und 3. Segment meist mit Eindrücken. Hierher eine ganze Reihe Arten.

Xylonomus Grav. 
Metathorax oben nicht oder ganz undeutlich gefeldert. Schienen schlank oder nur schwach verdickt. Beine schlank, die hintersten verlängert. Das 2. und 3. Segment ohne Quereindrücke. 53.

53. Gesicht nach unten deutlich verschmälert. Kopf hinter den Augen erweitert. Hinterleib mehr oder weniger sitzend, selten etwas gestielt.

Xorides Grav.

Gesicht nach unten kaum verschmälert. Kopf wenig aufgetrieben, hinter den Augen schwach verengt. Hinterleib lang und schmal, fast gestielt, die vorderen Segmente länger als breit.

Poemenia Holmgr.

\section{Unterfamilie. Ophioninae.}

In meinem Werke „Die Hymenopteren Mitteleuropas" habe ich die Ophioninen in 12 Tribus eingeteilt; daraus geht hervor, dass wir es hier mit Tieren von sehr verschiedenem Habitus zu tun haben und der Anfänger wird oft in Zweifel kommen, ob er ein Tier hierher oder zu den Pimplinen oder vielleicht zur nächsten Unterfamilie stellen soll. Die schwierige Tribus der Plectiscinen mag der weniger geübte zunächst ganz beiseite lassen und sich zuerst mit den stattlichen Arten der Ophioninen im engeren Sinne und den Anomalinen befassen. fehlt. 2 .

1. Der rücklaufende Nerv mündet vor dem Cubitalquernerv; die Areola

Der rücklaufende Nerv mündet hinter dem Cubitalquernerv oder in die Areola, wenn eine solche vorhanden ist, in seltenen Fällen ist er interstitial. 9.

2. Antennen kurz, nach dem Ende zu keulenförmig verdickt. Metathorax nicht gefeldert. Hierher zwei sehr zierliche, höchst seltene Arten, die eine davon reich gelb gezeichnet. (1. Tribus: Hellwigiini.)

Hellwigia Grav.

Antennen nicht keulenförmig, sondern borsten- oder fadenförmig, meist lang. 3.

3. Mittelschienen mit nur einem Sporn. Mesonotum runzlig-punktiert. Antennen ziemlich kurz. Hierher nur eine einzige Art, $N$. foliator F., mittelgross, schwarzbraun, mit rötlicher Zeichnung. (2. Tribus: Nototrachini.)

Nototrachys Marsh.

Mittelschienen mit 2 Sporen. Thorax fast glatt. Antennen sehr lang. (3. Tribus: Ophionini) 4.

4. Discocubitalnerv in der Mitte winklig gebrochen und einen Nervenast aussendend, der Basalteil mit dem Basalnerv stark konvergierend. Meist grosse, rotgelbe Arten.

Ophion Grav.

Discocubitalnerv nicht gebrochen, seine Basis mit dem Basalnerv nicht oder nur schwach konvergierend. 5.

5. Gesicht unter den Antennen mit starkem und spitzem Zahn. Kopf und Thorax gelb gefleckt; Hinterleib mit breiten gelben Binden. Die einzige, sehr grosse Art, G. picta Boie, lebt in Spinnern.

Gravenhorstia Boie.

Gesicht unter den Antennen ohne Zahn. Körper vorwiegend rotgelb gefärbt. 6 .

6. Basal- und Discocubitalnerv schwach konvergierend. Kopf nach hinten verschmälert. Metathorax an der Basis mit hoher Leiste. Die einzige Art, $S$. bombycivorus Grav., lebt bei Stauropus fagi. Stauropoctonus Brauns.

Basal- und Discocubitalnerv parallel oder schwach konvergierend. Kopf nach hinten nicht verschmälert. 7 . 
7. Discocubitalzelle mit 1 oder 2 Hornflecken. Mesonotum ohne Parapsidenfurchen.

Enicospilus Steph.

Discocubitalzelle ohne Hornflecken. 8.

8. Metathorax nur vorn mit einer zarten Querleiste. Basis des Radius doppelt geschwungen. Nervulus vor dem Basalnerv; Nervellus deutlich antefurkal. Die einzige Art, A. undulatus Grav., lebt bei Spinnern.

Allocamptus Thoms.

Metathorax vorn mit einer in der Mitte stark erhöhten Querleiste, ausserdem noch mehr oder weniger deutlich gefeldert. Basis des Radius nur einfach geschwungen. Nur 2 Arten.

Eremotylus Först.

9. Die hintersten Tarsen, besonders der Metatarsus, mehr oder weniger verdickt. Körper meist gross und durchweg schlank. Thorax runzlig-punktiert; Metathorax über die Hinterhüften hinaus verlängert. Flügel, wenigstens bei den europäischen Gattungen, ohne Areola. (4. Tribus: Anomalini) 10.

Die hintersten Tarsen nicht verdickt oder Thorax glatt. 22.

10. Der Aussennerv der Brachialzelle $(\alpha)$ trifft die Discocubitalzelle in der Mitte; die untere Seite der Discocubitalzelle bildet eine gerade Linie. Zähne der Mandibeln sehr ungleich. 11.

Der Aussennerv der Brachialzelle trifft die Discocubitalzelle vor der Mitte, die untere Seite der Discocubitalzelle bildet keine gerade Linie. Zähne der Mandibeln fast gleich. 13.

11. Der hinterste Metatarsus $4 \mathrm{mal}$ so lang wie das 2. Glied, fast länger als die 4 übrigen Glieder zusammen. Klauen rechtwinklig gekrümmt. Schildchen schwarz.

Heteropelma Wesm.

Der hinterste Metatarsus etwa doppelt so lang wie das folgende Glied. 12.

12. Schildchen gelb. Clypeus an der Spitze abgestutzt. E. circumflexum L. ist eine der häufigsten Anomalinen.

Exochilum Wesm.

Schildchen schwarz. Clypeus an der Spitze breit aufgebogen, in der Mitte tief ausgebuchtet, fast zweilappig.

Schizoloma Wesm.

13. Augen deutlich behaart. Nervellus nicht gebrochen. Gesicht und Schildchen gelb.

Trichomma Wesm. gelb. 14 .

Augen nicht behaart. Schildchen nur bei Anomalon biguttatum Grav.

14. Rücklaufender Nerv interstitial, d. h. er trifft auf den Cubitalquernerv (Areolarnerv). 15.

Rücklaufender Nerv deutlich hinter dem Cubitalquernerv mündend. 16.

15. Nervus parallelus in oder unter der Mitte der Brachialzelle. Clypeus am Ende schwach winklig vorgezogen. Antennen ziemlich kurz. Mesonotum ziemlich glatt und glänzend.

Erigorgus Först.

Nervus parallelus über der Mitte der Brachialzelle. Clypeus am Ende zugerundet oder etwas spitz vorgezogen.

Barylypa Först.

16. Die Endsporen der hintersten Schienen länger als die Breite des Schienenendes. Nervus parallelus aus oder unter der Mitte der Brachialzelle entspringend. Nervellus immer gebrochen. Grössere Arten. 17.

Die Endsporen der hintersten Schienen nicht länger als die Breite des Schienenendes. Nervus parallelus meist über der Mitte der Brachialzelle. Kleinere Arten. 19. 
17. Mesonotum glatt und glänzend. Parapsidenfurchen tief. Stirn ohne Leiste oder Zahn. In Deutschland nur eine grosse und seltene Art, H. heros Wesm. Habronyx Först.

Mesonotum punktiert. Parapsidenfurchen schwach oder fehlend. 18.

18. Stirn mit scharfer Leiste, die von oben betrachtet wie ein spitzer Zahn vortritt. Mesonotum vorn quer niedergedrückt. Klauen gekämmt. Antennengeissel grösstenteils rot.

Aphanistes Först.

Stirn ohne Leiste oder Zahn. Mesonotum nur bei $A$. biguttatum Grav. niedergedrückt; bei dieser Art das Schildchen gelb. Klauen nicht gekämmt. Antennengeissel meist schwarz.

Anomalon Grav.

19. Nervellus deutlich gebrochen und einen Nerv aussendend. Parapsidenfurchen deutlich. 20.

Nervellus im Hinterflügel nicht gebrochen. 21.

20. Nervus parallelus aus der Mitte der Brachialzelle entspringend. Die hintersten Tarsen stark verdickt.

Blaptocampus Thoms.

Nervus parallelus deutlich über der Mitte der Brachialzelle entspringend. Antennen zuweilen von Körperlänge.

Labrorychus Först.

21. Nervus parallelus unterhalb des oberen Aussenwinkels der Brachialzelle entspringend. Hinterschienen verlängert.

Agrypon Först.

Nervus parallelus interstitial, d. h. derselbe entspringt aus dem oberen Aussenwinkel der Brachialzelle, die Discoidalzelle läuft also unten in einem Punkte zusammen. Hinterschienen kurz. Kleine Arten.

Atrometus Först.

22. Stigma lang und schmal, sehr selten etwas breit. Radialzelle meist gestreckt. 23.

Stigma sehr gross und breit. Radialzelle meist kurz dreieckig; die beiden Abschnitte des Radius bilden einen steilen, nicht selten rechten Winkel. 73.

23. Areola nicht auffallend gross und nicht von regelmässig rhombischer Gestalt; oder wenn gross, dann die Klauen nicht oder zerstreut gekämmt. Die "7 $0^{7}$ ohne griffelförmige Anhängsel am Hinterleibsende. 24.

Areola sehr gross, meist regelmässig rhombisch, bei einer Gattung verschoben viereckig, mit ungleichen Seiten; in diesem Falle die Klauen dicht und lang gekämmt. Bohrer vorragend. Das letzte Bauchsegment der of gross; die $0^{7} 0^{7}$ mit 2 griffelförmigen Anhängseln am Hinterleibsende. (8. Tribus : Mesochorini) 70 . bogen. 25 .

24. Hinterleib gestielt, das 1. Segment nicht selten knieförmig ge-

Hinterleib sitzend, oder wenn etwas gestielt, der Stiel deprimiert. Areola vorhanden, meist gross und ein verschobenes Viereck bildend. Nervellus meist schräg und weit über der Mitte gebrochen. Klauen selten gekämmt. (7. Tribus: Banchini) 67.

25. Luftlöcher des 1. Segments deutlich hinter der Mitte. Luftlöcher des Metathorax meist rund. Klauen unbewehrt, höchstens mit zerstreuten Kammzähnen. Vorwiegend mittelgrosse oder kleine Arten; Färbung schwarz, höchstens die Hinterleibsmitte hell. (5. Tribus: Campoplegini) 26.

Luftlöcher des 1. Segments vor, selten in der Mitte. Luftlöcher des Metathorax länglich. Klauen dicht und lang gekämmt. Grössere Arten von rötlichgelber Färbung, die an Ophion erinnern. (6. Tribus: Paniscini) 64. 
26. Luftlöcher des Metathorax gestreckt; letzterer der Länge nach ausgehöhlt, ungefeldert, höchstens an der Basis mit Spuren von Leisten. Hinterleibsmitte gelb oder rot. Grosse oder mittelgrosse Arten. 27.

Luftlöcher des Metathorax rund. Mittelgrosse oder kleine Arten. Eine Ausnahme macht die Gattung Rhimphoctona, bei welcher jedoch der Metathorax gefeldert und nicht ausgehöhlt ist. 28.

27. Flügel mit Areola. Postpetiolus meist schwarz. Zahlreiche, schwer unterscheidbare Arten.

Campoplex Grav.

Flügel ohne Areola. Postpetiolus rot. In Deutschland nur Ch. decipiens Grav.

Charops Holmgr.

28. Clypeus in der Mitte des Endrandes mit einem spitzen Zähnchen. Areola ziemlich regelmässig, gestielt. Postpetiolus deutlich abgesetzt. Nervellus gebrochen.

Clypeus in der Mitte des Endrandes ohne Zahn. 29.

Sagaritis Holmgr.

29. Augen behaart. Gesicht des $\&$ nach unten stark verschmälert. 30 .

Augen nicht behaart. Gesicht des $q$ nach unten nicht oder nur schwach verschmälert. 31 .

30. Körper schlank. Postpetiolus flach. Radialzelle gestreckt; Endabschnitt des Radius nur schwach gekrümmt. Nur wenige Arten, am häufigsten C. leucocera Holmgr., das $q$ mit oben weisser Antennenbasis. Cymodusa Holmgr.

Körper klein und gedrungen. Postpetiolus an der Biegungsstelle stark bucklig. Radialzelle kurz; Endabschnitt des Radius stark gekrümmt. In Mitteleuropa nur Th. egregia Schmiedekn.; Antennenbasis des $q$ weiss gezeichnet, Hinterleibsmitte rot.

Thersitia Schmiedekn.

31. Augen innen deutlich ausgerandet. Hinterleib gegen das Ende meist keulenförmig, seltener von der Seite zusammengedrückt. Metathorax unvollständig gefeldert, der Länge nach ausgehöhlt. 32.

Augen innen nicht oder nur unmerklich ausgerandet. Hinterleib gegen das Ende selten keulenförmig verdickt. 33.

32. Hinterleib gegen das Ende keulenförmig; Bohrer versteckt. In Deutschland eine ganze Reihe Arten.

Casinaria Holmgr.

Hinterleib am Ende deutlich zusammengedrückt. Sehr ähnlich der Gattung Campoplex; hauptsächlich verschieden durch die rundlichen Luftlöcher des Metathorax.

Trophocampa Schmiedekn.

33. Flügel ohne Areola. 34.

Flügel mit Areola. 40.

34. Clypeus mit grossen und tiefen Seitengruben. Area superomedia nach vorn offen. Hinterleib nach hinten keulenförmig, schwarz; Bohrer nicht vorragend. Wenige Arten, am häufigsten $N$. aberrans Grav. Nepiesta Först.

Clypeus mit kleinen Seitengruben. Hinterleib nicht keulenförmig. 35.

35. Nervellus gebrochen. Metathorax mit kurzer dreieckiger Area superomedia, Costula fehlend, die Seitenfelder also miteinander verschmolzen. Die einzige Art, G. melanostoma Thoms., ist schwarz, Schenkel und Schienen grösstenteils rot.

Gonotypus Först.

Nervellus nicht gebrochen. 36.

36. Bohrer deutlich vorragend. 37.

Bohrer nicht über die Hinterleibsspitze hinausragend. 39. 
37. Kopf hinter den Augen nicht verengt, fast kubisch. Bei der einzigen, ziemlich grossen Art, Z. dorsalis Grav., sind die ganzen Beine und die Hinterleibsmitte braunrot.

Kopf quer, nach hinten verengt. Kleinere Arten. 38.

Zaporus Först.

38. Radialzelle sehr breit; die beiden Abschnitte des Radius bilden fast einen rechten Winkel.

Phaedroctonus Först.

Radialzelle nicht.sehr breit; die beiden Abschnitte des Radius bilden einen stumpfen Winkel.

Dioctes Först.

39. Kopf nach hinten etwas verengt. Seitenfelder des Metathorax voneinander getrennt. Grössere Arten mit meist rot gezeichnetem Hinterleib.

Eriborus Först.

Kopf ziemlich aufgetrieben, nach hinten nicht verengt. Seitenfelder des Metathorax verschmolzen, indem die Costula fehlt. Die einzige, sehr kleine Art, N. pusio Holmgr., ist schwarz, das 3. Segment an den Seiten gelb.

40. Radius gebogen, kaum winklig gebrochen. 41.

Nythobia Först.

Radius deutlich winklig gebrochen. 42.

41. Fussklauen ohne Kammzähne. Kopf nach hinten nicht verschmälert. Hinterleibsmitte, Schenkel und Schienen rot. Einzige Art D. crassicornis Grav.

Diadegma Först.

Fussklauen gekämmt. Kopf quer, hinter den Augen stark verengt. Schwarz, Beine rötlichgelb, die hintersten Hüften schwärzlich. Einzige Art $S$. thuringiacus Schmiedekn.

Sinophorus Först.

42. Metathorax der Länge nach ausgehöhlt. Bohrer ziemlich weit vorstehend. Hinterleib schwarz. 43.

Metathorax der Länge nach nicht ausgehöhlt. 44.

43. Nervellus nicht schief und nicht gebrochen. Kopf nach hinten nicht oder sehr wenig verschmälert.

Eulimneria Schmiedekn.

Nervellus schief und gebrochen. Kopf nach hinten verschmälert.

Omorgus Först. (zum Teil).

44. Kopf fast kubisch. Nervellus schief, deutlich gebrochen und einen starken Nerv aussendend. Klauen und Klauenglied kräftig. Robuste Arten. 45.

Kopf nicht kubisch oder Nervellus vertikal und nicht gebrochen. 46.

45. Fussklauen an der Basis ohne Kammzähne. Luftlöcher des Metathorax rund; Seitenfelder desselben verschmolzen.

Pyracmon Holmgr.

Fussklauen an der Basis mit Kammzähnen. Luftlöcher des Metathorax langgestreckt; Seitenfelder desselben voneinander getrennt. Die einzige Art, $R h$. fulvipes Holmgr., ist ein sehr grosses, höchst seltenes Tier.

46. Clypeus mit grossen und tiefen Seitengruben. 47.

Rhimphoctona Först.

Clypeus mit kleinen und mehr seichten Seitengruben.

49.

47. Stigma sehr gross. Nervulus und Nervellus sehr schief. Metathorax gefeldert. Bohrer etwa so lang wie der halbe Hinterleib. Kleine Arten.

Synetaeris Först.

Stigma nicht auffallend gross. Nervulus nicht oder wenig schief. Bohrer meist kürzer als der halbe Hinterleib. 48.

48. Areola gestielt. Hinterleibssegmente mit hellen Endrändern. Bohrer kaum vorstehend. Einzige Art B. marginella Thoms. Biolysia Schmiedekn. 
Areola meist fünfseitig und sitzend. Bohrer vorstehend. Kleine, gedrungene Arten mit meist hellgerandetem 2. Segmente.

Canidia Holmgr.

49. Metathorax über die Hüften hinaus verlängert. Area superomedia sehr lang; Costula vor der Mitte. Das 2. Segment lang; Bohrer dünn, weit vorragend. Klauen und Klauenglied sehr klein. Körper schlank.

Nemeritis Holmgr.

Metathorax nicht über die Hinterhüften hinaus verlängert. Körper weniger schlank. 50 .

50. Nervellus gebrochen, meist antefurkal. 51.

Nervellus nicht gebrochen, meist vertikal. 59.

51. Nervulus und Nervellus sehr schief. 52.

Nervulus und Nervellus nicht oder nur wenig schief. 53.

52. Metathorax deutlich gefeldert. Die mittleren Hinterleibssegmente meist mit hellen Endrändern. Bohrer fast versteckt.

Phobocampe Först.

Metathorax nicht gefeldert. Hinterleib schwarz; das 1. Segment mit langem und schmalem Stiel; Bohrer vorstehend. Einzige Art S. Kriechbaumeri Bridgm. Spudastica Först.

53. Areola den rücklaufenden Nerv vor der Mitte aufnehmend. 54.

Areola den rücklaufenden Nerv hinter, selten in der Mitte aufnehmend. 55.

54. Areola klein, gestielt. Endränder der Segmente oder Hinterleibsmitte rötlich. Antennen des + ohne weissen Ring.

Ecphoropsis Ashm.

Areola ziemlich gross, rhombisch. Höchstens das 2. Segment mit rotem Endrand. Antennen des $q$ mit weissem Ring. cf. Callidora Först. rundet.

55. Bohrer weit vorstehend. Postpetiolus verbreitert, an den Seiten ge-

Bohrer kurz, höchstens so lang wie das 1. Segment. Postpetiolus an den Seiten nicht gerundet. 56.

56. Das 2. Segment nicht länger als breit, sondern meist etwas breiter als lang; Bohrer dick. Thorax etwas bucklig. Hinterleib schwarz.

Das 2. Segment weit länger als breit. Bohrer dünn. 57.

57. Schulterbeulen und die Endränder der Segmente weisslich. Areola klein, ziemlich regelmässig.

Nepiera Först.

Schulterbeulen und Endränder der Segmente nicht weisslich. 58.

58. Areola unregelmässig, den rücklaufenden Nerv hinter der Mitte aufnehmend. Antennen des $q$ ohne weissen Ring. Geissel und Schienen dick.

Lathroplex Först.

Areola ziemlich gross, rhombisch, den rücklaufenden Nerv vor der Mitte aufnehmend. Antennen des $q$ mit weissem Ring.

Callidora Först.

59. Mittelbrust vor den Mittelhüften mit einem zweiteiligen Zahn oder Fortsatz. Nervus parallelus über der Mitte der Brachialzelle entspringend. Das 2. Segment kurz.

Lathrostizus Först.

Mittelbrust unbewehrt. Nervus parallelus meist aus der Mitte der Brachialzelle entspringend. 60 .

60. Kopf mehr oder weniger kubisch, hinter den Augen nicht verengt. 61.

Kopf nicht kubisch. Zähne der Mandibeln gleich. 62. 
61. Der untere Zahn der Mandibeln länger. Bohrer versteckt. Schaft unten hell. Hinterleibsmitte meist rot. Zahlreiche Arten. Olesicampe Först.

Zähne der Mandibeln gleich. Bohrer meist ziemlich weit vorstehend. Beine grösstenteils rot.

Meloboris Holmgr.

62. Basalnerv sehr steil aufsteigend; Stigma in der Regel breit. Hinterleib höchst selten hell gezeichnet; Bohrer bei den meisten Arten weit vorstehend. Angitia Holmgr.

Basalnerv weniger steil aufsteigend, mehr schräg. Bohrer nicht oder nur wenig vorstehend. Hinterleib oft rot gezeichnet. 63 .

63. Kopf hinter den Augen verengt. Schaft meist schwarz. Hinterleib nicht selten mit rotem Gürtel.

Anilastus Först.

Kopf hinter den Augen nicht oder wenig verengt. Schaft unten gewöhnlich hell. Hinterleib selten mit rotem Gürtel, meist an den Seiten rot.

Holocremnus Först.

64. Kopf gross und aufgetrieben, mit breiten Wangen. Schildchen nicht gerandet. Metathorax sehr unegal durch hohe Leisten, Höcker und Seitenzähne. Hierher in Deutschland nur eine Art, O. glaucopterus L., ein grosses Tier von gelbroter Färbung, das bei der Blattwespengattung Cimbex schmarotzt.

Opheltes Grav.

Kopf nicht oder wenig aufgetrieben, Wangen schmal. Schildchen wenigstens an der Basis gerandet. 65 .

65. Der zweite Abschnitt des Radius ist an der Basis, also an der Areola, nicht gebogen, sondern bildet eine gerade Linie. Luftlöcher des Metathorax rund. Nur eine Art: A. luteus Holmgr.

Absyrtus Holmgr.

Der zweite Abschnitt des Radius ist an seiner Basis steil nach oben geschwungen. Luftlöcher des Metathorax länglich. 66.

66. Nervulus weit hinter dem Basalnerv. Hinterhaupt durch eine Leiste abgegrenzt.

Paniscus Grav.

Nervulus interstitial. Hinterhaupt nicht durch eine Leiste vom Scheitel und den Wangen abgegrenzt. Parabatus Thoms.

67. Areola klein, dreiseitig, gestielt. Das letzte Rückensegment dreieckig zusammengedrückt, hinten spitz, oben mit einem Längsschlitz. Bohrer kurz, vor der Spitze oben mit Einkerbung, die Klappen hinter der Basis erweitert. Einzige Art $X$. fulvipes Holmgr.

Xenoschesis Först.

Areola gross, rhombisch oder verschoben vierseitig. 68.

68. Hinterleib sitzend. Discocubitalnerv fast gerade, nicht gebrochen. Schildchen meist mit Dorn. Augen innen ausgerandet. Antennenschaft aussen stark ausgeschnitten. Bohrer versteckt.

Banchus Grav.

Hinterleib etwas gestielt. Discocubitalnerv stets gebrochen und meist mit einem Ast. Augen nicht ausgerandet. Antennenschaft kaum ausgeschnitten. Bohrer vorstehend. 69.

69. Antennen gegen die Spitze verdünnt. Areola nicht regelmässig rhombisch. Bohrer weit kürzer als der Hinterleib. Exetastes Grav.

Antennen an der Spitze nicht verdünnt. Areola rhombisch. Bohrer so lang oder länger als der Hinterleib.

Leptobatus Grav.

70. Scheitel sehr verengt, die Nebenaugen fast die Augen berührend. Areola nicht regelmässig rhombisch, sondern unregelmässig vierseitig, schief und 
gestielt. Klauen dicht und lang gekåmmt. Das 2. Segment an der Basis mit deutlichen Gruben. Grosse rotgelbe Arten, die an Ophion erinnern.

Plesiophthalmus Först.

Scheitel nicht verengt, die Nebenaugen von den Augen weit abstehend. Kleinere Arten. 71.

71. Nervus parallelus unterhalb der Mitte der Brachialzelle entspringend. Nervulus hinter dem Basalnerv; Nervellus nicht gebrochen. Sehr kleine Arten.

Stictopisthus Thoms. springend. 72 .

72. Das 1. Segment mit scharfer Seitenleiste. Nervus parallelus aus der Mitte der Brachialzelle. Nervellus fast stets gebrochen. Astiphromma Först.

Das 1. Segment ohne scharfe Seitenleiste. Nervus parallelus oberhalb der Mitte der Brachialzelle entspringend. Nervellus nicht gebrochen. Zahlreiche, schwer unterscheidbare Arten.

Mesochorus Grav.

73. Die hintersten Beine weit länger und dicker als die vorderen. Die hintersten Schenkel unten mit starkem Zahn, wenn nicht, dann die Vorderflügel mit grosser rhombischer, gestielter Areola. Flügel mit dicken Nerven. (9. Tribus: Pristomerini) 74.

Die hintersten Beine nicht auffallend dicker und länger als die vorderen. Areola im Vorderflügel nicht gross und nicht rhombisch. Hinterschenkel unten ohne Zahn. 75.

74. Flügel ohne Areola. Die hintersten Schenkel unten hinter der Mitte mit einem starken Zahn. Bohrer dünn, mindestens so lang wie der halbe Hinterleib.

Pristomerus Curt.

Flügel mit grosser, unregelmässig viereckiger, gestielter Areola. Hinterschenkel ohne Zahn. Metathorax vollständig gefeldert, mit hohen Leisten. Bohrer kråftig, deutlich nach unten gekrümmt, etwa von halber Hinterleibslänge.

Demophorus Thoms.

75. Cubitalnerv im Hinterflügel gegen die Basis erloschen oder ganz fehlend. Die beiden Abschnitte des Radius bilden einen rechten Winkel. Flügel ohne Areola, der Cubitalquernerv sehr kurz. Bohrer meist deutlich vorstehend und gekrümmt. (10. Tribus: Porizonini) 76.

Cubitalnerv im Hinterflügel bis zur Basis deutlich. Die beiden Abschnitte des Radius bilden keinen rechten Winkel. 79.

76. Das 1. Segment linear, nach hinten nicht breiter werdend, die Luftlöcher desselben in oder vor der Mitte. Metathorax ziemlich vollständig gefeldert. 77.

Das 1. Segment nach hinten breiter werdend, die Luftlöcher hinter der Mitte. Metathorax unvollståndig gefeldert. 78.

77. Antennen borstenförmig, Geisselglieder kaum voneinander unterscheidbar. Hinterleib elliptisch, etwas flachgedrückt. Bohrer fast so lang wie der halbe Hinterleib. Die einzige Art, $O$. luteolator Grav., ist schwarz mit roter Hinterleibsmitte; man kann sie in Menge aus den bekannten Rosengallen ziehen. Orthopelma Taschenb.

Antennengeissel beim $q 18 \mathrm{gliedrig}$, perlschnurförmig. Das 1. Segment so lang wie der übrige Hinterleib, dieser birnförmig; Bohrer kaum vorstehend. Kopf und Hinterleib mit Ausnahme des 1. Segments lehmgelb. 
78. Schiensporen gekrümmt. Die hintersten Tarsen lang, die Glieder allmählich an Länge abnehmend. Thorax mehr oder weniger zylindrisch. Schenkel meist verdickt. Die Gattung zerfällt in 5 Untergattungen, deren Unterscheidung schwierig ist.

Porizon Fall.

Schiensporen kurz und gerade. Die hintersten Tarsen nicht stark verlängert, der Metatarsus im Verhältnis zu den folgenden Gliedern sehr lang. Thorax mehr oder weniger kurz. Die Gattung ist in eine Reihe Untergattungen zerlegt worden; diese und die zahlreichen Arten bieten grosse Schwierigkeiten und so eignet sich ihr Studium nicht für den Anfänger.

Thersilochus Holmgr.

79. Kopf nicht besonders klein; Clypeus weder konvex noch von der Seite zusammengedrückt. Hinterschienen normal, an der Basis nicht eingeschnürt. Körper sehr gestreckt; Thorax weit länger als breit. Hinterleib stark von der Seite zusammengeárückt, das 2 . Segment mindestens doppelt so lang als breit; Bohrer lang. Flügel ohne Areola. (11. Tribus: Cremastini) 80.

Kopf in der Regel klein; Clypeus konvex und gewöhnlich von der Seite zusammengedrückt. Hinterschienen verdickt und meist an der Basis deutlich eingeschnürt. Areola oft vorhanden. Die hierher gehörenden zahlreichen Arten sind durchweg kleine und meist zarte Tiere, sie sind von verschiedenem Habitus und bilden keine natürliche Gruppe; ihr Studium eignet sich nicht für den noch wenig Geübten. (12. Tribus: Plectiscini) 81.

80. Wangen, d. h. die Entfernung der Augen von der Mandibelbasis, kurz. Gesicht nicht verlängert; Clypeus meist deutlich vom Gesicht geschieden. Die zahlreichen Arten sind schwer voneinander zu unterscheiden. Cremastus Grav.

Wangen sehr lang. Gesicht verlängert, gewölbt; Clypeus nicht vom Gesicht geschieden. Einzige Art $P$. genalis Szepl.

Paracremastus Szepl.

81. Antennengeissel 12-, sehr selten 13gliedrig, meist hinter der Mitte spindelförmig verdickt. Areola 5 seitig oder fehlend. Kopf nach hinten nicht oder wenig verschmälert; Clypeus nicht konvex. Hinterschienen dick, an der Basis eingeschnürt. Die Gattung kann ebensogut zur Unterfamilie der Tryphoninen gestellt werden. Die zahlreichen kleinen Arten schmarotzen in Blattwespenlarven. Adelognathus Holmgr.

Antennen vielgliedrig, gegen das Ende nicht spindelförmig verdickt. Areola, wenn vorhanden, nicht 5 seitig. Clypeus meist konvex und von der Seite zusammengedrückt. Die zahlreichen Arten schmarotzen hauptsächlich in Larven von Dipteren. 82.

82. Flügel mit Areola. 83.

Flügel ohne Areola. 93.

83. Gesicht nach unten deutlich verschmälert. 84 .

Gesicht nach unten nicht verschmälert. 86 .

84. Nervellus postfurkal, nicht gebrochen. Augen gross, bei dem $q$ behaart. Einzige Art C. trichops Thoms.

Catomicrus Thoms.

Nervellus antefurkal, gebrochen und meist einen Nerv aussendend. Augen des $q$ nicht behaart. 85 .

85. Die hintersten Beine kräftig, Klauenglied und Klauen sehr gross. Segmente mit rötlichem Endrand.

Catastenus Först.

Beine nicht kräftig, das Klauenglied klein. Bohrer kaum vorragend. 
86. Metathorax glatt und glänzend, ohne alle Felderung. Nervellus nicht gebrochen. Bohrer lang. Aperileptus Först. Metathorax deutlich gefeldert. 87.

87. Clypeus ganz flach. 88.

Clypeus gewölbt und von der Seite mehr oder weniger zusammengedrückt. 92.

88. Hinterleibsstiel lang, linear, etwas gekrümmt. Segment $2-7$ dicht runzlig-punktiert, mit weisslichem Endrand; Bohrer so lang wie das 1. Segment. Einzige Art Ph. aciculatus Voll.

Phidias Voll.

Hinterleibsstiel kürzer. Hinterleib von anderer Skulptur und Färbung. 89.

89. Nervellus nicht gebrochen. Areola schief, 4 seitig. Antennen des ? gegen das Ende kolbig verdickt. Segment 2-4 hell gerandet. Bohrer etwas länger als das 1. Segment. In Deutschland $H$. tenuicinctus Först.

Holomeristus Först.

Nervellus antefurkal, deutlich gebrochen und einen Nerv aussendend. Areola

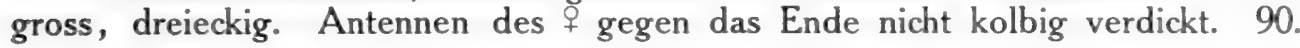

90. Metathorax oben mit nur 3 Längsfeldern, indem die Costula fehlt, hinten ohne Seitendorne.

Entypoma Först.

Metathorax oben mit 5 Feldern, Costula vorhanden. 91.

91. Metathorax hinten mit Seitendornen. Die hintersten Schenkel verdickt. Klauenglied und Pulvillus (der lappenförmige Körper zwischen den Klauen) gross.

Acroblapticus Schmiedekn.

Metathorax hinten ohne Seitendornen. Beine kaum verdickt. Klauenglied und Pulvillus klein.

Blapticus Först.

92. Clypeus gross. Schildchenseiten fast bis zur Spitze gerandet. Das 1. Segment runzlig-punktiert, die Luftlöcher eher vor der Mitte. Beine und Antennen meist schlank. Zahlreiche voneinander nicht scharf getrennte Arten. Plectiscus Grav.

Clypeus klein, fast versteckt, mit grossen Seitengruben. Schildchen höchstens an der Basis gerandet. Postpetiolus dicht gestreift, die Luftlöcher hinter der Mitte. Antennen und Beine kräftig, die ersteren gegen die Spitze verdünnt. Wenige seltene Arten, die vielleicht nur eine einzige, D. crassipes Thoms., bilden.

93. Metathorax hinten mit spitzen Seitenzähnen. 94.

Dialipsis Först.

Metathorax hinten ohne Seitenzähne. 95.

94. Gesicht nach unten nicht verschmälert. Das 1. Segment breit, mit 2 Kielen. Einzige Art $G$. flavipes Först.

Gnathochorisis Först.

Gesicht nach unten stark verschmälert. Das 1. Segment lang und dünn, ohne Kiele. Einzige Art S. alpigena Strobl. Stroblia Schmiedekn.

95. Kopf fast kubisch, das Gesicht unter den Antennen vorspringend. Antennenschaft zylindrisch. Schienen etwas zusammengedrückt. Bohrer versteckt.

Miomeris Först.

Gesicht unter den Antennen nicht vorspringend. Schaft meist kuglig. Schienen nicht zusammengedrückt. 96.

96. Das 1. Geisselglied kleiner als das 2. Parapsidenfurchen tief. Cubitalquernerv klein, punktförmig; Nervellus nicht gebrochen. Nur die $\sigma^{7} \sigma^{7}$ bekannt.

Das 1. Geisselglied so lang oder länger als das 2. 97. 
97. Kopf kurz; Scheitel tief ausgebuchtet, oben in der Mitte ohne Randleiste. 98.

Scheitel auch oben in der Mitte durch eine Randleiste vom Hinterhaupt getrennt. 99.

98. Nur das 1. und 2. Segment gerunzelt, letzteres mit glattem Endrand. Stigma im Vorderflügel breit. Antennen beim $\sigma^{7}$ mit 21 Gliedern, das 3. und 4. Geisselglied ausgebuchtet, die Ausbuchtung des 3. unten zahnartig vorspringend. Einzige Art $A$. signaticorne Först.

Die 3 ersten Segmente fein gerunzelt. Stigma schmal. Geisselglieder des $\sigma^{7}$ nicht ausgebuchtet. Apoclima Först.

99. Metathorax oben nicht deutlich und regelmässig gefeldert. Bohrer versteckt. 100 .

Metathorax oben deutlich gefeldert. 104.

100. Hinterleibsstiel kurz und breit. Antennen weniger als 30 gliedrig. Nervellus tief unter der Mitte gebrochen. Hinterleib in der Mitte oder grösstenteils rötlichgelb. Hierher 2 Arten, am häufigsten $H$. flavipes Först.

Hemiphanes Först.

Hinterleibsstiel lang und dünn. Antennen meist mit mehr als 30 Gliedern. 101.

101. Cubitalquernerv (Areolarnerv) sehr kurz oder fast fehlend. Die Geissel beim + nicht wirtelartig behaart, beim $\sigma^{7}$ Glied 5-7 deutlich ausgerandet.

Helictes Hal.

Cubitalquernerv deutlich, meist so lang wie seine Entfernung vom rücklaufenden Nerv. Beim $q$ die Geissel wirtelartig behaart, beim $o^{7}$ kein Glied ausgerandet. 102.

102. Metathorax kurz vor der Mitte tief eingeschnürt. Kopf klein, Augen gross. Körper, zumal die Brust, hell gezeichnet. Dicolus Först.

Metathorax kurz vor der Mitte nicht tief eingeschnürt, höchstens nahe der Basis mit einer eingedrückten Querlinie. 103.

103. Stirnseiten des $\&$ schwarz. Radius an der Spitze gekrümmt. Schiensporen meist ziemlich lang; Vorderschienen nicht aufgetrieben. Hinterleib flach. Megastylus Schiödte.

Stirnseiten des $q$ weiss. Radius am Ende kaum gekrümmt. Schiensporen kurz; Vorderschienen aufgetrieben. Hinterleib meist gegen das Ende deutlich zusammengedrückt. Kleinere Arten.

Myriarthrus Först.

104. Stigma sehr schmal. Kopf sehr klein; Antennen 18-20 gliedrig. Radialzelle breit dreieckig; Cubitalquernerv so lang wie seine Entfernung vom rücklaufenden Nerv; Nervellus nicht gebrochen. Das 1. Segment lang, linear, der übrige Hinterleib flach, glatt und glänzend.

Polyaulon Först.

Stigma nicht sehr schmal; in zweifelhaften Fällen der Cubitalquernerv sehr kurz oder fehlend oder der Nervellus deutlich gebrochen. 105.

105. Hinterleib sitzend, das 1 . Segment nach vorn wenig verschmälert. Parapsidenfurchen tief. 106.

Hinterleib deutlich gestielt, der Stiel meist lang und schmal. 107.

106. Hinterleib in der Basalhälfte fein runzlig-punktiert und matt, die Endsegmente mehr glatt und glänzend, mit gelblichem Endrand. Gesichtsseiten blassgelb. Cubitalquernerv ziemlich lang. Bohrer länger als der halbe Hinterleib. Einzige Art A. pimplarius Thoms. Allomacrus Först. 
Hinterleib, wie auch Kopf und Thorax glatt und glänzend. Cubitalquernerv sehr kurz. Mittlerer Teil des Mesonotums vorn mit 2 Zähnchen. Klauenglied sehr stark verdickt. Hinterleib zum Teil rotbraun; Bohrer kürzer als das 1. Segment. Hierher 1 oder 2 höchst seltene Arten. Symphylus Först. 107. Nervellus deutlich gebrochen. 108.

Nervellus nicht gebrochen. 109.

108. Die beiden Abschnitte des Radius bilden einen scharfen Winkel; Cubitalquernerv deutlich; Nervellus antefurkal, einen deutlichen Nerv aussendend. Parapsidenfurchen tief, bis fast über die Mitte. Hinterleibsmitte rötlichgelb. Einzige Art E. suspiciosa Först.

Entelechia Först.

Der 1. Abschnitt des Radius ist gebogen und bildet mit dem 2. keinen scharfen Winkel; Cubitalquernerv punktförmig; Nervellus keinen Nerv aussendend. Parapsidenfurchen kurz. Hierher zahlreiche Arten, die, wie bei Plectiscus, nicht scharf geschieden sind.

Proclitus Först.

109. Cubitalquernerv nicht punktförmig. Metathorax mit deutlicher Costula. Das 1. Geisselglied länger als das 2. Bohrer kurz und ziemlich dick. Das 1. Segment fast linear. Schiensporen sehr kurz. Eusterinx Först.

Cubitalquernerv punktförmig. Metathorax ohne Costu ja. 110.

110. Das 1. Segment runzlig-punktiert, matt. Bohrer die Hinterleibsspitze kaum überragend. Das mittlere hintere Metathoraxfeld durch einen scharfen Mittelkiel geteilt. Das 1. Geisselglied so lang wie das 2. Pantisarthrus Först.

Das 1. Segment mehr oder weniger glänzend, nicht rauh. Bohrer deutlich vorragend, länger als das 1 . Segment. Das mittlere hintere Metathoraxfeld ohne Mittelkiel. cf. Proclitus Först.

\section{Unterfamilie. Tryphoninae.}

Die Tryphoninen sind fast noch reicher an Formen als die eben behandelte Unterfamilie der Ophioninen. Es sind hauptsächlich 4 Merkmale, an denen sie sich erkennen lassen:

Die Areola im Vorderflügel ist 3 seitig oder fehlt ganz, nur bei der eigentümlichen Gattung Pseudocryptus ist sie 5 seitig; der Hinterleib ist nicht oder nur am Ende schwach von der Seite zusammengedrückt; das 1. Segment ist niemals knieförmig gebrochen und trägt die Luftlöcher in oder etwas vor der Mitte; der Bohrer ist versteckt oder ragt nur kurz hervor.

Am meisten sind die Tryphoninen den Pimplinen verwandt; da der Hauptunterschied in der Bohrerlänge beruht, so sind die Männchen sehr schwer zu unterscheiden und der weniger Geübte muss sich zuerst an weiblichen Exemplaren die Gattungsunterschiede klar machen.

Die Tryphoninen schmarotzen vorwiegend bei Blattwespen.

Die Systematik dieser Unterfamilie ist eine sehr schwierige. Bei dem knappen Raum, der mir hier zur Verfügung steht, kann ich sie nur in ihren Grundzügen darlegen; wer sich eingehender mit dieser Gruppe wie mit den übrigen befassen will, sei auf meine Opuscula Ichneumonologica verwiesen. Ich beschränke mich auch hier nur darauf, diejenigen Tribus näher zu erläutern, die in meinem soeben erwähnten Werke bereits behandelt sind.

Ich zerlege die Tryphoninen in die nachstehenden 5 Sektionen:

1. Schildchen durch eine schmale und tiefe Querspalte vom Mesonotum getrennt. Radius aus der Basis des langen Stigmas entspringend. Hinterleib birnförmig, langgestielt. Körper reich gelb gezeichnet. 
Schildchen durch eine Quergrube vom Mesonotum getrennt. Hinterleib nicht ausgeprägt birnförmig. 2 .

2. Gesicht mit abgegrenzter schildförmiger Erhöhung. Schildchen flach vierseitig, mit spitz vorstehenden Hinterecken. Areola gross, rhombisch. Körper mit rauher Skulptur; Hinterleib meist gelb bandiert.

V. Tryphonides aspidopi.

Gesicht ohne abgegrenzte schildförmige Erhöhung. Schildchen ohne spitze Hinterecken, mehr oder weniger gewölbt und hinten abgerundet. 3.

3. Der obere Zahn der Mandibeln zweiteilig, der Endrand der Mandibeln deshalb dreizähnig. Hinterleib an der Basis flach und breit; das 1. Segment nach vorn kaum verschmälert, an den Seiten vorn winklig vortretend.

III. Tryphonides schizodonti.

Der obere Zahn der Mandibeln nicht zweiteilig; der Endrand der Mandibeln deshalb höchstens mit 2 Zähnen. 4.

4. Gesicht flach; Clypeus davon meist getrennt. Das 1. Geisselglied stets länger als das zweite. Luftlöcher des Metathorax rundlich. Die hintersten Schenkel selten verdickt.

I. Tryphonides homalopi.

Gesicht stark aufgetrieben; Clypeus nicht davon getrennt. Das 1. und 2. Geisselglied meist von gleicher Länge. Luftlöcher des Metathorax meist gestreckt. Schenkel, besonders die hintersten, stark geschwollen und etwas breitgedrückt.

II. Tryphonides prosopi.

\section{Sektion. Tryphonides homalopi.}

1. Die hintersten Schienen ohne Endsporen, sehr selten mit einem einzigen sehr kurzen. Bohrer oft büschelförmig Eier tragend, Bohrerklappen einfach, am Ende oben nicht ausgeschnitten. (1. Tribus: Cteniscini) 2.

Die hintersten Schienen mit zwei deutlichen Endsporen. Bohrerklappen nicht selten vor dem Ende oben ausgebuchtet. 11.

2. Der untere Zahn der Mandibeln grösser und länger als der obere. 3.

Zähne der Mandibeln gleich. 4.

3. Fussklauen an der Wurzel sehr schwach oder gar nicht gekämmt. Clypeus am Ende abgestutzt. Acrotomus Holmgr.

Fussklauen bis über die Mitte hinaus stark gekämmt. Clypeus am Ende breit abgerundet. Beine mit Einschluss der Hüften rot. Anisoctenion Först.

4. Kopf und Thorax mit langer hellgrauer Behaarung. Hinterleib keulenförmig, das 1. Segment lang und schmal, an der Basis ohrartig erweitert.

Kopf und Thorax dünn und kurz behaart. 5 . Exyston Schiödte.

5. Körper dicht und stark punktiert. Schildchen hell gezeichnet. Area superomedia quer. 6 .

Körper sehr schwach punktiert, mehr glänzend. Area superomedia nicht quer. 8.

6. Hinterleib rot, Basis des 1. Segments schwarz, eckig vortretend. Metathorax runzlig-punktiert, undeutlich gefeldert. Einzige Art P. ictericus Grav.

Hinterleib schwarz, die Segmente mit gelben Endrändern. Metathorax mit deutlicher Felderung. 7. 
7. Die hintersten Schienen am Ende aussen mit kurzem Sporn. Seitenrand des 1. Segments mehrfach gebuchtet. Flügel am Saum stark verdunkelt; Areola gross. Die reiche Zeichnung von Kopf und Thorax und die breiten Hinterleibsbinden sattgelb. Einzige Art T. apiarius Grav. Tricamptus Först.

Die hintersten Schienen ohne Endsporn. Seitenrand des 1. Segments nicht gebuchtet. Hinterleibssegmente mit schmäleren helleren Endrändern. Hierher eine Reihe Arten, die bei Lophyrus schmarotzen.

Exenterus Hart.

8. Die hintersten Schienen mit kleinem Endsporn. Hinterleib keulenförmig, mit weisslichen Endbinden.

Die hintersten Schienen ohne Endsporn. 9.

Microplectron Först.

9. Das 2. Segment beiderseits mit eingedrückter schräger Furche. Segmente am Endrande mit in der Mitte verbreiterten weissen Flecken.

Diaborus Först.

Das 2. Segment an den Seiten ohne eingedrückte schräge Furchen. Hinterleib mit anderer Zeichnung. 10.

10. Vorderflügel mit Areola. Gesicht quer, mit parallelen Seiten. Schildchen meist schwarz. Zahlreiche Arten. Cteniscus Hal.

Vorderflügel ohne Areola. Gesicht nicht immer quer, nach vorn zuweilen etwas verengt.

Eridolius Först.

11. Parapsidenfurchen nicht oder nur schwach angedeutet; Metathorax meist vollständig gefeldert. Hinterleib sitzend, das 1. Segment kurz, meist mit Kielen, die Luftlöcher fast immer vor der Mitte. Augen unbehaart. Bohrer nicht selten eiertragend; Klappen einfach. Körper gedrungen. (2. Tribus: Tryphonini) 12.

Parapsidenfurchen mehr oder weniger deutlich. Metathorax bei den Arten mit sitzendem Hinterleib selten gefeldert. Hinterleib in der Regel gestielt, das 1. Segment meist lang und dünn, ohne Kiele, bei der artenreichen Subtribus der Mesoleiina dagegen kurz und oft mit Kielen, die Luftlöcher gewöhnlich etwas hinter der Mitte. Augen zuweilen behaart. Bohrer nicht eiertragend; Klappen nicht selten am Ende oben ausgebuchtet. Körper vorwiegend schlank. (3. Tribus: Mesoleptini) 25.

Anmerkung. Man wird oft in Zweifel kommen, für welche Frage man sich zu entscheiden hat; man mōge bei Arten mit sitzendem Hinterleib die erste Rubrik, bei Arten mit gestieltem Hinterleib die zweite Rubrik weiter verfolgen.

12. Klauenglied und Klauen kräftig, letztere nicht gekämmt. 13.

Klauen mehr oder weniger deutlich gekämmt. 19.

13. Das 2. und 3. Segment mit schiefliegenden Eindrücken. Areola sehr gross, rhombisch. Hinterleib schwarz. Einzige Art D. praerogator L.

Dyspetes Först.

Das 2. und 3. Segment ohne diese Eindrücke. Areola nicht auffallend gross. 14.

14. Hinterleib keulenförmig, an der Basis zahnartig erweitert. Die einzige Art, O. luteomarginatus Grav., ist schwarz, die Segmente mit schmalen gelben Endrändern.

Otoblastus Först.

Hinterleib an der Basis nicht zahnartig erweitert, meist rot gezeichnet. 15.

15. Clypeus am Endrande mit 2 deutlichen Zähnen. 16.

Clypeus am Endrande ohne Zähne. 17.

16. Flügel stark verdunkelt, ohne Areola. Metathorax glatt, ohne Leisten. Boëthus Först. 
Flügel schwach verdunkelt, mit Areola. Metathorax glänzend, mit starken Leisten. Hinterleib grösstenteils rot. Einzige Art $N$. proditor Grav.

Neleges Först.

17. Gesicht und Clypeus dicht anliegend weiss behaart; Clypeus am Ende mit langen gelben Wimperhaaren. Hinterleib an den Seiten rot; Bohrer ziemlich weit vorstehend. Einzige Art I. sericeus Brischke. Idothrichus Schmiedekn.

Gesicht und Clypeus wenig behaart; Clypeus ohne gelbe Wimperhaare. Hinterleib anders gefärbt. 18.

18. Clypeus durch eine erhöhte Querleiste geteilt. Metathorax fast stets vollständig gefeldert. Flügel mit Areola. Hinterleib mit wenigen Ausnahmen rot gezeichnet.

Tryphon Grav.

Clypeus ohne erhöhte Querleiste. Metathorax meist unvollständig gefeldert. Flügel oft ohne Areola. 52.

19. Antennen weit länger als der Körper, kräftig. Hintertarsen verdickt. Endrand des Clypeus mit starkem Zahn. Flügel ohne Areola. Hinterleibsmitte rötlichgelb.

Scolobates Grav.

Antennen höchstens so lang wie der Körper, meist dünn. Hintertarsen nicht deutlich verdickt. Endrand des Clypeus unbewehrt. Flügel meist mit Areola. 20.

20. Clypeus durch keine Querfurche vom Gesicht geschieden; Seitengruben desselben deutlich, oft tief.

Monoblastus Hart.

Clypeus durch eine Querfurche deutlich vom Gesicht geschieden; die Seitengruben nicht auffallend gross. 21.

21. Areola 3 seitig oder fehlend. 22.

Areola 5 seitig, meist etwas schief. 24.

22. Beine kurz und namentlich die hintersten Schenkel stark verdickt. Bohrer kurz und dick, gekrümmt.

Schenkel nicht besonders verdickt. 23 .

Erromenus Holmgr.

23. Bohrer kräftig, gerade. Antennen meist von Körperlänge. Metathorax gewöhnlich mit 5 oberen Feldern. Zahlreiche Arten.

Polyblastus Hart.

Bohrer kurz und dick, gekrümmt. Kleine Arten mit meist hinten rot gerandeten Hinterleibssegmenten.

cf. Grypocentrus Ruthe.

24. Bohrer kurz und breitgedrückt, hakenartig gebogen. Körper meist deutlich punktiert. Hinterleib sitzend, die Segmente hinten meist rot gerandet.

Grypocentrus Ruthe.

Bohrer kaum vorstehend, dünn. Körper klein, glänzend schwarz. Hinterleib fast gestielt. Einzige Art Ph. monilicornis Bridgm.

Phrudus Först.

25. Geisselglieder 7-14 beim $\sigma^{7}$ flachgedrückt, allmählich breiter werdend und dann wieder abnehmend. Pronotum oben mit Höcker. Bohrer versteckt. Flügel ohne Areola. Klauen gekämmt.

Euceros Grav.

Geisselglieder beim $0^{7}$ nicht verbreitert. Pronotum ohne Höcker. Bohrer meist deutlich sichtbar. 26.

26. Augen dicht behaart. Antennen dünn, beim $q$ meist mit weissem Ring. Flügel ohne Areola. Hinterleibsstiel lang, gekrümmt. Kleine und zarte Tiere. 27.

Augen nicht behaart. Körper kräftiger. 29. 
27. Clypeus sehr gross, an der Basis höckerig aufgetrieben. Segment 2 und 3 runzlig - punktiert. Körper oben schwarz, unten gelb. Einzige Art H. scabriculus Grav.

Hybophanes Först.

Clypeus ohne besondere Auszeichnung. Hinterleib nicht runzlig-punktiert. 28.

28. Körper dicht punktiert. Gesicht weiss, Mesonotum beim ㅇ grösstenteils rot. Einzige Art $N$. elegans Ruthe.

Neliopisthus Thoms.

Kopf und Thorax fast glatt. Gesicht schwarz, nach unten stark verengt. Antennen des $q$ meist 3 farbig.

Thymaris Först.

29. Flügelnervatur auffallend; der rücklaufende Nerv mündet vor dem Cubitalquernerv. Das 1. Segment lang und schmal, gebogen. Kopf und Thorax gelb gezeichnet; Hinterleibssegmente mit gelben Endrändern. Die einzige Art, E. argiolus Rossi, schmarotzt bei Polistes gallicus. Endurus Rond.

Flügelnervatur nicht auffallend; der rücklaufende Nerv mündet hinter dem Cubitalquernerv. 30 .

30. Areola im Vorderflügel 5 seitig, Aussennerv zuweilen fehlend. Antennen des + mit weissem Ring. Hinterleib glatt. 31 .

Areola 3 seitig oder fehlend, wenn annähernd 5 seitig, dann der Hinterleib nicht glatt. 33.

31. Palpen nicht auffallend verlängert. Radius aus oder etwas vor der Mitte des Stigmas entspringend. Das ganze Tier schwarz, Schenkel und Schienen rot. Einzige Art $P$. grisescens Grav.

Pseudocryptus Kriechb.

Palpen sehr lang. Radius hinter der Mitte des Stigmas entspringend. Area posteromedia vertieft. Hinterleibsmitte rot. 32 .

32. Flügel mit geschlossener 5 seitiger Areola. Seiten des Metathorax mit spitzem Zahn. Einzige Art O. armatus Thoms. Oxytorus Först.

Aussennerv der Areola fehlend. Metathorax hinten ohne spitze Seitenzähne. Einzige Art C. luridator Grav. Callidiotes Först.

33. Antennen lang und kräftig, in der Mitte oft etwas verdickt. Entweder die Klauen dicht und lang gekämmt .oder das Hinterleibsende nicht normal, eine nach oben gerichtete rundliche Öffnung oder einen Längsschlitz bildend. Bohrer kurz und dick. Grosse oder mittelgrosse Arten. 34.

Antennen nicht besonders dick und lang, meist dünn fadenförmig. Hinterleibsende normal, nicht nach oben gerückt oder ausgeschnitten. 35.

34. Klauen dicht und lang gekämmt. Hinterleibsende normal; Hinterleibsmitte meist gelb. - Verwandt damit sind einige sehr seltene Gattungen.

Ctenopelma Holmgr.

Klauen nicht gekämmt. Hinterleibsende nach oben gerückt. Zerfällt in verschiedene Untergattungen.

Notopygus Holmgr.

35. Mandibeln am unteren Rande nahe der Basis ausgebuchtet, der untere Zahn deutlich grösser. Das 1. Segment ohne Seitengruben, das 2. quer; Bohrer oft nach oben gekrümmt. Die hintersten Schenkel oft verdickt. 36.

Mandibeln am unteren Rande nicht ausgebuchtet, die Zähne meist gleich. Die hintersten Schenkel selten verdickt. 37.

36. Die hintersten Schenkel verdickt. Flügel ohne Areola; Nervus parallelus fast aus der Mitte der Brachialzelle entspringend.

Catoglyptus Holmgr.

Die hintersten Schenkel nicht verdickt. Areola klein oder fehlend; Nervus parallelus weit unter der Mitte der Brachialzelle entspringend. 
37. Kopf gross und mehr oder weniger kubisch. Metathorax meist vollständig gefeldert, Costula vor der Mitte. Areola in der Regel vorhanden. Hinterleibsstiel mit deutlichen Seitengrübchen. 38.

Kopf quer, selten annähernd kubisch, in letzterem Falle der Hinterleibsstiel ohne Seitengrübchen. Metathorax meist mit nur 2 Längsleisten. 42.

38. Kopf aufgetrieben, aber nicht ausgeprägt kubisch, sondern mehr quer. Körper dicht punktiert, matt. Das 1. Segment kurz, nicht gestielt, mit Kielen.

Trematopygus Holmgr.

Kopf kubisch. Hinterleib deutlich gestielt, das 1. Segment höchst selten mit Spuren von Rückenkielen. 39.

39. Klauen nicht gekämmt. Metathorax gefeldert. 40.

Klauen dicht gekämmt. Metathorax meist ungefeldert. 41.

40. Der untere Zahn der Mandibeln länger als der obere. Flügel fast stets mit Areola. Hierher zahlreiche Arten.

Perilissus Holmgr.

Zähne der Mandibeln gleich. Flügel in der Regel ohne Areola. Antennen und Schenkel sehr schlank. Körper mit blassgelber Zeichnung.

Eclytus Holmgr.

41. Metathorax vollständig gefeldert. Körper mittelgross, bei der bekanntesten der beiden Arten, $P$. stictica Grav., fast ganz rotgelb.

Prionopoda Holmgr.

Metathorax oben ganz ungefeldert. Hinterleibsstiel kurz und ziemlich breit, das 2. Segment quer. Körper klein.

Lathrolestes Först.

42. Hinterleibsstiel lang, schmal und gerade, ohne Seitengruben; Luftlöcher hinter der Mitte. Wangen kurz. Metathorax kaum gefeldert. Nervellus meist unter der Mitte gebrochen.

Mesoleptus Grav.

Hinterleib sitzend oder kurz gestielt, in zweifelhaften Fällen der Hinterleibsstiel mit Seitengruben oder deutlich gekrümmt oder nach hinten jäh erweitert. 43.

43. Das 1. Hinterleibssegment ohne Seitengruben. Hinterleib gestielt oder sitzend, im ersteren Falle der Stiel gebogen oder hinten jäh erweitert. Die hintersten Schienen mit kurzen Sporen, wenigstens überragen diese nicht die Mitte des Metatarsus. 44.

Das 1. Segment mit Seitengruben. Hinterleib meist sitzend, selten annähernd gestielt. Die hintersten Schienen mit langen Sporen, welche oft die Mitte des Metatarsus überragen. 47.

Anmerkung. Bei dem engen Raum, der hier zur Verfügung steht, können von beiden Abteilungen nur die Hauptgattungen angeführt werden.

44. Metathorax vollständig gefeldert. Kopf fast kubisch. Antennen länger als der Körper. Areola vorhanden. Hinterleib langgestielt. Bei der einzigen Art, S. geniculosus Holmgr., die Beine rot, die hintersten Kniee schwarz.

Sychnoleter Först.

Metathorax nicht vollständig gefeldert, gewöhnlich die Area superomedia und Längsleisten an den Seiten vorhanden. Kopf nicht kubisch. 45.

45. Mittelbrustseiten unterhalb des Speculums ohne Längseindruck. Flügel meist mit Areola, die beiden rücklaufenden Nerven einander genähert. Antennen und Hintertarsen oft mit weissem Ring. Euryproctus Holmgr.

Mittelbrustseiten unterhalb des Speculums mit langem, schrägem Eindruck. Flügel ohne Areola, die rücklaufenden Nerven voneinander entfernt. 46. 
46. Der untere Zahn der Mandibeln deutlich länger als der obere. Kopf nach hinten verschmälert; Clypeus weiss; Schläfen und Brustseiten glatt.

Phobetus Thoms.

Der untere Zahn der Mandibeln nicht oder kaum länger als der obere. Kopf nach hinten nicht verschmälert; Mund und Hüften rot. Ipoctonus Först.

47. Clypeus vorn niedergedrückt und dadurch ausgerandet erscheinend. Schildchengrube mit 5 oder 6 Längsleisten. Metathorax fast vollständig gefeldert, Leisten schwach. Flügel ohne Areola. Bohrer versteckt. Beim $q$ die inneren Augenränder, beim $\sigma^{7}$ das Gesicht weiss. Hinterleib ausgedehnt rot. Die einzige Art, $S$. vesparum Curt., lebt in den Nestern von Vespa vulgaris und rufa.

Sphecophaga Westw.

Clypeus ohne diese Bildung. Schildchengrube ohne Leisten. Bohrer nicht versteckt. 48.

48. Hinterleib deutlich gestielt, das 1. Segment mindestens doppelt so lang als am Ende breit. Hinterleibsmitte meist rot. 49.

Hinterleib sitzend; Körper mehr oder weniger gedrungen. 52.

49. Metathorax vollständig gefeldert. Kleine Arten. 50.

Metathorax oben nur mit 2 parallelen Leisten. Ziemlich grosse Arten. 51.

50. Clypeus an der Spitze mit starren hellen Borsten. Flügel ohne Areola. Mesonotum glatt und glänzend.

Phaestus Först.

Clypeus an der Spitze ohne starre Borsten. Areola vorhanden, sitzend. Mesonotum matt.

Hodostates Först.

51. Seiten der Mittelbrust stark runzlig-punktiert.

Seiten der Mittelbrust fein lederartig.

Lagarotus Thoms. Alexeter Först.

52. Metathorax vollständig gefeldert, nur die Costula zuweilen undeutlich. 53. Metathorax nicht vollständig gefeldert. 54 .

53. Clypeus in der Mitte des Endrandes höckerartig vorspringend. Die hintersten Schienen rötlich, am Ende verdunkelt.

Pantorhaestes Först.

Clypeus in der Mitte des. Endrandes nicht höckerartig vorspringend. Die hintersten Schienen weiss, am Ende breit schwarz.

Synomelix Först.

54. Antennen und die hintersten Tarsen mit weissem Ring. Flügel ohne Areola; rücklaufender Nerv nicht weit hinter dem Cubitalquernerv; Nervellus in der Mitte gebrochen.

Enoecetis Först.

Antennen und die hintersten Tarsen nicht gleichzeitig mit weissem Ring oder Flügel mit anderer Nervatur. - Eine ungemein artenreiche Gattung, welche in eine Reihe von Untergattungen zerlegt worden ist, auf welche hier nicht eingegangen werden kann.

Mesoleius Holmgr.

\section{Sektion. Tryphonides prosopi.}

1. Antennenschaft mehr oder weniger eiförmig. Augen innen ausgerandet. Metathorax mit ovalen Luftlöchern. Areola meist fehlend oder dreieckig. 2.

Antennenschaft verdickt, zylindrisch. Augen ganz. Metathorax mit kreisförmigen Luftlöchern. Areola meist fünfeckig oder fehlend. Das 1. Segment mit rauher Skulptur. (3. Tribus: Orthocentrini) 9.

2. Gesicht unter den Antennen nicht aufgetrieben, flach. Flügel mit grosser, fast rhombischer Areola. Körper schwarz, mit grober Skulptur; Hinterleib breit sitzend, längsrunzlig; das 1. Segment und die Basis des zweiten mit je zwei Kielen. (1. Tribus: Tylocomnini.)

Tylocomnus Holmgr. 
Gesicht unter den Antennen aufgetrieben, oft sehr stark. Körper glatt, oder wenn mit rauher Skulptur, dann Flügel ohne Areola. (2. Tribus: Exochini) 3.

3. Hinterleib gestielt. Areola vorhanden. 4.

Hinterleib sitzend oder fast sitzend. 5.

4. Hinterschienen mit 1 Endsporn. Hinterleibsmitte rot. Antennen gegen das Ende verdickt.

Periope Hal.

Hinterschienen mit 2 Endsporen. Hinterleib rot, an der Basis schwarz.

Ischyrocnemis Holmgr.

5. Parapsidenfurchen bis zur Mitte deutlich. Antennen dick, das 1. Geisselglied sehr kurz, fast quer, nicht länger als das 2. Metathorax und das 1. Segment gerunzelt. Einzige Art $\mathrm{H}$. crassicornis Holmgr. Hyperacmus Holmgr.

Parapsidenfurchen fehlend oder ganz kurz. Das 1. Geisselglied länger als das 2.6.

6. Hinterleib glatt und glänzend, das 2. Segment ohne Kiel. 7.

Hinterleib an der Basis oder durchaus durch Runzlung oder Streifung rauh. Die ersten Segmente mit Kielen. Flügel ohne Areola. 8.

7. Kopf unmittelbar hinter den Augen senkrecht abgeschnitten; Gesicht sehr weit vorstehend. Das 1 . Segment gegen die Basis stark verengt. Flügel ohne Areola.

Polyclistus Först.

Kopf hinter den Augen verlängert; Gesicht weniger stark vorstehend. Das 1. Segment gegen die Basis wenig verengt. Flügel zuweilen mit Areola. Exochus Grav.

8. Die hintersten Schenkel stets verdickt. Cubitalquernerv nicht schräg. Das 2. Segment mit 1 oder 3 Kielen. Kleinere Arten. Chorinaeus Holmgr.

Die hintersten Schenkel kaum verdickt. Cubitalquernerv lang und schräg. Das 2. Segment mit 2 Kielen. Grössere Art.

Drepanoctonus Pfank.

9. Metathorax ganz ohne Leisten. Hinterleib gegen das Ende messerförmig zusammengedrückt. Neuratelus Ratzeb.

Metathorax mit Leisten. Hinterleib nicht oder wenig von der Seite zusammengedrückt. 10 .

10. Nervellus schräg, meist unterhalb der Mitte gebrochen. Nervus parallelus unterhalb der Mitte der Brachialzelle entspringend. Zahlreiche, schwer unterscheidbare Arten.

Orthocentrus Grav.

Nervellus vertikal, nicht gebrochen. Nervus parallelus aus oder über der Mitte der Brachialzelle entspringend. 11. gerade.

11. Cubitalnerv im Hinterflügel bis zur Basis deutlich. Bohrer lang und

Cubitalnerv im Hinterflügel an der Basis erloschen. Bohrer kurz, wenn lang, dann gekrümmt. Stenomacrus (Först.) Thoms.

\section{Sektion. Tryphonides schizodonti.}

Hierher nur die Tribus der Bassini; die mittelgrossen bis kleinen Tiere leben vorwiegend in Dipterenlarven, namentlich Syrphiden.

1. Die vorderen Hinterleibssegmente mit eingedrückter Querlinie. Die hintersten Schienen in der Mitte breit weiss, an Basis und Spitze schwarz.

Bassus F.

Die vorderen Hinterleibssegmente ohne eingedrückte Querlinie. 2. 
2. Gesicht fein lederartig, matt. 3 .

Gesicht glänzend, glatt oder zerstreut punktiert. 4.

3. Parapsidenfurchen fehlend. Schaft nicht tief ausgeschnitten.

Homotropus Först.

Parapsidenfurchen tief. Schaft bis zur Mitte ausgeschnitten. Flügel ohne Areola. Hinterleibsmitte rot.

Zootrephes Först.

4. Luftlöcher des Metathorax sehr gross. Schildchengrube mit erhabenen Längsleisten. Flügel ohne Areola. Bioblapsis Först.

Luftlöcher des Metathorax klein. Schildchengrube ohne Leisten. 5.

5. Flügel ohne Areola. Hinterleibsmitte meist rot.

Promethes Först.

Flügel mit Areola. Hinterleib schwarz.

Phthorima Först.

\section{Sektion. Tryphonides sphinctonoti.}

Hierher nur die Tribus der Sphinctini mit einer einzigen Gattung und einer einzigen Art, Sphinctus serotinus Grav. Das merkwürdige, sehr seltene Tier lebt bei Cochlidion limacodes Hufn. (Limacodes testudo Schiff.).

\section{Sektion. Tryphonides aspidopi.}

Auch zu dieser Sektion gehört, wenigstens in Europa, nur eine einzige, durch Struktur und Färbung leicht kenntliche Gattung, die Gattung Metopius Panz. Die wenigen Arten sind auffallende und schöne Tiere, welche in Schmetterlingsraupen, namentlich Spinnern, schmarotzen.

\section{Familie Agriotypidae.}

Diese Familie wird nur durch eine einzige Art gebildet, den merkwürdigen Agriotypus armatus Walk. Sowohl der Bau des Körpers als die wunderbare Lebensweise verleihen diesem Tiere eine besondere Stellung und wir haben in ihm sicherlich eine uralte Form der Ichneumoniden. Dadurch, dass das 2. Segment mit seinem Endrand nicht über die Basis des dritten greift, sondern mit diesem durch eine Sutur verbunden ist, ist das Tier mit den Braconiden verwandt, während es sich durch das Vorhandensein von 2 rücklaufenden Nerven und durch das Verschmelzen der 1. Cubital- mit der 1. Discoidalzelle eng an die Ichneumoniden anschliesst. - Die Gattung Agriotypus wurde im Jahre 1832 von Curtis aufgestellt, ohne dass von der merkwürdigen Lebensweise etwas bekannt war. Erst im Jahre 1848 machte Kolenati auf Phryganeidengehäuse aufmerksam, die an dem einen Ende ein horniges Band trugen, woraus er schon richtig auf das Vorhandensein eines Schmarotzers schloss. Durch Kriechbaumer und Siebold wurde dann die eigentümliche Lebensweise weiter aufgeklärt. Agriotypus taucht demnach unter Wasser, um die Larven verschiedener Köcherfliegen anzustechen. Früher nahm man an, dass das erwähnte hornige Band von der Phryganeidenlarve herrühre; nach neueren Untersuchungen von Prof. Dr. G. W. Müller in Greifswald gibt jedoch die Agriotypus-Larve beim Verspinnen das Band von sich, das wahrscheinlich als Respirationsorgan dient. 
Kopf von vorn gesehen annähernd dreieckig. Stirn mit zwei breiten und tiefen Längsfurchen, welche die Antennenbasis erreichen; Augen stark vortretend, nackt; Antennen 31 gliedrig; Schaft und Geisselglieder zylindrisch, letztere fein wirtelig behaart, undeutlich voneinander getrennt; beim 9 die Behaarung schwächer. Thorax bucklig; Schildchen in einen ziemlich langen, am Ende nach oben gebogenen Dorn ausgehend; Metathorax weniger lang als breit, von der Basis an abschüssig, mit 4 Längsleisten; Luftlöcher gestreckt. Radialzelle kurz, von der Flügelspitze entfernt; Stigma gross und breit; Areola fehlend. Beine schlank; Vorderschienen mit einem gekrümmten Sporn, die andern Schienen mit zwei geraden; Klauen einfach. Hinterleib gestielt, der Stiel sehr schmal, leicht gekrümmt, an der Basis am breitesten und höchsten und hier auch die Luftlöcher tragend, oben mit 2 Längskielen und dazwischen mit glatter Rinne; der eigentliche Hinterleib eiförmig, flach, schwach glänzend, beim + etwas breiter als beim $\sigma^{7}$; Bohrer kurz vorstehend; beim $\sigma^{7}$ der Hinterleib mit einer zweiteiligen Spitze endend.

Der ganze Körper schwarzbraun bis schwarz. Flügel mit 3 dunklen Querbinden, welche beim ơ schwächer ausgeprägt sind. Länge 5-8 mm. Die Art ist über das mittlere und nördliche Europa verbreitet, namentlich in Gebirgsbächen; wegen der eigentümlichen und versteckten Lebensweise vielfach übersehen. - Die Zucht ist nicht schwer; die an dem hornigen Bande leicht kenntlichen Phryganeidengehäuse werden in Wasser oder feuchtem Moos gehalten, können aber später, wenn die Verpuppung eingetreten ist, ganz gut trocken aufbewahrt werden.

Agriotypus armatus Walk.

\section{Familie Braconidae.}

\section{Charakteristik.}

Ein nur einigermassen geübtes Auge wird auch ohne nähere Untersuchung einen Braconiden ohne weiteres von einem Ichneumoniden unterscheiden können. Die ersteren sind durchweg kleine und zarte Tiere, wenigstens was die heimischen Formen betrifft und nur wenige von diesen, beispielsweise die Gattungen Helcon und Zele erreichen Mittelgrồsse, dagegen sind von den Tropenformen viele

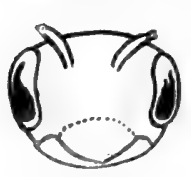

Abb. 18.

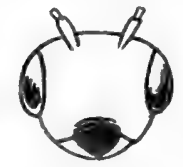

Abb. 19.

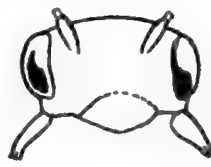

Abb. 20 . durch Grösse und Farben, namentlich auch der Flügel ausgezeichnet. Aber auch die kleinen Ichneumoniden-Arten sind unschwer als solche zu erkennen, weil ihnen allen ein viel lebhafteres Wesen eigentümlich ist, was den Braconiden abgeht, bei denen sich durchweg eine Trägheit der Bewegungen, im besonderen auch des Fluges kundgibt. Lebhafte Farben fehlen den Braconiden; Schwarz, Braun und Braungelb bilden das Kolorit; nirgends finden wir das lebhafte Weiss, Gelb und Rot, die zierlichen Farbenkontraste, namentlich den weissen Antennenring und das weisse Schildchen, wie es so vielen Ichneumoniden eigentümlich ist.

Während alles dieses nur nebensächliche Unterschiede sind, haben wir als Hauptunterscheidungsmerkmale das Fehlen des zweiten rücklaufenden Nerven und den verschiedenen Hinterleibsbau zu betrachten.

Die Braconiden würden kurz in folgender Weise zu charakterisieren sein: 
Flüg el selten fehlend, mit Stigma und nur einem rücklaufenden Nerven, ohne lanzettförmige Zelle; die 1 . Cubitalzelle selten mit der 1 . Discoidalzelle verschmolzen. Beine meist schlank, Trochanteren 2 gliedrig; Schienen mit Endsporen. Hinterleib sitzend oder gestielt; das 2. und 3. Segment nicht durch ein bewegliches Gelenk verbunden, sondern entweder am Rücken verwachsen oder nur mit Querfurche. Eine Ausnahme machen die Aphidiinen (Flexiliventres), bei denen das 2. und 3. Segment durch eine dehnbare Haut verbunden sind, wodurch der Körper nach unten biegsam ist. - Lebensweise parasitisch; die Larven schmarotzen in den Eiern, Larven und Puppen anderer Insekten.

Kopf meist von Thoraxbreite; Scheitel entweder ohne Grenze in das Hinterhaupt übergehend oder von demselben durch eine mehr oder weniger

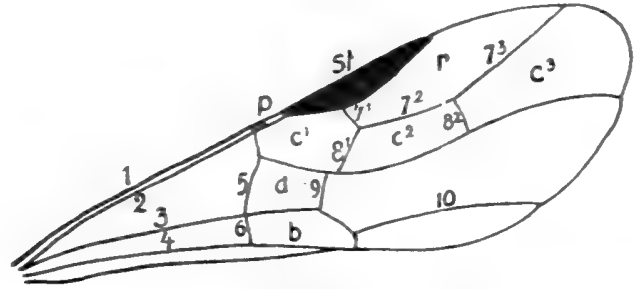

Abb. 21. Vorderflügel von Bracon.

1 costa; 2 subcosta; 3 cubitus; 4 brachium; 5 nervus basalis; 6 nervulus; 7 radius; $71,72,73$ 1., 2. und 3. Abschnitt des radius; $81,8^{2}$ 1. und 2. Cubitalquernerv (nervus transversocubitalis); 9 nervus recurrens; 10 nervus parallelus; p parastigma; st stigma; $r$ cellula radialis; $c^{1}, c^{2}, c^{3}$ 1., 2. und 3. Cubitalzelle (cellula cubitalis); d Discoidalzelle (cellula discoidalis); b Brachialzelle (cellula brachialis).

deutliche Leiste getrennt; Augen oval, innen oft ausgerandet; Antennen meist faden- oder borstenförmig, selten viel kürzer als der Körper, in vielen Fällen denselben an Länge übertreffend, selten in der Mitte etwas verdickt, höchst selten gekniet oder keulenförmig; beim Zählen der Antennenglieder wird der Schaft als das 1. Glied betrachtet. Clypeus in der Regel vom Gesicht durch eine mehr oder minder deutliche Furche getrennt, beiderseits mit punktförmiger Grube, der Vorderrand gerade oder gerundet, in einzelnen Fällen winklig vorgezogen oder mit Endzähnchen. In Bezug auf die Mundbildung lassen sich 3 Fäle unterscheiden, die für die Systematik ausserordentlich wichtig sind; in dem ersteren, dem hăufigsten Falle sind die Mandibeln nach innen gebogen und berühren oder überragen sich mit den Enden; die Mundöffnung selbst ist durch den Clypeus bedeckt oder erscheint höchstens als schmaler Querspalt (Abb. 18); im zweiten Falle haben die Mandibeln dieselbe Bildung, aber der Clypeus ist tief ausgerandet, so dass zwischen ihm und den Mandibeln eine runde Öffnung entsteht (Abb. 19); im dritten Falle schliesslich sind die Mandibeln kurz und breit, mit den Spitzen weit voneinander entfernt und nach aussen gebogen (Abb. 20).

Der Thorax hat eine analoge Bildung wie bei den Ichneumoniden, doch ist zu bemerken, dass der Metathorax nur selten Spuren von Felderung zeigt, so dass diese im Gegensatz zu den Ichneumoniden bei den Braconiden gar keine Rolle spielt; dagegen ist die Flügelnervatur für die Systematik von der grössten Bedeutung, da sie noch weit mannigfaltiger als bei den Ichneumoniden ist, weswegen auch die Mehrzahl der Tribus und Gattungen auf sie gegründet ist.

Die Nomenklatur ergibt sich am besten aus der obenstehenden Abbildung des Vorderflügels von Bracon. Im Vorderflügel laufen Costa und Subcosta dicht nebeneinander und bilden durch ihre Verschmelzung am Ende das Parastigma; das Stigma selbst ist meist halbelliptisch, am Ende spitz ausgezogen, es kann aber auch so schmal werden, dass es die Costa kaum an Dicke übertrifft. Der Verlauf des Radius ist sehr verschieden, sein Ende liegt meist näher der 
Flügelspitze als dem Stigma; bei manchen Gruppen, namentlich bei den Mikrogasterinen und Aphidiinen, erreicht der Radius die Flügelspitze nicht. In derselben Richtung, wie der Radius, läuft unter diesem der Cubitus; er entspringt entweder aus dem Basalnerv oder aus dem Parastigma; im ersteren Falle ist die Discoidalzelle gestielt, wie auf dem abgebildeten Flügel von Bracon, und zwar würde als Stiel das obere Stück des Basalnerven zwischen Subcosta und

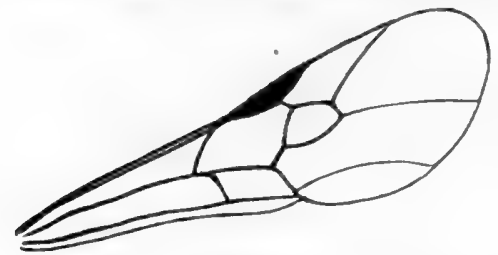

Abb. 22. Vorderflügel von Chelonus.

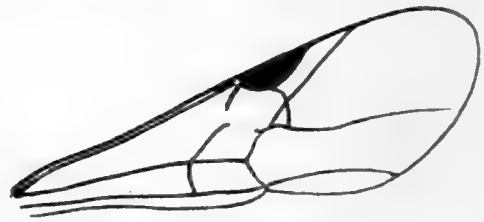

Abb. 23. Vorderflügel von Agathis.

Ursprung des Cubitus zu verstehen sein. Von Wichtigkeit ist es, ob die Brachialzelle nach aussen unten, also unterhalb des Ursprunges des Nervus parallelus geschlossen ist. In manchen Fällen könnte man über diesen Punkt in Zweifel sein, dann mag als Regel dienen, dass, wenn die Ursprungsstelle des Nervus parallelus aus dem Aussennerv der Brachialzelle winklig oder gebrochen erscheint, man von einer geschlossenen Brachialzelle spricht, während im anderen Falle der Aussennerv geschwungen in den Nervus parallelus übergeht; letzterer wird als interstitial bezeichnet, wenn er aus dem oberen Endwinkel der Brachialzelle entspringt. Die 1. Cubitalzelle ist zuweilen mit der 1. Discoidalzelle verschmolzen, wie dieses bei den Ichneumoniden regelmässig der Fall ist; selten verschmilzt die 1. Cubitalzelle mit der 2.; letztere entspricht der Areola der Ichneumoniden, doch ist sie nur bei wenigen Gattungen auffallend kleiner als die daneben liegenden Cubitalzellen. Sehr geringen Wert

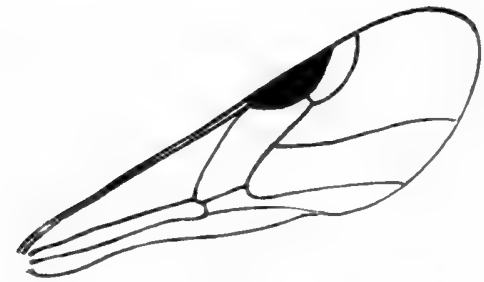

Abb. 24. Vorderflügel von Perilitus. Die 1. Cubital- mit der 1. Discoidalzelle verschmolzen.

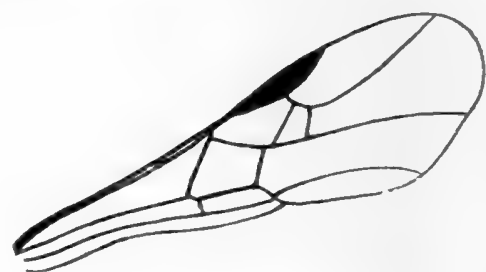

Abb. 25. Vorderflügel von Meteorus.

für die Systematik hat der Hinterflügel; das Nötige ergibt sich aus der Zeichnung. Nur bei einigen wenigen Gattungen und bei einigen Arten sonst geflügelter Gattungen sind die Flügel verkümmert oder fehlen ganz. Die Beine bieten kaum ein besonderes Merkmal; bei einigen Arten kommen gezähnte Hinterschenkel vor; die Länge der hintersten Schiensporen ist zuweilen für die Systematik von Wert.

Der Hinterleib zeigt verschiedenartigen Bau und Habitus; er kann gestreckt oder gedrungen, komprimiert oder deprimiert, gewölbt oder flach, gestielt oder ungestielt sein; der letztere Fall ist der häufigere. Er besteht aus 8 Segmenten, von denen die 7 vorderen Luftlöcher tragen; die Luftlöcher des 1. Segments treten oft knotenförmig vor und liegen meist hinter der Mitte. Nur sehr selten sind alle 8 Rückensegmente sichtbar; die hinteren vom 4 . an gerechnet, sind in den meisten Fällen von den vorderen mehr oder weniger verdeckt. Während die 3 vorderen Rückensegmente miteinander so verbunden 
sind, dass sie sich einander nur berühren, greifen die hinteren Rücken- und die Bauchsegmente übereinander. In manchen Fällen verschmelzen die Rückensegmente so, dass keine oder nur eine schwache Spur von Querteilung sichtbar ist; am besten zeigt sich dieses bei Chelonus und den verwandten Gattungen. Eine Sonderstellung nehmen die Aphidiinen oder Flexiliventren ein, indem sich bei ihnen zwischen dem 2. und 3. Segment eine dünne, dehnbare Haut befindet,

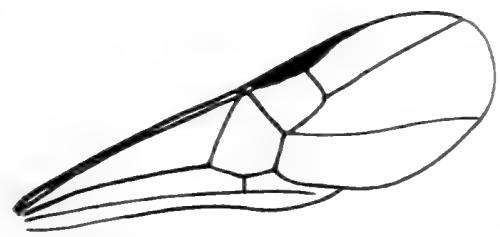

Abb. 26. Vorderflügel von Blacus.

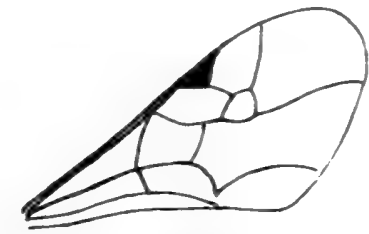

Abb. 27. Vorderflügel von Proterops.

wodurch der Hinterleib, wie schon der Name Flexiliventren besagt, eine grosse Biegsamkeit nach unten erhält.

Der Unterschied der Geschlechter ist in den meisten Fällen leicht, eine Ausnahme machen die Gattungen Chelonus und Ascogaster. Die wenigste Schwierigkeit bieten natürlich die Gattungen, wo die 우 einen vorstehenden Bohrer besitzen, aber auch bei den übrigen Gattungen lassen sich die $\sigma^{7} \sigma^{7}$ an der geringeren Grösse, den längeren, meist mehrgliedrigen Antennen, dem namentlich am Ende flacheren Hinterleibe usw. erkennen.

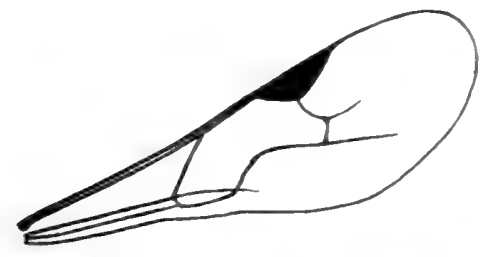

Abb. 28. Vorderflūgel von Aphidius.

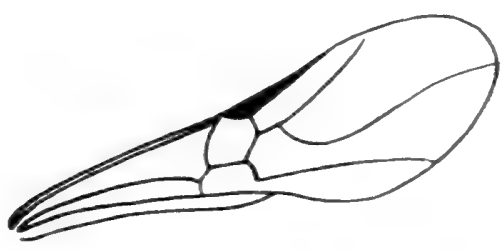

Abb. 29. Vorderflügel von Paxylomma.

\section{Die Lebensweise der Braconiden}

ist eine parasitische; sie stimmen darin ganz mit den Ichneumoniden überein. Die Larven leben im Innern ihrer Wirte, in seltenen Fällen aussen an denselben; im ersteren Falle werden die Eier mit Hilfe des mehr oder weniger langen Bohrers in das Innere des Wirtes gebracht; im letzteren Falle werden sie demselben durch eine Art Stiel angeheftet. Die Larven haben 12 Segmente, nicht eingerechnet den provisorischen Kopfanhang; statt der Beine tragen sie beiderseits auf den mittleren Segmenten eine Reihe ausstülpbarer Mamellen oder kleiner Höcker. Nach Ratzeburg machen die Larven im Innern des Wirtes 3 Wandlungen durch; haben sie dann ihre Reife erreicht, dann verlassen sie, meist jede durch eine besondere selbstgebohrte Öfnung, den Wirt, um sich entweder, was meist der Fall ist, auf der toten Raupe selbst oder in deren Nähe einzuspinnen. Als allbekanntes Beispiel kann die Kohlweisslingsraupe und ihr Schmarotzer, der Apanteles glomeratus L., dienen. Ich bemerke überhaupt bei dieser Gelegenheit, dass sich diese namentlich von Ratzeburg angestellten Beobachtungen über das Larvenleben speziell auf die Arten der Gattung Microgaster (im weiten Sinne) beziehen. Im Gegensatz zu den Arten, 
deren Larven den Wirt vor dem Einspinnen verlassen, stehen die Arten, deren Larven sich im Wirte selbst verpuppen; zu ihnen gehören namentlich die Rogadinen und Aphidiinen. Die Kokons selbst sind von weisser, gelber oder brauner, einige sogar von grünlicher Färbung; manche sind aussen hart und glatt, andere sind von einer flockigen Hülle umgeben; ebenso verschieden ist die Anordnung; viele sind einzeln irgend einem Substrat angesponnen, die Kokons von Meteorus hängen an einem Faden, bei Apanteles formosus Wesm. sitzen sie auf einem langen Stiele; die Kokons der Microgasterinen finden sich fast ausnahmslos gehäuft und sind dann nicht selten von einer gemeinsamen flockigen Hülle umgeben; in manchen Fällen zeigen sie sogar eine regelmässige Anordnung.

Bis jetzt hat man noch nicht Braconiden als sekundäre Parasiten oder Schmarotzer zweiten Grades kennen gelernt, dagegen werden sie selbst von solchen angestochen, namentlich sind dieses Arten der Gattungen Mesochorus, Hemiteles und Pezomachus, sowie verschiedene Chalcididen. Auch die parasitisch in Blattläusen lebende Cynipidengattung Allotria befällt nach Bignell nicht die Blattläuse selbst, sondern die darin schmarotzenden Arten der Gattung Aphidius.

Die Braconiden schmarotzen vorzugsweise in Schmetterlingsraupen, viele auch in Dipterenlarven, namentlich Pilzmücken; in Neuropteren und Orthopteren sind bis jetzt keine nachgewiesen worden. Da sich unter den befallenen Raupen sehr viele schädliche Arten finden, so ergibt sich daraus, dass wir die Braconiden als eminent nützliche Tiere zu betrachten haben, namentlich sind es die an Arten und Individuen so zahlreichen Microgasterinen, insbesondere die Arten der Gattung Apanteles, deren Nutzen hauptsächlich in die Wagschale fällt.

\section{Geographische Verbreitung.}

Was diese betrifft, so finden wir dieselbe Erscheinung wie bei den Ichneumoniden. Die grösste Zahl der Gattungen und Arten finden wir auch hier in der gemässigten Zone, sogar die kalte Zone weist noch eine ganze Anzahl von Repräsentanten auf; gerade die artenreichsten Gattungen wie Microgaster, Microplitis, Apanteles, Opius, Alysia, Dacnusa, Aphidius usw. finden sich vorzugsweise in den Ländern der gemässigten Zone; in den heissen Ländern dagegen wiegen die grossen und lebhaft gefärbten, meist buntflügeligen Arten von Bracon, Vipio, Iphiaulax und verwandter Gattungen vor; auch die Unterfamilie der Agathidinen, die im gemässigten Klima nur kleine Formen aufweist, zeigt in den Tropen eine Reihe grosser und buntgefärbter Arten.

\section{Literatur über Braconiden.}

Ich übergehe die zahlreichen älteren, ebenso die kleineren neueren Schriften und Aufsätze über die Braconiden und führe nur die wichtigeren Arbeiten an. Es war ein merkwürdiges Zusammentreffen, dass sich drei tüchtige Forscher, der Engländer Haliday, der Deutsche Nees von Esenbeck und der Belgier Wesmael fast gleichzeitig, ohne dass der eine von der Absicht des andern etwas wusste, an die Bearbeitung dieser Schlupfwespenfamilie gingen. So fördernd dieses Beginnen für die Kenntnis dieser Gruppe war, so viel Schwierigkeiten entstanden später für die Nomenklatur daraus, da es galt, zahlreiche Prioritätsfragen zu schlichten. Die Titel dieser drei Werke sind:

Haliday, An Essay on the Classification of the Parasitic Hymenoptera of Britain, which correspond with the Ichneumones minuti of Linnaeus. Entom. Magazine 1833-1838. 
Nees von Esenbeck, Hymenopterorum Ichneumonibus affinium Monographiae. 1834.

Wesmael, Monographie des Braconides de Belgique. 1835-1838.

In diesen drei Werken wird nur die Systematik behandelt, biologische Fragen werden kaum gestreift; im Gegensatz dazu finden wir in dem dreibändigen Werke Ratzeburgs: „Die Ichneumonen der Forstinsekten in forstlicher und entomologischer Beziehung. 1844-1852" eine Fülle von Notizen über Bau, Entwicklung und namentlich Zuchtresultate der einzelnen Arten; die Systematik freilich war damals noch nicht genügend geklärt und lässt manches zu wünschen übrig. Ausschliesslich der Systematik wandte sich wieder Ruthe zu; in einer Reihe von Aufsätzen und Monographien suchte er die Resultate der oben erwähnten drei Hauptwerke in Einklang zu bringen und weiter auszubauen; seine Arbeiten sind in den Jahren 1851-1862 erschienen, und zwar die „Beiträge zur Kenntnis der Braconiden“ in der Stettiner Entomol. Zeitung und die "Deutsche Braconiden" in der Berliner Entomol. Zeitschrift. Im Jahre 1862 publizierte Förster eine "Synopsis der Familien und Gattungen der Braconiden"; wie in seiner gleichen Arbeit über die Ichneumoniden stellt er darin eine ganze Menge neuer Gattungen auf; da er bei jeder Gattung wenigstens eine Art als Type anführt, hat die Arbeit mehr Wert als die Ichneumoniden-Tabelle; immerhin sind die meisten Gattungen als zu sehr zersplittert, zumal diejenigen, wo eine neue Art, aber ohne Beschreibung, als Type angeführt wird, nicht verwandt worden. In seinen „Beiträge zur Kenntnis einiger Braconidengattungen“ gab Reinhard eine Fortsetzung der Ruthe'schen Arbeiten. Die Aufsätze sind 1862-1881 zuerst in der Berliner, später in der Deutschen Entom. Zeitschrift erschienen. Alle diese Arbeiten sich anzuschaffen ist jetzt nicht mehr nötig, denn wir haben jetzt ein dreibändiges, freilich ziemlich teures Gesamtwerk über die europäischen Braconiden durch T. A. Marshall; es bildet einen Teil des bekannten Andréschen Werkes "Species des Hyménoptères d'Europe et d'Algérie" und ist französisch geschrieben; der erste Band ist im Jahre 1888, der zweite 1896, der dritte in den nächstfolgenden Jahren erschienen. Seit dieser Zeit sind verschiedene Abhandlungen von V. Szepligeti erschienen, ich selbst habe die Gattungen Vipio, Bracon und Meteorus monographisch bearbeitet.

\section{Systematik der Braconiden.}

Ich zerlege die Braconiden in 7 Sektionen, die zusammen in 27 Unterfamilien zerfallen:

1. Artikulation zwischen dem 2. und 3. Segmente, wie bei den übrigen Segmenten durch eine dehnbare Haut gebildet, so dass der Hinterleib leicht nach unten gebogen werden kann. Antennen meist bogenförmig nach unten gebogen. Flügelnervatur meist unvollständig. Hinterleib deutlich gestielt. Kleine Arten.

VI. Flexiliventres.

Artikulation zwischen dem 2. und 3. Segmente fest, nicht beweglich. 2.

2. Mandibeln kurz, nach aussen gebogen, mit den Spitzen sich nicht berührend (Abb. 20).

V. Exodontes.

Mandibeln nach innen gebogen, mit den Spitzen sich berührend oder kreuzend. 3.

3. Clypeus tief ausgerandet; zwischen ihm und den Mandibeln eine mehr oder weniger kreisrunde Öffnung (Abb. 19).

I. Cyclostomi. 
Mundöffnung durch den Clypeus bedeckt oder nur als Querspalte erscheinend (Abb. 18). 4.

4. Die 3 ersten Hinterleibssegmente miteinander verwachsen, stark gerunzelt, ohne oder mit ganz seichten Suturen. Körper meist schwarz, unten konkav. bunden. 5 .

II. Cryptogastres.

Segmente mit deutlichen Suturen, höchstens 2 und 3 miteinander eng ver-

5. Flügel mit einer sehr kleinen 2. Cubitalzelle; bei vielen Microgasterinen ist dieselbe nur in der Anlage vorhanden. Hinterleib niemals gestielt.

III. Areolarii.

Flügel mit 2 oder 3 Cubitalzellen; in letzterem Falle die 2. Cubitalzelle nicht auffallend klein, auch nicht in der Anlage vorhanden. Hinterleib zuweilen gestielt. 6.

6. Cubitus aus dem oberen Ende des Basalnerven oder aus dem Parastigma entspringend. Hinterleib nur bei Cenocoelius am oberen Rande des Metathorax eingefügt.

IV. Polymorphi.

Cubitus aus dem Radius entspringend, entweder am Ende des 1. Radiusabschnittes oder noch etwas dahinter (Abb. 29). Beine, namentlich die hintersten, lang und schlank. Hinterleib am oberen Rande des Metathorax eingefügt.

VII. Paxylommates.

\section{Übersicht der Unterfamilien.}

\section{Sektion. Cyclostomi.}

1. Hinterhaupt nicht oder nur an den Seiten ganz schwach gerandet. 2. Hinterhaupt scharf gerandet, nur bei manchen Doryctinen weniger scharf. 3 .

2. Nervulus interstitial, d. h. er fällt mit dem Ursprung des Basalnerven zusammen. In der Mehrzahl robustere Tiere.

1. Braconinae.

Nervulus deutlich postfurkal, d. h. er steht hinter dem Ursprunge des Basalnerven. Durchweg zarte Tiere.

2. Exothecinae.

3. Vorderflügel mit 2, sehr selten mit nur 1 Cubitalzelle. + zuweilen ungeflügelt. 4.

Vorderflügel mit 3 Cubitalzellen. 5.

4. Kopf kubisch. Suturen zwischen den Hinterleibssegmenten deutlich. $q$ stets geflügelt. Hinterflügel der $0^{7} \sigma^{7}$ zuweilen mit einem Stigma.

3. Hecabolinae.

Kopf quer. Hinterleib nur zwischen dem 1. und 2. Segmente mit einer tiefen Sutur. + ungeflügelt oder mit Flügelstummeln. Hinterflügel der $\sigma^{\pi} \sigma^{\pi}$ ohne Stigma.

4. Pambolinae.

5. Hinterleib deutlich gestielt. Bohrer mehr oder weniger lang.

Hinterleib sitzend oder fast sitzend. 6.

5. Spathiinae.

6. Kopf kubisch, hinter den Augen nicht oder kaum verschmälert. Hinterflügel der o" $0^{7}$ zuweilen mit einem Stigma.

6. Doryctinae.

Kopf quer, hinter den Augen mehr oder weniger verschmälert. 7.

7. Nervus parallelus interstitial. Bohrer vorstehend. Durchweg kleine Tiere.

Nervus parallelus nicht interstitial. Bohrer meist sehr kurz oder versteckt. In der Mehrzahl mittelgrosse Tiere.

8. Rogadinae. 


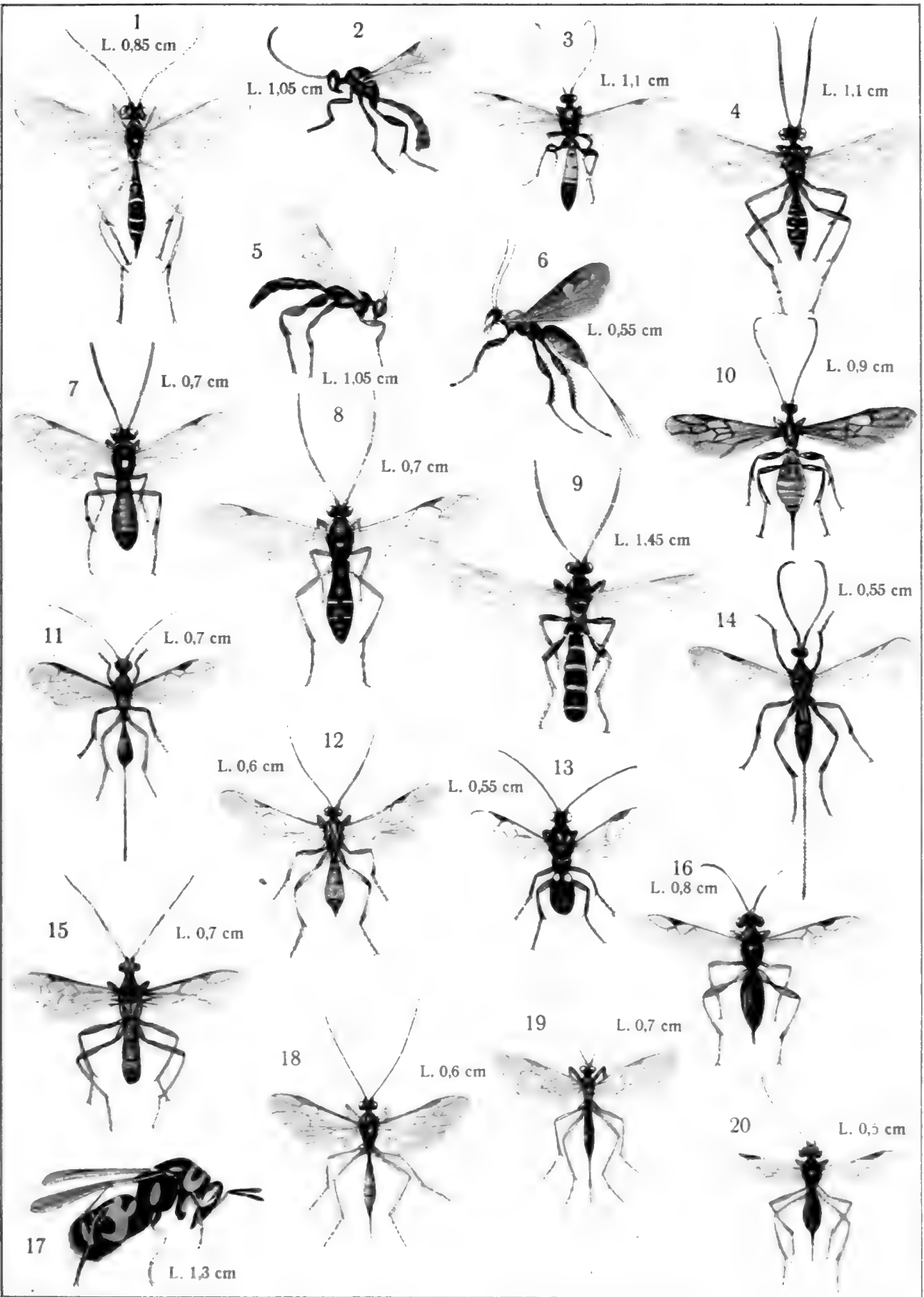

1. Eclytus ornatus. 2. Tryphon rutilator.

3. Colpotrochia elegantula.

4. Euceros egregius

5. Exochus gravipes. 6. Bracon urinator. 7. Bassus lactatorius. 8. Homotropus lateralîs. 9. Metopius micratorius. 10. Iphiaulax impostor. 11. Spathius exarator. 12. Rogas cirom scriptus. 13. Chelonus oculator. 14. Microdus tumidulus. 15. Heterogamus dispar. 16 4lys manducator. 17. Leucospis gigas. 18. Meteorus ictericus. 19. Macrocentrus tharacios. 



\section{Sektion. Cryptogastres.}

2 Cubitalzellen. Bauch konkav, mit scharfen Seitenkanten. Kleine Tiere. geschlagen.

9. Sigalphinae.

3 Cubitalzellen. Bauch konkav, die Seitenränder mehr oder weniger um-

\section{Sektion. Areolarii.}

Parapsidenfurchen undeutlich oder fehlend, nur bei Cardiochiles deutlich. Radialzelle sehr gross, fast die Flügelspitze erreichend, der äussere Abschnitt des Radius jedoch meist verwischt und undeutlich. Bohrer höchstens von Hinterleibslänge.

11. Microgasterinae.

Parapsidenfurchen sehr deutlich. Radialzelle klein und schmal, von der Flügelspitze entfernt, der äussere Abschnitt des Radius deutlich. Bohrer mehr oder weniger lang.

12. Agathidinae.

\section{Sektion. Polymorphi.}

1. Vorderflügel mit 2 Cubitalzellen. 2.

Vorderflügel mit 3 Cubitalzellen. 6.

2. Hinterleib gestielt. 3.

Hinterleib sitzend. 4.

3. Stigma länglich oval. Radialzelle meist sehr kurz. Hinterhüften nicht verlängert. Hinterleib unten dem Metathorax angeheftet.

13. Euphorinae.

Stigma sehr lang und schmal. Radialzelle gross, am Ende zugespitzt. Hinterhüften sehr lang und schmal. Hinterleib dem oberen Rande des Metathorax eingefügt.

cf. 27. Paxylommatinae.

4. Brachialzelle aussen unten, d. h. unterhalb der Einlenkungsstelle des Nervus parallelus geschlossen.

16. Calyptinae.

Brachialzelle aussen unten offen, indem der Aussennerv bogenförmig in den Nervus parallelus übergeht. 5 .

5. Radius gerade, der 1. Abschnitt desselben deutlich, ziemlich lang. Bohrer meist gerade.

17. Blacinae. gebogen.

Radius gebogen, der 1. Abschnitt kurz, fast fehlend. Bohrer einwärts

6. Hinterleib gestielt. 7.

Hinterleib sitzend oder fast sitzend. 8.

7. Hinterleib flach, die Endsegmente deutlich sichtbar; Bohrer weit vorstehend, dünn. Radialzelle langgestreckt. Körper meist ausgedehnt gelblich gefärbt.

14. Meteorinae.

Hinterleib stark zusammengedrückt; das 2. Segment schliesst die folgenden ein; Bohrer kurz, breitgedrückt und gekrümmt. Radialzelle sehr kurz. Körper schwarz.

15. Helorimorphinae.

8. Radialzelle sehr kurz, dreieckig, am Vorderrande nicht länger als das Stigma. Bohrer wenig vorragend.

19. Ichneutinae.

Radialzelle verlängert, am Vorderrande länger als das Stigma. 9.

9. Kopf fast kubisch; Scheitel ausgehöhlt, meist mit einem Nebenauge in der Aushöhlung. Hinterschenkel meist verdickt und oft mit einem Zahn. Grosse bis sehr grosse Arten.

20. Helconinae. 
Kopf quer; Scheitel nicht ausgehöhlt. Hinterschenkel nicht verdickt und nicht gezähnt. Kleine, selten mittelgrosse oder grosse Arten. 10.

10. Körper schlank; Hinterleib verlängert, mehr oder weniger linear, etwas über den Hinterhüften eingefügt.

21. Macrocentrinae.

Körper klein und gedrungen; Hinterleib oval, mit Ausnahme von Cenocoelius nicht oberhalb der Hinterhüften eingefügt. 11.

11. Scheitel scharf gerandet. Die 2. Cubitalzelle schmal viereckig, selten dreiseitig. Bohrer meist verlängert.

22. Diospilinae.

Scheitel mit Ausnahme von Ademon nicht gerandet. Die 2. Cubitalzelle meist breit trapezförmig. Bohrer selten weit vorstehend. Zwischen Clypeus und Mandibeln meist eine Querspalte.

23. Opiinae.

\section{Sektion. Exodontes.}

Vorderflügel mit 3 Cubitalzellen; selten die Flügel verkümmert oder fehlend.

Voderflügel mit nur 2 Cubitalzellen. 24. Alysiinae. 25. Dacnusinae.

\section{Sektion. Flexiliventres.}

Kopf quer, nur bei Dyscritus kubisch; Antennen meist bogenförmig nach abwärts gebogen. Parapsidenfurchen selten vorhanden. Nervus parallelus mit Ausnahme von Dyscritus interstitial. Bohrer kurz vorstehend. 26. Aphidiinae.

\section{Sektion. Paxylommates.} gezeichnet.

Durch die auffallende Flügelnervatur vor allen anderen Braconiden aus27. Paxylommatinae.

\section{Übersicht der Gattungen. \\ 1. Unterfamilie. Braconinae.}

1. Stirn ausgehöhlt. Radialzelle fast die Flügelspitze erreichend. 2. Stirn flach, höchstens mit seichter Furche. Radialzelle oft kurz. 3.

2. Schaft einfach; die beiden folgenden Antennenglieder meist von gleicher Länge. Das 2. Segment ohne Mittelfeld, kürzer als das dritte.

Schaft an der Spitze mit zahnartigen Fortsätzen; das 2. Antennenglied kürzer als das dritte. Das 2. Segment mit Mittelfeld, so lang als das dritte. Hierher A. denigrator Nees, schwarz, auch die Flügel, Hinterleib gelb.

Atanycolus Först.

3. Schaft zylindrisch. Luftlöcher des Metathorax deutlich. Discoidalzelle innen nicht breiter als aussen. In Deutschland nur wenige Arten; zahlreiche ansehnliche, oft buntgefärbte Arten in den heissen Ländern.

Zerfällt in die beiden Untergattungen:

Iphiaulax Först. Radialzelle lang, die Flügelspitze erreichend. Clypeus ohne Haarpinsel. Eine der auffallendsten und schönsten Braconiden ist I. impostor Scop. Schwarz, auch Flügel und Beine; Hinterleib brennend rot.

Vipio (s. str.) Latr. Radialzelle kurz, weit vor der Flügelspitze endend. Clypeus meist mit Haarpinseln. Bohrer lang. Färbung in der Regel dunkelgelb; Mesonotum mit 3 schwarzen Längsflecken. 
Schaft kurz, zylindrisch. Luftlöcher des Metathorax undeutlich. Innenseite der Discoidalzelle viel breiter als die Aussenseite. Radialzelle meist die Flügelspitze erreichend. In Deutschland zahlreiche Arten.

Bracon F. (Abb. 21).

\section{Unterfamilie. Exothecinae.}

1. Metathorax mit starken Seitendornen. Antennen des + mit weissem Ring. Phaenodus Först.

Metathorax ohne Seitendornen. Antennen nicht weiss geringelt. 2.

2. Das 2. und 3. Segment durch eine tiefe Querfurche geteilt; die folgenden undeutlish voneinander getrennt. Bohrer höchstens von ${ }^{1 / 4}$ Hinterleibslänge. In Deutschland Ph. dimidiata Nees.

Phanomeris Först.

Die Suturen zwischen allen Segmenten sehr undeutlich. 3.

3. Scheitel hinten nicht gerandet. 4.

Scheitel hinten mit feinem Rand. 7.

4. Der Radius entspringt deutlich vor der Mitte des Stigmas.

Exothecus Wesm.

Der Radius entspringt aus oder jenseits der Mitte des Stigmas. 5.

5. Der rücklaufende Nerv mündet am Anfang der 2. Cubitalzelle.

Bathystomus Först. stitial. 6.

Der rücklaufende Nerv mündet am Ende der 1. Cubitalzelle oder ist inter-

6. Der Radius entspringt zwischen Mitte und Ende des Stigmas. Hinterleibsmitte gelb. Segment 1 und 2 gestreift. Die Art ähnelt einem Bracon. Nur das $0^{7}$ bekannt.

Xenarcha Först.

Der Radius entspringt aus der Mitte des Stigmas. Hinterleib braun, das 1. Segment schwarz. Bohrer kürzer als der halbe Hinterleib. Rhysipolis Först.

7. Hintertarsen kürzer als ihre Schienen; diese bei dem of meist stark verdickt. Metathorax durch Leisten in mehrere Felder geteilt. Rhyssalus Hal.

Hintertarsen nicht kürzer als ihre Schienen; diese bei dem $\sigma^{7}$ nicht auffallend verdickt. Metathorax höchstens mit Mittelkiel. 8.

8. Radius etwas vor der Mitte des Stigmas entspringend. Antennen des i an der Spitze eingerollt. Von den wenigen Arten am häufigsten $C$. decorator Hal.

Radius etwas hinter der Mitte des Stigmas entspringend. Antennen des i an der Spitze nicht eingerollt. Hierher O. lanceolator Nees; eine zweite Art ist fraglich.

Oncophanes Först.

\section{Unterfamilie. Hecabolinae.}

1. Vorderflügel mit nur einer Cubitalzelle, indem alle Cubitalqueradern fehlen. Bohrer kaum vorstehend. Die einzige Art, A. aphidiiformis Rtzb., lebt bei Cecidomyia salicina Geer.

Vorderflügel mit 2 Cubitalzellen. 2.

Achoristus Rtzb.

2. Die 1. Cubitalquerader fehlt; es ist also die 1. Cubitalzelle sehr gross. Hinterflügel des $\sigma^{7}$ an der Basis mit Stigma. Die einzige deutsche Art, C. incompletus Rtzb., lebt bei Pissodes notatus F.

Caenophanes Först. (Synodus Rtzb.).

Die 2. Cubitalquerader fehlt; es ist also die 2. Cubitalzelle verhältnismãssig gross. 3. 
3. Nervulus vorhanden; die Brachialzelle also nach innen geschlossen. 4 . Nervulus fehlend; die Brachialzelle also nach innen offen. 7.

4. Radialzelle am Ende nicht geschlossen. Hinterschienen des $\sigma^{7}$ verdickt, keulenförmig; $q$ unbekannt. Die einzige winzige Art, A. clavipes Reinh., wurde aus Tannenzapfen gezogen.

Acrisis Först. verdickt. 5.

Radialzelle am Ende geschlossen. Hinterschienen des $\sigma^{7}$ nicht keulenförmig

5. Radialzelle klein und schmal, von der Flügelspitze ziemlich weit entfernt. Fast der ganze Hinterleib längsrissig; Bohrer von Hinterleibslänge. Die einzige Art, E. aciculatus Reinh., lebt bei Agrilus viridis. Eucorystes Reinh.

Radialzelle bis fast zur Flügelspitze reichend. Nur die 2 oder 3 vorderen Segmente längsrissig. 6 .

6. Mitteltarsen sehr kurz. Das $0^{7}$ mit einem Stigma an der Basis der Hinterflügel. Bohrer länger als der Körper. Die einzige Art, H. sulcatus Curt., lebt bei Holzkäfern.

Hecabolus Curt.

Mitteltarsen nicht besonders kurz. Das $0^{7}$ ohne Stigma im Hinterflügel. Bohrer etwas kürzer als der Körper.

Monolexis Först.

7. Nervus parallelus interstitial. Bohrer ungefähr von Hinterleibslänge. Die 3 deutschen Arten leben in Holzkäfern.

Ecphylus Först.

Nervus parallelus nicht interstitial. Bohrer so lang wie das letzte Segment. Die einzige Art, E. exiguus Marsh., bisher nur aus England bekannt.

Euchasmus Marsh.

\section{Unterfamilie. Pambolinae.}

In Europa nur 1 Gattung. - Hinterleib sitzend, eiförmig; das 1. Segment mit 2 Kielen, vom 2. durch eine tiefe Querfurche getrennt; das 2. und 3. Segment miteinander verwachsen, sehr gross; die übrigen Segmente versteckt. ㅇ ungeflügelt oder mit Flügelstummeln; $\sigma^{7}$ geflügelt; Oberflügel mit 2 Cubitalzellen. Alle Arten sind sehr selten und noch nicht scharf geschieden; die eine Art wurde aus einem Cryptocephalus gezogen.

Pambolus Hal. (Dimeris Ruthe, Arrhaphis Ruthe).

\section{Unterfamilie. Spathiinae.}

In Europa nur 1 Gattung mit mehreren Arten; am bekanntesten S. exarator L. (clavatus Panz.), welcher bei der Totenuhr (Anobium pertinax L.) und einigen anderen Holzkäfern schmarotzt. Man findet das zierliche Tier häufig an Stubenfenstern.

Spathius Nees.

\section{Unterfamilie. Doryctinae.}

1. Das 2. und 3. Hinterleibssegment durch eine deutliche Querfurche voneinander getrennt. 2 .

Die Furche zwischen dem 2. und 3. Hinterleibssegment undeutlich oder verwischt. 4.

2. Rücklaufender Nerv in die 2. Cubitalzelle. Nervus parallelus interstitial. Segment $1-5$ längsrissig. Die einzige Art, $R h$. aciculatus Ruthe, ist ein kleines, schlankes Tier, schwarzbraun mit rötlichem Kopf und dunkelgebänderten Flügeln. 
Rücklaufender Nerv in die 1. Cubitalzelle. Nervus parallelus nicht interstitial. Hinterleib grösstenteils glatt. 3 .

3. Schaft einfach; die beiden folgenden Antennenglieder meist von gleicher Länge. Das 2. Segment ohne dreieckiges Mittelfeld an der Basis, kürzer als das dritte.

cf. Coeloides Wesm.

Schaft dick, an der Spitze mit zahnartigen Fortsätzen, das 2. Antennenglied deutlich kürzer als das dritte. Das 2. Segment an der Basis mit dreieckigem Mittelfeld, so lang wie das dritte.

cf. Atanycolus Först.

4. Antennen sehr kurz, nur $1^{1}$ mal so lang als der Kopf. Der hinterste Metatarsus an der Basis erweitert, länger als die 4 folgenden Glieder zusammen. Einzige Art $H$. mystacinus Wesm. Histeromerus Wesm.

Antennen nicht kurz, meist viel länger als Kopf und Thorax. Der hinterste Metatarsus nicht länger als die 4 folgenden Glieder zusammen. 5.

5. Radius und Cubitus von der Basis der 2. Cubitalzelle an bis zum Flügelrand stark verdickt; Hinterflügel des $\sigma^{7}$ mit deutlichem Stigma. Bohrer von ${ }^{2} / 3$ Hinterleibslänge. Die einzige sehr kleine Art, C. Hartigi Rtzb., ist braungelb und lebt bei Bostrichus bidens F.

Radius und Cubitus einfach, nicht verdickt. 6.

Caenopachys Först.

6. Rücklaufender Nerv in die 1. Cubitalzelle oder interstitial. Nervus parallelus nicht interstitial. In Deutschland etwa 10 Arten, welche alle bei Holzkäfern schmarotzen.

Doryctes Hal.

Rücklaufender Nerv in die 2. Cubitalzelle. Nervus parallelus interstitial. Flügel getrübt, mit helleren Querbinden. Die wenigen Arten schmarotzen ebenfalls bei Holzkäfern.

Dendrosoter Wesm.

\section{Unterfamilie. Hormiinae.}

Nervulus stark postfurkal, also weit hinter dem Ursprung des Basalnerven. Antennen mit 11 oder 12 Gliedern. Die einzige Art, Ch. rubiginosus Nees, ist $1-2 \mathrm{~mm}$ lang, braunrot und lebt bei verschiedenen Kleinschmetterlingen und Bruchus-Arten.

Chremylus Hal.

Nervulus interstitial. Antennen fast perlschnurförmig, mit 17-25 Gliedern. Die einzige Art, $H$. moniliatus Nees, lebt bei Kleinschmetterlingen.

Hormius Nees.

\section{Unterfamilie. Rogadinae.}

Alle Arten schmarotzen in Schmetterlingsraupen.

1. Die 2. Sutur, d. h. die Querfurche zwischen dem 2. und 3. Segment verwischt. 2.

Die 2. Sutur deutlich. 4.

2. Hintertarsen kürzer als ihre Schienen; diese bei dem $0^{\circ}$ meist stark verdickt. Metathorax zum Teil gefeldert.

cf. Rhyssalus Hal.

Hintertarsen nicht kürzer als ihre Schienen; diese beim $0^{7}$ nicht verdickt. Metathorax nicht gefeldert. 3.

3. Die 2. Cubitalzelle trapezförmig. Hinterleib nicht länger als Kopf und Thorax, beim $q$ höchstens an der Spitze komprimiert; Bohrer mindestens so lang wie der halbe Hinterleib. Wenige Arten, am häufigsten $C$. exsertor Nees. 
Die 2. Cubitalzelle rechteckig. Hinterleib länger als Kopf und Thorax zusammen, beim + vom 2. Segment an zusammengedrückt; Bohrer wenig vorstehend. Die einzige Art, $P$. unicolor Wesm., ist rostgelb und etwa 5-6 mm lang. Petalodes Wesm.

4. Das 3. Glied der Maxillarpalpen stark beilförmig verbreitert. Bohrer ziemlich vorstehend. Hinterleibssegmente vom dritten an mit dicken Hinterrändern. Von den beiden Arten ist $P$. luteum Nees ein ziemlich grosses, ganz rostgelbes Tier; die zweite Art, P. tricolor Wesm., ist gelb und schwarz, mit grossem schwarzem Flügelstigma; beide Arten schmarotzen mit Vorliebe bei Cochlidion limacodes Hufn.

Pelecystoma Wesm.

Maxillarpalpen fadenförmig, kein Glied verdickt. Bohrer kaum vorstehend. 5.

5. Die 2. Cubitalzelle quadratisch; der erste Abschnitt des Radius länger als der zweite. + mit dreifarbigen, weissgeringelten Antennen. Die einzige Art, H. dispar Curt., wurde aus Agrotis segetum gezüchtet. Heterogamus Wesm.

Die 2. Cubitalzelle viel breiter als hoch, deshalb der erste Abschnitt des Radius länger als der zweite. Antennen des $q$ nicht dreifarbig. In Deutschland etwa 20 Arten. Rogas Nees.

\section{Unterfamilie. Sigalphinae.}

Hinterleib mit 5 deutlichen Segmenten, indem Segment 4 und 5 nicht vollständig unter den vorhergehenden versteckt sind. Das 2 . Segment länger als das 3. Nur wenige seltene Arten. Allodorus Först.

Hinterleib mit nur 3 mehr oder weniger deutlichen Segmenten. Das 2. Segment kürzer als das 3 . In Deutschland etwa 10 kleine Arten, die mit Vorliebe bei Rüsselkäfern, namentlich der Gattung Apion schmarotzen.

Sigalphus Latr.

\section{Unterfamilie. Cheloninae.}

1. Hinterleib ohne alle Querteilung, aus nur 1 Stücke bestehend. 2. Hinterleib aus 3 Teilen bestehend. 3 .

2. Die 1. Cubital- und die 1. Discoidalzelle miteinander verschmolzen. Augen behaart. Zahlreiche schwer unterscheidbare kleine Arten von schwarzer, an der Hinterleibsbasis zuweilen hell gezeichneter Färbung, welche, soweit bekannt ist, bei Kleinschmetterlingen leben.

Chelonus Jur. (Abb. 22).

Die 1. Cubital- und die 1. Discoidalzelle voneinander getrennt. Augen kahl. Die zahlreichen Arten stimmen in Habitus und Färbung ganz mit Chelonus überein und leben ebenfalls bei Kleinschmetterlingen. Ascogaster Wesm.

3. Mittelschienen aussen stark ausgebuchtet. Färbung vorwiegend rostgelb. Hierher 2 kleine Arten, am häufigsten Ph. dentata Panz., Schmarotzer von Kleinschmetterlingen. Phanerotoma Wesm.

Mittelschienen aussen nicht ausgebuchtet. Färbung schwarz. Grössere Arten. 4.

4. Hinterleibsende aufgetrieben, mit goldglänzendem Haarfleck, die letzten Segmente versteckt. Bauch am Ende mit 2 Zähnen; Bohrer nicht vorragend. Die einzige, sehr seltene Art $S$. irrorator F. lebt in Raupen der Eulengattungen Acronycta und Mamestra.

Sphaeropyx III.

Hinterleibsende nicht aufgetrieben und ohne goldglänzenden Haarfleck, die letzten Segmente sichtbar. Bauch am Ende ohne Zähne; Bohrer etwas vorstehend. Beine gelb und schwarz. Einzige Art A. alternipes Nees. 


\section{Unterfamilie. Microgasterinae.}

Eine durch den grossen Nutzen der zahlreichen Arten von Microgaster (im weiten Sinne) höchst wichtige Familie.

1. Mesonotum mit deutlichen Parapsidenfurchen. Antennen vielgliedrig. Radius stark gebogen. Flügel mit 3 Cubitalzellen, die 2. gross, vierseitig. Im Süden des Gebietes $C$. saltator Nees; schwarz mit rotem Mesonotum.

Cardiochiles Nees.

Parapsidenfurchen fehlend oder nur angedeutet. Antennen mit höchstens 21 Gliedern. Radius gerade oder wenig gebogen. Die 2. Cubitalzelle klein, dreieckig, oft unvollständig. 2 .

2. Antennen mit 13-16 Gliedern. 3.

Antennen mit mindestens 18 Gliedern. 4.

3. Vorderflügel mit 2 Cubitalzellen. $M$. spartii Hal., schwarz mit rötlichem Kopf, lebt bei der Kleinschmetterlingsgattung Nepticula.

Mirax Hal.

Vorderflügel mit 3 Cubitalzellen; Flügel weisslich, Nervatur undeutlich. E. berolinense Ruthe, schmarotzt bei Ameisen, Formica rufa und pratensis.

4. Antennen mit 18 Gliedern. 5.

Elasmosoma Ruthe.

Antennen mit 20 oder 21 Gliedern. 7.

5. Vorderflügel mit 2 Cubitalzellen, indem die mittlere kleine nur in der Anlage vorhanden und aussen nicht geschlossen ist. In Deutschland an 50 Arten. Apanteles Först.

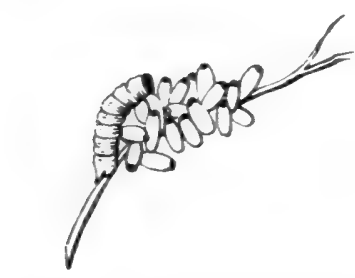

Abb. 30.

Kokons von Apanteles rubripes Hal. mit dem Rest der Raupe, aus welcher die Larven geschlüpft sind.

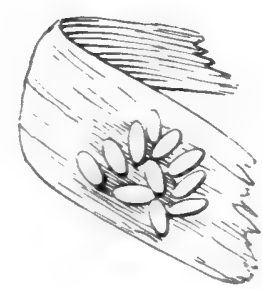
Abb. 31.
Kokons von Apanteles popularis Ha!.

(Nach Marshall.)

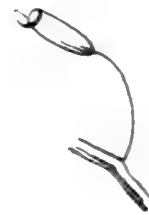

Abb. 32.

Langgestielter Kokon von Apanteles formosus Wesm.

Vorderflügel mit 3 Cubitalzellen, indem die mittlere kleine aussen geschlossen ist. 6.

6. Die Endsporen der hintersten Schienen sehr kurz. Brustseiten mit krenulierter Furche. Das 2. Segment ohne Quereindruck. In Deutschland etwa 15 Arten.

Microplitis Först.

Die Endsporen der hintersten Schienen lang, fast so lang wie der Metatarsus. Brustseiten meist ohne krenulierte Furche. Das 2. Segment mit deutlichem Quereindruck. In Deutschland etwa 20 Arten.

Microgaster Latr.

7. Antennen mit 20 Gliedern. Cubitus aus dem Basalnerv entspringend. Am häufigsten $A$. subfasciatus Hal., eine winzige Art, schwarz mit dunkelgebänderten Flügeln, welche namentlich in Nepticula-Arten lebt.

Acaelius Hal.

Antennen mit 21 Gliedern. Cubitus aus dem Parastigma entspringend. Die einzige Art, D. rufa Först., ist grösstenteils rötlich. Dirrhope Först. 


\section{Unterfamilie. Agathidinae.}

1. Kopf schnabelartig verlängert; der Raum zwischen den Augen und Mandibeln sehr lang. 2.

Kopf nicht schnabelartig verlängert; der Raum zwischen den Augen und Mandibeln kurz. 4.

2. Stirnaushöhlung klein, beiderseits nicht gerandet. Der 2. Cubitalquernerv ohne Anhang. Kleinere, meist ganz schwarz gefärbte Arten. In Deutschland etwa 10 Arten, die bei Kleinschmetterlingen, namentlich der Gattung Coleophora schmarotzen.

Agathis Latr. (Abb. 23).

Stirnaushöhlung gross, beiderseits scharf gerandet. Der 2. Cubitalquernerv mit einem Anhang aus seiner Mitte. 3.

3. Zwischen den Antennen 2 senkrechte Lamellen. Bohrer kaum vorstehend. Körper schwarz und rot, gross oder mittelgross. Die beiden Arten bewohnen mehr den Süden und dürften kaum im Gebiete vorkommen.

Zwischen de Antennen keine Lamellen Bophrys Forst. Die einzige ziemlich grosse Art, $C$. desertor $L$, Bst rostgelb mit dunterleibslänge. und lebt bei Phlyctaenodes verticalis.

Cremnops Först.

4. Vorderflügel nur mit 2 Cubitalzellen. Radialzelle schmal und spitz, vom Flügelende entfernt. Hinterbeine verdickt. Etwa 4 Arten, am häufigsten $O$. obscurator Nees, eine kleine ganz schwarze Art, die bei Kleinschmetterlingen lebt.

Vorderflügel mit 3 Cubitalzellen. 5.

Orgilus Hal.

5. Die 1. Cubitalzelle mit der 1. Discoidalzelle verschmolzen. Kleinere ganz schwarz, selten zum Teil rötlich gefärbte Arten, welche täuschende Âhnlichkeit mit Agathis haben. In Deutschland etwa 8 Arten.

Microdus Nees.

Die 1. Cubitalzelle von der 1. Discoidalzelle getrennt. Grössere Arten, wovon in Deutschland etwa 5-6 vorkommen.

Earinus Wesm.

\section{Unterfamilie. Euphorinae.}

1. Antennen gerade, nicht gekniet; Schaft nur selten etwas verlängert oder verdickt. 2 .

Antennen 1- oder 2 mal gekniet; Schaft sehr verlängert. 8.

2. Gesicht aufgetrieben, nach oben mit zwei anliegenden Wülsten oder Hörnern, welche die Antennenbasis umfassen. Antennenschaft dick und etwas verlängert. Die 1. Cubitalzelle mit der 1. Discoidalzelle verschmolzen. Bohrer vorstehend. Die wenigen Arten sind sehr selten, am häufigsten noch $C$. flaviceps Marsh.; schwarz mit rotgelbem Kopf, Schaft und Prothorax.

Gesicht einfach, ohne besondere Auftreibung. 3.

Cosmophorus Ratzeb.

3. Augen sehr gross, fast die ganzen Kopfseiten einnehmend. Kopf stark quer, von vorn gesehen dreieckig; Antennen lang und dünn. Die 1. Cubitalmit der 1. Discoidalzelle verschmolzen. Hinterleib seitlich zusammengedrückt, fast linear; Bohrer kurz, mit breiten Klappen. Die einzige Art, M. boops Wesm., ist sehr selten. Myiocephalus Marsh.

Augen nicht auffallend gross. 4 . 
4. Das 1. Segment linear, länger als der übrige Hinterleib; Postpetiolus kaum verbreitert. Kopf gross, kubisch. Die 1. Cubitalzelle von der 1. Discoidalzelle getrennt. Bohrer sehr kurz. Die einzige, rostgelbe Art, W. cremasta Marsh., ist höchst selten.

Wesmaelia Först.

Das 1. Segment nicht länger als der übrige Hinterleib; Postpetiolus breiter als der Petiolus. 5.

5. Radialzelle lang, bis nahe an die Flügelspitze reichend. Wenige, vorwiegend rostgelb gefärbte Arten.

Microctonus Wesm. krümmt. 6.

Radialzelle kurz, weit von der Flügelspitze entfernt; Radius stark ge-

6. Antennenschaft verdickt und ziemlich lang, unten lang behaart; Antennen beim ơ 18 gliedrig, von Körperlänge. Die 1. Cubital- mit der 1. Discoidalzelle verschmolzen. Die einzige, höchst seltene Art, E. Halidayanus Först., nur im männlichen Geschlecht bekannt.

Eutanycerus Först.

Antennenschaft kurz und ohne auffallende Behaarung. 7.

7. Bohrer versteckt. Metathorax hinten nicht senkrecht abgestutzt und auch nicht ausgehöhlt. Die 1. Cubital- von der 1. Discoidalzelle geschieden. Etwa 5 oder 6 Arten, am bekanntesten E. pallipes Curt., Schmarotzer der Käfergattung Orchesia.

Euphorus Nees.

Bohrer vorstehend. Metathorax hinten senkrecht abgestutzt und ausgehöhlt. Die 1. Cubital- mit der 1. Discoidalzelle meist verschmolzen. Etwa 15 nicht leicht unterscheidbare Arten, die vorwiegend bei Käfern leben.

Perilitus Nees (Abb. 24).

8. Die 1. Cubital- von der 1. Discoidalzelle getrennt. Antennen des? keulenförmig. Bohrer von ${ }^{2}{ }_{3}$ Hinterleibslänge. Die einzige, höchst seltene und nur im weiblichen Geschlecht bekannte Art, E. clavicornis Wesm., ist schwarz mit gelblichen Antennen und Beinen.

Eustalocerus Först.

Die 1. Cubital- mit der 1. Discoidalzelle verschmolzen. Antennen des 9 gegen das Ende kaum verdickt. Zwei höchst seltene Arten, schwarzbraun mit gelbrotem Kopf oder Gesicht; bei der einen, S. fulviceps Westw., ist das 1 . und 3. Antennenglied stark verlängert; bei der zweiten, S. macroscapa Ruthe, ist der Schaft nur beim +9 sehr lang, beim $\sigma^{7}$ nur so lang, wie die beiden năchster Glieder zusammen. Streblocera Westw.

\section{Unterfamilie. Meteorinae.}

Kopf quer, meist von Thoraxbreite; Antennen dünn und lang. Radialzelle fast bis zur Flügelspitze reichend; von den 3 Cubitalzellen ist die zweite aufrecht rechteckig oder nach oben etwas verschmälert. Bohrer vorstehend. In Deutschland an die 30 Arten; man vergleiche meine Monographie. Ihre Färbung ist rötlichgelb und braun; sie schmarotzen bei Schmetterlingen und Käfern.

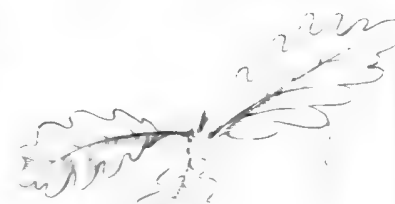

\section{Unterfamilie. Helorimorphinae.}

Kopf quer, glatt, nach hinten nicht verschmälert; Antennen so lang wie Kopf und Thorax, 18 gliedrig, gegen das Ende perlschnurförmig. Thorax gedrungen, mit fingerhutähnlicher Skulptur; Metathorax steil abfallend. Radialzelle 
sehr kurz; Stigma kurz und breit; von den 3 Cubitalzellen ist die zweite ziemlich klein, unregelmässig, nach oben etwas verschmälert. Hinterleib wie poliert, langgestielt, Stiel gekrümmt; das 2. Segment die übrigen einschliessend, seitlich zusammengedrückt; Bohrer kurz und stumpf. - Die einzige Art, H. egregia Schmiedekn., ist schwarz mit bräunlicher Antennenbasis und Beinen, Länge etwa $4 \mathrm{~mm}$; sie wurde von mir bei Blankenburg in Thüringen entdeckt.

Helorimorpha Schmiedekn.

\section{Unterfamilie. Calyptinae.}

Radialzelle lanzettförmig, nicht bis zur Flügelspitze reichend. 2 Cubitalzellen; die erste von der 1. Discoidalzelle getrennt. Cubitus aus dem Basalnerv. Brachialzelle nach aussen unten geschlossen. Bohrer meist lang.

Hinterleib mit 8 Rückensegmenten; das erste deutlich länger als breit, gegen die Basis wenig verschmälert. Etwa $4-5$ Arten, am häufigsten $E$. extensor L., der bei verschiedenen Kleinschmetterlingen lebt.

Eubadizon Nees.

Hinterleib mit nur 3 oder 4 sichtbaren Rückensegmenten; das erste kaum länger als an der Spitze breit, gegen die Basis deutlich verschmälert. In Deutschland an 15 Arten, die in Käfern, namentlich Holzkäfern, schmarotzen.

Calyptus Hal.

\section{Unterfamilie. Blacinae.}

Radialzelle fast die Flügelspitze erreichend; Radius fast gerade. 2 Cubitalzellen; die erste von der 1 . Discoidalzelle getrennt. Brachialzelle nach aussen unten offen. Bohrer vorstehend, gerade oder nur ganz schwach gekrümmt.

Der Cubitus entspringt aus dem Basalnerv, die 1. Discoidalzelle ist also gestielt. Das 1. Geisselglied kürzer als das zweite. Die 3 deutschen Arten sind vorwiegend rotgelb gefärbt; sie leben bei Schmetterlingen, Käfern und auch verschiedenen Blattwespen.

Pygostolus Hal.

Der Cubitus entspringt aus dem Parastigma, die 1. Discoidalzelle ist also sitzend. Das 1. Geisselglied fast stets länger als das zweite. In Deutschland ungefähr 10 Arten von brauner oder gelbbrauner Färbung, die bei Schmetterlingen und Käfern, besonders Rüsselkäfern, schmarotzen; $B$. ruficornis Nees gehört zu den gemeinsten Braconiden.

Blacus Nees (Abb. 26).

\section{Unterfamilie. Leiophroninae.}

Radius gekrümmt, der 1 . Abschnitt desselben kürzer als der senkrechte Durchmesser des Stigmas. Endsegmente des + eingeschlagen, so dass der kurze und gekrümmte Bohrer nach vorn gerichtet ist.

Mesonotum mit mehr oder weniger deutlichen Parapsidenfurchen. Hinterleibsmitte zuweilen rot. Nur wenige Arten; die eine wurde aus einer Motte, Ptocheuusa paupella Z., gezogen.

Leiophron Nees.

Mesonotum glatt, ohne Spur von Parapsidenfurchen. Die beiden in Deutschland vorkommenden Arten sind glänzend schwarz, am häufigsten C. lucidator Nees; die zweite Art, C. fusciper Nees, wurde aus Elachista trapeziella Stt. gezüchtet.

Centistes Hal.

\section{Unterfamililie. Ichneutinae.}

Radius hinter der kleinen 2. Cubitalzelle ziemlich steil zum Vorderrande gehend; Radialzelle dadurch kurz dreieckig. Schmarotzer von Blattwespen.

Die 2. Cubitalzelle oben viel länger als der 2. Cubitalquernerv. Flügel nur leicht getrübt; Hinterleib braun. Antennen nicht sehr lang. Wenige, nicht 
scharf voneinander geschiedene Arten; am häufigsten I. reunitor Nees, der in den Larven von Nematus (im weiten Sinne) lebt.

Ichneutes Nees.

Die 2. Cubitalzelle oben kürzer als der 2. Cubitalquernerv. Antennen sehr lang. Die einzige Art, $P$. nigripennis Wesm., ist schwarz, auch die Flügel; Hinterleib lebhaft gelb; sie erinnert dadurch sehr an einen Vipio oder Bracon; lebt bei Hylotoma atrata und enodis.

Proterops Wesm. (Abb. 27).

\section{Unterfamilie. Helconinae.}

Flügel mit 3 Cubitalzellen, die zweite breit trapezförmig. Hierher die grössten aller Braconiden. Etwa 8 Arten, welche bei Holzkäfern, namentlich Böcken, schmarotzen; man findet deshalb die Arten an altem Holz, Baumstrünken, Holzklaftern usw.

Helcon Nees.

\section{Unterfamilie. Macrocentrinae.}

Antennen sehr lang. Mesonotum mit deutlichen Parapsidenfurchen. Radialzelle lang, fast die Flügelspitze erreichend. Beine verlängert. Die Arten schmarotzen bei Schmetterlingen.

Scheitel nicht gerandet. Die hintersten Schiensporen kurz. Hinterleib linear; das 1. Segment so lang oder kaum länger als das zweite; Bohrer meist länger als der Hinterleib. Körper klein bis mittelgross. 5-6 Arten.

Macrocentrus Curt.

Scheitel gerandet. Die hintersten Schiensporen sehr lang. Hinterleib nach hinten verbreitert; das 1. Segment viel länger als das zweite; Bohrer weit kürzer als der Hinterleib. 3-4 mittelgrosse und grosse Arten, meist von rötlichgelber Färbung, am häufigsten $Z$. testaceator Curt.

Zele Curt.

\section{Unterfamilie. Diospilinae.}

Es ist schwer, ein gemeinsames charakteristisches Merkmal für diese Unterfamilie aufzustellen, da sie aus sehr verschiedenartigen Elementen besteht. Kopf gross, zuweilen kubisch. Von den 3 Cubitalzellen ist die zweite klein und nicht selten rechteckig. Bohrer mehr oder weniger weit vorstehend.

1. Metathorax steil abgestutzt; Hinterleib am oberen Rande desselben, weit über den Hinterhüften cingefügt. Körper gedrungen; Kopf gross, breiter als der Thorax. Parapsidenfurchen deutlich, punktiert. Zweite Cubitalzelle unten noch einmal so breit wie oben. Beine kurz und dick. Bohrer von Hinterleibslänge. Die beiden Arten: C. agricolator L., Antennen 31-34gliedrig, Kopf des $q$ rot, Hinterleib schwarz, und $C$. analis Nees, Antennen 25 gliedrig, Kopf des $\&$ mit rotem Gesicht und Wangen, Hinterleibsspitze rot, leben bei Holzkäfern, und zwar den Gattungen Magdalinus, Pogonocherus und Scolybus. Die Gattung hat einen so eigenen Habitus, dass man eine besondere Unterfamilie daraus machen kann.

Cenocoelius Hal.

Metathorax allmählich abfallend; Hinterleib am unteren Rande desselben eingefügt, unmittelbar über den Hinterhüften. 2.

2. Die 2. Cubitalzelle klein, dreieckig, mit der Spitze nach oben; Radius hinter derselben gerade, fast die Flügelspitze erreichend. Antennen lang. Bohrer so lang wie Kopf und Thorax. Die beiden Arten erinnern an die Gattung Meteorus; sie sind sehr selten; am häufigsten noch $M$. Wesmaeli Rtzb., im Spätsommer auf Eichengebüsch.

Microtypus Rtzb.

Die 2. Cubitalzelle rechteckig oder trapezförmig. 3. 
3. Der Cubitus entspringt aus dem Parastigma. 2. Cubitalzelle aufrecht rechteckig, selten nach oben etwas verschmälert. 4 .

Der Cubitus entspringt aus dem Basalnerv. 2. Cubitalzelle trapezförmig. 6.

4. Clypeus vorn abgestutzt oder zugerundet. Hierher etwa 10 kleine, schwer unterscheidbare Arten, die meisten einfarbig schwarz, welche fast alle bei Käfern schmarotzen.

Diospilus Hal.

Clypeus vorn in der Mitte zugespitzt oder winklig vorgezogen. 5.

5. Antennen des $\sigma^{7}$ am Ende keulenförmig verdickt. Die einzige, seltene Art, $A$. diversicornis Wesm., ist ein ziemlich grosses Tier von 5-6 mm Länge und lebt bei Holzkäfern, namentlich Melandrya caraboides.

Aspidogonus Wesm.

Antennen des $0^{7}$ am Ende nicht verdickt. Von den beiden Arten ist am häufigsten $B$. abietis Rtzb.; das Tier ist etwa $3-4 \mathrm{~mm}$ lang, sieht einem Diospilus sehr ähnlich und lässt sich am leichtesten aus Tannenzapfen züchten, wo es bei Anobium-Arten lebt.

Baeacis Först.

6. Metathorax vollständig gefeldert. Das 1 . Segment gestreift, mit zwei Kielen. Die beiden Arten sind bis jetzt erst aus England bekannt: D. hastifer Marsh. ist 4-5 mm lang und hat 37-40 gliedrige Antennen; D. aculeator Marsh. ist nur 2,5-3,5 $\mathrm{mm}$ lang und hat 27-33 gliedrige Antennen; beide sind schwarz mit rötlichen Beinen; die letztere Art lebt wahrscheinlich bei Phyllobius alneti $\mathrm{F}$., der besonders auf Urtica dioica vorkommt. Dolops Marsh.

Metathorax ungefeldert. Das 1. Segment glatt, in der Mitte mit Längskiel. Bohrer um ein Viertel länger als der Körper. Die einzige, sehr seltene Art, D. lancifer Hal., ist ein sehr schlankes, braunes Tier von etwa $3-4 \mathrm{~mm}$ Länge.

Dyscoletes Hal.

\section{Unterfamilie. Opiinae.}

Die Opiinen bilden den Übergang zur Sektion der Exodonten, mit denen sie eine grosse Âhnlichkeit haben. Es sind durchweg kleine bis sehr kleine Tiere, deren Unterscheidung grosse Übung erfordert. Der Clypeus schliesst sich entweder eng an die Mandibeln an oder es bleibt eine Querspalte offen. Radialzelle gross; 3 Cubitalzellen, die 2. breiter als hoch. Bohrer in der Regel sehr kurz, höchstens von Körperlänge. Vor dem Schildchen befindet sich bei vielen Arten ein vertiefter Punkt oder ein Grübchen, was für die Artunterscheidung von Wichtigkeit ist. Aus diesem Grunde empfiehlt es sich, die Tiere lieber aufzukleben als zu nadeln. Die Arten leben fast ausschliesslich bei kleinen Dipteren; man findet sie deshalb besonders an schattigen, grasigen Stellen.

1. Hinterkopf deutlich gerandet. Kopf, Thorax und die 2 oder 3 ersten Segmente fein gerunzelt oder punktiert, matt. Der Radius reicht nicht bis zum Flügelrand; Radialzelle oft nicht geschlossen. Die beiden Arten, am häufigsten $A$. decrescens Nees, finden sich an Wassergräben auf Nasturtium officinale.

Ademon Hal.

Hinterkopf nicht gerandet. Körper grösstenteils glatt und glänzend. Radialzelle nur bei einer sehr seltenen Diachasma-Art offen. 2.

2. Das 2. Segment mit zwei gekrümmten und punktierten Querfurchen. Die 2. Cubitalzelle klein, eher etwas höher als breit. Bohrer sehr kurz. Die einzige, ziemlich seltene Art, G. pumilio Nees, ist 1,5-2 $\mathrm{mm}$ lang und hat blassgelbe Antennenbasis, Beine und Hinterleibsmitte.

Gnamptodon Hal.

Das 2. Segment ohne Eindrücke oder Querfurchen. Die 2. Cubitalzelle mit Ausnahme von Hedylus breiter als hoch. 3. 
3. Der 2. Abschnitt des Radius kürzer als der 1. Cubitalquernerv, die obere Seite der 2. Cubitalzelle also kürzer als die Innenseite. Hinterleib fast gestielt. Die einzige Art, H. habilis Marsh., ist nur im männlichen Geschlecht und bis jetzt erst aus England bekannt; sie ist schwarz, Kopf, Prothorax, Seiten des Mesonotums und Hinterleibsmitte hellrot; Beine blassgelb; Länge $3 \mathrm{~mm}$.

Hedylus Marsh.

Die 2. Cubitalzelle breiter als hoch. Hinterleib sitzend oder fast sitzend. 4.

4. Die obere Seite der 2. Cubitalzelle deutlich länger als die innere Seite. 5.

Die obere Seite der 2. Cubitalzelle von gleicher Länge wie die innere Seite. 6.

5. Stigma sehr lang und schmal; Radius aus der äussersten Basis desselben entspringend. Die einzige Art, E. abnormis Wesm., ist schwarz; Hinterleib und Beine rötlich.

Eurytenes Först.

Stigma kürzer und breiter; Radius nicht aus der äussersten Basis desselben entspringend. In Deutschland 30-40 meist sehr kleine und schwer unterscheidbare Arten, die bei Fliegen schmarotzen.

Opius Wesm.

6. Stigma verlängert, schmal; Radius vor, selten in der Mitte desselben entspringend. Etwa 8-10 Arten.

Biosteres Först.

Stigma kurz oval oder fast dreieckig; Radius meist hinter der Mitte desselben entspringend. Die wenigen Arten sind sehr selten. Diachasma Först.

\section{Unterfamilie. Alysiinae.}

Eine sehr artenreiche Unterfamilie, ausgezeichnet wie die folgende durch die merkwürdige Mandibelbildung; diese ist auch der einzige Unterschied von der vorhergehenden Unterfamilie der Opiinen. Kopf meist gross mit erweiterten Wangen; Antennen vielgliedrig, nicht selten länger als der Körper; Flügel zuweilen stummelhaft oder fehlend; das 1 . Segment runzlig, die übrigen meist glatt; Bohrer vorstehend, aber höchst selten länger als der Hinterleib. Die zahlreichen Arten schmarotzen bei kleinen Fliegen und finden sich mit Vorliebe an schattigen, feuchten Orten, namentlich im Spätsommer und Herbst.

1. Flügel verkürzt oder ganz fehlend. 2.

Flügel vollständig ausgebildet. 4 .

2. Flügel ganz fehlend. Die einzige, sehr kleine Art, Ch. apterus Nees, ist grösstenteils rostrot und findet sich an grasigen Plätzen. Chasmodon Hal.

Flügel verkürzt und meist schmal. 3.

3. Flügel mit deutlicher Nervatur und langem, verdicktem Stigma. + meist mit normalen Flügeln. Einzige Art $A$. contracta $\mathrm{Hal}$.

Alloea Hal. $0^{7}$.

Flügel ohne deutliche Nervatur, mit kurzem Stigma. Hinterleib stark zusammengedrückt. Einzige Art $P$. inops Först.

Panerema Först.

4. Der 1. Cubitalquernerv ebenso lang oder länger als der 2. Abschnitt des Radius. 5.

Der 1. Cubitalquernerv kürzer als der 2. Abschnitt des Radius, nur bei 1 oder 2 seltenen Adelura-Arten gleich lang. 12.

5. Das 4. Antennenglied länger als das 3. Stigma gross. Bohrer von Hinterleibslänge. Sehr selten.

Das 4. Antennenglied nicht länger als das 3. 6.

Idiasta Först.

6. Das 2. Segment punktiert oder gestreift, matt. 7.

Das 2. Segment glatt und glänzend. 8. 
7. Das 2. Segment punktiert, in der. Mitte mit Querfurche. Stigma gross und breit. Die einzige, kleine und zarte Art, T. aurora Hal., ist rötlichgelb, Kopf, Metathorax und Hinterleibsbasis schwarz.

Trachyusa Ruthe.

Hinterleib dicht längsstreifig, matt, das 2. Segment ohne Quereindruck. Körper gedrungen, 4-5 mm lang. Von den beiden sehr seltenen Arten ist die eine, A. sigalphoides Marsh., schwarz mit gelblichen Schienen und Tarsen; die andere Art, $A$. rhogaleus Marsh., ist schwarz, der Hinterleib vom 3. Segment an braunrot. Beide Arten wurden von mir bei Gumperda in Thüringen entdeckt und sind sonst nicht wiedergefunden worden. Asyntactus Marsh.

8. Nervus parallelus interstitial. Stigma gestreckt. Bohrer sehr kurz. Kleine Arten. 9.

Nervus parallelus nicht interstitial. 10.

9. Metathorax mit Kiel. Antennen mit 21 Gliedern. Die einzige Art, A. contracta Hal., ist schwarz mit rötlichen Beinen; das $\sigma^{7}$ hat verkürzte und schmale Flügel.

Alloea Hal. ?.

Metathorax ohne Kiel. Antennen länger als der Körper, mit 30-34 Gliedern. Die einzige Art, C. circe Hal., ist schwarz, Kopf, Basis des 2. Segmentes und Beine rötlich.

Cratospila Först.

10. Brustseiten mit glatter oder ganz ohne Furche. Der rücklaufende Nerv deutlich in die 2. Cubitalzelle. Hierher 4 kleine schwarze, seltene Arten.

Pentapleura Först.

Brustseiten mit krenulierter Furche. Der rücklaufende Nerv selten in die 2. Cubitalzelle. 11.

11. Stigma kurz; Radius hinter der Mitte desselben entspringend. Hierher eine Reihe Arten, am bekanntesten A. manducator Panz. Alysia Latr.

Stigma verlängert; Radius vor der Mitte desselben entspringend. Hinterleib meist rot gezeichnet. Hierher 4 Arten.

Tanycarpa Först.

12. Die 1. Cubitalzelle mit der 1. Discoidalzelle verschmolzen. Hierher A. cephalotes Hal., neuerdings in mehrere Arten zerlegt.

Aphaereta Först.

Die 1. Cubitalzelle von der 1. Discoidalzelle getrennt. 13.

13. Stigma fehlend, nur die Vorderrandsader an der entsprechenden Stelle etwas dicker und gegen die Flügelspitze allmählich verdünnt. Hierher zahlreiche kleine und sehr kleine Arten.

Aspilota Först.

Stigma zwar linear und zuweilen sehr lang aber doch von der übrigen Vorderrandsader deutlich abgesetzt. 14.

14. Nervus parallelus interstitial oder fast interstitial. Antennen sehr lang, vielgliedrig. Bohrer kaum vorstehend. Wenige kleine und schwer unterscheidbare Arten.

Adelura Först.

Nervus parallelus aus der Mitte der Brachialzelle. Bohrer vorstehend, etwas gekrümmt. Hierher $O$. pumila Nees.

Orthostigma Ratzeb.

\section{Unterfamilie. Dacnusinae.}

Mit der vorhergehenden Unterfamilie eng verwandt. Radialzelle meist gross; Radius gegen das Ende in der Regel geschweift, die konkave Seite nach unten. Bohrer kurz.

1. Die 3 ersten Hinterleibssegmente gerunzelt oder dicht gestreift. 2.

Nur das 1. Segment gerunzelt, sehr selten auch die Basis des 2. 3. 
2. Kopf quer. Hinterschildchen mit Dorn. Die 3 Arten sind nicht selten. Symphya Först. (Oenone Hal.).

Kopf kubisch. Hinterschildchen ohne Dorn. Die beiden ziemlich robusten Arten, $P$. liparae Gir. mit zum Teil rotem und $P$. melas Gir. mit ganz schwarzem Hinterleib, leben in den durch die Fliegengattung Lipara erzeugten Schilfgallen.

Polemon Gir.

3. Das 1. Segment breiter als lang. 2. Sutur deutlich. Die einzige Art, E. marginalis Hal., hat rötliche Hinterleibsspitze.

Epimicta Först.

Das 1. Segment länger als breit. 2. Sutur verwischt. 4.

4. Kopf kubisch. Körper linear. 5.

Kopf quer. Körper gedrungener. 6.

5. Radius vor dem Ende nach innen geschwungen. Die einzige, ziemlich grosse Art, Ch. circulator Grav. (anceps Curt.), hat grösstenteils roten Hinterleib und findet sich auf sumpfigen Wiesen.

Chaenon Curt. (Copısura Schiödte).

Radiusende gleichmässig gekrümmt. Die wenigen Arten sind nicht scharf geschieden; sie sind nicht selten.

Coelinius Nees.

bare Arten.

6. Radiusende nach vorn geschwungen. Zahlreiche schwer unterscheid-

Radiusende gleichmässig gekrümmt. Die ziemlich seltenen Arten finden sich auf Pflanzen am Rande von Gewässern. 7.

7. Augen nackt. Thorax glatt. Stigma stark verlängert, linear.

Gyrocampa Först.

Augen behaart. Thorax fein punktiert, matt. Stigma weniger verlängert, zuweilen sehr kurz. 8.

8. Stigma lang und meist linear; Radius vor der Mitte desselben entspringend. Nur wenige sehr seltene Arten.

Chorebus Hal.

Stigma kurz und dick; Radius aus der Mitte desselben entspringend. Die einzige Art, Ch. conjungens Nees, ist schwarz mit rötlichen Beinen.

Chaenusa Hal.

\section{Unterfamilie. Aphidiinae.}

Hinterleib länger als Kopf und Thorax, die 3 ersten Segmente gelenkig miteinander verbunden, die Verbindung zwischen dem 2. und 3. Segment durch eine dehnbare Membran hergestellt, so dass der Hinterleib leicht nach unten gebogen werden kann. Die zahlreichen hierher gehörenden Arten sind durchweg kleine Tiere; alle schmarotzen bei Blattläusen und werden dadurch höchst nütźlich; die ebenfalls in Blattläusen vorkommenden Arten der Cynipidengattung Allotria schmarotzen wahrscheinlich bei den Aphidiinen, würden also Parasiten zweiten Grades sein. Die Unterscheidung der Arten ist sehr schwierig.

1. Kopf kubisch, fast länger als breit. Nervus parallelus aus der Mitte der Brachialzelle. Antennen 24gliedrig. Die einzige Art, D. planiceps Marsh., ist gelblich, oben zum Teil verdunkelt.

Dyscritus Marsh. stitial. 2.

Kopf quer, hinter den Augen nicht verlängert. Nervus parallelus inter-

2. Die 1. Cubitalzelle von der 1. Discoidalzelle geschieden. 3.

Die 1. Cubitalzelle mit der 1. Discoidalzelle vollständig verschmolzen. 5. 
3. Das Cubitalfeld ohne alle Quernerven. Die Larven dieser Gattung verlassen vor der Verpuppung die Blattläuse, während bei den übrigen Aphidiinen die Verwandlung in der Blattlaus selbst erfolgt. Die häufigste Art, $P$. volucre Hal., schmarotzt bei einer grossen Anzahl von Blattlausarten.

Praon Hal.

Vorderflügel mit 3 Cubitalzellen, indem die beiden Cubitalquernerven vorhanden sind. 4.

4. Antennen bei $\$ 0^{7}$ mit nur 11 Gliedern. Hinterleib sitzend oder fast sitzend, beim + hinten zusammengedrückt. Nur wenige Arten.

Ephedrus Hal. (Elassus Wesm.).

Antennen lang, mit 19-22 Gliedern. Hinterleib beim + spatelförmig; das 1. Segment linear. Bei der einzigen Art, T. deltiger Hal., sind Antennenbasis, Beine und der grösste Teil des Hinterleibs gelblich.

Toxares Hal.

5. Hinterleib eiförmig oder rundlich. Antennen $13-16$ gliedrig. Flügel oft getrübt, die Nervatur meist verloschen. Wenige ziemlich seltene Arten.

Hinterleib schmal lanzettförmig. Flügel selten getrübt. 6 .

Monoctonus Hal.

6. Antennen mit 10-13, in der Regel mit 11 Gliedern. Beim $q$ die Hinterleibsspitze mit 2 hornigen, etwas gebogenen Anhängen, welche etwas länger als der Bohrer sind. Stigma ziemlich breit; Radius gegen das Ende erloschen, länger als bei Aphidius. Nur wenige Arten.

Trioxys Hal.

Antennen mit 11-27 Gliedern, in der Regel mit mehr als 13 Gliedern. † ohne hornige Anhänge. Stigma durchschnittlich schmäler, Radius kürzer als bei Trioxys. Zahlreiche Arten. Aphidius Nees (Abb. 28).

\section{Unterfamilie. Paxylommatinae.}

Kopf breiter als der Thorax, mit grossen Augen und Nebenaugen; Clypeus schnabelartig verlängert. Thorax kurz und buckelig. Hinterleib deutlich länger als Kopf und Thorax, gekrümmt, nach hinten verbreitert und zusammengedrückt; das 1. Segment schmal; Hinterleibsende schräg abgestutzt; Bohrer kurz. Die beiden Arten leben bei Ameisen.

Der Cubitus entspringt deutlich hinter dem Ende des 1. Radiusabschnittes; der Radius zerfällt also in 3 Abschnitte. Der hinterste Metatarsus ist kaum ein Drittel länger als die 4 folgenden Glieder zusammen. Die einzige Art, $P$. buccata Breb., ist schwarzbraun mit rötlichgelben Beinen und lebt bei Myrmica scabrinodis und Lasius brunneus.

Paxylomma Breb. (Abb. 29).

Der Cubitus entspringt am Ende des 1. Radiusabschnittes; der Radius zerfällt also nur in 2 Abschnitte. Der hinterste Metatarsus ist doppelt so lang wie die 4 folgenden Glieder zusammen. Die einzige Art, E. cremieri Rom., ist schwarzbraun, Schulterflecken und Schildchen gelblich, Beine rötlichgelb, die hintersten Schienen dunkel; sie wird bis $6 \mathrm{~mm}$ lang und lebt bei Formica fuliginosa und rufa. Eurypterna Först. 


\section{Familie Stephanidae.}

Diese kleine, hauptsächlich in Afrika verbreitete Familie ist in Deutschland nur durch eine einzige, höchst auffallende und höchst seltene Art vertreten. Stephanus bedeutet Kranz oder Krone; gleich einer fünfzackigen Krone stehen nämlich um das vordere Nebenauge 5 spitze Höcker.

Stephanus Jur.

Kopf kuglig; Antennen dünn borstenförmig. Prothorax halsförmig verlängert; Schildchen durch punktierte Linien in 3 Teile geteilt; Metathorax lang, mit grober Skulptur. Vorderflügel mit geschlossener Radial-, Cubital- und Discoidalzelle. Hinterschenkel stark verdickt, unten mit 3 grossen Zähnen. Hinterleib langgestreckt und gestielt, oberhalb der Hinterhüften eingefügt; Bohrer länger als der Körper. Die einzige Art ist schwarz; Wangen weiss gefleckt; Hinterleib rostrot, am Ende schwarz; Länge 8-17 mm; die Art schmarotzt bei Holzkäfern.

Stephanus serrator F. (S. coronatus Panz.).

\section{Familie Evaniidae.}

Die zu dieser kleinen Familie gehörenden Tiere sind unter sich grundverschieden und lassen sich mit Leichtigkeit in 3 Unterfamilien zerlegen; gemeinsam ist allen nur die hohe Einlenkung des Hinterleibs. Evania und Brachygaster schmarotzen bei Blattiden, Gasteruption bei Bienen und Grabwespen und Aulacus bei Holzkäfern und der Holzwespengattung Xiphydria.

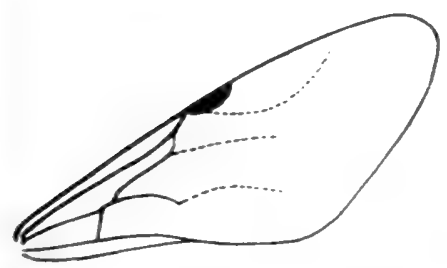

Abb. 34. Vorderflügel von Brachygaster.

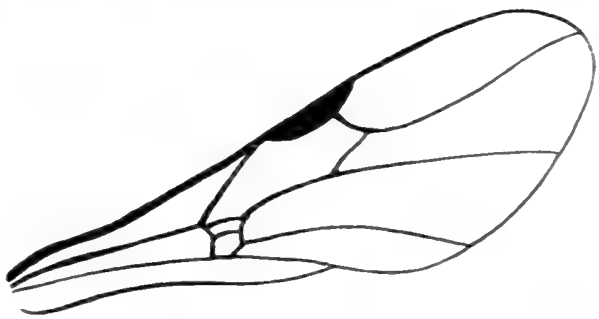

Abb. 35. Vorderflügel von Gasteruption.

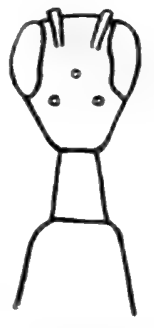

Abb. 36. Kopf v. Gasteraption.

Literatur. Über die Evaniiden haben wir zwei gediegene Arbeiten; die erste, ein umfangreiches klassisches Werk, ist von A. Schletterer unter dem Titel "Die Hymenopteren-Gruppe der Evaniiden" in den Annalen des Hofmuseums in Wien 1889 erschienen; die zweite neuere Arbeit ist von J. Kieffer in „E. André, Species des Hyménoptères, 1905“ veröffentlicht worden.

\section{Übersicht der Unterfamilien und Gattungen.}

1. Körper gedrungen. Antennen in beiden Geschlechtern mit 13 Gliedern. Thorax stark entwickelt, annähernd würfelförmig; Hinterbrust mit einem gegabelten Fortsatz zwischen den Hinterhüften. Hinterleib im Verhältnis zu Kopf 
und Thorax sehr klein, stark zusammengedrückt, mit dem Thorax durch einen dünnen, linearen Stiel verbunden; Bohrer sehr kurz. (1. Unterfam.: Evaniinae) 2.

Körper schlank, namentlich bei Gasteruption lang und dünn. Antennen beim $q$ mit 14, beim $\sigma^{7}$ mit 13 Gliedern. Hinterbrust ohne Fortsatz. Hinterleibsstiel nicht linear, nach hinten allmählich dicker werdend; Bohrer meist lang. 3.

2. Vorderflügel mit geschlossener Cubital-, Discoidal- und Brachialzelle. In den südlichen Ländern von Mitteleuropa 2 Arten: E. appendigaster L. mit glänzendem, fein punktiertem Kopf und schwach getrübten Flügeln; lebt bei Periplaneta americana und orientalis; $E$. punctata Brullé mit dicht und grob punktiertem Scheitel und stark getrübten Flügeln.

Evania F.

Vorderflügel ohne Cubital- und Discoidalzelle; nur an der Basis mit Nerven und Zellen. Die einzige, etwa 3-4 mm lange Art, B. minuta Ol., ist weit verbreitet und an den meisten Orten, wie z. B. hier in Thüringen, nicht selten; sie schmarotzt bei Ectobia lapponica und germanica (Abb. 34).

Brachygaster Leach.

3. Antennen höchstens so lang wie der halbe Körper; Schaft nicht besonders verdickt. Flügel nur mit einer geschlossenen Cubitalzelle. Körper dünn und langgestreckt; Bohrer oft von Körperlänge, am Ende meist weiss. In Deutschland etwa 20 Arten, die man hauptsächlich an heissen Sandwänden, Balkenwerk usw., nicht selten auch auf Doldenblüten antrifft (Abb. 35 und 36). (2. Unterfam.: Gasteruptioninae.) Gasteruption Latr. (Foenus F.).

Antennen deutlich länger als der halbe Körper; Schaft stark verdickt. Vorderflügel mit 2 Cubital- und 2 Discoidalzellen. Körper kräftíg und gedrungen. (3. Unterfam.: Aulacinae) 4.

4. Prothorax an den Schultern abgerundet. Fussklauen unten mit flachem Zahn. In Europa nur A. striatus Jur.; Kopf glatt; Mesonotum und Schildchen quergestreift; Kopf vorn und Beine und Hinterleib grösstenteils rot.

Aulacus Jur.

Prothorax an den Schultern dornartig vorgezogen. Fussklauen unten mit 4 Zähnen; die Spitze der Klauen bildet den 5. Zahn. In Deutschland 4 Arten; alle haben rote Hinterleibsmitte und mit Ausnahme einer einzigen dunkel gefleckte Flügel.

Pristaulacus Kieff.

1. 와. 2 .

Gasteruption Latr.

ธా 23.

2. Bohrer so lang wie der Körper oder noch länger. 3.

Bohrer deutlich kürzer als der Körper. 10.

3. Hinterrand des Scheitels deutlich kragenartig aufgestülpt. 4.

Hinterrand des Scheitels nicht kragenartig, höchstens mit feiner Leiste. 8.

4. Vor dem Halskragen 3 grubenförmige Eindrücke. 5.

Vor dem Halskragen keine Eindrücke. 7.

5. Oberseite des Kopfes vollkommen glatt und glänzend.

Oberseite des Kopfes mit deutlicher Skulptur. 6.

G. Tournieri Schlett.

6. Kopf matt, deutlich quergestreift. Das 2. Geisselglied doppelt so lang wie das erste. Grosse Art von $16-17 \mathrm{~mm}$. G. pedemontanum Tourn.

Kopf matt, höchstens undeutlich quergestreift. Das 2. Geisselglied nur um die Hälfte länger als das erste. Kleinere Art von 9-13 mm. G. terrestre Tourn. 
7. Bohrer mindestens so lang wie der Körper. Kopf matt, fein quergestreift. Mesonotum grob quergestreift. $14-16 \mathrm{~mm}$. G. Thomsoni Schlett. Bohrer $1^{1 / 3}$ so lang wie der Hinterleib. 13.

8. Hinterrand des Kopfes als schwache Leiste vortretend. Mesonotum ziemlich grob, wenn auch nicht scharf quergestreift. $12-13 \mathrm{~mm}$.

G. distinguendum Schlett.

Hinterrand des Kopfes einfach, keine Leiste bildend. Mesonotum wenigstens vorn fein lederartig. 9.

9. Mesonotum durchaus fein lederartig. Kleine Art von $8-9 \mathrm{~mm}$.

G. subtile Thoms.

Mesonotum hinten fein quergestreift. Grössere Art von $12-17 \mathrm{~mm}$.

10. Bohrerklappen am Ende weiss oder rot. 11.

G. Kriechbaumeri Schlett.

Bohrerklappen ganz schwarz. 15.

11. Hinterrand des Scheitels kragenartig aufgestülpt. 12.

Hinterrand des Scheitels einfach. 14.

12. Bohrer etwas kürzer als der Hinterleib, Mandibeln rostrot mit schwarzer Spitze. $10 \mathrm{~mm}$.

Bohrer um ein Drittel länger als der Hinterleib. 13.

G. erythrostomum Dahlb.

13. Seiten des Prothorax regelmässig und ziemlich dicht gestreift. $12-16 \mathrm{~mm}$.

Seiten des Prothorax mit groben Querrunzeln. $14 \mathrm{~mm}$.

G. obliteratum Ab.

G. granulithorax Tourn.

14. Bohrer etwas länger als der Hinterleib. Das 2. Geissclglied doppelt so lang wie das erste. $11-12 \mathrm{~mm}$. $\quad$ G. lugubre Schlett.

Bohrer etwas kürzer als der Hinterleib. Das 2. Geisselglied um die Hälfte länger als das erste. $11-12 \mathrm{~mm}$.

G. paternum Schlett.

15. Bohrer deutlich länger als der Hinterleibsstiel. 16.

Bohrer höchstens so lang wie der Hinterleibsstiel. Kopf matt. 19.

16. Hinterrand des Kopfes deutlich kragenartig aufgestülpt, aber ohne Grübchen. 17.

Hinterrand des Kopfes einfach. Bohrer kürzer als der Hinterleib. 18.

17. Kopf glatt und glänzend. Bohrer so lang wie der Hinterleib. $11-16 \mathrm{~mm}$.

G. pyrenaicum Guér.

Kopf vollkommen matt. Bohrer kürzer als der Hinterleib. 8-16 mm.

G. Freyi Tourn.

18. Thorax grob runzlig; Pronotum zweizähnig. Antennen unten rötlich. $10-12 \mathrm{~mm}$.

G. bidentulum Thoms.

Thorax ziemlich glatt; Pronotum nicht zweizähnig. Antennen ganz schwarz. Kopf sehr glatt und glänzend. 10-12 mm. G. laeviceps Schlett.

19. Körper vorherrschend rostrot. Das 2. Geisselglied nur um die Hälfte länger als das erste. 9-11 mm. G. rubricans Guér.

Kopf und Thorax ganz, Hinterleib zum grössten Teil schwarz. 20.

20. Mesonotum sehr grob und unregelmässig gerunzelt; Schulterecken stark vortretend. $10-12 \mathrm{~mm}$.

G. tibiale Schlett.

Mesonotum fein lederartig, matt. Schulterecken kaum vortretend. 21. 
21. Wangen und Mandibeln lang, letztere rot. Unterseite der Antennen und die Endhälfte der mittleren Segmente rötlich. 10-12 mm.

Wangen kurz oder sehr kurz. 22.

G. longigena Thoms.

22. Kopf hinten einfach gerandet, nicht leistenartig scharf. Mesonotum fein chagriniert. Die häufigste Art. 8-12 mm.

G. affectator L.

Kopf hinten leistenartig scharf gerandet. Mesonotum lederartig runzlig. $9-12 \mathrm{~mm}$.

G. rugulosum $\mathrm{Ab}$.

23. Hinterrand des Kopfes deutlich kragenartig aufgestülpt. 24.

Hinterrand des Kopfes einfach, seltener als Querleiste vortretend. 30.

24. Vor dem Halskragen 3 grubenförmige Eindrücke. 25.

Vor dem Halskragen keine Eindrücke. 27.

25. Oberseite des Kopfes glatt und glänzend. G. Tournieri Schlett.

Oberseite des Kopfes matt. 26.

26. Mesonotum sehr grob und unregelmässig gerunzelt. Kopf um die Ocellen fein quergestreift. Grosse Art, bis $16 \mathrm{~mm}$. G. pedemontanum Tourn.

Mesonotum mit regelmässigen und ziemlich feinen Querstreifen. Kleinere Art, 9-11 mm.

G. terrestre Tourn.

27. Kopf glatt und stark glänzend. Mesonotum sehr grob und unregelmässig gerunzelt. $11-15 \mathrm{~mm}$.

G. pyrenaicum Guér.

Kopf matt, mit Querstreifen. 28.

28. Die hinteren Metatarsen weiss gezeichnet. Hinterleibsmitte zum Teil rot. $14-16 \mathrm{~mm}$.

G. Thomsoni Schlett.

Die hinteren Metatarsen und der Hinterleib ganz schwarz. 29.

29. Das 3. Antennenglied um ein Viertel länger als das zweite. $12-14 \mathrm{~mm}$.

G. obliteratum Ab.

Das 3. Antennenglied um ein Drittel länger als das zweite. $14 \mathrm{~mm}$.

G. granulithorax Tourn.

30. Kopf oben poliert und stark glänzend. Hals kurz. $12 \mathrm{~mm}$.

Kopf oben matt, zuweilen quergestreift. 31 .

G. laeviceps Schlett.

31. Hinterhauptsrand scharf leistenförmig. 32.

Hinterhauptsrand einfach, nicht als scharfe Leiste vortretend. 34.

32. Wangen und Mandibeln lang. Unterseite der Antennengeissel rot.

Wangen und Mandibeln nicht lang. 33.

G. longigena Thoms.

33. Das 2. Geisselglied kaum länger als das erste, das 3. länger als die beiden ersten zusammen. $11-13 \mathrm{~mm}$. $\quad$. distinguendum Schlett.

Das 2. Geisselglied um die Hälfte länger als das erste, das 3. so lang wie die beiden ersten zusammen. $9-10 \mathrm{~mm}$. $\quad G$. rugulosum $\mathrm{Ab}$.

34. Das 3. Geisselglied länger als die beiden ersten zusammen, das zweite kaum länger als das erste. $16 \mathrm{~mm}$.

G. Kriechbaumeri Schlett.

Das 3. Geisselglied kürzer als die beiden vorhergehenden zusammen; das 2. wenigstens um die Hälfte länger als das erste. 35 .

35. Mesonotum sehr grob unregelmässig gerunzelt. Hinterhüften quergestreift. $\quad 10-11 \mathrm{~mm}$.

G. tibiale Schlett.

Mesonotum mit feinerer Skulptur, lederartig. 36. 
36. Mesonotum fein lederartig. Beine grösstenteils schwarzbraun. 8-11 mm. G. affectator L. Mesonotum mit gröberer Skulptur, lederartig runzlig. Beine grösstenteils rot. $9-12 \mathrm{~mm}$.

G. rubricans Guér.

\section{Familie Trigonalidae.}

Diese kleine merkwürdige Familie ist in Europa nur durch eine Gattung mit einer einzigen Art, einem leicht kenntlichen Tiere, vertreten. Die Art hat den Autoren viel Kopfzerbrechen gemacht, man wusste nicht, an welchen Platz im System man sie stellen sollte. Erwähnt wird sie zuerst von Degeer; er rechnet sie zum grossen Genus Sphex. Bereits Spinola weiss nicht recht, was er mit dem Tiere anfangen soll. Wer es zum erstenmal vor die Augen bekömmt, wird es für einen Pompiliden halten, wegen der grossen Ähnlichkeit mit den Agenia-Arten. In der Tat spricht sich auch Taschenberg für eine Zusammengehörigkeit mit dieser Familie aus. Dagegen sprechen nun aber die 2 gliedrigen Trochanteren. Shuckard und Marshall reihen die Gattung bei den Aulacinen ein; Förster schliesslich erhob

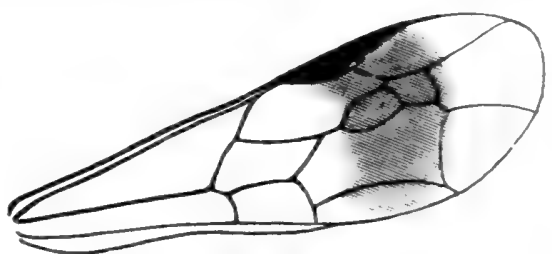

Abb. 37. Vorderflügel von Trigonalys.

Trigonalys zum Rang einer Familie, Diplomorpha, welche Cresson in Trigonalidae umtaufte. Während neuere Autoren geneigt sind, diese kleine Familie den Ichneumoniden anzugliedern, finde ich, wie ich bereits in meinen „Die Hymenopteren Mitteleuropas" gesagt habe, eine grössere Verwandtschaft mit den Mutilliden.

Die einzige in Europa vorkommende Art ist aus den Nestern von Vespa und Polistes gezogen worden.

\section{Trigonalys Westw.}

Kopf gross, annähernd quadratisch, so breit wie der Thorax, oben ziemlich flach; Hinterrand scharf, kragenartig abgeschnürt; Antennen in der Mitte des Gesichts am unteren Rande von vorspringenden Lamellen eingefügt, fast von Körperlänge, fadenförmig, bis hinter die Mitte allmählich verdickt und dann zugespitzt; Schaft dick, oval. Clypeus am Ende leicht ausgerandet; Oberlippe klein, wenig sichtbar, am Ende mit langen Haaren; Mandibeln kräftig, die eine mit 2, die andere mit 3 grossen und spitzen Zähnen. Prothorax glänzend, von oben nicht sichtbar, seitlich bis zu den Flügelschuppen reichend und hier als dreieckige Lamelle vorspringend. Der übrige Thorax grob runzlig punktiert, matt; Mesonotum mit tiefen, mit Querleisten versehenen Parapsidenfurchen, beiderseits neben dem Rande mit einer glatten Längsschwiele; Schildchen flach; Metathorax konvex, mit einer ziemlich tiefen Längsfurche. Vorderflügel mit ziemlich grossem Stigma; Radius gleichmässig gekrümmt; von den 4 vollständigen Cubitalzellen ist die 1. etwa so gross wie die 4., während die beiden mittleren gleich gross sind, die 2. ist oben kurz gestielt; der 1. rücklaufende Nerv mündet nicht weit vor dem Ende der 1. Cubitalzelle, der 2. ist mit dem 3. Cubitalquernerv interstitial oder mündet kurz dahinter. Beine schlank wie bei einem Ichneumon; Trochantern 2 gliedrig; die hintersten Schiensporen fast die Mitte des Metatarsus erreichend; Fussklauen am Ende gespalten. Hinter- 
leib oben flach, glänzend, fein und zerstreut punktiert, nach vorn verschmälert, nach hinten zugespitzt und eingebogen; das 1. Rückensegment an der Basis mit grosser ovaler Grube; die folgenden Segmente wenig voneinander abgesetzt. Das $\sigma^{7}$ ist schlanker und hat an der Aussenseite der mittleren Antennenglieder, etwa vom 9. oder 10. an, längliche, glänzende Erhabenheiten (Tyloiden).

Das ganze Tier schwarz, dünn gelblich oder graulich behaart; die vorderen Schienen und Tarsen zum Teil gelblich. Flügel mit breiter dunkler Querbinde, die in der Basalhälfte der Radialzelle fleckenartig schwarz auftritt; Stigma gelb. Länge 9-12 mm. Das Tier ist weit verbreitet, aber überall selten; an bestimmte Fundplätze ist es nicht gebunden; man bekommt es meistens beim Abstreifen von Gras; einmal fand ich es auf Eichengebüsch (Abb. 37).

Trigonalys hahni Spin. (T. nigra Westw.).

\section{Chalcididae.}

\section{Charakteristik.}

Die Chalcididen bilden die arten-, wenn auch nicht die formenreichste, auf jeden Fall aber die schwierigste Gruppe der Hymenopteren. Ihren Namen haben sie erhalten von der vorwiegend metallischen, meist heller oder dunkler grünen Färbung des Körpers; welch reizende Objekte für die Sammlung würden viele sein, wenn sie nur grösser wären. Der Unterschied von den Proctotrupiden ist in der Tabelle angegeben, gleichwohl ist eine scharfe

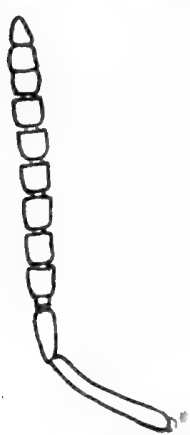

Abb. 38. Fübler von Dibrachys Boucheanus.

Grenze zwischen beiden Familien nicht zu ziehen, so kann z. B. die Gruppe der Mymarinen zu beiden gestellt werden.

Kopf meist quer und von Thoraxbreite; Augen gross, oval, niemals ausgerandet; Antennen gekniet, indem der Schaft mehr oder weniger lang ist und die Geissel damit einen Winkel macht; zwischen dem Pedicellus und der eigentlichen Geissel befinden sich 1-3 sehr kleine und schmale, oft sehr schwer erkennbare Zwischenglieder, die man als Ringel oder Ringglieder (annelli) bezeichnet; die Antennen mancher Männchen sind durch besondere .Bildungen ausgezeichnet, namentlich durch Äste oder wirtelige Behaarung. Von Wichtigkeit für die Systematik ist die Bezahnung der Mandibeln; dieselben können 2-4 Endzähne besitzen; die Zahl der Zähne ist nicht selten bei der rechten und linken Mandibel ungleich.

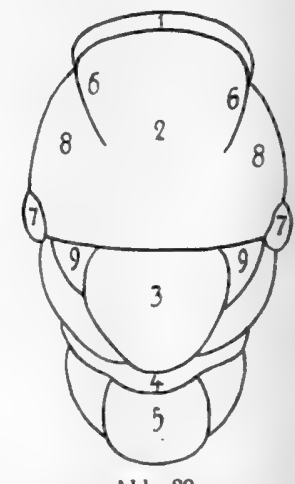

Abb. 39.

Thorax von Pteromalus. 1 Prothorax; 2 Mesothorax 3 Schildchen; 4 Dorsellum 5 Metathorax; 6 Parapsidenfurchen; 7 Tegulae; 8 Scapulae; 9 Axillae.

Der Prothorax reicht seitlich nicht bis zur Flügelbasis; meist ist er kurz und quer, seltener rechteckig oder quadratisch, zuweilen nach vorn halsartig verschmälert; ist das Pronotum vorn kragenartig abgesetzt, so bezeichnet man diesen Teil als Collare. Die Brustseiten sind gewöhnlich durch Furchen geteilt, seltener ungeteilt, wie bei den Encyrtinen und Eupelminen. Wie bei den Ichneumoniden bildet der Metathorax durch seine Form und Skulptur sehr gute Unterscheidungsmerkmale. Von höchster Wichtigkeit für die Systematik ist die Nervatur des Vorderflügels; dieselbe ist sehr einfach. 
Der einzige Nerv, die Subcosta oder der Submarginalnerv, begleitet zunächst den Flügelrand bis etwas vor der Mitte, um sich dann mit ihm zu vereinigen; letzteren Teil bezeichne ich als Marginalnerv; am Ende desselben erstreckt sich ein am Ende meist knopfartig verdickter Ast schräg in die Flügelfläche; er wird als Radius bezeichnet; die Fortsetzung des Marginalnervs jenseits des Radius führt die Bezeichnung Postmarginalnerv. Die verschiedenen Längen dieser Nerven bilden eines der wichtigsten Hilfsmittel für die Systematik. Die Beine bieten ebenfalls gute Merkmale; namentlich ist es die Form und Zahl der Schienensporen und die Zahl der Tarsenglieder, auf welche es bei der Einteilung der Hauptgruppen ankommt. Was den Hinter-

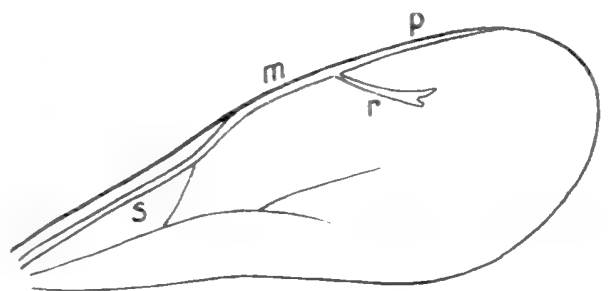

Abb. 40. Vorderflügel von Lamprotatus. s Subcosta; m Marginalnerv; r Radius; p Postmarginalnerv. leib betrifft, so dreht sich die Hauptfrage darum, ob er gestielt oder sitzend ist, eine scharfe Grenze lässt sich freilich nicht ziehen. Der Bohrer entspringt, wie bereits beim Unterschiede von den Proctotrupiden betont wurde, etwas vor der Hinterleibsspitze; er ist in der Regel versteckt oder ragt nur kurz vor, doch finden sich auch zahlreiche Fälle, wo der Bohrer eine bedeutende Länge hat, wie z. B. bei der Unterfamilie der Toryminen.

\section{Lebensweise der Chalcididen.}

Fast alle Chalcididen sind Schmarotzer, nur eine Gruppe aus der Unterfamilie der Eurytominen, speziell die Gattung Isosoma, lebt in Pflanzen und erzeugt gallenähnliche Gebilde. Alle Insektenordnungen werden von diesen winzigen Parasiten heimgesucht, am meisten haben es diese jedoch auf die Lepidopteren abgesehen. Es werden nicht bloss die Larven und Puppen der verschiedenartigsten Insekten, sondern auch die Eier derselben angestochen. Ihre Hauptrolle spielen die Chalcididen jedoch als Schmarotzer zweiten und dritten Grades, und zahllose Entdeckungen sind auf diesem Gebiete noch zu machen. Wie wir unter den Ichneumoniden Arten haben, die unter Wasser tauchen, um ihre Opfer aufzusuchen, so haben wir auch unter den Chalcididen Arten, die auf dieses Element angewiesen sind, ganz besonders ist Prestrvichia aquatica Lubbock zu erwähnen, die mit ihren gewimperten Flügeln geschickt im Wasser umherrudert und die Eier von allerlei Wasserinsekten ansticht. - Bei der Verwandlung verfertigen die Larven keine Kokons, sondern werden zu sogenannten Mumienpuppen. Bei ihrer Winzigkeit können natürlich eine grosse Anzahl von Individuen bei einem einzigen Wirte schmarotzen, und es drängt sich da oft die Frage auf, ob die Eier von einem oder mehreren Weibchen gelegt worden sind. Die entwickelten Wespen entschlüpfen nur durch ein oder nur durch wenige winzige Löcher.

Es ist nicht so leicht, den Nutzen der Chalcididen genau festzustellen. Wenn die so schädlichen Schildläuse fast einzig und allein nur durch Chalcididen vernichtet werden, und zwar durch die formenreichen, zum Teil auch farbenprächtigen Arten der Encyrtinen, wenn zahllose Borkenkäfer diesen winzigen Feinden zum Opfer fallen, so liegt der Nutzen ja klar, aber ich habe schon oben erwähnt, dass die Chalcididen, wenigstens nach meinen Untersuchungen, meist sekundäre Schmarotzer sind, und in diesem Falle würde ihre Wirksamkeit doch nur als eine schädliche zu bezeichnen sein. Um ein Beispiel anzuführen, will ich erwähnen, dass gerade die nützlichen Microgaster-Arten stark von Chalcididen heimgesucht werden. 


\section{Sammeln und Präparieren der Chalcididen.}

Bei dem gewaltigen Arten- und Individuenreichtum dieser Familie ist es eine leichte Aufgabe, sich umfangreiches Material zu verschaffen, die Schwierigkeiten kommen erst, wenn es gilt, das Material zu verarbeiten. Wer sich den gerade bei den Chalcididen so mühevollen Weg des Determinierens erleichtern und wer den Wert seiner Sammlung erhöhen will, dem rate ich dringend, sich der Zucht dieser Tiere zu widmen. Bei gefangenen Exemplaren muss man Stück für Stück vornehmen, bei gezüchteten weiss man, dass man es nur mit vielen Exemplaren einer oder weniger Arten zu tun hat; trotz oft recht merklicher Unterschiede wird man doch bald die Zusammengehörigkeit erkennen. Ich will ein recht schlagendes Beispiel anführen. Mayr hat die Chalcididengattung Eurytoma nur nach gezüchteten Exemplaren bearbeitet, er unterscheidet nur eine kleine Anzahl Arten; nun vergleiche man damit die Menge Arten dieser Gattung, welche Thomson nach gefangenen Stücken aufstellt. Auf dem Papiere machen sich ja diese Unterschiede zwischen den einzelnen Arten ganz gut, fängt man aber an, Exemplare darnach zu bestimmen, so wird man bald finden, wie wenig zuverlässig und wie schwankend die angegebenen Unterscheidungsmerkmale sind. Statt also Hunderte von meist wertlosen, weil unbestimmbaren Individuen einzufangen, ist es weit ratsamer, sorgfältige Zuchten vorzunehmen. Anfangs tut man gut, nur solche Wirtstiere zur Zucht zu benützen, welche leicht einzutragen sind, und zwar tut man das zu einer Zeit, wo die Schmarotzer sich schon so weit entwickelt haben, dass sie nahe dem Ausschlüpfen sind, das bezieht sich besonders auf das Züchten aus Gallen, Schwämmen, Blattminen, Stengeln, Rinden, Tannenzapfen usw. Die beste Zeit zum Eintragen würde bei allen diesen Sachen Ausgang Winter oder Anfang Frühjahr sein. Am leichtesten und lohnendsten ist die Zucht aus Pflanzengallen, ich meine darunter nicht allein die bekannten Eichen-, Rosen- und Weidengallen, sondern alle möglichen Deformationen an Pflanzen, namentlich die durch Gallmücken (Cecidomyia-Arten) hervorgerufenen; gerade diese liefern eine grosse Anzahl von Insassen. Die Gallen tut man am besten in Einmachgläser, welche oben mit feiner Gaze zugebunden sind; von Zeit zu Zeit sieht man nach, ob etwas ausgekommen ist. Gallen, die nicht feucht gehalten zu werden brauchen, kann man auch einfach in gutschliessende grössere oder kleinere Kästen tun, die man mit weissem Papier auskleidet, um auch die winzigsten Sachen leicht erkennen zu können. Hochinteressant ist auch die Zucht aus Blattläusen. Hier trägt man aber nur Blattläuse ein, denen man ansieht, dass sie von Schmarotzern besetzt sind; diese angestochenen Blattläuse sind leicht zu erkennen an ihrem glasig aufgetriebenen, gelblich oder braun gefärbten Körper; sie sitzen meist regungslos zwischen den übrigen Blattläusen. Man erhält bei der Zucht vornehmlich die kleinen Braconiden aus der Unterfamilie der Aphidiinen und die wahrscheinlich bei diesen schmarotzenden Cynipiden aus der Unterfamilie der Allotriinen. Die interessanteste Ausbeute habe ich gehabt bei der Zucht von Schildläusen, bei diesen schmarotzt die wunderbare formen- und farbenreiche Gruppe der Encyrtinen; man könnte sie die Kolibris unter den Chalcididen nennen. Die Zucht ist sehr einfach; man braucht nur die mit Schildläusen besetzten Pflanzenteile in Kästen zu tun oder aber, wenn man Massenzucht treiben will, man bringt so viel Material als möglich in ein Zimmer, am besten ein solches mit nur einem Fenster; es gehört freilich ein gutes Auge dazu, die Tiere am Fenster zu erkennen und einzufangen; nun, gute Augen muss jeder haben, der sich mit Chalcididen beschäftigt.

Das Töten der eingefangenen oder gezüchteten Tiere geschieht wie bei den Ichneumoniden am besten mit Schwefeläther. Einzelne Exemplare töte ich 
in einem Probierzylinder mit Schwefeldampf; ich befestige in dem Korke ein abgekürztes, zugespitztes Schwefelholz, brenne es an und verschliesse damit das Gläschen; es genügt schon ein kleiner Teil Schwefeldampf. Ich spiesse meine Chalcididen, soweit es nur irgend geht, mitten durch das Mesonotum an Silbernadeln; die ganz feinen Sachen lege ich auf den Rücken und spiesse sie von unten, in der Vertiefung der Mittelbrust gleitet die Nadelspitze nicht so leicht $a b$, diese darf nur ganz wenig aus dem Mesonotum hervorragen. Die gespiessten Exemplare kommen auf Klötzchen aus dem Marke der Kerria japonica, wie es bei den Ichneumoniden angegeben ist. Lockere Nadeln können unten leicht mit einem Tröpfchen Klebstoff befestigt werden. Arten, die sich nicht gut anstechen lassen, werden auf schmale und spitze Dreiecke von Kartonpapier geklebt; man bedenke immer dabei, dass diese reizenden und zierlichen Tiere auch recht elegant präpariert sein müssen; man nehme also, wie gesagt, nicht breite Dreiecke, wie man sie oft zu sehen bekommt, sondern recht schmale, und stecke sie an feine Stahlnadeln und dann befestige man das Tier nur mit der äussersten Hinterleibsspitze, indem man mit einer Nadelspitze nur einen winzigen Teil Gummi aufträgt.

\section{Literatur über Chalcididen.}

Der Ruhm, die Erforschung dieser schwierigen Gruppe der Hymenopteren zuerst in wissenschaftliche Bahnen gelenkt $\mathrm{zu}$ haben, es war dies in den dreissiger Jahren des vorigen Jahrhunderts, gebührt den Engländern Westwood, Haliday und wohl auch Walker, letzterer freilich hat auch viel Unbrauchbares geliefert. Gleichzeitig war es Nees von Esenbeck, der den Braconiden, Chalcididen und Proctotrupiden sein klassisches, wenn auch jetzt längst überholtes Werk, Hymenopterorum Ichneumonibus Affinium Monographiae, 1834, widmete. In den vierziger und fünfziger Jahren erschien dann Ratzeburgs hervorragendes Werk über die Ichneumonen der Forstinsekten, in welchem auch die Chalcididen behandelt sind. Während die vorher genannten Werke nur für eingehendere Arbeiten noch eingesehen werden müssen, bildet Ratzeburgs Werk auch heute noch die umfassendste Arbeit über die durch Zucht erhaltenen Ichneumonen und ist deshalb für jeden, der sich mit diesem Kapitel beschäfttigt, unentbehrlich. Die Grundzüge der heutigen Systematik, enthaltend die Übersicht der Unterfamilien und Gattungen, sind niedergelegt in Försters Schrift: Hymenopterol. Studien, 2. Heft, 1856. Ein neueres, abgeschlossenes Werk, das auch die Arten behandelt, ist Thomsons Bearbeitung der schwedischen Chalcididen: Hymenoptera Scandinaviae, Tom. IV und V, Pteromalus, Lund 1875 und 1878. Die umfangreichste Arbeit über die Chalcididen ist meine jüngst in "Wytsman, Genera Insectorum" erschienene Abhandlung; auf 550 Quartseiten gibt sie eine tabellarische Übersicht und die ausführlichen Diagnosen sämtlicher Gattungen, sowie eine Aufzählung aller bisher beschriebenen Arten der Erde. Beigefügt sind 8 Tafeln mit zum Teil kolorierten Abbildungen. - Ein Anfänger würde wohl angesichts des ungeheueren Gebietes, das sich vor ihm eröffnet, und der Schwierigkeit, die bisher angeführte Literatur zu benützen, zu bald den Mut verlieren; zum Glück besitzen wir 2 Schriften, die so recht geeignet sind, den Ungeübten in dies schwierige Studium einzuführen und ihn mit den beiden schönsten Gruppen dieser zierlichen Familie sowohl systematisch als biologisch bekannt zu machen; es sind die beiden Publikationen Mayrs: „Die europäischen Torymiden, Wien 1874" und „Die europäischen Encyrtiden, Wien 1876“. 


\section{Systematik der Chalcididen.}

Die früheren Autoren, wie Walker und Förster, teilten die Chalcididen nach der Zahl der Tarsenglieder in . 3 Gruppen ein, Pentameren, Tetrameren und Trimeren. Nun war aber der Übelstand, dass bei einigen Gattungen die Zahl der Tarsenglieder bei den Geschlechtern verschieden ist; so haben die Weibchen von Tetracampe und Platynochilus 5, die Männchen nur 4 Tarsenglieder. Thoms on sah sich deshalb nach einem anderen HauptunterscheidungsMerkmal um und fand es in der Beschaffenheit der vordersten Schiensporen. Danach zerfallen die Chalcididen in 2 Sektionen, von denen die erstere die Pentameren, die zweite die Tetrameren und Trimeren enthält.

\section{Übersicht der Unterfamilien.}

1. Vorderschienen mit einem grossen gekrümmten Endsporn. Antennen meist vielgliedrig. Marginalnerv kürzer als die Entfernung von ihm bis zur Flügelbasis; Radius meist lang. Tarsen 5 gliedrig. (1. Sektion: Macrocentri) 2.

Vorderschienen mit einem kurzen, dünnen und geraden Sporn. Antennen meist weniggliedrig. Marginalnerv in der Regel lang, oft länger als die Entfernung zwischen ihm und der Flügelbasis; Radius und Postmarginalnerv gewöhnlich kurz, letzterer nicht selten ganz fehlend. Tarsen 4-, selten 3 gliedrig, nur bei den of der Gattungen Tetracampe und Platynochilus 5 gliedrig. (2. Sektion: Microcentri) 12.

2. Hinterschenkel stark verdickt, unten meist mit Zähnen oder Dornen; Hinterschienen stark gekrümmt und am Ende in eine Spitze ausgezogen; Hinterhüften stark verlängert. Die europäischen Arten nicht metallisch gefärbt. 3 . gerade. 4.

Hinterschenkel höchst selten verdickt; Hinterschienen mehr oder weniger

3. Vorderflügel wie bei den Faltenwespen der Länge nach gefaltet. Bohrer auf den Rücken geschlagen. Grosse, schwarz und gelb gezeichnete Arten, welche fast nur im Süden vorkommen; sie schmarotzen bei Bienen.

Leucospidinae.

Vorderflügel nicht gefaltet. Bohrer, wenn vorragend, nicht auf den Rücken gebogen. Kleinere, schwarze Arten mit hell gezeichneten Beinen.

4. Thorax stark entwickelt und hoch gewölbt. 5.

Chalcidinae.

Thorax nicht besonders entwickelt und nicht stark gewölbt. 6 .

5. Radius nicht entwickelt. Schildchen von besonderer Bildung, hinten oft gegabelt. Hinterleib lang gestielt, seitlich zusammengedrückt; das 2. Segment schliesst die folgenden ein. In Mitteleuropa 2 Gattungen; sie sind schwarzgrün gefärbt und leben bei Ameisen.

Eucharidinae.

Radius kurz, aber deutlich. Hinterleib fast sitzend, oft dreieckig; das 2. und 3. Segment nehmen den grössten Teil des Hinterleibs ein. Körper kurz und gedrungen, grubig punktiert, metallisch grün, blau oder golden gefärbt.

Perilampinae.

6. Pronotum stark entwickelt, fast quadratisch oder rechteckig, seltener nach vorn konisch verlängert. 7 .

Pronotum nicht besonders entwickelt, kurz und quer. 9.

7. Hinterhüften gross und lang, weit grösser als die Vorderhüften, 3 seitig zusammengedrückt oder wenigstens oben mit scharfer Kante. Radius sehr kurz, 
der Knopf dicht am Flügelrande sitzend. Bohrer fast durchweg weit vorragend. Lebhaft grün, blau oder golden, selten schwarz gefärbte Arten. Toryminae.

Hinterhüften wenig grösser als die Vorderhüften; wenn viel grösser, dann Prothorax und Hinterbeine, ebenso der Postmarginalnerv stark verlängert. Bohrer selten vorragend. 8.

8. Pronotum quadratisch oder rechteckig. Hinterleib beim $q$ rundlich oder oval, seltener mehr lanzettlich, von der Seite zusammengedrückt; das letzte Bauchsegment etwas vorspringend. Körper schwarz oder zum Teil gelb, nicht metallisch.

Eurytominae.

Pronotum konisch verlängert. Hinterleib oben flach. Vorder- oder Hinterschenkel geschwollen oder Hinterbeine verlängert. Körper metallisch.

Cleonyminae.

9. Mittelbrustseiten wenigstens beim $q$ nicht durch Furchen oder Gruben geteilt, schildförmig erhaben. Sporn der Mittelschienen zum Springen dienend, deshalb meist lang und kräftig oder an der Basis erweitert. 10.

Mittelbrustseiten durch Furchen oder Gruben geteilt, nicht schildförmig erhaben. Sporn der Mittelschienen meist gewöhnlich, nicht stark. 11.

10. Marginalnerv lang. Mesonotum niedergedrückt, mit mehr oder weniger deutlichen Parapsidenfurchen. Scheitel hinten nicht gerandet. Körper gestreckt, metallisch grün oder blau.

Eupelminae.

Marginalnerv kurz, in den meisten Fällen punktförmig. Mesonotum leicht gewölbt, ganz ohne Parapsidenfurchen. Scheitel hinten meist scharf gerandet. Körper nicht gestreckt, sondern mehr oder weniger gedrungen, oft sehr klein, vielfach ohne metallische Färbung, nicht selten hell gezeichnet. Encyrtinae.

11. Die hintersten Schienen mit 2 Endsporen, sehr selten nur mit einem; in diesem Falle ist der Radiusknopf gross und rund und der Bohrer ist sehr lang.

Miscogasterinae.

Die hintersten Schienen nur mit 1 Endsporn. Bohrer höchst selten lang; in diesem Falle ist der Radiusknopf klein. Diese und die vorhergehende Familie sind schwer voneinander zu unterscheiden, noch schwieriger ist die Trennung der Gattungen und von den zahlreichen Arten sind nur wenige klargestellt.

Pteromalinae.

12. Hinterhüften sehr gross und verbreitert; Hinterschenkel flach zusammengedrückt; Tarsen sehr lang. Mittelbrustseiten ungeteilt und nicht eingedrückt. Marginalnerv sehr lang, Radius sehr kurz oder fehlend. $\sigma^{\text {t }}$ mit ästigen Antennen. drückt. 13.

Hinterbeine von normaler Bildung. Mittelbrustseiten geteilt und einge-

13. Tarsen mit 4, höchst selten mit 5 Gliedern. Vorderflügel nicht kurz und breit, mit normaler Nervatur und Behaarung. Postmarginalnerv zuweilen fehlend.

Tarsen mit 3 Gliedern. Vorderflügel kurz und breit, am Ende breit abgerundet, in der Regel reihenweise behaart. Winzige und seltene Tiere.

Trichogramminae.

\section{Unterfamilie. Leucospidinae.}

In Europa nur die Gattung Leucospis F. Die auffallenden, schwarz und gelb gefärbten Tiere sind von den übrigen Chalcididen ganz verschieden und erinnern mehr an Faltenwespen; sie schmarotzen in den Nestern von Bienen. Bis in die südliche Schweiz, z. B. Sierre im Rhonetal und das südliche Tirol, 
z. B. Bozen reichen 3 Arten; die grosse $L$. gigas F., die durch den kolbigen, oben eingedrückten Hinterleib ausgezeichnete $L$. Biguetina Jur. und die kleinere L. dorsigera F.; letztere geht vielleicht noch weiter nach Norden.

\section{Unterfamilie. Chalcidinae.}

Eine in den heissen Ländern in zahlreichen Gattungen und Arten vorkommende Unterfamilię. In Mitteleuropa, speziell Deutschland, finden sich folgende Gattungen:

1. Hinterleib lang gestielt. 2.

Hinterleib kurz gestielt oder sitzend. 3.

2. Mittelschienen ohne Endsporn. Thorax einfarbig schwarz. In Mitteleuropa 3 Arten: S. sispes L. Hinterschenkel rot; schmarotzt bei Stratiomys-Arten; $S$. myrifex Sulzer, Hinterschenkel und Hinterleibsstiel gelb und $S$. melanaris Dalm., Tegulä und 3 Makeln der Hinterschenkel weisslich. Smicra Spin.

Mittelschienen mit deutlichem Endsporn. Thorax und Beine gelb gezeichnet. Hinterleibsstiel kürzer und kräftiger als bei Smicra. Die einzige Art, $S$. xanthostigma Dalm., scheint mehr in Nordeuropa vorzukommen.

Spilochalcis Thoms.

3. Antennen in der Mitte der Stirn' eingefügt. Die hintersten Schienen an der Spitze dornartig vorgezogen. Hinterschenkel unten mit zahlreichen Zähnchen. In Deutschland verschiedene Arten; sie leben vorwiegend in Schmetterlingsraupen.

Antennen unmittelbar über dem Clypeus eingefügt.

4. Metathorax hinten an den Seiten nicht zahnartig vorspringend. Körper gestreckt, nicht bucklig. Hinterschenkel mit etwa 12 kleinen Zähnen. In Deutschland nur $H$. armata Panz. Haltichella Spin.

Metathorax hinten beiderseits mit breiten Zähnen. Körper gedrungen, stark bucklig. Marginal- und Postmarginalnerv, sowie Radius nicht entwickelt. Die einzige, höchst seltene Art, H. Graffi Ratzeb., lebt in den Larven von Ameisenlöwen; durch Zucht würde das Tier am ehesten zu erhalten sein.

Hybothorax Ratzeb.

\section{Unterfamilie. Eucharidinae.}

Wie die vorhergehende Unterfamilie hat auch diese ihre Hauptverbreitung in den heissen Ländern, namentlich Südamerika; es finden sich dort die wunderlichsten Formen, namentlich zeigt das Schildchen die merkwürdigsten Bildungen. Die Arten scheinen ausschliesslich bei Ameisen zu schmarotzen. Von den zahlreichen Gattungen gehen nur 2 bis Mitteleuropa:

Schildchen einfach, nicht 2 zähnig. Antennen perlschnurförmig. Körper dunkelgrün, kräftig und gedrungen; Hinterleibsstiel von mässiger. Länge. Die einzige Art, E. adscendens $\mathrm{F}$, geht bis nach Nordthüringen. Eucharis Latr.

Schildchen hinten tief gabelförmig geteilt. Thorax erzgrün, mit Goldglanz, der langgestielte, stark seitlich zusammengedrückte Hinterleib schwarz. Als nördlichster Fundort der einzigen Art, S. cynipiformis Rossi, ist mir Bozen bekannt; dort ist das auffallende Tier an manchen Stellen nicht selten.

\section{Unterfamilie. Perilampinae.}

Stilbula Spin.

Als typische Gattung ist Perilampus Latr. zu erwähnen; die wenigen übrigen Gattungen kommen sehr selten vor. Der Körper bei Perilampus ist kurz und gedrungen, die Stirn tief ausgehöhlt, Antennen kurz und dick; Thorax 
mit grober, fingerhutähnlicher Skulptur; der Hinterleib ist wie poliert, sitzend, kleiner als der Thorax. Die wenigen Arten schmarotzen hauptsächlich bei Schmetterlingen.

\section{Unterfamilie. Toryminae.}

Die Toryminen sind entschieden die schönste Gruppe der Chalcididen; die zahlreichen Arten sind fast alle prächtig grün, blau oder zum Teil golden gefärbt, nur selten tritt ein düsteres Schwarz auf. Da wir die ausgezeichnete monographische Bearbeitung durch Mayr besitzen, eignet sich diese Unterfamilie ganz besonders zu einem Spezialstudium, zumal auch die Zucht der Tiere nicht viel Mühe macht. Aus den erwähnten Gründen habe ich diese Gruppe auch hier etwas ausführlicher behandelt.

Die Toryminen leben meistens in Gallen oder sonstigen Pflanzendeformationen, welche von Insekten bewohnt sind, nur einige Arten der Gattungen Monodontomerus und Megastigmus legen ihre Eier in freilebende Insekten und zwar Hautflügler oder Schmetterlinge. Um den oft tief unter der Oberfläche sitzenden Gallenbewohner zu treffen, besitzen die meisten Toryminen einen langen Bohrer und es steht die Länge des Bohrers zur Dicke der Galle stets im richtigen Verhältnis; doch ist erwiesen, dass auch kleine Gallen von Arten mit langem Bohrer, wie z. B. von Torymus regius, angestochen werden; möglicherweise geschieht dies nur dann, wenn die entsprechenden Gallen nicht vorhanden sind.

\section{Übersicht der Gattungen.}

1. Mesonotum mit deutlichen Parapsidenfurchen. Hinterleib meist poliert, ohne Querreihen von tief eingedrückten Punkten; Bohrer deutlich vorstehend, oft sehr lang. 2.

Mesonotum ohne deutliche Parapsidenfurchen. Hinterleib beim $q$ spitz konisch, mit Querreihen tief eingedrückter Punkte; Bohrer nur kurz vorstehend. Körper ziemlich bucklig. Alle Arten leben in Gallen. (5. Tribus: Ormyrini.)

2. Die hintersten Schenkel stark geschwollen, mit 6-8 Zähnen; die hintersten Schienen stark gekrümmt. Radius sehr kurz, Knopf fast sitzend. Die Gattung bildet ein Mittelglied zwischen den Chalcidinen und Toryminen. Im Gebiete nur $P$. pachymerum Walk., das in den Eiern der bekannten Gottesanbeterin, Mantis religiosa L., lebt. (1. Tribus: Podagrionini.)

Podagrion Spin.

Die hintersten Schenkel nicht auffallend verdickt; die hintersten Schienen nicht gekrümmt. 3.

3. Hinterschenkel am Unterrande gekerbt oder mit 1 oder 2 Zähnen, meist schwach verdickt. (2. Tribus: Monodontomerini) 4.

Hinterschenkel einfach, am Unterrande weder gekerbt, gesägt oder gezähnt. Radius sehr kurz, Knopf fast sitzend. 8.

4. Schildchen an der Spitze ohne eingedrückte Querlinie. 5.

Schildchen an der Spitze mit eingedrückter Querlinie. 7.

5. Färbung lebhaft blau oder blaugrün. Flügel hyalin. Hinterschenkel unten mit einem feinen Zähnchen. Die hierher gehörenden 5-6 Arten sind kleine Tiere mit kurzem Bohrer. Von Torymus unterscheiden sie sich durch das Zähnchen an der Unterseite der Hinterschenkel.

Holaspis Mayr.

Färbung schwarz oder dunkelgrün oder dunkelviolett. Flügel getrübt. 6.

6. Hinterleib braun oder schwarzbraun, auch Kopf und Thorax meist schwarz. Augen behaart. Hinterrand des 1 . Segments nicht eingeschnitten. Die hintersten 
Schenkel ohne oder mit ganz, undeutlichem Zahn. Die eine der beiden Arten, $O$. stigma $\mathrm{F}$., kann man in Anzahl aus den bekannten Rosengallen züchten; die andere, weit seltenere Art, O. tibialis Först., lebt in den Gallen von Aulax potentillae.

Oligosthenus Först.

Kopf und Thorax dunkelgrün oder dunkelblau; Hinterleib dunkelviolett, beim + an der Basis rötlich. Hinterrand des 1. Segments beim + winkelig ausgeschnitten. Die hintersten Schenkel mit deutlichem Zahne. Einzige Art C. caliginosus Walk.

Cryptopristus Först.

7. Mesonotum mit grober, fingerhutähnlicher Skulptur. Hinterrand des 1. Segments ausgeschnitten. Bohrer meist von Körperlänge. Körper vorwiegend blau und rotgolden gefärbt. Die 3 in Europa vorkommenden Arten schmarotzen bei in Brombeerstengeln nistenden Grabwespen, namentlich der Gattung Pemphredon. In Deutschland hauptsächlich D. calcaratus Nees. Kopf und Thorax blau, Hinterleib grüngolden.

Diomorus Walk.

Mesonotum mit feinerer Skulptur. Körper weniger lebhaft gefärbt, trüb erzgrün oder blaugrün. Flügel nicht selten fleckig getrübt. Hinterrand des 1. Segments gerade. Bohrer meist kurz. Die 6-8 Arten leben vorwiegend bei Schmetterlingen, man fängt sie nicht selten auch an Stubenfenstern; die eine Art, M. nitidus Newp., zieht man häufig aus den Nestern der bekannten Mauerbiene, Chalicodoma muraria $\mathrm{F}$.

Monodontomerus Westw.

8. Schildchen vor der Spitze durch eine stark vertiefte Querlinie geteilt und hinter derselben ganz glatt. Bohrer mindestens von Hinterleibslänge, meist länger. Alle Arten von lebhaft grüner oder blauer Färbung. Die bekannteste Art, S. saphirina Boh., kann man in Menge aus den Schwammgallen von Biorrhiza terminalis $\mathrm{F}$. ziehen.

Schildchen vor der Spitze ohne vertiefte Querlinie. 9.

9. Antennen mit 2 Ringeln. Färbung trübgrün; Kopf und Thorax fast glanzlos. Flügel hyalin. Bohrer kurz. Die beiden bekannten Arten sind höchst selten; die eine, L. papaveris Först., lebt in den Gallen von Aulax papaverix Perr. und jaceae Schenck, die andere, L. Mayri Wachtl, in den Gallen von Aulas scorzonerae Gir.

Lochites Först.

Antennen mit nur 1 Ringel. Flügel oft getrübt. Bohrer nicht selten von Körperlänge. Zahlreiche lebhaft grün, blau, golden, kupferfarbig usw. gefärbte Arten.

Um dem Anfänger die Möglichkeit zu bieten, seine Fänge oder Zuchten bis zu den Arten bestimmen zu können, gebe ich im nachfolgenden eine Bestimmungstabelle der Weibchen der an prachtvollen Arten so reichen Gattung Torymus. Gefangene Männchen sind schwer zu bestimmen, man achte also auf das $\mathrm{Zu}$ sammenfliegen der Geschlechter oder, was das sicherste ist, man suche beide durch Zucht zu erlangen. Ich bringe um so lieber diese Tabelle, als in der Monographie von Mayr eine solche nicht gegeben ist.

\section{Torymus Dalm.}

우

1. Hinterleibsbasis mit einer deutlichen gelben Querbinde. 2.

Hinterleibsbasis ohne gelbe Querbinde. 8.

2. Das 2. Geisselglied mehr als doppelt so lang wie dick. Hüften ganz gelb. Flügel mit einer bräunlichen Wolke. Bohrer etwas kürzer als der Körper. 
Erzgrün, Hinterleibsende kupferrot. Aus den von Hormomyia fagi herrührenden Buchengallen.

T. fulgens $\mathrm{F}$.

Das 2. Geisselglied nicht so lang. Hinterhüften nicht ganz gelb. 3.

3. Scheitel nicht blau. Vorderflügel bräunlich getrübt. 4 .

Scheitel blau. 7.

4. Bohrer länger als der Körper. Das ganze Tier purpurfarbig, nur die Hinterleibsbasis rötlichgelb. Antennenschaft und Beine rötlichgelb, Hüften erzgrün. In Eichengallen.

T. erucarum Schrank.

Bohrer höchstens so lang wie der Körper. 5.

5. Bohrer kürzer als der Hinterleib. Erzgrün; Scheitel kupferig angelaufen. Beine rötlichgelb; Hüften grün, am Ende gelb.

Bohrer deutlich länger als der Hinterleib. 6.

6. Hinterhüften nur an der Basalhälfte grün. Bohrer so lang als der Körper. Kopf grün, Scheitel purpurfarbig oder goldig rot; Thorax grün oder blaugrün; Hinterleib hinten grün, meist purpurn überlaufen. Beine blassgelb. Aus Aulax glechomae.

T. glechomae Mayr.

Hinterhüften mit Ausnahme der unteren Spitze grün. Bohrer gewöhnlich so lang wie der Thorax mit dem Hinterleibe. Grün, Scheitel purpurn; Hinterleib mit rotgelber Binde, hinten kupferig angelaufen. In Eichengallen.

T. abdominalis Boh.

7. Hinterhüften ausser der unteren Spitze ganz blau. Kopf und Thorax blau, Hinterleibsende kupfer- oder purpurfarbig. Hinterschienen braun. In Eichengallen.

T. nobilis Boh.

Hinterhüften rötlichgelb, an der Basis grün oder blau. Kopf und Thorax grün oder blau. Hinterschienen rötlichgelb. Mit Vorliebe auf sumpfigen Wiesen.

8. Bohrer so lang oder länger als der Körper. 9. $T$. ventralis Fonsc.

Bohrer kürzer als der Körper. 20.

9. Das 1. Geisselglied nicht schmäler als die folgenden Glieder. Grössere Arten. 10.

Geissel verdickt, das 1. Glied schmäler als die folgenden. Sehr kleine Arten. (Untergattung Lioterphus Thoms.) 19.

10. Antennenschaft ganz dunkel, höchstens an der Basis unten gelb. 11. Antennenschaft auf der Unterseite oder ganz gelb. 14.

11. Körper kupferfarben mit Goldschimmer. cf. T. fuscipes Boh.

Körper grün oder blau oder violett. 12.

12. Glänzend grün, Beine gelb, alle Hüften und die hintersten Schenkel grün. T. borealis Thoms. dunkel. 13.

Hinterleib blaugrün oder violett. Auch die Vorderschenkel grösstenteils

13. Der längere Sporn der Hinterschienen viel kürzer als der halbe Metatarsus. Bohrer deutlich länger als der Körper. In Gallen von Rhodites eglanteriae.

T. eglanteriae Mayr.

Der längere Sporn der Hinterschienen erreicht nicht ganz die Mitte des Metatarsus. Bohrer kaum länger als der Körper. Schmarotzt bei Saperda populnea.

T. quercinus Boh. 
14. Die 4 Vorderschenkel braun, grün angelaufen. Violett oder trübgrün. 15. Wenigstens die 4 Vorderschenkel ganz oder fast ganz gelb. 16.

15. Violett oder blau. Bohrer $1^{1} / 2$ mal so lang wie der Körper. Wurde aus Fichtenzapfen gezogen.

T. azureus Boh.

Dunkelgrün. Bohrer doppelt so lang als der Körper. T. caudatus Boh.

16. Hinterleib unten und vorn an den Seiten rötlichgelb. Grün, Hinterleib oben blau, violett oder grün. Beine gelb, Hüften grösstenteils grün. Aus Eichen- und Ahorngallen.

T. incertus Först.

Hinterleib unten und vorn an den Seiten nicht gelb. 17.

17. Hinterleib fast ganz rotgolden. Kopf und Thorax blaugrün mit goldigem Schimmer, Seiten des Thorax und Hinterhüften meist feurig rot. In Gallen von Rhodites rosae.

Hinterleib grün, selten blaugrün. 18.

18. Körper grün, selten etwas bläulich. Schaft fast ganz gelb. Beine gelb. Diese häufige Art lebt in zahlreichen Eichengallen.

$T$. regius Nees.

Kopf und Thorax goldig schimmernd; Hinterleib grün. Schaft unten und Schenkel und Schienen rötlichgelb.

T. Bohemani Thoms.

19. Grün oder blaugrün. Schaft unten gelb. Beim $\sigma^{7}$ die ganzen Antennen sattgelb. Diese winzige Art lebt in Birkenkätzchen. Man bekommt sie oft in Menge, wenn man im Mai und Juni Birken mit dem Netz abstreift.

T. pallidicornis Boh.

Erzgrün. Schaft unten nicht hell. Antennen des $\sigma^{7}$ nicht ganz gelb.

20. Antennenschaft ganz dunkel. 21.

T. Mölleri Thoms.

Antennenschaft wenigstens unten gelb. 29.

21. Bohrer so lang oder länger als der Hinterleib. 22.

Bohrer kürzer als der Hinterleib. 27.

22. Scheitel und Hinterleib kupferfarbig. 23.

Scheitel und Hinterleib nicht kupferfarbig. 24.

23. Kopf und Thorax trübgrün; Scheitel, Brustseiten und Metathorax zum Teil kupferfarben. Bohrer wenig länger als der Hinterleib. Kleinere Art.

T. chlorocopes Boh.

Fast der ganze Körper goldig kupferfarben. Bohrer wenig kürzer als der Körper. Grössere Art. T. fuscipes Boh.

24. Die 4 Vorderschenkel bräunlichgelb, in der Mitte blau oder grün. Kopf und Thorax blaugrün, Hinterleib zum Teil violett. Bohrer so lang wie der Hinterleib mit dem halben Thorax. Lebt in den knospenförmigen Gallen von Hormomya juniperina L. an Wacholder. T. juniperi L. (amethystinus Boh.).

Alle Schenkel metallisch. 25.

25. Blaugrün oder violett. Gelenke der Beine braungelb. Tarsen weissgelb. Grössere Art. Bohrer so lang wie der Hinterleib mit $1 / 2$ oder $2 / 3$ des Thorax. Aus Gallen von Lasioptera eryngii Gir.

Trübgrün. Bohrer wenig länger als der Hinterleib. 26.

26. Flügel unter dem Stigma leicht getrübt. Gelenke und Tarsen braun. Grössere Art.

T. alpinus Thoms.

Flügel hyalin. Gelenke und Tarsen blassgelb. Sehr kleine Art. Aus Eichengallen von Cecidomyia subulifex.

T. pygmaeus Mayr. 


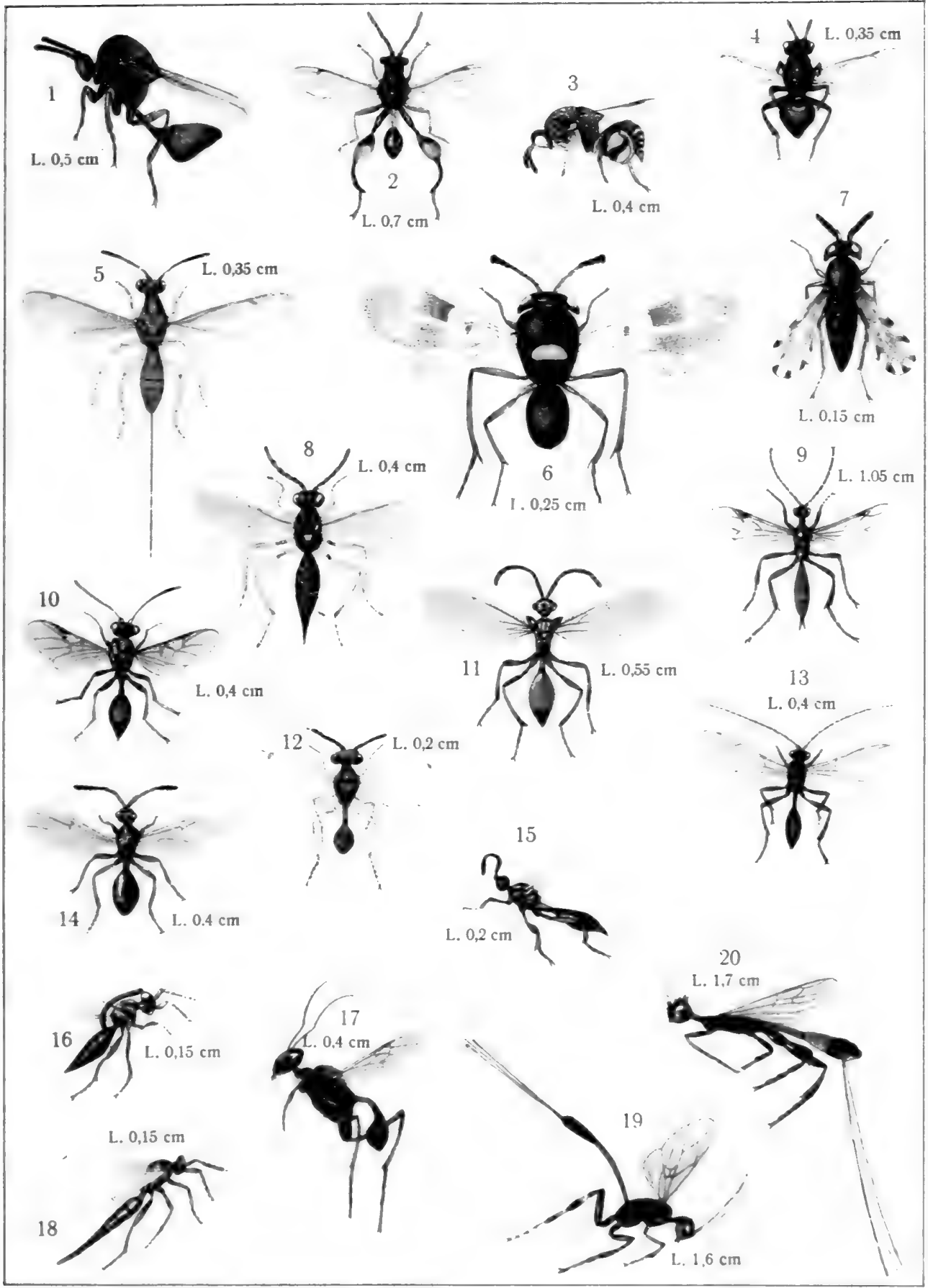

1. Eucharis adscendens. 2. Smicra myrifex. 3. Chalcis flavipes. 4. Perilampus violaceus.

5. Torymus regius. 6. Eucomys scutellata. 7. Cerapterocerus mirabilis. 8. Hyperteles elongatus.

9. Serphus gravidator. 10. Helorus anomalipes. 11. Belyta sanguinolenta. 12. Derostenus conformis. 13. Cinetus iridipennis. 14. Aneurhynchus ruficornis. 15. Paramesius rufipes. 16. Inostemma Boscii. 17. Brachygaster minuta. 18. Epimeces subulatus. 19. Gasteruption granulithorax, 20. Stephanus serrator. 

27. Schienen blaugrün. Blau oder blaugrün; Gelenke der Beine gelb. Sehr kleine Art. Aus blasig aufgetriebenen jungen Blättern von Medicago falcata.

Schienen gelb oder rötlich. 28.

T. medicaginis Mayr.

28. Grünlich kupferfarben. Schienen und Tarsen rötlich. Grössere Art.

T. cupratus Boh. (non Mayr).

Grün. Beine gelb, Schenkel und die hintersten Schienen grün. Kleinere Art.

T. frater Thoms. (parellinus Mayr).

29. Bohrer kürzer als der halbe Hinterleib. Grün, Thorax zum Teil blau, Hinterleib kupferfarbig. Kleinere Art.

T. brachyurus Boh.

Bohrer selten etwas kürzer als der Hinterleib. 30.

30. Vorderflügel getrübt oder mit dunklem Fleck. Körper zum Teil purpurn. Schenkel und Schienen meist rötlichgelb. 31.

Vorderflügel vollkommen hyalin. 36.

31. Grün, Scheitel feurig oder purpurrot, Hinterleib namentlich gegen das Ende purpurn. Antennenschaft grösstenteils und Beine rötlichgelb, Hinterhüften grün. Bohrer so lang wie Hinterleib und Thorax.

Scheitel anders gefärbt. Bohrer kürzer. 32.

T. igniceps Mayr.

32. Vorderflügel mit braunem Fleck am Radiusknopf. Hinterleib kupferfarbig. Bohrer so lang wie der Hinterleib.

Vorderflügel mit dunkler Trübung. 33.

T. spilopterus Boh.

33. Schaft lang, ganz rötlichgelb. Costalzelle, d. h. der Raum zwischen dem Vorderrand und der Subcosta, schmal. Metathorax gestreckt. Bohrer so lang wie der Hinterleib. 34.

Schaft nur unten rötlichgelb. Costalzelle breit. Metathorax kurz. Bohrer etwas länger als der Hinterleib. Thoraxseiten hinten purpurn. 35.

34. Schaft gekrümmt, am Ende verbreitert. Hinterleib mehr blaugrün.

T. scaposus Thoms. purpurn.

T. purpurascens Boh.

35. Grün; Brustseiten hinten und Hinterleib purpurn. In Eichengallen.

T. amoenus Boh.

Grün; Brustseiten hinten und Hinterleib goldig-purpurn. Etwas grōsser als die vorige Art und Bohrer etwas länger. $\quad T$. pleuralis Thoms.

36. Wenigstens die Hinterschenkel blau oder grün. 37.

Alle Schenkel gelb, höchstens dunkel gefleckt. 61.

37. Kopf oder Thorax ganz oder teilweise violett, kupfrig oder golden. 38.

Kopf und Thorax ganz grün oder blau. 39.

38. Bohrer so lang wie der Hinterleib oder etwas kürzer. Vorderschenkel wenigstens grün gestreift. Costalzelle schmal. Erzgrün, zum Teil kupfrig oder golden.

$T$. arcticus Thoms.

Bohrer so lang wie der Hinterleib mit dem halben oder ganzen Thorax. Vorderschenkel meist ganz oder grösstenteils gelb. Wurde aus Cecidomyia rosae gezogen.

T. abbreviatus Boh.

39. Bohrer mindestens so lang wie der Hinterleib mit dem halben oder ganzen Thorax. 40.

Bohrer kürzer als der Hinterleib mit dem halben Thorax. 50. 
40. Kopf oder Thorax ganz oder teilweise blau. 41.

Kopf und Thorax grün, nicht blau gezeichnet. 46.

41. Alle Schenkel grün oder blaugrün; Gelenke der Beine, Schienen und Tarsen gelb. Man zieht diese Art häufig aus den Blütenköpfen von Kompositen, welche mit Trypetinen besetzt sind.

T. cyanimus Boh.

Die vorderen Schenkel gelb oder nur grün gestreift. 42.

42. Schön hellgrün oder blaugrün, an den Seiten blass goldig.

Weniger lebhaft grün, Thoraxseiten nicht goldig. 43.

cf. T. dauci Curt.

43. Vorderhüften am Ende gelb. Hinterleib blau, vorn zuweilen braun, gegen das Ende meist grün. Lebt in den kegelförmigen Gallen von Hormomyia fagi Hart. auf Buchenblättern.

T. cultriventris Ratzeb.

Auch die Vorderhüften ganz grün. 44.

44. Blaugrün oder blau, Seiten des Thorax grün. Kleinere Art. Wurde aus Linum usitatissimum gezogen.

T. lini Mayr.

Oberseite von Kopf und Thorax vorwiegend grün. Grössere Arten. 45.

45. Grün, stellenweise blau, Hinterleib nicht selten etwas feurig angelaufen. Der längere Sporn der Hinterschienen reicht nicht ganz bis zur Mitte des Metatarsus. Lebt in den durch Cecidomyia-Arten auf Weiden verursachten Gallen.

T. tipulariarum Zett.

Grün, die hintere Hälfte des Thorax gewöhnlich blau. Der längere Sporn der Hinterschienen reicht bis oder etwas über die Mitte des Metatarsus. Häufig in den Stengelgallen von Hieracium.

T. hieracii Mayr.

46. Schön hellgrün, an den Seiten blass goldig. Vorderschenkel gelb, aussen schwach grün angelaufen. Mit $T$. socius Mayr in Cecidomyia-Gallen in den Früchten von Pimpinella saxifraga, Pastinaca und Daucus. T. dauci Curt.

Körperseiten ohne goldigen Schimmer. 47.

47. Der längere Sporn der Hinterschienen reicht bis zur Mitte des Metatarsus oder über dieselbe hinaus. Aus Eichengallen, besonders von Neuroterus lenticularis $\mathrm{Ol}$.

T. hibernans Mayr. tarsus. 48.

Der längere Sporn der Hinterschienen reicht nicht bis zur Mitte des Meta-

48. Vorderhüften in der Endhälfte rotgelb. Auch die Vorderschenkel ganz oder grösstenteils gelb.

cf. T. abbreviatus Boh.

Auch die Vorderhüften ganz grün. 49.

49. Hinterschenkel grün mit gelbem Ende oder nur in der Mitte grün. Aus Gallen von Cecidomyia artemisiae. T. artemisiae Mayr.

Innenseite der Hinterschenkel gelb. Aus von Cecidomyia-Arten verursachten Weidengallen.

cf. T. tipulariarum Zett.

50. Antennenschaft ganz oder fast ganz gelb. Alle Schenkel grün. 51.

Antennenschaft nur unten gelb. 52.

51. Körper gedrungen, blaugrün. Schildchen mit Spur einer Querfurche wie bei Syntomaspis. Flügel weisslich, mit blassgelber Nervatur. Schienen und Tarsen hellgelb. Bohrer länger als der Hinterleib. Aus Gallen an Limoniastrum. 
Körper gestreckter, grün oder blaugrün. Schildchen ohne Querfurche. Flügel hyalin. Hinterschienen schwärzlich. Bohrer so lang oder etwas kürzer als der Hinterleib. Mit $T$. dauci Curt. aus denselben Gallen gezogen.

52. Alle Schenkel grün. Hinterschienen grün oder braun. 53.

T. socius Mayr.

Vorderschenkel ganz oder grösstenteils gelb. 54.

53. Grün oder blaugrün. Die hintersten Schienen dunkelbraun. Der längere Sporn der hintersten Schienen reicht bis oder fast bis zur Mitte des Metatarsus. Kleinere Art. Aus Gallen von Cecidomyia corni Gir. auf Cornus sanguinea.

T. corni Mayr.

Lebhaft grün. Die hintersten Schienen grün. Der längere Sporn der Hinterschienen reicht über die Mitte des Metatarsus hinaus. T. euchlorus Boh.

54. Innenseite der Hinterschenkel gelb. Aus Weidengallen.

Hinterschenkel anders gezeichnet. 55.

cf. T. tipulariarum Zett.

55. Hinterleib blaugrün mit 2 violett-bronzefarbigen Querbinden, an den Seiten feurig-erzfarbig. Vorderschenkel gelb mit grünem Wisch, Hinterschenkel grün, an beiden Enden gelb. Aus Gallen von Rhodites eglanteriae Hart.

Hinterleib ohne Querbinden. 56.

T. viridis Först.

56. Lebhaft hellgrün oder blaugrün, an den Seiten blass goldig. Der längere Sporn der Hinterschienen erreicht die Mitte des Metatarsus nicht.

cf. T. dauci Curt.

Körperseiten ohne Goldschimmer. Der längere Sporn der Hinterschienen erreicht die Mitte des Metatarsus. 57.

57. Alle Hüften grün. Schön hellgrün, Thorax meist zum Teil blau, oft auch die Hinterleibsbasis. Der längere Sporn der Hinterschienen überragt die Mitte des Metatarsus. In Gallen von Neuroterus lenticularis und laeviusculus an Eichen.

T. sodalis Mayr.

Vordere Hüften am Ende gelb oder der längere Sporn der Hinterschienen erreicht kaum die Mitte des Metatarsus. 58.

58. Bohrer etwas kürzer als der Hinterleib. Grün oder blau, Schaft und Beine grösstenteils gelb. Schenkel dick. 59.

Bohrer etwas länger als der Hinterleib, letzterer zum Teil blau oder violett. 60 .

59. Bohrer nur wenig kürzer als der Hinterleib. Brustseiten goldig schinmernd. Grün oder blaugrün, Hinterleib meist blau. Aus Gallen von Cecidomyia galii Winn.

T. galii Boh.

Bohrer fast um die Hälfte kürzer als der Hinterleib. Brustseiten kaum goldig schimmernd. Schienen blassgelb. $T$. liogaster Thoms.

60. Grün oder blaugrün, Hinterleib zuweilen violett. Kleinere Art. Aus Gallen von Cecidomyia urticae Perr. auf Urtica dioica. T. urticae Perr.

Grün, Hinterleib blaugrün, Brustseiten goldgrün. Grössere Art.

T. contubernalis Boh.

61. Bohrer um $1 / 3$ kürzer als der Hinterleib. Grüngolden; Antennen unten gelblich. Die vordersten Hüften ganz, die mittleren am Ende gelb.

Bohrer mindestens so lang wie der Hinterleib, meist lä̀nger. 62. 
62. Auch die vorderen Hüften ganz grün. 63.

Die vorderen Hüften ganz oder in der Endhälfte gelb. 64.

63. Bohrer so lang wie Thorax und Hinterleib. Kopf und Thorax grün. Scheitel zum Teil blau; Hinterleib erzgrün, das 1. Segment blau. Hinterschenkel aussen erzfarbig.

T. druparum Mayr (non Boheman).

Bohrer so lang wie der Hinterleib oder nur wenig länger. Grün. Seiten feurig rot angelaufen. Schaft ganz gelb. Von dem sehr ähnlichen T. auratus durch den steten Mangel der blauen Farbe und den kürzeren Bohrer verschieden. Aus Eichengallen von Trigonaspis megaptera Panz. T. flavipes Walk.

64. Die ersten Geisselglieder doppelt so lang als dick. Grün oder erzgrün, kupfrig angelaufen. Antennenschaft grösstenteils gelb. Beine gelb. Die hintersten Hüften ganz, die mittleren grösstenteils erzgrün. Bohrer so lang wie der Hinterleib mit dem halben oder fast ganzen Thorax. Lebt in den kegelförmigen Gallen von Hormomyia fagi Hart. auf Buchenblättern. T. speciosus Boh.

Geissel gedrungen, mit kurzen Gliedern. Färbung schön grün oder blaugrün. Bohrer meist kürzer. 65 .

65. Der längere Sporn der Hinterschienen reicht bis über die Mitte des Metatarsus hinaus. Schaft nur auf der Unterseite gelb. Grün oder blaugrün, Seiten des Thorax zuweilen goldig. Bohrer so lang wie der Hinterleib mit $1 / 3$ oder ${ }^{1 / 2}$ des Thorax. Diese sehr häufige Art lebt in vielen Eichengallen.

T. auratus Fonsc.

Der längere Sporn der Hinterschienen erreicht nicht die Mitte des Metatarsus. Schaft meist ganz gelb. 66 .

66. Kopf nach vorn nicht stark verschmälert. Das letzte Bauchsegment fein behaart. Grün oder blaugrün, Thoraxseiten zuweilen feurig rot angelaufen. Bohrer so lang wie der Hinterleib mit $1 / 3$ oder ${ }^{1} / 2$ des Thorax. In Rosen- und Brombeergallen.

T. macropterus Walk.

Kopf nach vorn stark verschmälert. Das letzte Bauchsegment nicht behaart. Grün. Hinterleib mit blauen Binden, auch der Kopf zuweilen blau.

T. triangularis Thoms.

\section{Unterfamilie. Encyrtinae.}

Die vielgestaltigste und farbenreichste Unterfamilie der Chalcididen; indem hier auch eine ganze Reihe nichtmetallischer Farben auftreten. Da wir wie über die Toryminen auch über diese Gruppe eine ausgezeichnete Arbeit von Mayr haben, so eignen sich die Encyrtinen ganz besonders zu einem Spezialstudium und ich gebe deshalb auch hier eine dem jetzigen Standpunkte entsprechende Bestimmungstabelle wenigstens der Weibchen, auf die sich der Anfänger zunächst beschränken muss. - Hochinteressant und hochwichtig ist auch die Lebensweise dieser zum Teil sehr winzigen Tiere. Die Mehrzahl der Arten lebt bei Schildläusen und wird dadurch ausserordentlich nützlich, viele leben auch in den Eiern und Raupen von Schmetterlingen, nur wenige schmarotzen bei Hymenopteren, Coleopteren und Dipteren. So liefern diese prächtigen Tiere dem Systematiker und Biologen ein überaus reiches Material.

1. Tarsen 4 gliedrig. Antennen 3 gliedrig. Subcosta nicht bis zum Flügelvorderrande reichend, mit einer Verdickung endend. Marginalnerv und Radius fehlen. Die einzige Art, A. chionaspidis Auriv., ist fast über die ganze Erde verbreitet.

Arrhenophagus Auriv. 
Tarsen 5 gliedrig. Antennen mit weit mehr Gliedern. Subcosta bis zum Flügelvorderrande reichend. 2.

2. Körper sehr flach, glatt und glänzend. Antennenfaden (Geissel mit Ausschluss der Ringglieder und Endkeule) 5 gliedrig. Flügel ziemlich lang gewimpert. Zwei Arten, am bekanntesten $M$. testaceus Ratzeb., ein winziges gelbbraunes Tierchen. Lebt in Coccus racemosus auf Fichten.

Metallon Walk. (Rhopus Först. Mayr).

Körper mehr oder weniger konvex, selten stark glänzend. 3.

3. Der horizontale Scheitel bildet mit der schief nach hinten gerichteten Stirn einen spitzen Winkel; beide sind durch scharfe Kanten getrennt; Kopf von der Seite gesehen dreieckig. Antennen kurz. Körper blau oder blaugrün; Flügel mit dunkler Zeichnung. Bei der einen der beiden Arten Nacken und Schildchen mit zwei langen und schmalen Anhängseln. Leben in Schildläusen auf Eichen und Linden.

Habrolepis Först.

Stirn und Scheitel nicht in einem spitzen Winkel zueinander gestellt und durch keine Querkante getrennt. 4.

4. Schaft, Faden und Keule sehr breit flachgedrückt. 5.

Schaft, Faden und Keule nicht zugleich stark breitgedrückt. 8.

5. Flügel vollständig, mit dunkler Zeichnung. Körper blaugrün. Scheitelkante scharf. 6. fehlend. 7.

Flügel fast stets rudimentär. Körper erzgrün oder braun. Scheitelkante

6. Flügelspitze mit radienförmiger Zeichnung. Mesonotum fast glatt. Die einzige, höchst zierliche Art, C. mirabilis Westw., lebt in Schildläusen an Obstbäumen und Gräsern.

Cerapterocerus Westw.

Flügel gebräunt, am Ende hyalin. Mesonotum schuppig-punktiert. Die einzige Art, E. cornigerum Walk., lebt ganz wie die vorhergehende.

Eusemion Dahlb.

7. Kopf von oben betrachtet kurz. Thorax flach. Die eine Art, A. fulvescens Walk., ist schwarzbraun; die andere, A. Heydeni Mayr, erzgrün. Anusia Först.

Kopf dick. Thorax nicht flach; Mesonotum eingeschnürt. Die einzige Art, M. macrocera Schellenb., ist dunkel erzgrün, oft purpurn angelaufen, das Schildchen samtschwarz. Mira Schellenb.

8. Schildchen am Ende mit langem Haarbüschel. 9.

Schildchen am Ende ohne Haarbüschel. 10.

9. Pedicellus kürzer als das 1. Fadenglied. Mesonotum ohne silberweisse Haare. Körper nicht metallisch. Etwa 5 in Schildläusen lebende Arten; am bekanntesten E. scutellata Swed., schwarz, Schildchen mit grossem gelbem Querfleck.

Eucomys Först.

Pedicellus länger als das 1. Fadenglied. Mesonotum ganz oder nur hinten anliegend silberweiss behaart. Körper zum Teil metallisch. Alle 5 Arten leben in Schildläusen; am bekanntesten Ch. formosus Boh., Antennen mit weissem Ring, Flügel dunkel, im Basaldrittel wasserhell, Schildchen gelb.

Chiloneurus Westw.

10. Schildchen an der Basis mit zwei tiefen Grübchen. Schaft über den Scheitel hinausragend. Flügel rudimentär. Kopf, Thorax und Schildchen stark glänzend. Körper rotgelb, oben grün schimmernd. Nur 1 Art: E. rufum Dalm.

Schildchen an der Basis ohne Grübchen. 11. 
11. Schildchen fast kreisrund, gelb. Schaft nicht verbreitert, die Geissel dagegen, ebenso die Keule, flachgedrückt. Thorax mit silberglänzender $\mathrm{Be}-$ haarung. Flügel stummelhaft, nur bis an das Thoraxende reichend. Die einzige Art, B. pascuorum Mayr, lebt in Schildläusen an Gräsern. Baeocharis Mayr.

Schildchen 3 seitig. Körper anders gefärbt. 12.

12. Kopf mit dichter, grob fingerhutartiger Punktierung, wodurch derselbe fast wie mit Edelsteinchen besetzt erscheint. Körper kurz und gedrungen. 13.

Kopf nicht mit einer solchen Skulptur. 14.

13. Flügel hyalin, Marginalnerv sehr kurz oder fehlend. Mesonotum und Schildchen mit ganz ähnlichen Skulpturen wie der Kopf. Die bekannteste Art, B. clavicornis Dalm., ist dunkel blaugrün, Antennenkeule gross, breitgedrückt, am Ende schräg abgestutzt.

Bothriothorax Ratzeb.

Flügel ganz oder teilweise gebräunt, Marginalnerv nicht sehr kurz. Mesonotum und Schildchen chagriniert, mit zerstreuten groben Punkten. 4 Arten, am häufigsten $P h$. aeneus Dalm., blauschwarz, Flügel dunkel, an der Spitze mit hellem Rand.

Phaenodiscus Först.

14. Keule sehr schief von der Spitze bis nahe zur Basis gestutzt. 15.

Keule nicht sehr schief gestutzt. 16.

15. Körper blau oder erzgrün, nicht gelb gezeichnet. Flügel nicht dunkel gefleckt. Die 5 Arten leben in Schmetterlingsraupen. Litomastix Thoms.

Körper zum Teil gelb gezeichnet. Flügel meist mit dunklem Fleck. Hierher 3 Arten; die bekannteste, H. flaminius Dalm., hat weisse Antennenkeule; sie lebt in Coccinella-Larven.

Homalotylus Mayr.

16. Stirn und Scheitel dicht punktiert, ohne zerstreute grössere Punkte. Mesonotum meist mit rundlichen oder länglichen Punkten. Antennenschaft dünn, Keule lang und schwach gebogen. Flügel hyalin. Die 8 Arten leben in den Raupen von Kleinschmetterlingen.

Nicht alle diese Merkmale zugleich vorhanden. 17.

17. Flügel rudimentär, sehr selten entwickelt; in diesem Falle ist das Schildchen flach oder die Spitze desselben ist deutlich abgesetzt und hell gefärbt. 18.

Flügel vollständig ausgebildet. Schildchen quer gewölbt, am Ende nicht abgestutzt. 20 .

18. Schaft stark blattartig verbreitert, Geissel dünn. Flügel sehr selten vorhanden, braun gebändert. Die einzige Art, D. hemiptera Dalm., ist schwarz mit schwachem Metallschimmer.

Dinocarsis Först.

Schaft nicht blattartig erweitert. 19.

19. Das 1. Fadenglied nur so lang als dick; Schaft ziemlich kurz. Flügel sehr selten entwickelt; Radius sehr kurz. Die einzige Art, Ch. inepta Dalm., ist braunschwarz mit Kupferglanz.

Choreia Westw.

Das 1. Fadenglied deutlich länger als dick; Schaft lang. Flügel stummelhaft oder entwickelt; Marginalnerv, Radius und Postmarginalnerv sehr lang. Die 4 oder 5 Arten sind metallisch grün oder blaugrün oder purpurn, oft zum Teil rot oder gelb.

Ericydnus Walk.

20. Gesicht zwischen den Antennen mit Kiel. Das letzte Bauchsegment vorspringend. 21.

Gesicht zwischen den Antennen ohne Kiel. Das letzte Bauchsegment nicht vorspringend. 22. 
21. Stirn breit. Radius und Postmarginalnerv ziemlich lang. Die einzige Art, $S$. orbitalis Thoms., ist gelbbraun mit gelben Augenrändern und sonstiger gelber Zeichnung.

Stenoterys Thoms.

Stirn schmal. Postmarginalnerv nicht entwickelt. Dunkel erzfarben ohne gelbe Zeichnung. Die einzige Art, $T$. diversicornis Westw., ist ausgezeichnet durch die mit 4 Kammstrahlen versehenen Antennen des Männchens.

Tetracnemus Westw.

22. Antennenfaden mit nur 4 Gliedern. Radius doppelt so Iang wie der quadratische Marginalnerv. Hinterleib länglich-oval, schmäler als der Thorax. Die einzige Art, C. jugaeus Walk., ist trüb erzfarben, die Kniee heller.

Cercobelus Walk.

Antennenfaden mit 6, bei Holcothorax zuweilen nur mit 5 Gliedern. Körper anders gefärbt. 23.

23. Mesonotum und Schildchen glanzlos. Marginalnerv kürzer als der Radius. 24.

Mesonotum stets mehr oder weniger glänzend. 26.

24. Mesonotum und Schildchen fein längsgestreift; Schildchen stark erhaben. Körper sehr klein, blau, grün oder schwärzlich. Es sind 4 Arten bekannt, die in Raupen von Kleinschmetterlingen schmarotzen.

Ageniaspis Dahlb. (Holcothorax Mayr).

Mesonotum dicht und fein fingerhutartig punktiert. Körper gewöhnlich nicht metallisch. 25 .

25. Fadenglieder dicker als lang; Keule etwas länger als der halbe Faden. Marginalnerv nicht vorhanden. Mesonotum und Schildchen mit anliegenden kurzen, gelblichen Haaren. Die 3 Arten leben in Schildläusen; am bekanntesten A. punctipes Dalm. Aphycus Mayr.

Fadenglieder länger als dick; Keule so lang oder etwas länger als die beiden letzten Fadenglieder zusammen. Marginalnerv stets vorhanden. Vor der Flügelbasis ein weisser Mondfleck. Die 5 Arten leben in Schildläusen; am bekanntesten $B$. sericea Dalm.

Blastothrix Mayr.

26. Vorderflügel nicht gewimpert. Antennen sehr lang und besonders die Geissel sehr dünn, die Geisselglieder mindestens 5 mal so lang wie dick. Marginalnerv nicht vorhanden. Die einzige Art, P. longicornis Walk., ist braunschwarz mit Metallschimmer; sie lebt in Schildläusen auf Eichen.

Vorderflügel gewimpert. Geisselglieder weit kürzer. 27.

Psilophrys Mayr.

27. Schwarz; Thorax zum Teil gelbrot. Endhälfte der Vorderflügel verdunkelt. Metathorax an den Seiten mit weisssn Filzflecken. Einzige Art $P$. morio Dalm.

Prionomastix Mayr.

Körper anders gefärbt, meist metallisch. 28.

28. Marginalnerv $1^{1} 2 \mathrm{mal}$ so lang wie der Radius. Antennen fadenförmig, dünn und lang. Die einzige, mehr in Südeuropa vorkommende Art, L. histrio Mayr, ist gelb oder rötlichgelb, Thorax zum Teil dunkelbraun.

Leptomastix Först.

Marginalnerv viel kürzer. Körper anders gefärbt, fast stets metallisch. 29.

29. Antennenkeule sehr lang und zylindrisch, so lang als der Fadenflügel hyalin. Die einzige Art, S. sceptriger Först., ist grün oder blaugrün; Antennen gelb.

Antennenkeule weit kürzer。 30 . 
30. Metathorax hinten beiderseits mit weisser Haarmakel. Körper blau oder grünlichblau. 31 .

Metathorax hinten ohne weisse Haarmakeln. 33.

31. Thorax vor der Flügelbasis mit weisslichem Fleck. Antennen lang und schlank, Geisselglieder 4-5 mal länger als dick. Körper, namentlich der Hinterleib, gestreckt; Bohrer so lang wie der halbe Hinterleib, dick. Die einzige Art, C. subplanus Dalm., ist blaugrün, der Hinterleib kupferig mit blaugrüner Basis.

Cerchysius Westw.

Thorax vor der Flügelbasis ohne weissen Fleck. Bohrer versteckt oder von $1 / 3$ Hinterleibslänge, im letzteren Falle dünn. 32.

32. Bohrer nicht vorstehend. Körper blau; Flügel meist mit gebogener Querbinde vor dem Aussensaume. Von den drei Arten ist die bekannteste T. cyaneus Dalm., sie lebt in Schildläusen an Gräsern. Trichomasthus Thoms.

Bohrer vorstehend, von $1 / 3$ Hinterleibslänge, dünn. Die einzige Art, $C$ puncticollis Thoms., ist dunkelblau; Hinterleib schwarzblau; Flügel hyalin.

Caenocercus Thoms.

33. Antennen sehr dünn, Pedicellus etwa $3 \mathrm{mal}$ so lang als dick. Keule kaum dicker als die Fadenglieder, letztere schwer voneinander unterscheidbar. Kopf und Thorax glatt und glänzend. Die einzige sehr kleine Art, L. glaphyra Walk., ist blaugrün und violett, der Hinterleib bronzefarbig, an der Basis grün. Liothorax Mayr.

Antennen dicker, Faden nicht besonders dünn, die Gelenke der Glieder deutlich zu erkennen, Keule dicker als der Faden. Kopf und Thorax mit deutlicher Skulptur. 34.

34. Das letzte Bauchsegment etwas dornartig über die Hinterleibsspitze vorstehend und den Bohrer einschliessend. Geissel ziemlich kurz, die Glieder nicht länger als dick, gegen das Ende an Grösse zunehmend. Die einzige Art, $P$. mitratus Dalm., ist lebhaft grün mit Erz- oder Kupferschimmer, Flügel hyalin. Prionomitus Mayr.

Das letzte Bauchsegment nicht dornartig vorstehend. Körper verschiedenartig gefärbt; Kopf und Mesonotum deutlich chagriniert, Stirn neben den Augen meist mit Reihen grösserer Punkte; Antennen oft mit hellem Ring; Flügel nicht selten mit Binden. Hierher zahlreiche Arten.

Encyrtus Latr.

\section{Proctotrupidae.}

\section{Charakteristik.}

Die Proctotrupiden bilden keine homogene Gruppe der Hymenopteren, sondern sie bestehen aus den verschiedenartigsten Elementen, die unter sich recht wenig Ähnlichkeit haben, namentlich sind es die Unterfamilien der Dryininen, Bethylinen, Emboleminen, Helorinen und Mymarinen, die zum Ganzen nicht passen wollen und von denen jede einen Sondertypus bildet. Dieses missliche Verhältnis ist längst eingesehen worden und man hat versucht, die er- 
wähnten Unterfamilien an einer passenderen Stelle im System unterzubringen. So werden neuerdings die Dryininen, Bethylinen und Emboleminen als Bethylidae zu einer eigenen Familie vereinigt und neben die Grabwespen gestellt. Auch ich bin in meinen "Hymenopteren Mitteleuropas" dieser Neuerung gefolgt; im

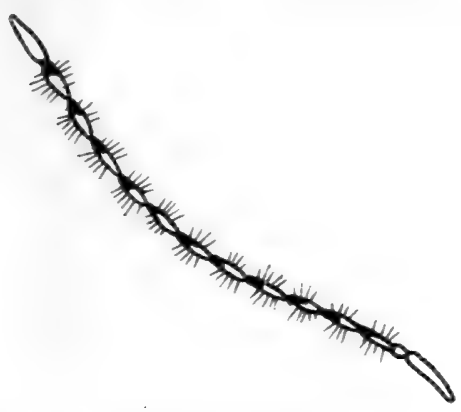

Abb. 41.

Antenne von Diapria verticillata Latr. $\sigma^{7}$.

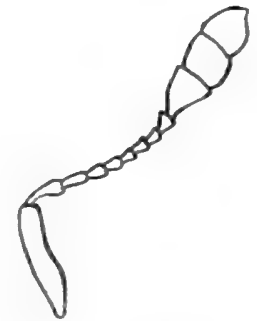

Abb. 42. Antenne von Loxotropa dispar Nees 9 .

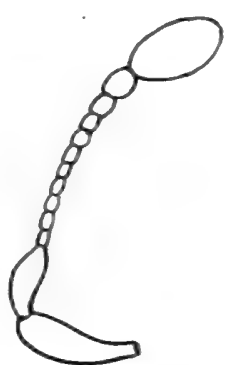

Abb. 43. Antenne von Monelata cincta Hal. 9 .

Gegensatz dazu werden sie von Kieffer in seinem grossen Werke bei den Proctotrupiden belassen. Ebenso schwankend ist die Stellung der Mymarinen; während Ashmead sie zu den Chalcididen rechnet, bilden sie bei Kieffer den

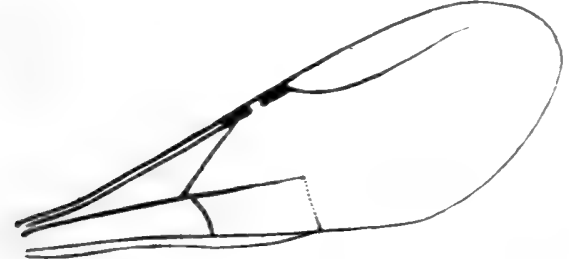

Abb. 44. Vorderflügel von Pseudisobrachium.

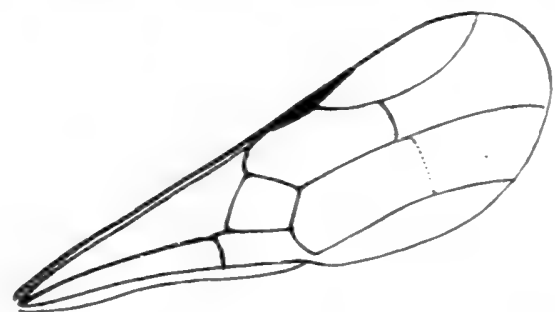

Abb. 45. Vorderflügei von Embolemus.

Schluss der Proctotrupiden. Aus dem Gesagten geht hervor, dass es nicht möglich ist, eine kurze präzise Diagnose dieser Unterfamilie zu geben; Kieffer charakterisiert sie mit folgenden Worten: „Die Proctotrupiden sind kleine, oft

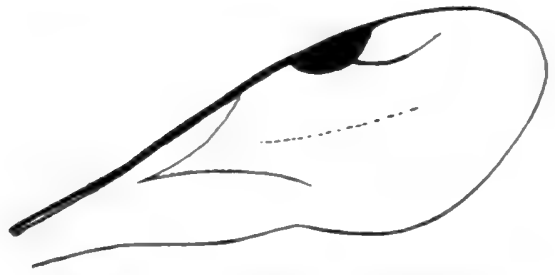

Abb. 46. Vorderflügel von Conostigmus.

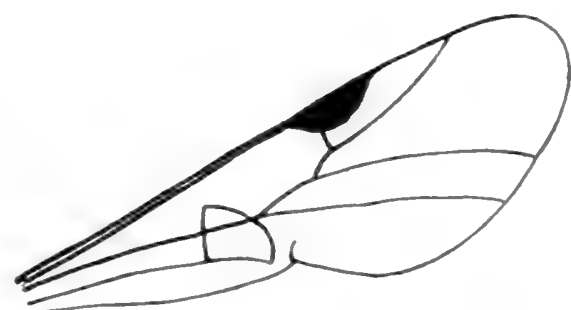

Abb. 47. Vorderflügel von Helorus.

sehr kleine, selten mittelgrosse, parasitisch lebende Hymenopteren von fast durchweg schwarzer oder brauner, selten noch hellerer Färbung, ohne Metallschimmer. Die Seiten des Prothorax erstrecken sich wie bei den Ichneumoniden, Cynipiden usw. nach hinten bis zum Ursprung der Flügel, während dies bei 
den Chalcididen nicht der Fall ist. Die Flügelnervatur ist sehr verschieden und für die einzelnen Unterfamilien so charakteristisch, dass dieselben sofort daran erkannt werden können; während viele eine verzweigte Nervatur besitzen, fehlen bei bestimmten Gruppen Nerven fast ganz. Flügellose Formen oder solche mit stummelhaften Flügeln, es sind dies meist Weibchen, finden sich bei allen Unterfamilien, mit Ausnahme der Helorinen. Die Trochantern bestehen nur aus einem Glied; eine Ausnahme macht die Gattung Helorus, wo sie 2 gliedrig sind. Der Legebohrer ist meist versteckt oder steht nur ganz wenig vor.“

Kopf in der Regel quer; Augen gewöhnlich oval, Nebenaugen meist zu dreien, bei den flügellosen Formen oft fehlend, Antennen gerade oder gekniet,

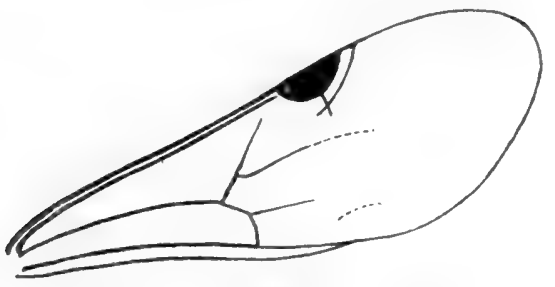

Abb. 48. Vorderflügel von Serphus.

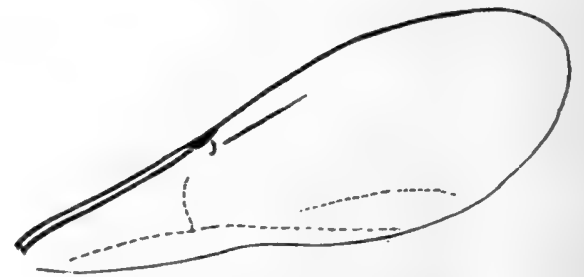

Abb. 49. Vorderflügel von Basalys.

in der Mitte des Gesichts oder tief unten eingefügt, von der mannigfachsten Form und Gliederzahl und deshalb für die Systematik ausserordentlich wichtig. Prothorax bei manchen Gruppen stark verlängert, Mesonotum meist mit drei vertieften Längslinien, Schildchen und Hinterschildchen bei manchen Gattungen in einen Dorn auslaufend. Bereits oben ist erwähnt worden, dass die Flügelnervatur ausserordentlich verschieden und für die einzelnen Unterfamilien ganz charakteristisch ist; besser als eine lange Beschreibung werden die beigefügten Abbildungen zur Erläuterung dienen.

Die Beine bieten keine besonderen Merkmale, eine Ausnahme machen nur die Weibchen verschiedener Gattungen der Dryininen, bei welchen die vordersten Fussklauen zangenartig erweitert sind. Die Tarsen sind stets in der Zahl von 5 vorhanden. Auch über die Struktur des Hinterleibs lässt sich nichts Besonderes sagen; von Wichtigkeit ist auch hier, ob er sitzend oder gestielt ist; von ganz besonderer Form ist der Hinterleib bei der Gattung Helorus.

\section{Lebensweise der Proctotrupiden.}

Alle hierher gehörenden Tiere sind Schmarotzer und stechen nach Art der übrigen Schlupfwespen andere Insekten, seltener Spinnen und Tausendfüsser an. Die Dryininen leben vorwiegend aussen an Zikaden; die DryinusArten im besonderen schmarotzen bei der Gattung Cixius, die Arten von Gonatopus bei den Gattungen Deltocephalus und Typhlocyba. Die Bethylinen heften sich an Käferlarven und Schmetterlingsraupen. Die wunderliche Gattung Helorus lebt bei den Neuropteren-Gattungen Chrysopa und Hemerobius; das grosse Heer der Ceraphroninen lebt im Innern von Blattläusen und Gallmückenlarven; die echten Proctotrupiden greifen Käferlarven an, daneben auch die übrigen Insektenordnungen, ja sie sind sogar aus Tausendfüssern (LithobiusArten) gezüchtet worden; als Wirte der zahlreichen Belytinen und Diapriinen kommen hauptsächlich Pilzmücken in Betracht; die Scelioninen machen ihre Entwicklung vorzugsweise in Insekteneiern durch, namentlich von Orthopteren und 
Hemipteren, finden sich aber auch in Spinneneiern; was schliesslich die an Gattungen und Arten so unendlich reichen Platygasterinen betrifft, so suchen sie ihre Opfer unter den Dipteren, namentlich den Cecidomyiden, den kleinen Tipuliden und Musciden.

\section{Sammeln und Präparieren der Proctotrupiden.}

Taschenberg sagt in seinem hübschen, nun freilich schon längst veralteten Werkchen über die Hymenopteren Deutschlands bei der kurzen Erwähnung der Proctotrupiden folgendes: „Wer diesen Tieren mehr Aufmerksamkeit schenken will, darf kein Anfänger mehr sein und muss gründliche Studien machen." Das ist sehr richtig, immerhin trifft diese Bemerkung viel besser für die Chalcididen zu, denn die Proctotrupiden zeigen eine viel grössere Mannigfaltigkeit im Körperbau, die Flügelnervatur ist für die einzelnen Unterfamilien viel bezeichnender und ganz besonders ist die Antennenbildung wegen der leichten Unterscheidbarkeit der einzelnen Glieder weit bequemer zu benutzen als dies bei den Chalcididen der Fall ist, wo man oft trotz der stärksten Vergrösserung nicht ins klare kommt. Was ich bei den Chalcididen über Fang und Zucht gesagt habe, gilt auch hier. Fangen kann man die Tiere schon vom zeitigsten Frühjahre an, da viele von ihnen überwintern; mit der fortschreitenden Jahreszeit wird der Fang immer reicher ausfallen, um dann im Spätsommer und Herbst seinen Höhepunkt zu erreichen, weil um diese Zeit die in Pilzfliegen lebenden Belytinen und Diapriinen namentlich an schattigen Stellen an Waldrändern, in Schluchten usw. oft in unglaublichen Mengen auftreten. Das dankbarste Feld bietet sich dem Züchter dar; oben ist kurz angedeutet, wo die Tiere hauptsächlich leben. Ein Riesengebiet liegt da noch unbebaut. - In bezug auf die Präparation bemerke ich, dass fast alle Tiere auf feine schmale Papierdreiecke mit der Hinterleibsspitze aufgeklebt werden müssen, wie das schon bei den Chalcididen beschrieben ist. Der Thorax ist zu hart, um leicht mit einer feinen Silbernadel durchstochen werden zu können, dann muss das für die Systematik so wichtige Mesonotum womöglich unversehrt sein.

\section{Literatur über Proctotrupiden.}

Die erste bedeutende und grundlegende Arbeit über diese schwierige Familie der Hymenopteren ist die bereits bei den Chalcididen erwähnte Schrift Försters: Hymenopterologische Studien, Heft 2, 1856; seine Einteilung ist auch heute noch massgebend. Die von Thomson in den Jahren 1857-1861 erschienene Bearbeitung der skandinavischen Proctotrupiden war mehr ein Versuch und ist heute längst überholt. Ein gediegenes Werk ist Ashmeads „Monograph of the North American Proctotrypidae, 1893“; obwohl darin in erster Linie die nordamerikanischen Gattungen und Arten behandelt werden, sind sämtliche von Förster aufgestellten Gattungen näher charakterisiert und durch Zeichnungen erläutert. Alle bis jetzt erwähnten Schriften sind jetzt so gut wie überflüssig geworden. Seit einigen Jahren behandelt J. J. Kieffer in eingehender und gediegener Weise die Proctotrupiden in „E. André, Species des Hyménoptères d'Europe et d'Algérie“. Bis jetzt sind die 8 ersten Unterfamilien beendigt. Wer sich also dem Spezialstudium der Proctotrupiden widmen will, findet in diesem umfangreichen, freilich auch kostspieligen Werke alles, was er braucht, vereinigt. 


\section{Systematik der Proctotrupiden.}

Übersicht der Unterfamilien.

1. Geflügelte Formen. 2.

Ungeflügelte Formen 12.

2. Hinterflügel mit deutlichem Basallappen. 3.

Hinterflügel ohne Basallappen. 5.

3. Kopf länglich oval, horizontal gestellt. Antennen in beiden Geschlechtern 12- oder 13 gliedrig. Mittelschienen mit 2 Endsporen. 1. Bethylinae.

Kopf nicht länglich oval, mit senkrecht gestellter Vorderseite. Antennen in beiden Geschlechtern 10 gliedrig. Mittelschienen mit höchstens 1 Sporn. 4.

4. Kopf rundlich. Vorderflügel mit schmalem Stigma und mit geschlossener 1. Cubital- und 1. Discoidalzelle. Vorderfüsse des Weibchens am Ende ohne Schere.

2. Emboleminae.

Kopf quer oder fast kubisch. Vorderflügel meist mit grossem Stigma. Vorderfüsse des Weibchens am Ende fast stets mit Schere.

3. Dryininae.

5. Hinterleib an den Seiten nicht scharf gerandet. 6 .

Hinterleib an den Seiten scharf gerandet. Antennen nahe am Munde eingelenkt. 11.

6. Schildchen durch zwei schräge, von der Mitte der Basis ausgehende Bogenlinien in 3 Teile geteilt. Antennen beim ? mit 9-11, beim ơ mit 10 oder 11 Gliedern. Flügel meist mit deutlichem Stigma; Radialzelle nie geschlossen.

4. Ceraphroninae.

Schildchen durch schräge Linien nicht geteilt. Antennen entfernt vom Mundrande eingefügt. Flügel mit oder ohne Stigma, im ersteren Falle die Radialzelle geschlossen. 7 .

7. Vorderflügel mit deutlichem Stigma; Radialzelle geschlossen. 8.

Vorderflügel ohne Stigma, nur zuweilen das Ende der Subcosta etwas verdickt. 9.

8. Antennen beim + und $\sigma^{7}$ mit 15 Gliedern. Klauen gekämmt. Hinterleibsstiel lang, zylindrisch. Flügelnervatur sehr kompliziert. 5. Helorinae.

Antennen beim $q$ und $\sigma^{7}$ mit 13 Gliedern. Klauen einfach oder gespalten. Hinterleib sitzend oder nur kurz gestielt, beim $q$ in einen schwach gekrümmten Schwanz verlängert, welcher den Bohrer enthält. Flügelnervatur einfach; Radialzelle kurz.

6. Proctotrupinae.

9. Hinterflügel langgestielt oder linear; alle Flügel am Rande mit langen Wimperhaaren. Antennen des 9 meist mit stark verdicktem Endgliede. Sehr zarte und winzige Tiere.

11. Mymarinae.

Hinterflügel nicht gestielt und nicht linear. Vorderflügel nicht auffallend lang gewimpert. 10.

10. Hinterflügel mit geschlossener Zelle an der Basis. Vorderflügel meist mit vollständigem Basalnerv, und daher mit geschlossener Basalzelle, meist auch mit einer Radialzelle. Antennen mit 14 oder 15 Gliedern.

7. Belytinae.

Hinterflügel ohne jede Zelle. Vorderflügel gewöhnlich ohne Basal- und ohne Radialzelle. Antennen mit 12-14 Gliedern.

8. Diapriinae. 
11. Vorderflügel fast stets mit Subcosta, Marginalnerv und Radius. Antennen in der Regel mit 12 Gliedern, selten mit 11 oder 7, wenn die Glieder der Keule verwachsen sind.

9. Scelioninae.

Vorderflügel meist ohne alle Nerven, selten die Subcosta vorhanden, die aber den Vorderrand nicht erreicht, sondern knopfförmig endet. Antennen mit 10 , selten mit 8 oder 9 Gliedern.

10. Platygasterinae.

12. Hinterleib an den Seiten nicht gerandet. 13.

Hinterleib an den Seiten gerandet. Antennen nahe am Munde eingelenkt. 19.

13. Antennen nahe am Munde eingelenkt. 14.

Antennen in der Mitte des Gesichtes eingelenkt. 17.

14. Kopf länglich oval, horizontal gestellt. Antennen mit 12 oder 13 Gliedern. Vordertarsen am Ende ohne Schere.

Kopf quer oder rundlich. 15.

1. Bethylinae.

15. Vorderschienen am Ende mit 2 Sporen. Schildchen durch 2 schräge Bogenlinien in 3 Teile geteilt.

4. Ceraphroninae.

Vorderschienen mit einem zweiteiligen Endsporn. Schildchen nicht durch Längslinien geteilt. 16.

16. Kopf rundlich. Vordertarsen am Ende ohne Schere. 2. Emboleminae. Kopf quer. Vordertarsen des $q$ am Ende mit Schere.

3. Dryininae.

17. Hinterleib des $q$ am Ende in einen scharf gekrümmten Schwanz verlängert, welcher den Legebohrer enthält. Der vordere Sporn unten mit hyaliner Lamelle. o stets geflügelt.

6. Proctotrupinae.

Hinterleib des $q$ am Ende nicht schwanzartig ausgezogen. Der vordere Sporn zweiteilig, ohne Lamelle. 18.

18. Antennen des $\subsetneq$ mit 14 Gliedern. $\sigma^{7}$ stets geflügelt. 7. Belytinae. Antennen des + mit 12 oder 13, die des $\sigma^{7}$ mit 14 Gliedern.

19. Antennen mit 12 Gliedern oder die 4 oder 5 Endelieder Diaprinae. vereinigt. Der vordere Sporn zweiteilig.

Antennen mit 10 Gliedern. Der vordere Sporn dreiteilig.

10. Platygasterinae.

\section{Unterfamilie. Bethylinae.}

Antennen mit 12 oder 13 Gliedern, in beiden Geschlechtern gleich. Viele Weibchen sind flügellos und von den Männchen ganz verschieden; von den Mutillen unterscheiden sie sich durch den länglich ovalen Kopf. Die Arten leben äusserlich an Käferlarven und Schmetterlingsraupen.

1. Flügel vollständig entwickelt; Radialzelle offen oder fehlend. 2.

Flügel verkümmert oder fehlend. 13.

2. Nervulus weit vor dem Ursprung des Basalnerven stehend. 3.

Nervulus interstitial, d. h. mit dem Basalnerv zusammentreffend. 4.

3. Augen nackt. Hierher eine ganze Reihe Arten. Bethylus Latr. $+0^{7}$ (non Förster nec Ashmead $=$ Perisemus Först.).

Augen deutlich behaart. In Mitteleuropa $A$. boops Thoms.

Anoxus Thoms. of (non Ashmead). 
4. Radius deutlich. 5.

Radius fehlend 12.

5. Basalnerv mit einem hakenförmigen, nach unten gerichteten Nervenast. Antennen mit 13 Gliedern.

Goniozus Först. $90^{7}$.

Basalnerv ohne Nervenast. 6. Zahn.

6. Pronotum mit Längsfurche. Metathorax beiderseits hinten mit starkem Pronotum ohne Längsfurche. Metathorax hinten ohne Seitenzähne. 7.

7. Metathorax verlängert, hinten nicht gerandet. 8.

Metathorax hinten gerandet. 9.

8. Pronotum mit Querfurche vor dem Hinterrand. Augen nackt. In Europa $P$. depressa $\mathrm{F}$., das $P$ ist ungeflügelt.

Pristocera Kl. o".

Pronotum ohne Querfurche. Augen behaart. Von den wenigen Arten am häufigsten $P$. carpentieri Kieff. Pseudisobrachium Kieff. $\sigma^{7}$.

9. Radius sehr kurz; Stigma nur durch eine schwache Verdickung des Marginalnervs angedeutet. Augen behaart. Antennen 13 gliedrig.

Laelius Ashm. of $\sigma^{7}$ (Bethylus Först. non Latr.).

Radius lang, die Radialzelle nur an der Spitze offen. 10.

10. Mesonotum ohne Parapsidenfurchen. Antennen 12 gliedrig. Schildchenbasis mit zwei voneinander getrennten Gruben. In Mitteleuropa nur eine Art: I. nigricorne Nees (Omalus nigricornis und fuscicornis Nees).

Isobrachium Först. $+\sigma^{7}$ (non Ashmead).

Mesonotum mit deutlichen Parapsidenfurchen. Antennen 13gliedrig. 11.

11. Schildchen an der Basis mit 2 kleinen Gruben. Pronotum viel länger als das Mesonotum. Hierher eine ganze Reihe Arten.

Epyris Westw. 웅 (non Ashmead).

Schildchen an der Basis mit Querfurche; sonst wie vorige Art.

Rhabdepyris Kieff. 웅․

12. Antennen mit 13 Gliedern. Die hierher gehörenden Arten leben an Käferlarven, z. B. bei Ptinus.

Scleroderma Latr. if ${ }^{7}$.

Antennen mit 12 Gliedern. Die Arten leben ebenfalls in Käferlarven.

13. Antennen 12 gliedrig. 14 .

Cephalonomia Westw. $+0^{7}$.

Antennen 13gliedrig. 16.

14. Mittelschienen gedörnelt. Metathorax nach hinten verbreitert. Nur das + bekannt. In Europa nur eine Art, $S$. rufa Först., das ganze Tier rot.

Mittelschienen nicht gedörnelt. 15.

Sclerochroa Först. ㅇ.

15. Nebenaugen vorhanden. Parapsidenfurchen deutlich. Klauen mit einem Zahn. Bethylus Latr.

Nebenaugen fehlend. Mesonotum ohne Parapsidenfurchen. Klauen einfach. Cephalonomia Westw. 9 .

16. Metathorax flach, mit einer oder mehreren Längsleisten. 17.

Metathorax ohne Längleiste und hinten ohne Seitenzähne. Schildchen fehlend. 18.

17. Pronotum mit deutlicher Längsfurche. Hinterecken des Metathorax stark zahnartig vorspringend. Mesitius Spin. + (non Ashmead). 
Pronotum ohne Längsfurche. Hinterecken des Metathorax nicht zahnartig vorspringend.

Epyris Westw. \& (non Ashmead).

18. Alle Schienen auf der Aussenseite unbewehrt. Metathorax fast vierseitig. Kopf quadratisch. Antennen sehr schlank fadenförmig.

Scleroderma Latr. ㅇ.

Mittelschienen auf der Aussenseite gedörnelt. Metathorax an der Basis oder in der Mitte etwas verengt. 19.

19. Das Metanotum springt bis zur Mitte der Seitenlappen des Mesonotums vor; der Mittellappen des Mesonotums ist also nach hinten um die Hälfte kürzer als die Seitenlappen.

Pristocera KI. ㅇ.

Das Metanotum springt nicht nach vorn zwischen die Seitenlappen des Mesonotums vor; die 3 Teile des Mesonotums also nach hinten von gleicher Länge. Augen punktförmig oder fehlend.

Pseudisobrachium Kieff. \& (Isobrachium Ashm. non Först.).

\section{Unterfamilie. Emboleminae.}

Diese kleine Unterfamilie ist in Europa nur in 2 Gattungen mit je einer Art vertreten. Über die Lebensweise ist wenig bekannt; eine hierher gehörende Art hat sich als äusseren Schmarotzer der Orthopterengattung Trigonidium erwiesen.

Flügel in beiden Geschlechtern vollkommen entwickelt. Nebenaugen gross. Einzige Art E. Ruddei Westw.

Embolemus Westw. + o?

Flügel ganz rudimentär. Nebenaugen sehr klein. Schaft sehr klein. Nur das $q$ bekannt. Die einzige Art $P$. rufescens Westw. ist ganz rotgelb.

Pedinomma Först. (Myrmecomorpha Westw.).

\section{Unterfamilie. Dryininae.}

Die Weibchen mehrerer Gattungen sind ausgezeichnet durch Raubfüsse, mit denen sie sich jedenfalls an die Wirte anklammern. Alle Arten leben äusserlich an Cicadinen, häufiger an den Larven als an den vollkommenen Insekten.

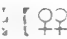

1. Flügel verkümmert oder ganz fehlend. Vorderbeine mit Raubfüssen. Scheitel zuweilen tief sattelförmig eingedrückt. 2.

Flügel normal entwickelt. 4.

2. Kopf hinten nicht gerandet; Scheitel mehr oder weniger sattelförmig eingedrückt. Thorax 2- oder $3 \mathrm{knotig}$, ohne deutliches Schildchen. Flügel vollständig fehlend. Beine lang, Vorder- und Hinterhüften stark verlängert, alle Schenkel keulenförmig. Die schwer unterscheidbaren Arten erinnern an Ameisen. Als Männchen sind jedenfalls die Labeo-Arten zu betrachten. Gonatopus Ljungh.

Kopf hinten gerandet; Scheitel konvex. Thorax nicht 2- oder 3 knotig; Schildchen deutlich. Flügelstummel vorhanden. 3.

3. Parapsidenfurchen vollståndig fehlend. Kopf fast 2 mal so breit als der Thorax. Pronotum beinahe doppelt so lang als das

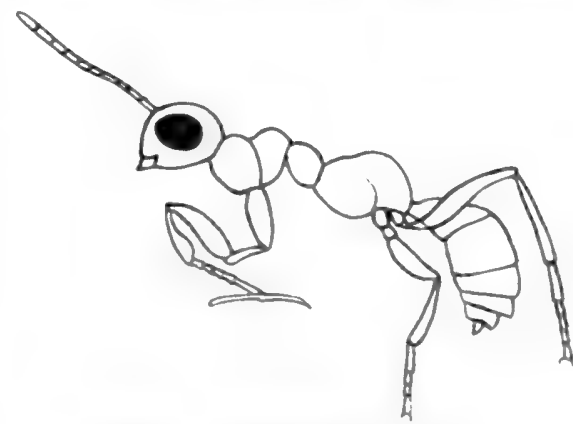

Abl, 50. Gonatopus bicolor Hal. 
Mesonotum. Die einzige, nur in Deutschland vorkommende Art, M. formicaeformis Ruthe, ist schwarzbraun, Kopf und Thorax fein punktiert und matt, fein seidenartig behaart.

Parapsidenfurchen wenigstens vorn deutlich.

Mystrophorus Först. Anteon Jur.

4. Vorderbeine einfach, ohne Scherenglied. Vorderflügel nur mit Subcosta und Radius; Stigma gross, halbelliptisch. Gesicht unten weiss. Die beiden Arten leben äusserlich an Typhlocyba-Arten; am bekanntesten $A$. melaleucus Dalm. Aphelopus Dalm.

Vorderbeine mit Scherenglied. Flügel ausser Subcosta und Radius noch mit 2 Basalzellen. 5.

5. Kopf hinten nicht gerandet; Scheitel sattelförmig eingedrückt; das dritte Antennenglied mehrmals länger als der Schaft. Flügel mit hellen und dunklen Querbinden. In Mitteleuropa nur D. formicarius Latr., ein etwa $8 \mathrm{~mm}$ grosses, höchst seltenes Tier.

Dryinus Latr.

Kopf hinten gerandet; Scheitel konvex; das 3. Antennenglied nicht doppelt so lang als der Schaft. Hierher zahlreiche Arten.

Anteon Jur.

\section{$0^{7} 0^{x}$}

1. Flügel verkümmert, löffelförmig. Hinterkopf mit geradem und scharfem Rand. Die einzige Art, $M$. formicaeformis Ruthe, ist etwa $3 \mathrm{~mm}$ lang.

Flügel vollständig entwickelt. 2 .

Mystrophorus Först.

2. Vorderflügel nur mit Subcosta und Radius; Basalzellen fehlen. Stigma halbelliptisch. Hinterleib stark komprimiert. Clypeus oder der untere Teil des Gesichts weiss.

Aphelopus Dalm.

Vorderflügel ausser Subcosta und Radius noch mit 2 Basalzellen. Hinterleib nicht komprimiert. 3.

3. Stigma gross, halbelliptisch. Augen unbehaart. Klauen zweiteilig.

Stigma sehr schmal. Augen dicht behaart. Klauen einfach. Anteon Jur. Meinung die Männchen von Gonatopus.

Labeo Hal.

\section{Unterfamilie. Ceraphroninae.}

Kopf von vorn gesehen oval oder rundlich; Antennen gekniet, an der Basis des Clypeus eingefügt, beim + mit 10 oder 11, höchst selten mit nur 9, beim $0^{7}$ mit 11, ausnahmsweise mit nur 10 Gliedern. Flügel meist mit grossem, selten mit linearem Stigma und mit Radialnerv; Radialzelle nicht geschlossen. Flügellose Formen nicht selten. Hinterleib sitzend, an den Seiten nicht gerandet. Die zahlreichen Arten schmarotzen bei Aphiden, Cocciden, Cecidomyiden, Musciden und Syrphiden.

1. Flügel vollständig entwickelt, mit deutlichem Radius. 2.

Flügel fehlend oder stummelhaft, ohne deutlichen Nerv. 10.

2. Vorderflügel mit grossem Stigma. Antennen in beiden Geschlechtern mit 11 Gliedern. 3.

Vorderflügel mit linearem, also so gut wie fehlendem Stigma. Antennen des 9 mit 10 , des $\sigma^{7}$ mit 11 Gliedern. 8 .

3. Körper ganz flach. Mund an der Unterseite des Kopfes. Mesonotum ohne Längsfurche. Die beiden Arten wurden bisher nur in Frankreich gefunden. 
Körper nicht abgeplattet. Mund am Vorderrande des Kopfes. Mesonotum höchst selten ohne Längsfurche. 4 .

4. Mesonotum ohne Längsfurche oder nur mit einer einzigen in der Mitte. Antennen des $\sigma^{7}$ entweder sägeförmig oder mit Ästen.

Mesonotum mit 3 Längsfurchen. 5.

Dendrocerus Ratzeb. (Atritomus Först.).

5. Flügel kahl, am Rande nicht gewimpert; Stigma halbkreisförmig.

Trichosteresis Först.

Flügel fein behaart, am Rande gewimpert; Stigma länger als breit. 6 .

6. Metathorax an seiner Basis mit einem gegabelten, selten einfachen Dorn.

Metathorax ohne Dorn. 7.

Megaspilus Westw. (Habropelte Thoms.).

7. Augen deutlich behaart. Nebenaugen im Dreieck. Hinterleib nicht gestielt, an der Basis gestreift. Antennen des $\sigma^{7}$ mit zylindrischen Gliedern. Zahlreiche Arten.

Conostigmus Dahlb. (Megaspilus aut.).

Augen nackt. Nebenaugen in gerader oder leicht gebogener Linie. Hinterleib mit kurzem, gestreiftem Stiel. Antennen des $0^{7}$ gesägt, seltener mit Ästen (Dendrocerus Först. non Ratzeb.).

Lygocerus Först. (Ceraphron Thoms. non Jur.).

8. Mesonotum mit 3 Längsfurchen. Hinterleibsbasis mit 3 Längsleisten. \& flügellos. Lagynodes Först.

Mesonotum ohne oder nur mit einer einzigen Längsfurche. Hinterleibsbasis kurz längsstreifig. † meist geflügelt. 9.

9. Mesonotum mit deutlicher Längsfurche. Antennenglieder des $\sigma^{7}$ zylindrisch. Ceraphron Jur. (non Thoms.).

Mesonotum ohne Längsfurche. Antennengeissel des $\sigma^{7}$ gesägt. Aphanogmus Thoms.

10. Kopf stark abgeplattet, Stirn und Scheitel eine Fläche bildend. Thorax seitlich zusammengedrückt. Kopf und Thorax matt, Hinterleib glänzend, bei der einen Art messerförmig. Antennen des $q 10$ gliedrig. $0^{7}$ unbekannt. Die beiden bekannten Arten sind nur $1 \mathrm{~mm}$ lang.

Synarsis Först.

Kopf nicht abgeplattet; Stirn und Scheitel gegeneinander geneigt. 11.

11. Augen sehr klein, kürzer als die Wangen oder ihre Entfernung vom Scheitelrande, fein behaart. Mesonotum, Schildchen und Metathorax deutlich. Hinterleib an der Basis mit 2-4 Grübchen, von denen Längsstreifen ausgehen. Am häufigsten $L$. pallidus Boh.; $\&$ fast ganz gelbrot, $\sigma^{\prime \prime}$ zum Teil schwarz.

Lagynodes Först. rand. 12 .

Augen gross, viel länger als die Wangen oder ihre Entfernung vom Scheitel-

12. Mesonotum mit 3 Längsfurchen. Antennen mit 11 Gliedern in beiden Geschlechtern. 13.

Mesonotum mit 1 oder 2 Längsfurchen oder ganz ohne solche. 14.

13. Metathorax an seiner Basis mit einem gegabelten, selten einfachen Dorn.

Metathorax ohne Dorn. Augen behaart. Megaspilus Westw. (Habropelte Thoms.).

Conostigmus Dahlb. (Megaspilus aut.).

14. Mesonotum mit 2 Längsfurchen. Antennen mit 11 Gliedern in beiden Geschlechtern. $\&$ und $\sigma^{7}$ flügellos. Hierher D. dimidiatus Thoms. Kopf $2 \mathrm{mal}$ 
so breit wie der Thorax; schwarz. Schaft, Thorax mit Ausnahme von Schildchen und Metathorax, sowie Beine rot. Länge reichlich $1 \mathrm{~mm}$. Dichogmus Thoms.

Mesonotum mit nur einer oder ohne Längsfurche. $\sigma^{7}$ geflügelt. 15.

15. Fühler des + mit 11 Gliedern. Mesonotum mit oder ohne Längsfurche.

Antennen des o t nur mit 10 Gliedern. 16.

Dendrocerus Ratzeb.

16. Mesonotum mit deutlicher Längsfurche. Schildchen ziemlich flach.

Ceraphron Jur.

Mesonotum mit undeutlicher oder ganz fehlender Längsfurche. Schildchen stark konvex.

Aphanogmus Thoms.

\section{Unterfamilie. Helorinae.}

Hierher nur die Gattung Helorus Latr., die durch die eigentümliche Flügelnervatur und die Form des Hinterleibs sattsam charakterisiert ist. Von den wenigen Arten ist die bekannteste $H$. anomalipes Panz.; hier in Thüringen ist die Art gar nicht selten; sie lebt nach Förster bei der Neuropteren-Gattung Hemerobius.

\section{Unterfamilie. Proctotrupinae.}

Kopf quer, selten etwas aufgetrieben; Antennen in beiden Geschlechtern 13 gliedrig; Mandibeln am Ende meist zugespitzt. Vorderflügel mit grossem, halbrundem oder elliptischem Stigma und sehr kurzer Radialzelle (Abb. 48). Hinterleib konisch-oval, beim + hinten in eine Art Schwanz oder Tubus ausgezogen, beim $\sigma^{7}$ mit 2 schmalen und spitzen Anhängseln. Die Arten leben mit Vorliebe bei Pilzmücken und verschiedenen anderen kleinen Dipteren, eine wurde auch aus einem Tausendfuss, Lithobius forficatus, gezüchtet.

1. Metathorax glatt, ohne Längskiel. \& ungeflügelt. Hierher 3 Arten.

Paracodrus Kieff. (Codrus Thoms.).

Metathorax wenigstens mit Längskiel in der Mitte, meist mit feinen Runzeln. i geflügelt. 2 . Arten.

2. Mesonotum mit 2 deutlichen Parapsidenfurchen. In Deutschland wenige

Mesonotum ohne Parapsidenfurchen. 3.

Disogmus Först.

3. Die Fussklauen der Vorder- und Mittelbeine dreiteilig, das letzte Fussglied selbst verdickt. Kopf des + meist kuglig; Antennen dick, mit kurzen Gliedern. Exallonyx Kieff.

Alle Fussklauen einfach. Kopf quer; Antennen schlank, mit verlängerten Gliedern. Hierher zahlreiche Arten. Serphus Schrank (Proctotrupes Latr.).

Serphus zerfällt in die folgenden 3 Untergattungen:

1. Hinterleib zum Teil rot; Legebohrer des $q$ fadenförmig, mindestens halb so lang wie der Hinterleib. Hierher die grössten Arten.

Serphus Schrank.

Hinterleib schwarz. Meist kleinere Arten. 2.

2. Hinterleib kurz gestielt; Legebohrer des ${ }^{\circ}$ nach hinten allmählich zugespitzt. Metathorax oben fein runzlig, selten nach vorn glatt.

Phaenoserphus Kieff.

Hinterleib sitzend; Legebohrer fadenförmig. Metathorax oben glatt und in Felder geteilt.

Cryptoserphus Kieff. 


\section{Unterfamilie. Belytinae.}

Kopf quer oder rundlich; Augen meist behaart; Antennen auf einer Stirnerhöhung, beim + mit 15 , seltener mit 14 , beim $\sigma^{7}$ gewöhnlich mit 14 Gliedern, das 3. Glied beim $\sigma^{7}$ in der Regel ausgerandet. Pronotum nach vorn meist halsartig verschmälert; Mesonotum fast stets mit deutlichen Parapsidenfurchen; Metathorax kurz, in der Regel mit Längskiel. Die charakteristische Flügelnervatur ergibt sich am besten aus der Zeichnung.

Die Hinterflügel besitzen in der Regel eine geschlossene Basalzelle. Schenkel verdickt; die vordersten Schienen mit 1, die Mittel- und Hinterschienen mit je 2 Endsporen; Tarsen lang und schlank mit 5 Gliedern. Hinterleib deutlich gestielt, das 2. Segment sehr gross.

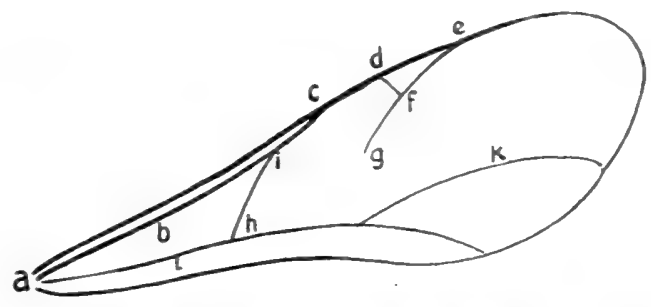

Abb. 51. Vorderflügel von Cinetus.

a c Costa; a b c Subcosta; cd Marginalnerv; de Postmarginalnerv; df Stigmaticalnerv; fe Radialnerv; fo Rūcklaufender Nerv; hi Basalnerv; $k$ Discoidalnerv; 1 Analnerv.

Die Mehrzahl der Arten lebt bei pilzbewohnenden Dipteren und findet man im Spätsommer und Herbst auf Gebüsch an schattigen Stellen in Wäldern und Schluchten manche Art in grosser Menge.

\section{우}

1. Stirn flach, die Antennen auf keiner Erhöhung sitzend. Augen nackt. Mesonotum ohne Parapsidenfurchen. Beide Geschlechter geflügelt. Hierher wenige Arten, am auffallendsten I. dorsiger Curt. mit blassgelber Färbung.

Ismarus Hal.

Antennen auf einer Stirnerhöhung eingelenkt. Augen meist behaart. Mesonotum mit tiefen Parapsidenfurchen oder Flügel fehlend oder rudimentär. 2.

2. Parapsidenfurchen undeutlich. Schildchen an der Basis ohne Grube. Nebenaugen und Flügel vollständig fehlend. Antennen 14 gliedrig. Endglied der Hintertarsen fast so lang wie die 3 vorhergehenden Glieder zusammen. Augen nackt. Nur das $q$ bekannt. In Deutschland nur A. Ashmeadi Mayr, von braunroter Färbung. Das letzte Antennenglied blassgelb. Anommatium Först.

Parapsidenfurchen tief. Schildchengrube deutlich. Flügel wenigstens als Stummel vorhanden. Endglied der Hintertarsen kürzer. Augen meist behaart. 3.

3. Hinterschildchen mit einem starken Dorn. 4.

Hinterschildchen ohne Dorn. 6.

4. Antennen mit 14 Gliedern. Das grosse Rückensegment ohne Längsfurche. Hierher nur $A$. Marshalli Kieff. Acanthopsilus Kieff.

Antennen mit 15 Gliedern. Das grosse Rückensegment mit Längsfurche. 5.

5. Hinterleibsstiel höchstens doppelt so lang wie breit; Hinterleib hinten nicht konisch zugespitzt. Flügelmitte meist fleckig getrübt. Oxylabis Först.

Hinterleibsstiel 3- oder $4 \mathrm{mal}$ so lang wie breit; Hinterleibsende konisch zugespitzt. In Mitteleuropa 2 Arten, $P$. semirufa Kieff. mit rötlichgelbem, $P$. fuscicornis Kieff. mit rotbraunem Hinterleibe.

Paroxylabis Kieff.

6. Hinterleibsstiel kurz und dick, oben mit herzförmiger Erhöhung. Basis des 2. Bauchsegments nach vorn erweitert. 7.

Hinterleibsstiel oben ohne herzförmige Erhöhung. Das 2. Bauchsegment nach vorn nicht erweitert. 8. 
7. Schaft einfach, am Ende ohne Zähnchen. Augen behaart. Prothorax ohne filzige Behaarung. Bei der einzigen Art, C. productus Kieff., sind Beine und Hinterleib grösstenteils rot.

Cardiopsilus Kieff.

Schaft am Ende mit 2 Zähnchen. Augen nackt. Prothorax filzig behaart. Die wenigen Arten mehr in Südeuropa. Acanosema Kieff.

8. Das 3. Antennenglied so lang wie die folgenden zusammen. Hinterleibsstiel kurz. In Deutschland D. Westwoodi Först. ơ unbekannt. Diphora Först.

Das 3. Antennenglied viel kürzer als die folgenden zusammen. 9.

9. Schaft am Ende beiderseits mit Zähnchen. Mandibeln schnabelartig vorstehend. In Europa 2 Arten.

Schaft am Ende einfach, nicht gezähnt. 10. Rhynchopsilus Kieff.

10. Mediannerv, d. h. der mittlere Nerv von der Basis des Vorderflügels bis zum Ursprung des Basalnerven, fehlend. Mandibeln schnabelartig vorstehend. 2 Arten aus Schweden bekannt.

Opazon Hal.

Mediannerv vorhanden. Mandibeln nicht schnabelartig vorstehend. 11.

11. Der Längskiel des Metathorax gabelt sich nach hinten und schliesst einen dreieckigen Raum ein. Hierher zahlreiche Arten.

Längskiel des Metathorax hinten nicht gegabelt. 12.

Belyta Jur.

12. Hinterleib mit weniger als 6 Rückensegmenten oder das 3. Segment viel länger als das 4; Hinterleibsstiel lang. Radialzelle geschlossen. 13.

Hinterleib mit 6-8 Rückensegmenten, das 3. kaum länger als das 4. 18.

13. Marginalnerv $3 \mathrm{mal}$ so lang wie die kleine Radialzelle. Antennenglieder lang zylindrisch. In Deutschland M. lepidus Mayr; Körper glänzend, Hinterleib grösstenteils gelb. Macrohynnis Först.

Marginalnerv höchstens um die Hälfte länger als die Radialzelle oder Flügel rudimentär. 14.

14. Hinterleib mit 3 oder 4 Rückensegmenten. Antennen lang, Geisselglieder lang zylindrisch. 15.

Hinterleib mit mehr als 4 Segmenten. 16.

15. Das 2. Segment nicht stark verlängert, das 3. lang und stark von der Seite zusammengedrückt. Schaft lang und dünn. Hierher eine Reihe Arten.

Leptorhaptus Först.

Das 2. Segment sehr stark verlängert und zusammengedrückt, fast bis zur Hinterleibsspitze reichend, das 3. kurz und spitz und nach oben gerichtet. Wenige Arten.

Miota Först.

16. Die 3 letzten Segmente schmal, schwanzartig verlängert, zusammen so lang wie das 2. Segment. Nur die $\nmid+$ bekannt. Wenige mehr im Süden vorkommende Arten.

Scorpioteleia Ashm.

Die 3 letzten Segmente nicht in einen Schwanz ausgezogen. 17.

17. Hinterleib oben und unten konvex, so hoch wie breit. Mandibeln lang, gekreuzt. Zahlreiche Arten.

Xenotoma Först.

Hinterleib oben flach, unten konvex, viel breiter als hoch. Mandibeln klein, sich bedeckend. 3. Rückensegment viel länger als das 4. Zahlreiche Arten.

18. Thorax breiter wie hoch. Hierher 4 Arten, 2 davon mit verkürzten Flügeln. Paraclista Kieff.

Thorax ebenso hoch wie breit. 19. 
19. Flügel rudimentär. 20 .

Flügel normal entwickelt. 21.

20. Geisselglieder nicht länger als dick, mit Ausnahme des ersten und letzten. Das letzte Segment nicht länger als die 3 vorhergehenden zusammen und nicht deutlich komprimiert.

Aclista Först.

Die 8 ersten Geisselglieder länger als dick. Das letzte Segment länger als die 3 vorhergehenden zusammen und stark komprimiert. Acropiesta Först.

21. Radialzelle an der Spitze offen oder ganz fehlend. 22.

Radialzelle vorhanden und geschlossen. 25.

22. Augen nackt. Rücklaufender Nerv lang und nach unten gebogen. 23.

Augen behaart. Rücklaufender Nerv gegen den Basalnerv gerichtet oder undeutlich. 24.

23. Antennen 15 gliedrig, ohne Keule; Schaft einfach. Radialnerv vollständig fehlend.

Psilomma Först.

Antennen 14gliedrig, mit einer Keule von 6 Gliedern; Schaft am Ende mit 2 schwachen Zähnchen. Radialnerv angedeutet. Acanopsilus Kieff.

24. Hinterflügel ohne Zelle. Antennen mit 14 oder 15 Gliedern. Hinterleib nicht deprimiert, so hoch wie breit, mit 6 Rückensegmenten.

Pantolyta Först.

Hinterflügel mit einer geschlossenen Basalzelle. Antennen mit 15, selten mit 14 Gliedern. Hinterleib schwach deprimiert, etwas breiter als hoch, mit 7 oder 8 Rückensegmenten.

Aclista Först.

25. Alle Geisselglieder verlängert, das vorletzte noch um die Hälfte länger als dick. Hierher 3 Arten.

Zelotypa Först.

Wenigstens einige Geisselglieder nicht länger als dick. 26.

26. Hinterleibsende leicht nach oben gebogen. Antennen mit 14 oder 15 Gliedern. 27.

Hinterleibsende nicht nach oben gebogen. Antennen mit 15 Gliedern. 28.

27. Mandibeln klein, sich am Ende berührend.

Anectata Först.

Mandibeln lang, sichelförmig, gekreuzt. Die of sind nicht bekannt, wahrscheinlich unter Xenotoma.

Acoretus Hal.

28. Das letzte Rückensegment nicht länger als die 3 vorhergehenden zusammen und nicht deutlich komprimiert. Zahlreiche Arten. Pantoclis Först.

Das letzte Rückensegment viel länger als die 3 vorhergehenden zusammen und stark komprimiert.

Acropiesta Först.

1. Stirn flach, die Antennen auf keiner Erhöhung sitzend. Augen nackt. Mesonotum ohne Parapsidenfurchen.

Ismarus Hal.

Stirn mit einem Vorsprung, auf welchem die Antennen sitzen. Augen behaart, ausgenommen bei Psilomma. Parapsidenfurchen durchlaufend. 2.

2. Hinterschildchen mit Dorn. 3.

Hinterschildchen ohne Dorn. 4.

3. Hinterleib elliptisch; Hinterleibsstiel höchstens $2 \mathrm{mal}$ so lang wie dick. Oxylabis Först.

Hinterleib hinten konisch zugespitzt; Hinterleibsstiel 4 mal so lang wie dick. Paroxylabis Kieff. 
4. Schaft am Ende beiderseits mit einem Zähnchen. 5.

Schaft einfach, am Ende ohne Zähnchen. 6.

5. Prothorax nicht filzig behaart. Mandibeln gerade und parallel, schnabelartig von $1 / 3$ Kopflänge vorstehend.

Rhynchopsilus Kieff.

Prothorax filzig behaart. Mandibeln nicht schnabelartig vorstehend.

Acanosema Kieff.

6. Mediannerv, d. h. der Nerv, welcher von der Flügelbasis bis zum Ursprung des Basalnervs geht, fehlend. Mandibeln schnabelartig vorstehend.

Opazon Hal.

Mediannerv vorhanden. Mandibeln nicht schnabelartig vorstehend. 7.

7. Mesonotum mit 4 Längsfurchen. Antennen von Körperlänge, Geisselglieder nicht deutlich geschieden. + nicht bekannt. Einzige Art $T$. filicornis.

Tetrapsilus Kieff. $0^{7}$.

Mesonotum nur mit den beiden Parapsidenfurchen, der mittlere Teil ohne Längsfurchen. Geisselglieder deutlich voneinander geschieden. 8.

8. Der Längskiel des Metathorax gabelt sich nach hinten und schliesst einen dreieckigen Raum ein.

Längskiel des Metathorax einfach oder undeutlich. 9.

Belyta Jur.

9. Radialzelle an der Spitze offen oder ganz fehlend. 10.

Radialzelle geschlossen 12.

10. Radialzelle deutlich. Hinterflügel mit geschlossener Basalzelle.

Radialzelle kaum angedeutet. 11 .

Aclista Först.

11. Augen nackt. Rücklaufender Nerv nach unten gerichtet.

Psilomma Först.

Augen behaart. Rücklaufender Nerv gegen den Basalnerv gerichtet. Hinterflügel ohne Basalzelle.

Pantolyta Först. stiel lang.

12. Marginalnerv mehr als 2 mal so lang wie die Radialzelle. Hinterleibs-

Marginalnerv nicht $2 \mathrm{mal}$ so lang wie die Radialzelle. 13.

13. Rücklaufender Nerv entweder gerade und gegen den Basalnerv gerichtet oder ganz fehlend. 14.

Rücklaufender Nerv gebogen und nach hinten gerichtet. 16.

14. Hinterleibsstiel über $2 \mathrm{mal}$ so lang als breit. Leptorhaptus Först.

Hinterleibsstiel kurz, gewöhnlich kaum länger als breit, höchstens 2 mal so lang wie breit. 15 .

15. Hinterleibsende nach unten gebogen.

Hinterleibsende nicht nach unten gebogen.

Pantoclis Först. Anectata Först.

16. Mandibeln lang, gekreuzt. Marginalnerv gewöhnlich viel kürzer als die Radialzelle und kaum länger als der 1. Abschnitt des Radius. Xenotoma Först.

Mandibeln klein, sich bedeckend. Marginalnerv immer viel länger als der 1. Abschnitt des Radius, gewöhnlich so lang wie die Radialzelle. 17.

17. Hinterleibsstiel oben nicht deutlich gestreift. Das 2. Segment etwas von der Seite zusammengedrückt.

Leptorhaptus Först.

Hinterleibsstiel oben gestreift. Das 2. Segment nicht von der Seite zusammengedrückt.

Cinetus Jur. 


\section{Unterfamilie. Diapriinae.}

Die Unterschiede dieser Familie von der vorhergehenden sind in der Übersichtstabelle angegeben. Es ist im allgemeinen nicht schwer, eine Grenze zwischen beiden zu ziehen; immerhin gibt es eine Reihe Gattungen, welche eine scharfe Trennung unmöglich machen; Kieffer in seinem grossen Werke spricht sich deshalb für eine Vereinigung der beiden Unterfamilien aus.

Die meisten Arten leben in den Larven und Puppen von Dipteren, eine Reihe Arten gehören auch zu den Ameisenfreunden.

\section{Flügel normal entwickelt. 2.}

Flügel verkürzt oder ganz fehlend. 25.

2. Antennen mit 13 Gliedern. 3.

Antennen mit 12 Gliedern. 10.

3. Das stark verdickte Endglied der Antennen bildet für sich allein eine Keule. Schildchen an der Basis ohne Grube. Flügel am Ende abgerundet oder ausgerandet.

Monelata Först.

Das Endglied der Antennen bildet nicht allein eine Keule. Schildchen an der Basis mit 1 oder 2 Gruben. 4.

\section{Metathorax mit Dorn. 5.}

Metathorax unbewehrt oder mit lamellenartigem Zahn. 6 .

5. Hinterleib am Ende konisch zugespitzt. Die Basis des 2. Rückensegments greift nicht über das Ende des Hinterleibsstiels.

Paramesius Westw.

Hinterleib am Ende mehr abgerundet und etwas niedergedrückt. Die Basis des 2. Segments überragt nach vorn das Ende des Hinterleibsstiels.

6. Flügel am Ende ausgerandet oder abgestutzt.

Spilomicrus Westw. Flügel am Ende abgerundet. 7.

7. Die Subcosta reicht nicht über das Basaldrittel des Flügels hinaus. Antennen fadenförmig oder gegen das Ende allmählich verdickt.

Die Subcosta reicht ungefähr bis zur Mitte des Vorderrandes. 8.

Spilomicrus Westw.

8. Die Basis des 2. Segments greift über das Ende des Hinterleibsstiels. Spilomicrus Westw.

Die Basis des 2. Segments greift nicht über das Ende des Hinterleibsstiels. 9.

9. Hinterleib am Ende des 2. Segments breit abgestutzt. Marginalnerv punktförmig.

Hemilexis Först.

Hinterleib am Ende konisch zugespitzt und etwas von der Seite zusammengedrückt. Marginalnerv nicht punktförmig.

Paramesius Westw.

10. Mandibeln nach unten schnabelartig verlängert. Gesicht nicht normal. 11.

Mandibeln nicht schnabelartig vorstehend. Gesicht normal. 13.

11. Flügel ohne deutliche Nerven. Schildchen an der Basis mit 2 Gruben. Antennenschaft in der Mitte winklig erweitert oder am Ende schräg abgestutzt.

Flügel mit deutlicher Subcosta, Basal- und Marginalnerv und dem 1. Abschnitt des Radius. Schildchen nur mit einer Grube an der Basis. 12. 
12. Mesonotum mit 2 deutlichen Parapsidenfurchen. Synacra Först. Mesonotum ohne Parapsidenfurchen.

13. Flügel ohne Nerven. Kopf kuglig.

Flügel wenigstens mit deutlicher Costa und Subcosta. 14.

Prosynacra Kieff. Aneuropria Kieff.

14. Die Subcosta erreicht nicht den Flügelvorderrand und endet mit einer Verdickung. Parapsidenfurchen deutlich. 15.

Die Subcosta erreicht den Flügelvorderrand. 16.

15. Von der Endverdickung der Subcosta geht ein kurzer Nerv schräg in die Flügelfläche, entsprechend dem 1. Abschnitt des Radius. Basis des 2. Segments mit 3 Furchen. Aneurhynchus Westw.

Von dem Ende der Subcosta geht kein schräger Nerv aus. Das 2. Segment an der Basis ohne Furchen.

Labolips Hal.

16. Hinterleibsstiel halbkuglig, nur um $1 / 3$ schmäler als das 2. Segment.

Cyathopria Kieff.

Hinterleibsstiel zylindrisch, weit schmäler als das 2. Segment. 17.

17. Die Subcosta reicht bis zur Mitte des Vorderrandes. Basalnerv vorhanden. 18.

Die Subcosta reicht nicht über das Basaldrittel des Flügels hinaus. 19.

18. Antennen ohne deutliche Keule. Die 3 Arten leben bei Ameisen.

Antennen mit einer Keule von 5 Gliedern.

Neuropria Kieff.

19. Flügel mit Basalverv. 20.

Flügel ohne Basalnerv. 21.

20. Antennenkeule mit 3 grossen Gliedern. Zahlreiche Arten.

Antennenkeule mit 4 grossen Gliedern.

Loxotropa Först. Basalys Westw.

21. Kopf von oben gesehen deutlich länger als breit. Die 3 letzten Antennenglieder bilden eine abgesetzte Keule. Die einzige Art, G. longiceps Kieff., lebt bei Ameisen.

Geodiapria Kieff.

Kopf nicht länger als breit. 22 .

22. Kopf gross, von oben gesehen pentagonal. Antennenkeule mit 4 oder 5 Gliedern. Schildchen zuweilen mit Kiel. Die Arten leben bei Ameisen.

Kopf rundlich oder quer. 23.

Tetramopria Wasm.

23. Schildchen an der Basis ohne Grübchen. Antennenkeule mit 3 oder 4 Gliedern. Die wenigen kleinen Arten leben in Fliegenlarven.

Schildchen an der Basis mit 1 oder 2 Grübchen. 24.

Phaenopria Ashm.

24. Schildchen mit Längskiel, am Ende etwas zusammengedrückt.

Schildchen ohne Kiel, am Ende nicht zusammengedrückt.

Diapria Latr.

Trichopria Ashm.

25. Antennen mit 14 Gliedern. Hinterschienen zum Teil aufgetrieben. Nur das $q$ bekannt. In Deutschland P. Försteri Kieff. Polypeza Först.

Antennen mit 11-13 Gliedern. 26. 
26. Antennen mit 11 Gliedern; die beiden letzten Glieder bilden eine Keule. Hinterleibsstiel mit Querschuppe wie bei den Formiciden. Die beiden Arten leben bei der Ameisengattung Solenopsis.

Antennen mit 12 oder 13 Gliedern. 27.

Solenopsia Wasm.

27. Antennen mit 13 Gliedern. 28.

Antennen mit 12 Gliedern. 31.

28. Schildchen an der Basis ohne Grube, nicht vom Mesonotum getrennt, zuweilen ganz fehlend. Antennen mit grosser Keule. 29.

Schildchen an der Basis mit 1 oder 2 Gruben, deutlich vom Mesonotum getrennt. 5.

29. Antennenkeule mit 4 Gliedern. Kopf von oben gesehen fast quadratisch. Metathorax dicht filzig behaart. In Europa 2 sehr kleine Arten.

Antennenkeule mit 3 Gliedern. 30.

Eriopria Kieff.

30. Augen klein, behaart. Kopf rundlich. Schildchen nicht vorhanden. Die wenigen Arten wurden in Südeuropa gefunden; die $\sigma^{7} \sigma^{7}$ sind nicht bekannt. Symphytopria Kieff.

Augen gross, nackt. Kopf fast viereckig. Schildchen deutlich. Die einzige Art, A. pedestris Kieff., wurde bei Triest gefunden. Antropria Kieff.

31. Hinterleibsstiel mit grosser Querschuppe. Antennenkeule abgesetzt aber nicht gross, 4 gliedrig. Oo nicht bekannt. Einzige Art L. pedestris Kieff.

Hinterleibsstiel ohne Schuppe. 32.

Lepidopria Kieff.

32. Schildchen ohne Grube an der Basis, nicht vom Mesonotum getrennt. 33.

Schildchen mit 1 oder 2 Gruben an der Basis, deutlich vom Mesonotum getrennt. 35.

33. Kopf rundlich, etwas breiter als der Thorax. Die 3 oder 4 letzten Antennenglieder verdickt.

Kopf länger als breit. 34 .

Phaenopria Ashm.

34. Metathorax mit 3 Kielen. Die Antennenkeule besteht aus 3 grossen Gliedern. Die einzige europäische Art, A. fulvicornis Kieff., hat rote Antennen, das $?$ auch roten Thorax.

Atomopria Kieff.

Metathorax ohne Kiel. Antennen ohne Keule. Die einzige Art, P. pedestris Kieff., lebt bei Lasius niger. Das $\sigma^{7}$ ist nicht bekannt. Planopria Kieff.

35. Mandibeln schnabelartig verlängert. 36.

Mandibeln nicht schnabelartig verlängert. 37.

36. Scheitel vorn mit mehreren Zähnen. Antennenschaft in der Mitte winklig erweitert oder am Ende schräg abgestutzt.

Galesus Curt.

Scheitel ohne Zähne. Antennenschaft einfach. Thorax weit schmäler als Kopf und Hinterleib. Bohrer weit vorragend.

Synacra Först.

37. Kopf viereckig, niedergedrückt. Beine kurz und dick. Hierher 2 Arten, die mit Vorliebe am Meeresufer zwischen Tang usw. leben.

Kopf rundlich, nicht flachgedrückt. 38 .

Platymischus Westw.

38. Mesonotum ohne Parapsidenfurchen. 39.

Mesonotum mit deutlichen Parapsidenfurchen. 
39. Antennenkeule mit 3 Gliedern.

Loxotropa Först. Antennenkeule mit 4 Gliedern. Basalys Westw.

40. Schläfen, Seiten des Prothorax und Metathorax mit dichter weisser filziger Behaarung. Die Flügelstummel reichen bis zur Mitte des Hinterleibsstieles. Nur das + bekannt. Einzige Art G. subpilosa Kieff.

Glyptonota Först.

Schläfen, Pro- und Metathorax ohne auffallende Behaarung. 41.

41. Antennen ohne Keule oder dieselbe mit 5 Gliedern.

Aneurhynchus Westw. Antennen mit 4 gliedriger Keule. Einzige Art P. fuscicornis Kieff.

Pezopria Kieff.

1. Antennen mit 14 Gliedern. 2.

Antennen mit 13 Gliedern. 18. und gebogen.

2. Hinterleibsstiel mit Querschuppe. Das 4. Antennenglied keulenförmig Hinterleibsstiel ohne Schuppe. 3. Solenopsia Wasm.

3. Das 3. Antennenglied ausgerandet oder winklig. 4.

Das 4. Antennenglied ausgerandet oder winklig oder alle Glieder einfach. 7.

4. Mandibeln schnabelartig verlängert. 5 .

Mandibeln nicht schnabelartig verlängert. 6 .

5. Parapsidenfurchen durchlaufend. Der Schnabel steht fast senkrecht zum Gesicht.

Synacra Först. Gesichts.

Parapsidenfurchen fehlend. Der Schnabel liegt in der Verlängerung des

6. Antennengeissel nicht lang behaart. Prosynacra Kieff. Antennengeissel mit langen, wirtelförmig gestellten Haaren. Diapria Latr. 7. Schildchen ohne Grube an der Basis. Körper gedrungen.

Schildchen an der Basis mit 1 oder 2 Gruben. 8.

Phaenopria Ashm.

8. Gesicht nach hinten verlängert. Mandibeln schnabelartig. Flügel ohne deutlichen Nerv.

Galesus Curt.

Gesicht nach hinten nicht verlängert. Mandibeln nicht schnabelartig. 9.

9. Flügel stummelartig oder ganz fehlend. Geissel fein behaart. 10.

Flügel vollständig entwickelt. 12 .

10. Schaft sehr gross, breit und flach.

Platymischus Westw.

Schaft normal. 11.

11. Mesonotum ohne Parapsidenfurchen. Das 4. Antennenglied ausgerandet oder winklig.

Loxotropa Först.

Mesonotum mit deutlichen Parapsidenfurchen. Das 4. Antennenglied weder ausgerandet noch winklig.

Pezopria Kieff.

12. Die Subcosta erreicht nicht den Vorderrand des Flügels; sie endet mit einer Verdickung, von welcher meist noch ein kurzer schräger Ast, der 1. Abschnitt des Radius, ausgeht. Aneurhynchus Westw.

Die Subcosta erreicht den Vorderrand des Flügels oder sie fehlt ganz. 13. 
13. Parapsidenfurchen deutlich. Die Subcosta fehlt ganz.

Aulacopria Kieff.

Parapsidenfurchen fehlend oder hinten nur schwach angedeutet. Die Subcosta vorhanden, den Flügelvorderrand am Ende des 1. Drittels erreichend. 14.

14. Basalnerv vorhanden, vor dem Marginalnerv mündend. Antennengeissel ohne lange Haare. 15.

Basalnerv fehlend oder nur schwach; im letzteren Falle mündet er am Ende des Marginalnervs. Thorax glatt und glänzend. 16.

15. Das 3. Antennenglied kürzer als das 4. Mesonotum nicht länger als breit. Marginalnerv keilförmig, quer.

Basalys Westw.

Das 3. Antennenglied nicht deutlich kürzer als das 4. Mesonotum in der Regel länger als breit. Marginalnerv allmählich dreieckig erweitert.

Loxotropa Först.

16. Schildchen flach oder leicht gewölbt, ohne Längskiel. Antennengeissel mit abstehenden, zuweilen wirtelförmig gestellten Haaren. Trichopria Ashm.

Schildchen mit Längskiel, am Ende von der Seite zusammengedrückt. 17.

17. Kopf von oben gesehen pentagonal. Das 3. Antennenglied länger als das 4. Geissel ohne wirtelförmig gestellte Haare. Tetramopria Wasm.

Kopf nicht pentagonal. Geissel mit langen unregelmässig oder in Wirteln gestellten Haaren. Schenkel und Schienen keulenförmig.

Diapria Latr.

18. Schildchen ohne Grube an der Basis, vom Mesonotum nicht getrennt, letzteres ohne Parapsidenfurchen.

Monelata Först.

Schildchen an der. Basis mit 1 oder 2 Gruben. 19.

19. Flügel am Ende abgestutzt oder ausgerandet.

Entomacis Först.

Flügel am Ende abgerundet. 20.

20. Das 3. Antennenglied nicht halb so lang wie das 4. Das 2. Segment nicht scharf vom Hinterleibsstiel getrennt.

Paramesius Westw.

Das 3. Antennenglied so lang oder nur wenig kürzer als das 4. Das 2. Segment deutlich vom Hinterleibsstiel getrennt oder mit 1 oder 3 Furchen. 21.

21. Die Basis des 2. Segments greift nach vorn über das Ende des Hinterleibsstiels.

Spilomicrus Westw.

Die Basis des 2. Segments überragt nicht nach vorn das Ende des Hinterleibsstiels. 22.

22. Die Subcosta erreicht den Flügelvorderrand höchstens am Ende des 1. Drittels. Hinterleib kürzer als der Thorax; das 2. Segment reicht fast bis zum Hinterleibsende. $q$ unbekannt.

Tritopria Kieff.

Die Subcosta endet etwa in der Mitte des Flügelvorderrandes. 23.

23. Hinterleib hinter dem 3. Segment abgestutzt, die Endsegmente bilden eine dreieckige Spitze, die weit schmäler ist als das 3. Segment.

Hemilexis Först.

Hinterleib nach hinten allmählich verschmälert und am Ende abgerundet. Idiotypa Först. 


\section{Literaturverzeichnis.}

Das Riesengebiet der Schlupfwespen hat eine ausserordentlich umfangreiche, in zahlreichen Werken und periodischen Schriften zerstreute Literatur hervorgerufen. Im folgenden sind die wichtigsten Werke und Einzelarbeiten aufgeführt, soweit sie sich auf europäische Arten erstrecken.

1. Abeille de Perrin, Essai de classification des espèces françaises du genre Foenus F. (Bull. soc. hist. nat. Vol. XIll. Toulouse 1879.)

2. Adler, H., Über das Eierlegen von Paniscus. (Entom. Nachricht. V. 1879. S. 265).

3. André, Edm., Spécies des hyménoptères d'Europe et d'Algérie. Continué par Ernest André. Tome IV, $\mathrm{V}$ et V bis. Les Braconides par T. A. Marshall. (Beaune 1889-1901.)

Tome VII bis, S. 347-469. Les Evaniides par J. Kieffer. (Paris 1905.)

Tome VII bis, S. 471-490. Les Stephanides par J. Kieffer. (Paris 1905.)

Tome VII bis, S. 491-499. Les Trigonalides par J. Kieffer. (Paris 1905.)

Tome VII bis, S. 501-506. Les Agriotypides par J. Kieffer. (Paris 1905.)

Tome IX, X et XI. Les Proctotrypides par J. Kieffer et T. A. Marshall (noch nicht vollendet). (Paris, seit 1904.)

4. Ashmead, W. H., Monograph of the North American Proctotrypidae. With 18 plates. (Washington 1893.) (Auch die europäischen Gattungen sind. darin behandelt.)

5. - Classification of the Ichneumon Flies or the superfamily Ichneumonoidea. (Washington 1900.)

6. - On the genera of the Chalcid-flies belonging to the subfamily Encyrtinae. (Washington 1900.)

7. - Classification of the Chalcid Flies or the superfamily Chalcidoidea. (Pittsburg 1904.)

8. Aurivillius, C., Grönlands Insektfauna. Lepidopt. Hymenopt. (Stockholm 1890.)

9. Berthoumie u, V., Monographie des Ichneumonides d'Europe. Avec 4 suppl.; 5 planches. (Paris et Moulins. 1894-1899.)

10. Bignell, G. C., Parasites of Abraxas grossulariata. (The Entomologist Band XIII. 1880. S. 245.)

11. Blanchard, E., Histoire naturelle des Insectes. Vol. III. Hyménoptères. (Paris 1840.)

12. Boheman, C. H., En ny art af Insectslägtet Pimpla. (Kongl. Sv. Vet. Akad. Handl. Stockholm 1821.)

13. - Skandinaviska Pteromaliner. (Vetens. Akad. Handling. 1833 und 1836.)

14. Boie, F., Entomologische Beiträge. (Krögers Naturhistorisk Tidsskrift III, p. 315.1840 -41.)

15: Bouché, P. F., Naturgeschichte der Insekten, insbesondere in Hinsicht ihrer ersten Zustände als Larven und Puppen. (Berlin 1834.)

16. Boudier, H. P., Observations sur les habitudes de larves d'lchneumons. (Ann. Soc. Entom. de France, V. 1836. S. 357.)

17. Brauns, S., Die Ophionoiden. (Neubrandenburg 1889.)

18. - Neue Ichneumoniden der Schweiz. (Schaffhausen 1889.)

19. - Neue Schlupfwespen aus Mecklenburg. (Güstrow 1898.)

20. Bridgman, J. B., Hymenoptera in Norfolk. (The Entomologist XII. 1879. S. 54.)

21. - Three new Ichneumons (Cecidonomus n. g.). (Ibid. S. 263.)

22. - Some additions to Mr. Marshall's Catalogue of British Ichneumonidae. (Trans. Entom. Soc. London 1881. S. 143.)

23. - Further additions to Mr. Marshall's Catalogue etc. (Ibid. 1882, S. 41; 1883, S. 139; 1884, S. $421 ; 1886$, S. $335 ; 1887$, S. $361 ; 1889$, S. 409.$)$

24. Bridgman, J. B. and E. A. Fitch, Introductory Papers on Ichneumonidae. (The Entomologist. 1879-82.)

25. Brischke, C. G., Die Hymenopteren der Provinz Preussen. (Schrift. d. Physisch-Ökon. Ges. Königsberg. 1861-1871.) 
26. Brischke, C. G., Hymenopterolog. Notizen. (Entom. Monatsblätter 1876. S. 11; Deutsche Entom. Zeitschr. XXI. 1877. S. 285.)

27. - Kürzere Mitteilungen über die Gattung Pezomachus Grav. (Schrift. Naturf. Ges. Danzig. Neue Folge, Bd. IV, Heft II, 1877, und Heft III, 1878.)

28. - Die İchneumoniden der Provinzen West- und Ostpreussen. 4 Teile. (Ibid. 1878-1882.)

29. - Bemerkungen zu Tischbein's Zusätzen etc. europ. Ichneumon. (Entom. Nachr. 1881, S. 216.)

30. Brullé, Aug., Expédition scientifique de Morée. 3 vol. (Paris 1832-1836.)

31. - Etudes zoologiques sur la famille des Ichneumonides. (Mém. Acad. Scienc. de Dijon, tom. V. 1856.)

32. Cameron, P., Description of a new species of Torymus from Scotland with Notes on other British species of the genus. (Entom. Monthly Magaz. XVII. 1880-81.)

33. - On the Parasites and Inquilines of Nematus gallicola. (Scot. Nat. II. 1883. S. 111-116.)

34. - On Saw-fly Larvae and Ichneumons. (Ibid. S. 160.)

35. Capron, E., On the preservation of parasitic Hymenoptera. (The Entomologist XIII. 1880. S. 33.)

36. - Two additional british species of Braconidae. (Entom. Monthly Magaz. 1886.)

37. Christ, J. L., Naturgeschichte, Classification und Nomenclatur der Insecten vom Bienen-, Wespen- und Ameisengeschlechte. (Frankfurt a. M. 1791.)

38. Curtis, J., British Entomology. 16 vol. Vol. III. Hymenoptera. (London 1823-1840.)

39. - A guide to an arrangement of British insects. (London 1837.)

40. Dalla Torre, K. W., Catalogus Hymenopterorum. Lipsiae. Vol. III. Trigonalidae, Megalyridae, Stephanidae, Ichneumonidae, Agriotypidae, Evaniidae, Pelecinidae. 1891 und 92. Vol. IV. Braconidae. 1898. Vol. V. Chalcididae et Proctotrupidae. 1898.

41. Dalman, J. W., Nagra nya Genera och Species af Insekter beskrifna. (Sver. Ak. Handl. Vol. 39. 1818. S. 86.)

42. - Försök till uppstöllning af Insekt familjen Pteromalini. (Ibid. Vol. 41. 1820. S. 123-174.)

43. - Analectica entomologica. (Holmiae 1823.)

44. Degeer, Ch., Mémoires pour servir à l'Histoire des Insectes. 7 Vol. (Stockholm 1752-78.)

45. Destefani, Theod., Osservazioni biologiche sopra un Braconide aquatico, e descrizione di due altri Imenotteri nuovi. (Zool. Jahrbücher Vol. XV. S. 625-34, pl. 34. Jena 1902.)

46. Desvignes, Th., Description of a new British species of Ichneumon. (Transact. Entom. Soc., tom. III. 1854.)

47. - Catalogue of British Ichneumonidae in the British Museum. (London 1856.)

48. - Descriptions of new species of the genus Bassus. (Transact. Entom. Soc,, tom. I. 1862-64. S. 215.)

49. - Descriptions of two new species of Ephialtes. (Ibid. S. 226.)

50. - Two species of Pimpla, new to Britain. (Entom. Monthly Magaz. IV. 1867-68. S. 174.)

51. Dominique, J., Sur le groupe des Evaniides et ses représ. dans la région Nantaise. (Nantes 1892.)

52. Enderlein, G., Neue Evaniiden, Stephaniden, Mutilliden, Proctotrupiden und Chalcididen. (Archiv. f. Naturgesch. Vol. I, p. $187-220$, Fig. 2-6. 1901.)

53. Fabricius, J. Chr., Systema Entomologiae. (Flensburgi et Lipsiae 1775.)

54. - Species Insectorum. 2 Vol. (Hamburgi et Kilonii 1781.)

55. - Mantissa Insectorum. 2 Vol. (Hafniae 1787.)

56. - Entomologia systematica emendata et aucta. 4 Vol. (Hafniae 1792-94.)

57. - Entomologiae Systematicae Supplementum. (Hafniae 1798.)

58. -- Systema Piezatorum. (Brunsvigae 1804.)

59. Fallen, C. Fr., Specimen novum Hymenoptera disponondi methodum exhibens. (Lund 1813.)

60. Fitch, Edw., Hymenoptera bred from Cynips Kollari Galls. (The Entomologist XII. 1879. S. 113.)

61. - Hymenopterous Parasites of Lepidoptera. (Ibid. XIII. 1880. S. 67.)

62. - Economy of Chalcididae. (The Entomologist XV. 1882. S. 93.)

63. Förster, A., Beiträge zur Monographie der Pteromalinen. (Aachen 1841.)

64. - Über die Familie der Mymariden. (Linnaea Entomologicae II. 1847.)

65. - Hymenopterologische Studien. Heft II: Chalcidiae et Proctotrupii. (Aachen 1856.)

66. -- Eine Centurie neuer Hymenopteren. (Verh. naturh. Ver. preuss. Rheinlande VII. 1850. S. 276, 484, 500; VIII. 1851. S. 1 ; X. 1853. S. 266.)

67. - Zweite Centurie. (Ibid. XII. 1855. S. 226; XVI. 1859. S. 87.)

68. - Monographie der Gattung Pezomachus Grav. (Archiv f. Naturgesch. XVI. 1850. S. 49 und XVII. 1851. S. 26.) 
69. Förster, A., Stephanus anomalipes n. sp. (Verh. naturh. Ver. preuss. Rheinlande. Vol. 2. 1855. S. 228.)

70. - Synoptische Übersicht der Familien und Gattungen der Chalcidiae und Proctotrupii. (Jahresbericht der höheren Bürgerschule in Aachen, 1856.)

71. - Eine Centurie neuer Hymenopteren. (Verh. naturh. Ver. preuss. Rheinlande XVII. 1860. S. 90.)

72. -- Synopsis der Familien und Gattungen der Braconen. (lbid. XIX. 1862. S. 225.)

73. - Synopsis der Familien und Gattungen der Ichneumonen. (Ibid. XXV. 1868. S. 135.)

74. - Monographie der Gattung Campoplex Grav. (Verhandl. zool.-bot. Gesellsch. in Wien XVIII. 1868. S. 761.)

75. - Übersicht der Gattungen und Arten der Plectiscoiden. (Verh. naturh. Ver. preuss. Rheinlande XXVIII. 1871. S. 71.)

76. - Synoptische Übersicht der Gattungen und Arten in der Familie der Stilpnoiden. (Ibid. XXXIII. 1876.)

77. - Kleine Monographien parasitischer Hymenopteren. (Ibid. XXXV. 1878.)

78. Fonscolombe, Boyer de, Monographia Chalciditum Galloprovinciae circa Aquas Sextias degentium. (Annal. Scienc. Naturell. XIII. 1840.)

79. - Ichneumonologie Provençale ou Catalogue des Ichneumonides qui se trouvent aux environs d'Aix. (Ann. Soc. Entom. de France, tom. V-X. 1847-54.)

80. Friese u. Kiaer, Die arktischen Hymenopteren. Mit color. Kpfrt. (Jena 1902.)

81. Frisch, J. L., Beschreibung von allerley Insecten in Teutschland. 13 Vol. (Berlin 1720-1738.)

82. de Gaulle, J. J., Catalogue systématique et biologique des Hyménoptères de France. (Feuille des Jeunes Naturalistes. 1906-1908.)

83. Gehrs, Cl., Über ein paar Ichneumonidenarten. (Deutsch. Ent. Zeitschr. 1908. S. 465.)

84. - Die Männchen von Neoeryma stygium, Hemiteles pulchellus und Lissonota atropos. (Ibid. 1910. S. 370.)

85. Geoffroy, E. L., Histoire abregée des Insectes qui se trouvent aux environs de Paris. 2 vol. (Paris 1762.)

86. Giard, A., Sur quelques espèces nouvelles d'Hyménoptères parasitiques. (Paris 1895.)

87. Giraud, J., Notes sur quelques Hyménoptères. (Verh. zool.-bot. Ver. Wien IV. 1854. S. 601.)

88. - Observations sur quelques espèces d'Hyménoptères rares ou peu connues trouvées dans les environs de Vienne. (Ibid. VI. 1856. S. 179.)

89. - Description de quelques Hyménoptères nouveaux ou rares. (lbid. VII. 1857. S. 163.)

90. - Hyménoptères recueillis aux environs de Suse en Piemont et dans le département des Hautes-Alpes en France. (Ibid. XIII. 1863. S. 11.)

91. - Mémoire sur les Insectes qui vivent sur le Roseau commun. (Ibid. XIII. 1863. S. 1266.)

92. - Notice sur les déformations galliformes du Triticum repens et sur les insectes qui les habitent et déscription de trois espèces nouvelles du genre Isosoma Walk. (Ibid. S. 1289.)

93. - Notes sur quelques Hyménoptères très rares découverts en Autriche et déscription d'un Chalcidien nouveau. (lbid. S. 1306.)

94. - Mémoire sur les Insectes qui habitent les tiges sèches de la Ronce. (Ann. Soc. Entom. de France, sér. 4, tom. VI. 1866. S. 443.)

95. - Note sur trois Hyménoptères parasites. (Ibid. sér. 4, tom. IX. 1869. S. 145.)

96. - Observations hyménoptèrologiques. III. Des Galles d'un Lépidoptère sur le Limoniastrum Guyonianum et des parasites qui les habitent. (Ibid. sér. 4, tom. IX. 1869. S. 476.)

97. - Miscellanées hyménoptèrologiques. III. Description d'Hyménoptères nouveaux avec l'indication des moeurs de la plupart d'entre eux et remarques sur quelques espèces déjà connues. (Ibid. sér. V, tom. I. 1871. S. 375.)

98. Giraud et Laboulbène, Liste des éclosions observées par le docteur Giraud. (Ann. Soc. Entom. de France, sér. V, tom. VII. 1877. S. 397.)

99. Gmelin, J. Fr., Caroli a Linné Systema Naturae. Edit. XIII. 10 Vol. (Lipsiae 1788-93.)

100. Goeze, J. A. E., Beiträge zur Ökonomie einiger Insekten und zwar von kleinen IchneumonLarven in Blattläusen. (Naturforscher, Band XII. 1778.)

101. Goureau (Colonel le), Observations sur les moeurs des Eulophites (Chalcid.). (Ann. Soc. Entom. de France. sér. 3, tom. 1. 1853.)

102. Gravenhorst, J. L., Monographia Ichneumonum pedestrium. (Lipsiae 1788-93.)

103. - Monographia Ichneumonum Pedemontanae regionis. (Aug. Taurin. 1819.)

104. - Ichneumonologia Europaea. 3 Vol. (Vratislaviae 1829.)

105. - Ichneumonidum genuinorum species cornutae et calcaratae. (Beiträge zur Entomologie. Heft 1, S. 1. (Breslau 1829.)

106. - De speciebus nigris Ichneumonum. (Vratislaviae 1829.) 
107. Habermehl, H., Über die Lebensweise der lchneumoniden. (Jahresber. d. Gymnas. u. d. Realschule zu Worms. 1896.)

108. - Beiträge zur Kenntnis der Ichneumoniden. (Wissenschftl. Beilage zum Jahresber. d. Gymnasimus u. d. Realschule zu Worms. 1904.)

109. - Neue deutsche und schweizerische Ichneumoniden. (Deutsch. Ent. Zeitschr. 1909. S. 563 u. 627.$)$

110. - Berichtigung. (Ibid. 1910. S. 38.)

111. - Eine neue Schlupfwespe vom Niederrhein. (Ibid. 1910. S. 690.)

112. - Microcryptus Gravenhorsti. (Ibid. 1910. S. 691.)

113. - Bemerkungen zu einigen von mir beschriebenen Ichneumoniden. (Ibid. 1911. S. 341.)

114. - Über einige Typen der Thomsonschen Gattungen Cratocryptus und Stenocryptus im Vergleich mit einigen Typen der Gravenhorstschen Gattungen Cryptus und Phygadeuon. (Ibid. 1911. S. 431.)

115. - Revision der Cryptiden-Gattungen Cratocryptus C. G. Thomson und Cubocephalus Ratzeb. unter Berücksichtigung einiger Gravenhorstschen und Thomsonschen Typen. Mit 6 Textfig. (Ibid. 1911. S. 601.)

116. - Revision der Cryptiden-Gattung Stylocryptus C. G. Thomson. (Ibid. 1912. S. 165.)

117. Haliday, A. H., An Essay on the Classification of the Parasitic Hymenoptera of Britain, which correspond with the Ichneumones minuti of Linnaeus. (Entom. Magazine, 1833-38.)

118. - Note on Dryinus and Epyris; Addenda to the Genus Alysia. (Entom. Magazine V. 1838. S. 518.)

119. - Hymenoptera Britannica. Fasc. 1. Oxyura. Fasc. II. Alysia. (London 1839.)

120. - Contributions towards the Classification of the Chalcididae. (Transact. Entom. Soc. London, III. 1843. S. 295.)

121. Hartig, Th., UUber die gestielten Eier der Schlupfwespen. (Wiegmanns Archiv f. Naturgesch. III. 1837. S. 151.)

122. - Über einige parasitische Hymenopteren des Harzes. (Bericht. d. Naturw. Vereins d. Harzes. 1846. S. 15.)

123. Hellins, M. A., Ichneumonidae infesting larvae of Gyrinus natator. (Entomol. Monthly Magaz. XVIII. 1881. S. 88.)

124. Heymons. R., Süsswasserhymenopteren aus d. Umgebung Berlins. Mit 4 Textfig. (Deutsch. Ent. Zeitschr. 1908. S. 137.)

125. Holmgren, A. G., Monographia Tryphonidum Sueciae. 2 partes. (Holmiae 1856.)

126. - Ophionid slägtet Anomalon. (Oefvers. K. Vet. Acad. Forhandl., tom. XIV. 1857.)

127. - Berichtigung zur Monogr. Tryphonidum. (Stettin. ent. Zeit. XIX. 1858. S. 433.)

128. - Beitrag zur Kenntnis der Lebensweise der Ichneumoniden. (Zeitschr. für d. ges. Naturwissenschaften XIII. 1859. S. 196.)

129. - Monographia Pimplariarum Sueciae. (Holmiae 1860.)

130. - Monographia Ophionidum Sueciae. (Holmiae 1861.)

131. - Ichneumonologia Suecica. Tom. I. Ichneumonides Oxypygi (Holmiae 1864); Tom. II. Ichneumonides Amblypygi et Platyuri (Holmiae 1871); 'Tom. III. Ichneumonides pneustici (Holmiae 1889).

132. - Hymenopterorum species novae in circumnavigatione terrae (Freg. Eugenies Resa) collectae. (Holmiae 1868.)

133. - Om de Scandinav. arterna af Ophionid slägtet Campoplex. (Stockholm 1872.)

134. - Dispositio methodica Exochorum Scandinaviae. (Holmiae 1873.)

135. - Dispositio methodica Mesoleiorum Scandinaviae. (Stockholmiae 1876.)

136. - Enumeratio Ichneumonidum, exhibens species in alpibus Tiroliae captas. (Verhandl. Zoolog. botan. Gesellsch. Wien XXVIII. 1879. S. 167.)

137. - Adnotationes ad Ichueumonologiam Suecicam. (Entom. Tidsskrift. 1880. S. 22.)

138. Holmgren, E. A., und G. Zetterlund, En parasit hos Vanessa C-album (Hemiteles melanarius). (Entom. Tidsskr. 1881. S. 48.)

139. Howard, L. O., Biology of the Hymenoptera of the family Chalcididae. (Washington 1892.)

140. Jacobs, Dr., Notice sur le genre Trigonalis Westw. (Compt. rend. Soc. Entom. Belgique. 1878. S. 8.)

141. Judeich-Nitsche, Lehrbuch der Mitteleuropäischen Forstinsektenkunde. (Wien 1885.)

142. Jurine, L., Nouvelle méthode de classer les Hyménoptères. (Genève 1807.)

143. Kaltenbach, J., Die Pflanzenfeinde aus der Klasse der Insekten. (Stuttgart 1874.)

144. Kawall, H., Die Ichneumoniden in Kurland mit Berücksichtigung inländischer Ichneumoniden. (Correspondenz-Blatt Naturf. Ver. Riga VIII. 1855. S. 41.)

145. - Beobachtungen und Bemerkungen. (Stett. Entom. Zeit. XVlll. 1857. S. 192.) 
146. Kawall, H., Die den genuinen Ichneumoniden verwandten Tribus in Russland. (Bull. de Moscou. XXXVIII. 1865. S. 331.)

147. - Enneas Ichneumonidarum Curoniae. (Ibid. XLI. 1868. S. 503.)

148. Kessler, B. J., Die Schlupfwespen Gampoplex argentatus und Diospilus oleraceus und deren Wohnungstiere. (Cassel 1867.)

149. Kieffer, J. J., Etudes sur les Evaniides. (Ann. Soc. entom. de France. 1899. S. 113.)

150. - Note sur le genre Pristaulacus. (Ibid. S. 338.)

151. - Evaniidae, avec 1 planche. (In: Wytsman, Genera Insectorum. 1902.)

152. - Zwei neue Hymenopteren und Bemerkungen über einige Evaniiden. (Zeitschr. f. Hymen. und Dipt. Bd. III. 1903. S. 110.)

153. - Description de nouveaux Stephanides et Evaniides. (Bull. Soc. Hist. Nat. Metz. XI. 1904. S. $1-30$.)

(Im übrigen vergleiche man unter E. André, Spécies des Hyménoptères d'Europe et d'Algérie.)

154. Kirchner, L., Die von mir erzogenen Ichneumonen der Umgegend von Kaplitz. (Lotos. VI. 1856.)

155. - Die durch die Zucht blattlausartiger Insekten gewonnenen Schmarotzer-Hymenopteren der Kaplitzer Gegend. (Ibid. VI. 1856.)

156. - Catalogus Hymenopterorum Europae. (Vindobonae 1867.)

157. Klapaleck. A., Notizen über Agriotypus armatus Walk. (Entom. Monthly Magaz. XXV. 1889. S. 339 und 434; Archiv f. Landesdurchforschung v. Böhmen VIII. 1893. S. 52.)

158. Kollar, V., Beitrag zur Kenntniss über die geographische Verbreitung des Agriotypus armatus Walk. (Verhandl. Zoolog.-botan. Vereins in Wien. VII. 1857. S. 189.)

159. Kriechbaumer, J., Bemerkungen über Ephialtes. (Stettin. Ent. Zeit. XV. 1854. S. 153.)

160. - Beschreibung einer neuen Schlupfwespe (Amblyteles polyxanthus). (Mitteil. Schweizer Entom. Gesellsch. III. 1869. S. 129.)

161. - Neue Schlupfwespen aus den Alpen. (Ibid. III. 1872. S. 482 und VI. 1880. S. 12.)

162. - Atractogaster, n. g. Pimplidarum. (Stettin. Ent. Zeit. XXXIII. 1872. S. 6 und Entom. Nachricht. VI. 1878. S. 199.)

163. - Über drei in Bayern vorkommende Cryptiden. (Correspondenzbl. zoolog-mineral. Ver. Regensburg. XXVII. 1873. S. 23.)

164. - Über einige vermutliche Pseudo-Europäer unter den Schlupfwespen der Ichneumonologia Europaea. (Stettin. Ent. Zeit. XXXVI. 1875. S. 39.)

165. - Über Ichneumon xanthorius, quadrifasciatus, flavoniger und sexcinctus. (Ibid. S. 386.)

166. - Die Gattung Scolobates. (Entom. Nachricht. III. 1877. S. 133, 149.)

167. - Über Bassus fissorius Grav. (Ibid. S. 166.)

168. - Die europäischen Arten der Gattung Aulacus. (Correspondenzbl. zoolog.-mineral. Ver. Regensburg. XXXII. 1878. S. 35.)

169. - Neue Schlupfwespen aus Ungarn. (Entom. Nachricht. IV. 1878. S. 41.)

170. - Über Ephialtes. (Ibid. S. 193), Bassus ibaloides n. sp. (lbid. S. 211), Cryptus macrobatus und verwandte Arten (ibid. S. 211, 251), Ophion curvinervis und undulatus, sowie Sphalerus Kriechb. (= Arotes Grav.) (ibid. S. 249).

171. - Beitrag zur Kenntnis der Schlupfwespen-Gattung Ischnocerus. (Correspondenzbl. d. zoolog.mineral. Ver. Regensburg. XXXIII. 1879. S. 163.)

172. - Ein neuer Xylonomus. (lbid. S. 167.)

173. - Ophion pteridis, parvulus et minutus n. sp. (Entom. Nachricht. V. 1879. S. 89 u. 104.)

174. - Gezogene Schlupfwespen aus Dalmatien und über Ichneumon Fabricii. (Ibid. IV. 1880. S. $71,89,121$.)

175. - Ichneumoniden-Studien. (Ibid. S. 157, 209 ; ibid. VII. 1881. S. 1, 57, 133; ibid. VIII. 1882. S. $122,173$.

176. - Die Männchen von Ichneumon 9-albatus und mordax. (Correspondenzbl. d. zoolog.-mineral.Ver. Regensburg. XXXIV. 1880. S. 51, 83.)

177. - Ein um München entdecktes blaues Ichneumon-Männchen und das vermutliche Weibchen desselben. (Ibid. S. 99.)

178. - Brachycyrtus n. g. Cryptidarum. (Ibid. S. 161.)

179. - Neue Schlupfwespen. (Entom. Nachr. XII. 1886. S. 241.)

180. - Zur Kenntnis der Gattung Euceros. (lbid. XIV. 1888. S. 197); Das $\sigma^{7}$ des Euceros superbus (ibid. S. 353); Exetastes alpinus (ibid. S. 354).

181. - Pimpliden-Studien. (Ibid. XV. 1889. S. 73.)

182. - Tryphoniden-Studien. (Ibid. XVII. 1891. S. 34, 133, 247, 298; ibid. XVIII. 1892. S. 40.)

183. - Neue Ichneumonen des Wiener Museums. 2 Teile. (Wien 1888-90.) 
184. Kriech baumer, J., Ichneumoniden-Studien. (Ibid. XVIII. 1892. S. 37.)

185. - Xylonomiden- und Pimpliden-Studien. (Ibid. XVIII. 1892. S. 211.)

186. - Ophioniden-Studien. (lbid. S. 232.)

187. - Zwei neue Schlupfwespengattungen (Stenolabis und Polyomorus). (Ibid. XX. 1894. S. 58.)

188. - Die Gattung Tropistes und eine neue Art derselben. (Ibid. S. 260.)

189. - Ichneumonologica varia. (Ibid. XXII. 1896. S. 353; ibid. XXIII. 1897. S. 119, 165, 184; ibid. XIV. 1898. S. 309 ; ibid. XXV. 1899. S. 66, 295.)

190. - Ein Parasit der seltenen Eupithecia millierata (Parabatus millieratae). (lbid. XXIII. 1897. S. 316.)

191. - Mesochorus gigas nov. sp. (Ibid. S. 332.)

192. - Die Gattung Joppa. (Ibid. XXIV. 1898. S. 1, 33.)

193. - Über die Gattung Disophrys. (Ibid. S. 181.)

194. - Neue Schlupfwespen. (Ibid. XXVI. 1900. S. 169.)

195. - Über den Cryptus quadriguttatus Grav. (Ibid. S. 350.)

196. - Ichneumonologica varia; neue Ichneumoniden. (Zeitschr. f. Hym. u. Dipt. 1901.)

197. Kriechbaumer und Tisch bein, Bemerkungen zu Holmgren's Enumeratio Ichneumonidum, exhibens species in alpibus Tiroliae captas. (Berichte naturw.-med. Ver. in Innsbruck. XI. 1880. S. 1.)

198. Krieger, R., Hymenopteren-Fauna von Sachsen. 2 Abh. (Leipzig 1894.)

199. - Zwei neue Ichneumoniden von Borkum. (Entom. Nachr. XXIII. 1897. S. 7.)

200. - Über einige mit Pimpla verwandte Ichneumonidengattungen. (Leipzig 1898.)

201. - Über die Ichneumonidengattung Certonotus. (Zeitschr. f. Hym. u. Dipt. 1901.)

202. Kulagin, N. M., Materialien zur Naturgeschichte parasit. Hymenopteren. (Moskau 1894.)

203. Lange, C. F., Neue paläarktische Ichneumoniden. (Deutsch. Ent. Zeitschr. 1911. S. 540.)

204. Latreille, P. A., Histoire naturelle générale et particulière des Crustacés et des Insectes. 14. vol. (Paris 1802-1805.)

205. - Genera Crustaceorum et Insectorum. 4 vol. (Paris et Strassbourg 1806-1809.)

206. Lepeletier de St. Fargeau, Histoire naturelle des Insectes. Suites à Buffon. Hyménoptères. 4 vol. (Vol. IV par Aug. Brullé.) (Paris 1836-46.)

207. Linné, C. von, Systema Naturae. Edit. 10. (Stockholm 1758.)

208. Löw, Fr., Zoologische Notizen. (Verh. zoolog.-botan. Gesellsch. in Wien XVI. 1866. S. 951.)

209. Löw, H., Zur Verwandlungsgeschichte der Mymariden. (Stettin. Entom. Zeit. VIII. 1847. S. 339.)

210. Lubbock, J., On two aquatic Hymenoptera, one of which uses its wings in swimming (Polynema natans, Prestwichia aquatica). (Transact. Linn. Society London. XXIV. 1863. S. 135.)

211. Lucas, H., Note sur le Mesochorus testaceus Grav. parasite chez Cimbex amerinae. (Revue et Magaz. de Zoologie, tome VI. 1858. S. 17.)

212. - Note sur les parasites du genre Chalicodoma. (Annal. Soc. Entom de France. Sér. 3, tome VI. 1859. S. 112.)

213. Marchal, P., Les Cécidomyiens des céréales et leurs parasites. (Annal. Soc. Entom. de France, vol. 66. 1897. S. 80-93.)

214. - Notes biologiques sur les Chalcidiens et Proctotrupides obtenus par voie d'élevage. (Ibid. vol. 25. 1900. S. 102-112.)

215. - Sur un nouvel Hyménoptère aquatique (Limnodytes gerriphagus). (Ibid. vol. 25. 1900. S. $171-176$.

216. - Le parasitisme des Inostemma. (Bull. Soc. Zoolog. France. Vol. 27. 1902. S. 78.)

217. - Le cycle évolutif du Polygnotus minutus Lind. (Bull. Soc. Entom. France 1903. S. 90-93.)

218. - Recherches sur la biologie et le développement des Hyménoptères parasites. Avec 5 planches. (Paris 1904.)

219. Marshall, T. A., Description of a new genus and species of British Hymenoptera, allied to Pezomachus (Oresbius castaneus). (Entom. Monthly Magaz. Vol. III. 1866. S. 195.)

220. - Description of British Hymenoptera (Proctotrupidae) new to science. (Ibid. S. 223.)

221. - On some British Diapriidae. (Ibid. Vol. IV. 1867. S. 201, 227.)

222. - Notes on some parasitic Hymenoptera, with description of new species. (lbid. Vol. V. 1868. S. 154.)

223. - Description of new species of Braconidae belonging to a genus new to Britain. (Ibid. Vol. VI. 1869. S. 228.)

224. - Ichneumonidum Britannicorum Catalogus. (Londini 1870.)

225. - A catalogue of British Hymenoptera (Chrysididae, Ichneumonidae, Braconidae and Evaniidae). (London 1872.) 
226. Marshall, T. A., Description of a new species of Aphidius (A. gregarius) from Great Britain. (Entom. Monthly Magaz. Vol. IX. 1872. S. 123.)

227. - Descriptions of two new species of Ichneumonidae from Great Britain. (Ibid. S. 240.)

228. - Catalogue of British Hymenoptera Oxyura. (London 1873.)

229. - Descriptions of a new genus and new species of European Oxyura. (Entom. Monthly Magaz. Vol. X. 1873. S. 207, 222.)

230. - New British species and corrections of Nomenclature. (Entomologist's Annual for 1874. S. 114.)

231. - Descriptions of two new British Ichneumonidae. (Entom. Monthly Magaz. Vol. XXII. 1875. S. 194.)

232. - Monograph of British Braconidae. 8 parts. With 15 col. plates. (London 1885-99.)

233. - Les Braconides in: Ed. André, Spécies des Hyménoptẻres d'Europe et d'Algérie. 3 Bände. Avec 53 planches color. et noires. (Beaune et Paris, 1889-1901.)

234. Masi, L., Contribuzioni alla conoscenza dei Chalcidici Italiani. (I. Teil : Bollet. del Laborat. di Zoolog. Generale e Agraria di Portici. I. 1907. S. 231-295. - II. Teil: Ibid. III. 1908. S. 86-149. - III. Teil : Ibid. IV. 1909. S. 3-38.)

235. Mayr, G., Die europäischen Torymiden. (Verhandl. zoolog.-botan. Gesellschaft in Wien. XXIV. 1874. S. 53.)

236. - Die europäischen Encyrtiden. (Ibid. XXV. 1875. S. 675.)

237. - Die Chalcidier-Gattung Olinx. (Ibid. XXVII. 1877. S. 155.)

238. - Die Arten der Chalcidier-Gattung Eurytoma. (Ibid. XXVIII. 1878. S. 297.)

239. - Die Schlupfwespen-Gattung Telenomus. (Ibid. XXIX. 1879. S. 697.)

240. Meunier, F., Sur les Mymaridae du Copal fossile. (Bull. Soc. Entom. France 1900. S. 192-195, fig. $1-6$.

241. - Sur les Mymaridae de l'Ambre et du Copal. (Ibid. S. 353-367, fig. 1 et 2.)

242. - Contribution à la Faune des Mymaridae. Ann. Soc. Scientif. Bruxelles. XXVI. 1901.)

243. Mik, J., Biologie von Gonatopus pilosus Thoms. (Wiener Entom. Zeitschr. Vol. 1. 1882. S. 215-221; Taf. 3, Fig. 4-10.)

244. Mocsáry, A., Drei neue Schlupfwespen aus Ungarn. (Entom. Nachr. IV. 1878. S. 209.)

245. - Heterogynidae faunae Hungaricae. (Publicationes mathem. et phys. ab Academia Hungarica scientiorum editae. Vol. XVII. 1881. S. 1-96.)

246. - Data ad cognitionem Ichneumonidum Hungariae. I. Ichneumones Wesm., cum. tab. col. (Budapest 1885)

247. - Hymenoptera parasitica educ. in collectione Musaei Nationalis Hungarici. (Budapest 1895.)

248. - Ungarns Hymenopteren. (Budapest 1898.)

249. - Rhyssae sociarumque species in collectione Musaei Nationalis Hungarici. (Budapest 1905.)

250. Morley, C., On the Ichneumonidous Group Tryphonides schizodonti Holmgr. (Transact. Entom. Soc. London 1906.)

251. - Ichneumonologia Britannica. The Ichneumons of Great Britain. 1. Ichneumoninae (Plymouth 1904). II. Cryptinae (Plymouth 1907). III. Tryphoninae (Plymouth 1911).

252. Müller, G. W., Notizen zu Agriotypus armatus Walk. (Zool. Jahrb. Vol. IV. Syst. 1889. S. 1132; ibid. Vol. V. Syst. 1891. S. 689; Naturwiss. Rundschau. Vol. VI. 1892. S. 167.)

253. Müller, O. F., Zoologiae Daniae prodromus, seu animalium Daniae et Norvegiae indigenorum characteres, nomina et synonyma. (Hafniae 1776.)

254. Nees von Esenbeck, C. G., Ichneumonides adsciti, in genera et familias divisi. Cum 5 tab. color. (Magaz. d. Gesellsch. Naturforsch. Freunde zu Berlin. V. 1811. S. 3; VII. 1814. S. 183 ; VIII. 1816. S. 243.)

255. - Lapton femoralis, eine neue Ichneumoniden-Gattung. (Ibid. VIII. 1816. S. 46.)

256. - Hymenopterorum Ichneumonibus affinium monographiae. 2 Vol. (Stuttgartiae et Tübingae, 1834.)

257. Newport, G., The Anatomy and Development of certain Chalcididae and Ichneumonidae. (Transact. Linn. Soc. London XXI. 1852. S. 61, 85.)

258. - Further Observations on the genus Anthophorabia. (Ibid. S. 79 ; Proc. Linn. Soc. London II. 1849. S. 23, 54; Ann. and Magaz. Nat. Hist. III. 1849. S. 513; IV. 1850. S. 122.)

259. - Further Observations on the habits of Monodontomerus. (Proc. Linn. Soc. London II. 1850. S. 70.)

260. Panzer, G. W. F., Fauna Insectorum Germaniae initia oder Deutschlands Insecten. (Nürnberg $1792-1810$.) (Fortgesetzt von Herrich-Schäffer, Regensburg 1829-1844.)

261. - Kritische Revision der Insectenfauna Deutschlands, nach dem System bearbeitet. 2 Vol (Nürnberg 1805-6.) 
262. Parfitt, E., Note on Cynips lignicola and description of its parasite. (Zoologist XIV. 1856. S. 5070.)

263. - Description of the male of Callimome flavipes. (Ibid. S. 5150.)

264. - Two new species of Ichneumonidae. (Entom. Monthly Magaz. XVIII. 1881. S. 78.)

265. - A new species of Hemiteles. (Ibid. S. 184.)

266. - New species of Ichneumonidae. (lbid. S. 253, 272.)

267. Pfankuch, K., Die Typen der Gravenhorstschen Gattungen Mesoleptus und Tryphon. (Zeitschr. f. syst. Hymen. u. Dipter. Teschendorf 1906-1907.)

268. - Die Typen der Gravenhorstschen Gattung Bassus. (Deutsch. Ent. Zeitschr. 1910. S. 271.)

269. - Über einige Typen der Holmgrenschen Gattung Bassus. (lbid. S. 280.)

270. - Eine neue Hemiteles-Art. (Ibid. S. 407.)

271. - Die Ichneumonidengattung Drepanoctonus. (Ibid. 1911. S. 687.)

272. - Das Männchen von Troctocerus elegans Woldst. (Ibid. 1912. S. 326.)

273. - Aus der Ichneumonologie (Brachycyrtus ornatus Kriechb. $\sigma^{7}$ und Lapton femoralis Nees =-). Mit 5 Textfig. (lbid. S. 456.)

274. - Vorschläge behufs Einheitlichkeit der Nomenclatur. (lbid. 1913. S. 70.)

275. - Die Typen der Gravenhorstschen Gattungen Exochus und Scolobates. (Ibid. S. 176.)

276. - Die Gattung Thaumatotypus Först. und ihre systematische Stellung. (Ibid. S. 513.)

277. Pfeffer, W., Die Ichneumoniden Württembergs, mit besonderer Berücksichtigung ihrer Lebensweise. I. Teil. (Jahreshefte d. Ver. für vaterländ. Naturkunde in Württemberg. 69. Jahrg. 1913.)

278. Pic, M., Note sur les Ichneumoniens de Digoin et des environs. (Macon 1898.)

279. Puhlman, E, Schmarotzer von Calamia lutosa. (Mitteil. Ver. f. Naturkunde in Krefeld, 1910. S. 34.)

280. Ratzeburg, J. Th. C., Die Forstinsekten oder Abbildungen und Beschreibungen der in den Wäldern Preussens und der Nachbarstaaten als schädlich oder nü̈zlich bekannt gewordenen Insekten. 3 Vol. 1837-44. Vol. III. Hymenoptera. (Berlin 1844.)

281. - Die Waldverderber und ihre Feinde. (Berlin 1841.) - 7. Aufl. von J. F. Judeich. (Berlin 1876.)

282. - Die Ichneumonen der Forstinsekten. 3 Bände. (Berlin 1844. 1848. 1852.)

283. - Über Entwickelung, Leben und Bedeutung der Ichneumonen. (Stettin. Ent. Zeitschr. V. 1844. S. 199.)

284. - Ichneumonologisches. (Ibid. VIII. 1847. S. 58.)

285. - Parasitologische Beiträge. (lbid. X. 1849. S. 131.)

286. - Réaumur, R. A. F., Mémoire pour servir à l'histoire des Insectes. 7 Vol. (Paris 1734-42.)

287. Reinhard, H., Beiträge zur Geschichte und Synonymie der Pteromalinen. (Berlin. Ent. Zeit. I. 1857. S. 70 ; II. 1858. S. 10.)

288. - Die in Blattläusen lebenden Pteromalinen. (Stettin. Ent. Zeit. XX. 1859. S. 191.)

289. - Über Cephalonomia formiciformis. (Berlin. Ent. Zeit. VI. 1862. S. 298.)

290. - Chelotelius, eine neue deutsche Hymenopteren-Gattung aus der Familie der Dryiniden. (Ibid. VII. 1863. S. 409.)

291. - Beiträge zur Kenntnis einiger Braconiden-Gattungen. I. Zur Systematik der Gattungen Microctonus, Diospilus, Leiophron und Centistes. (Berlin. Ent. Zeit. VI. 1862. S. 321.) II. Die Gattung Rogas. (lbid. VII. 1863. S. 248.) III. Nachtrag zur Gattung Rogas. Die Gattungen Pelecystoma, Petalodes, Doryctes, Corystes, Orgilus und Laccophrys. (Ibid. IX. 1865. S. 243.) IV. Die Gattungen Microdus, Chelonus, Ascogaster und Calyptus. (Ibid. IX. 1867. S. 352.) V. Die Gattungen Microgaster, Microplitis und Apanteles. (Deutsch. Ent. Zeitschr. XXIV. 1880. S. 353.) VI. Schluss (Apanteles). (Ibid. XXV. 1881. S. 33.)

292. Roman, A., Om Lapplands alpina ichneumonidfauna. (Entom. Tidskr. 1905.)

293. - Ichneumoniden aus dem Sarekgebirge. (Naturwissenschaftl. Untersuch. d. Sarekgebirg. Band IV. Zoologie. Stockholm und Berlin 1909.)

294. - Die Ichneumonidentypen C. P. Thunbergs revidiert von A. Roman. (Zoologiska Bidr. fran Uppsala, Band I. Uppsala 1912.)

295. Romand, B. E., Description d'une nouvelle espèce de Paxyllomma. (Ann. Soc. Ent. de France VII. 1838. S. 443.)

296. Rondani, C., Sopra tre specie di Imenotteri utili all' agricultura. (Archivo por la Zoologia, l'Anatomia e la Fisiologia. II. 1870. S. 10.)

297. - Degli Insetti parassiti delle lora Vittime. (Bullet. della Soc. Entom. Italiana 11I. 1871. S. 121. 217. IV. 1872. S. 41, 229, 321. VIII. 1876. S. 54, 120, 237. X. 1878. S. 9, 91, 161.)

298. - Sopra alcuni Vesparii parassiti. (Ibid. IV. 1872. S. 201.)

299. - Diagnosi di tre Vesparii microsimi insetticidi. (lbid. VIII. 1876. S. 83.) 
300. Rondani, C., Vesparia parasita non vel minus cognita. (Ibid. IX. 1877. S. 166.)

301. - Entodon viticola et antispilae n. sp. Chalcididarum. (Ibid. IX. 1877. S. 290.)

302. Rossi, P., Fauna etrusca, sistens Insecta, quae in provinciis Florentina et Pisana praesertim collegit. 2 Vol. (Liburni 1790.) (Neu herausgegeben und mit Notizen versehen von K. Illiger. Helmstadii 1807.)

303. - Mantissa Insectorum, exhibens species nuper in Etruria collectas, adjectis Faunae Etruriae illustrationibus ac emendationibus. (Pisae 1792-94.)

304. Ruthe, J. Fr., Beiträge zur Kenntnis der Braconiden. (Stettin. Ent. Zeit. XV. 1854. S. 343. XVI. 1855. S. 291, 327. XX. 1859. S. 103. Berlin. Ent. Zeit. II. 1858. S. 1.)

305. - Beiträge zur Geschichte der Ichneumoniden. (Stettin. Ent. Zeit. XVI. 1855. S. 51, 79.)

306. - Prodromus einer Monographie der Gattung Microctonus. (Ibid. XVII. 1856. S. 289.)

307. - Försters Systematik der Proctotrupier und A. H. Halidays Systematik der Diapriiden. (Berlin. Ent. Zeit. III. 1859. S. 118.)

308. - Verzeichnis der von Dr. Staudinger im Jahre 1856 auf Island gesammelten Hymenopteren. (Stettin. Ent. Zeit. XX. 1859. S. 305, 362.)

309. Saunders, Edw., On the habits and affinities of the Hymenopterous genus Scleroderma, with descriptions of new species. (Transact. Entom. Soc. London. 1881. S. 109.)

310. - Notes on Euchalcis vetusta Duf. and on the terminal segments of the females in Halticella and its allies. (Ibid. 1882. S. 291.)

311. Schiödte, G., Ichneumonidarum ad Daniae faunam pertinentium genera et species novae. (Magaz. d. Zoologie. tom. I. 1839. - Kröyers Naturhist. Tidsskr. III. 1840-41.)

312. Schletterer, Aug., Die Hymenopteren-Gattung Gasteruption Latr. (Foenus aut.). (Verhandl. zoolog.-botan. Ges. Wien XXXV. 1885.)

313. - Über die Hymenopteren-Gattung Evania F. (Ibid. XXXVI. 1886.)

314. - Monographie der Hymenopteren-Gattung Stephanus Jur. (Berlin. Ent. Zeit. XXX. 1889. S. $71-160$. Taf. 1.)

315. - Die Hymenopteren-Gruppe der Evaniiden monographisch bearbeitet. 3 Teile. (Ann. Hofmuseum Wien IV. 1889-90)

316. - Die Hymenopteren-Gattungen Leucospis, Polistomorpha und Marres. (Berlin 1890.)

317. - Zur Hymenopteren-Fauna von Istrien. (Programm der Realsch. in Pola. 1894.)

318. Schmiedeknecht, O., Monographische Bearbeitung der Gattung Pimpla. (Jena 1888.)

319. - Die europäischen Gattungen der Pimplarier. (Jena 1888.)

320. - Die Gattungen und Arten der Cryptinen. (Berlin 1890.)

321. - Die Ichneumoniden-Gattung Hemiteles; mit einer Übersicht der europäischen Arten. 2 Teile. (Budapest 1897.)

322. - Monographie der Gattung Pimpla. (Illustr. Wochenschrift für Entom. II. 1897.)

323. - Die Braconiden-Gattung Meteorus. (Ibid. II. 1897.)

324. - Das Studium der Braconiden nebst Revis. der europäischen Arten der Gattungen Vipio und Bracon. (Neudamm 1897.)

325. - Die paläarktischen Gattungen und Arten der Ichneumonidentribus der Lissonotinen. (Jena 1900.)

326. - Die Ichneumonidentribus der Anomalinen, nebst einer Übersicht sämtlicher Gattungen sowie der paläarktischen Arten. (Zeitschr. f. Hymen. u. Dipter. 1902 u. 1903.)

327. - Die Hymenopteren Mitteleuropas nach ihren Gattungen und zum grossen Teil auch nach ihren Arten analytisch bearbeitet. (Jena 1907.)

328. - Opuscula Ichneumonologica. (Blankenburg in Thüringen, seit 1902.)

Das mit Beihilfe des Kgl. Preuss. Ministeriums für Landwirtschaft etc. herausgegebene Werk enthält in deutscher Sprache die analytische Bearbeitung sämtlicher paläarktischen Ichneumoniden-Arten. Alle 3-4 Monate erscheint ein Heft. Erschienen sind bis Ende 1913 Heft 1-35, enthaltend die Ichneumoninen, Cryptinen, Pimplinen und den grössten Teil der Tryphoninen.

329. - Ichneumonidae Subfam. Pimplinae. (In: P. Wytsman, Genera Insectorum. Fasc. 62.) Avec 2 planches coloriées. (Bruxelles 1907.)

330. - Ichneumonidae Subfam. Cryptinae. (In: P. Wytsman, Genera Insectorum. Fasc. 75.) Avec 4 planches coloriées. (Bruxelles 1908.)

331. - Chalcididae. (In: P. Wytsman, Genera Insectorum. Fasc. 97.) Avec 8 planches coloriées. (Bruxelles 1909)

332. Schrank, J. P., Enumeratio Insectorum Austriae indigenorum. (Augustae Vindelicorum 1781.)

333. - Fauna Boica. 3 Bände. (Nürnberg, Ingolstadt, Landshut 1798-1803.)

334. Scopoli, J. A., Entomologia Carniolica, sistens Insecta Carnioliae indigena. (Vindobonae 1763.) 
335. Semen off (A. de), Revisio hymenopterorum Musei Zoologici Petropol. III. Evaniidae. (Bull. Acad. scienc. nat. Saint-Pétersbourg. Vol. 3. 1894.)

336. Shuckard, W. E., On the Aulacidae, a family of Hymen. pupivora and that Trigonalys is one of its components. (The Entomologist 1841. S. 115. - Revue Zoolog. IV. 1841. S. 356.)

337. Siebold, C. Th. E., Über Agriotypus armatus und Trichostoma picicorne. (Amtl. Bericht über die 34. Versamml. Deutsch. Naturforscher in Karlsruhe. 1858. S. 211.)

338. - Über Agriotypus armatus. (Stettin. Ent. Zeit. XXII. 1861. S. 59.)

339. Six, G. A., Over 6 merkwaard. inlandsche Pteromalinen en 1 Proctotrupide. ('s Gravenhage 1876.)

340. Smits van Burgst, C. A. L., Nutlige en Schadelijke Insecten. (Groningen 1908.)

341. - Dutch Ichneumonidae. First list. (Tijdschr. v. Entom. LIV. 1911.) Second list. (Ibid. LV. 1912.)

342. - Ichneumonidae. (Deutsch. Ent. Zeitschr. 1913. S. 462.)

343. Soli, G., Ichneumonidi Italiani. Disp. 1-3, con 12 tav. color. (Modena 1896-98.)

344. Spinola, M., Insectorum Liguriae species novae vel rariores. 2 Vol. (Genuae 1806-1808.)

345. Stephens, J. F., Illustrations of British Entomology. 11 Vol. (London 1828-35.)

346. - A systematical catalogue of British Insects. (London 1829.)

347. Stoll, O., Über die Zucht der Chalcididier. (Mitteil. Schweiz. Ent. Gesellsch. V. 1878. S. 277.)

348. Strobl, G., Hymenopteren aus Ungarn und Siebenbürgen. (Verhandl. u. Mitteil. d. Siebenbürg. Ver. f. Naturwissensch. zu Hermannstadt. Band 50. 1900. Hermannstadt 1901.)

349. - Ichneumoniden Steiermarks. 5 Teile. (Mitteil. d. Naturwissensch. Ver. f. Steiermark. Jahrg. 1900-1904. Graz 1901-1905.)

350. Szépligeti, V., Beiträge zur Kenntnis der ungar. Braconiden. (Ungar, џ. deutsch.) 3 Teile. (Budapest 1896-98.)

351. - Beiträge zur Kenntnis der Chelonus-Arten. (Budapest 1898.)

352. - Beiträge zur Kenntnis der ungar. Ichneumoniden. 2 Teile. (Budapest 1899-1900.)

353. - Neue Braconiden aus Ungarn. (Budapest 1900.)

354. - Joppinen des Ungar. Nationalmuseums. (Budapest 1900.)

355. - Übersicht der Gattungen und Arten der paläarktischen Braconiden. (Mathemat. u. naturwissenschaftl. Berichte aus Ungarn XIX. 1903. S. 145-203.)

356. - Die Braconiden. (In: P. Wytsman, Genera Insectorum. Fasc. 22 a und 22 b.) Avec 3 planches coloriées. (Bruxelles 1904.)

357. - Ichneumonidae, Subfam. Pharsalinae-Porizontinae. (In: P. Wytsman, Genera Insectorum. Fasc. 34.) (Bruxelles 1905.)

358. - Übersicht der paläarktischen Ichneumoniden. I. Teil. (Annales historico-naturales Musei nationalis hungarici. III. Budapest 1905.)

359. - Braconiden aus der Sammlung des Ungar. National-Museums. (Ann. Mus. National. Hungar. IV. 1906. S. 547618 und VI. 1908. S. 397-427.)

360. Taschenberg, E. L., Bemerkungen über die Arten der Gattung Pimpla bei Durchsict.t der Gravenhorstschen Typen. (Zeitschr. f. d. gesamten Naturwissensch. XXI. 1863. S. 50.)

361. - Die Schlupfwespenfamilie Pimplariae der deutschen Fauna. (Ibid. S. 245.)

362. - Die Schlupfwespenfamilie Cryptides mit besonderer Berücksichtigung der deutschen Arten. (Ibid. XXV. 1865. S. 1.)

363. - Die drei ersten Sektionen der Gattung Ichneumon Grav. unter Durchsicht der Typen aus Gravenhorsts Sammlung. (Ibid. XXVII. 1866. S. 228.)

364. - Die Hymenopteren Deutschlands nach ihren Gattungen und teilweise nach ihren Arten. (Leipzig 1866.)

365. - Die Arten der Gattung Ichneumon Grav. mit linealen oder lineal-elliptischen Luftlöchern des Hinterrückens. (Zeitschr. f. d. gesamt. Naturwissensch. Neue Folge. Band II. 1870. S. $209,369,449$.

366. - Einige neue südeuropäische Hymenopteren. (Ibid. IV. 1871. S. 305.)

367. - Zur Kenntnis der Gattung Ophion. (Ibid. XII. 1875. S. 421.)

368. - Hymenopterologische Ergänzungen zu früheren Arbeiten. (Zeitschr. f. d. gesamten Naturwissensch. Dritte Folge. Band V. 1881. S. 769.)

369. Thomson, C. G., Skandinaviens Proctotruper. (Stockholm 1858-62.)

370. - Opuscula Entomologica. Fasc. V-XXII. (Lund 1873-1897.)

371. - Hymenoptera Scandinaviae. 5 Bände. (Lund 1871 - 78.) (Tom. IV und V. Pteromalus Swed. 1875-78.)

372. - Notes hyménoptérologiques sur le genre Ichneumon. 4 parties. (Paris 1886-88.) 
373. Thomson, C. G., Notes hyménoptérologiques (genre Mesochorus). (Ann. Soc. Ent. France 1886.)

374. - Hymenopterologische Beiträge (Exochus und Verwandte). (Deutsch. Ent. Zeitschr. 1887.)

375. Thunberg, C. P., Ichneumonidea Insecta. Pars I. (Mém. Acad. St. Pétersbourg. VIII. 1822. S. 249.) - Pars II. (ibid. 1824. S. 285.)

cf. Roman.

376. Tischbein, P., Hymenopterologische Beiträge. (Stettin. Ent. Zeit. XIV. 1853. S. 347.)

377. - Beschreibung neuer Arten des Genus Ichneumon. (Ibid. XXIX. 1868. S. 248.)

378. -- Die Ichneumonen im Winterquartier. (lbid. XXXIl. 1871. S. 155.)

379. - Übersicht der europäischen Arten des Genus Ichneumon. (Ibid. XXXIV. 1873. S. 345, 417; XXXV. 1874. S. 104, 133, 228.)

380. - Zusätze und Bemerkungen zur Übersicht der europäischen Arten des Genus Ichneumon. (lbid. XXXVII. 1876. S. 273, 413; XL. 1879. S. 20; LII. 1881. S. 166.)

381. - Mitteilungen über Amblyteles uniguttatus und Ichneumon aulicus. (Ibid. XXXVI. 1875. S. 274.)

382. - Ein neuer Ichneumon aus Jaspidea celsia (Amblyteles celsiae). (Entom. Nachr. IV. 1878. S. 258, 277.)

383. Tournier, H., Tableau synoptique des espèces européennes du genre Foenus F. (Comptes rendus des séances de la Société Entomolog. de Belgique. XX. 1877. S. 6.)

384. - Note sur le Trigonalys nigra. (Ibid. XXII. 1879. S. 10.)

385. Trentepohl, J. J., Revisio critica generis Ichneumonis speciorum, quae Kiliae in St. Fabricii Museo adhuc superstites sunt. (Nova Acta Acad. Nat. Curios. XIIl. 1825. S. 31. - Feruss. Bullet. IX. 1826. S. 117. - Reimpress. Isis I. 1826. S. 55; II. S. 216; III. S. 293.)

386. - Kritische Revision der Gattung Cryptus F. (Isis VIIl. 1829. S. 817; IX. S. 929.)

387. - Zehn Arten der Gattung Ichneumon F. in seinem Systema Piezatorum beschrieben nach den Originalexemplaren in der Toender Lundschen Sammlung in Kopenhagen. (Isis VIII. 1829. S. 804.)

388. Tschek, C., Beiträge zur Kenntnis der österreichischen Pimplarien. (Verhandl. zoolog.-botan. Gesellsch. in Wien. XVIII. 1868. S. 269.)

389. - Beitråge zur Kenntnis der österreichischen Tryphoniden. (Ibid. S. 437.)

390. - Beiträge zur Kenntnis der österreichischen Cryptoiden. (Ibid. XX. 1870. S. 109, 403.)

391. - Ichneumonologische Fragmente. (lbid. XXI. 1871. S. 37.)

392. - Über einige Cryptoiden. (Ibid. XXII. 1872. S. 231.)

393. Ulbricht, A., Beiträge zur Insektenfauna des Niederrheins. Ichneumoniden der Umgegend. (Mitteil. d. Ver. f. Naturkunde in Krefeld. 1909. S. 1.)

394. - Ein neuer Hygrocryptus aus der niederrheinischen Bruchgegend. (Deutsch. Ent. Zeitschr. 1909. S. 782.)

395. - Ichneumoniden der Umgegend Krefelds. I. Nachtrag. (Mitteil. d. Ver. f. Naturkunde in Krefeld. 1910. S. 1.)

396. Verhoeff, C., Beiträge zur Biologie der Hymenopteren. Mit 2 Kupfertaf. (Jena 1892.)

397. - Über einige seltene Tracheaten der Rheinlande. (Beobachtung über Agriotypus armatus.) (Berlin. Ent. Nachr. XVIII. 1892. S. 4.)

398. Villers, Ch. J. de, Caroli Linnaei Entomologia; Faunae Suecicae descriptionibus aucta 4 Volumina. Hymenoptera Vol. III. S. 69-344. (Lugduni Batavorum 1789.)

399. Vollenhoven, S. C. Snellen van, Bij de afbeelding der larve en pop van Rhyssa persuasoria. (Tijdschr. voor Entom. IV. 1861. S. 176.)

400. - Drie niewe soorten van inlandsche Hymenoptera. (Ibid. X. 1867. S. 222.)

401. - Schetsen ten gebruike bij de Studie der Hymenoptera. I. Ichneumoniden. 's Gravenhage. 1868; II. Braconiden. 1869; III. Pteromalinen. 1871; IV. Proctotrupiden. 1873.

402. - Nieuwe naamlijst van Nederlandsche Vliesvleugelige Hymenoptera. (Tijdschr. voor Entom. XII 1869. S. 89 und XVI. 1873. S. 147.)

403. - Pinacographia. Illustrations of more than 1000 species of North West European Ichneumonidae sensu Linnaeano. Afbeeldingen van meer dan 1000 soorten van Nordwest Europeesche Sluipwespen. 9 partes. ('s Gravenhage 1875-1880.)

404. - Bijvoegsel tot de Nieuwe Naamlijst van Nederlandsche Vliesvleugelige Hymenoptera. (Tijdschr. voor Entom. XIX. 1876. S. 211.)

405. - Espèces nouvelles ou peu connues d'Hyménoptères térébrants. (lbid. XXI. 1878. S. 48.)

406. Wachtl, A., Zur Kenntnis der gallenerzeugenden Insekten Europas. Mit Kupfertaf. Wien 1876.)

407. - Ein neuer Megastigmus als Samenverwüster. Mit Kupfertaf. (Wien 1893.) 
408. Walckenaer, C. A. de, Faune Parisienne. Histoire abrégée des Insectes des environs de Paris. 2 Vol. Tom. II. S. 25-168. (Paris 1802.)

409. Walker, F., Monographia Chalciditum. (Entom. Magaz. I. 1883. S. 12, 115, 367, 455; II. 1835. S. $13,148,286,340,476$; III. 1836. S. $94,182,465$; IV. 1837. S. 9, 349, 439; V. 1838. S. 35, 102, 418. - Separat. London 1839.)

410. - On Psilus fucicola and Platymischus dilatatus. (Ibid. II. 1835. S. 117.)

411. - On the species of Platygaster. (Ibid. III. 1836. S. 217-274.)

412. - On the species of Teleas. (Ibid. III. 1836. S. $341-370$. )

413. On the Dryinidae. (Ibid. IV. 1837. S. 411-435.)

414. - Agriotypus armatus descends under the surface of the Water. (Ibid. IV. 1837. S. 83.)

415. - Descriptions of some Oxyuri. (Ibid. V. 1838. S. 453.)

416. - Descriptions of some Chalcidites discovered by C. Darwin. (Ibid. S. 469.)

417. - Species of Encyrtus. (Ibid. S. 518.)

418. - Descriptions of British Chalcidites. (Ann. of Nat. Hist. I. 1838. S. 307, 381, 449; II. 1839. S. 198,350 ; III. 1839. S. 177,415 ; IV. 1840. S. 29, 232.)

419. - Descriptions of some new species of Chalcidites in the collection of J. Curtis. (The Entomologist. 1841. S. 133, 217, 334.)

420. - Descriptions of some new species of Chalcidites. (Ann. and Magaz. Hist. XII. 1843. S. 103.)

421. - Descriptions of some British Chalcidites. (lbid. XIV. 1844. S. 18, 181.)

422. - On the species of Chalcidites inhabiting the Arctic Region. (Ibid. S. 331, 407.)

423. - On the habits of some Chalcidites. (The Zoologist. III. 1845. S. 848.)

424. - Parasitism of the Chalcidites. (Ibid. III. 1845. S. 1010, 1092, 1142, 1158; IV. 1846. S. 1233.)

425. - Characters of undescribed Species of British Chalcidites. (Proced. Linn. Soc. London. I. 1845. S. 261.)

426. - Notes on the Variations of structure in the British species of Eurytomidae. (Ann. and Magaz. Nat. Hist. XV. 1845. S. 496 und Proced. Linn. Soc. London. I. 1845. S. 233.)

427. - Characters of some undescribed species of Chalcidites. (Ann. and Magaz. Nat. Hist. XVII. 1846. S. $108,177,270$.)

428. - Descriptions of the Mymaridae. (Ibid. XVIII. 1847. S. 49.)

429. - List of the specimens of Hymenopterous Insects in the collection of the British Museum. 2 Partes. Chalcidites. (London 1846-48.)

430. - Notes on some Chalcidites in the collection of the Rev. F. W. Hope. (Ann. and Magaz. Nat. Hist. XIX. 1847. S. 227.)

431. - Notes on Chalcidites and descriptions of various new species. (Ibid. Sér. II. tom. III. 1849. S. 204 ; V. 1850. S. 125 ; VII. 1851. S. 210 ; IX. 1852. S. 39; X. 1852. S. 45.)

432. - Descriptions of Chalcidites. (Transact. Linn. Soc. London. XX. 1851. S. 153.)

433. - Characters of undescribed species of the Family Chalcididae. (Journal of Entomol. I 181. S. 172.)

434. Notes on Chalcidites and Characters of undescribed species. (Transact. Entom. Soc. London. 1862. S. 345.)

435. - Characters of undescribed Species of Smiera. (Ibid. 64. S. 181.)

436. Notes on Chalcididae and Description of a New species of Megastigmus. (Ibid. 1869. S. 313.)

437. - Notice of Dr. Mayrs Essay „Die Europäischen Torymiden“. (Cistula Entomologica. XI. 1874. S. 325.)

438. - Notes on Chalcidiae. 7 parts. (London 1871-72.)

439. Wasmann, E., Über die Gäste von Tetramorium caespitum, sowie über einige andere Myrmekophilen. (Nederl. Ent. Ver. 1898. S. 60.)

440. - Weitere Nachträge zu den Ameisengästen von Holländisch Limburg. (Tijdschr. v. Entomol. XLII. 1899. S. 158.)

441. - Vergleichende Studien über Ameisen- und Termitengäste. (Haag 1890.)

442. - Kritisches Verzeichnis der myrmekophilen und termitophilen Arthropoden. Mit Angabe der Lebensweise und Beschreibung neuer Arten. (Berlin 1894.)

443. Wesmael, C., Monographie der Braconides de Belgique. (Nouv. Mém. Acad. de Bruxelles. IX. 1835. S. 252; X. 1837. S. 68 ; XI. 1838. S. 166. Extrait. Annal. Soc. Entom. de France. IV. 1835. S. 65.)

444. - Notice sur le Bracon initiator l'ennemi du Scolytus de Aruitor. (Bullet. Acad. Bruxelles. IV. 1838. S. 220.)

445. Note sur les Charactères d'Euceros Grav. genre d'lchneumonides. (Ibid. VII. 1840. S. 360.) 
446. Wesmael, C., Tentamen dispositionis methodicae Ichneumonum Belgiae. (Nouv. Mém. Acad. Bruxelles. XVIII. 1844. S. 238.)

447. - Mantissa Ichneumonum Belgiae. (Bull. Acad. Bruxelles. XV. 1848. S. 138, 292.)

448. -... Adnotationes ad descriptionem Ichneumonum Belgiae. (Ibid. XVI. 1849. S. 35.)

449. - Revue des Anomalons de Belgique. (lbid. XVI. 1849. S. 115.)

450. - Notice sur les Ichneumonides de Belgique appartenant au genre Metopius, Banchus et Coleocentrus. (Ibid. S. 621.)

451. - Ichneumones platyuri Europaei. (Ibid. XX. 1853. S. 287.)

452. - Ichneumones amblypygi. (Ibid. XXI. 1854. S. 77.)

453. - Ichneumonologica Miscellanea. (Ibid. XXII. 1855. S. 362.)

454. - Ichneumonologica Otia. (ibid. XXIV. 1857. S. 355.)

455. - Remarques critiques sur diverses espèces d'Ichneumons de la collection de feu le Prof. Gravenhorst. (Mém. couror. Acad. Belg. Collect. VIII. 1859. S. 99.)

456. - Ichneumonologica documenta. (Bull. Acad. Bruxelles. XXIV. 1867. S. 441.)

457. Westwood, J. O., Note on Psilus Boscii et Dryinus formicarius. (Literary Gazette 1827.)

458. - On the Chalcididae. (Zoolog. Journ. IV. 1828. S. 225.)

459. - On Ichneumonidae. (Magaz. Nat. Hist. III. 1830. S. 452, 476.)

460. - Description du genre Cerocephala. (Magaz. Zoolog. 1832.)

461. - Parasites upon the Cabbage Caterpillars. (Magaz. of. Nat. Hist. V. 1832. S. 301.)

462. - Description of several new British forms among the Parasitic Hymenoptera. (Philosoph. Magaz. Ser. 3. tom. I. 1832. S. 127; II. S. 443; III. 1833. S. 342.)

463. - Further notice of the British parasitic Insects. (Magaz. of Nat. Hist. VI. 1833. S. 414.)

464. - On Leucospis, a genus of Hymenopterous Insects. (Entom. Magaz. II. 1835. S. 212.)

465. - Descriptions of two new Genera belonging to the family Chalcididae. (Ibid. IV. 1837. S. 435.)

466. - Description of a new genus of British parasitic Hymenopterous Insects. (Ibid. S. 257.)

467. - Die Hymenopteren-Gattung Leucospis monographisch behandelt. (Germars Zeitschr. für Entomol. I. 1839. S. 237.)

468. - Monopraph upon the Hymenopterous genus Scleroderma. Transact. Entom. Soc. Lindon. II. 1839. S. 237.)

469. - On the Evaniidae and some allied genera. (Ann. and Magaz. Nat. Hist. VII. 1841. S. 535.)

470. - On Evania and some allied Genera. (Transact. Entom. Soc. London. III. 1843. S. 237.)

471. - On the Economy of the Genus Palmon Dalm. (Ibid. IV. 1847. S. 256.)

472. - On Melittobia Andouini. (Ibid. V. 1848. Proced. Linn. Soc. II. 1849. S. 37.)

473. - The Cock Roach Parasite (Evania appendigaster. (Gardeners Chronicle 1854. S. 533.)

474. - - Thesaurus entomologicus Oxoniensis; or Illustrations of new, rare and interesting Insects. 4 parts. (Oxford 1873 und 1874.)

475. - Descriptions of some minute Hymenopterous Insects. (Transact. Linn. Soc. London. Sér. 2. tom. I. 1879. S. 584.)

476. - Observations on the Hymenopterous genus Scleroderma Kl., and some allied groups. (Transact. Entom. Soc. London. 1881. S. 117.)

477. - On the supposed abnormal habits of certain species of Eurytomides, a group of the Hymenopterous family Chalcididae. (Ibid. 1882. S. 307.)

478. White, A., Notice of a species of Monodontomerus parasitic in the cells of Anthophora retusa. (Proced. Linn. Soc. II. 1849. S. 29.)

479. Woldstedt, F. W., Materialier till en Ichneumonologia Fennica. (Helsingfors 1873.)

480. - Bidrag till Kännedom af Finlands Tryphonider. (Helsingfors 1874.)

481. - Zur Kenntnis der um St. Petersburg vorkommenden Ichneumoniden. (Petersburg 1877.)

482. - Über eine Sammlung schlesischer Ichneumoniden. (Petersburg 1877.)

483. - Zwei neue russische Schlupfwespen. (Stettin. Ent. Zeit. XLI. 1880. S. 174.)

484. Zetterstedt, J. L., Insecta Lapponica descripta. Hymenoptera. (Lipsiae 1840.) 


\section{Inhalt.}

\section{Einleitung und allgemeiner Teil.}

Einleitende Bemerkungen über Schlupfwespen.

Leben und Treiben derselben. Schmarotzer ersten, zweiten und weiteren Grades; dem entsprechend nützliche und schädliche Arten. Allgemeine Charakteristik ihres Körperbaues. Bestimmungstabelle der 8 Familien.

\section{Bearbeitung der einzelnen Familien.}

\section{Ichneumonidae.}

1. Charakteristik

2. Körperbau der Ichneumoniden . . . . . . . . 118

Kopf und dessen Teile. Thorax. Die verschiedenen Felder des Metathorax und ihre Wichtigkeit für die Systematik. Die Benennung der verschiedenen Nerven und Zellen der Flügel und ihre Bedeutung für die Systematik. Beine. Bildung des Hinterleibs; sitzender oder gestielter Hinterleib. Bohrer. Unterschied der Geschlechter.

3. Lebensweise der Ichneumoniden - $\dot{C}^{\circ} \cdot{ }^{\circ} \cdot$ Alle sind Schmarotzer. Die verschiedenen Wirte, in der Mehrzahl Schmetter-
linge. Art und Weise des Anstechens. Entwicklung bis zum vollkommenen Insekt. Grössenunterschiede je nach dem Wirte.

4. Geographische Verbreitung . . . . . . . . . . . . . . 125

5. Bedeutung der Ichneumoniden im Haushalte der Natur . . . . . . . . . . . . 125 Ihr grosser Nutzen. Necere Experimente im grossartigen Masstab zur Vertilgung verheerend auftretender Schmetterlinge.

6. Sammeln und Präparieren der Ichneumoniden .

Netz und Fangflasche. Tötungsmittel. Wichtigkeit der Zucht.

7. Geschichtliches; kurzer Abriss der Literatur über Ichneumoniden . . . . . . . . . 127

8. Systematik der Ichneumoniden . . . . . . . . . . . . . . . . 129

Bestimmungstabelle der 5 Unterfamilien. Übersicht der in Mitteleuropa, speziell in Deutschland vorkommenden Gattungen.

\section{Agriotypidae.}

Agriotypus armatus Walk. einziger Vertreter der Familie; seine Lebensweise.

Geschichtlicher Abriss. Beschreibung und Zucht des Tieres

\section{Braconidae.}

1. Charakteristik Unterschied von den İchneumoniden. Mangel an lebhafter Färbung. Die einzelnen Körperteile. Verschiedenheit der Mundbildung. Wichtigkeit der Flügelnervatur für die Systematik. Bau des Hinterleibs. Unterschied der Geschlechter.

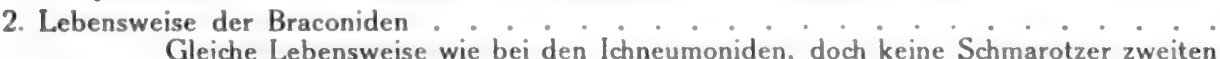

Grades. Ahnlicher Nutzen. 
3. Geographische Verbreitung . . . . . . . . . . . . . . 174

4. Die wichtigste Literatur über Braconiden . . . . . . . . . . . . . . 174

5. Systematik der Braconiden . . . . . . . . . . . . . . . 175

Einteilung in 7 Sektionen und 27 Unterfamilien.

\section{Stephanidae.}

Stephanus serrator F. einziger. Vertreter der Familie in Deutschland . . . . . . . . 193

\section{Evaniidae.}

1. Charakteristik . . . . . . . . 193

Geringe Ähnlichkeit der 3 Unterfamilien untereinander. Wirte.

2. Literatur . . . . . . . . . . . . . . . . 193

3. Systematik . . . . . . . . . . . . . 193

Übersicht der Unterfamilien und Gattungen.

4. Bestimmungstabelle der in Deutschland und den angrenzenden Gebieten vorkommenden Arten der Gattung Gasteruption

\section{Trigonalidae.}

Trigonalys hahni Spin., einzige in Europa vorkommende Art. Schwierigkeit, die Art im System unterzubringen. Verschiedenheit der Auffassung bei den Autoren. Lebensweise.

Diagnose .

\section{Chalcididae.}

1. Charakteristik Artenzahl. Schwierigkeit der Systematik. Körperfärbung vorwiegend metallisch. Unterschied von den Proctotrupiden. Körperbau.

2. Lebensweise der Chalcididen .

Alle Arten Schmarotzer, mit Ausnahme einiger Eurytominen. Vorwiegend Schmarotzer zweiten Grades; viele Arten deshalb als schädlich zu bezeichnen. Von ganz besonderem Interesse die im Wasser lebenden Arten.

3. Sammeln und Präparieren der Chalcididen
Wichtigkeit der Zucht. Die geeignetste Zeit zum Eintragen von Zuchtmaterial. Gallen und sonstige Pflanzendeformationen, sowie Blatt- und Schildläuse ganz besonders zur Zucht geeignet. Töten, Annadeln und Aufkleben der Tiere.

4. Die wichtigste Literatur über Chalcididen . . . . . . . . . . . . . . . . . 201

5. Systematik der Chakididen .. . . . . . . . . . . . . . . . . . . 202

Frühere und jetzige Einteilungsprinzipien. Übersicht über die Sektionen und Unterfamilien. Bestimmungstabellen der Gattungen der wichtigsten Unterfamilien. Die Torymiden die schönste Gruppe der Chalcididen. Bestimmungstabelle der of der Gattung Torymus.

\section{Proctotrupidae.}

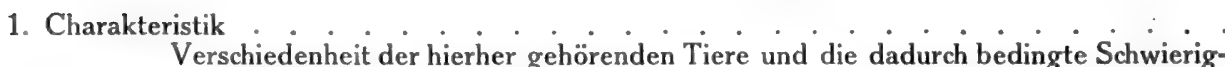
keit, eine scharfe Diagnose der Familie zu geben. Körperbau.

2. Lebensweise der Proctotrupiden
Die verschiedenen Wirte; ausser Insekten auch Spinnen und Tausendfüsser.

3. Sammeln und Präparieren der Proctotrupiden
Geeignete Fangplätze. Zucht und Präparation wie bei den Chalcididen. Schwierigkeit, die Tiere zu nadeln.

4. Die wichtigste Literatur über Proctotrupiden . . . . . . . . . . . . . . . . 219

5. Systematik der Proctotrupiden . . . . . . . . . . . . . . . . . 220 familien.

Bestimmungstabelle der Unterfamilien und der Gattungen der 8 ersten Unter- 


\section{Systematischer Teil.}

Die Namen der Familien, Unterfamilien und Tribus sind gespertt, die der Synonymen kursiv gedrudkt.

\begin{tabular}{|c|c|c|c|c|c|c|c|c|c|c|c|c|c|}
\hline & & & Seite & & & & & Seite & & & & & Seite \\
\hline abbreviatus & & & 209,210 & Amblyteles & & . & 132, & , 135 & Ascogaster & & . & . & 182 \\
\hline & & & . . 207 & amoenus . & & & & 209 & Ashmeadi . & & & & 227 \\
\hline bsyrtus . & & & 156 & Anarthronots & & . & & 148 & Aspidogonus & & . & . & 188 \\
\hline campsis. & & & 182 & Anectata & & . & 229 , & 230 & Aspilota & & . & & 190 \\
\hline Acanopsilus & & & . 229 & Aneurhynchu & & . & 232 , & 234 & Astiphromma & & . & & 157 \\
\hline canosema. & & & 228,230 & Aneuropria & & . & & 232 & Asyncrita. & & . & . & 143 \\
\hline Acanthocryptus & & & . . 141 & Angitia . & . & . & . & 156 & Asyntactus & & . & & 190 \\
\hline canthopsilus & & & 227 & Anilastus & . & & . & 156 & atalantae. & & . & & 145 \\
\hline Achoristus . & & & 179 & niseres & . & . & & 159 & Atanycolus & & . & 178 & 181 \\
\hline iculatus . & & & . $\quad 159$ & Anisobas . & & & 131, &, 134 & Ateleute. & & . & & 160 \\
\hline ista . & & & 229,230 & Anisoctenion & & & & 162 & Atomopria & & . & & 233 \\
\hline coelius . . & & & . 183 & Anisopygus & & . & 133, & 135 & Atractodes & & . & . & 144 \\
\hline Acoenitini. & & & 144 & Anomalini & & . & . . & 151 & Atractogaster & & . & & 145 \\
\hline tus. . & & & . . 149 & ipes & & . & . & 226 & Atritomus . & & . & & 25 \\
\hline Acolobus . & & & 131,134 & Anomalon & & & & 152 & Atrometus & & . & & 152 \\
\hline & & & . . 229 & imatium & & . & & 227 & inae & & . & . & \\
\hline $\mathrm{Act}$ & & & 180 & Anoxus & & & & 221 & ulacus. & & . & & 194 \\
\hline lapticus & & & 159 & & . & & & 224 & & & & & \\
\hline Acropiesta . & & & 229 & tropria. & & & & 233 & & & & & 212 \\
\hline ienus & & & 139 & & . & & & 213 & Automalus & & & 132 & 133 \\
\hline omus . & & & 162 & leticus & . & & & 135 & azureus. & & . & . . & 208 \\
\hline gnathus & & & 158 & & . & & & 183 & & & & & \\
\hline & & & 190 & leptus & . & & & 159 & Baeacis . & & & & 88 \\
\hline & & & 188 & ereta & & & & 190 & tharis & & & . & 21 \\
\hline dens & & & 204 & Aphanistes & • & & & 152 & mus & & . & & 36 \\
\hline & & & 214 & Aphanoroptr & & & & 148 & chini & & & . & \\
\hline erus & & & . . 138 & mus & & & 225 , & 22 & ius. & & . & . & 156 \\
\hline . . & & & 196,197 & Aphelopus & & & & 224 & pa & & & & 151 \\
\hline idinae & & & 177,184 & liinae & & . & 178 , & 191 & alys & & & 232 , & 235 \\
\hline & & & . 184 & Aphidius . & & & & 192 & & & & & 133 \\
\hline spis . & & & . 215 & ycus. & & & & 21 & $\sin i$ & & & & 168 \\
\hline ypida & & & 117,169 & & & & & 16 & & & & & 168 \\
\hline pus. & & & . 170 & Apoclima & & . & & 16 & hystomus & & & & 179 \\
\hline reutes & & & . 139 & ligaste & & & & 10 & & & & & \\
\hline on & & & 152 & Aptesis & & . & & 142 & 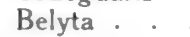 & & & 228 & 230 \\
\hline & & & 21 & & & & & 20 & tinae & & 220 , & & \\
\hline attatus & & & 132 & entris & & . & & 13 & linae & & & 220 & 221 \\
\hline & & & 16 & & & & & 14 & & & & 221 , & \\
\hline imptus & & & 151 & larii & & & 176, & & lum & & & & \\
\hline orus. & & & . 182 & & & & & 16 & & & & & \\
\hline Alloe: & & & 189,190 & & & & & 20 & lapsis. & & & & 169 \\
\hline acrus & & & . 160 & tus $(O x$ & & & & 16 & sia. & & & & \\
\hline & & & 135 & us $(A g$ ) & & ypus) & & 17 & teres & & & & \\
\hline & & & 208 & & & & & 14 & cinae & & & 177, & \\
\hline & & & 133 & phag & & & & 21 & us . & & & & \\
\hline & & & . 190 & & & & & 13 & Blapticus . & & & & \\
\hline Alysiinae & & & 178,189 & rtemisiae & & & & & Blaptocampus & & & & \\
\hline
\end{tabular}


Inhalt.

\begin{tabular}{|c|c|c|c|c|c|c|c|c|c|c|c|c|c|}
\hline & & & & Seite & & & & Seite & & & & & \\
\hline astothrix & - & & & 215 & Chorinaeus & & & 168 & Diachasma & & - & & \\
\hline & & & & 163 & & & & & & & : & & \\
\hline Iani . & . & . & . & 208 & halus & . & & 207 & romus & . & . & & \\
\hline ycivorus & s & & & 150 & & & 228 & 230 & psis. & & & & \\
\hline & - & - & . & 207 & latorius . & . & & 131 & a & & 232 & & \\
\hline thorax & $\mathrm{x}$ & . & & 214 & & & & 137 & riinae & & 220 , & & \\
\hline & & . & 141, & 149 & & . & & 151 & hiaspis & & - . & & \\
\hline & is & . & & 140 & & & & 214 & & pha & . & & \\
\hline & . & . & . & 143 & leonyminae & . & . & 203 & & . & . & . & \\
\hline & & . & . & 194 & & & & 181 & & . & . & & \\
\hline & & . & . & 146 & & . & . & 146 & & . & . & . & \\
\hline & & . & & 209 & & & & 226 & & . & . & & \\
\hline & . & . & & 179 & us . . & . & & 191 & rsis & . & . & & \\
\hline idae & e & . & 116. & 170 & ptus & . & & 141 & & . & . & 132 & \\
\hline & & . & 176, & 178 & & . & 178 & 181 & & . & . & & \\
\hline & & & & & & & & & rus. & & & & \\
\hline reus & . & . & . & 216 & & & & 14 & $\operatorname{lin} a$ & & . & 178, & \\
\hline & . & . & . & 140 & & . & & 14 & & . & . & & \\
\hline & . & . & . & 181 & hus & & & 13 & & . & . & & \\
\hline & . & . & . & 179 & & . & & 14 & & . & . & & \\
\hline & . & & & 132 & & & & & & . & . & & \\
\hline & . & . & . & 206 & & & & 1. & & & & & \\
\hline & . & - & & & & . & & & & . & . & & \\
\hline & . & . & . & 149 & & & & 2 & ndu & um & & 195, & \\
\hline & . & . & & 16 & & . & & & & . & . & & \\
\hline & . & . & & 15 & & & & 21 & & . & & & \\
\hline & . & . & 177, & & & & & 21 & ornis & . & . & & \\
\hline & . & . & . . & 186 & rus & & & 18 & & . & . & & \\
\hline ineta & & . & . & 14 & is $(\mathrm{Di}$ & & & 15 & & . & . & & \\
\hline & gini & . & & 15 & $(\mathrm{Hy}$ & & acmus) & 16 & & . & & & \\
\hline ex & . . & . & . & 15 & & . & & 14 & inae & & - & 176 , & \\
\hline & . & . & . & & & . & & 19 & & nus & . & & \\
\hline & . & . & . & 18 & & . & & & & & & & \\
\hline & . & . & & & & & & & & . & 220 & 221 , & \\
\hline & & . & & 22 & & & & 18 & & . & . . & & \\
\hline & . & . & & 1. & & . & 129 & 13 & & . & . & & \\
\hline & . & . & 131 & 13 & & & 138 & & & . & . & & \\
\hline & . & . & . . & 158 & astre & & 175 & 177 & & . & . . & & \\
\hline & & . & & & & & & & & & & & \\
\hline & & . & & 15 & & . & & & & . & - & & \\
\hline & . & . & & & & & & & & & & & \\
\hline & . & . & . & 18 & & . & . & & & . & . & & \\
\hline & . & . & & 13 & & & & & & . & & & \\
\hline & 8 & . & & 18 & & . & & & & . & . & & \\
\hline & a & . & & 22 & & & & & & . & & & \\
\hline & & & 225 & 22 & & & & & & . & &. & \\
\hline & & e 220 & 0,221 , & & & & . & & riae & . & $\therefore$ & & \\
\hline & & . & & & & & & & & . & & & \\
\hline & . . & . & . & & & & & & & . & & & \\
\hline & . & . & . & & & & & & & & & & \\
\hline & . & . & & & $\mathrm{mi}$ & . & 175 & & & & & & \\
\hline & & . & & & & & & & & & e 220 & 22 & \\
\hline & e & . & 117 & 1 & ynipiformis & & & & & . & . . & & \\
\hline & & 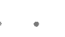 & 202 & & & & & & & & & & \\
\hline & . & . & - & 204 & & & & & & . & & & \\
\hline & & & & & inae & & 178, & & & • & & & \\
\hline & . & . & 130 & 1 & & & & 21 & & . & & & \\
\hline & . & . & & & & & & & & . & & & \\
\hline & e & . & 177 & 18 & & & & 1. & & . & & & \\
\hline & & . & . . & & & & & 14 & & & & & \\
\hline & - & & • & 2 & & & & & & . & & & \\
\hline & & . & & & & & 225 & & & & & & \\
\hline & & & & & oter. & & & & & . & & & \\
\hline & & & & & & & & & & & & & \\
\hline & & & & & & & & & & & & & \\
\hline
\end{tabular}


Inhalt.

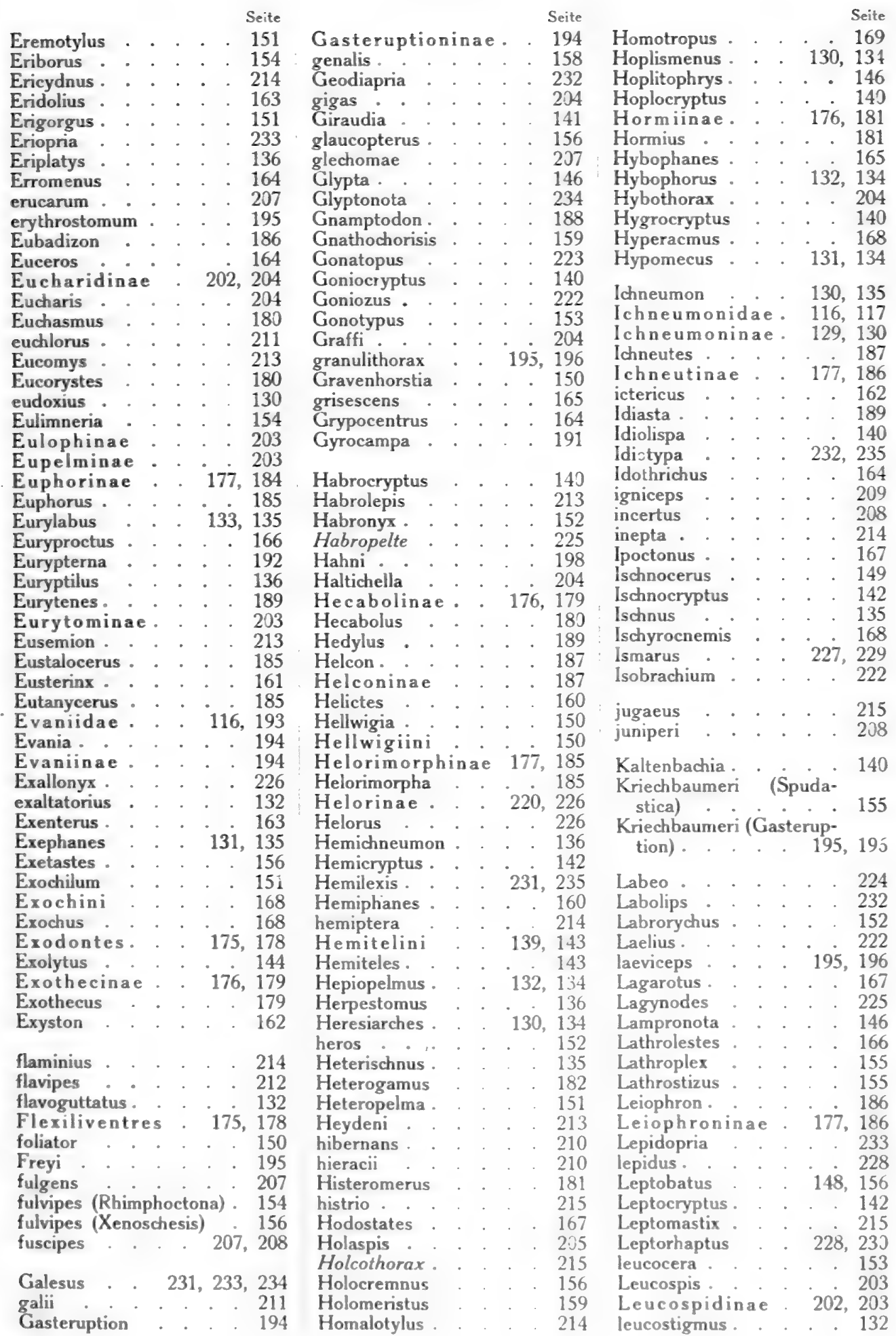




\begin{tabular}{|c|c|c|c|c|c|c|c|c|c|c|c|c|c|c|}
\hline & & & & Seite & & & & & Seite & & & & & \\
\hline imerodes & . & . & 132,1 & 134 & Microplectron & & & . & 163 & Oronotus & & & & \\
\hline & . & . & . $\cdot 2$ & 210 & litis. & & . & . & 183 & Orotylus . & & & & \\
\hline ogaster. & . & . & . & 211 & Microtypus & & . & . . & 187 & Orthocentri & ini & & & \\
\hline loterphus & & . & & 207 & & & . & & 194 & Orthocentrus & . & & & \\
\hline iothorax . & . & . & 2 & 216 & Miomeris . & & . & . & 159 & elma. & . & & & \\
\hline Lissonota : & & & & 148 & & & . & & 228 & gma. & . & & & \\
\hline Lissonotini & . & . & 1 & 144 & iv & & . & . & 213 & astus. & . & & & \\
\hline yptus & . & & & 141 & mirabilis . & & & & 213 & labis . & . & & 227, & \\
\hline dromus & . & & 131,1 & 134 & Mirax . . & & & . & 183 & Oxytorus . & & & & \\
\hline nathus & . & . & & 141 & Miscogaste & & nae & & 203 & & & & & \\
\hline Litor & . & . & . & 214 & . & - & . & . & 136 & pallidicornis & - & & & \\
\hline & . & . & & 142 & . & & . & & 216 & . . & . & & & \\
\hline & . & & 2 & 206 & & - & & & 208 & olinae & . & & 176 & \\
\hline mis & . & . & & 215 & a. & & . & 231, &, 235 & 15 .. & . & & & \\
\hline & . & & & 196 & rnis & . & & & 164 & & & & & \\
\hline pa. & . & . & 232,2 & 235 & astus & & - & . & 164 & . & . & & & \\
\hline & . & & & 195 & & & & & 192 & ini. & . & & & \\
\hline . & . & . & 15 & 156 & onto & & erin & & 205 & thrus & . & & & \\
\hline & . & & 13 & 132 & ome & eru & & 205, & 206 & s. & . & & 229 & \\
\hline ycorina . & • & . & . & 145 & is . & • & . & & 180 & . & . & & 229 & \\
\hline & . & & . & 225 & & & & & 215 & lestes & - & & & \\
\hline rocentr & i . & & & 202 & nae & & & & & s. & . & & : & \\
\hline & inae & & 178,18 & 187 & us & & & & 160 & & & & & \\
\hline & . & &.$\quad 18$ & 187 & & & & & 204 & & • & & & \\
\hline & . & & 21 & 213 & Mystrophorus & & . & & 224 & stus & . & & & \\
\hline otus & & & & 13 & & & & & & & & & 231, & \\
\hline ohynnis . & . & & 228,2 & 23 & Jolom & & & & 16 & bis. & & & 227, & \\
\hline & 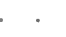 & & . $\cdot 21$ & 21 & hus & & & & 16 & . & - & . & & \\
\hline & . & - & . & 15 & rus & & & & & & & & & \\
\hline alli & • & . & . & & dius & & & & 14 & & - & . & & \\
\hline & . & . & . & & s. & & & & & & & & & \\
\hline & & . & & & & & & 131, &, 13 & mati & & & 177, & \\
\hline & & . & & & & & & & 15 & num & & & 194, & \\
\hline & • & . & & & & & & & & & . & & & \\
\hline & & & . & & & & & & & ma . & - & & . & \\
\hline & • & & & & & & & 232 , & 23 & eura. & . & & & \\
\hline & • & & & & & & & & 206 & npina & & & 202, & \\
\hline & & & & & & & & . & 207 & pus . & . & & & \\
\hline & • & & & & & & & & 16 & . & . & & & \\
\hline nia . & & - & & & & & & & & s & . & & & \\
\hline & & . & & & b & & & & 15 & . & . & & & \\
\hline todes & $s$ & . & & & & & & & & us. & . & & & \\
\hline & & & & & & & & & 13 & . & . & & & \\
\hline orin & & . & & & & & & & & . & . & & & \\
\hline $\mathbf{s}$. & & . & & & Nyxeophilus & & & & & & . & & & \\
\hline & & . & & & & & & & & & & & & \\
\hline & . & . & & & & & & & & hini & & & 139 & \\
\hline $\operatorname{tin} i$ & . & & & & & & & 195, & & us : & . & & . . & \\
\hline & & & & & & & & & & & . & & & \\
\hline & & . & 138,14 & 14 & & & & & & & . & & & \\
\hline & . & • & & 14 & nus & & & & & & . & & & \\
\hline & & & & 21 & & & & 154, & & & & & & \\
\hline inae & . & & 177,1 & & anes & & & & & & . & & 232 & \\
\hline & & & & & & & & 228 , & & ohus & 3 & & & \\
\hline ini. & . & & & & & & & & & & . & & & \\
\hline & & & & & & & & & & & . & & & \\
\hline & . & . & & & & & & 129 , & & & . & & & \\
\hline & & & . & & & & & & & & . & & . & \\
\hline ptus. & & & 14 & 14 & ae. & & & 178, & & & . & & . & \\
\hline & & & & & & & & & & & & & & \\
\hline & & & & 18 & alis & & & & & ampe. & . & & . & \\
\hline & & & & & & & & & & & . & & & \\
\hline aster & & & 177,18 & 18 & & & & & & & . & & . & \\
\hline & & & & & Orn & & & & & Phygadeuon. & & & & \\
\hline
\end{tabular}


Seite

Phygadeuonini . 139, 141

Phytodietus. . . . 148

Picroscopus . . . . . 162

Picrostigeus . . . . . 168

pictus . . . . . . . 132

Pimpla ..... . . . 146

pimplarius . . . 160

Pimplinae . . . 129, 144

Pimplini . . . . 144

Planopria . . . . . 233

Platyceraphron .. . . 224

Platygasterinae ... 221

Platylabus ..... 133, 135

Platymischus . . 233, 234

Plectiscini .. . . . 158

$\begin{array}{llllll}\text { Plectiscus . . . } & \text {. } & \text {. } & \text { - } & 159 \\ \text { Plectocryptus } & \text {. } & \text {. } & \text {. } & \text {. } & 141\end{array}$

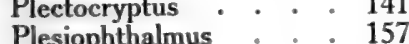

pleuralis . . . . . 209

Podagrion . . . . 205

Podagrionini. . . 205

Poemenia . . . . 150

Polemon . . . . 191

Polyaulon . . . . . 160

Polyblastus . . . . 164

Polyclistus . . . . 168

Polymorphi . . . . 176

Polypeza . . . . 232

Polyrhembia . . . . 144

Polysphincta . . . . 146

Porizon . . . 158

Porizonini. . . . 157

praerogator . . . . 163

Praon . . . . . 192

Prionomastix . . . . 215

Prionomitus . . . . 216

Prionopoda . . . . . 166

Pristaulacus . . . . 194

Pristocera . . . 222, 223

Pristomerini . . . 157

Pristomerus . . . 157

Probolus . . . 133, 135

Procinetus . . . . 147

Proclitus . . . . . 161

Proctotrupes . . . . 226

Proctotrupidae . 117, 216

Proctotrupinae 220, 221, 226

proditor . . . 164

Promethes . . . . 169

Proscus . . . . . 138

Prosynacra - . 232, 234

Proterops . . . . . 187

Pseudisobrachium 。 222, 223

Pseudocryptus . . . 165

pseudonymus . . . . 133

Psilomma . . . 229, 230

Psilophrys. . . . . 215

Pteromalinae . . . 203

pulchellus . . . . . 211

punctata . . . . 194

punctipes . . . . . 215

pusio . . . . . . 154

purpurascens . . . 209

Pycnocryptus . . . 140

pygmaeus .
Seite

Pygostolus . . . . . 186

Pyracmon . . . . . 154

Pyramidophorus . 132, 133

pyrenaicum . . . 195, 196

quadriannulatus .

131

quercinus . . . . . 207

regius . . . . . . 208

Rhabdepyris . . . . 222

Rhaconotus . . . . 180

Rhimphoctona . . . '154

Rhopus . . . . . 213

Rhynchopsilus . . 228, 230

Rhyssa . . . . . 145

Rhyssalus . . . . . 179

Rhyssolabus . . . 133, 135

Rogadinae . . 176,181

Rogas.

182

rubricans

Ruddei

195,196

rugulosum

223

Sagaritis . . . . . 153

saphirina . . . . . 206

sapphyrinus . . . . 208

scabriculus . . . . . 165

scaposus . . . . . 209

Scelioninae . . . . 221

sceptriger . . . . . . 215

Sceptrophorus . . . 215

Schizoloma . . . 151

Schizopyga . . 146

Sclerochroa . . . . 222

Scleroderma . . . 222, 223

Scolobates . . . 164

Scorpioteleia . . . . 228

scutellata . . . . . 213

Seleucus . . . . . 143

sericea . . . . . . 215

sericeus . . . . 164

serotinus . . . . . . 169

Serphus . . . . . 226

serrator . . . . 193

Sigalphinae . . 177, 182

Sigalphus.

signaticorne

Sinophorus

sispes

Smicra.

socius . 211

sodalis . . . . . . . 211

Solenopsia . . . 233, 234

Spathiinae . . 176, 180

Spathius . . . . 180

speciosus

Sphaeropyx

Sphecophaga

Sphinctini.

Sphinctus

Spilochalcis

Spilocryptus

Spilomicrus

spilopterus

Spudastica
Stauropoctonus . . . . 150

Stenodontus . . . . . 136

Stenolabis . . . . . 147

Stenomacrus . . . . . 168

Stenoterys . . . . . 215

Stephanidae . . 116, 193

Stephanus . . . . 193

Stibeutes . . . . . 142

Stiboscopus . . . . . 142

stictica. . . . . . 166

Stictopisthus . . . . . 157

stigma . . . . . . 206

Stilbops . . . . . 145

Stilbula . . . 204

Stilpnini . . . 138, 143

Stilpnus . . . . . 144

Stiphrosomus . . . 165

Streblocera . . . . 185

striatus . . . . . 194

Stroblia . . . . . 159

Stylocryptus . . . . . 142

subplanus . . . . . . 216

subtile . . . . . . 195

Sychnoleter . . . . 166

Symphya . . . . . 191

Symphylus . . . . . 161

Symphytobria . . . . 233

Symplecis . . . . . 158

Synacra . . 232, 233, 234

Synarsis . . . . . 225

Synetaeris . . . . 154

Synomelix . . . . 167

Syntomaspis . . . . 206

Syzeuctus . . . . . 147

Tanycarpa . . . 190

Taschenbergia . . . 147

Teleutaea. . . . . 146

tenuicinctus . . . . . 159

terrestre . . . 194, 196

Tetracnemus . . . . 215

Tetramopria . . . 232, 235

Thalessa . . . . 145

Thaumatotypus . . . . 143

Theronia . . . 145

Thersilochus . . . 158

Thersitia . . . . 153

Thomsoni . . . 195, 196

thuringiacus . . . . 154

Thymaris . . . . 165

Thyraeella . . . . 137

tibiale . . . . 195, 196

tibialis.... 206

tipulariarum . . . . 210

Toryminae . . 203, 205

Torymus ... 206

Tournieri . . 194, 196

Toxares . . . 192

Trachyarus . . . . 136

Trachyusa . . . . 190

Tranosema . . . . 155

Trematopygus . . . 166

triangularis . . . . 212

Tricamptus $\quad 163$

Trichocryptus . . . 141 
Inhalt.

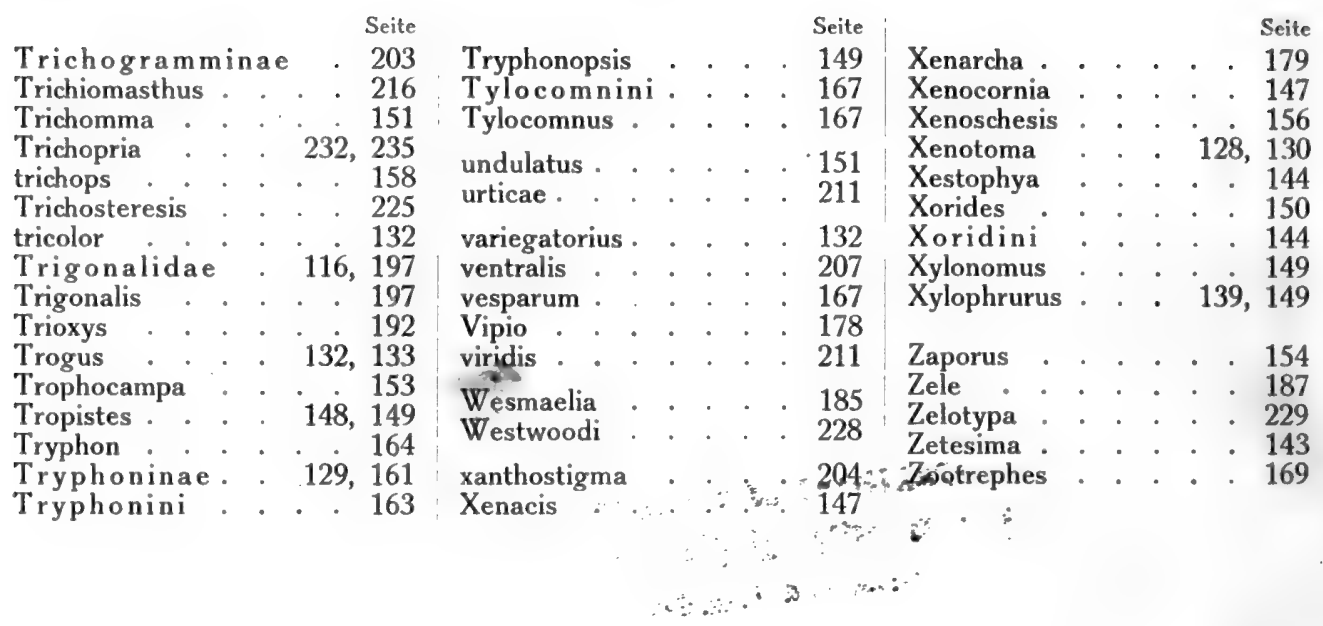



QL

567

.4

53

Bd.2

Biological

\& Medical
Schröder, Christoph.

Wilhelm Varcus (ed.)

Die Insekten

Mitteleuropas insbesondere

Deutschlands

PLEASE DO NOT REMOVE

CARDS OR SLIPS FROM THIS POCKET

UNIVERSTYY OF TORONTO LIBRARY 
